CLOVIS EDUARDO NUNES HEGEDUS

\title{
A INTRODUÇÃO DE NOVOS PRODUTOS E O PROCESSO DE DIFUSÃO DAS INOVAÇÕES NA ESTRATÉGIA DAS EMPRESAS: \\ UMA ANÁLISE DE BENS DURÁVEIS
}

\author{
Tese apresentada à Escola \\ Politécnica da Universidade de São \\ Paulo para a obtenção do título de \\ Doutor em Engenharia
}


CLOVIS EDUARDO NUNES HEGEDUS

\title{
A INTRODUÇÃO DE NOVOS PRODUTOS E O PROCESSO DE DIFUSÃO DAS INOVAÇÕES NA ESTRATÉGIA DAS EMPRESAS: UMA ANÁLISE DE BENS DURÁVEIS
}

\author{
Tese apresentada à Escola \\ Politécnica da Universidade de São \\ Paulo para a obtenção do título de \\ Doutor em Engenharia
}

Área de Concentração: Engenharia de Produção

Orientador: Prof. Dr. Afonso Carlos Correa Fleury 
AUTORIZO A DIVULGAÇÃO DESTE TRABALHO, POR QUALQUER MEIO TRADICIONAL OU ELETRÔNICO, PARA FINS DE ESTUDO E PESQUISA, DESDE QUE DEVIDAMENTE CITADA A FONTE.

Hegedus, Clovis Eduardo Nunes

A introdução de novos produtos e o processo de difusão das inovações na estratégia das empresas: uma análise de bens duráveis. São Paulo: 2006.

205p.

Tese (Doutorado) - Escola Politécnica da Universidade de São Paulo. Departamento de Engenharia de Produção.

1. Difusão das Inovações 2. Estratégia de Inovação 3. Bens Duráveis. 4. Domicílios brasileiros. I. Universidade de São Paulo. Escola Politécnica. Departamento de Engenharia de Produção. II. t. 
DEDICATÓRIA

À Regina, com meu amor, e aos filhos Carolina, Eduardo e Guilherme. 
Um trabalho somente é válido quando auxilia a sociedade e seus membros a se tornarem melhores. 


\section{AGRADECIMENTOS}

Finalizar um trabalho é sempre uma satisfação, principalmente de uma atividade em que muito se espera do esforço individual. Mas afirmar que o desenvolvimento de uma tese é um trabalho solitário está demais distante da realidade, pois se assim tivesse ocorrido provavelmente seu término não seria alcançado. Sem o apoio de muitos ao longo da jornada, essa não se findaria.

Agradeço particularmente ao orientador, Prof. Dr. Afonso Carlos Correa Fleury, pela paciência nas idas e vindas durante o desenvolvimento do trabalho, e que apesar de todos os percalços, foi fundamental para que o destino final fosse alcançado.

Aos professores Paulo Cauckick Miguel, pelos detalhados comentários e críticas ao trabalho, além do incentivo nos corredores e Abraham Yu nas observações durante a qualificação. Aos professores Marco Aurélio de Mesquita e Luis Fernando de Abreu, que com comentários diretos, permitiram entender melhor a estrutura de interpretação dos dados obtidos.

Aos amigos André Abramczuck, Cid Nardy e Luciano Mazza, que sempre se dispuseram a ouvir-me e a fornecer-me interessantes observações e sugestões, particularmente a Cid Nardy, que por diversas vezes apresentou comentários críticos para a condução dos trabalhos. A Luis Leme, do IBGE, que com suas observações precisas, permitiu que eu rapidamente compreendesse os elementos básicos do SPSS e também a estrutura de dados impressos e eletrônicos do IBGE - Instituto Brasileiro de Geografia e Estatística.

A Marina, bibliotecária da Escola de Administração Mauá, sempre disposta a auxiliar e encontrar a literatura que parecia impossível localizar. À Vera, da biblioteca da EPRO. 
Aos colegas da pós-graduação do departamento de Engenharia de Produção, cujas conversas e discussões foram de muita valia na persistência em acabar o trabalho.

Finalmente aos meus queridos familiares, minha esposa Regina, que com muita paciência ouviu reclamos e ilações sobre o desenvolvimento do trabalho e meus filhos Carolina, Eduardo e Guilherme. À minha mãe.

A todos os outros que de uma ou outra forma contribuíram para que esse trabalho chegasse a bom termo. 


\section{RESUMO}

O trabalho trata da difusão das inovações, explorando conceitos já discutidos pela literatura pertinente. A revisão dessa literatura foi feita tanto nos modelos qualitativos quanto nos quantitativos, o que permitiu verificar que o tema é bastante amplo e de grande importância para a sociedade e as empresas. Diferentes áreas como Sociologia, Antropologia, Marketing, Economia, Administração e Engenharia de Produção; foram analisadas para identificar como o fenômeno da difusão é estudado.

A inovação é um tema presente em todas as corporações modernas, seja pela pressão mercadológica ou tecnológica, portanto, é considerada fundamental para o sucesso de uma organização. Assim, o trabalho explorou como as empresas tratam sua estratégia de inovar, quando e se incorporam conceitos sobre difusão das inovações na sociedade, de forma a aumentar as chances de sucesso de um novo produto.

Foi estudado o comportamento da difusão dos seguintes bens duráveis nos domicílios brasileiros: televisores, rádios, geladeiras, freezer e filtros de água; e também a existência de canalização interna de água. Para suportar esse estudo, foram consultadas as diversas pesquisas realizadas periodicamente pelo IBGE, como Censos Decenais, PNADs, POF, seja na forma impressa ou em base eletrônica de dados, como na análise de microdados (resultados brutos das entrevistas), os quais foram processados com o auxílio de software estatístico SPSS.

Foram identificadas as curvas de difusão dos itens citados, na seguinte seqüência: total do Brasil, segmentado em área urbana e rural e segmentando a população em cinco diferentes classes de renda. Em seguida os resultados foram submetidos à análise estatística de freqüência, de eventuais correlações entre os grupos de inovações, nas classes de renda e entre classes de renda, assim como a adesão de algumas das curvas de difusão em relação às propostas dos modelos teóricos. Os resultados permitem assumir que a classe 
de renda mais alta desempenha um importante papel no processo de difusão das inovações, podendo seu comportamento servir de indicador para o processo que ocorrerá nas outras camadas de renda. Complementarmente, e para suportar algumas das afirmações feitas ao longo do trabalho também foram realizadas pesquisas de preços de diferentes eletrodomésticos desde 1960, em seus valores históricos, corrigidos pelo índice IPC-FIPE SP e pela quantidade de salários mínimos vigentes na época.

O trabalho resultou na proposta de dois modelos: um representando o papel da classe de renda mais alta em relação ao processo de difusão das inovações e um segundo, com base no primeiro, representando como incorporar o processo de difusão das inovações na estratégia das empresas.

Como conclusão final é possível afirmar que os resultados devem auxiliar as empresas na administração de uma inovação, permitindo monitorar as tendências que deverão se projetar no restante do ciclo de vida do produto.

Palavras-chave: difusão de inovações; estratégia empresarial; inovações; domicílios; eletrodomésticos; bens duráveis; novos produtos. 


\begin{abstract}
The thesis is dealing with diffusion of innovations, exploring the subjects in many of their studies. The scope of this literature review has included both qualitative and quantitative models, allowing the perception of the enormous efforts already done in such area, as well as their importance. The research has included different areas, as Sociology, Anthropology, Marketing, Economy, Administration, Production Engineering, checking how they take care about this theme.
\end{abstract}

Modern corporations assume innovation discussions as a result of nowadays technology and market pressure, assuming their impact for successful organizations. So, the work explores how companies deal with their innovation strategy, when and if diffusion of innovation concepts is considered in order to increase their new product success.

The study checked the following durable goods diffusion response in Brazilian houses: TV sets, radios, refrigerators, freezers and water filters, complemented by how home water canalization diffusion happened. Researches previously made by IBGE - Statistic and Geography Brazilian Institute - as decennial census, PNADs, POF supported the work, in their printed or electronic forms, even in the original research data. SPSS was used to support data treatment.

Diffusion curves of the above mentioned items were researched, in the following patterns: Brazil, split in rural and urban areas, and divided into five different incoming revenues. Frequencies and correlations among innovation groups, incoming revenues results were analyzed, as well as the adherences against the theorized distributions. The results afford to assume that richest people have an important point in innovation diffusion processes, and their behavior can be used as an indicator to the other incoming revenues categories. To support some thesis conclusions, home appliances prices were researched since 1960, in historical values, updated by IPC-FIPE - SP index and by minimum wage quantities at the time the price were published. 
The work has proposed two models: the first modeling the top wage incoming behavior in the diffusion of innovation process and the second model, supported by the first, representing how companies' strategy should care about innovation diffusion.

As a final conclusion it is possible to say the results should help organizations in the new product administration responses, by monitoring the tendencies and projecting them in the future product life cycle.

Key words: diffusion of innovations; companies' strategies; innovations; houses; home appliances; durable goods; new products. 


\section{SUMÁRIO}

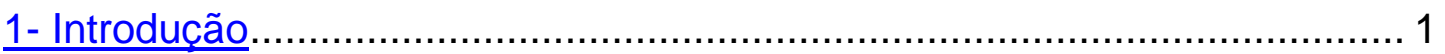

1.1 - Algumas considerações iniciais ………………........................ 1

1.2 - Em relação aos propósitos da tese .............................................. 2

1.3 - Contribuição esperada da pesquisa .............................................. 10

1.4 - Sobre as atividades de pesquisa de campo ................................... 13

1.5 - Objetivos deste trabalho ......................................................... 15

1.6 - Desenvolvimento proposto para a tese ………….......................... 16

2- Metodologia de pesquisa.............................................................. 17

$2.1-$ O processo de pesquisa científica ……....................................... 17

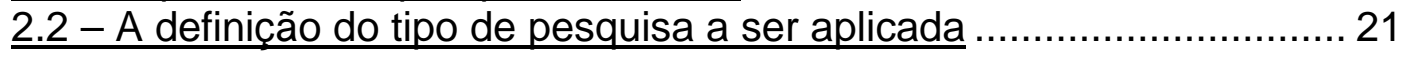

2.3 - Estratégia de pesquisa ............................................................. 23

3- O conceito de novo produto / novo serviço.............................................. 28

3.1 - Como são classificadas as inovações............................................ 28

3.2 - Uma proposta de classificação dos diferentes tipos de inovação de

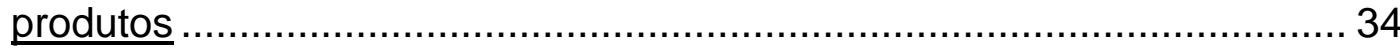

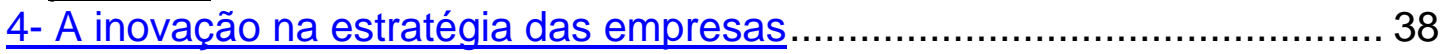

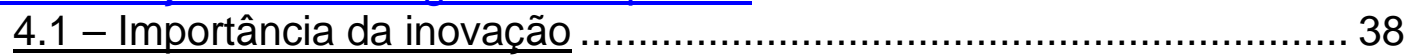

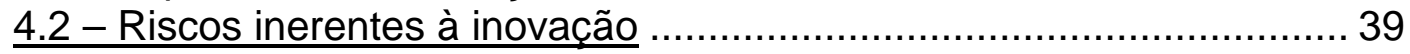

4.3 - O marketing na estratégia de inovação......................................... 44

4.4 - O consumidor e a estratégia de inovaçãa ........................................ 49

5- O processo de difusão da inovação ………………......................... 52

5.1 - Como as pessoas percebem a inovação ………………………... 52

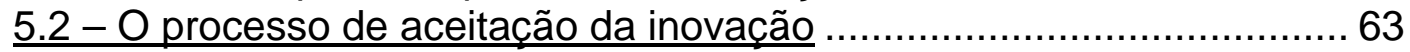

6- Modelos quantitativos de difusão da inovaçãão ……………………….......6 66

6.1 - Analisando alguns modelos de inovação ……………………..........6 66

6.2 - Comentários e restrições aos modelos quantitativos ……………..... 73

7- Estudo empírico - pesquisa de campo ………................................... 75

7.1 - A difusão de algumas inovações nos domicílios brasileiros.............. 78

7.2 - A difusão das inovações nas áreas urbanas e rurais .......................... 85

7.3 - A difusão das inovações em diferentes classes de renda................. 91

7.4 - A evolução dos preços de varejo das inovações ……………......... 98

7.5 - Correlações do processo de difusão ……………......................... 104

7.6 - Analisando o conjunto de dados ................................................ 108

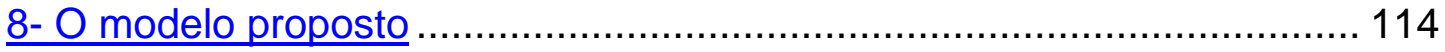

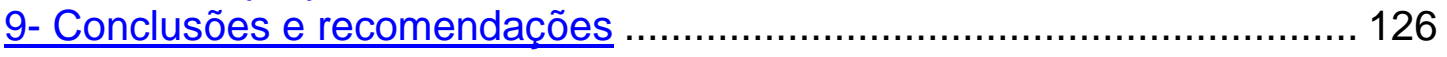

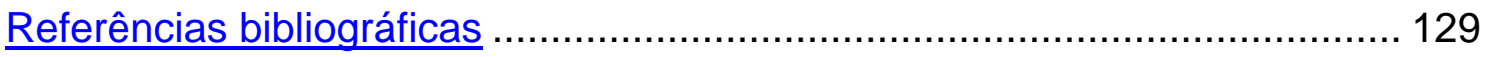

APÊNDICE 1 - Tabulação dos dados da pesquisa....................................... 146

APÊNDICE 2 - Preços de diferentes produtos ao longo do tempo ................. 153

APÊNDICE 3 - Resultados das análises de correlação da difusão ................ 186

APÊNDICE 4 - Resultados da análise de aderência e ajuste de tendência das

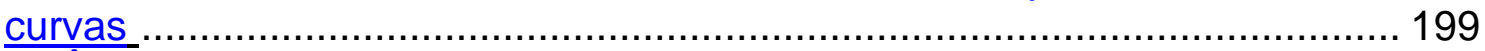

APÊNDICE 5 - Comparação entre o processo de difusão de inovações em São

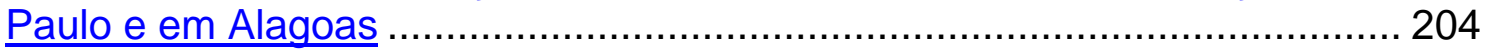




\section{ÍNDICE DE TABELAS}

\section{CAPÍTULO 1}

Tabela 1.1 - Conhecimento e utilização de ferramentas para

desenvolvimento de novos produtos

Tabela 1.2 - Número de dissertações e teses que exploraram o tema

difusão da inovação no Brasil desde 1987.

\section{CAPÍTULO 2}

Tabela 2.1 - Pesquisa Qualitativa versus Pesquisa Quantitativa

Tabela 2.2 - Premissas para escolha dos padrões quantitativos ou qualitativos

Tabela 2.3 - Situações relevantes para diferentes estratégias de pesquisa.

Tabela 2.4 - Relacionando as questões da pesquisa com a estratégia.

\section{CAPÍTULO 3}

Tabela 3.1 - Características dos três tipos de P\&D

Tabela 3.2 - Tipos de projetos explorados pelos diferentes níveis de desempenho das empresas em P\&D.

\section{CAPÍTULO 4}

Tabela 4.1 - Taxa de sucesso de novos produtos em relação a concepções iniciais de produtos possíveis de serem realizados.

Tabela 4.2 - Características dos três tipos de P\&D

Tabela 4.3 - Exemplos de evidência científica que sugere que a comunicação entre marketing e P\&D aumentam a chance de sucesso de novos produtos.

Tabela 4.4 - Relação entre os diferentes estágios no desenvolvimento de novos produtos e as ferramentas aplicáveis para auxilio ao Marketing........ Tabela 4.5 - Foco do cliente versus foco da empresa.

\section{CAPÍTULO 5}

Tabela 5.1 - Descrição das diferentes disposições para a tecnologia das pessoas em geral.

Tabela 5.2 - Crenças diferentes dos segmentos de adoção de tecnologia..

Tabela 5.3 - Comparação entre proposta de Rogers e Parasuraman /

Colby

Tabela 5.4 - Comparação entre propostas de Rogers e Thomas em relação ao processo de aquisição.

\section{CAPÍTULO 7}

Tabela 7.1 - Porcentuais de domicílios no Brasil com instalação elétrica e rádios.

Tabela 7.2 - Preços de geladeiras desde 1960.

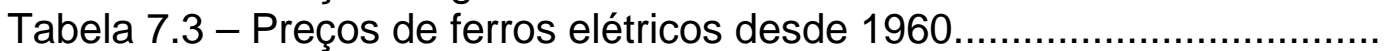

Tabela 7.4 - Preços de televisores desde 1960.

Tabela 7.5 - Preços de aparelhos de rádio desde 1960. 
Tabela 7.7 - Preços de máquinas de lavar roupa desde 1960.

Tabela 7.8 - Análise do processo de difusão de diferentes inovações nos domicílios permanentes do Brasil em classes de renda distintas.

Tabela 7.9 - Análise do processo de difusão das diferentes inovações nos domicílios permanentes do Brasil em uma mesma classe de renda.

Tabela 7.10 - Teste K-S para geladeiras e televisores em relação à distribuição exponencial......

Tabela $7.5-\mathrm{R}^{2}$ para ajuste de tendência de curvas pelo método dos mínimos quadrados para televisores e geladeiras.

\section{APÊNDICE 1}

Tabela A1.1 - Domicílios particulares permanentes com

geladeira.

Tabela A1.2 - Domicílios particulares permanentes com aparelhos de rádio.

Tabela A1.3 - Domicílios particulares permanentes com aparelhos de TV.

Tabela A1.4 - Correlação de Pearson da difusão de TVs, geladeiras, rádios, canalização interna de água e filtros de água.

Tabela A1.5 - Domicílios particulares permanentes com canalização interna de água

Tabela A1.6 - Domicílios particulares permanentes com filtro de água.

Tabela A1.7 - Difusão de aparelhos celulares móveis no Brasil desde seu início

Tabela A1.8 - Processo de difusão e abandono de televisores preto e branco nos domicílios permanentes no Brasil.

Tabela A1.9 - Difusão dos aparelhos de rádio nos domicílios permanentes no Brasil.

Tabela A1.10 - Difusão de televisores nos domicílios permanentes no

Brasil.....

Tabela A1.11 - Difusão de geladeiras nos domicílios permanentes no Brasil.

Tabela A1.12 - Difusão da energia elétrica da rede geral de energia para os domicílios permanentes no Brasil

Tabela A1.13 - Difusão da canalização interna de água nos domicílios permanentes no Brasil

Tabela A1.14 - Difusão de filtros de água nos domicílios permanentes no

Brasil.

Tabela A1.15 - Difusão de televisores por classe de renda nos domicílios no Brasil

Tabela A1.16 - Abandono de TVs P\&B por classe de renda nos domicílios no Brasil

Tabela A1.17 - Difusão de geladeiras por classe de renda nos domicílios no Brasil.

Tabela A1.18 - Difusão de aparelhos de rádio por classe de renda nos domicílios no Brasil.

Tabela A1.19 - Difusão de sistemas internos de canalização de água por classe de renda nos domicílios no Brasil.

Tabela A1.20 - Difusão dos filtros de água nos domicílios permanentes no 
Brasil.

Tabela A1.21 - Atualização do salário mínimo desde 1959 pelo IPC-SP

FIPE e INPC do IBGE (desde 1979).

APÊNDICE 2

Tabela A2.1 - Códigos de produtos para fins de classificação usados na pesquisa

Tabela A2.2 - Preços de produtos de 1960 até 2005: em valores

históricos, em valores atualizados e em quantidades de salários mínimos..

\section{APÊNDICE 3}

Tabela A3.1 - Correlações no processo de difusão de diferentes inovações nos domicílios particulares permanentes no Brasil.

Tabela A3.2 - Correlações no processo de difusão de geladeiras nos domicílios particulares permanentes no Brasil pelas diferentes classes de renda.

Tabela A3.3 - Correlações no processo de difusão de filtros de água nos domicílios particulares permanentes no Brasil pelas diferentes classes de renda.

Tabela A3.4 - Correlações no processo de difusão de aparelhos de rádio nos domicílios particulares permanentes no Brasil pelas diferentes classes de renda

Tabela A3.5 - Correlações no processo de difusão de televisores nos domicílios particulares permanentes no Brasil pelas diferentes classes de renda.

Tabela A3.6 - Correlações no processo de difusão de canalização interna de água nos domicílios particulares permanentes no Brasil pelas diferentes classes de renda.

Tabela A3.7 - Correlações no processo de difusão de freezer nos domicílios particulares permanentes no Brasil pelas diferentes classes de renda.

Tabela A3.8 - Correlações no processo de difusão na classe de renda de até 1 SM.

Tabela A3.9 - Correlações no processo de difusão na classe de renda de $1 \mathrm{SM}$ até $2 \mathrm{SM}$

Tabela A3.10 - Correlações no processo de difusão na classe de renda de $2 \mathrm{SM}$ até $5 \mathrm{SM}$

Tabela A3.11 - Correlações no processo de difusão na classe de renda de $5 \mathrm{SM}$ até $10 \mathrm{SM}$.....

Tabela A3.12 - Correlações no processo de difusão na classe de renda acima de $10 \mathrm{SM}$

\section{APÊNDICE 4}

Tabela A4.1 - Quantidade porcentual de domicílios possuidores de televisores e geladeiras

Tabela A4.2 - Ajuste de curva de tendência para geladeiras.

Tabela A4.3 - Ajuste de curva de tendência para canalização interna de água 


\section{APÊNDICE 5}

Tabela A5.6 - Comparação dos processos de difusão de geladeiras em Alagoas e São Paulo, para diferentes classes de renda.

Tabela A5.2 - Comparação dos processos de difusão de canalização interna de água em Alagoas e São Paulo, para diferentes classes de renda.

Tabela A5.3 - Comparação dos processos de difusão de televisores em Alagoas e São Paulo, para diferentes classes de renda.

Tabela A5.4 - Comparação dos processos de difusão de microcomputadores em Alagoas e São Paulo, para diferentes classes de renda. 


\section{ÍNDICE DE FIGURAS}

\section{CAPÍTULO 1}

Figura 1.1 - Fatores que influem no processo de definição de estratégia de desenvolvimento de novos produtos

\section{CAPÍTULO 2}

Figura 2.1 - Triângulo de acréscimo do conhecimento

Figura 2.2 - Modelo de ciclo de pesquisa

\section{CAPÍTULO 3}

Figura 3.1 - Diferentes graus de inovação e produtos daí decorrentes.........

\section{CAPÍTULO 4}

Figura 4.1 - Porcentual de novos produtos bem sucedidos, que falharam e que foram abortados.

\section{CAPÍTULO 5}

Figura 5.1 - Seqüência e proporção das categorias de adotantes entre a população que eventualmente o adotaria

Figura 5.2 - Ciclo de vida de um produto / serviço.

Figura 5.3 - Modelos de processo de adoção / difusão da inovação.

Figura 5.4 - Fatores que afetam o desenvolvimento de um novo produto tendo como foco o potencial comprador.

Figura 5.5 - Modelo de Rogers do processo de difusão da inovação.

\section{CAPÍTULO 6}

Figura 6.1 - Representação da curva de influência externa.

Figura 6.2 - Representação da curva de influência interna.

Figura 6.3 - Representação da curva de influência interna - modelo de Gompertz.

\section{CAPÍTULO 7}

Figura 7.1 - Processo de difusão de geladeiras nos domicílios do Brasil.....

Figura 7.2 - Processo de difusão de aparelhos receptores de rádios nos

domicílios do Brasil.

Figura 7.3 - Processo de difusão de televisores nos domicílios do

Brasil....

Figura 7.4 - Processo de difusão da canalização interna de água nos domicílios particulares permanentes do Brasil.

Figura 7.5 - Processo de difusão de filtros de água nos domicílios particulares permanentes no Brasil

Figura 7.6 - Processo de difusão de celulares móveis em operação no Brasil.

Figura 7.7 - Difusão de televisores preto e branco nos domicílios brasileiros acompanhado do processo de abandono deste tipo de equipamento.

Figura 7.8 - Processo de difusão de aparelhos receptores de rádio no Brasil - segmentado em região urbana e rural 
Figura 7.9 - Processo de difusão de aparelhos de TV no Brasil segmentado em região urbana e rural.

Figura 7.10 - Processo de difusão de geladeiras no Brasil - segmentado

em região urbana e rural.

Figura 7.11 - Possibilidade de acesso dos domicílios à energia elétrica

proveniente da rede geral no Brasil - segmentado em região urbana e

rural.

Figura 7.12 - Difusão do uso de instalações com canalização interna de água no Brasil - segmentado em zona urbana e rural.....

Figura 7.13 - Difusão e abandono de filtros de água nos domicílios

permanentes no Brasil

Figura 7.14 - Difusão de televisores nos domicílios no Brasil, separado

por diferentes classes de renda.

Figura 7.15 - Abandono da TV preto e branco pelas diferentes classes de renda de domicílios no Brasil.

Figura 7.16 - Difusão de geladeiras nos domicílios no Brasil, separado por diferentes classes de renda

Figura 7.17 - Difusão de aparelhos de rádio nos domicílios no Brasil, separado por diferentes classes de renda.

Figura 7.18 - Difusão de canalização interna de água nos domicílios no

Brasil, separado por diferentes classes de renda.

Figura 7.19 - Difusão e abandono do filtro de água nos domicílios no

Brasil, por classe de renda.

Figura 7.20 - Proporção das diferentes classes de renda em salários

mínimos em relação ao número total de domicílios no Brasil....

Figura 7.21 - Evolução do salário mínimo brasileiro desde 1959 corrigido

pelo IPC-SP FIPE e INPC do IBGE (a partir de 1979).

Figura 7.22 - Processo de difusão das geladeiras nos domicílios

particulares permanentes brasileiros - detalhamento ano a ano

103

Figura 7.23 - Ajuste de curva por reta da função de difusão de geladeiras, renda acima de $10 \mathrm{SM}$.

Figura 7.24 - Ajuste de curva pela exponencial para função de difusão de geladeiras, renda acima de $10 \mathrm{SM}$....

Figura 7.25 - Ajuste de curva por polinômio de segundo grau para a função de difusão de geladeiras, renda acima de $10 \mathrm{SM}$.

Figura 7.26 - Ajuste de curva por polinômio de terceiro grau para a função de difusão de geladeiras, renda acima de 10 SM.

Figura 7.27 - Ajuste de curva pela curva S para a função de difusão de

geladeiras, renda acima de $10 \mathrm{SM}$.

Figura 7.28 - Ajuste de curva por reta da função de difusão de televisores, renda acima de $10 \mathrm{SM}$.

Figura 7.29 - Ajuste de curva pela exponencial para função de difusão de televisores, renda acima de $10 \mathrm{SM}$

Figura 7.30 - Ajuste de curva por polinômio de segundo grau para a função de difusão de televisores, renda acima de 10 SM....

Figura 7.31 - Ajuste de curva por polinômio de terceiro grau para a função de difusão de televisores, renda acima de 10 SM.

Figura 7.32 - Ajuste de curva pela curva S para a função de difusão de televisores, renda acima de 10 SM. 


\section{CAPÍTULO 8}

Figura 8.1 - Análise do processo de desenvolvimento de um novo produto I serviço.

Figura 8.2 - Como ocorre o processo de difusão das inovações nas diferentes classes de renda tendo a classe de renda mais alta como referência

Figura 8.3 - Revisão da estratégia de inovação por uma empresa

\section{APÊNDICE 4}

Figura A4.1 - Análise da curva estimada para difusão de geladeiras, em classes de renda acima de $10 \mathrm{SM}$, em domicílios brasileiros.

Figura A4.2 - Análise da curva estimada para difusão de canalização interna de água, em classes de renda acima de 10 SM, em domicílios brasileiros

Figura A4.3 - Análise da curva estimada para difusão de televisores, em classes de renda acima de 10 SM, em domicílios brasileiros. 


\section{1- Introdução}

\section{1 - Considerações iniciais}

O processo de mudança na sociedade, decorrente de novas tecnologias, tem sido um dos pilares básicos da profunda alteração das condições alcançadas pela humanidade. As mudanças ocorrem com grande velocidade, o conhecimento avança de maneira jamais sonhada e a compreensão dos diversos processos que norteiam a sociedade são preocupações fundamentais da ciência.

É necessário entender o impacto das invenções e das inovações no ser humano, e como este reage a tais fatores, pois é sabido que as pessoas não reagem de maneira igual a informações e conhecimentos novos (Strang e Soule, 1998; Rogers, 2003). Compreender como ocorre o processo de difusão dos valores e do conhecimento na sociedade humana é um tema importante para a sociedade em geral e, em particular, para as empresas. Em relação à sociedade, para melhorar a compreensão das suas relações internas; e, quanto às empresas, para uma melhor adequação de sua estratégia em relação aos seus consumidores (Strang e Soule, 1998; Rogers, 2003; Collard, Shennan e Tehrani, 2005)

Sendo o processo de difusão de inovação uma das preocupações necessárias para um negócio, surge a questão: como o processo de elaboração da estratégia de uma empresa incorpora, em sua definição, o processo de difusão? E em particular, como o processo de difusão de uma inovação é incorporado por uma empresa quando da definição da estratégia de desenvolvimento de um novo produto? 
É reconhecido que o processo de difusão de um novo produto na sociedade pode levar anos, ou décadas ${ }^{1.1}$, e isso causa uma implicação direta às atividades de desenvolvimento de novos produtos a empresas em geral, pois elas precisam se preparar, adequando recursos para atendimento da demanda, no momento certo.

\section{2 - Em relação aos propósitos da tese}

Esta tese discute os conceitos de difusão da inovação $0^{1.2}$, as estratégias de inovação das empresas e como a integração desses conceitos poderia auxiliar no aumento do sucesso, quando da introdução de inovações em um mercado.

O significado de inovação e o processo de sua difusão vêm sendo objeto de discussão há várias décadas, podendo-se encontrar os primeiros estudos sistemáticos sobre o tema na década de 1940. Entretanto, discussões sobre o tema remontam há mais de século, com estudos de Gabriel Tarde e Georg Simmel em fins do século XIX e início do século XX. Nestes casos, foram identificadas pessoas que apresentavam comportamentos diferenciados em relação a propostas de inovações e que, sendo percebidos como referências pelos demais membros de um determinado grupo social, agiam como verdadeiros catalisadores de um fenômeno que deflagrava um processo de adoção da inovação, processo esse que pode ser representado por meio de uma curva S (Rogers, 2003) $)^{1.3}$.

\footnotetext{
${ }^{1.1}$ Diversas áreas têm estudado o fenômeno da difusão de uma inovação, relatando períodos de séculos, como o uso do bronze, da domesticação de animais, ou mais recentemente de décadas como o uso da geladeira, celular, televisão, etc.

1.2 "Difusão é um processo pelo qual uma inovação é comunicada através de certos canais ao longo do tempo entre os membros de um sistema social". (Rogers, 2003, p. 11). Mais especificamente, em relação à tecnologia: "difusão é comumente utilizada para descrever o processo pelo qual indivíduos e empresas em uma sociedade / economia adotam uma nova tecnologia, ou repõem uma velha tecnologia por uma nova". (Hall, 2004). O estudo da inovação e sua difusão mostram uma característica interessante, uma vez que um inovador tem sucesso, ele continua a inovar novamente. (Hall, 2004).

${ }^{1.3}$ Everett Rogers é um dos principais nomes na área de pesquisa da difusão da inovação, tendo lançado seu primeiro livro sobre o tema em 1962, atualizando-o aproximadamente a cada dez anos e sendo uma referência nessa área do conhecimento. Este estudo tomou como base a quinta edição deste livro. Everett Rogers faleceu em setembro de 2004.
} 
É tema recorrente, nos meios de comunicação, a questão da competitividade entre empresas e que tem remetido ao problema da inovação como um dos fatores fundamentais para o sucesso de uma organização, o que reforça a preocupação acadêmica de que inovar é estratégico para as empresas. A importância estratégica do desenvolvimento de novos produtos passou a ser crescente nas empresas e, além da pressão por inovação, outros aspectos também pressionam, como tempo para o mercado, confiabilidade, estruturas adequadas para suprir as potenciais demandas.

Assim pode-se entender a importância em inovar para as empresas, e que esse é um fator decisivo em seus negócios, pois a inovação apresenta-se como um dos fatores de diferenciação e de sobrevivência das empresas (Plsek, 1997; Jonash e Sommerlatte, 2001; Daft, 2002; Slack, Chambers e Johnston, 2002; Noke e Radnor, 2004; Hughes, 2005; Koudal e Coleman, 2005). A inovação deve ser parte fundamental entre as responsabilidades da alta administração (Jonash e Sommerlatte, 2001; Thomke, 2003; Hagen e Lodha, 2004; Chakravorti, 2004). A importância da inovação no desenvolvimento dos sistemas econômicos foi discutida por Schumpeter demonstrando que ela é um dos fatores fundamentais no surgimento dos ciclos econômicos (alto crescimento seguido de depressão) que ocorrem na sociedade (Schumpeter, 1988; Fagerberg, 2003). A abordagem de Schumpeter foi retomada no início da década de 1980, pelas escolas chamadas de neoschumpeterianas ou evolucionárias, dando, assim, um enorme impulso às discussões sobre a importância estratégica da inovação, seja no nível microeconômico ou macroeconômico, pela construção ou redução de lacunas ("gaps") na tecnologia e que permitem, aos países, manter ou reduzir a diferença entre eles (Castelacci e outros, 2005). Esta condição reflete claramente a pressão sofrida pelas empresas para inovar, seja por seu mercado, seja por outros "stakeholders", principalmente na sociedade em que ela está inserida.

Mas não basta às empresas inovar, mas sim inovar com sucesso. Pesquisas históricas informam que $85 \%$ das novas idéias de produtos nunca chegam ao mercado, e das $15 \%$ restantes, entre 50 a $70 \%$ falham em produzir lucros 
satisfatórios (Koudal e Coleman, 2005). Entre as razões que são apontadas para o fracasso está o desconhecimento do mercado, da tecnologia, da infraestrutura interna, da tecnologia e do consumidor (Cooper, 2000; Cooper, Edgett e Kleinschmidt, 2004a; Cooper, Edgett e Kleinschmidt, 2004b; Cooper, Edgett e Kleinschmidt, 2004c; Koudal e Coleman, 2005). Portanto, diversos aspectos devem ser considerados quando da definição da estratégia de desenvolvimento de novos produtos por uma empresa.

Entretanto, diversos autores afirmam que as empresas falham em definir claramente sua estratégia de desenvolvimento de novos produtos. A conexão entre tecnologia e estratégia é freqüentemente fraca (Leonard-Barton, 1995), somente poucas empresas investem em infra-estrutura correta para suportar a inovação (Koudal e Coleman, 2005), o consumidor é esquecido na maioria dos processos de desenvolvimento de novos produtos (Goffin e New, 2001; Babbar, Behara e White, 2002) e que, apesar de vários modelos quantitativos de difusão da inovação, a maioria das empresas não consegue identificar como incorporar essas expectativas e como ocorrerá a difusão de seus produtos entre os consumidores. (Gopalakrishnan e Damanpour, 2000; Koudal e Coleman, 2005)

Em relação ao aspecto interação empresa - consumidores, somente $13 \%$ de um total de 650 empresas pesquisadas no continente norte-americano e na Europa crêem que interagem satisfatoriamente com seus consumidores, segundo a visão de seus próprios executivos (Koudal e Coleman, 2005). E a pressão por inovar aumenta, pois pesquisa feita pela Deloitte indica que, em 2007, espera-se que 35\% dos resultados das empresas sejam provenientes de novos produtos. A mesma pesquisa mostra que, na visão dos investidores, entre 36 a 80\% do valor de mercado das 100 maiores empresas de manufatura do mundo estão baseados em produtos futuros e não nos produtos atuais. (Koudal e Coleman, 2005).

Diferentes abordagens têm sido feitas propondo a integração de diferentes áreas de uma empresa no processo de desenvolvimento de novos produtos, como a engenharia simultânea, organizações matriciais, etc. (Zajac, Golden e 
Shortell, 1991; Hart, 1995; Hartley, 1998; Daft, 2002; Ringland, 2003; Hui, 2004; Xu e outros, 2004). A estratégia de inovação inclui a preocupação com diversos fatores que compõem uma organização, mas que somente faz sentido caso venha ao encontro dos desejos dos consumidores da cadeia de fornecimento, na qual a empresa está inserida.

É intuitivo que a compreensão correta das informações do consumidor permite que um produto aumente sua chance de sucesso, mas como obter esse sucesso está longe de ser um problema amplamente equacionado pelas empresas e pela teoria. A literatura não é definitiva sobre alguns aspectos relacionados ao comportamento do consumidor em relação a novos produtos, e uma delas está relacionada ao processo de difusão da inovação entre os diversos segmentos da sociedade. Rogers (2003) discute de maneira ampla este fenômeno, mas somente dá indicações da importância do tema, sem oferecer uma solução definitiva. Outros autores têm abordado o tema (Mahajan, Muller e Srivastava, 1990; Aggarwal, Cha e Wilemon, 1998; Boyd e Mason, 1999; Moreau, Lehmann e Markman, 2001; Im, Bayus e Mason, 2003; Langley, Pals e Ortt, 2005).

Como a difusão da inovação é objeto de discussão já há um bom tempo, isso acabou despertando o interesse dos especialistas em propor modelos que procuraram equacionar os conceitos, de forma a torná-lo uma ferramenta útil às empresas. Essa preocupação decorre da necessidade de melhor compreensão de como ocorre e do entendimento de quando ocorrerá a real decolagem ("takeoff") de vendas do produto, pois a estratégia empresarial está ligada a esse fenômeno, como gastos com divulgação, recursos em geral, investimentos, taxa de retorno, etc. A partir do impacto, na estratégia de negócios das empresas, de quando um novo produto ou serviço atingirá as diversas fases de seu ciclo de vida, criou-se espaço para o desenvolvimento de modelos matemáticos que antecipassem o processo de difusão da inovação para fins da área de marketing, sendo um dos principais, aquele proposto por Frank Bass em 1969 (Deroïan, 2002). A principal preocupação dos modelos foi a tentativa de antecipar previsões de demanda futura de novos produtos. Entretanto, a própria literatura é um pouco cética sobre a possibilidade de 
plena aplicação dos modelos. Por exemplo, Tidd, Bessant e Pavitt (1997) criticam parcialmente o modelo de Bass, ao afirmar que as pesquisas têm falhado em demonstrar um modelo robusto de previsão da difusão da inovação entre potenciais consumidores.

Por outro lado, não há dúvidas sobre o fato de que o conhecimento do processo de difusão da inovação aperfeiçoa os esforços das atividades de marketing e, conforme McDonald, Corkindale e Sharp (2003), os ganhos podem ser relacionados:

- "pela identificação daqueles indivíduos do mercado-alvo que irão adotar inicialmente a inovação;

- pela luz que lançam sobre a natureza e o tamanho do mercado potencial de um novo produto;

- pela visualização de como aumentar o grau de aceitação de uma inovação, por parte de uma população ou mercado, de forma a conseguir uma taxa mais alta de adesão da maioria da população;

- pela indicação do tempo de adesão de cada parcela da população."

Novamente, apesar da importância do controle deste fenômeno, uma revisão de decisões relativas ao desenvolvimento de produtos, na literatura, não aponta a incorporação da difusão da inovação na fase de projeto como parte das preocupações explícitas do setor (Krishnan e Ulrich, 2001). Isto reforça a idéia de que um maior aprofundamento no tema "processo de difusão da inovação e sua contribuição para a estratégia das empresas" é um assunto que pode auxiliar na melhor compreensão do porquê o tema não ser explorado suficientemente. (Rogers, 2003). O contraditório é que o impacto da ignorância do tema, em termos de resultados financeiros para as empresas, pode custar muito caro (Foster, Golder e Tellis, 2004).

Conforme identificado por meio da literatura, são vários os fatores que concorrem para o processo de definição de uma estratégia de inovação e que influenciam a tomada de decisão correta para a obtenção de um produto que seja bem sucedido. Não será objeto desse trabalho discutir as diversas 
entradas, várias delas já exaustivamente analisadas na literatura de marketing e estratégia, mas apenas a contribuição do reconhecimento da importância da incorporação dos conceitos da difusão da inovação como um elemento que deverá auxiliar na melhoria da decisão de inovar ou não, desenvolvendo um produto que melhor se ajuste às expectativas do mercado, propiciando uma maior garantia de retorno econômico às empresas.

Assim, pode-se representar, na figura 1.1, uma visão simplificada da área que será estudada e do tema que será explorado nesta tese.

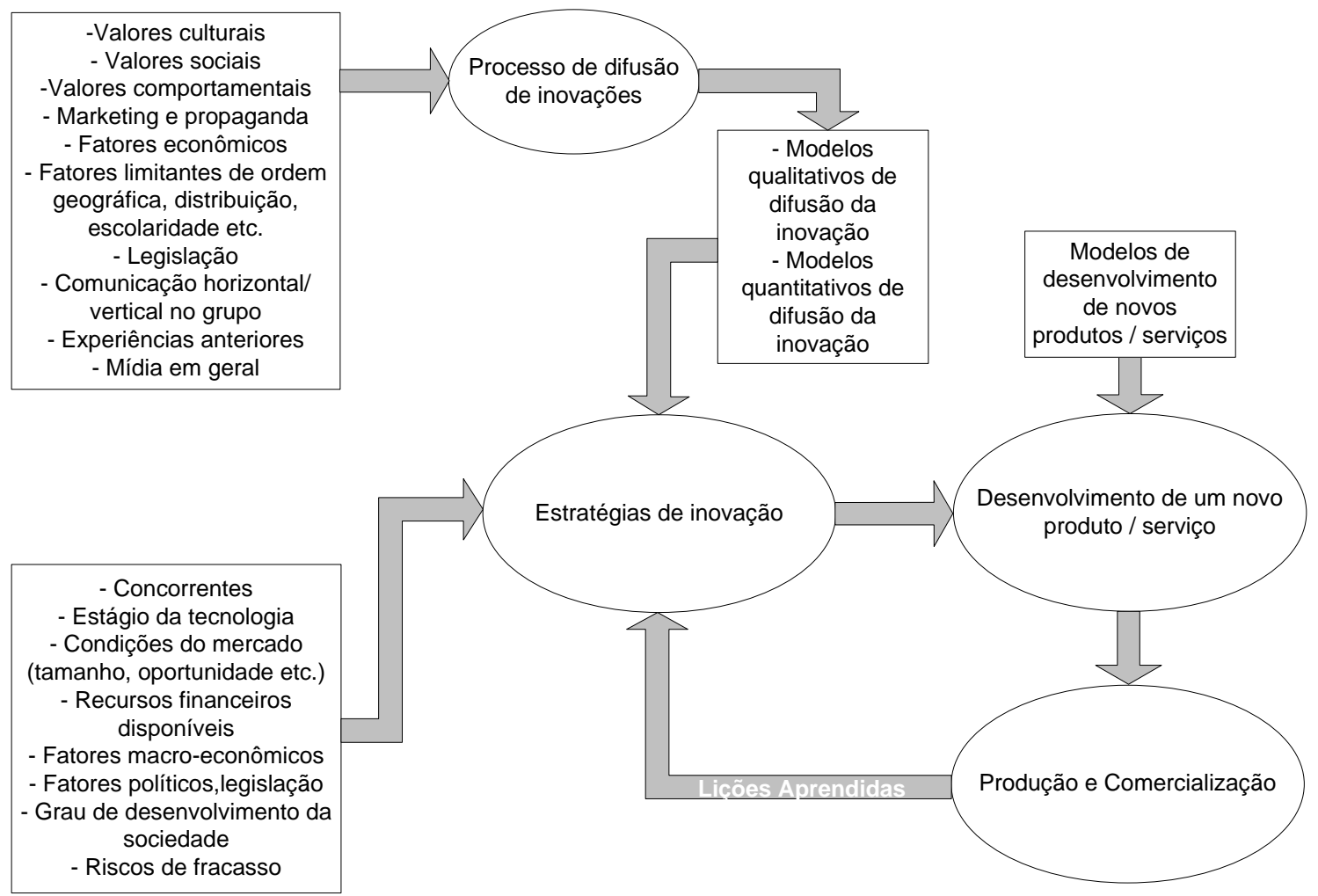

Figura 1.1 - Fatores que participam do processo de definição de estratégia de desenvolvimento de novos produtos.

A estratégia de produção é dependente de diversos fatores (Platts e Gregory, 1990; Buxey, 2000; Vereecke e Dierdonck, 2002; Slack, Chambers e Johnston, 2002) e entre eles está o que permite o correto dimensionamento dos recursos produtivos, como o fenômeno conhecido como incremento expressivo do volume produzido ("production ramp-up") $)^{1.4}$, e que permitirão, se corretamente explorados, auxiliar o gerente de operações de uma empresa na definição da

1.4 "Production ramp-up" é o período entre o fim do processo de desenvolvimento de um produto e o alcance da plena capacidade de produção. (Terwiesch e Bohn, 2001). 
sua estratégia, administrando, entre outros, dois fatores conflitantes deste período: baixa capacidade de produção e alta demanda ou vice-versa. (Terwiesch e Bohn, 2001). Isso apóia a preocupação da pesquisa sobre a compreensão do processo de resposta dos consumidores a um produto ou serviço como fundamental, na definição da estratégia de um negócio. A importância dessa compreensão é demonstrada por vários autores, dentre os quais alguns são abaixo exemplificados.

Para que o resultado esperado pelas empresas seja alcançado, isto é, que um produto ofereça retorno econômico satisfatório, vários aspectos devem ser discutidos e considerados, sendo um deles o entendimento e a incorporação das necessidades dos clientes e consumidores no desenvolvimento de novos produtos (Perin, Sampaio e Faleiro, 2004). A tradução correta das necessidades expressas pelos clientes em necessidades reais é fundamental para o sucesso de um produto (Juran, 2002). Entender e incorporar o processo de difusão da inovação nas fases de desenvolvimento de um produto pode auxiliar no posterior processo de sua difusão e aceitação pelos usuários, possivelmente aumentando seu potencial de sucesso econômico (Conde e Ruíz, 2001; Rogers, 2003). Corroborando tais afirmações, podem ser citados os estudos de três casos de insucesso de novos produtos que ignoraram o processo de difusão da inovação e que falharam no mercado: Betamax da Sony, CD-I da Phillips e o Newton da Apple. (Rosen, Schroeder e Purinton, 1998). A incorporação de conceitos que atendam aos anseios dos consumidores pode aumentar a chance de sucesso, pois "desde que a característica do produto tenha aceitação entre os compradores com maior disposição (para a tecnologia), terá uma boa probabilidade de ganhar aceitação no futuro entre outros consumidores". (Parasuraman e Colby, 2002, p. 94-5)

"Examinando as pontuações TRI (technology readiness index - índice de disposição para a tecnologia) dos clientes existentes, uma empresa pode ajudar na resposta a uma variedade de perguntas pertinentes às estratégias de tecnologia que utiliza. Por exemplo, qual é o nível geral de disposição dos nossos clientes para interagir efetivamente com produtos e serviços baseados em tecnologia? Como ele se compara com o público em geral em relação à 
tecnologia? Existem segmentos distintos em nossa base de clientes que diferem em termos de disposição para a tecnologia? Se a resposta for positiva, qual a extensão e as características distintivas desses segmentos: alguma característica demográfica, de estilo de vida ou de comportamento de compra? As respostas a essas perguntas podem fornecer insights úteis a questões da extensão dos sistemas baseados em tecnologia como os veículos para interações entre cliente-empresa, os tipos de sistemas provavelmente mais adequados, o ritmo ao qual os sistemas devem ou podem ser implementados e os tipos de suporte necessários para os clientes que tiverem problemas com os sistemas baseados em tecnologia." (Parasuraman e Colby, 2002, p. 50)

Tabela 1.1 - Conhecimento e utilização de ferramentas para desenvolvimento de novos produtos. Reproduzido de Nijssen e Frambach, 1998.

\begin{tabular}{|c|c|c|c|c|}
\hline FERRAMENTA & $\begin{array}{l}\text { Conhecimento } \\
\text { da ferramenta } \\
\text { em porcentual } \\
\text { dos } \\
\text { respondentes }\end{array}$ & $\begin{array}{l}\text { Porcentagem } \\
\text { daqueles que } \\
\text { conhecem a } \\
\text { ferramenta e } \\
\text { que também a } \\
\text { utilizam }\end{array}$ & $\begin{array}{l}\text { Porcentagem } \\
\text { dos usuários } \\
\text { que utilizam a } \\
\text { ferramenta } \\
\text { freqüentemente }\end{array}$ & $\begin{array}{l}\text { Porcentagem dos } \\
\text { usuários que } \\
\text { utilizam } \\
\text { frequentemente a } \\
\text { ferramenta em } \\
\text { relação ao total de } \\
\text { usuários }\end{array}$ \\
\hline Brainstorming & $100 \%$ & $60 \%$ & $50 \%$ & $30,0 \%$ \\
\hline $\begin{array}{ll}\text { Testes pelo } \\
\text { usuário }\end{array}$ & $100 \%$ & $68 \%$ & $38 \%$ & $25,8 \%$ \\
\hline Grupos de foco & $96 \%$ & $80 \%$ & $58 \%$ & $44,5 \%$ \\
\hline Conjoint Analysis & $96 \%$ & $72 \%$ & $35 \%$ & $24,2 \%$ \\
\hline $\begin{array}{l}\text { Testes simulados } \\
\text { de mercado }\end{array}$ & $92 \%$ & $20 \%$ & $0 \%$ & $0,0 \%$ \\
\hline Minitestes & $88 \%$ & $44 \%$ & $33 \%$ & $12,8 \%$ \\
\hline $\begin{array}{l}\text { Modelos de } \\
\text { Difusão }\end{array}$ & $68 \%$ & $24 \%$ & $13 \%$ & $2,1 \%$ \\
\hline $\begin{array}{l}\text { Análise } \\
\text { morfológica }\end{array}$ & $60 \%$ & $36 \%$ & $38 \%$ & $8,2 \%$ \\
\hline $\begin{array}{ll}\text { Modelos } & \text { de } \\
\text { predição } & \text { de } \\
\text { mercado } & \end{array}$ & $56 \%$ & $44 \%$ & $88 \%$ & $21,7 \%$ \\
\hline $\begin{array}{l}\text { QFD - } \\
\text { desdobramento } \\
\text { da função } \\
\text { qualidade }\end{array}$ & $52 \%$ & $48 \%$ & $39 \%$ & $9,7 \%$ \\
\hline
\end{tabular}


A tabela 1.1 mostra pesquisa realizada com empresas belgas e holandesas e que aponta interessante informação sobre o uso de modelos de difusão da inovação no desenvolvimento de novos produtos.

Nota-se que mesmo o QFD, uma ferramenta reconhecida como de aplicação restrita, tem uma relação de aplicação de uso freqüente aproximadamente cinco vezes maior (10\%) que os modelos de difusão no desenvolvimento de novos produtos $(2,1 \%)$, o que comprova o grande potencial de exploração do tema. (Nijssen e Frambach, 1998).

\section{3 - Contribuição esperada da pesquisa}

O trabalho irá verificar como uma melhor compreensão do processo de aceitação de um novo produto pelos consumidores pode impactar a estratégia de inovação de uma empresa, isto é, como um melhor entendimento do processo de aceitação de uma inovação pelos consumidores direciona a estratégia empresarial de desenvolvimento de um novo produto, aumentando sua chance de sucesso.

Como conseqüência das pesquisas realizadas, que serão denominadas de pesquisa de campo, outro resultado esperado desse trabalho é conhecer melhor o fenômeno de difusão da inovação no Brasil, ao menos no segmento de eletrodomésticos, a recepção das famílias às inovações e as características dessa receptividade ao longo do tempo. Esses resultados quase inexistem no Brasil, inclusive nos resultados de pesquisas e censos publicados pelo IBGE ou em estudos feitos pelo IPEA, conforme levantamento realizado. Pode-se citar apenas um artigo publicado em 1983, em que um estudo sobre o impacto do CDC - crédito direto ao consumidor - é feito na tentativa de explicar o forte crescimento ocorrido nas vendas de eletrodomésticos desde a década de 1960 (Sabóia, 1983). 
Mas, ainda que seja destacada a relevância do tema, faz-se necessária a análise de sua originalidade ${ }^{1.5}$, e este segundo aspecto foi verificado por meio de pesquisa do tema difusão da inovação no banco de teses e dissertações da Capes, a qual confirmou que o tema quase não foi explorado no Brasil, sendo que o conceito estudado é o da inovação em geral, estratégia empresarial e implementação da inovação e não como ela se difunde entre a população consumidora e seus impactos na estratégia de inovação. Isto demonstra que o tema é original no Brasil, além de que a abertura desta discussão é importante, pois o tema inovação, seus desdobramentos, implicações e resultados é um dos assuntos que tem ganhado destaque cada vez maior, em função de sua importância.

Como conseqüência, pode-se considerar original o tema difusão da inovação para a pesquisa de uma tese, ao menos no Brasil, pois a pesquisa à base de teses e dissertações da CAPES (Banco de Teses) mostrou que, desde 1987 até início de 2005, poucas dissertações e teses abordaram o tema e, ainda assim, grande parte delas explorou o conceito de forma parcial ou como apoio, sem procurar fazer um maior detalhamento do tema, com exceção de uma delas que aborda o tema difusão da inovação na área de administração da produção / engenharia da produção, mas que pesquisa o impacto e a incorporação da difusão da inovação para a gestão do ciclo de vida no desenvolvimento de novos produtos, e não de produtos radicalmente inovadores, e, com a restrição de serem produtos cujos atores são outros que não o mercado consumidor em geral (médicos e hospitais) e que, portanto, possuem outros mecanismos que influem na processo de difusão da inovação, mecanismos estes mais controláveis. (Rimoli, 2001),

O resultado da pesquisa é mostrado na tabela 1.2 .

\footnotetext{
1.5 Original, assim como o conceito de novo, está relacionado ao grau de desconhecimento de uma pessoa e do grupo em que ela está inserida, de um tema, um produto, uma idéia.
} 
Tabela 1.2 - Número de dissertações e teses que exploraram o tema difusão da inovação no Brasil desde 1987.

\begin{tabular}{|c|c|c|c|}
\hline & Ano defesa & Área & Quantidade \\
\hline Dissertação & & \multirow{2}{*}{$\begin{array}{l}\text { Administração da } \\
\text { Produção }\end{array}$} & - \\
\hline Tese & 2001 & & 1 \\
\hline Dissertação & $\begin{array}{l}1988(2), \quad 1991(2), \\
1994,1998,2000 \text { e } \\
2001\end{array}$ & \multirow[t]{2}{*}{ Agricultura } & 8 \\
\hline Tese & 1992 & & 1 \\
\hline Dissertação & 2001 & \multirow[t]{2}{*}{ Construção Civil } & 1 \\
\hline Tese & & & - \\
\hline Dissertação & 1997 & \multirow{2}{*}{$\begin{array}{l}\text { Difusão tecnologia } \\
\text { nas empresas }\end{array}$} & 1 \\
\hline Tese & & & - \\
\hline Dissertação & 2000 & \multirow[t]{2}{*}{ Educação } & 1 \\
\hline Tese & 1999 & & 1 \\
\hline Dissertação & & \multirow[t]{2}{*}{ Esporte } & - \\
\hline Tese & 2001 & & 1 \\
\hline Dissertação & 1995 e 1998 & \multirow[t]{2}{*}{ Marketing } & 2 \\
\hline Tese & & & - \\
\hline Dissertação & 2001 & \multirow{2}{*}{$\begin{array}{ll}\text { Processo } & \text { de } \\
\text { manufatura, P\&D } & \end{array}$} & 1 \\
\hline Tese & & & - \\
\hline Dissertação & 1998 & \multirow[t]{2}{*}{ Serviços } & 1 \\
\hline Tese & & & - \\
\hline Dissertação & $\begin{array}{l}1992,1998,1999 \text { e } \\
2001\end{array}$ & \multirow[t]{2}{*}{$\begin{array}{ll}\text { Sistemas } & \text { de } \\
\text { Informação } & \end{array}$} & 4 \\
\hline Tese & & & - \\
\hline Dissertação & $2000(2)$ & \multirow{2}{*}{$\begin{array}{l}\text { Sistemas } \\
\text { organizacionais }\end{array}$} & 2 \\
\hline Tese & 2001 & & 1 \\
\hline Dissertação & 1995 & \multirow{2}{*}{$\begin{array}{l}\text { Teoria Difusão da } \\
\text { Inovação }\end{array}$} & 1 \\
\hline Tese & 1996 & & - \\
\hline Dissertação & 1989,1994 e 1999 & \multirow[t]{2}{*}{ Vestuário, têxtil } & 3 \\
\hline Tese & & & - \\
\hline Dissertação & 1997 e 2000 & \multirow[t]{2}{*}{ Outros } & 2 \\
\hline Tese & & & - \\
\hline \multirow{2}{*}{\multicolumn{2}{|c|}{ TOTAL }} & Dissertações & 27 \\
\hline & & Teses & 5 \\
\hline
\end{tabular}




\section{4 - Sobre as atividades de pesquisa de campo}

Para o desenvolvimento do trabalho, e após levantamento na literatura, foi pesquisado se o fenômeno seria aplicável às condições existentes na sociedade brasileira e, caso a resposta fosse positiva, discutir sua importância na definição de estratégias de desenvolvimento de novos produtos. Entretanto, uma primeira ressalva é que o tema difusão da inovação decorrente do desenvolvimento de novos produtos aplica-se a diversos segmentos que poderiam ser objeto de estudo nessa tese, mas sua universalização tornaria o trabalho muito extenso.

Como anteriormente afirmado, o processo de difusão de novos produtos e novas tecnologias demanda tempo para que seu uso atinja toda a sociedade que é alvo potencial. Isso implica a necessidade de confirmação da ocorrência de processos de difusão na sociedade, que tenham sido devidamente controlados e registrados, e essa condição introduz uma restrição na análise do campo a ser estudado.

Uma análise dos diversos registros existentes sobre tais condições remeteu aos levantamentos periódicos feitos pelo IBGE - Instituto Brasileiro de Geografia e Estatística. As pesquisas do IBGE são amplamente utilizadas como suporte para uma série de decisões macroeconômicas e microeconômicas na Brasil e, portanto, podem ser consideradas válidas para suportar conclusões e a veracidade dos dados. Mas as conclusões e os cruzamentos de dados das pesquisas são publicados apenas em parte, por questões de custos e por escaparem do escopo pretendido. Mesmo os censos decenais têm publicado apenas parte de seus levantamentos. Isso poderia não atender às expectativas de procura dos resultados que referendariam ou não as propostas dessa tese. A partir daí, foi identificado que uma extensa base está disponível no formato chamado de microdados, o que permitiu proceder a uma pesquisa mais aprofundada de possíveis correlações e daí extrair diversas conclusões. 
Destacada a primeira dificuldade da pesquisa, restou a necessidade de encontrar produtos que poderiam ser considerados inovadores quando de sua introdução e de como medir quando ocorreu tal fato. Uma pesquisa inicial aos questionários e pesquisas realizadas no Brasil identificou que alguns produtos ou comportamentos poderiam ser considerados como inovação nos domicílios, e, assim, ficou estabelecido que dentre estes produtos seriam considerados os seguintes: o rádio, a televisão, a geladeira, os filtros de água, a canalização interna de água. Os três primeiros bastante dependentes da existência da energia elétrica, o mesmo não ocorrendo com o caso de filtros.

Passada essa fase, foi dado início ao levantamento do conjunto de dados disponíveis, com pesquisas no IBGE e seu banco de dados, bem como na análise dos microdados. A base de pesquisa foi definida na unidade conhecida como domicílio particular permanente, pois como a questão explorada é a inovação, interessou saber quando esta ocorreu pela primeira vez. ${ }^{1.6}$

Em um primeiro momento, uma análise dos dados disponíveis confirmou a existência de curvas sigmoidais de difusão da inovação, conforme previsto por Rogers e outros. Uma segunda análise dividiu a população em diferentes classes de renda, para verificar se o comportamento mantinha-se constante, e ficou identificado que as curvas não apresentavam formas iguais, quando da segmentação. As curvas apresentavam padrões distintos, tendendo a formas exponenciais (típicas de processos de difusão de inovação dependentes principalmente de influência externa), quando referidas às mais altas classes de renda e curvas sigmoidais típicas, quando se referindo às classes de renda de menor poder aquisitivo (indicando um grande peso de processos de influência interna para a ocorrência da difusão).

Como o processo de pesquisa abrangeu um período de pouco mais de 60 anos, em relação ao uso de canalização interna de água (censo de 1940) até períodos de 35 anos, para produtos como geladeiras, televisões, rádios e filtros

\footnotetext{
${ }^{1.6}$ A pesquisa incluiu o uso do software SPSS para manipulação dos dados.
} 
de água, alguns pontos foram pesquisados: se houve impacto da situação econômica brasileira em seus momentos de retração (principalmente nos períodos de 1981-1983 e 1990-1992) quanto a uma eventual descontinuidade do processo de difusão dos diversos produtos nos domicílios, e se o poder aquisitivo de compra dos produtos citados tinha se alterado ao longo desse período. Para surpresa, o impacto é bastante pequeno e pouca influencia tem na continuidade da difusão. ${ }^{1.7}$ Essa situação permitiu concluir que a difusão de um novo produto oferece uma razoável previsibilidade.

A penúltima fase da pesquisa foi a de verificar se o preço dos produtos estaria entre os fatores que apoiaram ou limitaram a difusão, principalmente entre as classes de menor poder de renda. Para responder à tal questão, foi realizada uma pesquisa de preços, em diversos períodos, principalmente em anúncios de jornais de grande circulação na cidade de São Paulo.

Uma análise complementar foi sobre o processo de abandono de uma inovação e que segue uma curva oposta ao processo de difusão da inovação. Esta análise foi feita em relação a televisões branco e preto, rádios e filtros de água.

Finalmente, a pesquisa procurou identificar as possíveis correlações entre as curvas de difusão das inovações escolhidas, sua intensidade e, daí, encontrar padrões ou similaridades, bem como a correspondência entre as curvas encontradas a partir dos dados e as previstas nos modelos teóricos.

\section{5 - Objetivos deste trabalho}

São objetivos deste trabalho:

Verificar a validade de utilização de alguns dos modelos de difusão da inovação no segmento de eletrodomésticos no Brasil.

\footnotetext{
${ }^{1.7}$ Notar que aqui não está sendo discutido o fenômeno da reposição, que claramente é influenciado pela situação econômica.
} 
Como a compreensão do processo de difusão de inovações pode auxiliar a estratégia de inovação das empresas no desenvolvimento de novos produtos.

Para testar a validade do objetivo proposto, foi feita uma análise da literatura sobre o tema, e assim, verificar qual a importância que os estudiosos dão ao tema, bem como sua abrangência. Entendido que o assunto tem sua importância reconhecida em diferentes áreas da gestão de negócios, o passo seguinte foi proceder ao levantamento histórico do processo ocorrido de difusão das inovações e, em seguida, se tem validade proposta de utilização dos modelos para auxiliar a estratégia de inovação das empresas. Para 0 levantamento e a validação propostos nos objetivos, algumas questões foram formuladas no capítulo 7, e que tiveram como alvo comprovar a importância do tema e, conseqüentemente, sua importância na definição das estratégias de inovação das empresas brasileiras.

\section{6 - Desenvolvimento proposto para a tese}

O trabalho de que trata esta tese foi dividido nas seguintes etapas:

Após a definição dos objetivos da tese, foi discutida a metodologia de pesquisa a ser explorada. Em seguida, procedeu-se a uma revisão da literatura quanto ao que é entendido como um novo produto ou serviço; a importância da inovação para o sucesso competitivo das empresas; como o processo de difusão da inovação ocorre e os modelos que foram propostos para tal.

Analisado o tema, passou-se à pesquisa de campo para comprovar a existência do processo de difusão das inovações no Brasil e, como cruzamento das informações obtidas na literatura com a pesquisa, foram propostos dois modelos: o primeiro, para representar como o processo de difusão das inovações se dá no Brasil e um segundo, tendo como base o primeiro, para auxiliar as empresas no entendimento do processo de uma inovação e em como monitorá-lo, antecipando seus efeitos. 


\section{2- Métodos e técnicas de pesquisa}

O tema difusão da inovação, objeto dessa tese, tem sido estudado em diversas áreas do conhecimento, como agricultura, geografia, marketing, medicina, saúde, sociologia; e a abordagem de pesquisa mostra-se ampla, realizada tanto de forma quantitativa, como qualitativa, utilizando-se de estratégias que incluíram pesquisas do tipo exploratória, estudos de casos - único e múltiplos, pesquisa histórica, etc. (Rogers, 2003, cap.2). Uma análise, em algumas das pesquisas feitas, mostrou que não está estabelecida uma metodologia específica que ofereça um melhor suporte ou que se configure como um padrão principal nessa área.

\section{1 - O processo de pesquisa científica}

Uma primeira preocupação que surge ao pesquisador é como compreender o objeto de seu trabalho, como conseguir comprovar suas proposições, como verificar a validade de seu constructo e como estruturar sua pesquisa, de forma a validar seus resultados. Ele parte de crenças iniciais (baseadas em representações mentais próprias do mundo), que formam seu desejo de investigação sobre um determinado problema. Essas crenças transformam-se em perguntas sobre o que o desafia. Assim, o primeiro passo será procurar algum método que sistematize e oriente a resposta às questões feitas.

Os primeiros a sistematizar o processo de análise e compreensão do mundo foram os filósofos gregos, que, muitas vezes empregavam um raciocínio dedutivo, silogístico, a partir do universal (Gardner, Kornhaber e Wake, 1998). A ciência moderna está baseada nos conceitos propostos na Grécia antiga, reforçada por Descartes, Locke e Kant, que estruturaram as bases dos modernos métodos de investigação da realidade e que resultaram em alguns requisitos básicos, entre os quais o de que a possibilidade de comprovação das conclusões encontradas seja pelo uso de métodos iguais àqueles inicialmente 
realizados, similares ou contraditórios. A comprovação das propostas de pesquisa, baseadas no método, conduz a criação ou alteração da teoria.

Em um primeiro momento, um pesquisador irá se defrontar com quatro situações:

a) a comprovação de uma hipótese afirmativa, por meio de sua convalidação;

b) a negação de uma hipótese afirmativa, pela comprovação de sua falsidade;

c) a comprovação de uma hipótese negativa, pela convalidação de sua falsidade;

d) a negação de uma hipótese negativa, pela comprovação de sua falsidade.

Todas as alternativas apresentadas são válidas do ponto de vista científico, entretanto, para a maioria das pesquisas, são feitas propostas baseadas nas alternativas "a" e "b". Eventualmente, a alternativa "c" pode surgir como conseqüência dos resultados de uma pesquisa, porém é raro a pesquisa seguir a proposição "d". Para esta pesquisa, pretende-se buscar a alternativa "a".

Por outro lado, a complexidade do mundo em que vivemos implica em diferentes formas para sua análise, resultando em diferentes tipos de pesquisas, classificadas e desenvolvidas com diferentes métodos, principalmente quando os aspectos que são abordados envolvem aspectos sociais, como no caso em tela. Há vários métodos que permitem apoiar uma pesquisa e estes mesmos diferenciam os tipos de pesquisa, sendo que sua aplicabilidade depende do objeto sob análise. Isso, muitas vezes, implica uma relação de compromisso entre a integridade dos dados versus a amplitude da pesquisa, conforme pode ser visto na figura 2.1. (Bonoma, 1985) 


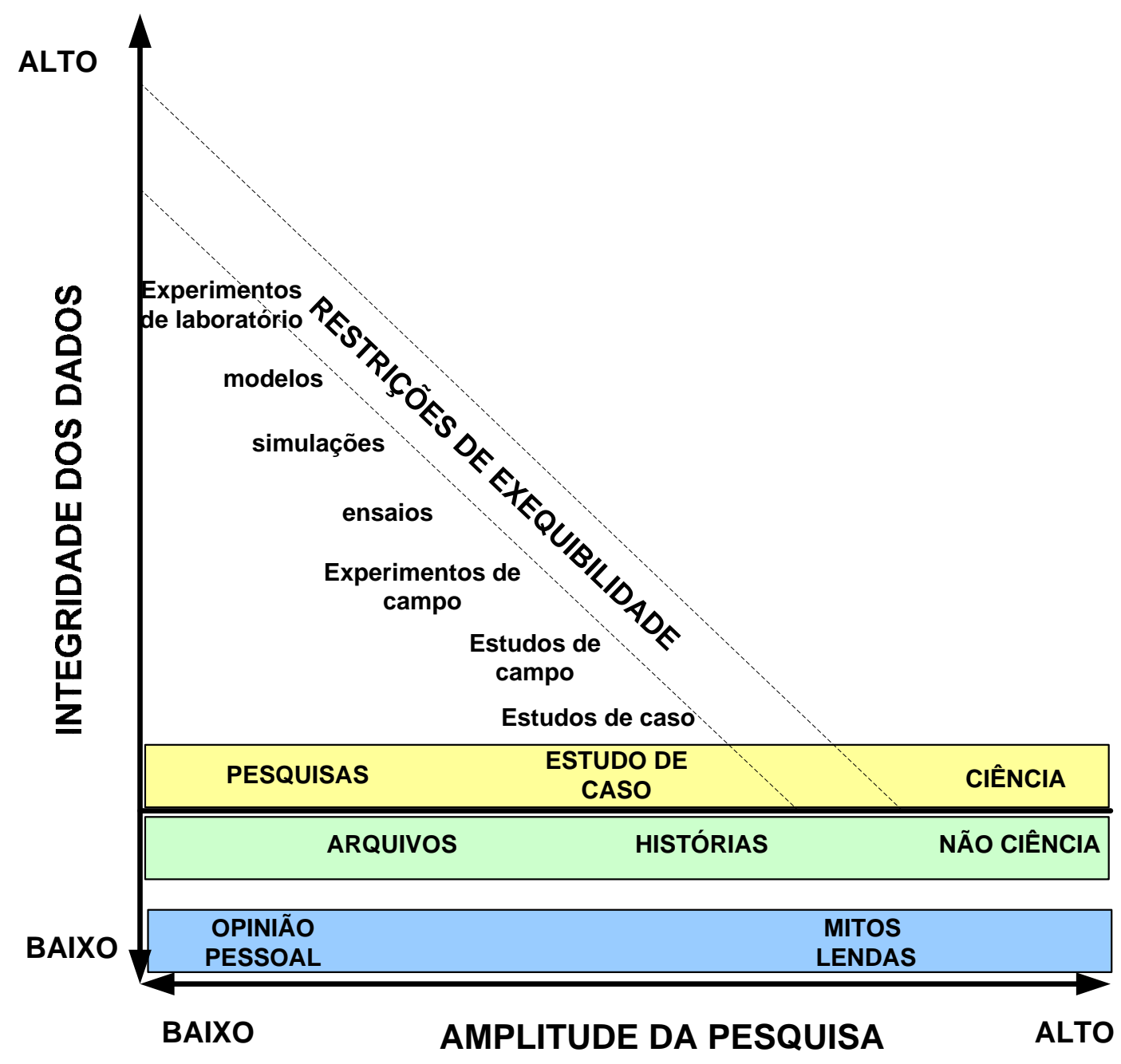

Figura 2.1 - Triângulo de acréscimo do conhecimento. Adaptado de Bonoma (1985).

O uso de diferentes metodologias está relacionado ao compromisso de comprovação e validação de uma teoria. Conforme mostrado na figura 2.1 , os experimentos de laboratório permitem um maior grau de integridade dos dados, estabelecendo métodos facilmente reproduzíveis, mas com uma amplitude de pesquisa estreita, exigindo uma grande limitação do número de variáveis sob análise e onde as inter-relações sejam claras.

Do outro lado da escala, encontram-se os estudos de caso, que, por envolverem um grande número de variáveis, conhecidas ou não, e que podem influenciar os resultados e conclusões, foram considerados como uma abordagem não-científica, por vários pesquisadores. Este tipo de restrição é apontado em Bonoma (1985), Yin (2001), Voss, Tsikriktsis e Frohlich (2002), 
Woodside e Wilson (2003), quando justificam a viabilidade de estudos de caso como um instrumento científico. À medida que se caminha de experimentos de laboratório para estudos de caso, aumenta-se a quantidade de variáveis envolvidas e não controláveis, portanto, dificultando a reprodução do experimento e o pesquisador precisa ter ciência disso. Essa uma forte razão, segundo vários autores, para suas restrições a essa abordagem.

Bonoma (1985) coloca histórias, lendas e mitos, e arquivos como não-ciência, e aí é necessária uma interpretação cuidadosa, pois esses são fontes de informação básica para várias áreas do conhecimento, como História, Antropologia, Sociologia e, assim, mostra como é delicada e difícil a classificação de métodos de pesquisa. Marshall e Rossman (1995), sem se preocupar com classificações, propõem uma seqüência de atividades que compõe o que denominam de ciclo de pesquisa, entendendo que uma pesquisa científica deve seguir um método e uma abordagem seqüencial como mostrado na figura 2.2 .

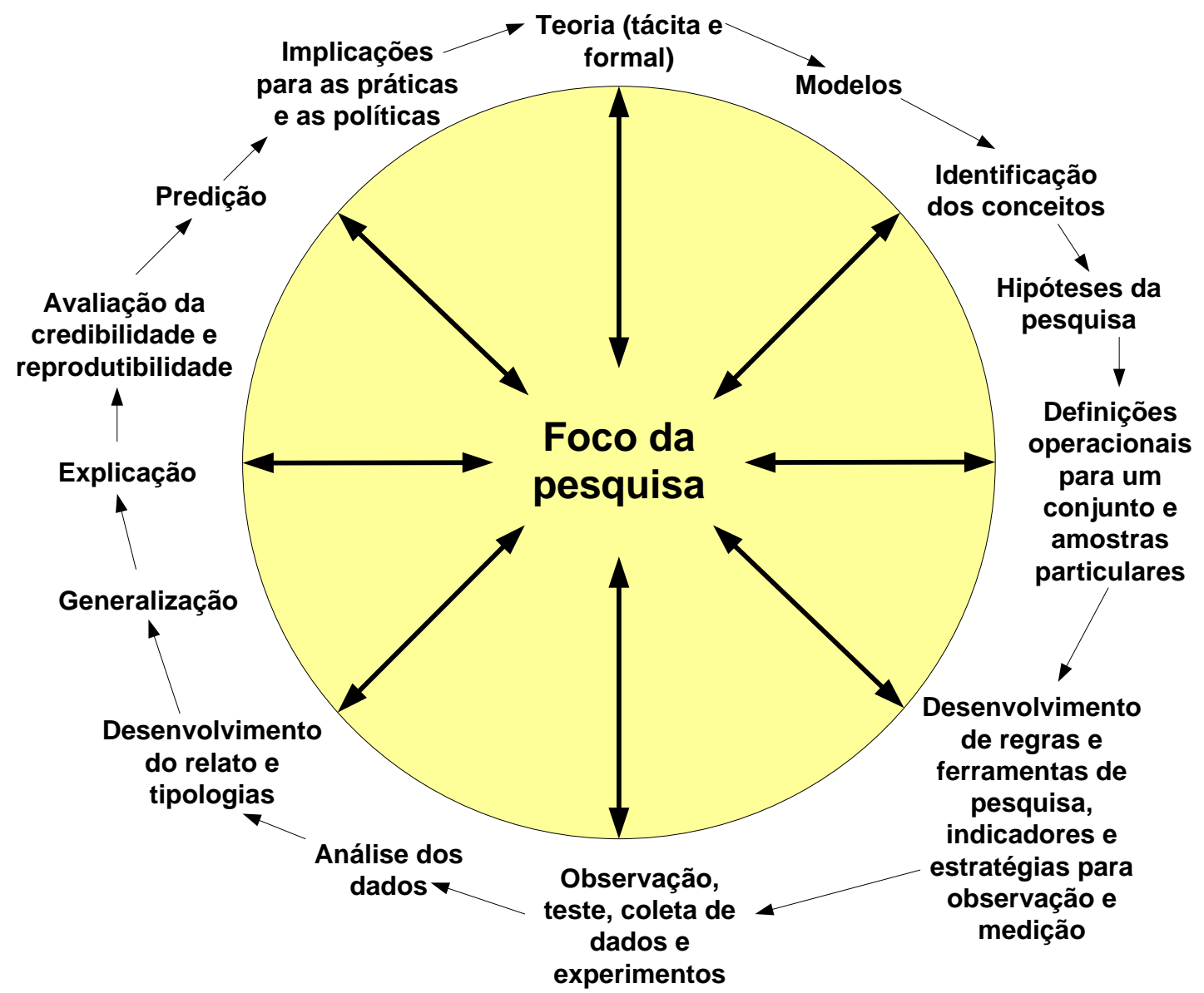

Figura 2.2 - Modelo de ciclo de pesquisa. (Marshall e Rossman, 1995, p. 17) 
$\mathrm{Na}$ figura 2.2, vê-se que o processo de pesquisa é permanente, sendo as teorias construídas sobre pesquisas anteriormente realizadas. A seqüência representa a pesquisa como um processo contínuo, onde cada novo ciclo está baseado nas descobertas e conclusões anteriormente realizadas. As autoras propõem o início do ciclo tendo como base a teoria formal (escrita) e a tácita (conhecimento existente no meio ou suas percepções), que permitem a proposição de modelos que orientam quais são os conceitos que devem ser explorados e, conseqüentemente, testados pelo estabelecimento de hipóteses que serão objeto de verificação na pesquisa, comprovando-as ou não. Propostas as hipóteses, deve ser objeto de atenção do pesquisador como serão recortadas as estratégias e metodologias de verificação, quanto às amostras, ferramentas de pesquisa e indicadores, direcionando os esforços do pesquisador. O estágio seguinte implica coletar dados e analisá-los, antecedido de propostas claras sobre como fazê-lo. Os relatos do estudo seguem como seqüência natural dos estágios anteriores. O desenvolvimento das etapas seguintes pode ou não conduzir a generalizações, embora sempre permitam uma melhor explicação de um fenômeno.

Uma das etapas importantes em um processo de pesquisa é a sua construção, assim permitindo sua reprodução por outros pesquisadores, de forma que os resultados possam ser comprovados. Como conseqüência, o método da pesquisa precisa ser construído de maneira clara e compreensível. Finalmente, o pesquisador deve propor suas conclusões e respectivas implicações para a realidade.

\section{2 - A definição do tipo de pesquisa a ser aplicada}

As pesquisas podem ser exploradas de maneira quantitativa ou qualitativa, e as vantagens e as desvantagens de cada uma delas, bem como requisitos e critérios estão listados na tabela 2.1. Essas afirmações devem ser entendidas como relativas, não implicando, necessariamente, que a escolha sobre a coleta de dados resulte um modelo determinado de pesquisa. 
Tabela 2.1 - Pesquisa Qualitativa versus Pesquisa Quantitativa (reproduzido de McDaniel e Gates - 2003, p. 121)

\begin{tabular}{|c|c|c|}
\hline $\begin{array}{l}\text { Dimensão } \\
\text { Comparação }\end{array}$ & Pesquisa Qualitativa & Pesquisa Quantitativa \\
\hline Tipo de pergunta & $\begin{array}{lll}\text { Perguntas } & \text { com } & \text { grande } \\
\text { profundidade } & & \end{array}$ & $\begin{array}{l}\text { Perguntas com profundidade } \\
\text { limitada }\end{array}$ \\
\hline Tamanho da amostra & Pequena & Grande \\
\hline Informação por entrevistado & Muitas & Varia \\
\hline Administração & $\begin{array}{l}\text { Requer entrevistadores } \\
\text { habilidades especiais }\end{array}$ & $\begin{array}{l}\text { Menos habilidades especiais } \\
\text { requeridas }\end{array}$ \\
\hline Tipo de análise & Subjetiva, interpretativa & Estatística, sumarização \\
\hline Hardware & $\begin{array}{l}\text { Gravadores, projetores, vídeo, } \\
\text { fotos, guias de discussão }\end{array}$ & $\begin{array}{l}\text { Questionários, computadores, } \\
\text { documentos impressos }\end{array}$ \\
\hline Capacidade para replicar & Baixa & Alta \\
\hline Treinamento do pesquisador & $\begin{array}{l}\text { Psicologia, sociologia, psicologia } \\
\text { social, comportamento do } \\
\text { consumidor, marketing, pesquisa } \\
\text { de marketing }\end{array}$ & $\begin{array}{l}\text { Estatística, modelos de } \\
\text { decisões, sistemas de apoio a } \\
\text { decisões, programação de } \\
\text { computador, marketing, } \\
\text { pesquisa de marketing }\end{array}$ \\
\hline Tipo de pesquisa & Exploratória & Descritiva ou causal \\
\hline
\end{tabular}

Creswell (1994) propõe o levantamento de algumas questões que deverão definir o tipo de pesquisa a ser escolhido. Essas questões são mostradas na tabela 2.2 .

Tabela 2.2 - Premissas para escolha dos padrões quantitativos ou qualitativos. (Creswel, 1994, p. 5)

\begin{tabular}{|c|c|c|c|}
\hline Premissas & Pergunta & Quantitativo & Qualitativo \\
\hline $\begin{array}{l}\text { Premissa } \\
\text { Ontológica }\end{array}$ & $\begin{array}{l}\text { Qual } \\
\text { natureza da } \\
\text { realidade? }\end{array}$ & $\begin{array}{l}\text { Realidade é objetiva e única, } \\
\text { externa ao pesquisador. }\end{array}$ & $\begin{array}{l}\text { Realidade é subjetiva e múltipla, de } \\
\text { acordo com os participantes do } \\
\text { estudo. }\end{array}$ \\
\hline $\begin{array}{l}\text { Premissa } \\
\text { epistemológica }\end{array}$ & $\begin{array}{l}\text { Qual a } \\
\text { relação do } \\
\text { pesquisador } \\
\text { com o que } \\
\text { está sendo } \\
\text { pesquisado? }\end{array}$ & 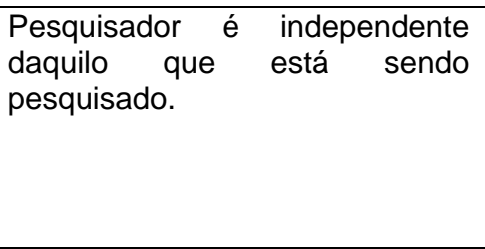 & $\begin{array}{l}\text { Pesquisador interage com o que está } \\
\text { sendo pesquisado. }\end{array}$ \\
\hline $\begin{array}{l}\text { Premissa } \\
\text { axiológica }\end{array}$ & $\begin{array}{l}\text { Qual é } 0 \\
\text { papel das } \\
\text { estimativas? }\end{array}$ & $\begin{array}{l}\text { Livre de estimativas e não } \\
\text { tendencioso. }\end{array}$ & $\begin{array}{llll}\text { Carregado } & \text { de } & \text { estimativas } & \text { e } \\
\text { tendencioso. } & & & \end{array}$ \\
\hline $\begin{array}{l}\text { Premissa } \\
\text { retórica }\end{array}$ & $\begin{array}{l}\text { Qual é o tipo } \\
\text { de linguagem } \\
\text { da pesquisa? }\end{array}$ & $\begin{array}{l}\text { Formal. } \\
\text { Baseada em um conjunto de } \\
\text { definições. } \\
\text { Voz impessoal. } \\
\text { Uso de termos aceitos } \\
\text { quantitativamente. }\end{array}$ & $\begin{array}{l}\text { Informal. } \\
\text { Decisões amplas. } \\
\text { Voz pessoal. } \\
\text { Uso de termos aceitos } \\
\text { qualitativamente. }\end{array}$ \\
\hline $\begin{array}{l}\text { Premissa } \\
\text { metodológica }\end{array}$ & $\begin{array}{l}\text { Qual é } 0 \\
\text { processo de } \\
\text { pesquisa? }\end{array}$ & $\begin{array}{l}\text { Processo dedutivo. } \\
\text { Causa e efeito. } \\
\text { Projeto estático - categorias são } \\
\text { isoladas antes do estudo. } \\
\text { Independente do contexto. } \\
\text { Generalizações conduzem a } \\
\text { predições, explicações e } \\
\text { compreensão. } \\
\text { Precisa e confiável por meio de } \\
\text { validação e confiabilidade. }\end{array}$ & $\begin{array}{l}\text { Processo indutivo. } \\
\text { Geração de fatores mutuamente } \\
\text { simultâneos. } \\
\text { Projeto dinâmico - categorias são } \\
\text { identificadas durante o processo de } \\
\text { pesquisa. } \\
\text { Contexto restrito. } \\
\text { Padrões, teorias desenvolvidas para } \\
\text { a compreensão do fenômeno. } \\
\text { Preciso e confiável por meio da } \\
\text { verificação. }\end{array}$ \\
\hline
\end{tabular}


O objeto de estudo desse trabalho é o processo de difusão de inovações de bens duráveis no Brasil.

Esta pesquisa objetiva comprovar a existência de um padrão de difusão das inovações na sociedade brasileira e identificar a existência de parâmetros que possam auxiliar no conhecimento e estabelecimento de estimativas de demanda, sua velocidade de expansão e se há padrões identificáveis nela. A pesquisa terá como base o processo de difusão de novos produtos e serão escolhidos alguns dos que hoje fazem parte de um domicílio. A base de informações para a pesquisa será, a priori, os dados do IBGE sobre domicílios brasileiros, encontrados nos Censos Demográficos, nas PNAD (Pesquisa Nacional por Amostra de Domicílios) e nas POF (Pesquisa de Orçamentos Familiares).

Segundo Creswel (1994), é possível identificar se a pesquisa que se pretende conduzir é do tipo qualitativo ou quantitativo, sendo que para esta tese as respostas às premissas ontológicas, epistemológicas, axiológicas e retórica fornecem respostas que se encaixam na abordagem quantitativa, não ficando clara qual a resposta à premissa metodológica. Isso encaminha a pesquisa para um viés quantitativo que possa suportar os resultados esperados.

\section{3 - Estratégia de pesquisa}

Definido o tipo de pesquisa que será utilizado, a seqüência do processo conduz o pesquisador à escolha do método a ser utilizado. Segundo Bonoma (1985), a escolha de uma determinada estratégia de pesquisa requer o estabelecimento de uma solução de compromisso entre a integridade dos dados e a amplitude da pesquisa (ver figura 2.1). Yin (2001), analisando a escolha da estratégia de pesquisa, propõe três condições: a) tipo de questão proposto; b) extensão do controle que o pesquisador tem sobre eventos comportamentais efetivos e c) grau de enfoque em acontecimentos históricos em oposição a acontecimentos contemporâneos e, em seguida, apresenta algumas estratégias de pesquisa, quais sejam: experimento, levantamento, análise de arquivos, pesquisa 
histórica e estudo de caso; identifica situações relevantes que as diferenciam entre si, conforme tabela 2.3.

Tabela 2.3 - Situações relevantes para diferentes estratégias de pesquisa.(Yin, 2001,p.24)

\begin{tabular}{|l|lcc|}
\multicolumn{1}{|c|}{ Estratégia } & \multicolumn{1}{|c|}{$\begin{array}{c}\text { Forma da questão } \\
\text { da pesquisa }\end{array}$} & $\begin{array}{c}\text { Exige controle } \\
\text { sobre eventos } \\
\text { comportamentais? }\end{array}$ & $\begin{array}{c}\text { Focaliza } \\
\text { acontecimentos } \\
\text { contemporâneos? }\end{array}$ \\
\hline Experimento & Como, por que & Sim & Sim \\
\hline Levantamento & $\begin{array}{l}\text { Quem, o que, onde, } \\
\text { quantos, quanto }\end{array}$ & Não & Sim \\
\hline Análise de arquivos & $\begin{array}{l}\text { Quem, o que, onde, } \\
\text { quantos, quanto }\end{array}$ & Não & Não \\
\hline Pesquisa histórica & Como, por que & Não & Sim \\
\hline Estudo de caso & Como, por que & Não & \\
\hline
\end{tabular}

No presente trabalho, a própria lógica mostra que, apesar de desejável, é amplamente demonstrado que não há como ter controle sobre eventos comportamentais, descartando a estratégia de experimento. A questão que definiu o objetivo do trabalho foi "por que", e isso conduziria o direcionamento da estratégia ao estudo de caso ou à pesquisa histórica. Também foi o de analisar a importância do conhecimento do processo da difusão das inovações, na definição da estratégia de inovação, pelas empresas.

Por outro lado, Marshall e Rossman (1995, p. 40) contrapõem Yin, afirmando que, ao contrário do que este autor afirma, a escolha de uma determinada abordagem de pesquisa freqüentemente define a estratégia de coleta de dados. Dessa maneira, as autoras também propõem uma estrutura para análise e auxílio na escolha do tipo de pesquisa a ser realizada, conforme tabela 2.4. Assim, dentre os propósitos do estudo, há de se analisar quais são eles, isto é, explorar, explanar, descrever ou predizer. Deve-se ressaltar que, em geral, os modelos representam parcialmente a realidade, portanto, a pesquisa aqui proposta não se encaixa perfeitamente nos limites propostos pelas autoras. Uma avaliação dos critérios sugeridos parece indicar a possibilidade de um estudo exploratório e as perguntas sugeridas parecem oferecer suporte à resposta ao objetivo proposto, mas não de maneira clara e contundente, pois a pesquisa descritiva também pode ser considerada para entender o fenômeno. 
Tabela 2.4 - Relacionando as questões da pesquisa com a estratégia. (Marshall e Rossman, 1995, p. 41)

\begin{tabular}{|c|c|c|c|}
\hline Propósito do estudo & $\begin{array}{c}\text { Pergunta da } \\
\text { pesquisa }\end{array}$ & $\begin{array}{c}\text { Estratégia da } \\
\text { pesquisa }\end{array}$ & $\begin{array}{c}\text { Exemplos de } \\
\text { técnicas de coleta } \\
\text { de dados }\end{array}$ \\
\hline \multicolumn{4}{|l|}{ Exploratória } \\
\hline $\begin{array}{l}\text { Investigar fenômenos } \\
\text { pouco } \\
\text { compreendidos } \\
\text { Identificar / descobrir } \\
\text { variáveis importantes } \\
\text { Gerar hipóteses para } \\
\text { futuras pesquisas }\end{array}$ & $\begin{array}{l}\text { O que está } \\
\text { acontecendo neste } \\
\text { programa social? } \\
\text { Quais são os temas } \\
\text { preponderantes, } \\
\text { padrões, categorias } \\
\text { nas estruturas dos } \\
\text { significados dos } \\
\text { participantes? } \\
\text { Como estão estes } \\
\text { padrões interligados? }\end{array}$ & $\begin{array}{l}\text { Estudo de caso } \\
\text { Estudo de campo }\end{array}$ & $\begin{array}{ll}\text { Observação } & \\
\text { participativa } & \\
\text { Entrevista } & \text { em } \\
\text { profundidade } & \\
\text { Entrevista } & \text { de } \\
\text { elementos-chave } & \end{array}$ \\
\hline \multicolumn{4}{|l|}{ Explanatória } \\
\hline $\begin{array}{l}\text { Explicar as forças } \\
\text { que ocasionam o } \\
\text { fenômeno em } \\
\text { questão. } \\
\text { Identificar } \\
\text { relacionamentos } \\
\text { causais plausíveis } \\
\text { que estruturam o } \\
\text { fenômeno }\end{array}$ & $\begin{array}{l}\text { Quais eventos, } \\
\text { crenças, atitudes e } \\
\text { políticas estão dando } \\
\text { forma a este } \\
\text { fenômeno? } \\
\text { Como estas forças } \\
\text { interagem com o } \\
\text { resultado } \\
\text { fenômeno? }\end{array}$ & $\begin{array}{l}\text { Estudo de casos } \\
\text { múltiplos } \\
\text { História } \\
\text { Estudo de campo } \\
\text { Etnografia }\end{array}$ & $\begin{array}{l}\text { Observação } \\
\text { participativa } \\
\text { Entrevista } \\
\text { profundidade } \\
\text { Questionários } \\
\text { pesquisa } \\
\text { Análise } \\
\text { documentos }\end{array}$ \\
\hline \multicolumn{4}{|l|}{ Descritiva } \\
\hline $\begin{array}{l}\text { Documentar } \\
\text { fenômeno } \\
\text { interesse. }\end{array}$ & $\begin{array}{lr}\text { Quais são } & \text { os } \\
\text { comportamentos } & \\
\text { preponderantes, } & \\
\text { eventos, atitudes, } \\
\text { estruturas } \\
\text { processos } \\
\text { ocorrem que } \\
\text { fenômeno? }\end{array}$ & $\begin{array}{l}\text { Estudo de campo } \\
\text { Estudo de caso } \\
\text { Etnografia }\end{array}$ & 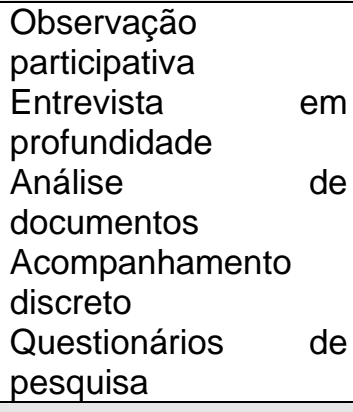 \\
\hline \multicolumn{4}{|l|}{ Preditiva } \\
\hline 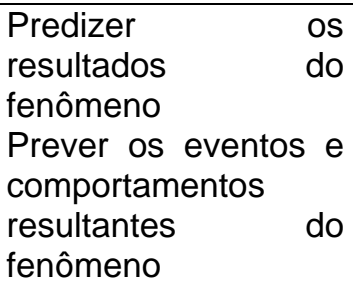 & $\begin{array}{l}\text { O que ocorrerá como } \\
\text { resultado deste } \\
\text { fenômeno? } \\
\text { Quem será afetado? } \\
\text { De que maneira? }\end{array}$ & $\begin{array}{l}\text { Experimento } \\
\text { Quase-experimento }\end{array}$ & $\begin{array}{l}\text { Questionários de } \\
\text { pesquisa (grandes } \\
\text { amostras) } \\
\text { Kinésica } \\
\text { proxêmica } \\
\text { Análise do conteúdo }\end{array}$ \\
\hline
\end{tabular}

Por outro lado, o trabalho explorará dados históricos para verificação da difusão de inovações, permitindo, assim, aumentar a compreensão do

\footnotetext{
${ }^{2.1}$ Kinésica, em inglês kinesics, que significa a análise e o estudo da linguagem corporal. Proxêmica, em inglês proxemics, foi definida pelo antropólogo Edward Hall como o estudo da percepção e uso do espaço na interação humana.
} 
fenômeno no Brasil e utilizar modelos quantitativos teóricos que pretendem delinear os processos de difusão. Dessa forma, as conclusões da pesquisa estão alicerçadas em aspectos quantitativos e, de acordo com Bertrand e Fransoo (2002), a metodologia a ser explorada pode ser classificada como a pesquisa empírica baseada no modelo teórico, e que pode ser resumida nas seguintes etapas:

- basear as observações empíricas em teorias desenvolvidas anteriormente;

- identificar o tipo de processo em relação ao qual as presunções serão consideradas;

- verificar se há critérios claros que permitirão, no futuro, a validação dos resultados;

- identificar hipóteses a partir das premissas básicas, e que deverão ser verificadas ao longo da pesquisa;

- criar um método objetivo de medição ou fazer observações;

- coletar e documentar os dados resultantes das medições e observações;

- interpretar os dados, o que muitas vezes inclui análise estatística dos dados;

- interpretar os resultados contra os modelos teóricos.

A seqüência apresentada foi um dos roteiros básicos assumidos no trabalho, apesar das dificuldades em se definir corretamente todos os estágios de maneira conclusiva, pois esse processo de pesquisa ainda está em sua infância e há pouco consenso sobre o que significa uma boa pesquisa empírica quantitativa (Bertrand e Fransoo, 2002).

Assim, o desenvolvimento do trabalho abordará as seguintes etapas:

- Identificar como a literatura analisa o processo de difusão de inovações e seus impactos;

- Analisar a estratégia de inovação e como interagem as diversas áreas na elaboração dessa estratégia;

- Verificar como ocorreu o processo de inovação de algumas inovações que adentraram os domicílios brasileiros; 
- Verificar a adesão entre o processo ocorrido e as propostas dos modelos teóricos de difusão da inovação;

- Analisar se há, e quais as contradições entre os resultados medidos e a teoria;

- Verificar extensões das propostas teóricas, de maneira a aprofundar o conhecimento do processo sob análise;

- Finalmente, com base no conhecimento obtido, propor um modelo qualitatitvo que contribua quando da análise e gerenciamento de uma inovação.

No próximo capítulo, terá inicio o levantamento da literatura sobre o tema básico deste trabalho. 


\section{3- O conceito de novo produto / novo serviço}

O objetivo deste capítulo é responder a questões como: O que é um novo produto ou serviço? Qual o grau de inovação que ocorre quando se trata de diferentes tipos de novos produtos? Como são classificados os novos produtos segundo a literatura? E propor uma classificação para reunir as diversas propostas encontradas.

O conceito do que seja um novo produto recebe diferentes classificações dos diferentes autores, mas sempre ligados ao conceito de inovar (Clark e Fujimoto, 1991; Wheelwright e Clark, 1992; Aggarwal, Cha e Wilemon, 1998; Moreau, Lehmann e Markman, 2001; Danaher, Herdie e Putsis Jr., 2001; Daft, 2002; Teng, Grover e Güttler, 2002; Saaksjarvi, 2003; Rogers, 2003; Adams, 2004) e, assim, é possível definir (para efeitos desta tese) que: produto ou serviço novo é o resultado de uma alteração que tenha sido introduzida em relação ao existente ou praticado até aquele momento e que era desconhecida para o potencial usuário.

A noção de que o termo "novo produto ou serviço" está diretamente ligado ao fato de inovar é natural, entretanto, a inovação afeta um produto de diferentes formas, desde mudanças simples até alterações que mudam a forma pela qual a sociedade se estrutura, se relaciona, seus fatores culturais e sociais, suas condições econômicas, entre outros. Isso cria um vínculo mútuo entre a inovação, como esta influencia a sociedade, e, em contrapartida, como a sociedade influencia as inovações. (Blackmore, 2000; Babbar, Behara e White, 2002; Pech, 2003; Langley, Palls e Ortt, 2005).

\section{1 - Como são classificadas as inovações}

Há grande discussão na literatura sobre as diferentes percepções em relação às inovações, o esforço necessário para diferentes tipos de inovações, etc., enfim, se seria possível analisar as inovações como tendo uma abordagem 
única. Fica claro que a inovação precisa ser classificada nas suas diferentes expressões e formas, de maneira a permitir seu estudo. Portanto, em seguida, será feita uma pesquisa na literatura sobre algumas das classificações propostas por diferentes autores, em relação aos vários tipos de inovações.

Robertson propôs, em 1971, uma divisão das inovações em três categorias: descontínua, dinamicamente contínua e contínua. (Chakravarty e Dubinsky, 2005).

Clark e Fujimoto (1991, p. 134) estabelecem quatro categorias de inovação, ou de produtos novos, que são descritos a seguir:

1- não há mudanças básicas no "layout", projeto do equipamento ou ferramentas;

2- há manutenção de grande parte do "layout" e projeto do equipamento, mas ferramentas, gabaritos e moldes são redesenhados;

3- o "layout" básico é alterado e novos equipamentos, ferramentas, gabaritos e moldes são elaborados;

4- um conceito revolucionário de produto implica em grande quantidade de recursos de engenharia avançada.

Wheelwright e Clark (1992) classificam o grau de mudança em produto e em processo de projetos de desenvolvimento:

- P\&D Avançados - geralmente são precursores dos desenvolvimentos comerciais, servem para provar a viabilidade técnica de uma determinada concepção de produto e validar o conhecimento técnico existente, de modo a verificar a possibilidade de comercialização;

- Único / Radical - gera um novo produto totalmente inovador;

- Plataforma ou próxima geração - o grau de inovação é menor que no anterior, mas há geração de produtos com novos conceitos (novas plataformas); 
- Derivados e híbridos - desenvolvimentos de produtos com pequenas variações em uma mesma plataforma tecnológica são considerados de uma mesma família;

- Sustentação - trata-se de projetos para manter, suportar ou adaptar os produtos existentes.

Roussel, Saad e Bohlin (1992, p. 57) dividem as inovações em P\&D em três tipos, conforme mostrado na tabela 3.1.

Tabela 3.1 - Características dos três tipos de P\&D. (Roussel, Saad e Bohlin, 1992, p. 57)

\begin{tabular}{|l|l|}
\hline Tipo de P\&D & \multicolumn{1}{c}{ Características } \\
Incremental & Normalmente hábil exploração do conhecimento técnico e científico \\
& existente de novas maneiras; baixo risco e modesta recompensa. \\
& Criação de novos conhecimentos para a empresa - e possivelmente \\
& para o mundo - para um objetivo comercial específico; maior risco e \\
& elevada recompensa. \\
Fundamental & Criação de novos conhecimentos para a empresa - e provavelmente \\
& para o mundo - para ampliar e aprofundar o entendimento da empresa \\
& de uma área técnica ou científica; alto risco e aplicabilidade incerta às \\
& necessidades comerciais.
\end{tabular}

Aggarwal, Cha e Wilemon (1998) afirmam que uma categoria especial de novos produtos deva ser considerada a de "Really New Products (RNP)" - ou produtos realmente novos - que são aqueles que revolucionam categorias de produtos ou definem novas categorias. Podem ser identificados como um melhor entendimento da categoria de Wheelwright e Clark (1992) de único I radical.

Veryzer Jr. (1998) procurou representar e resumir as diferentes categorias de novos produtos, conforme figura 3.1. 


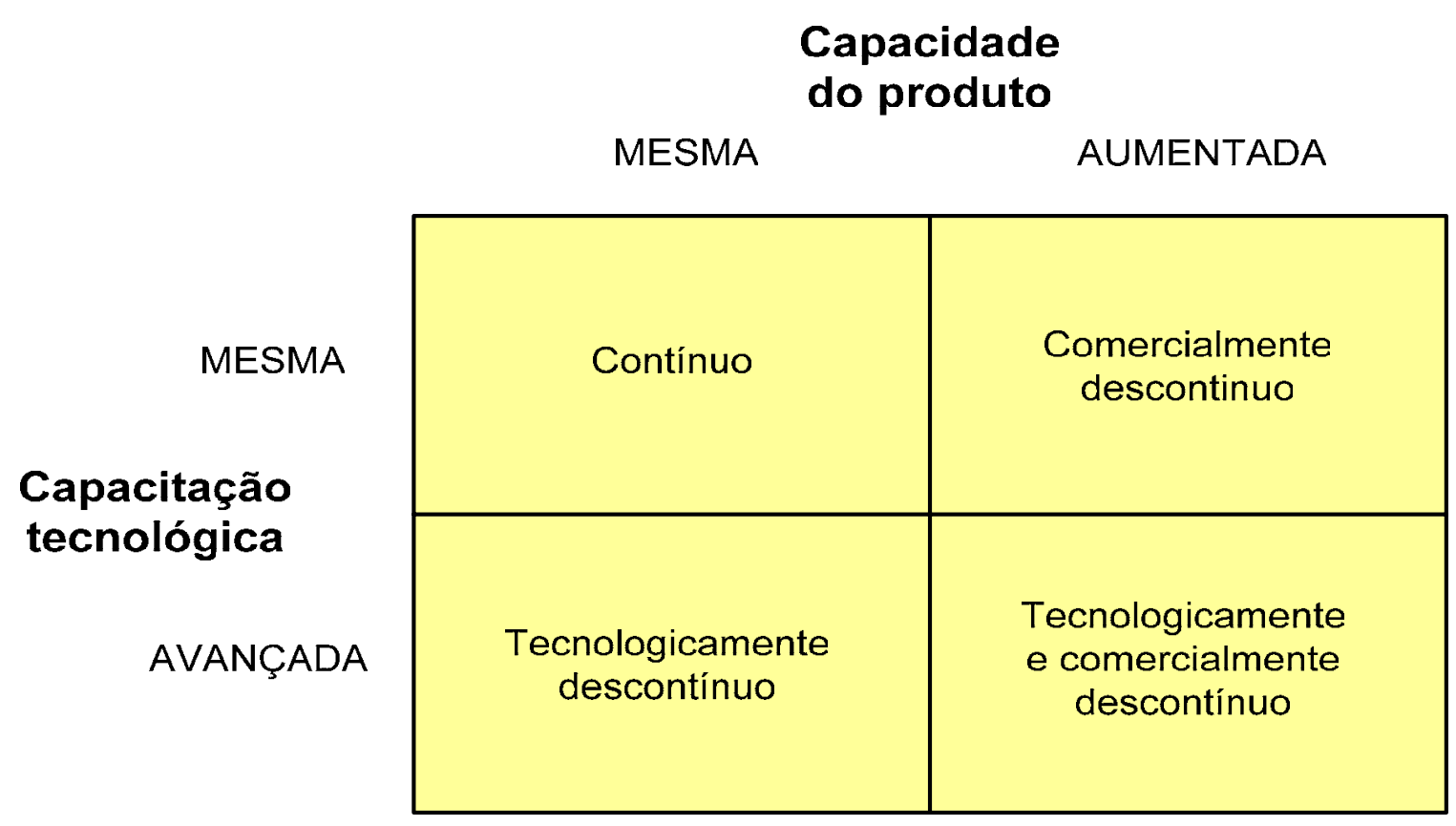

Figura 3.1 - Diferentes graus de inovação e produtos daí decorrentes. (Veryzer Jr., 1998).

Na figura 3.1, a dimensão de "capacidade do produto" representa a maneira como o consumidor percebe e experimenta o produto, e a dimensão "capacitação tecnológica" o quanto a tecnologia avança em relação às fronteiras existentes. Essa representação permite perceber que o conceito de um novo produto ou serviço tem ligação com o grau de familiaridade que as pessoas apresentam em relação à inovação, pois se não há requisito de maior capacitação tecnológica, e o produto é utilizado pelo mesmo segmento ou dentro das mesmas condições, não há porque se preocupar com um processo de difusão da inovação, pois o produto é visto como conhecido pelo potencial usuário. No caso de capacidade aumentada, o segmento usuário muda, portanto, começam a surgir as barreiras de aprendizagem, de credibilidade. Quando ocorrem mudanças tecnológicas acentuadas, o usuário é obrigado a aprender e é necessário mostrar que as vantagens do esforço de aprendizado e do risco serão recompensadas. No quarto quadrante, encontram-se os casos de inovações radicais já discutidos anteriormente, que, além de precisarem vencer as barreiras de aprendizagem, devem seduzir a cadeia de suprimentos que o risco compensará, inclusive quanto a possíveis canibalizações de tecnologias existentes e as perdas daí conseqüentes. 
Uma diferente classificação proposta divide os produtos entre os que oferecem continuidade de inovação (a compreensão do produto está diretamente relacionada a conhecimentos prévios do consumidor) e inovações descontínuas (o conhecimento prévio dificulta a compreensão do novo produto) (Moreau, Lehmann e Markman, 2001). Pode-se somar a esta uma terceira categoria denominada de inovação de gerações múltiplas - que envolve produtos que requerem mais que uma inovação vinda de diferentes partes do conceito ${ }^{3.1}$ oferecido ao consumidor, como por exemplo telefones celulares e serviços disponíveis (Danaher, Herdie e Putsis Jr., 2001).

Outra proposta divide a inovação de produtos em quatro categorias distintas: (Saaksjarvi, 2003)

- Produtos de inovação contínua - somente pequenas modificações são incorporadas;

- Produtos de inovação dinâmica - envolvem a criação de novos produtos ou modificações dos existentes;

- Produtos de inovação descontínua - representam a criação de produtos desconhecidos anteriormente, que requerem um grande aprendizado por parte dos consumidores;

- Produtos com inovações de múltiplas gerações - envolvem a mudança de diversos serviços ou produtos que compõem o conceito oferecido ao consumidor.

Pesquisa ${ }^{3.2}$ feita pela "American Productivity and Quality Center", que avaliou 17 melhores práticas de empresas americanas nos últimos anos, reforça as

\footnotetext{
${ }^{3.1}$ Conceito - "intenção global do produto ou serviço como percebidos da perspectiva do consumidor. O conceito não é uma declaração das diversas pequenas peças e partes que compramos, em vez disso é a forma como os consumidores e, espera-se, também a organização, seus funcionários e acionistas percebem os benefícios do produto ou serviço". (Slack, Chambers e Johnston, 2002, p. 141).

3.2 A pesquisa usou metodologia própria da APQC, incluindo métodos quantitativos e qualitativos, explorando diferentes indústrias, com retorno de 105 unidades de negócio (sendo $51 \%$ pertencentes ao setor de manufatura); a média de vendas era de US\$ 400 milhões e média de empregados de 1.500. (Cooper, Edgett e Kleinschmidt, 2004a).
} 
divisões propostas, pois cita que o desenvolvimento de novos produtos é distribuído como: (Cooper, Edgett e Kleinschmidt, 2004b)

- desenvolvimentos de menor extensão no produto, como aqueles relacionados a mudanças exteriores e promocionais: representam 9,5\% dos desenvolvimentos;

- mudanças incrementais: representam 32,7\% dos desenvolvimentos;

- revisões de maior extensão dos produtos: representam 24,2\% dos desenvolvimentos;

- novos produtos para o negócio: representam 21,9\% dos desenvolvimentos; e

- inovações verdadeiras ou produtos novos para o mundo: que representam 10,2\% dos desenvolvimentos.

Os autores ressalvam que $1,5 \%$ dos projetos desenvolvidos pelas empresas foi por elas classificado como outros tipos de projetos e que não se encaixava nos perfis acima descritos.

As empresas não exploram a inovação da mesma maneira e, segundo a mencionada pesquisa da APQC, há diferenças nas abordagens feitas entre as empresas consideradas. Assim, foram feitos cortes entre aquelas que apresentam melhor desempenho nos resultados apresentados pelos esforços de $P \& D$, em um total de $20 \%$, consideradas como localizadas no topo do "ranking"; aquelas que apresentam os piores desempenhos representam outros $20 \%$ e as restantes foram consideradas médias em termos de desempenho inovativo, representando 60\% das 105 unidades de negócio pesquisadas. (Cooper, Edgett e Kleinschmidt, 2004b). Os resultados estão mostrados na tabela 3.2. . $^{3.3}$

\footnotetext{
3.3 Note-se que o número de empresas no Brasil que inovam e diferenciam produtos representam apenas 1,7\% (1.199 empresas) do total de empresas com mais que 10 funcionários aqui existentes, segundo pesquisa PINTEC 2000 (Pesquisa Industrial de Inovação Tecnológica) do IBGE - Instituto Brasileiro de Geografia e Estatística, e isto mostra a importância da implantação de uma política incentivadora de inovação e da discussão do tema inovação no país. (De Negri, Salerno e Castro, 2005)
} 
Tabela 3.2 - Tipos de projetos explorados pelos diferentes níveis de desempenho das empresas em P\&D. (Cooper, Edgett e Kleinschmidt, 2004b)

\begin{tabular}{|lrrr|}
\hline & $\begin{array}{l}\text { Melhores } \\
\text { desempenhos }\end{array}$ & $\begin{array}{l}\text { Piores } \\
\text { desempenhos }\end{array}$ & \multicolumn{2}{l|}{$\begin{array}{l}\text { Desempenho } \\
\text { médio }\end{array}$} \\
\hline $\begin{array}{l}\text { desenvolvimentos de menor extensão } \\
\text { no produto }\end{array}$ & 5,89 & 12,31 & 9,45 \\
$\begin{array}{l}\text { mudanças incrementais } \\
\text { revisões de maior extensão dos }\end{array}$ & 28,21 & 40,42 & 32,74 \\
produtos & 25,00 & 19,15 & 21,97 \\
novos produtos para o negócio & & & \\
inovações verdadeiras ou produtos & 15,89 & 7,42 & 10,23 \\
novos para o mundo & & & \\
TOTAL* & 99,10 & 99,30 & 98,53 \\
\hline
\end{tabular}

* as colunas não somam 100\% devido a uma pequena porcentagem de "outros" projetos

Duas características principais foram identificadas na revisão feita: a) à medida que a literatura se aproxima dos dias atuais, as classificações propostas aumentam em quantidade para atender o aumento do conhecimento sobre 0 tema; b) identifica-se, entre as propostas dos vários autores, que a inovação pode ser vista num amplo espectro entre extremos, isto é, desde pequenas modificações, quase ou completamente imperceptíveis aos usuários e ao processo produtivo, até mudanças que irão alterar, de maneira profunda, o modo de vida da sociedade. Dentro desta vasta gama, o processo de difusão da inovação deverá ocorrer de maneira diferente, influenciado por alguns parâmetros que incluem, entre outros: esforço dos desenvolvedores, tecnologia, familiaridade, custo de compreensão pelos usuários e difusão na sociedade. Em função dessa quantidade de variáveis e diferenças, este trabalho irá propor, em seguida, uma classificação tomando como base o que foi identificado na literatura.

\section{2 - Uma proposta de classificação dos diferentes tipos de inovação de produtos}

Inicialmente, há de se considerar que alguns pontos suportam a decisão de inovar ou não, e estes influenciam a percepção da inovação, bem como sua aceitação. Tais pontos são: (Rogers, 2003; Hall, 2004) 
a) Vantagem relativa - como a inovação é percebida como melhor que a situação ou condição existente e que pode ser medida em termos econômicos, além de prestígio social, conveniência e satisfação.

b) Compatibilidade - como uma inovação é consistente com os valores existentes, experiências anteriores do indivíduo e suas necessidades. Quanto maior a compatibilidade, maior a probabilidade de rápida aceitação.

c) Complexidade - como uma inovação é percebida como difícil de ser compreendida e utilizada.

d) Experimentação - como uma inovação pode ser experimentada em uma base limitada e em estágios.

e) Observabilidade - como os resultados de uma inovação são visíveis aos demais participantes do grupo.

f) Conhecimento - como as pessoas tomam ciência da existência da inovação e suas características.

g) Regras e leis - como os indivíduos são obrigados a aceitar uma inovação por imposição legal.

Essas diversas classificações não deixam clara a relação entre as características propostas para diferentes tipos de inovações e as diversas características que são observadas para que sua difusão seja percebida entre aqueles para os quais as inovações são criadas. Tais abordagens retratam a visão do ponto de vista da tecnologia, da empresa e não se essa é a real percepção do potencial usuário.

Uma inovação pode ser compreendida como o resultado da mudança da tecnologia, da criatividade e também da percepção dos usuários e, dessa forma, será proposta uma divisão de novos produtos em cinco categorias que sejam relacionadas ao processo de percepção e impacto da inovação. Essa divisão terá como base as diversas classificações propostas e, por outro lado, os diversos pontos que suportam a decisão de inovar ou não, por parte do consumidor, e será apresentada em seguida. 
- Novos produtos decorrentes de inovações contínuas - são decorrência de melhorias e pequenos aperfeiçoamentos em produtos existentes, como por exemplo, alterações na parte frontal de um veículo; novas versões de processadores de computadores, com velocidades de processamento mais rápidas, mas que pertençam à mesma família, etc. As características que se fazem presentes e que atraem para a inovação são vantagem relativa e observabilidade. O processo de difusão da inovação é basicamente de influência externa, isto é, da mídia;

- Novos produtos decorrentes de inovações dinamicamente contínuas produtos baseados em novos conceitos que não afetam a sua percepção e compreensão, como por exemplo, novas famílias de processadores, novos modelos ou categorias de automóveis, etc. Entre os aspectos percebidos estão a compatibilidade (por serem inovações internas não facilmente perceptíveis ao usuário) e a observabilidade;

- Novos produtos decorrentes de inovações descontínuas - produtos que alteram profundamente a compreensão de uma característica considerada básica e fundamental de um produto anterior, como por exemplo, automóveis elétricos, câmeras fotográficas digitais, etc. Neste caso, os aspectos de compatibilidade, complexidade, experiência e conhecimento devem ser analisados, pois influenciam o processo de difusão de maneira mais intensa. $O$ fator vantagem relativa deve ocorrer tão logo o produto comece a ser percebido pelo mercado;

- Novos produtos decorrentes de inovações multidisciplinares - produtos que requerem a compreensão de mais de um tipo de característica que o afetam, em geral envolvendo um produto e o serviço a ele relacionado, sem o qual nenhum dos dois consegue operar, como, por exemplo, telefones celulares (o aparelho propriamente dito e os serviços da operadora), serviços de uso e transmissão de TV a cabo, tecnologias que envolvem sistemas amplos de informação como EIS (executive information systems - sistemas de informações gerenciais), etc. Os 
aspectos de compatibilidade, complexidade, experimentação e conhecimento influem na forma como ocorrerá a difusão da inovação;

- Novos produtos decorrentes de inovações que criam novas categorias de produtos - produtos que criam novos mercados até então inexistentes, apresentando pouca ou nenhuma base de comparação para se correlacionar ao conhecimento prévio e que alteram o modo como a sociedade opera, como por exemplo, o rádio e a televisão em seus primórdios, computadores pessoais, a Internet, etc. Neste caso, o conhecimento e a observabilidade têm uma grande influência no processo de difusão.

Segundo diversos autores (Slack, Chambers, Johnston, 2002; Gaither e Frazier, 2002; Corrêa e Caon, 2002), é praticamente inexistente um produto puro, assim como um serviço puro, havendo uma maior ou menor participação de um ou de outro. ${ }^{3.2}$ Isso implica assumir que as propostas feitas para produtos englobam as percepções de serviços e vice-versa. Apesar de a literatura ser relativamente restrita (quando comparada a estudos sobre produtos) quanto à análise e à classificação de serviços para fins de inovação, em geral, os autores baseiam suas premissas dentro dos mesmos parâmetros que norteiam o desenvolvimento de produtos, afirmando que os estudos e práticas estão embasados naquilo que é analisado para produtos. (Froehle, 2000; Lenfle, 2004).

Tendo sido discutido o que significa uma inovação, como podem ser compreendidos diferentes tipos de inovação, como o usuário percebe essas inovações e quais os fatores que ocorrem no processo de percepção e aceitação da inovação, de maneira a auxiliar na sua difusão, passa-se a analisar como uma empresa pode e deve aproveitar tais condições na definição de sua estratégia de inovação.

\footnotetext{
${ }^{3.2}$ A combinação de serviços e produtos oferecidos para o cliente pode ser denominada de Pacote. (Slack, Chambers e Johnston, 2002)
} 


\section{4- A inovação na estratégia das empresas}

\section{1 - Importância da inovação}

A segunda característica a ser analisada, em relação ao objetivo proposto, é o quanto a inovação é importante e estratégica para as empresas em geral, tema deste capítulo. A pergunta a ser aqui respondida é qual a importância da inovação para os negócios e para as empresas em relação ao desenvolvimento de novos produtos e serviços.

Diversos autores afirmam que a inovação é elemento básico na estratégia das empresas em competir pelos consumidores e mercados, e isso permite afirmar que a inovação é fundamental para uma estratégia bem-sucedida das empresas (Porter, 1993; Plsek, 1997; Porter, 1999; Drucker, 2000; Churchill Jr. e Peter, 2000; Costa, 2003; Hagen e Lodha, 2004; Verhees e Meulenberg, 2004). Há forte correlação entre o sucesso de uma empresa e sua tendência em inovar (Noke e Radnor, 2004). A inovação resulta em alterações nas estratégias de contratação de trabalhadores (Svizzero e Tisdell, 2003). A necessidade de inovação é parte das estratégias governamentais para o desenvolvimento das empresas de um país (Simonis, 2001). A estratégia de inovação está relacionada a dois fatores: velocidade de adoção e quantidade de inovações adotadas em um determinado período de tempo, que refletem no tipo preferencial de inovação adotada, isto é, de produto ou de processo (Gopalakrishnan e Damanpour, 2000). O sucesso de uma empresa, em função dos ciclos de vida de muitos produtos estarem se reduzindo, das alterações nos mercados decorrentes de avanços tecnológicos, da maior facilidade de acesso da população em conhecer estas tecnologias e seus benefícios, tem submetido as empresas a uma maior pressão para inovar, com vistas a se manter no negócio (Boyd e Mason, 1999)

A inovação introduz riscos (Tidd, Bessant e Pavitt, 1997). Blau e outros (2004), ao analisarem o setor farmacêutico, retratam o risco e os custos que o desenvolvimento de novos produtos traz, ressaltando que cuidados durante as 
diversas fases de desenvolvimento de um novo produto podem reduzir os custos e perdas decorrentes de um processo mal planejado. Os autores afirmam serem as conclusões aplicáveis a outros segmentos da indústria.

Pode-se depreender que no mundo atual há uma forte pressão por inovar, e que a importância da inovação para a estratégia das empresas é decorrência do intenso desenvolvimento tecnológico, do encurtamento das distâncias e da aproximação das pessoas, por meio das novas tecnologias de comunicação, da maior disponibilidade do conhecimento, da facilidade de comparação e da expectativa de novos produtos pelos consumidores. Isto conduz as empresas à necessidade de constantemente inovar, lançar novos produtos. Todavia, desenvolver novos produtos nem sempre é sinônimo de sucesso.

\section{2 - Riscos inerentes à inovação}

O cuidado com o fracasso e a perda de recursos é conseqüência das altas taxas de insucesso de novos produtos e que, segundo Churchill Jr. e Peter (2000), variam de $33 \%$ a $90 \%$. Cooper (2000) afirma que a taxa de sucesso é de aproximadamente 8\%. Por outro lado, Cooper, Edgett e Kleinschmidt (2004a) afirmam ser voz corrente que "novos produtos falham em um nível alarmante. Aproximadamente um em dez conceitos de produtos atinge a fase comercial, enquanto apenas um em quatro projetos de desenvolvimento é um sucesso comercial".

Cooper, Edgett e Kleinschmidt (2004a) demonstram, por meio de pesquisa ${ }^{4.1}$ feita, que os resultados porcentuais de novos projetos que adentram o estágio de desenvolvimento, e que são bem-sucedidos, falharam ou foram abortados antes de seu lançamento comercial, pelas empresas. Este resultado é mostrado na figura 4.1.

4.1 A pesquisa foi suportada pelo "American Productivity and Quality Center". Para mais informações, ver capítulo 3 desta tese. 


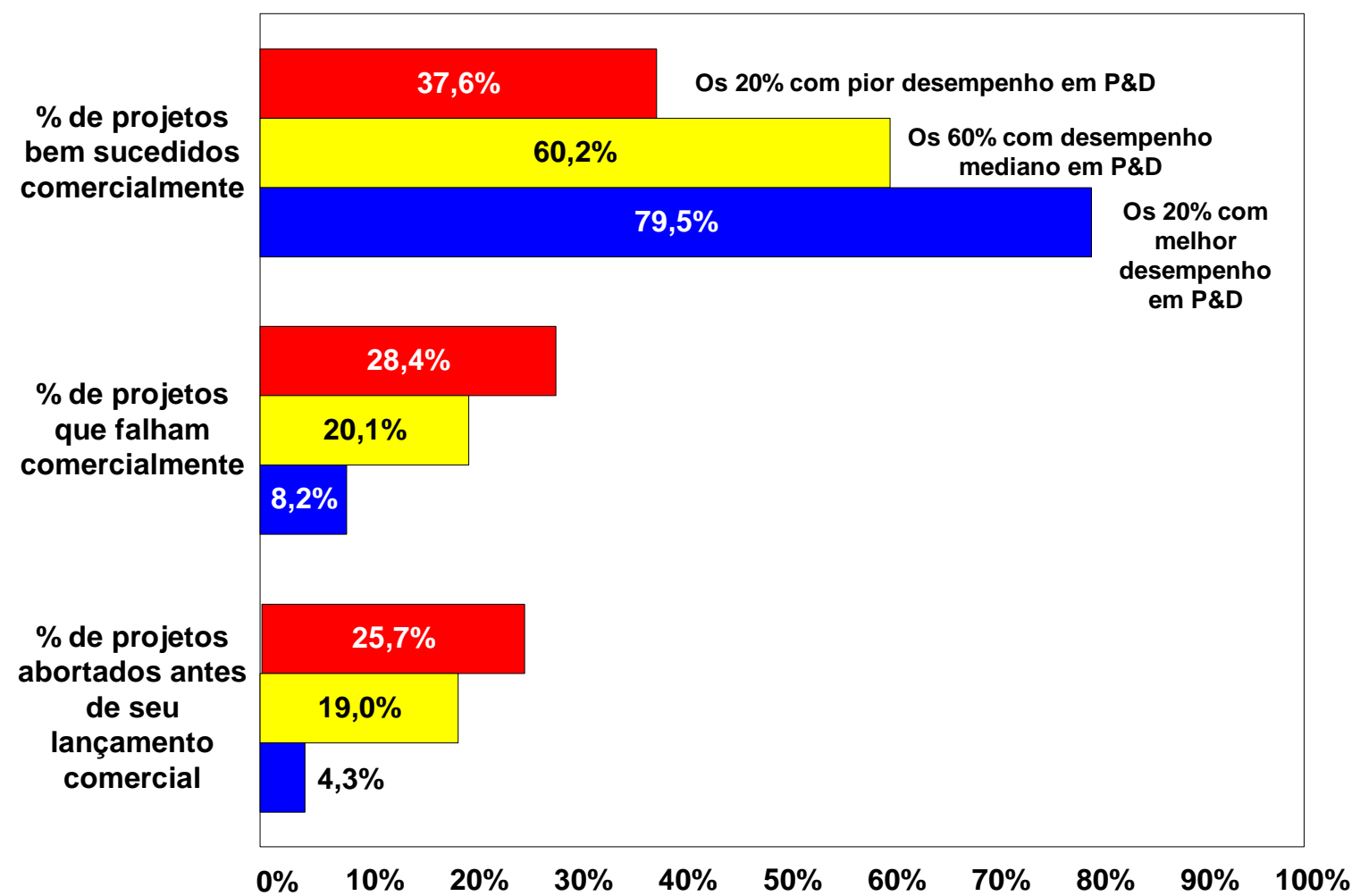

Figura 4.1 - Porcentual de novos produtos bem-sucedidos, que falharam e que foram abortados. (Cooper, Edgett e Kleinschmidt, 2004a)

Os autores citados no parágrafo anterior separam as empresas em três categorias (piores, medianas e melhores em desempenho), classificando-as conforme duas dimensões que consideram particularmente robustas:

- a rentabilidade total dos esforços em desenvolvimento de novos produtos, como atende aos objetivos do negócio, o sucesso que apresentam em relação aos concorrentes e como segue o cronograma.

- como os esforços de desenvolvimento de novos produtos permitem abrir novos mercados, tecnologias e categorias de produtos para o negócio.

As empresas que apresentam melhores desempenhos, quanto ao sucesso de lançamento de novos produtos, são aquelas que têm uma estratégia inovadora mais bem definida e, assim, conseguem melhores taxas de sucesso. Estas empresas têm uma melhor qualidade no seguimento de suas políticas de desenvolvimento (Cooper, Edgett e Kleinschmidt, 2004c). 
Numa indústria química, a taxa de sucesso de novos produtos pôde ser identificada conforme resumido na tabela 4.1 (Daft, 2002),

Tabela 4.1 - Taxa de sucesso de novos produtos em relação a concepções iniciais de produtos possíveis de serem realizados - Reproduzido de Daft (2002).

\begin{tabular}{|lc|}
\hline $\begin{array}{l}\text { Etapas no processo de desenvolvimento de um novo } \\
\text { produto }\end{array}$ & Taxa de sucesso \\
\hline $\begin{array}{l}\text { Alcançam o estágio em que todos os problemas técnicos } \\
\text { foram resolvidos e os projetos transferidos para a } \\
\text { produção }\end{array}$ & $57 \%$ \\
\hline Colocado à venda e efetivamente comercializado & $31 \%$ \\
\hline Alcançam sucesso econômico & $12 \%$ \\
\hline
\end{tabular}

Os números mostrados nessa tabela reforçam a importância de contribuições que auxiliem as empresas a procurar mecanismos para a redução dos fracassos, pois o número daqueles produtos que alcançam sucesso é muito baixo.

Uma análise mais completa das condições de sucesso de cada tipo de inovação foi proposta por Roussel, Saad e Bohlin (1992, p. 59), que analisam as condições ligadas a cada um de três tipos de P\&D, mostrada na tabela 4.2.

Nota-se que os autores fazem uma análise dos resultados médios encontrados em diferentes tipos de indústrias, de maneira a permitir que as informações sejam orientativas para um estudo amplo dos cuidados em inovar. Há de se considerar que os tempos aqui indicados devem ter sido alterados em decorrência de mudanças tecnológicas e organizacionais implementadas nos últimos anos nos processos de desenvolvimento de novos produtos. Também é importante notar que os resultados mostrados na tabela 4.2 tratam, principalmente, do processo de $P \& D$ e não, necessariamente, daqueles decorrentes do desenvolvimento de novos produtos e serviços. 
Tabela 4.2 - Características dos três tipos de P\&D . (Roussel, Saad e Bohlin (1992, p. 59)

\begin{tabular}{|c|c|c|c|c|}
\hline Tipo de P\&D & $\begin{array}{l}\text { Probabilidade } \\
\text { de sucesso } \\
\text { técnico }\end{array}$ & $\begin{array}{l}\text { Tempo para } \\
\text { conclusão }\end{array}$ & $\begin{array}{l}\text { Potencial } \\
\text { competitivo }\end{array}$ & $\begin{array}{l}\text { Duração da } \\
\text { vantagem } \\
\text { competitiva } \\
\text { conquistada }\end{array}$ \\
\hline Incremental & $\begin{array}{l}\text { Muito alta, } \\
\text { tipicamente de } \\
40 \text { a 80\%. }\end{array}$ & $\begin{array}{llll}\text { Curto, } 6 \text { a } 24 \\
\text { meses }\end{array}$ & $\begin{array}{l}\text { Modesto, mas } \\
\text { necessário. }\end{array}$ & $\begin{array}{l}\text { Curta, } \\
\text { tipicamente } \\
\text { imitável pelos } \\
\text { concorrentes. }\end{array}$ \\
\hline Radical & $\begin{array}{l}\text { Modesta nos } \\
\text { primeiros } \\
\text { estágios, } \\
\text { tipicamente de } \\
20 \text { a } 40 \% .\end{array}$ & $\begin{array}{l}\text { Modesto, } 2 \text { a } 7 \\
\text { anos. }\end{array}$ & Grande. & $\begin{array}{l}\text { Longa, muitas } \\
\text { vezes } \\
\text { patenteável. }\end{array}$ \\
\hline Fundamental & $\begin{array}{l}\text { Difícil de avaliar } \\
\text { nos primeiros } \\
\text { estágios; } \\
\text { depende do } \\
\text { conceito de } \\
\text { P\&D. }\end{array}$ & $\begin{array}{l}\text { Longo, de } 4 \text { a } \\
10 \text { anos. }\end{array}$ & Grande. & $\begin{array}{l}\text { Longa, muitas } \\
\text { vezes passível } \\
\text { de proteção, por } \\
\text { ser patenteável. }\end{array}$ \\
\hline
\end{tabular}

Uma consideração óbvia para aumentar a taxa de sucesso de novos produtos é a proposta de que seu desenvolvimento seja feito de maneira que eles sejam percebidos de forma diferenciada, com benefícios únicos aos consumidores e agregando valor aos seus usuários. Quando estas considerações são levadas em conta no desenvolvimento de novos produtos, aqueles que as incorporam podem proporcionar, em relação àqueles que não as incorporam, os seguintes resultados: sucesso até cinco vezes maior, participação de mercado acima de quatro vezes e lucratividade superior até quatro vezes. (Cooper, 2000)

Por outro lado, há algumas armadilhas que conduzem à maior probabilidade de fracasso e que podem ser identificadas, como as listadas abaixo (Cooper, 2000; Datta e Mukherjee, 2001; Rimoli, 2001; Slack, Chambers e Johnston, 2002; Rogers, 2003): 
- Produtos idênticos ou muito parecidos aos dos concorrentes - quando a tendência normal de imitar o sucesso de concorrentes conduz, muitas vezes, a disputas baseadas em preço (normalmente uma condição que ocorre no estágio do ciclo de vida de maturidade ou declínio do produto);

- "Monumentos" à criatividade da área de engenharia - quando são desenvolvidos produtos que precisarão aguardar o surgimento do mercado para seu uso ou aplicação;

- Preocupação excessiva com a redução do ciclo de vida do projeto e dos custos de desenvolvimento - conduzindo à necessidade de reduzir a extensão das inovações, situação típica de novos produtos decorrentes de inovações contínuas;

- Pouco tempo de pesquisa do mercado, necessidades dos concorrentes e posicionamento da tecnologia - conduzindo a leituras erradas e viciadas do real potencial do novo produto;

- Despreocupação em relação ao mercado alvo - desconhecer ou ignorar o mercado de destino do novo produto é outro fator que conduz ao fracasso;

- Inexistência de critérios ou filtros de seleção das idéias e conceitos durante todo o processo de desenvolvimento - não analisar a viabilidade (investimentos necessários), a aceitabilidade (retorno) e a vulnerabilidade (riscos) de um conceito em desenvolvimento é outra armadilha para não se alcançar o sucesso;

- Abordagem seqüencial no desenvolvimento de novos produtos conduzindo a uma excessiva burocratização e perda da criatividade, além do tempo correto de entrada de mercado; 
- Desenvolvimento de novos produtos que desconsideram diferentes características de grupos de consumidores, na decisão de aceitar ou não um novo produto, quando da percepção de sua existência.

- Desconhecimento ou subestimação do processo de difusão de seus produtos entre os potenciais usuários, como se depreende do estudo de Rimoli (2001), que, mesmo tendo sido focalizado em um segmento específico, poderia ter questionada sua extensão a outros segmentos.

Os aspectos listados demonstram uma série de fatores que concorrem para dificultar o sucesso de uma inovação e que a estratégia de inovação de uma empresa precisa tomar certos cuidados para aumentar a chance de sucesso econômico de uma nova idéia.

As considerações apresentadas até o momento indicam que o processo de inovar não pode ser casual, sem o cuidado de uma integração de diversos e diferentes aspectos na estratégia empresarial.

\section{3 - O marketing na estratégia de inovação}

A inovação, apesar de ser um processo de alto risco, é fundamental para o sucesso de uma empresa. Porter (1999, p. 174) reforça que "as empresas atingem a vantagem competitiva através das iniciativas de inovação. Elas abordam a inovação no seu sentido mais amplo, abrangendo novas tecnologias e novas maneiras de fazer as coisas". Churchill Jr e Peter (2000, p. 279) afirmam que o líder de mercado tende a ser inovador.

É natural que uma das áreas que apresentam uma forte contribuição para o sucesso de uma inovação no mercado é a área de marketing, o que implica na necessidade da compreensão de seu papel na estratégia de inovação. Além do mais, apesar de ser fator fundamental para o sucesso de um novo produto, a passagem dos dados de forma consistente do marketing para as áreas de P\&D é, muitas das vezes, superficial, como resumem Urban e Hauser (1993, p. 31) 
na tabela 4.3, mostrada adiante. A importância de um bom processo de comunicação entre marketing e P\&D é fundamental para a inovação (Van Den Bulte e Moenaert, 1998; Lievens e Moenaert, 2001). A estratégia das empresas deve incluir os canais de comunicação internos como um dos fatores para o seu sucesso (Nonaka e Takeuchi,1997; Parente, Pegels e Suresh, 2002; Amidon, 2003; Cavusgil, Calantone e Zhao, 2003).

Marketing pode ser definido como "o processo de planejar e executar a concepção, o apreçamento, a promoção e a distribuição de idéias, bens e serviços para criar trocas que satisfaçam os objetivos individuais $e$ organizacionais..... Quando as duas partes (cliente e empresa) podem se comunicar e entregar os bens e serviços desejados, a troca pode ocorrer." McDaniel e Gates (2003).

Um reforço à importância do marketing pode ser identificado em Churchill Jr. e Peter (2000) que, ao analisarem os motivos que levam novos produtos ao fracasso, informam que a principal razão "é a incapacidade de adequar o produto aos desejos e necessidades dos clientes. As organizações carecem dessa capacidade quando não pesquisam completamente as necessidades dos clientes..." A literatura é bastante vasta sobre a importância do marketing, como coletar dados e tratá-los, de forma a permitir que a empresa possa definir estrategicamente seu negócio (Davies-Cooper e Jones, 1995). É papel do marketing a clara definição do mercado alvo, ao longo do ciclo de vida do produto, e como serão incorporadas as diferentes necessidades de cada um dos grupos que predominam em todas as etapas do ciclo de vida do produto (Rosen, Schroeder e Purinton, 1998).

Estando clara a participação do marketing no processo de inovação, depreende-se da tabela 4.3 que as pesquisas relacionadas demonstram alguns fatores fundamentais para o sucesso no desenvolvimento de novos produtos: sinergia entre áreas, comunicação estruturada, cooperação e trabalhos de desenvolvimento integrados. Apesar de reconhecida esta importância, grande parte das empresas americanas não o fazem (Tracey, 2004). 
Tabela 4.3 - Exemplos de evidência científica que sugere que a comunicação entre marketing e P\&D aumentam a chance de sucesso de novos produtos - (Grifin e Hauser, 1992 em Urban e Hauser, 1993, p. 31)

\begin{tabular}{|c|c|c|c|}
\hline Pesquisa feita por & Amostragem & Tipo de empresa & Evidências (lista parcial das evidências encontradas) \\
\hline Cooper (1983) & 58 projetos & Indústria em geral & $\begin{array}{l}\text { Projetos que equilibram entradas de marketing e P\&D têm maiores } \\
\text { chances de sucesso. }\end{array}$ \\
\hline Cooper (1984) & 122 empresas & $\begin{array}{l}\text { Eletrônica, } \\
\text { equipamentos } \\
\text { pesados, química e } \\
\text { materiais }\end{array}$ & $\begin{array}{l}\text { Estratégias gerenciais que equilibram entradas de marketing e P\&D } \\
\text { têm uma maior porcentagem de sucesso em seus novos produtos e } \\
\text { maior porcentagem de retorno das vendas provindas de seus novos } \\
\text { produtos. }\end{array}$ \\
\hline $\begin{array}{l}\text { Cooper e de Brentani } \\
\text { (1991) }\end{array}$ & 106 projetos & Serviços financeiros & $\begin{array}{l}\text { Sinergia (isto é, integração entre especialistas da empresa, } \\
\text { habilidades gerenciais e recursos em pesquisa de mercado) foi a } \\
\text { correlação básica de sucesso (correlação }=0,45 \text { ). }\end{array}$ \\
\hline $\begin{array}{l}\text { Cooper e Kleinschmidt } \\
\text { (1987) }\end{array}$ & $\begin{array}{l}125 \text { empresas, } 203 \\
\text { projetos }\end{array}$ & Manufatura & $\begin{array}{l}\text { Sinergia com o mercado e sinergia tecnológica estão ambas } \\
\text { relacionadas significativamente com o sucesso. }\end{array}$ \\
\hline Dougherty (1987) & 5 empresas, 16 projetos & $\begin{array}{l}\text { Indústria, consumidor e } \\
\text { serviços }\end{array}$ & $\begin{array}{l}\text { Maior comunicação e comunicação entre todos os participantes } \\
\text { separam os projetos bem-sucedidos daqueles que foram } \\
\text { malsucedidos. }\end{array}$ \\
\hline de Brentani (1989) & $\begin{array}{l}115 \text { empresas, } 276 \\
\text { projetos }\end{array}$ & $\begin{array}{l}\text { Serviços financeiros, } \\
\text { serviços gerenciais, } \\
\text { transporte, } \\
\text { comunicação }\end{array}$ & $\begin{array}{l}\text { Vendas, participação de mercado e redução de custos estão } \\
\text { correlacionados com a comunicação entre funções (correlação entre } \\
\text { vendas e participação de mercado }=0,38 \text {, correlação com redução } \\
\text { de custos }=0,29 \text { ). }\end{array}$ \\
\hline $\begin{array}{l}\text { Gupta, Raj e Wilemon } \\
\text { (1985) }\end{array}$ & $\begin{array}{lr}167 \text { empresas, } 107 \\
\text { executivos de } P \& D, 109 \\
\text { executivos de marketing }\end{array}$ & Alta tecnologia & $\begin{array}{l}\text { Falta de comunicação foi listada como uma das barreiras primárias } \\
\text { para conseguir integração entre marketing e P\&D. }\end{array}$ \\
\hline
\end{tabular}


Tabela 4.3 (continuação) - Exemplos de evidência científica que sugere que a comunicação entre marketing e P\&D aumentam a chance de sucesso de novos produtos. (Grifin e Hauser, 1992 em Urban e Hauser, 1993, p. 31)

\begin{tabular}{|c|c|c|c|}
\hline $\begin{array}{l}\text { Hise, O'Neal, } \\
\text { Parasuraman e McNeal } \\
\text { (1990) }\end{array}$ & $\begin{array}{l}252 \text { vice-presidentes de } \\
\text { marketing }\end{array}$ & $\begin{array}{l}\text { Grandes empresas de } \\
\text { manufatura }\end{array}$ & $\begin{array}{l}\text { Alto nível de esforço conjunto no projeto de novos produtos é um } \\
\text { fator significativo na determinação do sucesso. Isto é verdadeiro } \\
\text { para ambos os segmentos: industrial e de bens de consumo. }\end{array}$ \\
\hline $\begin{array}{l}\text { Moenaert e Souder } \\
\text { (1990) }\end{array}$ & Revisão da literatura & Produtos e serviços & $\begin{array}{l}\text { Integração das funções está relacionada positivamente ao sucesso } \\
\text { inovativo. }\end{array}$ \\
\hline Pelz e Andrews (1966) & $\begin{array}{l}1311 \text { cientistas e } \\
\text { engenheiros }\end{array}$ & $\begin{array}{l}\text { Cientistas } \\
\text { engenheiros }\end{array}$ & $\begin{array}{l}\text { Relacionamento positivo entre } 0 \text { número de interações e o } \\
\text { desempenho. }\end{array}$ \\
\hline Pinto e Pinto (1990) & $\begin{array}{l}72 \text { grupos em hospitais, } \\
262 \text { participantes }\end{array}$ & Serviços de saúde & $\begin{array}{l}\text { Forte correlação entre cooperação interfuncional e o sucesso } \\
\text { (resultados das tarefas percebidas e resultados psicossociais) do } \\
\text { projeto (correlação }=0,71 \text { ). }\end{array}$ \\
\hline Souder (1988) & $\begin{array}{l}56 \text { empresas, } 289 \\
\text { projetos }\end{array}$ & Consumo e indústria & $\begin{array}{l}\text { Maior a harmonia entre marketing e P\&D, melhor a perspectiva de } \\
\text { sucesso. }\end{array}$ \\
\hline $\begin{array}{l}\text { Takeuchi e Nonaka } \\
\text { (1986) }\end{array}$ & $\begin{array}{l}6 \text { projetos nos EUA e } \\
\text { Japão }\end{array}$ & Consumo e indústria & $\begin{array}{l}\text { Fertilização cruzada e grupos auto-organizados conduzem ao } \\
\text { sucesso. }\end{array}$ \\
\hline
\end{tabular}


É claro que um dos cuidados, na elaboração de um correto processo de desenvolvimento de novos produtos, passa pela melhoria dos canais de comunicação e pela integração das diversas áreas envolvidas nesse processo. Rimoli (2000) reforça a importância da integração, para que aumente a probabilidade de sucesso de um novo produto. Porém, não há como informar, integrar, se as entradas de dados dos consumidores (a serem realizadas pelo marketing) não forem executadas corretamente. A discussão sobre como ocorre a coleta de informações e necessidades dos consumidores e respectivas ferramentas já está bastante consolidada na literatura de marketing. Como ela ocorre, para fins de desenvolvimento de novos produtos, está resumida na tabela 4.4, proposta por Nijssen e Frambach (1998).

Tabela 4.4 - Relação entre os diferentes estágios no desenvolvimento de novos produtos e as ferramentas aplicáveis para auxilio ao Marketing. (Nijssen e Frambach, 1998)

\begin{tabular}{|c|c|}
\hline $\begin{array}{l}\text { Questões básicas } \\
\text { sobre novos produtos }\end{array}$ & Ferramentas aplicáveis \\
\hline Que produto desenvolver? & $\begin{array}{l}\text { Brainstorming, análise morfológica, sinética }{ }^{4.2} \text { ("synectics"), grupos } \\
\text { de foco, observação do usuário, método Delphi. }\end{array}$ \\
\hline $\begin{array}{l}\text { Como deveria ser o produto } \\
\text { projetado? }\end{array}$ & $\begin{array}{l}\text { Conjoint Análise, QFD - desdobramento da função qualidade, } \\
\text { teste de conceito, teste de protótipo, teste de uso real. }\end{array}$ \\
\hline Como introduzir o produto? & $\begin{array}{l}\text { Minitestes, teste de simulação de mercado, avaliação limitada de } \\
\text { mercado, investigação de mercado, teste de mercado. }\end{array}$ \\
\hline $\begin{array}{l}\text { Qual é a previsão antecipada } \\
\text { de sucesso do novo produto? }\end{array}$ & $\begin{array}{l}\text { Modelos de predição de mercado, modelos de difusão, modelos } \\
\text { econômicos (Análise do ROI - retorno sobre investimento; prazo } \\
\text { de retorno). }\end{array}$ \\
\hline
\end{tabular}

4.2 É uma abordagem de solução de problemas em grupo. Projetada para explorar os diversos recursos de grupos, é utilizada em situações onde um indivíduo sozinho não consegue resolver um determinado problema. Permite envolver outros indivíduos interessados no processo, que podem ser clientes (consumidores ou usuários), corpo organizacional (gerentes de linha ou especialistas), recursos externos como pessoas e membros de instituições, ou então os diversos "stakeholders".(Georgiou, 1994) 
A importância do marketing para o processo de desenvolvimento de novos produtos fica demonstrada, e também fica reforçada a sua necessidade em compreender o consumidor.

\section{4 - O consumidor e a estratégia de inovação}

Estabelecido o envolvimento do marketing com o processo de inovação e de sua interface com o consumidor dos novos produtos, há de se proceder a uma rápida análise de algumas das características do consumidor, pois é importante identificar como ocorre o processo de entendimento e tradução das necessidades e desejos do mercado.

Pode-se afirmar que as pessoas reagem de maneira diferente em relação ao desconhecido, mas, em média, tendem a ser conservadoras; vai daí que quanto menor a alteração introduzida na inovação oferecida, menor o índice de rejeição e mais acentuado o processo de difusão da inovação. Segundo Rogers (2003), os grupos sociais têm conceitos e paradigmas que bloqueiam a percepção das vantagens decorrentes de uma inovação. O mesmo autor enfatiza que as redes sociais, o processo de aceitação pelos pares e o processo de comunicação entre os diversos segmentos de uma determinada sociedade implicam em aspectos fundamentais para o sucesso de uma inovação. Conforme inúmeros casos relatados por ele, não observar que as percepções variam entre diferentes pessoas de um grupo social pode conduzir ao fracasso da empreitada. Não abordar os segmentos corretos (neste processo) pode reduzir ou até impossibilitar o processo de aceitação. O autor ainda ressalta que permitir a reinvenção, isto é, a possibilidade de o usuário alterar ou adaptar uma inovação, aumenta a possibilidade de aceitação e uso da inovação. Tais considerações são reforçadas por outros autores (Holak e Lehmann, 1990; Strang e Soule, 1998; Rapaille, 2001; Goffin e New, 2001; Babbar, Behara e White, 2002; Spolaore e Wacziarg, 2005). 
Outro aspecto a ser considerado nos dados de entrada para a correta compreensão dos desejos dos consumidores é mostrado por Rosen, Schroeder e Purinton (1998), na tabela 4.5.

Tabela 4.5 - Foco do cliente versus foco da empresa. Reproduzido de Rosen, Schroeder e Purinton (1998).

\begin{tabular}{|l|l|}
\hline \multicolumn{1}{|c|}{ Foco do cliente } & \multicolumn{1}{c|}{ Foco da empresa } \\
\hline Características & Projeto \\
\hline Conseqüências, ganhos obtidos & Custo \\
\hline Facilidade na operação & Facilidade para produzir \\
\hline Qualidades únicas & Tecnologias proprietárias \\
\hline Consumo & Produção \\
\hline
\end{tabular}

A comparação feita pelos autores mostra que a empresa deve perceber que a visão do cliente não é imediatamente correspondida pelas expectativas ou leituras feitas pela empresa, e que isso pode significar dificuldades de interpretação. A essa condição some-se que há restrições e dificuldades na incorporação das necessidades dos consumidores nas fases iniciais de um novo projeto. A compreensão das necessidades dos consumidores é importante para o sucesso de um novo produto. (Sua, Chenb e Shab, 2005)

Todavia, é importante ressalvar que estudos conduzidos por Berthon, Hulbert e Pitt (2004) concluem que uma visão estratégica voltada somente ao atendimento dos desejos dos consumidores pode conduzir a empresa a desenvolvimentos incrementais de inovações, inibindo a aplicação de estratégias de inovações radicais. Por outro lado, empresas voltadas somente à importância da inovação conseguem melhores resultados em estratégias de inovações radicais, sendo menos propensas a competir em mercados estáveis, onde as inovações incrementais são estratégias preponderantes. Os mesmos autores discutem que empresas voltadas a estratégias de inovações radicais têm maior sucesso em ambientes mais turbulentos e instáveis, enquanto as demais saem-se melhor em ambientes mais estáveis e controlados. 
Segundo as diversas análises feitas neste capítulo, a importância da inovação é demonstrada como importante para a estratégia das empresas, devendo ser parte das preocupações da empresa no caminho do sucesso. Alguns pontos a serem incorporados à definição da estratégia de uma empresa incluem: a melhoria da comunicação entre as áreas da empresa, a compreensão das necessidades dos consumidores, as relações sociais, os riscos de focalização excessiva em temas específicos e prioridades pessoais. Mas as respostas às seguintes questões não estão claras: Os consumidores demonstram igualmente as mesmas percepções sobre uma inovação e um novo produto? Como isso ocorre e se ocorre de maneira uniforme entre a população? Como isso deve ser considerado na estratégia de inovação de uma empresa? Por que é importante analisar este problema?

Um outro fator conduz à preocupação em relação ao estudo do tema difusão da inovação e pode ser retratado pela afirmação de Hall (2004):

"Tradicionalmente, a difusão é um dos três pilares sobre o qual se apóia a introdução bem-sucedida de novos produtos, processos e práticas que adentram a sociedade, sendo os outros dois a invenção (uma nova idéia) e a comercialização / inovação (redução de uma invenção à prática). De alguma maneira é a parte mais fácil do processo porque é mais previsível por meios observáveis que os outros dois."

O próximo capítulo discutirá o tema difusão da inovação, no intuito de verificar o que a literatura tem manifestado a esse respeito, e se essas questões já foram esclarecidas. 


\section{5- O processo de difusão da inovação}

\section{1 - Como as pessoas percebem a inovação}

Como o propósito desta tese é a análise da forma como o processo de difusão da inovação pode ser incorporado na definição das estratégias de inovação das empresas, este capítulo procurará discorrer sobre este processo. Ao seu final, espera-se que o fenômeno de difusão seja compreendido como mais um dos fatores que impõem cuidados e merece ser considerado para que ocorra 0 sucesso econômico de um novo produto.

As pessoas são influenciadas por um grande número de fatores que moldam seu comportamento, entre eles os valores adquiridos da família, da cultura e da sociedade em que vivem. A esse conjunto de fatores devem-se acrescentar os econômicos, os decorrentes da educação formal recebida, etc. Em função desse contexto, diferentes pessoas reagem de maneira diversa a determinadas condições com as quais se defrontam. Os traços de comportamento se manifestam de maneira diferente e, assim, é possível distinguir várias categorias de indivíduos numa determinada população. Vários estudiosos procederam a classificações específicas, em diversas áreas de estudo, para melhor compreender o ser humano e propor algum modelo da realidade, na expectativa de compreendê-la (Dubois, 1993; Bemowski, 1995a; Bemowski, 1995b; Bemowski, 1996; Gardner, Kornhaber e Wake, 1998; Catânia, 1999; Rapaille, 2001).

Conforme discutido, na introdução deste trabalho, a preocupação com o tema vem do início do século XX, sendo analisada por setores como a sociologia, antropologia, economia, marketing, etc. A partir dos anos de 1950, com a contribuição realizada por Everett Rogers, o tema difundiu-se, ganhou importância, e passou a ser denominado de difusão da inovação (Strang e Soule, 1998; Schiffman e Kanuk, 2000; Engel, Blackwell e Miniard, 2000; Wejnert, 2002; Hall, 2004; Akhavein, Frame e White, 2005; Langley, Pals e Ortt, 2005; Deffuant, Huet e Amblard, 2005). 
Segundo Rogers (2003, p. 282-5), a resposta dos indivíduos a um novo produto permite classificá-los conforme cinco tipos principais: ${ }^{5.1}$

- Inovadores (innovators) - uma característica que poderia defini-los seria a de empreendedorismo. O padrão desse tipo de indivíduos é o desafio, o desejo de assumir riscos. Têm postura mais cosmopolita e se aproximam de grupos exclusivos e de interesse comum. Pré-requisitos razoavelmente comuns entre eles são: melhores condições financeiras para assumir os riscos de inovar, capacidade de compreender a tecnologia e seus desenvolvimentos de maneira mais ampla e desejo de assumir riscos inerentes à situação de ousar, bem como preparo para aceitar e recuperar-se de decisões e escolhas erradas. Não se preocupam em abandonar as referências do grupo social, em favor de uma inovação. O inovador, normalmente, não é muito considerado pelo grupo social no qual está inserido, mas desempenha importante papel ao servir de porta de entrada de novos conceitos desenvolvidos fora daquele grupo social;

- adotantes iniciais (early adopters) - uma característica que os definiria seria a respeitabilidade. Identificam-se bem com o grupo social a que pertencem e são considerados como formadores de opinião pelo grupo. Por terem um enfoque mais local em seu relacionamento, atuam como referências para os demais grupos, servindo como ponte entre os inovadores e esses outros grupos. Servem como deflagradores do processo de difusão da inovação. São referências para os demais e são por estes consultados em relação à inovação e, portanto, sabem que devem ser críticos em relação a uma inovação, para que possam manter a condição de referencial. Reduzem a incerteza dos demais membros do grupo social em relação à inovação. Servem como aprovadores da inovação aos olhos dos demais;

\footnotetext{
${ }^{5.1}$ A tradução dos termos seguiu aquela encontrada nos livros de Schiffman e Kanuk (2000) e Engel, Blackwell e Miniard (2000).
} 
- maioria inicial (early majority) - uma característica básica deste grupo é a ponderação. Geralmente tendem a adotar a inovação antes da maioria e servem como importante ponte para a difusão para os demais membros dos outros grupos. Raramente lideram uma mudança, mas são importantes no processo de criação de uma massa crítica de adotantes da inovação. Em geral, demoram mais na sua decisão, analisando-a de forma cuidadosa. São importantes elos de conexão nas redes sociais do grupo por estarem conectados a muitos de seus membros;

- maioria tardia (late majority) - uma característica básica sua é o ceticismo. Tendem a adotar a inovação devido às pressões sociais de seus pares e a fatores econômicos. Somente adotam a inovação quando percebem que uma importante parcela do grupo social já a adotou. Evitam o risco, em parte por uma condição financeira mais restrita;

- retardatários (laggards) - uma característica sua é o tradicionalismo. Em muitos casos, isolam-se do grupo social a que pertencem. Tendem a se fechar em grupos que agem e pensam da mesma forma, e adotam uma inovação por falta de alternativas. São descrentes em relação a mudanças e preferem a condição existente, evitam mudanças. Adotam uma inovação quando ela está incorporada ao modo de vida do grupo social. Muitos adotam essa postura em função de uma condição financeira restrita. Evitam riscos.

Cabe aqui uma ressalva em relação a indivíduos que tenham uma visão muito diferente dos paradigmas praticados em um determinado momento, pois podem ser confundidos como retardatários em não aceitar uma determinada inovação ao perceberem desvantagens não vistas pelos demais. (Rogers, 2003, p. 194).

É também largamente aceito que se pode identificar uma distribuição do total de população nas diversas categorias, conforme mostrado na figura 5.1. 


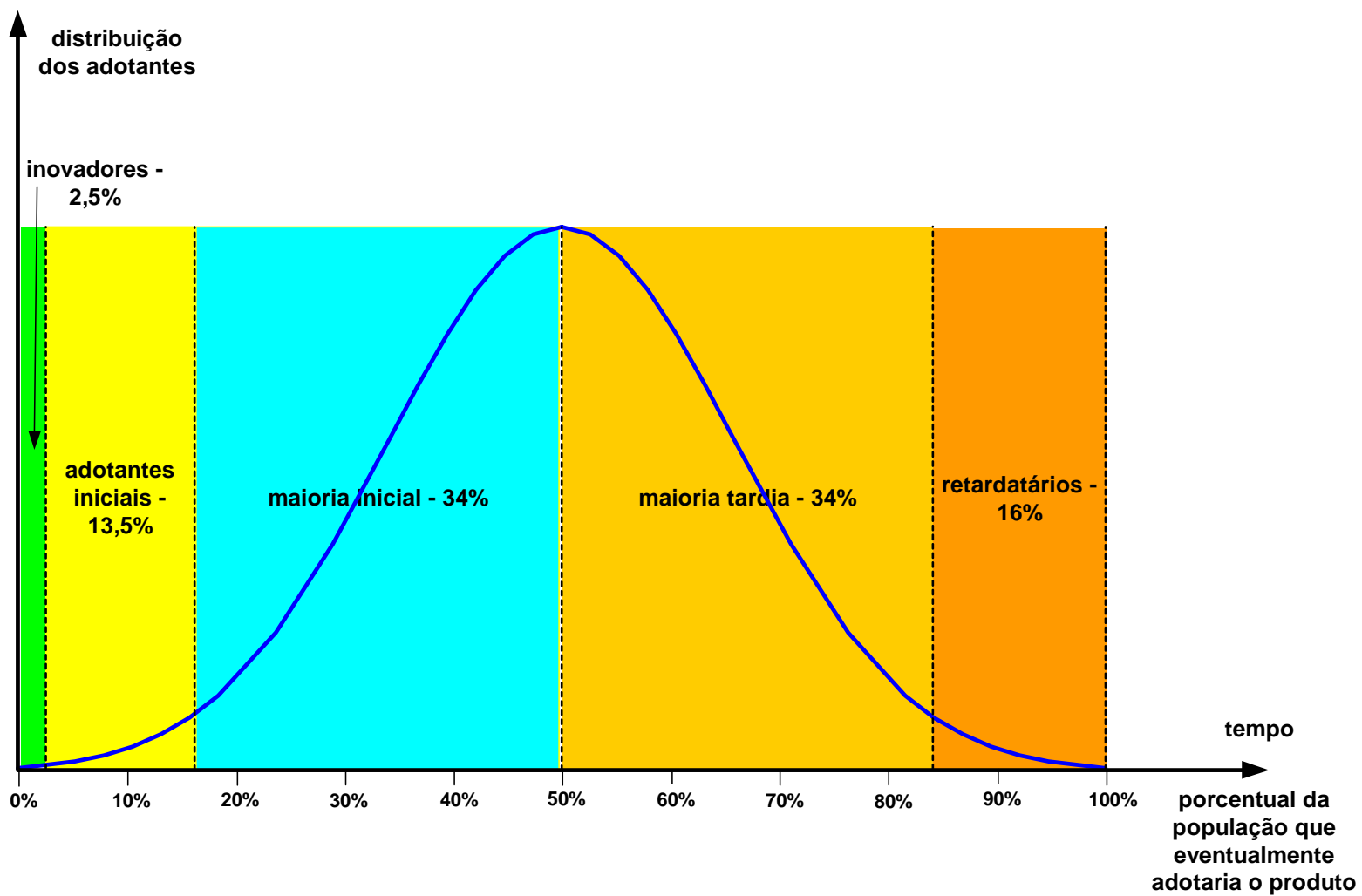

Figura 5.1 - Seqüência e proporção das categorias de adotantes entre a população que eventualmente o adotaria - Reproduzido de Rogers (2003) com explicações complementares do autor

A evolução desse processo de adoção pode ser relacionada a uma curva do tipo $\mathrm{S}$ de ciclo de vida de um produto e que pode ser vista na figura 5.2.

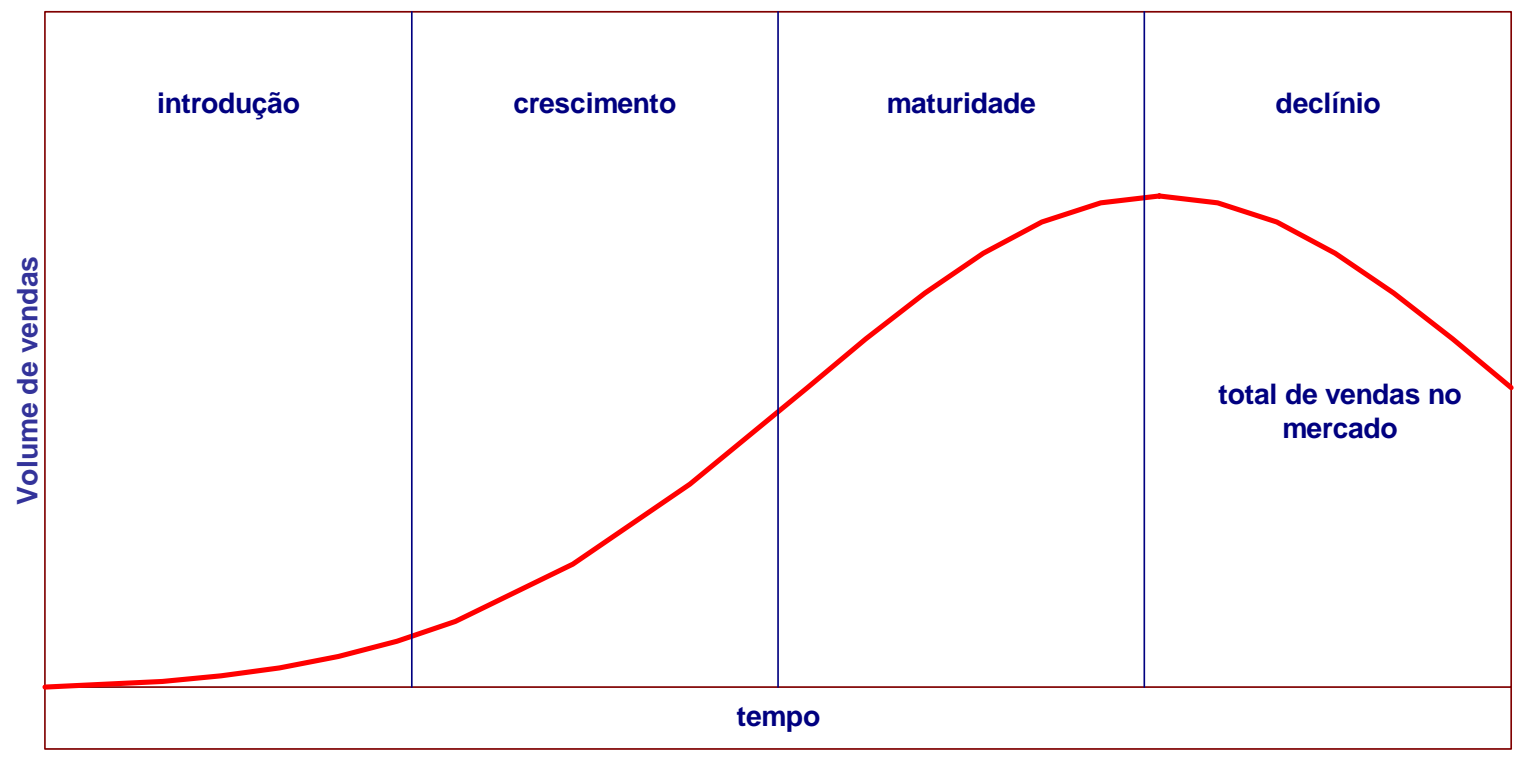

Figura 5.2 - Ciclo de vida de um produto / serviço. (Slack, Chambers e Johnston, 2002) O conceito de ciclo de vida é hoje considerado básico na literatura de marketing, produção e economia, mostrando um processo que representa as diversas etapas na vida de um produto ou serviço. Entretanto, um dos grandes desafios é a análise da fase inicial, conhecida como "ramp-up" - utilizado no 
setor produtivo ou "take-off" - utilizado no setor de marketing. Este ponto é considerado crucial para uma melhor administração e sucesso, quando do lançamento de um novo produto (Golder e Tellis, 1997; Terwiesch e Bohn, 2001; Montaguti, Kuester e Robertson, 2002; Tellis, Stremersch e Yin, 2003; Foster, Golder e Tellis, 2004).

Entre os diversos elementos que caracterizam o processo de difusão da inovação é clara a importância daqueles que permitem que o processo de difusão tenha início, ou seja possível: expertises - especialistas (Alba e Hutchinson, 1988); surrogate buyers - consultores de compras (Aggarwal, Cha e Wilemon, 1998); innovators e early adopters - inovadores e adotantes iniciais (Rogers, 2003); technovators - tecnófonos ou tecnoentusiasta ${ }^{5.2}$ (Saaksjarvi, 2003). Estas são denominações feitas por diversos autores para indicar e discutir a importância deste grupo no processo de difusão de inovações.

Parasuramam e Colby (2002, p. 36-45) propõem que os consumidores também podem ser classificados em cinco diferentes categorias e que cada uma delas tem um conjunto de crenças diferentes, conforme se vê na tabela 5.1.

Tabela 5.1 - Descrição das diferentes disposições para a tecnologia das pessoas em geral. Resumido de Parasuraman e Colby (2002)

\begin{tabular}{|ll|}
\hline Facetas de disposição para a tecnologia & Definição \\
\hline Otimismo (contribuinte) & Visão positiva da tecnologia e a crença de \\
& que ela oferece às pessoas maior \\
& controle, flexibilidade e eficiência. \\
Caráter Inovador (contribuinte) & Tendência a ser pioneiro em tecnologia e \\
& líder de pensamento. \\
Desconforto (inibidor) & Falta de controle percebido sobre a \\
& tecnologia e sentimento de ter sido \\
Insegurança (inibidor) & subjugado por ela. \\
& Desconfiança e ceticismo a respeito da \\
& capacidade da tecnologia em funcionar \\
& corretamente.
\end{tabular}

5.2 Tecnoentusiasta ou tecnófono - tradução utilizada em Engel, Blackwell e Miniard (2002) para designar pessoas que "ficam excitadas pela tecnologia em si, qualquer que seja o uso" e que coincide, de certa forma, com o conceito proposto por Saaksjarvi (2003). 
As características de cada uma das cinco categorias propostas por Parasuraman e Colby (2002) são apresentadas na tabela 5.2.

Tabela 5.2 - Crenças diferentes dos segmentos de adoção de tecnologia. (Parasuraman e Colby, 2002, p. 54)

\begin{tabular}{lcccc}
\hline & \multicolumn{2}{c}{ Contribuinte } & \multicolumn{2}{c}{ Inibidor } \\
\cline { 2 - 5 } & Otimismo & $\begin{array}{c}\text { Caráter } \\
\text { Inovador }\end{array}$ & Desconforto & Insegurança \\
\hline Exploradores & Alto & Alto & Baixo & Baixo \\
\hline Pioneiros & Alto & Alto & Alto & Alto \\
\hline Céticos & Baixo & Baixo & Baixo & Baixo \\
\hline Paranóicos & Alto & Baixo & Alto & Alto \\
\hline Retardatários & Baixo & Baixo & Alto & Alto \\
\hline
\end{tabular}

Dessa maneira, é possível traçar um paralelo das cinco categorias propostas por Rogers (2003) com aquelas propostas por Parasuraman e Colby (2002). Tais categorias podem ser entendidas como correspondentes, conforme tabela 5.3.

Tabela 5.3 - Comparação entre proposta de Rogers e Parasuraman / Colby

\begin{tabular}{|c|c|}
\hline Rogers (2003) proposta em 1962 & Parasuraman e Colby (2002) proposta em 2001 \\
\hline Inovadores & Exploradores \\
Adotantes iniciais & Pioneiros \\
Maioria inicial & Céticos \\
Maioria tardia & Paranóicos \\
Retardatários & Retardatários \\
\hline
\end{tabular}

Um cuidado deve ser tomado em relação à categoria inovador (Rogers, 2003) ou explorador (Parasuraman e Colby, 2002), quando se trata de novos produtos decorrentes de inovações descontínuas, pois esta condição pode ser percebida como negativa para a aceitação de um novo produto pelos inovadores, ao não conseguirem transferir sua "expertise" ao novo produto tendo como base o anterior similar ou correspondente, assim, induzindo que os 
inovadores dificultem o processo de difusão ao se sentirem inseguros (Moreau, Lehmann e Markman, 2001).

Um resumo dos diversos modelos de como ocorre o processo de adoção de um produto ou inovação é apresentado na figura 5.3. (Antil, 1988; Engel, Blackwell e Miniard, 2000).

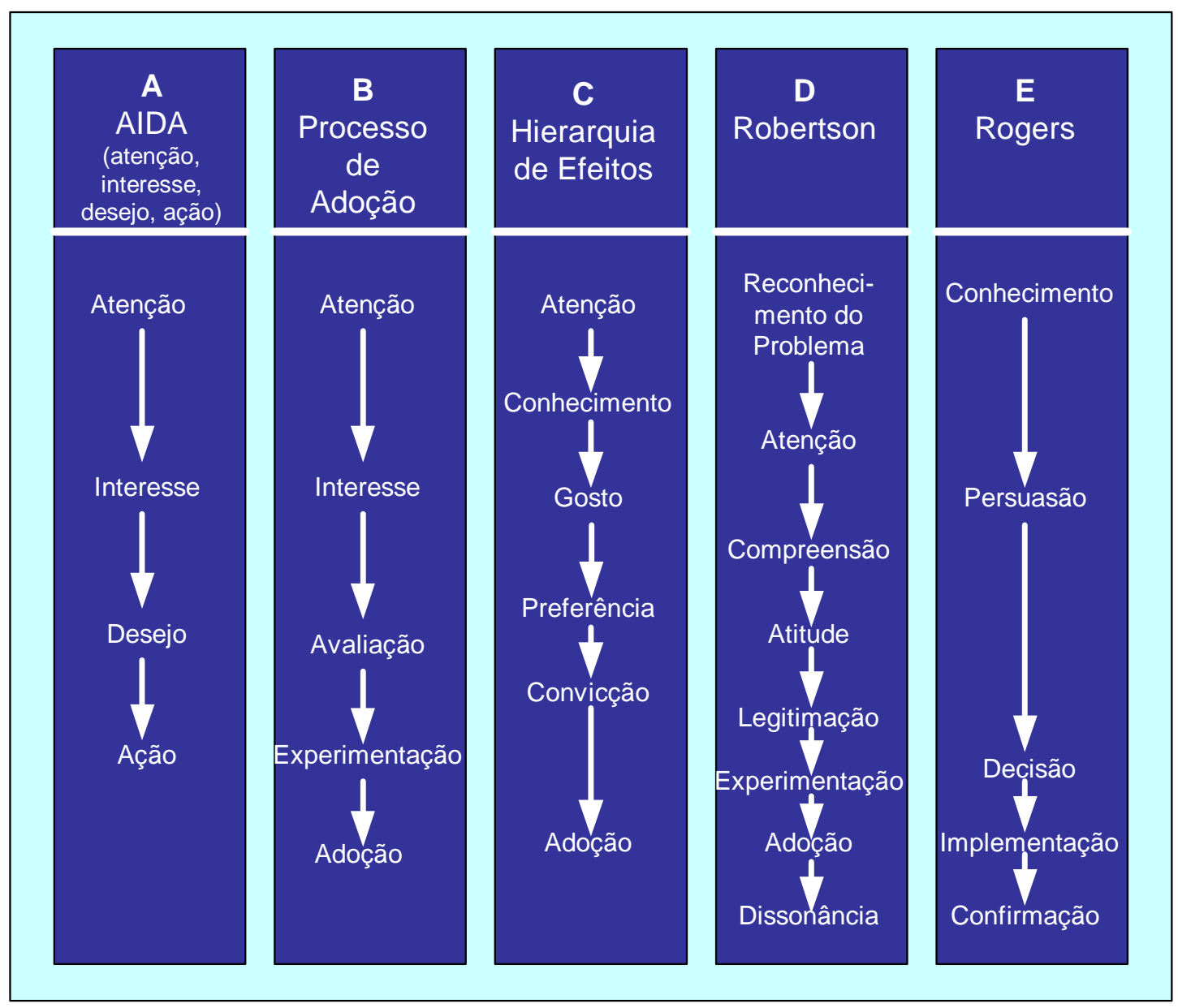

Figura 5.3 - Modelos de processo de adoção de uma inovação. Fonte: Antil (1988); Engel, Blackwell e Miniard (2000).

O processo de decisão de uma compra é um processo complexo e bastante discutido na literatura de marketing (Churchill Jr. e Peter, 2000; Jamal e Goode, 2001; Chandon, Morwitz e Reinartz, 2004; Gurley, Lin e Ballou, 2005).

Um resumo do processo de decisão de uma compra e que envolve um número grande de fatores está representado na figura 5.4 (Thomas, 1993, p. 55). 


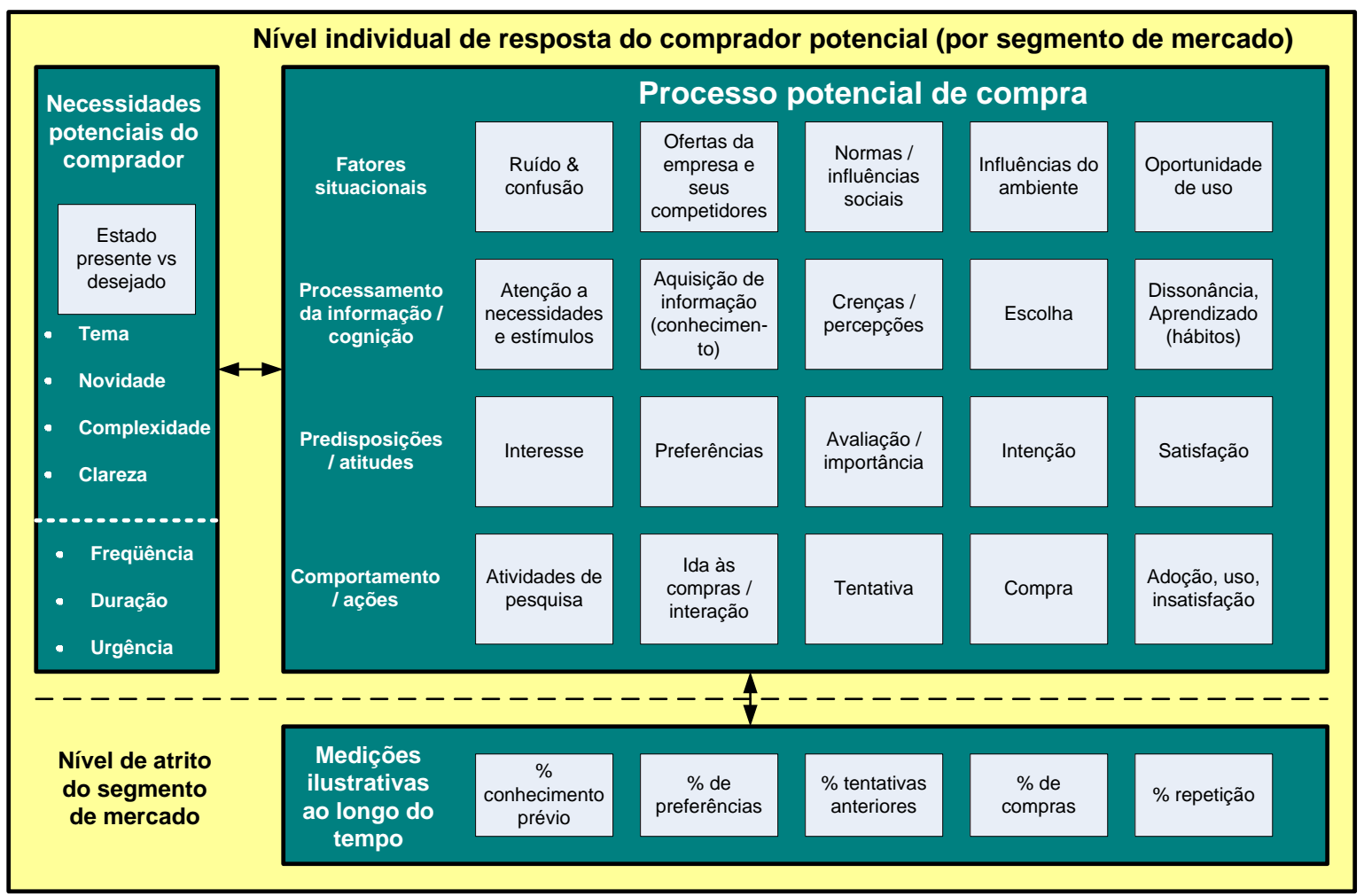

Figura 5.4 - Fatores que afetam o desenvolvimento de um novo produto tendo como foco o potencial comprador. Reproduzido de Thomas (1993, p. 55)

Segundo Thomas (1993, p. 56), o indivíduo é influenciado por diversos fatores na tomada de decisão para atender a seus desejos e necessidades. Esses fatores podem se encadear, como o caso de uma pessoa se alimentar de uma comida bastante salgada e em seguida sentir sede, sendo provocada a tomar água, ou então, desejar usar um determinado tipo de roupa para ser aceito por seu grupo.

A figura 5.4 (Thomas, 1993) mostra a participação de diferentes considerações que são feitas pelo comprador para atender a suas necessidades potenciais. Com base nas colocações do autor, é possível afirmar que o processo de difusão da inovação pode ser influenciado por:

- Tema - percepção individual da necessidade, como sede, frio, etc. Maior a percepção da necessidade, maior a busca por informações sobre o produto, maior a probabilidade de sua difusão; 
- Novidade - experiência anterior dos potenciais compradores e que influi no processo de decisão de aquisição - pode retardar o processo de adoção de um novo produto;

- Complexidade - extensão de recursos ou atributos desejados pelo comprador de maneira a atender a suas necessidades e expectativas; isto resulta em maior quantidade de informação a ser disponibilizada. A complexidade implica em mais tempo na decisão de compra, consultas a outras fontes para a criação de maior segurança na decisão;

- Clareza - implica na certeza ou precisão da compreensão das necessidades e de que elas serão atendidas; quanto maior a certeza do atendimento das necessidades manifestadas, mais rápido o processo de aquisição. Muitas vezes, principalmente para produtos realmente inovadores, essa certeza não existe, o que também retarda a adoção desses novos produtos;

- Freqüência - periodicidade com que a necessidade é manifestada. Maior a periodicidade que se manifesta o desejo, maior o interesse pelo produto, maior o nível de informação obtido, maior a velocidade na adoção de um novo produto;

- Duração - significa o tempo durante o qual o desejo permanece em nível consciente ou inconsciente, gerando tensão e retomada do desejo. Maior a duração do desejo, maior a probabilidade de difusão de um novo produto;

- Urgência - a percepção do tempo decorrente entre a manifestação do desejo e de seu atendimento pode ser afetada pela redução da tensão criada pela expectativa de satisfação de uma determinada necessidade. Quanto maior a urgência, mais rápido o processo de difusão de uma inovação.

Os fatores listados são influenciados por quatro aspectos comportamentais, que ocorrem em nível individual e são influenciadas por, no mínimo, cinco atividades que surgirão no início, durante ou após o processo de compra:

- Fatores situacionais - Ruído e confusão (gerados por diferentes percepções do grupo em relação ao produto ou por informações contraditórias); ofertas da empresa e de seus competidores (influem no crescimento de possíveis comparações sobre o produto e enriquecimento do nível de informação do potencial comprador); normas e influências sociais (fatores que limitam ou 
incentivam uma decisão pelo apelo do grupo ao qual o indivíduo pertence, e entre as quais pode colocar-se a moda); influências do ambiente (decorrentes de mudanças inevitáveis da tecnologia - cartões de acesso a contas bancárias por exemplo - ou de mudanças impostas pela legislação - uso da internet para envio de imposto de renda); oportunidades de uso (ocasiões especiais que permitem uma leitura diferenciada de um novo produto, decorrente de situações como férias, eventos sociais, etc.).

- Processamento da informação / cognição - Atenção a necessidades e estímulos (ocorre em nível racional ou cognitivo, pois o interesse despertado por um determinado assunto induz ao aumento do interesse na obtenção de informações sobre o novo produto - Alba e Hutchinson, 1987); aquisição de informação - conhecimento (conseqüência direta da atenção despertada e que invoca os conhecimentos similares ou anteriores existentes de experiências ou informações recebidas, quando o assunto parece ser importante para resolver um problema maior, o processo de procura de conhecimento - Catânia, 1999); crenças e percepções (os conhecimentos adquiridos ou recuperados são classificados de acordo com as experiências anteriores ou expectativas do que iria ou irá ocorrer (Boulding e outros, 1993) e, assim, são geradas expectativas sobre um novo produto); escolha (as crenças e percepções formam a base para a decisão de comprar ou não um novo produto e o nível de conhecimento e de expectativas despertadas completam a opção de comprar imediatamente, retardar a compra ou rejeitá-la); dissonância, aprendizado - hábitos (surgem dúvidas se a decisão de compra deva ser tomada, o que implica em busca de informações complementares para que a decisão possa ser tomada (Soutar e Sweeeney, 2003; Braun-La Tour e La Tour, 2005) e, efetuada a decisão, acontece o aprendizado do processo ocorrido e que pode ser armazenado na memória de curto ou longo prazo - Mowen e Minor,1998).

- Predisposições / atitudes - interesse (em função de uma necessidade ou simplesmente curiosidade, o potencial comprador tem sua atenção chamada para um produto, que pode ser um novo produto); preferências (o processo de escolha é baseado em condições que incluem aspectos como marca, cores, embalagens, design, etc. (Villas Boas, 2004) e esses podem ser fatores que 
despertam o interesse inicial por um novo produto); avaliação / importância (o comprador compara as informações obtidas e inicia a análise dos possíveis ganhos a serem obtidos com o novo produto - Conchar e outros, 2004); intenção (caso as etapas anteriores sejam identificadas positivamente, o comprador reforça sua atitude em experimentar ou comprar o novo produto Conchar e outros, 2004); satisfação (o atendimento das expectativas geradas pela experimentação ou pelo uso de um novo produto podem reforçar a atitude de recompra ou indicação a terceiros - Hegedus, 2000).

- Comportamento / ações - atividades de pesquisa (o processo de decisão implica na busca de informações que gerem segurança à tomada de decisão (Schoormans e outros, 1995) e isso é particularmente importante quando da identificação de um novo produto); ida às compras / interação (neste estágio é incrementado o processo de aquisição de informação e conhecimento sobre o novo produto); tentativa (a possibilidade de testar um produto novo permite que o comprador reforce negativamente ou positivamente as informações anteriormente conseguidas sobre o produto, seus benefícios. A possibilidade de "test-drives", amostras e a internet têm facilitado esse estágio); compra (envolve o atendimento das expectativas anteriormente geradas e que são ponderadas no estágio de negociação, crédito, disponibilidade, etc. - Gurley, Lin e Ballou, 2005); adoção (no caso de novos produtos, pode resultar na mudança dos padrões e valores anteriormente estabelecidos, conduzindo o comprador a um estágio de satisfação ou de rejeição. Em ambos os casos, ele se tornará um elemento a reforçar positiva ou negativamente o processo de divulgação do novo produto - Rosen, 2000; Alkemade e Castaldi, 2005).

A proposta de Thomas, discutida e complementada pelas leituras de diversos autores, permite que ela seja relacionada ao modelo de difusão da inovação proposto por Rogers e que é o próximo objeto da discussão. 


\section{2 - O processo de aceitação da inovação}

Entre os diversos modelos, mostrados na figura 5.3 para explicar o processo de aceitação de uma inovação, o mais discutido e reconhecido é aquele proposto por Rogers ${ }^{5.3}$, portanto, esse será o modelo tomado como base. A figura 5.5 mostra de maneira detalhada o modelo proposto por Rogers (2003) para o processo de decisão em relação a uma inovação.

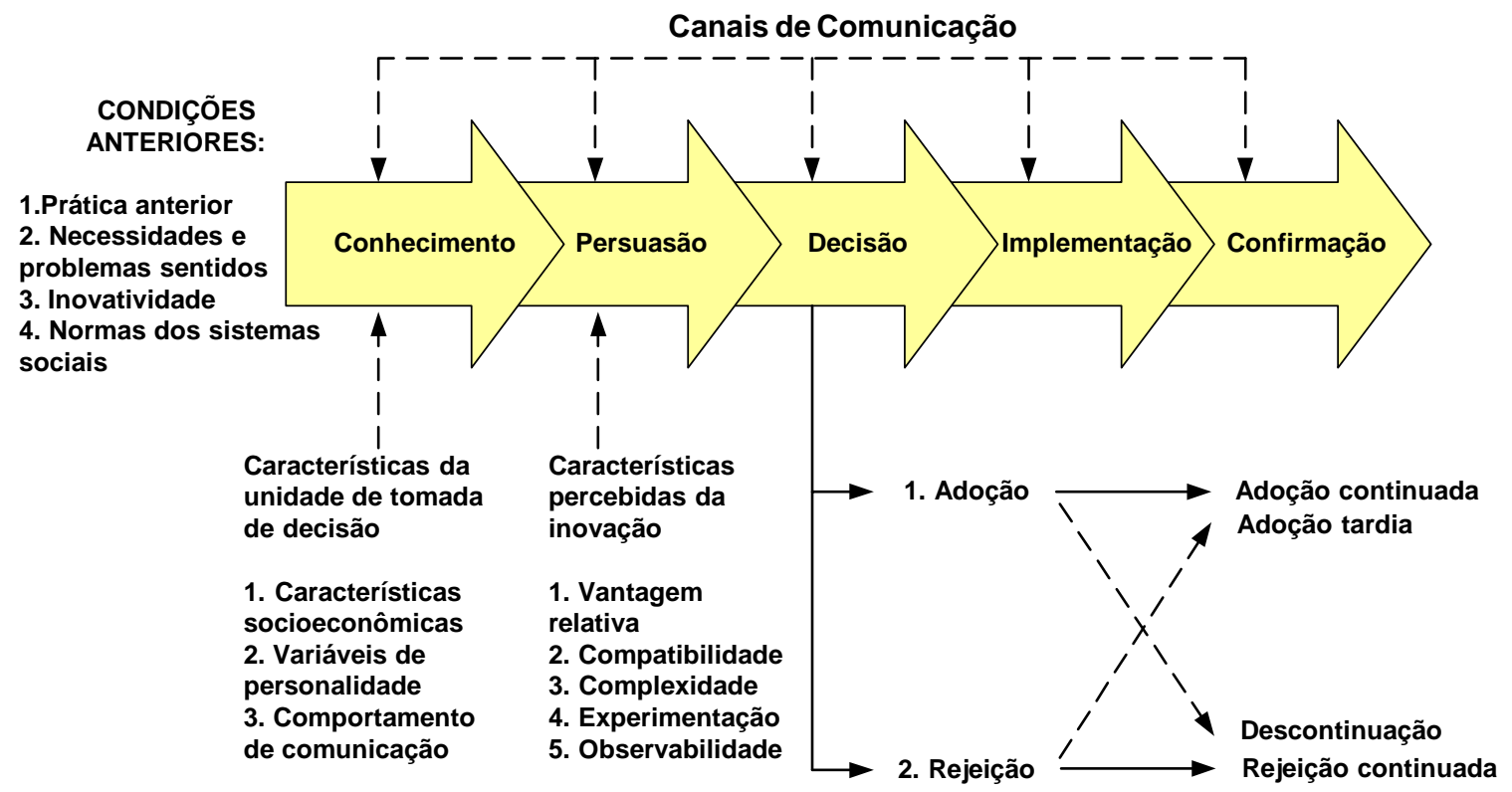

Figura 5.5 - Modelo de Rogers do processo de difusão da inovação. Reproduzido de Rogers (2003)

Rogers explica o fenômeno de compreensão e aceitação de uma inovação, por meio de diversas etapas. A fase de conhecimento acaba ressaltando a grande importância da atividade de propaganda ou marketing, de maneira a mostrar, à sociedade, a existência de um novo produto ou conceito.

\footnotetext{
${ }^{5.3}$ As pesquisas feitas na literatura da área de difusão da inovação mostraram que este é o modelo mais citado e discutido, sendo aceito como referência, tanto nesta área (difusão) como na área de marketing.
} 
Tabela 5.4 - Comparação entre propostas de Rogers e Thomas em relação ao processo de aquisição.

\begin{tabular}{|l|l|}
\hline \multicolumn{1}{|c|}{ Rogers (2003) } & \multicolumn{1}{c|}{ Thomas (1993) } \\
\hline Conhecimento & \% de conhecimento prévio \\
\hline Persuasão & \% de preferências \\
\hline Decisão & \% de tentativas anteriores \\
\hline Implementação & \% de compras \\
\hline Confirmação & \% de repetição \\
\hline
\end{tabular}

Um sexto fator foi posteriormente incorporado à proposta feita por Rogers, em 1962, que é o fator risco. Ostlund (1974) em Boyd e Mason (1999)

A compreensão do processo de aceitação e adoção ou rejeição de uma inovação é importante para as empresas e sua estratégia de negócio porque permite estimar o comportamento do ciclo de vida do produto, resultando em melhor projeto da capacidade do processo, sua extensão, como será o crescimento de produção até atingir o volume projetado ("production ramp-up"). Terwiesch e Bohn (2001).

A importância de se conhecer o ciclo de vida de um produto é encontrada em Levitt (1990, p. 177) que propõe três perguntas operacionais que devem ser feitas por um executivo de uma empresa:

- "Dado um novo produto ou serviço proposto, como e até onde a forma e a duração de cada estágio (do ciclo) podem ser previstas?

- Dado um produto existente, como determinar em que estágio ele está?

- Dados todos esses conhecimentos, como eles podem ser usados de forma eficaz?"

Aceitando-se, portanto, que aumentar o conhecimento em relação ao ciclo de vida do produto é importante para uma empresa, e que entender o processo de difusão de uma inovação auxilia nesse conhecimento, fica estabelecido, inicialmente, que entender os processos de difusão da inovação apóia a estratégia da empresa em geral, e em particular o processo de 
desenvolvimento de um produto. Para tanto, o processo de difusão da inovação é amplamente estudado e confirmado pela teoria e pela prática de marketing (Engel, Blackwell e Miniard, 1999; Schiffman e Kanuk, 1999; Shimp, 2002; Rogers 2003; Tellis, Stremersch e Yin, 2003), o que o torna um importante instrumento de suporte ao desenvolvimento de produtos de sucesso.

Lynn e Gelb (1996) ampliam a discussão, afirmando que nações diferentes (e conseqüentemente suas culturas) podem também ser fatores que influenciam no processo de difusão da inovação. Os autores questionam se a compreensão da capacidade de aceitar uma inovação em um país não deveria conduzir a implementação de outros mecanismos que facilitassem a introdução de um novo produto. Assim, parece estar claro, na literatura, que a inovação segue um processo de difusão dependente de uma série de fatores que influenciam o ato de aquisição, devendo ser considerados para o sucesso dos negócios de uma empresa. Esses fatores influenciam a velocidade de crescimento ou aceitação de um novo produto e, conseqüentemente, têm impacto direto na estratégia de operação das empresas, especialmente em como distribuir os recursos ao longo do ciclo de vida e em particular, em como administrar a fase chamada "production ramp-up" e a estratégia de manufatura. Assim, o conhecimento dos aspectos que diferenciam grupos e seu comportamento são importantes como suporte às empresas, na definição de suas estratégias de inovação.

Os diversos estudos procuraram também quantificar ou modelar matematicamente o comportamento, de forma a fornecer mecanismos preditivos, e esses modelos, que se podem denominar de modelos matemáticos de difusão da inovação, serão objeto de discussão do próximo capítulo. 


\section{6- Modelos quantitativos de difusão da inovação}

Alguns modelos quantitativos de difusão da inovação serão objeto deste capítulo, com o propósito de auxiliar na compreensão do fenômeno e nas extensões da pesquisa.

Inicialmente, modelos matemáticos de difusão foram desenvolvidos para explicar os processos epidêmicos, sendo um marco o modelo proposto em 1927, por Kermack e McKendrick (que atualmente são amplamente utilizados em epidemiologia), segundo Sterman (2000, p. 303). Como os modelos quantitativos de difusão da inovação são similares aos modelos de difusão de processos infecciosos, muito do que foi desenvolvido na área é aplicável aos processos de difusão da inovação e de aceitação de novos produtos. (Mahajan e Peterson, 1985; Sterman, 2000).

\section{1 - Analisando alguns modelos quantitativos}

Há um grande número de abordagens matemáticas que pretendem modelar o processo de difusão da inovação (Valente, 1993) e, conforme Teng, Grover e Güttler (2002), quatro delas, ligadas ao grupo de modelos fundamentais, têm sido largamente utilizadas e têm um ponto em comum: a taxa de difusão é proporcional ao número de adotantes potenciais, em um determinado período. Serão considerados os seguintes autores, como referência para a discussão que se segue: Mahajan e Peterson (1985); Mahajan, Muller e Srivastava (1990); Valente (1993); Kodama (1995); Sterman (2000) e Teng, Grover e Gütler (2002).

Considerando $\mathrm{g}(\mathrm{t})$ como o coeficiente de difusão, tem-se:

- modelo de influência externa - este modelo assume que não há comunicação entre os membros de um sistema social; todas as influências são geradas fora do sistema, isto é, são decorrentes da 
propaganda e de empresas de consultorias e de divulgação. A taxa de difusão é constante $(g(t)=a)$ e o modelo é representado por:

$$
N(t)=m \cdot\left(1-e^{-a \cdot t}\right)
$$

Ou então pode ser representado por:

$$
\ln \left[\frac{1}{\left(1-\frac{N(t)}{m}\right)}\right]=a \cdot t
$$

Onde,

$\mathrm{N}(\mathrm{t})$ - número de adotantes da inovação no período de tempo

$$
\mathrm{t}(0 \leq \mathrm{N}(\mathrm{t}) \leq \mathrm{m})
$$

$\mathrm{m}$ - número total de potenciais adotantes no sistema social considerado, em condições de saturação da difusão;

a - corresponde a uma taxa constante e pré-determinada de difusão da inovação dependente da influência interna.

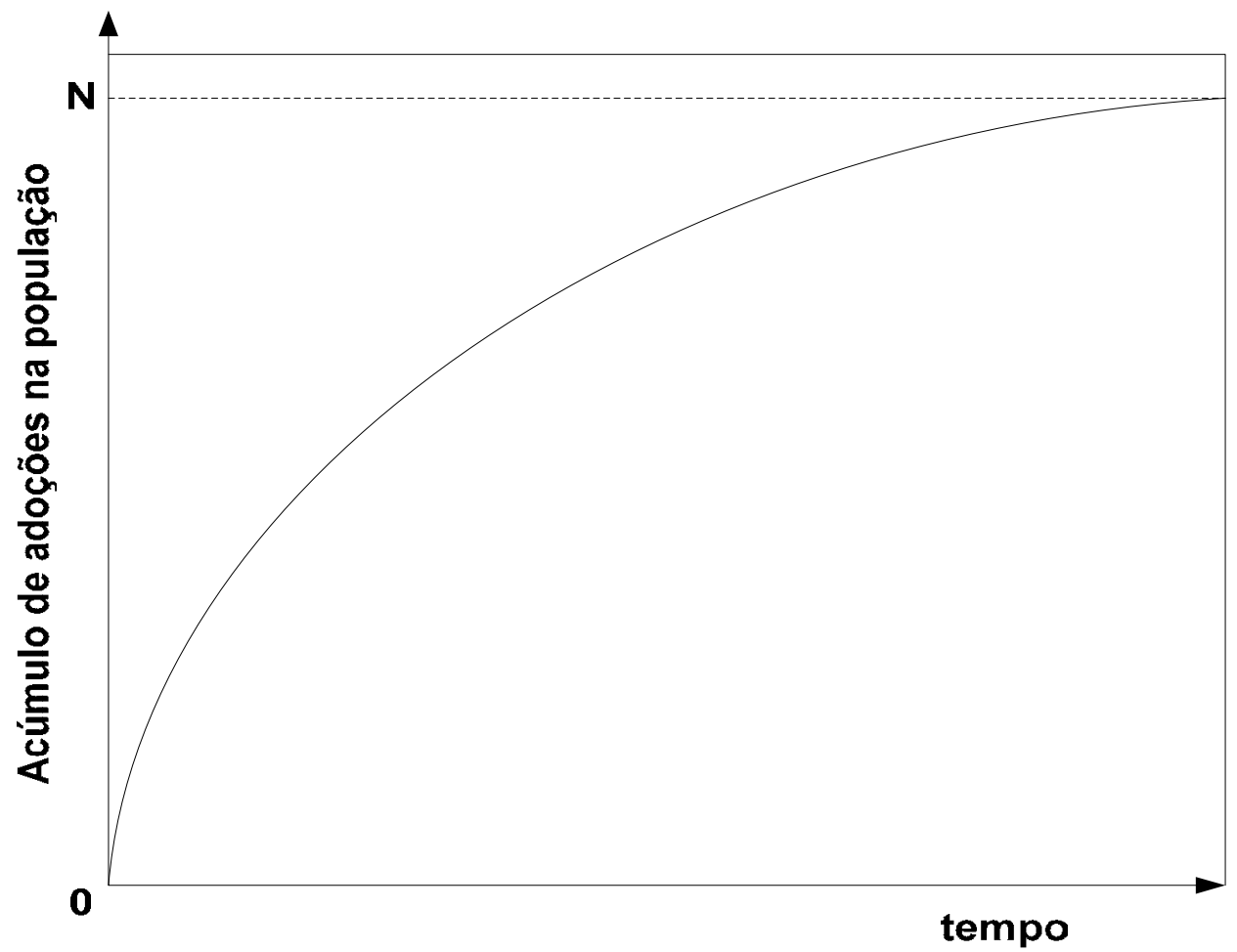

Figura 6.1 - Representação da curva de influência externa. (Mahajan e Peterson. 1985) 
Um das restrições desse modelo é limitar-se, unicamente, a verificar uma parte do complexo problema que atua no processo de decisão do consumidor. Pode ser aplicável a determinadas situações, onde o processo de difusão ocorre com produtos que trazem em si uma pequena inovação, como seria o caso de novos produtos decorrentes de inovações contínuas ou de novos produtos decorrentes de inovações dinamicamente contínuas. Sterman (2000) afirma que "o processo de comunicação boca a boca (word of mouth) ${ }^{6.1}$ decai quando as pessoas se acostumam com uma inovação". Sua aplicação é limitada ao não considerar os fatores internos que causam desvios na interpretação dos resultados ou então não conseguem identificar e antecipar o fenômeno de difusão, o que dificulta o planejamento da empresa e sua resposta aos diversos grupos de consumidores, e, como conseqüência, introduz riscos maiores nas diversas etapas do ciclo de vida do produto.

$\mathrm{Na}$ figura 6.1, é mostrado o formato genérico que a curva de difusão de influência externa apresenta, segundo Mahajan e Peterson (1985). A curva tem formato exponencial e é entendida como uma resposta a meios externos somente, como a propaganda ou outros agentes externos.

- modelo de influência interna (curva logística) - este modelo considera que na difusão somente haja influência da interação entre os membros internos do sistema social e $g(t)=b N(t)$, onde " $b$ " é um coeficiente de imitação ou de influência interna:

$$
N(t)=\frac{m}{1+\frac{\left(m-m_{0}\right)}{m_{0}} \cdot e^{-b \cdot m \cdot\left(t-t_{0}\right)}}
$$

Ou então pode ser representado por:

\footnotetext{
${ }^{6.1}$ Comunicação boca a boca ou Word of mouth - WOM - é o processo de informação sobre produtos e serviços comunicada verbalmente (Hoyer e Macillin, 1997; Evans e Berman, 1997; Engel, Blackwell e Miniard, 2000).
} 
$\ln \left[\frac{N(t)}{m-N(t)}\right]=\ln \left[\frac{m_{0}}{m-m_{0}}\right]+b \cdot m .\left(t-t_{0}\right) \quad$ (equação 6.4)

Onde,

$\mathrm{N}(\mathrm{t})$ - número de adotantes da inovação no período de tempo

$\mathrm{t}(0 \leq \mathrm{N}(\mathrm{t}) \leq \mathrm{m})$;

$\mathrm{m}$ - número total de potenciais adotantes no sistema social considerado, em condições de saturação da difusão;

$\mathrm{m}_{0}$ - número de adotantes iniciais no sistema social considerado (em algumas situações pode ser assumido como igual a um);

b - corresponde a uma taxa constante e pré-determinada de difusão da inovação dependente da influência externa;

De maneira oposta ao modelo de influência externa, nesse modelo são considerados somente fatores internos, decorrentes do contato entre os membros de um determinado grupo social.

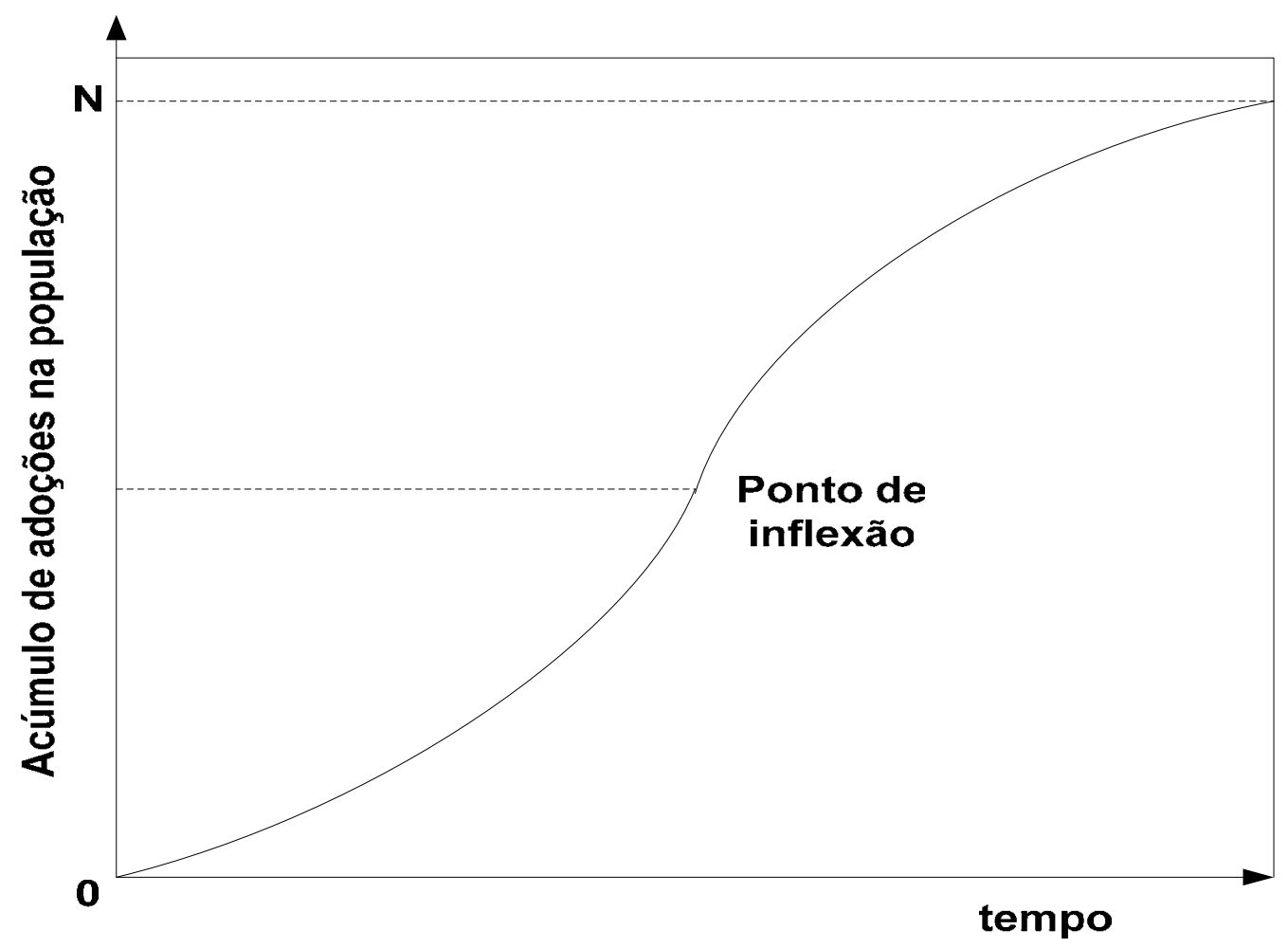

Figura 6.2 - Representação da curva de influência interna. (Mahajan e Peterson, 1985) 
O processo de difusão depende da maneira como o grupo é formado, se o grau de interação e transmissão de informações e conhecimento entre os membros do grupo é alto ou baixo, se há um maior grau de homofilia ${ }^{6.2}$ ou heterofilia $a^{6.3}$, A moda pode ser um importante fator a influenciar os parâmetros deste modelo.

Por ser um modelo que considera somente o fator de influência interna, ele pode ser melhor aplicado em situações em que haja um certo grau de isolamento do grupo social, seja por questões geográficas, ou de conviç̧ões. Mas esse fato não é a regra na sociedade moderna e, conseqüentemente, o modelo se mostra limitado.

- modelo de influência interna (curva de Gompertz) - é parecido com o modelo logístico e assume que a taxa de adoção é uma função do logaritmo do número de adotantes potenciais e "b" é o coeficiente de imitação ou influência interna:

$$
N(t)=m \cdot e^{-\ln \left(\frac{m}{m_{0}}\right) \cdot e^{-b \cdot\left(t-t_{0}\right)}}
$$

Ou então pode ser representado por:

$$
\ln \left[\frac{\ln m-\ln N(t)}{\ln m-\ln m_{0}}\right]=-b .\left(t-t_{0}\right) \quad \text { (equação 6.6) }
$$

Onde,

$$
\begin{aligned}
& N(t) \text { - número de adotantes da inovação no período de tempo } \\
& t(0 \leq N(t) \leq m) ;
\end{aligned}
$$

\footnotetext{
${ }^{6.2}$ Homofilia - diz-se de pessoas que têm conhecimentos comuns ou níveis de compreensão dos fatos dentro de perspectivas parecidas, o que facilita o processo de comunicação de conhecimento entre elas.

${ }^{6.3}$ Heterofilia - diz-se de pessoas, que devido a diferentes níveis culturais ou de percepção do mundo, apresentam dificuldade no processo de comunicação de conhecimentos entre si.
} 
$\mathrm{m}$ - número total de potenciais adotantes no sistema social considerado, em condições de saturação da difusão;

$\mathrm{m}_{0}$ - número de adotantes iniciais no sistema social considerado (em algumas situações pode ser assumido como igual a um);

b - corresponde a uma taxa constante e pré-determinada de difusão da inovação dependente da influência externa;

O modelo de Gompertz, por trabalhar com conceitos e restrições parecidos com aqueles estabelecidos para o de curva logística, segue as mesmas considerações anteriormente apresentadas.

O modelo de Gompertz é um caso especial do modelo proposto por Richards em 1959 (Sterman, 2000, p.299), para o caso de "m" ser igual a um ${ }^{6.4}$. Esse caso foi proposto pela ocorrência de uma situação de solução impossível para o modelo de Richards ${ }^{6.5}$. (Sterman, 2000, p.299)

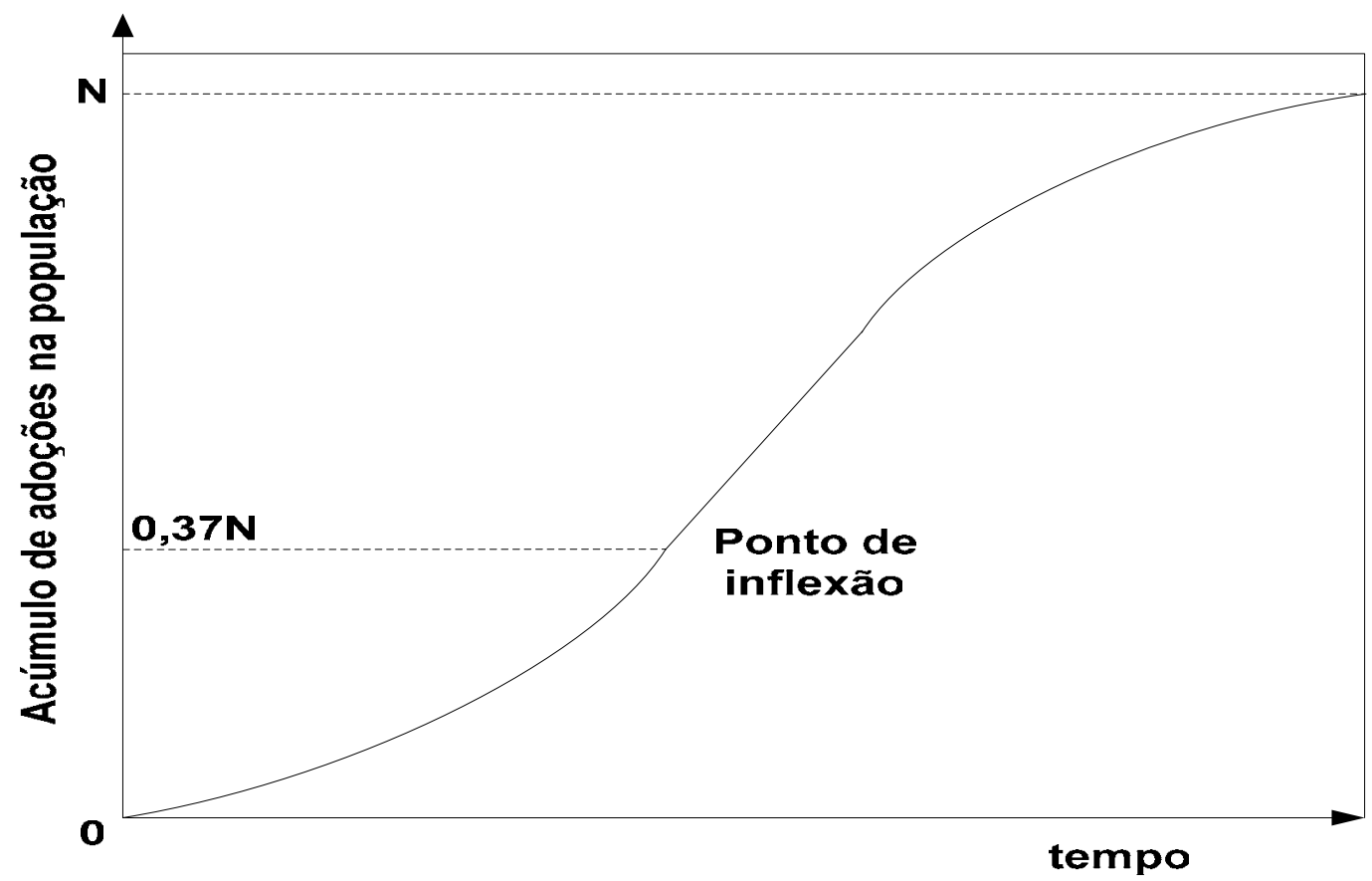

Figura 6.3 - Representação da curva de influência interna - modelo de Gompertz. (Mahajan e Peterson, 1985)

${ }^{6.4}$ ver o significado de $\mathrm{m}$ nas explicações dos termos das equações de difusão.

${ }^{6.5} \mathrm{O}$ modelo de Richards é representado como: (Sterman, 2000)

$N(t)=m \cdot\left(1-c . e^{-b . t}\right)^{1 /(1-m)}$

modelo de Gompertz. 
Pode-se entender que a melhor aplicação desse modelo está ligada às condições de novos produtos decorrentes de inovações contínuas ou de novos produtos decorrentes de inovações dinamicamente contínuas. Esse modelo também seria útil para os casos de novos produtos decorrentes de inovações que criam novas categorias de produtos, desde que considerados seus estágios iniciais, onde a população a ser considerada seria o potencial grupo de inovadores.

- modelo de influência mista (modelo de Bass) - é composto por influências internas e influências externas. Assume que os adotantes potenciais de uma inovação são influenciados internamente pelos membros do sistema social e também por influências externas ao sistema. O modelo é amplamente utilizado na área de marketing para previsão de vendas de bens de consumo duráveis.

$N(t)=\frac{m-\frac{a \cdot\left(m-m_{0}\right)}{\left(a+b \cdot m_{0}\right)} \cdot e^{-(a+b \cdot m) \cdot\left(t-t_{0}\right)}}{1+\frac{b \cdot\left(m-m_{0}\right)}{\left(a+b \cdot m_{0}\right)} \cdot e^{-(a+b \cdot m) \cdot\left(t-t_{0}\right)}} \quad$, (equação 6.7)

Onde,

$\mathrm{N}(\mathrm{t})$ - número de adotantes da inovação no período de tempo $\mathrm{t}(0 \leq \mathrm{N}(\mathrm{t}) \leq \mathrm{m})$;

$\mathrm{m}$ - número total de potenciais adotantes no sistema social considerado, em condições de saturação da difusão;

$\mathrm{m}_{0}$ - número de adotantes iniciais no sistema social considerado (em algumas situações pode ser assumido como igual a um);

a - corresponde a uma taxa constante e pré-determinada de difusão da inovação dependente da influência interna;

b - corresponde a uma taxa constante e pré-determinada de difusão da inovação dependente da influência externa; 
O modelo de Bass apresenta restrições em ampla explicação do fenômeno, destacando-se o fato de a taxa de influência externa ser assumida como constante, o que não ocorre na prática, pois a propaganda, análises em revistas, de consultores, etc., raramente se mantêm, indefinidamente, ao longo do desenvolvimento do ciclo de vida do produto. Contudo, esse modelo é bastante explorado nos diversos estudos sobre difusão da inovação e demonstra uma maior capacidade de aproximação da realidade. Uma de suas vantagens, em relação aos modelos apresentados, é o fato de abranger fatores influenciadores da difusão proveniente tanto de processos internos quanto externos, permitindo que seja considerada uma situação mais próxima da real.

É considerado um bom modelo e é bastante utilizado para análise da difusão de produtos classificados como novos produtos decorrentes de inovações descontínuas ou novos produtos decorrentes de inovações multidisciplinares.

\section{2 - Comentários e restrições aos modelos quantitativos}

Um problema dos diversos modelos é que a constante de difusão é desconhecida a priori, e isto dificulta a previsão da variação da demanda e, conseqüentemente, a estratégia de produção a ser seguida durante as diferentes fases do ciclo de vida.

Os modelos apresentados consideram um ou outro fator de influência, interna ou externa, de forma isolada, com exceção do modelo de Bass, que incorpora duas constantes: "a" - taxa de difusão decorrente da influência externa e "b" taxa de difusão decorrente da influência interna. Todavia, para uma boa aplicação deste modelo à fase de P\&D e produção, os dois fatores (influência interna e externa) precisam ser determinados a priori, o que, em geral, é feito por meio de extrapolações de resultados obtidos a posteriori a partir de produtos similares, o que introduz um fator novo de risco. Uma segunda dificuldade é aquela ligada ao fator " $m$ " - número total de potenciais adotantes e que nem sempre representam toda a população existente (Mahajan e 
Peterson, 1985). Como determinar "m" passa, então, a ser fundamental para que se possa determinar o volume de participantes de cada segmento (inovadores, adotantes iniciais, etc.) e, portanto, como deve ser conduzida a estratégia de operações.

Sterman (2000) aponta que a alteração do número total da potencial população decorre de fatores como nascimentos, mortes, imigrações; assim, os modelos apresentados, ao considerarem $\mathrm{g}(\mathrm{t})$ - coeficiente de difusão - constante, assim como "m", introduzem uma condição que os distancia da realidade. Os modelos são melhor aplicados em condições de difusão mais rápida, onde se pode assumir que os parâmetros $\mathrm{g}(\mathrm{t}) \mathrm{e}$ " $\mathrm{m}$ " não sofrem uma grande alteração.

Segundo a literatura, o fator " $m$ " pode estar ligado ao preço do produto, que define a faixa econômica que será alvo do produto, e a alteração significativa de preço conduz a reavaliações da população total a ser considerada como suscetível. Outra restrição aos modelos surge quando os processos de difusão se dão de forma lenta, e este aspecto foi discutido por Deroïan (2002). Os modelos também têm dificuldades em explicar os fenômenos decorrentes da moda, seja pelo rápido decremento do processo de comunicação boca a boca, seja pela percepção dos formadores de opinião de que a novidade não os diferencia mais e, portanto, eles a abandonam. (Sterman, 2002)

Apesar dessas diversas dificuldades apresentadas na literatura, a perspectiva de explorar a aplicação dos modelos quantitativos é um caminho interessante para auxiliar nos objetivos deste trabalho. Portanto, após a revisão dos diversos aspectos da literatura sobre as implicações dos conceitos da difusão da inovação nas diversas áreas da sociedade, bem como sobre a estratégia das empresas, no próximo capítulo serão relatados os resultados das pesquisas realizadas para verificar se tais condições ocorriam nos domicílios brasileiros e, caso sejam identificados, como os resultados devem ser considerados para auxiliar as empresas a tirar proveito para melhorar seus resultados. 


\section{7- Estudo empírico - pesquisa de campo}

A revisão da literatura mostrou que o processo de difusão das inovações é um padrão recorrente nas mais diversas áreas da sociedade humana e segue alguns modelos ou formas de respostas, seja o caso de uma distribuição conhecida como logística (influência mista ou interna) ou exponencial (influência externa), ambas apresentadas no capítulo sobre modelos matemáticos e que pretendem estimar a resposta dos consumidores a uma inovação.

O processo de difusão de inovações é um fenômeno que, entre outros, permite retratar a forma como a sociedade responde ao surgimento de um novo produto; logo, parece evidente que esse conceito deva ser considerado quando do processo de decisão estratégica de lançamento de uma inovação no Brasil, assim corroborando a necessidade da discussão proposta nos objetivos iniciais, que são analisar as condições propostas de "Verificar a validade de utilização de alguns dos modelos de difusão da inovação no segmento de eletrodomésticos no Brasil" e "Como a compreensão do processo de difusão de inovações pode auxiliar a estratégia de inovação das empresas no desenvolvimento de novos produtos".

$\mathrm{Na}$ fase de estruturação da pesquisa, algumas restrições foram incorporadas para seguir as recomendações da literatura. (Kodama, 1995; Rogers, 2003). A primeira é o universo de pesquisa. Para efeitos de pesquisa, é necessário identificar uma abordagem que seja representativa do processo em discussão e que, ao mesmo tempo, permita testar as considerações propostas. Dessa forma, o produto ou produtos escolhidos foram aqueles considerados como uma inovação na maneira de viver das pessoas na sociedade, e alguns dos produtos que causaram essa mudança foram identificados. Outra preocupação foi decidir qual a unidade básica de pesquisa a ser estabelecida. Assim, foi escolhida a denominada unidade 
domiciliar ou domicílio particular permanente ${ }^{7.1}$, que congrega as famílias, pois uma mesma família pode ter ou adquirir mais de um determinado produto, o que causaria dificuldades extras à pesquisa, além de essa informação mostrar-se desnecessária para definir quando uma inovação adentrou um domicílio pela primeira vez. O interesse da repetição de compra de um produto pelo consumidor é objeto de estudo da área do marketing e está fora dos objetivos deste trabalho. Por outro lado, a escolha do domicílio como unidade básica da pesquisa auxiliou na escolha dos produtos que poderiam ser objeto da pesquisa.

Uma outra consideração é a de que a difusão da inovação precisaria estar o mais possível distante da influência direta de políticas públicas, pois estas poderiam introduzir distorções no processo de difusão, ao interferir diretamente no processo de escolha do indivíduo. Entretanto, em alguns momentos, inovações que dependem direta ou indiretamente do poder público foram consideradas com objetivo comparativo ou ilustrativo.

A pesquisa focalizou os chamados bens duráveis em domicílios e que podem ser exemplificados pelos aparelhos de rádio, de televisão, geladeiras, máquinas de lavar roupa, microcomputadores, acesso à internet, filtros de água (o IBGE os classifica como bem durável), liquidificador, etc. Outras mudanças na forma de construir ou mudar hábitos podem ser entendidas como introdução de inovações: uso de sanitários internos, canalização interna de água, etc. Assim, alguns itens foram selecionados: a primeira escolha recaiu sobre o rádio, por ser um dos mais antigos bens elétricos presentes nos domicílios e pela forma como facilitou e permitiu às pessoas perceberem o mundo e suas atividades de lazer. A segunda escolha, por decorrência natural, foi a televisão, que alterou profundamente as

\footnotetext{
7.1 Entende-se que um domicílio inclui a família que nele reside, inclusive agregados, sendo necessário restringir qual o tipo de domicílio a ser explorado. Uma pesquisa junto ao IBGE mostrou que a divisão nas pesquisas se dá como domicílio particular permanente, domicílio particular improvisado e domicílio coletivo. Para efeitos do trabalho pretendido, o domicílio coletivo (que pode ser exemplificado por hotéis) pode não representar a decisão e a escolha do indivíduo. O domicílio particular improvisado, pela sua própria condição, não representa uma situação natural da sociedade. Assim, foi escolhido, como alvo da pesquisa, o domicílio particular permanente, que representa a grande maioria dos domicílios brasileiros.
} 
atividades de lazer das pessoas, gerando uma grande e poderosa indústria. Do ponto de vista das condições de alimentação e saúde, a geladeira transformou radicalmente a forma de alimentação, seu armazenamento, bem como ocasionou uma profunda transformação na indústria alimentícia em geral. Este foi o terceiro item da pesquisa. Mas logo sobreveio a dúvida se a disponibilidade de acesso à rede de energia elétrica externa seria um fator inibidor do uso das inovações propostas inicialmente ${ }^{7.2}$, e, como conseqüência, foram selecionadas algumas inovações que não dependiam direta ou indiretamente da energia elétrica: o filtro de água e as instalações internas de rede de água.

Definidas as inovações que seriam objeto da pesquisa, o passo seguinte foi identificar como e se o processo ocorreu. Uma fonte natural de informações e subsídios são as pesquisas do IBGE - Instituto Brasileiro de Geografia e Estatística - sobre o comportamento e condições da população brasileira, entre os quais os Censos Demográficos Decenais, as PNAD - Pesquisa Nacional de Amostragem Domiciliar e as POF - Pesquisa de Orçamento Familiar, entre outras.

A difusão da inovação é o objeto do estudo e o alvo a ser identificado foi quando uma inovação ocorreu pela primeira vez no domicílio particular permanente e, para melhor esclarecer esse processo, a pesquisa foi estruturada em algumas etapas diferentes e complementares, de maneira a comprovar ou rejeitar a importância do estudo, permitindo responder à validade do objetivo inicial desse trabalho. Assim, foram propostas algumas etapas para esclarecer algumas questões: 1) Como ocorre (para os produtos escolhidos) o processo de difusão das inovações na sociedade brasileira e se esse processo apresenta um comportamento similar ao proposto na literatura? 2) Há diferenças entre o comportamento da população que vive em áreas urbanas e o da que vive em áreas rurais? 3) As inovações se difundem de maneira igual nas diferentes classes de renda da população? 4) As diferenças nos preços iniciais de uma inovação e preços posteriores são fatores

\footnotetext{
${ }^{7.2}$ Apesar de a impressão inicial conduzir a essa leitura, isto não corresponde à verdade dos fatos, pois os dois primeiros podem ser acionados por baterias automotivas ou células solares e o último deles (a geladeira), por meio de queima de algum combustível, como o querosene.
} 
fundamentais no processo de difusão de uma inovação? 5) Inovações diferentes apresentam padrões comuns no processo de difusão?

Para facilitar a leitura e interpretação dos resultados, sua apresentação, na medida do possível, será feita na forma gráfica. Entretanto, as tabelas de origem desses dados estão disponíveis em apêndices. Assim, o estudo iniciou com a questão 1 proposta.

\section{1 - A difusão de algumas inovações nos domicílios brasileiros}

O levantamento dos dados disponíveis foi, sempre que possível realizado nas fontes citadas do IBGE, acrescidos de outras fontes sempre que se fez necessário. Neste caso as fontes serão citadas ao longo do texto.

O processo de difusão de uma inovação ocorre de acordo com um parâmetro básico que é o tempo e, obviamente, um período maior auxilia a melhor identificar as etapas iniciais e a respectiva evolução. Portanto, o primeiro estágio da pesquisa foi identificar quando os itens objeto da pesquisa foram reportados em pesquisas do IBGE. O resultado encontrado: instalações de rede de água de uso interno, a partir do Censo de 1940 (por não ser um bem durável, será utilizado como parâmetro de comparação); rádios, televisores e geladeiras já foram relatados no Censo de 1960; filtros de água possuem dados a partir de $1970^{7.3}$.

Assim, para responder à primeira pergunta definiu-se que seriam utilizados os dados disponíveis nos censos decenais brasileiros, ou as PNADs mais próximas aos censos que permitiriam identificar a situação apresentada. Os resultados em relação aos itens (rádios, televisores e geladeiras) estão representados nas figuras $7.1,7.2$ e 7.3 e as tabelas que os suportam, no apêndice 1.

\footnotetext{
${ }^{3}$ A data de início da operação da televisão no Brasil é conhecida, tendo iniciado em 1950; do rádio, por volta da década de 1920/1930 e da geladeira pode ser assumido em meados de 1940. Em relação aos filtros de água e canalização interna de água, não há como determinar as datas de início de sua difusão, mesmo de maneira estimativa.
} 


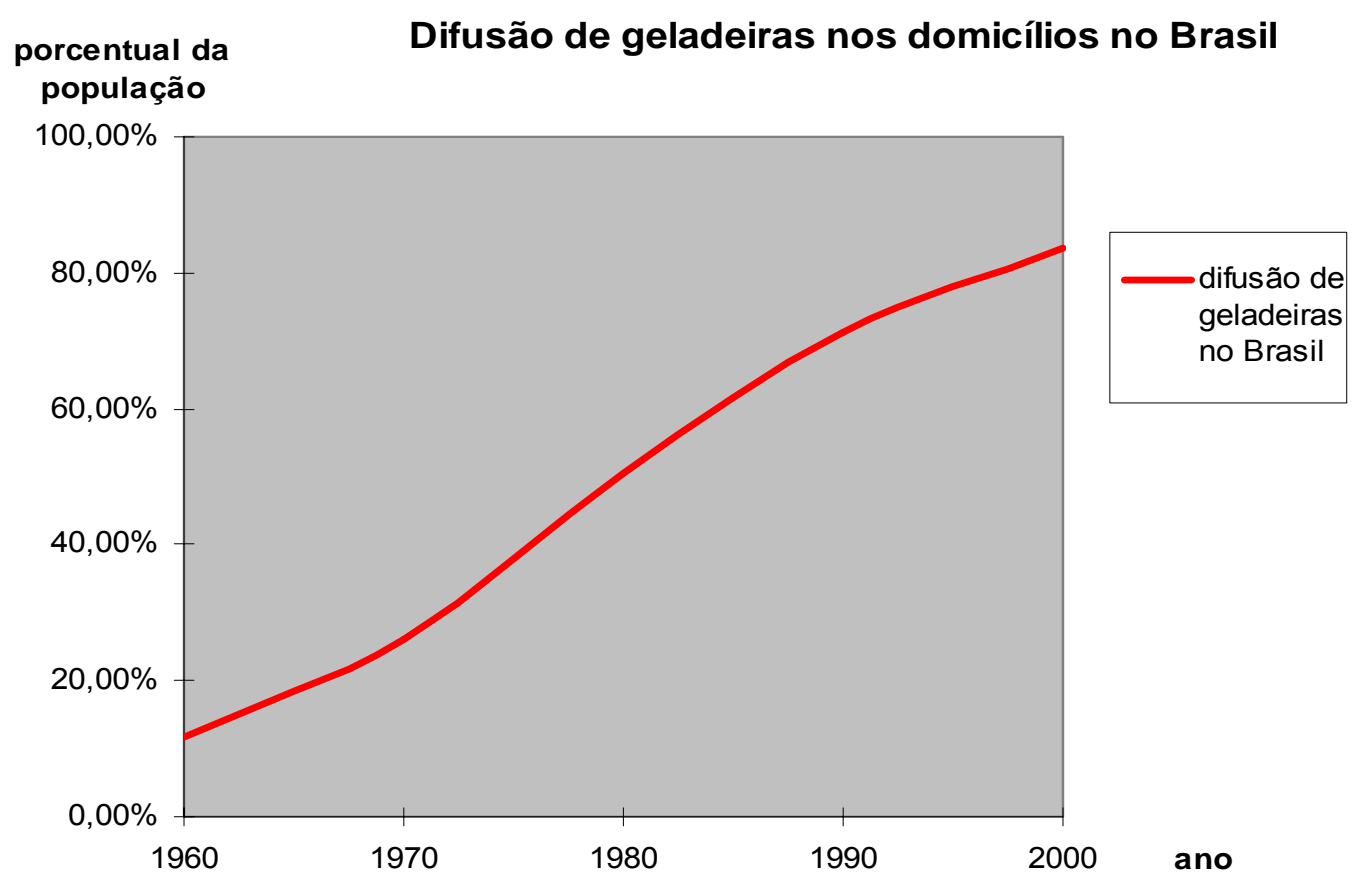

Figura 7.1 - Processo de difusão de geladeiras nos domicílios do Brasil. Fonte dos dados IBGE.

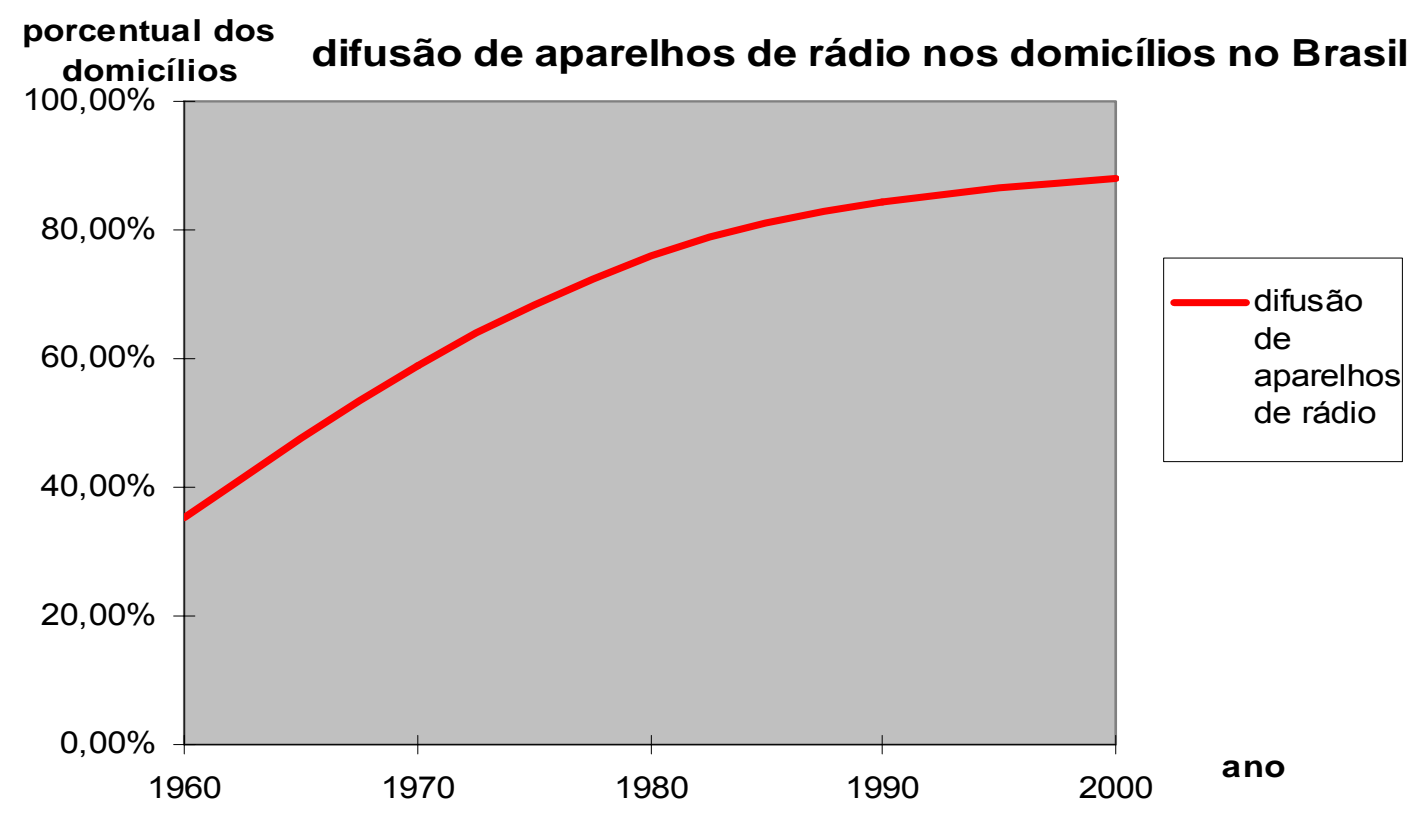

Figura 7.2 - Processo de difusão de aparelhos receptores de rádios nos domicílios do Brasil. Fonte dos dados - IBGE. 


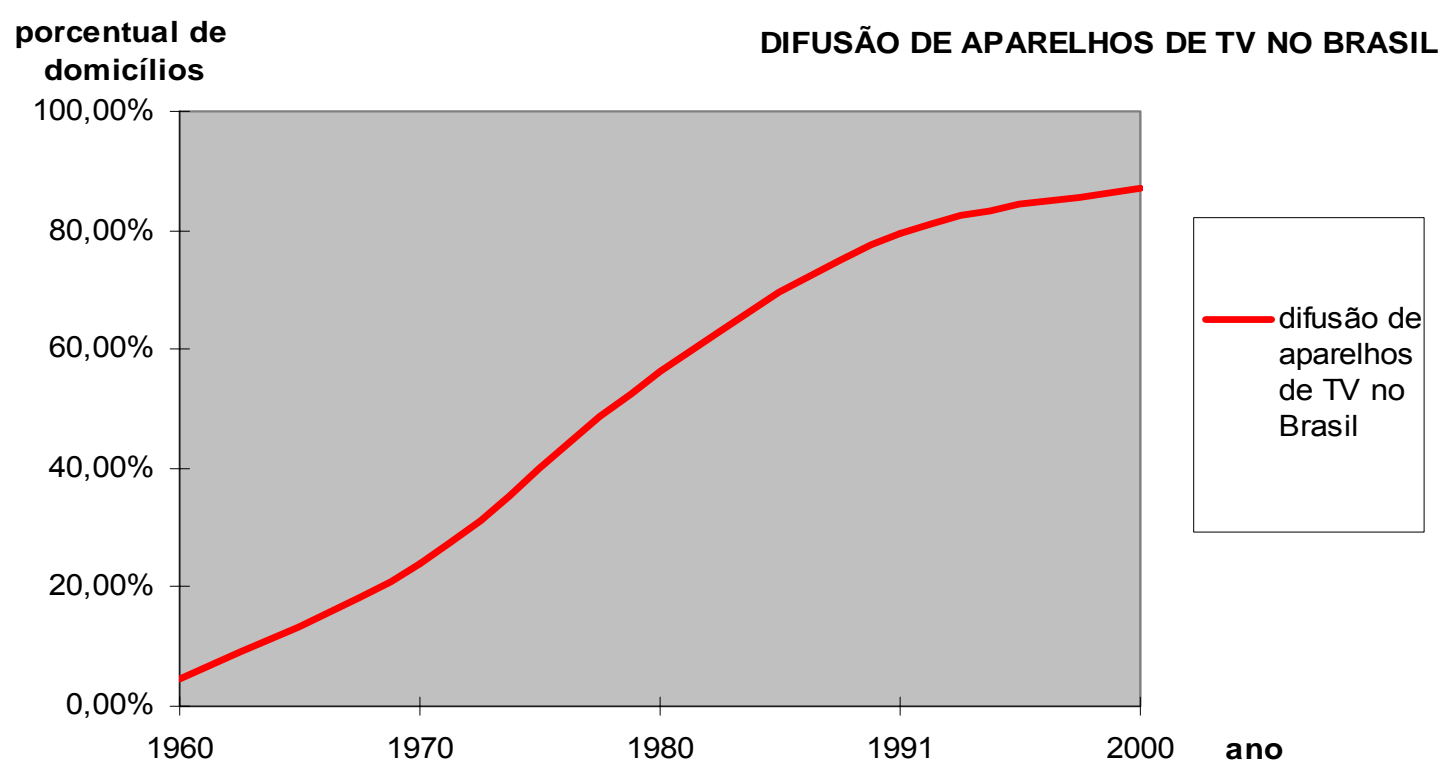

Figura 7.3 - Processo de difusão de televisores nos domicílios do Brasil. Fonte dos dados IBGE.

Os formatos das distribuições de probabilidade de aquisição, ao longo do tempo, mostram-se similares àqueles identificados para as distribuições de difusão logística de uma inovação. (Majahan e Peterson, 1985; Sterman, 2000; Rogers, 2003). Os televisores passaram por um processo de difusão mais rápida que as geladeiras, entretanto as últimas estão um pouco mais distantes da saturação, não sendo esse o caso dos rádios e dos televisores. Para os rádios, o formato da curva de difusão não pode ser visualmente identificado, porém, é possível afirmar que os outros dois casos (televisores e geladeiras) parecem atender à proposta de Lawton e Lawton (1979) em Mahajan e Peterson (1985), que é um parâmetro de difusão de 0,50 para inovações de produtos de consumo.

Uma análise da possível correlação entre o processo de difusão dos três produtos mostra que os coeficientes de correlação de Pearson são altos ${ }^{7.4}$, e uma análise feita com o SPSS mostra que os coeficientes variam entre 0,957 (rádio/geladeira),

\footnotetext{
${ }^{7.4}$ As correlações encontradas devem ser aceitas apenas como indicativas, devido ao pequeno tamanho da amostra, i.e, $\mathrm{N}=5$.
} 
0,974 (rádio/TV) até 0,995 (geladeira/TV), sendo mais significativos para a relação rádio/TV e TV/geladeira. (ver Tabela A4 do apêndice 1)

A pesquisa ainda foi realizada para os outros dois itens: filtros de água e rede interna de água e os resultados estão representados nas figuras 7.4 e 7.5.

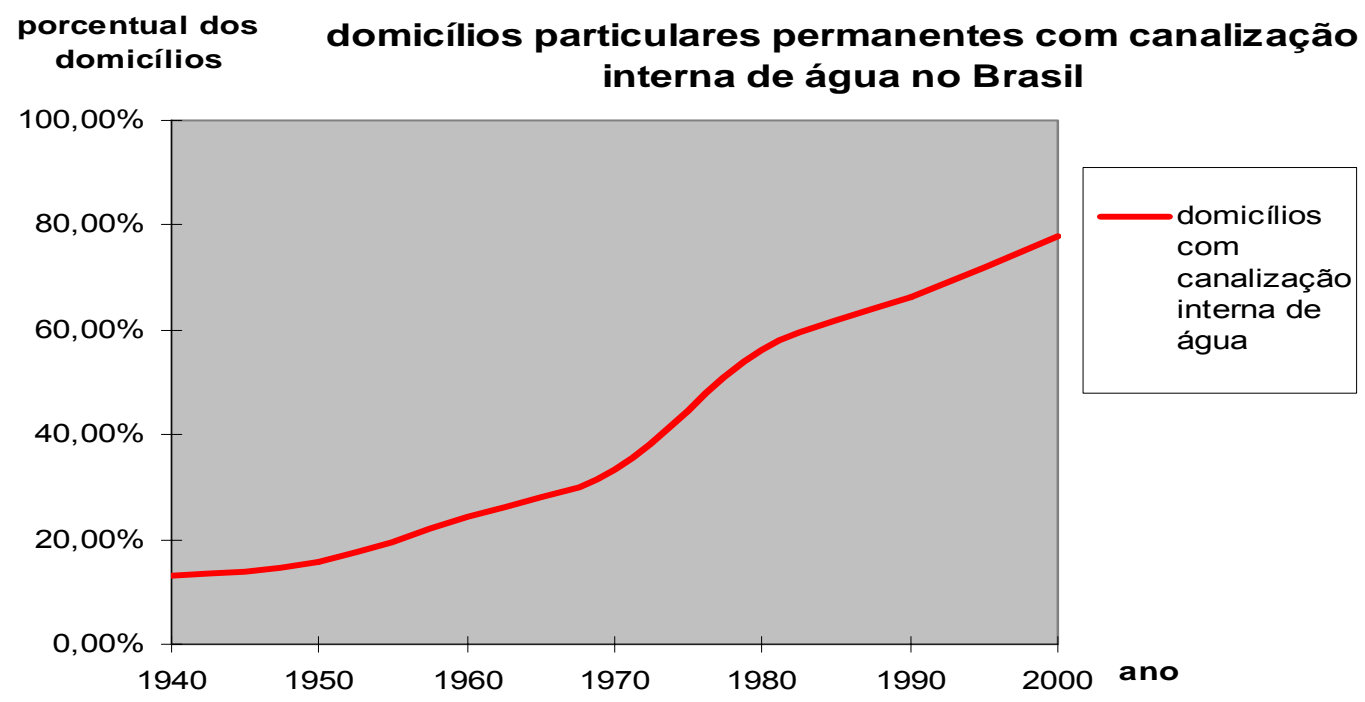

Figura 7.4 - Processo de difusão da canalização interna de água nos domicílios particulares permanentes do Brasil. Fonte dos dados - IBGE. porcentual do filtros de água nos domicílios particulares permanentes
domicílios no Brasil

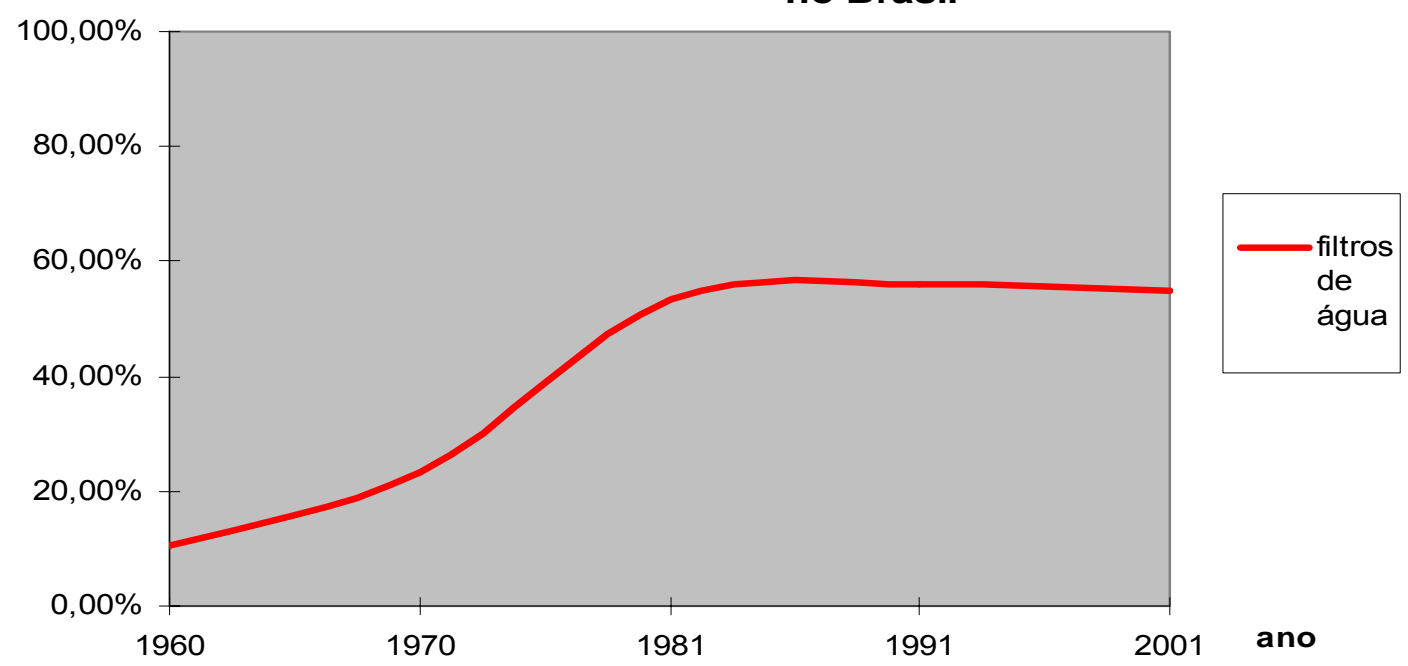

Figura 7.5 - Processo de difusão de filtros de água nos domicílios particulares permanentes no Brasil. Fonte dos dados - IBGE.

Nota: dados de 1960 são estimados e, em 1980 e 2000, não foram pesquisados filtros de água. 
Os resultados mostram um comportamento de difusão correspondente aos esperados na literatura, mas nota-se que os filtros de água entraram em um processo de abandono da inovação, possivelmente pela substituição de água mineral em garrafões. A quantidade oscilou durante a década de 1990, mas passou a declinar, de maneira contínua, a partir de 1996, quando esteve presente em $58,06 \%$ dos domicílios particulares permanentes, reduzindo para $51,35 \%$ em 2004 , proporcionando uma redução de $13 \%$ em oito anos.

A análise da instalação de rede interna de água e dos filtros de água retrata um processo ligado ao conceito de comodidade, somado ao de saúde e higiene ${ }^{7.5,} \mathrm{e}$ que mantém um formato similar ao da distribuição logística que foi detectado para televisores e geladeiras, o que reforça que o processo de difusão de inovações é uma característica que se repete em diferentes tipos de produtos e mesmo de costumes e hábitos na sociedade (Rogers, 2003).

Os levantamentos suportam as afirmações encontradas na literatura, reforçando que, em relação a alguns produtos eletrodomésticos e outras inovações no Brasil, a situação é similar. Mas, apesar de fugir aos propósitos iniciais dessa pesquisa, surgiu a dúvida se esse fenômeno estaria restrito à unidade básica escolhida, o domicílio particular permanente e, para tanto, foi realizado um levantamento da quantidade de aparelhos celulares no Brasil e de sua difusão. Esse levantamento, diferentemente dos anteriores, procurou verificar a quantidade de unidades vendidas e em operação no país, ao longo dos anos. A base dos dados para o estudo foi a ANATEL - Agência Nacional de Telecomunicações, e o resultado encontrado é mostrado na figura 7.6 (ver Tabela A7 no apêndice 1).

\footnotetext{
${ }^{7.5} \mathrm{~A}$ introdução do uso de água corrente nos domicílios brasileiros, bem como a de instalações sanitárias, pode ser considerada uma inovação em relação aos costumes e práticas comuns, há séculos, em nossa sociedade.
} 


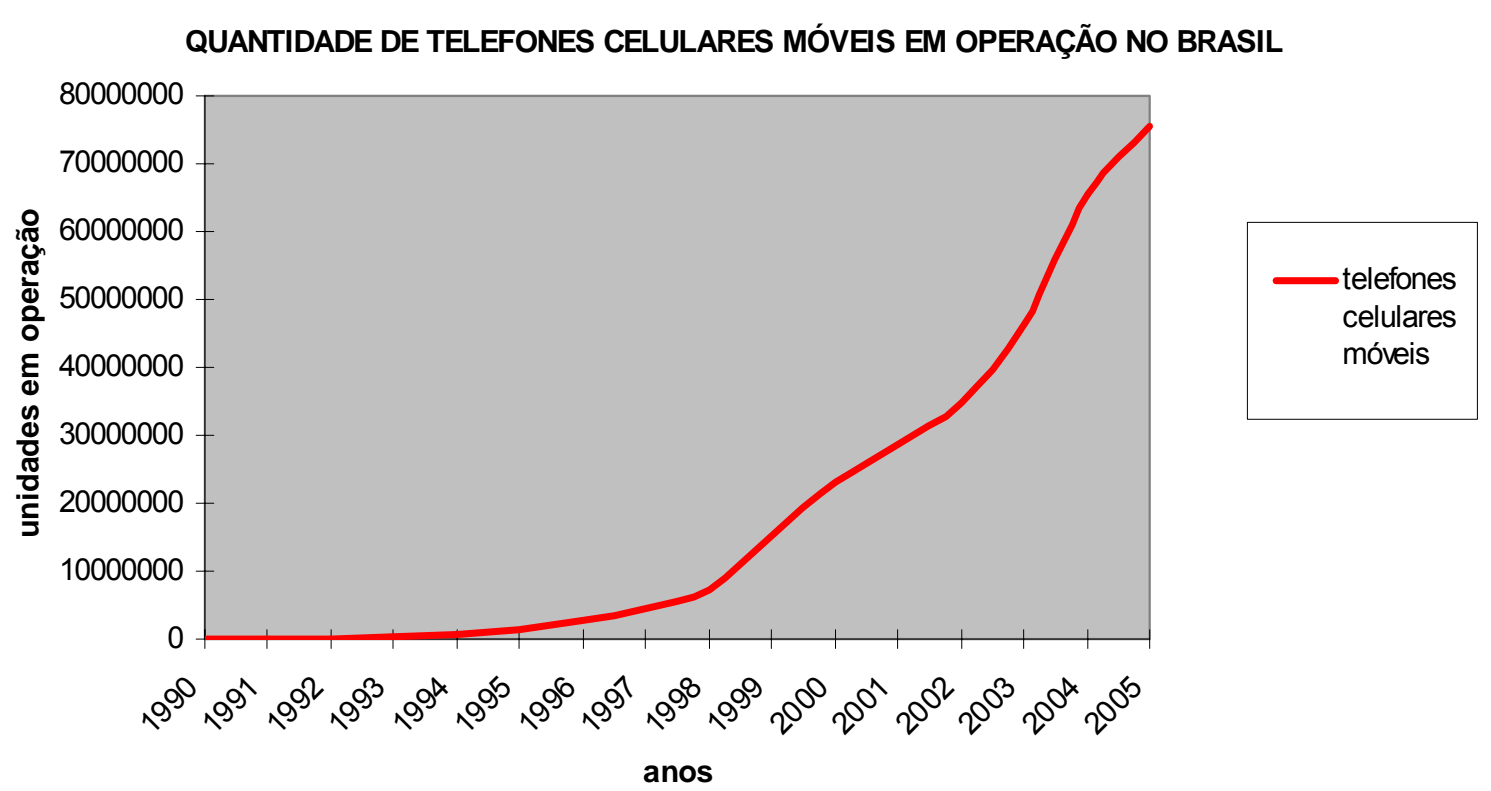

Figura 7.6 - Processo de difusão de celulares móveis em operação no Brasil. Fonte dos dados - Anatel.

O processo de crescimento apresenta características muito próximas da curva logística de difusão. O início da operação dos celulares no Brasil data de 1990 e, apesar de inicialmente haver restrições e/ou incentivos do governo em relação à política de expansão (o que pode gerar distorções no processo de difusão), notase que, aparentemente, o processo tomou seu curso normal de difusão natural na sociedade, a partir da privatização.

Se os celulares indicam uma situação de mercado em franca expansão, provavelmente já claramente avançando na etapa onde se concentra a maioria tardia (conforme as categorias propostas por Rogers, 2003) e correspondendo ao estágio de maturidade no ciclo de vida de um produto, por outro lado, rádios e televisores atingiram um estágio de saturação. Vê-se que, a partir de 1998, é possível detectar um decréscimo na quantidade de rádios, de acordo com as diversas PNADs, pois, em 1996, ponto máximo de difusão, 90,36\% dos domicílios declararam ter este equipamento; já na PNAD de 2003, apenas $87,83 \%$ apontaram o produto. $\mathrm{O}$ item aparelhos receptores de rádio parece ter entrado em um estágio inverso de difusão, o abandono. $\mathrm{O}$ mesmo fato foi percebido com filtros 
de água, pois começaram a declinar a partir de 1996, quando alcançaram 58,06\% dos domicílios, e na PNAD de 2003, estavam presentes apenas em 52,60\% dos domicílios. Isso mostra um fenômeno apontado por Rogers (2003), que é o processo de abandono de uma inovação e que é sugerido como um processo inverso ao da difusão. Esse interessante fenômeno de abandono de uma inovação ou produto pode ser identificado na TV preto e branco que, apesar de ter sido objeto de uma substituição por características mais atrativas (cor $x$ preto $\mathrm{e}$ branco), ainda está presente em alguns dos lares no Brasil, conforme se pode ver na figura 7.7 .

\section{DIFUSÃO DE TVS P\&B NOS DOMICÍLIOS NO BRASIL}

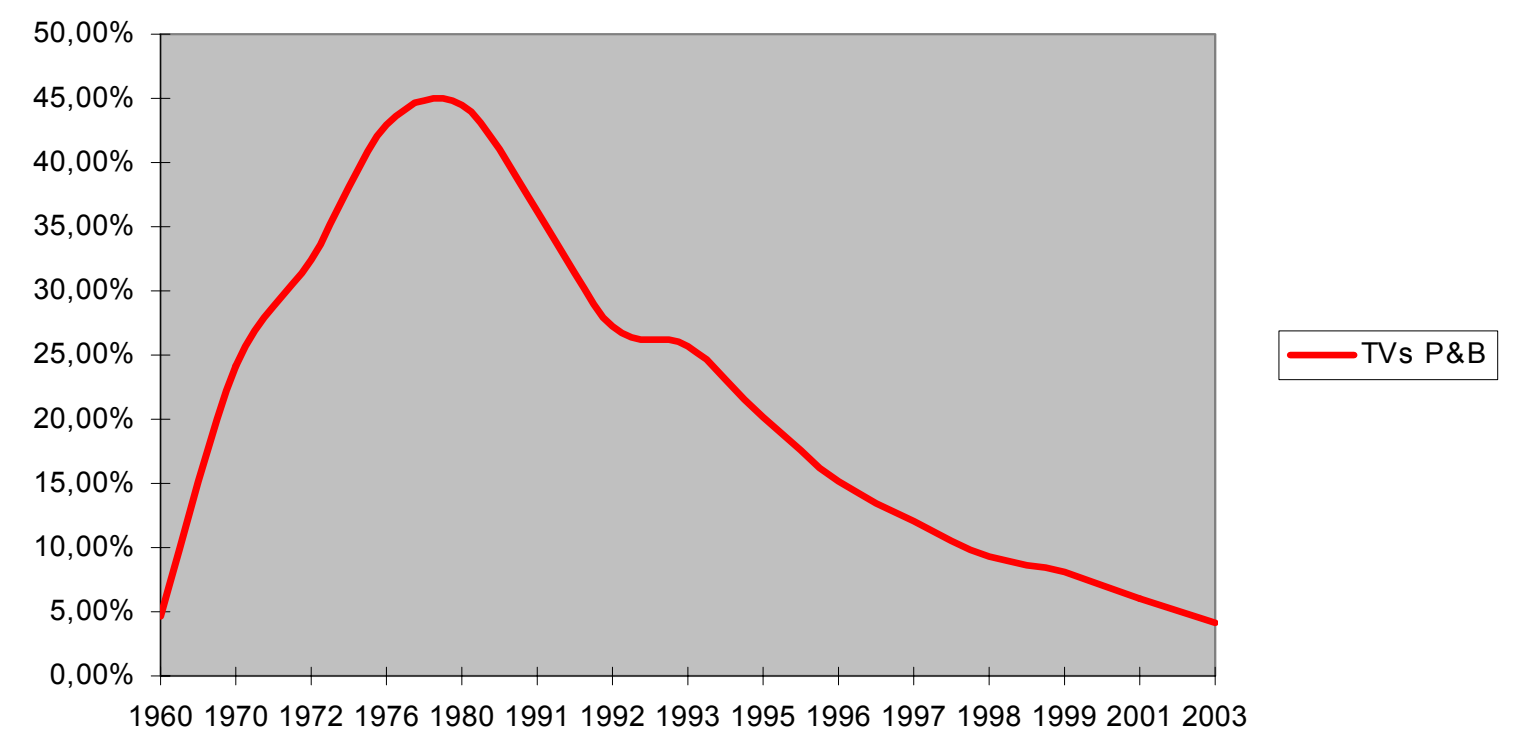

Figura 7.7 - Difusão de televisores preto e branco nos domicílios brasileiros acompanhado do processo de abandono deste tipo de equipamento. Fonte dos dados - IBGE.

Obs.: Por ser o objetivo meramente representativo do processo, não houve a preocupação em identificar intervalos próximos, em termos de períodos de tempo.

Apesar de não ser objeto regular das pesquisas do IBGE, o ferro elétrico estava presente em um total de $44,82 \%$ dos domicílios brasileiros em 1972, alcançando $74,34 \%$ em 1988. Um levantamento de máquinas de lavar roupa mostra que, apesar de estarem disponíveis para venda antes de 1960, atingiam somente $3,43 \%$ dos domicílios em 1972, 30,39\% em 1996 e 34,49\% deles em 2004. No primeiro caso, bem como no segundo, é possível perceber que o processo de 
difusão está ocorrendo, mas de forma bastante mais lenta que para outros produtos como televisores e geladeiras. Isto confirma a literatura que cita que o coeficiente de difusão varia entre os diferentes tipos de inovações e, assim, nesses casos, a pesquisa feita quanto a inovações em domicílios brasileiros parece não corroborar o número proposto de 0,50 do parâmetro de difusão média proposto por Lawton e Lawton (1979) em Mahajan e Peterson (1985). ${ }^{7.6}$ Uma possível razão para explicar essa condição é admitir que há produtos ou inovações que têm como potencial toda a sociedade e outros que parte da sociedade não identifica seu potencial de uso e os ignorará, sendo seu universo potencial menor. Ou então, que os valores da sociedade se contrapõem e dificultam o processo de percepção de sua importância para o bem-estar ou satisfação das pessoas.

Torna-se claro que o processo de difusão, mesmo com variações no coeficiente de difusão, ocorre nos domicílios permanentes brasileiros, de maneira similar ao proposto na literatura. Mas deve-se notar que a literatura pesquisada sempre mostra os processos de difusão sem segmentar os diferentes tipos de população e, como segunda etapa da pesquisa, foi verificado se haveria diferenças entre o comportamento da população residente em áreas urbanas e o da residente em áreas rurais. ${ }^{7.7}$ As mesmas inovações foram verificadas e isso está relatado no item a seguir.

\section{2 - A difusão das inovações nas áreas urbanas e rurais}

$\mathrm{Na}$ segmentação em áreas urbanas e rurais, foram levantadas as curvas de difusão dos itens objeto da pesquisa, e se elas seguiam o que havia sido

\footnotetext{
7.6 O modelo proposto por Lawson e Lawson (1979): $\frac{d N(t)}{d(t)}=p^{*} . \underline{N}_{0}+N(t) \cdot\left[N_{T}-N(t)\right]$; onde

$\mathrm{p}^{*}$ = parâmetro médio de difusão da inovação$$
\frac{d(t)}{d(t)}-\frac{N_{T}+N_{0}}{N_{T}}
$$

$\mathrm{N}_{0}=$ o número efetivo de adotantes iniciais $\left(\mathrm{N}_{0}\right.$ é calculado para a situação de $\mathrm{N}(\mathrm{t})$ no período $\mathrm{t}=1$ )

$\mathrm{N}_{\mathrm{T}}=$ número total de potenciais adotantes no sistema social no período $\mathrm{t}$

7.7 A população urbana pode ser diferenciada da população rural pelas características de proximidade e pelo aumento de atividades econômicas secundárias e terciárias.
} 
anteriormente identificado para o Brasil como um todo. Em princípio, as curvas encontradas são similares às anteriores, conforme se vê na figura $7.9 .^{7.8}, 7.10$ e 7.11, notando-se apenas uma defasagem no processo de difusão, com a área urbana oferecendo uma resposta mais rápida às inovações. As curvas se mostram similares para televisores e geladeiras, mas diferente para rádios.

\section{Difusão de rádios no Brasil}

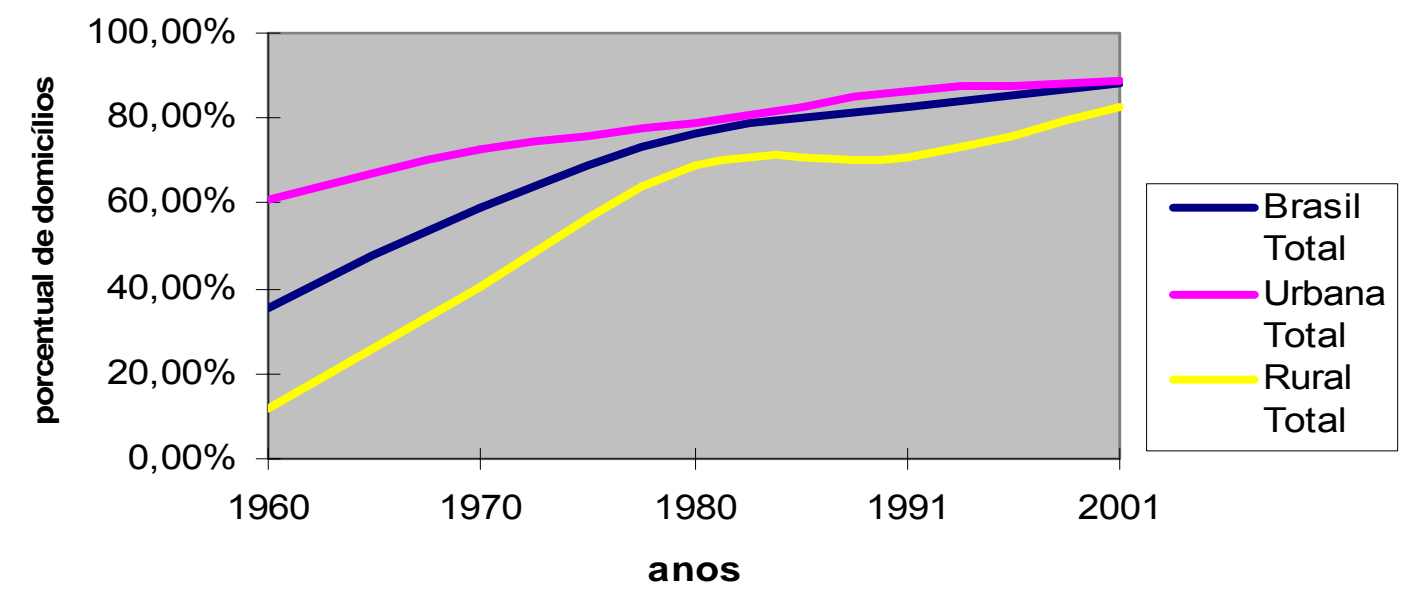

Figura 7.8 - Processo de difusão de aparelhos receptores de rádio no Brasil - segmentado em região urbana e rural. Fonte dos dados - IBGE.

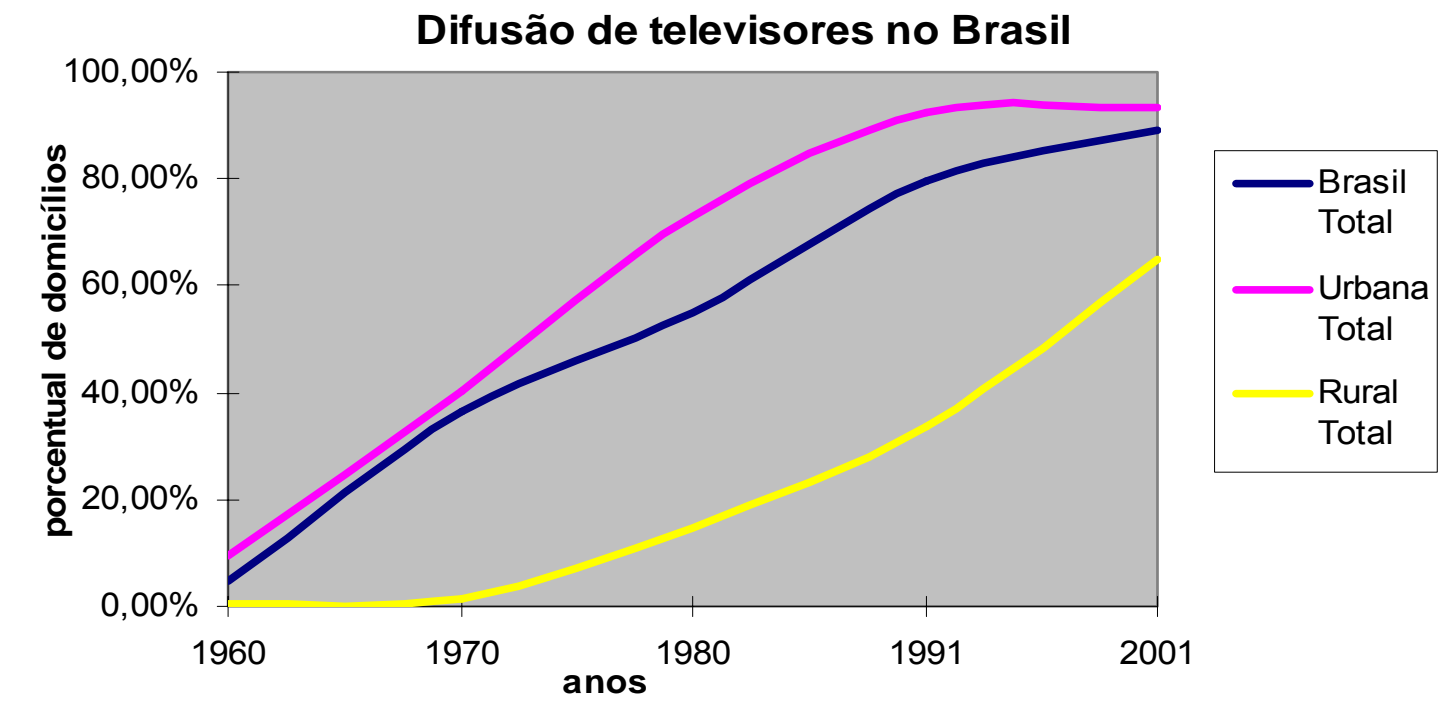

Figura 7.9 - Processo de difusão de aparelhos de TV no Brasil - segmentado em região urbana e rural. Fonte dos dados - IBGE.

\footnotetext{
${ }^{7.8}$ A pequena queda no processo de difusão que aparenta ocorrer em 1991 pode ser decorrente da mudança de metodologia do IBGE, aí introduzido, ou então, conseqüência da profunda perda de liquidez ocorrida na época do chamado Plano Collor.
} 


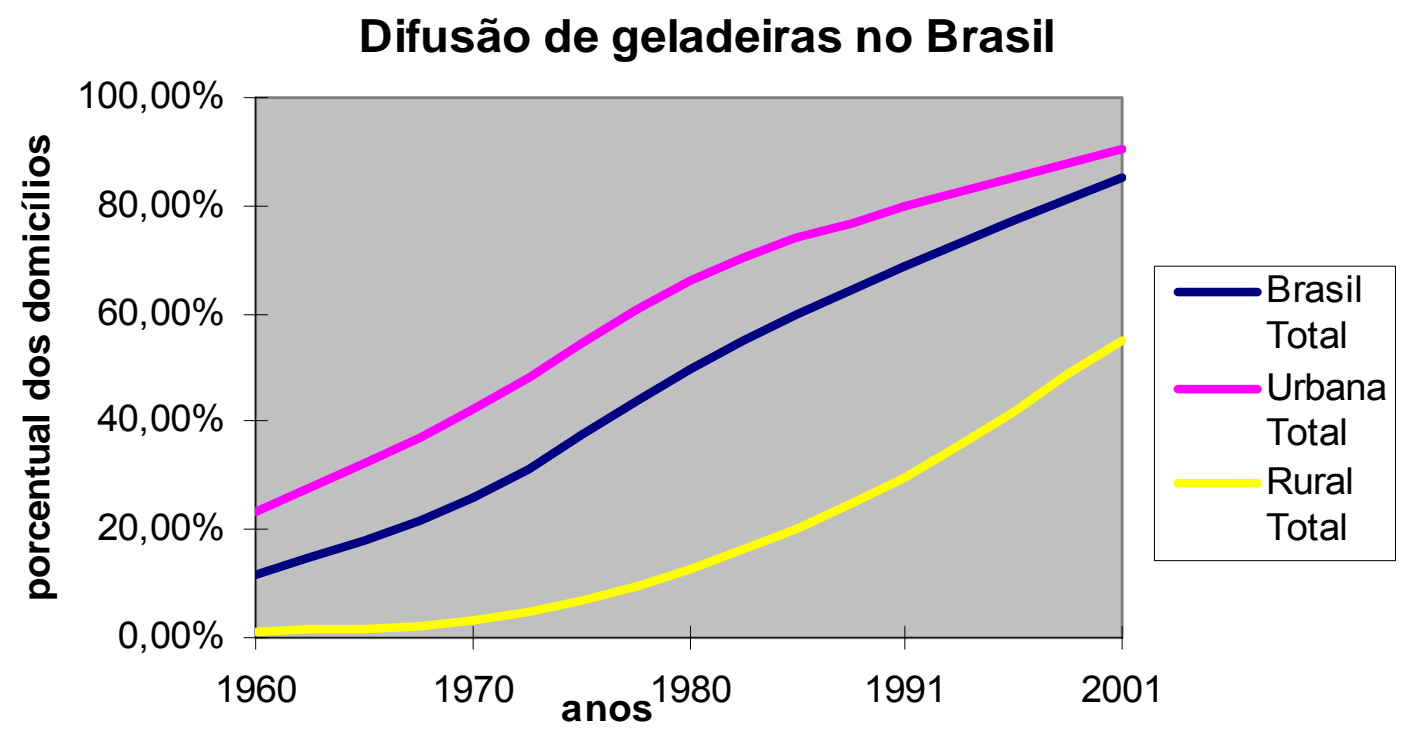

Figura 7.10 - Processo de difusão de geladeiras no Brasil - segmentado em região urbana e rural. Fonte dos dados - IBGE.

No caso dos rádios, o processo de difusão apresentou defasagem entre as zonas urbanas e rurais, pois, se na década de 1960, já havia uma significativa penetração do rádio no meio urbano, ele estava praticamente iniciando sua difusão na zona rural, precisando de aproximadamente 20 anos para se aproximar significativamente da quantidade existente em domicílios urbanos. Considerando que o rádio deu início às suas transmissões em 1923, no Rio de Janeiro, estando presente na maioria das capitais brasileiras entre meados até o fim da década de 1930, o processo básico de difusão nas zonas urbanas tomou algo em torno de 25 a 30 anos e, na zona rural, entre 40 a 50 anos, pois, as ondas curtas já permitiam o acesso ao rádio desde a década de 1940. (Castro, 2005) $)^{7.9}$

O levantamento foi repetido para os outros dois itens e o resultado pode ser visto nas figuras 7.9 e 7.10. Percebe-se que a defasagem se mantém entre a área urbana e a rural, repetindo o fenômeno de retardamento na difusão entre uma e outra área. Um argumento sobre essa defasagem poderia provir da demora quanto ao suprimento de energia elétrica nas áreas rurais (os três primeiros itens sob análise apresentam uma grande dependência da energia elétrica, apesar da

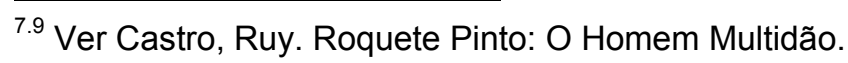


possibilidade de operar estes produtos sem conexão à rede geral de energia elétrica) e, para verificar essa condição, foi identificado o processo da difusão da energia elétrica no Brasil desde 1940, mostrada na figura 7.11.

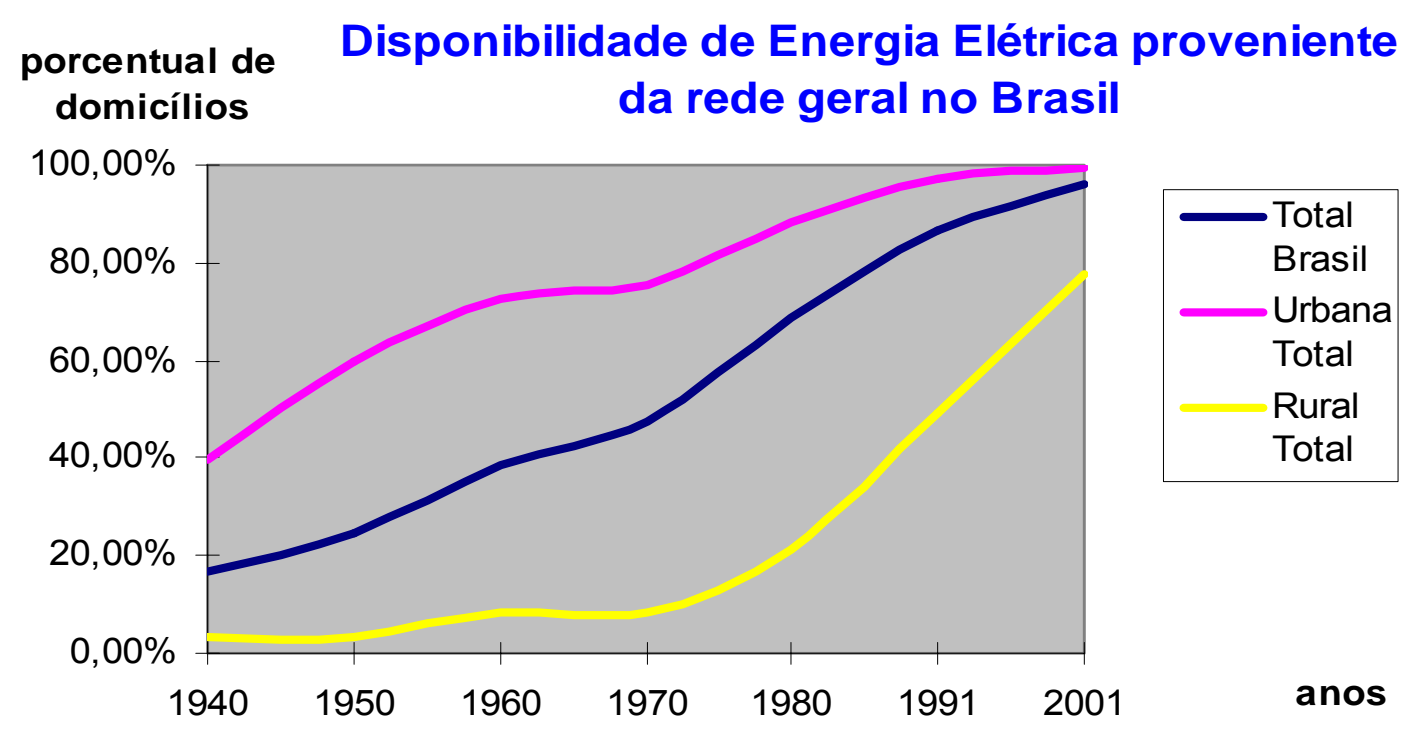

Figura 7.11 - Possibilidade de acesso dos domicílios à energia elétrica proveniente da rede geral no Brasil - segmentado em região urbana e rural. Fonte dos dados - IBGE.

Os resultados apontam na direção da importância da energia elétrica para a difusão, podendo este ser um fator impeditivo. Sem dúvida, a indisponibilidade de energia foi uma das causas a retardar a difusão nos domicílios da área rural, e nota-se que a disponibilidade de energia elétrica nos domicílios rurais sempre esteve à frente da presença de televisores ou geladeiras nos mesmos locais. Mas é interessante notar que, em determinadas épocas, o rádio se fez presente na zona rural em porcentual maior que a disponibilidade de energia elétrica proveniente da rede geral (ver tabela 7.1). Mas resta a dúvida se a energia elétrica poderia ser o fator fundamental para a ocorrência do processo de difusão do tipo de produtos escolhidos.

O rádio não mostra claramente esta dependência (ver tabela 7.1) e, para comprovar se o rádio não seria um caso em particular, foi verificado o processo de difusão das outras duas inovações - a instalação e uso de rede interna canalizada 
de água e os filtros de água, ambos independentes do fornecimento de eletricidade. O resultado é mostrado nas figuras 7.12 e 7.13 .

Tabela 7.1 - Porcentuais de domicílios no Brasil com instalação elétrica e rádios. Fonte dos dados - IBGE.

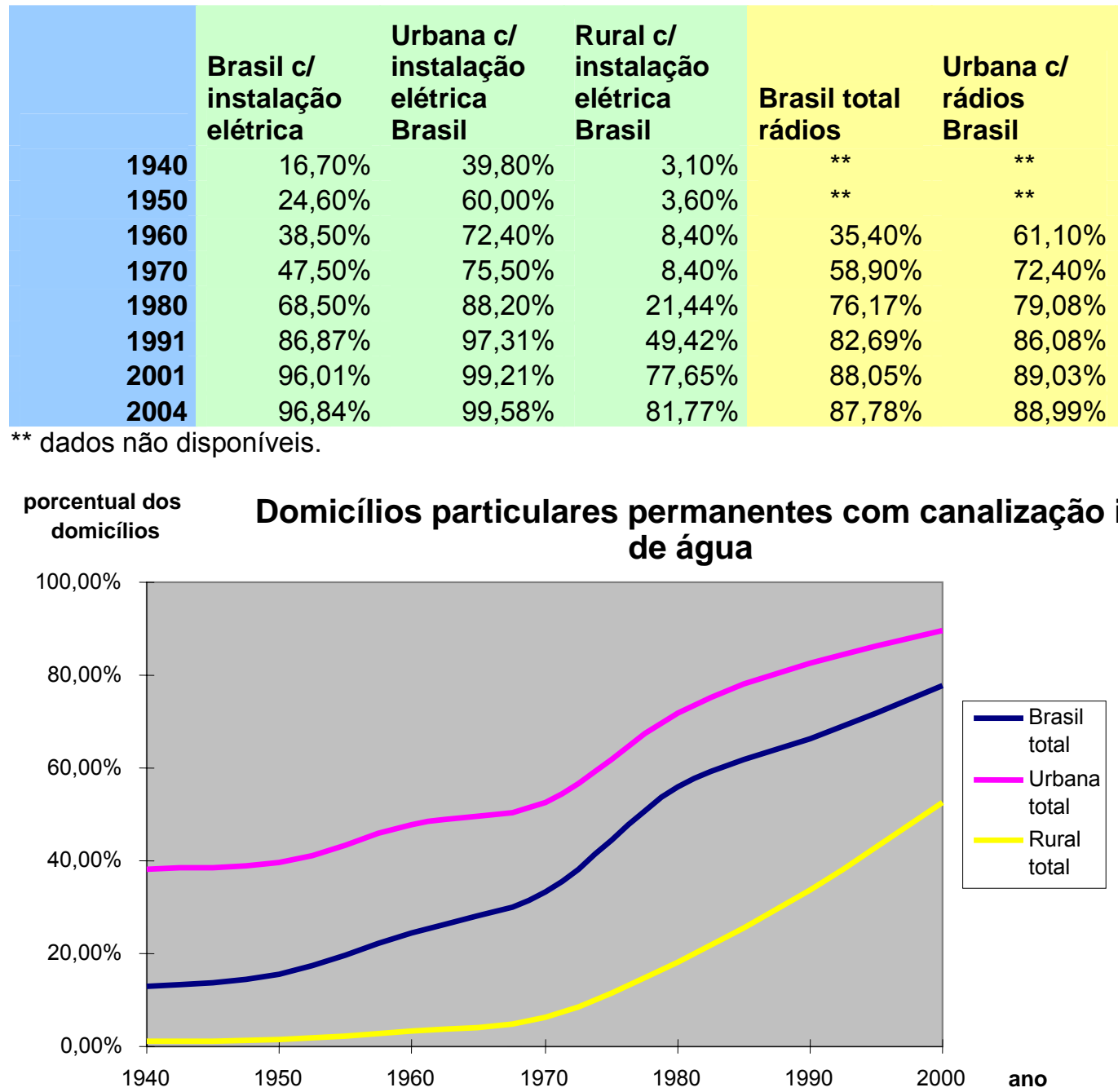

Figura 7.12 - Difusão do uso de instalações com canalização interna de água no Brasil segmentado em zona urbana e rural. Fonte dos dados - IBGE.

O processo encontrado na introdução de canalização interna de água reproduz um comportamento similar aos anteriormente mostrados, reforçando que a resposta da sociedade brasileira a novos produtos segue os formatos das curvas de difusão das inovações, e que há um tempo de retardamento na resposta às inovações da área rural em relação à área urbana. 
Em relação aos filtros de água em domicílios permanentes, e considerando que as pesquisas disponíveis não mostram a separação entre áreas urbanas e rurais antes de 1981, optou-se por proceder ao levantamento a partir de 1981, com um intervalo de aproximadamente cinco anos. Como já apontado, os filtros de água estão em um processo de abandono da inovação. Entretanto, é interessante notar que, nesse caso, há um tempo de retardamento do início do abandono do produto na área urbana em relação à área rural, comprovando a defasagem de resposta entre essas áreas.

\section{porcentual de domicílios \\ Difusão dos filtros de água nos domicílios permanentes no Brasil}

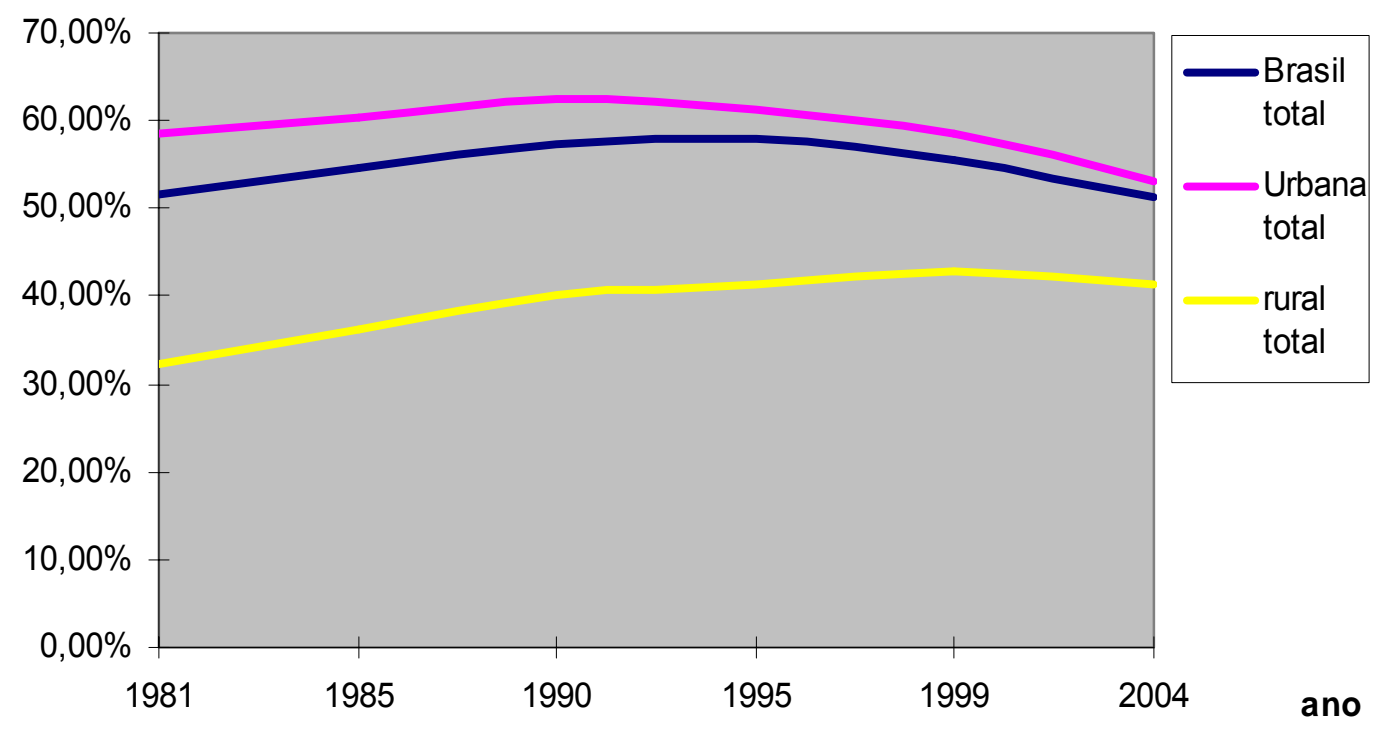

Figura 7.13 - Difusão e abandono de filtros de água nos domicílios permanentes no Brasil segmentado em área urbana e rural. Fonte dos dados - IBGE.

É interessante observar que o processo de difusão apresentou respostas independentes, quando se procedeu a algum tipo de segmentação, reforçando a necessidade de a pesquisa aprofundar a questão, para melhor entender 0 fenômeno na sociedade brasileira. $\mathrm{O}$ aprofundamento poderia dar-se de diversas maneiras, e a opção foi explorar os padrões de difusão nas diferentes classes de rendas, se obedeceria a padrões comuns de difusão e se esses padrões se 
repetiam para diferentes tipos de produtos. Os resultados são mostrados no próximo item do capítulo.

\section{3 - A difusão das inovações em diferentes classes de renda}

Identificado que há diferenças nas formas de resposta a inovações, quando se segmenta a população em área urbana e área rural, tema esse não discutido na literatura revista, uma dúvida surgiu: o processo de difusão de uma inovação apresenta características e respostas comuns, quando se comparam diferentes classes de renda domiciliar no Brasil?

Na literatura pesquisada não foram encontrados estudos sobre como o processo de difusão ocorre, quando se trata de diferentes classes de renda. Segundo Rogers (2003), um dos mecanismos que auxilia no processo de difusão de uma inovação são as condições de homofilia (identidade de valores e conhecimento), e entre os que dificultam o processo estão as de heterofilia (diferenças de valores e conhecimento). Sabe-se que entre as diversas condições que separam as pessoas nas diferentes classes de renda estão valores e nível de escolaridade, podendo se presumir que haja uma condição de homofilia dentro das mesmas classes de renda, e de heterofilia entre diferentes classes de renda. Nota-se que, aqui no Brasil, o nível de renda está correlacionado ao nível de escolaridade (IBGE, 2004a).

Segundo o IBGE, o Brasil foi um dos primeiros países a pesquisar classes de renda, criando uma base histórica dessa variável e possibilitando analisar a população sob essa ótica. Isso permitiu que se aprofundassem os trabalhos, mas daí surgiu uma dificuldade extra, pois nem todos esses dados estavam disponíveis nos documentos impressos e disponíveis do IBGE, sendo necessário que a pesquisa se aprofundasse nos microdados (conjunto bruto dos resultados das entrevistas realizadas). Esta análise foi feita com o suporte do software SPSS, versão 11.0. 
Nesse estágio, o estudo iniciou pelos televisores, anteriormente identificado como o item que apresenta o maior grau de penetração nos domicílios brasileiros. Os resultados são mostrados na figura 7.14 .

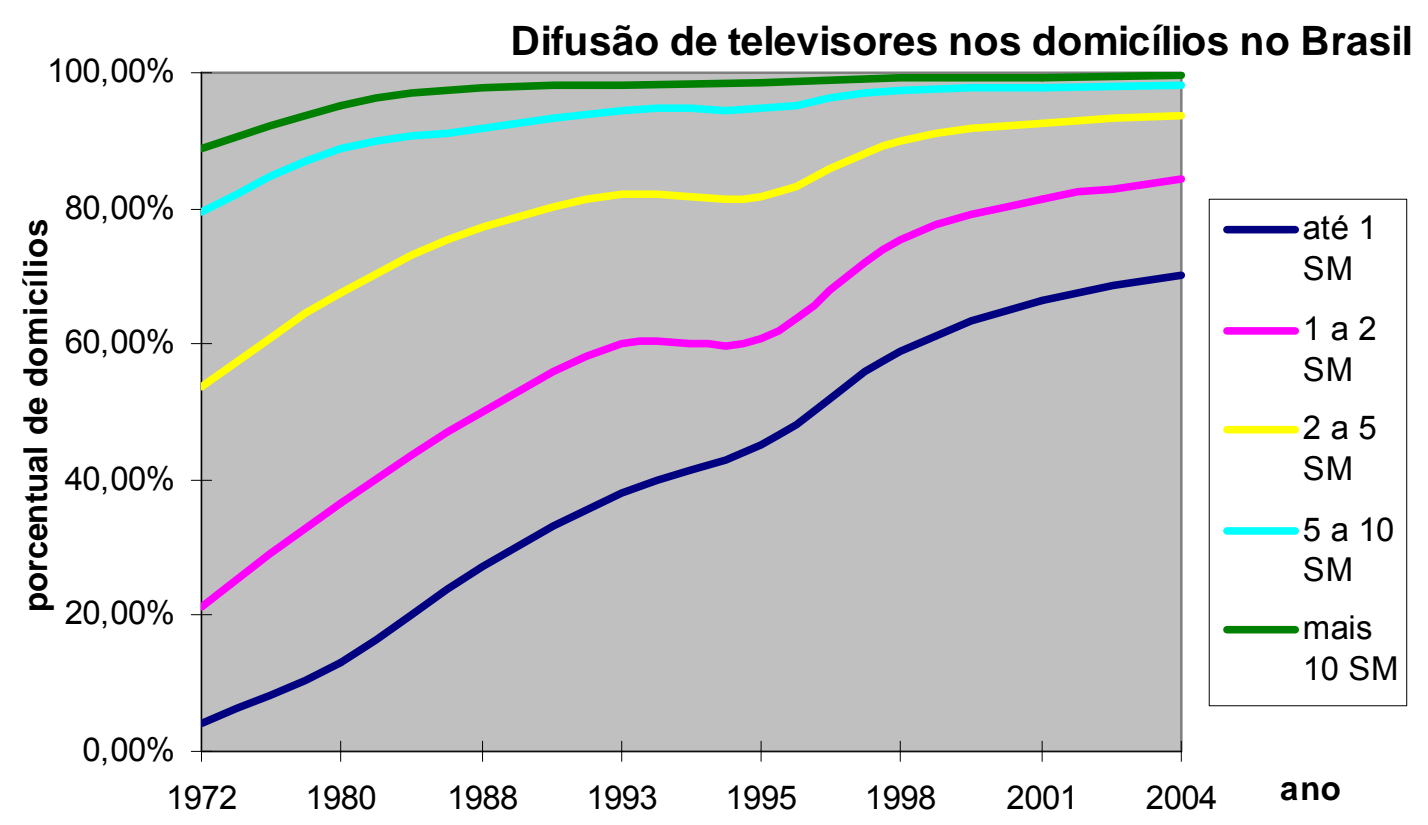

Figura 7.14 - Difusão de televisores nos domicílios no Brasil, separado por diferentes classes de renda. Fonte dos dados - IBGE.

Feitas as divisões de porcentuais pelas diferentes classes de renda, alguns aspectos chamaram a atenção:

$1^{\circ}$. O processo de difusão de televisores no Brasil não seguiu o mesmo tipo de distribuição para diferentes classes de renda, isto é, para as camadas de mais alta renda, o processo de resposta à inovação parece seguir uma curva típica de influência externa (Mahajan e Peterson, 1985), indicando um processo de comunicação interpessoal de pequeno impacto na decisão, o que não ocorreu nas camadas de mais baixa renda, onde o processo de comunicação interpessoal parece estar fortemente presente, observando uma distribuição de influência interna ou de influência mista.

$2^{\circ}$. As curvas de difusão se mostraram diferentes para classes de renda distintas, entretanto, o processo de difusão está presente em todas elas. Se no caso das classes de mais alta renda (acima de 10 salários mínimos), os 
televisores já estavam presentes em torno de 86\% dos domicílios em 1972, nos domicílios de mais baixa renda (até um salário mínimo), na mesma época, representavam um porcentual de 5,5\%. Em 2003, o porcentual do item nos domicílios com renda até um salário mínimo já representava algo em torno de $70 \%$, enquanto, na faixa de renda entre um a dois salários mínimos, já estavam presentes em $85 \%$ deles.

$3^{\circ}$. A televisão começou a operar no Brasil, em São Paulo, em 1950, e demorou em torno de 15 a 25 anos para estar presente em todas as principais cidades no país, e atingir potencialmente todos os que detêm a maior parcela de rendimentos. Ainda assim, o processo demorou por volta de 50 anos para atingir uma parcela significativa (superior a 2/3) da camada de rendimento mais baixo.

Como havia sido anteriormente identificado que os televisores preto e branco estão em processo final de abandono, foi retomada a questão de como esse processo teria ocorrido nas diferentes camadas de renda, conforme a figura 7.15.

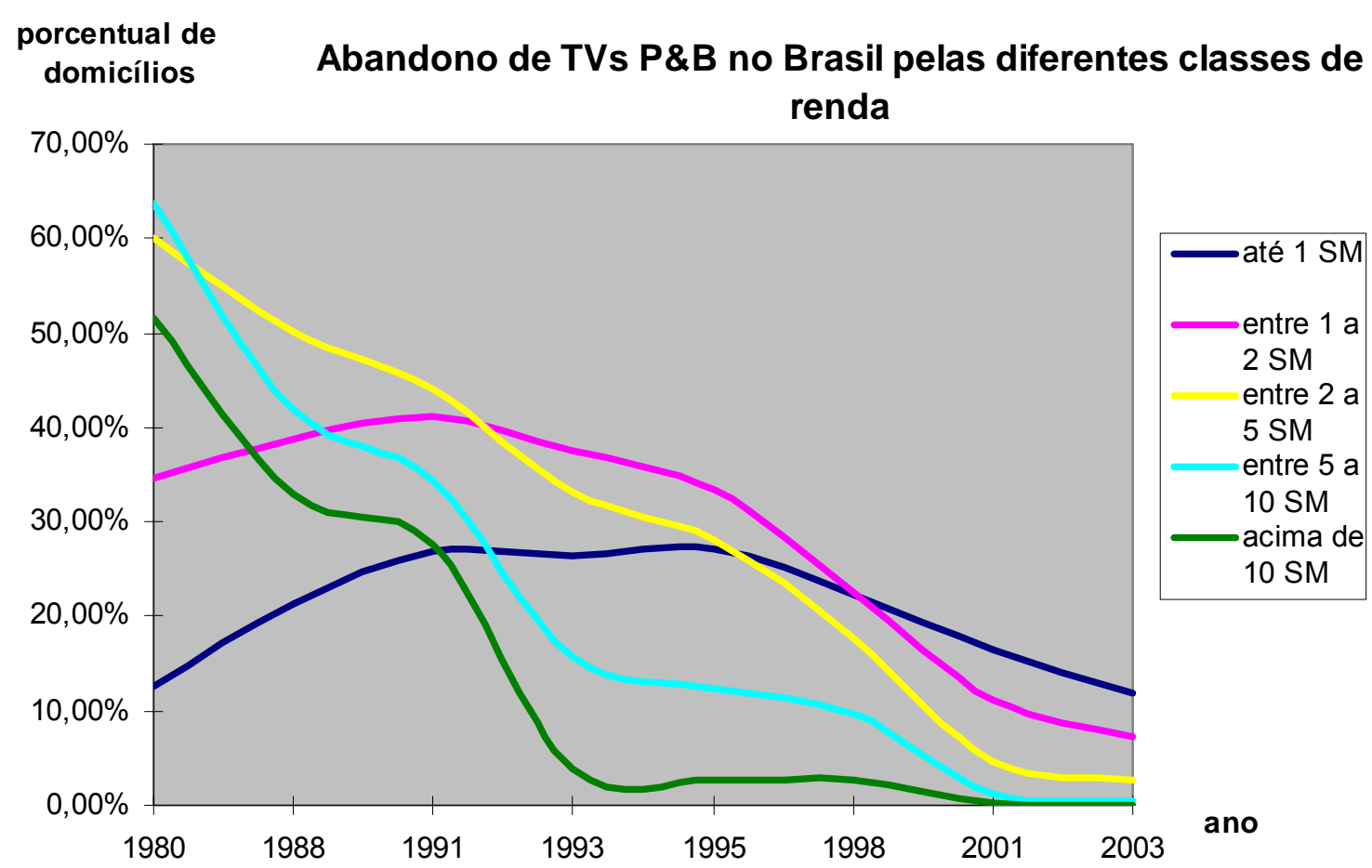

Figura 7.15 - Abandono da TV preto e branco pelas diferentes classes de renda de domicílios no Brasil. Fonte dos dados - IBGE. 
Assim como as classes de renda assumem um produto com um grau de retardamento em relação ao que ocorre nas classes de renda mais alta, no caso do abandono, o fenômeno se repete. Isso poderia ser resultado das diferenças de poder aquisitivo e potencial possibilidade de compra do novo bem. Percebe-se que os televisores preto e branco passavam por um processo de difusão nas classes de renda mais baixa, enquanto já era claro que estavam sendo abandonados pelas camadas de renda mais alta, mas o processo de crescimento se inverte, mesmo nas classes de menor poder aquisitivo e o abandono do produto tem início. Essa constatação reforça a leitura de que há diferentes comportamentos entre condições econômicas, culturais e comportamentais diferentes.

Mas o fenômeno poderia ser entendido como restrito ao produto televisores, e outras análises mostraram que um comportamento similar ocorria para as demais inovações objeto da pesquisa. As figuras 7.16 e 7.17 mostram o processo de difusão para rádios e geladeiras.

\section{difusão de geladeiras por classe de renda no Brasil}

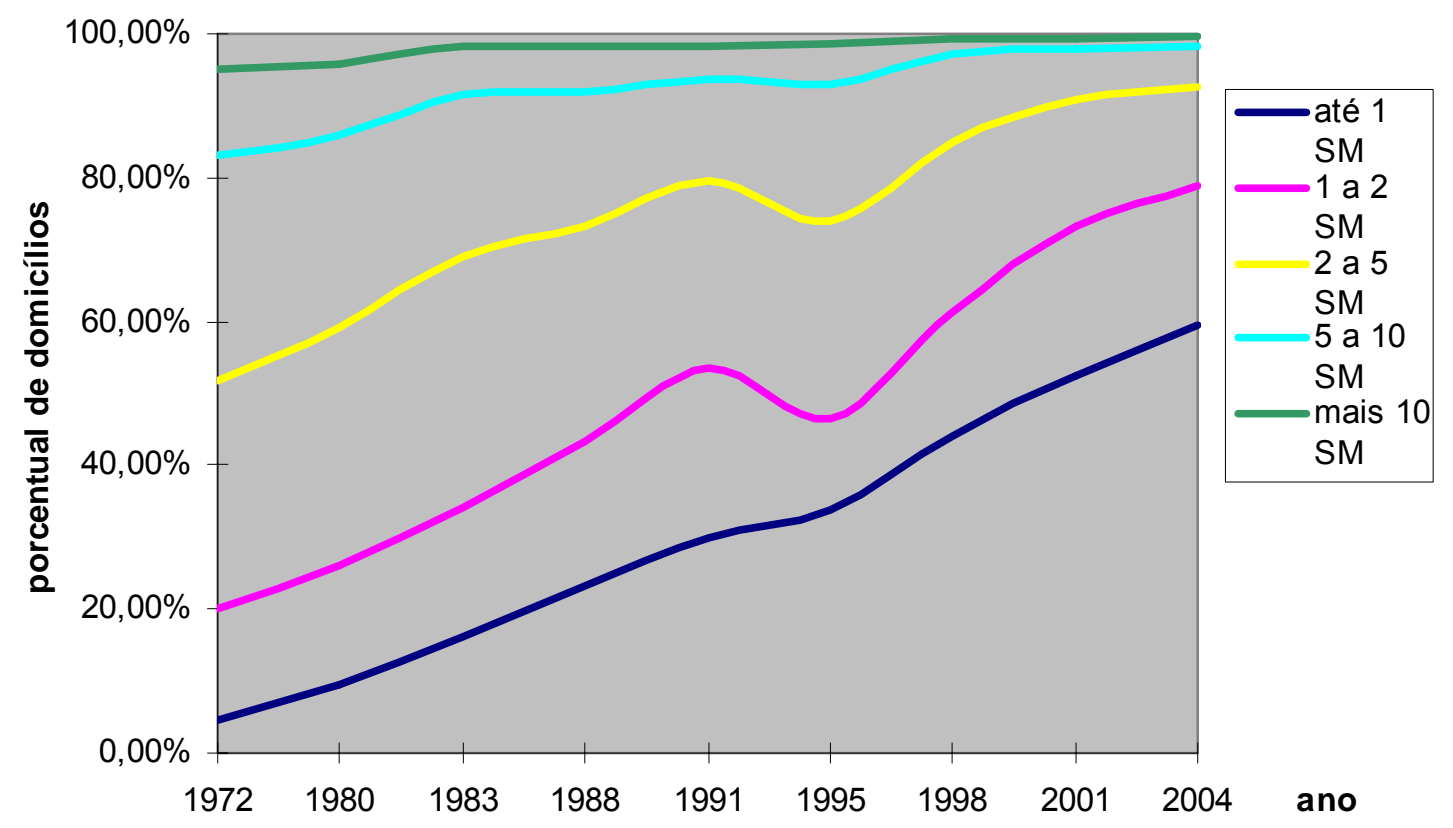

Figura 7.16 - Difusão de geladeiras nos domicílios no Brasil, separado por diferentes classes de renda. Fonte dos dados - IBGE. 
Difusão de aparelhos de rádio nos domicílios no Brasil por classe de renda

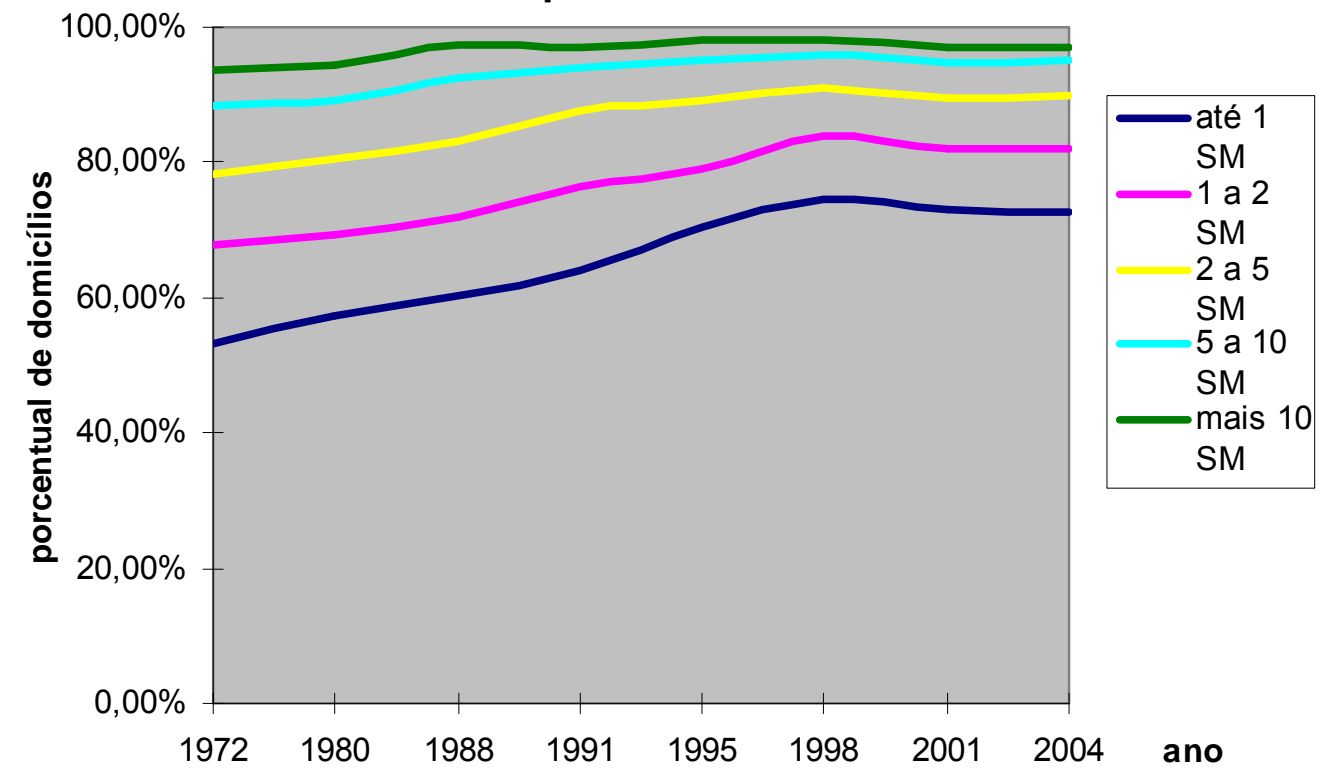

Figura 7.17 - Difusão de aparelhos de rádio nos domicílios no Brasil, separado por diferentes classes de renda. Fonte dos dados - IBGE.

\section{difusão de canalização interna de água nos domicílios no Brasil}

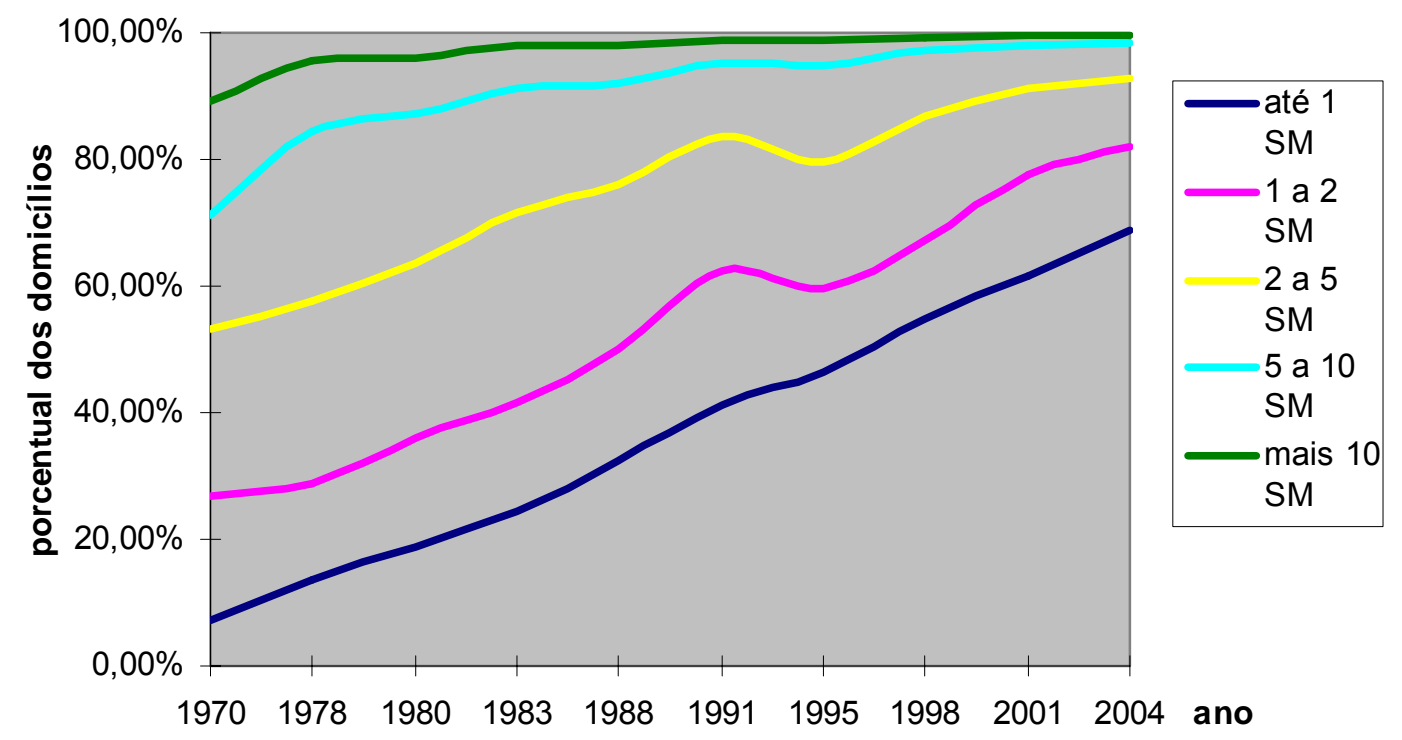

Figura 7.18 - Difusão de canalização interna de água nos domicílios no Brasil, separado por diferentes classes de renda. Fonte dos dados - IBGE. 


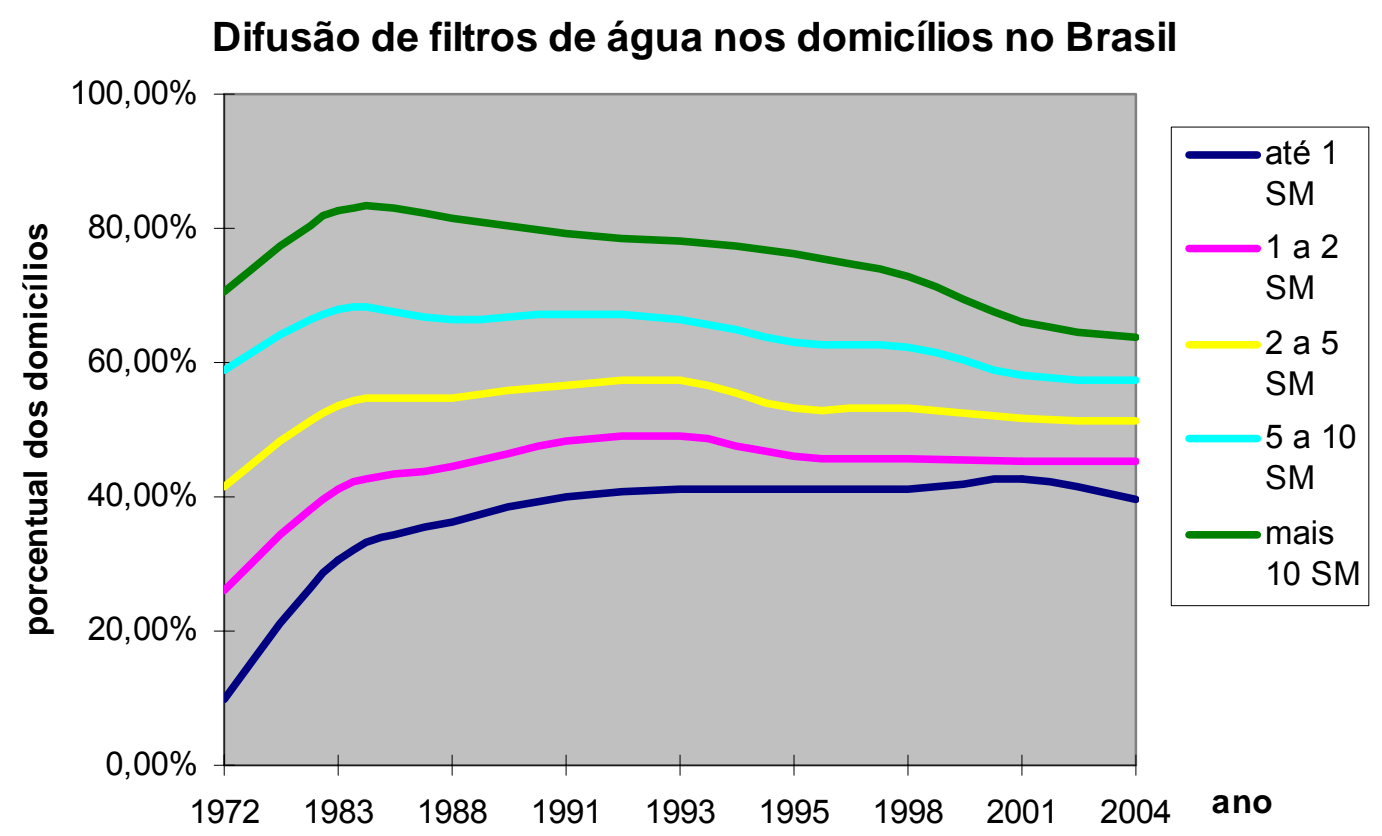

Figura 7.19 - Difusão e abandono do filtro de água nos domicílios no Brasil, por classe de renda. Fonte dos dados - IBGE.

Os comentários feitos inicialmente para os televisores se repetem para as demais inovações, e algumas conclusões podem ser assumidas:

- as inovações atingem mais rapidamente as classes de renda com maior poder aquisitivo;

- maior o poder aquisitivo, mais rápida a adesão à inovação, reforçando a existência de um tipo de resposta no formato exponencial para essas classes, isto é, o formato da curva de resposta é mais condizente com o modelo de influência externa puro;

- menor o poder aquisitivo analisado pelas classes de renda em salários mínimos vigentes à época, mais a curva se aproxima da curva de influência interna ou mista, ou seja, mais tende a se aproximar do fenômeno de convencimento pelos pares ou por suas atitudes.

Aqui novamente se percebe que o processo de abandono está ocorrendo com os filtros de água. Iniciou pelas classes de renda mais altas e foi se propagando às 
demais, conforme se vê na figura 7.19. Isso reforça o processo de adoção de uma inovação como um fenômeno social, isto é, a sociedade cria regras e as difunde como uma forma de conduta.

Na difusão de canalização interna de água, mostrado na figura 7.18, o processo se repete e confirma um padrão de comportamento anteriormente verificado. Também aqui se identifica que, em torno de 1995, há uma alteração brusca na expansão da difusão, a qual logo em seguida é retomada. Esta ocorrência fica bem representada nos televisores, nas geladeiras e nas canalizações internas de água e, procurando entender melhor o que estaria ocorrendo, foi realizado um levantamento dos porcentuais das diferentes classes de renda em relação ao total de domicílios, e esse resultado está mostrado na figura 7.20.

\section{porcentual de classes de renda sobre total domicílios}

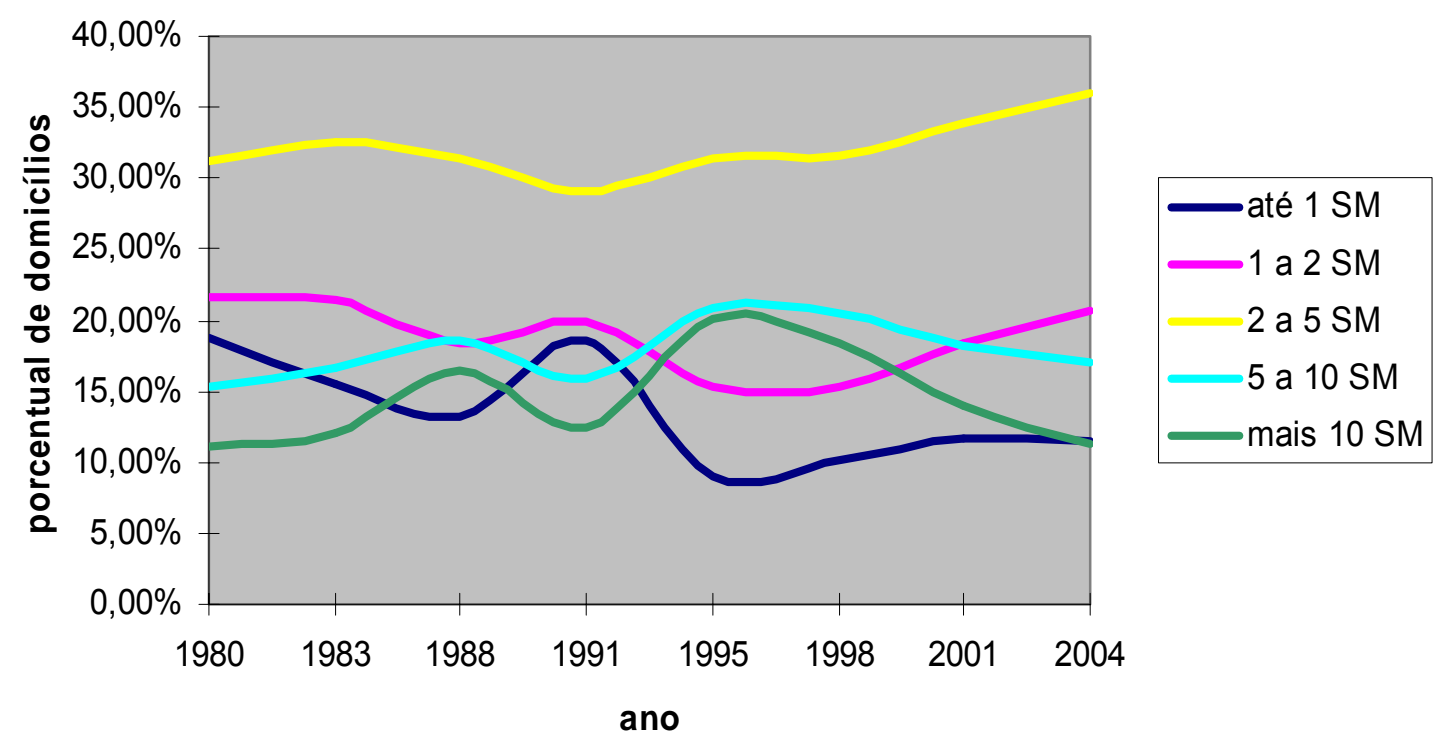

Figura 7.20 - Proporção das diferentes classes de renda em salários mínimos em relação ao número total de domicílios no Brasil. Fonte dos dados - IBGE.

Uma primeira leitura é pouco esclarecedora, entretanto, se percebe que, no período, houve uma rápida migração dos domicílios de classe de renda mais baixa para faixas mais altas e isso suporta a leitura que, ao subirem de categoria de 
renda, em um curto prazo de tempo, os domicílios carreguem seu menor índice de inovações e contaminem os níveis mais altos. Essa situação somente parece não surgir nos aparelhos de rádio, mas, nessa época, praticamente todas as categorias já estavam próximas da saturação. Apesar dessa momentânea retração no processo de difusão, ela é imediatamente retomada em todas as classes de renda de menor poder aquisitivo.

A segmentação da população reforçou a existência de diferenças nas formas de resposta das diversas categorias de renda, demonstrando que a representação das curvas de difusão geral, na sociedade, apenas mostra a tendência média. A leitura segmentada da sociedade abre uma nova fonte de informação para uma empresa ao elaborar sua estratégia de inovação de um produto. Pode-se depreender dos gráficos que uma inovação é aceita na forma exponencial pela mais alta classe de renda, permitindo que o processo possa ser antecipado para as demais camadas. Esta afirmação será objeto de comprovação adiante.

Há uma percepção geral de que os produtos ficam mais baratos ao longo do tempo, permitindo que as classes de renda de menor poder aquisitivo possam adquiri-lo, e indicando que a difusão de uma inovação possa ser fortemente influenciada pelo fator preço. Em sendo essa presunção verdadeira, deve-se aceitar que o processo de difusão ocorre nas condições verificadas como conseqüência da espera da redução dos preços pelas camadas de renda mais baixa. Assim, a seqüência da pesquisa procurou esclarecer se esse fato realmente ocorria e qual a sua intensidade. Esta a discussão no próximo item.

\section{4 - A evolução do preço de varejo das inovações}

A primeira etapa dessa parte da pesquisa identificou como proceder a um levantamento dos preços de produtos, ao longo de diversos anos. Ficou definido que, para se ter uma razoável compatibilidade com as datas de pesquisa feitas pelo IBGE, seriam levantados os preços, do mês de setembro, de diversos 
produtos de uso domiciliar. A pesquisa foi feita em jornais e suas respectivas propagandas e resultados estão listados no apêndice 2. Para efeitos de comparação, definiu-se que os preços seriam atualizados pelo índice de correção da FIPE-SP e pela quantidade de salários mínimos vigentes na época. A pesquisa ainda foi restrita aos meses de setembro de cada decênio, isto é, na mesma época de cada censo decenal, dos anos de 1960, 1970, 1980, 1990, 2000 e aos meses de novembro/dezembro de 2005. Foram pesquisados os jornais "O Estado de São Paulo" e "Folha de São Paulo" e, para os anos de 2000 e 2005, alguns encartes de empresas colocadas em jornais ou distribuídas ao público, além de, em 2005, também terem sido pesquisados preços pela internet. As pesquisas às fontes escritas foram efetuadas, em grande parte, nas hemerotecas da Biblioteca Municipal Mário de Andrade de São Paulo e no Arquivo do Estado de São Paulo. Foi adotada uma estratégia tomando-se como base a proposta por Sabóia (1983).

Apesar do senso comum, os preços das inovações de uso domiciliar não sofreram grandes alterações nos seus valores de venda, ao longo das décadas, exceção feita a 1990, onde a alta inflação não permitiu uma referência clara. Nos outros períodos, inclusive na época atual, os preços em quantidades de salários mínimos são próximos, e, como o que interessa a esse estudo é o momento da primeira aquisição de uma inovação para um domicílio, o valor que importa é o menor valor encontrado para um bem durável (quando o indivíduo poderia comprar). Os seis menores valores para compra encontrados nos anúncios podem ser vistos nas tabelas 7.2 a 7.7 ; os demais preços encontram-se no apêndice 2.

Tabela 7.2 - Preços de geladeiras desde 1960.

preço de geladeiras em quantidades de salários mínimos

$\begin{array}{ccccccc}\begin{array}{l}\text { ano } \\ \text { preço }\end{array} & \mathbf{1 9 6 0} & \mathbf{1 9 7 0} & \mathbf{1 9 8 0} & \mathbf{1 9 9 0} & \mathbf{2 0 0 0} & \mathbf{2 0 0 5} \\ \text { I } & 1,82 & 2,51 & 2,36 & 3,88 & 2,58 & 2,56 \\ \text { II } & 2,48 & 2,67 & 2,57 & 4,06 & 2,77 & 2,80 \\ \text { III } & 2,69 & 3,19 & 2,58 & 4,11 & 3,30 & 2,80 \\ \text { IV } & 2,91 & 3,50 & 2,65 & 4,11 & 3,30 & 2,86 \\ \text { V } & 3,11 & 3,62 & 2,89 & 4,28 & 3,64 & 3,00 \\ \text { VI } & 3,11 & 3,62 & 2,89 & 4,38 & 3,64 & 3,33\end{array}$

Conforme se vê na tabela 7.2, as geladeiras mantiveram seu preço ao longo do tempo e, assim, não foi qualquer tipo de redução de preços ao longo do tempo 
que permitiu ou incentivou o processo de sua difusão. Na tabela 7.3, identifica-se que os ferros elétricos já foram mais baratos que o são atualmente. Os televisores (tabela 7.4) mantêm um padrão próximo ao das geladeiras e o mesmo ocorre com os fogões a gás (tabela 7.6). A única exceção encontrada está na tabela 7.7, em relação às máquinas de lavar roupa, mas isto talvez seja decorrente da pequena quantidade de publicações de preços encontradas nos primeiros períodos de pesquisa.

Tabela 7.3 - Preços de ferros elétricos desde 1960. preço de ferro elétrico em quantidades de salários mínimos

$\begin{array}{cllllll}\begin{array}{l}\text { ano } \\ \text { preço }\end{array} & \mathbf{1 9 6 0} & \mathbf{1 9 7 0} & \mathbf{1 9 8 0} & \mathbf{1 9 9 0} & \mathbf{2 0 0 0} & \mathbf{2 0 0 5} \\ \text { I } & 0,03 & 0,04 & 0,08 & 0,35 & 0,10 & 0,13 \\ \text { II } & 0,03 & 0,04 & 0,08 & 0,35 & 0,11 & 0,14 \\ \text { III } & -- & 0,05 & 0,19 & 0,36 & 0,13 & 0,17 \\ \text { IV } & -- & 0,10 & -- & 0,37 & 0,16 & 0,20 \\ \text { V } & -- & 0,32 & -- & 0,38 & 0,25 & 0,26 \\ \text { VI } & -- & 0,32 & -- & 0,53 & 0,27 & 0,26\end{array}$

Tabela 7.4 - Preços de televisores desde 1960.

\begin{tabular}{ccccccc} 
& \multicolumn{6}{c}{ preço de televisores em quantidades de salários mínimos } \\
Ano & $\mathbf{1 9 6 0}$ & $\mathbf{1 9 7 0}$ & $\mathbf{1 9 8 0}$ & $\mathbf{1 9 9 0}$ & $\mathbf{2 0 0 0}$ & $\mathbf{2 0 0 5}$ \\
preço & & & & & & \\
I & 2,08 & 2,13 & 2,09 & 3,45 & 1,56 & 1,90 \\
II & 2,58 & 2,67 & 2,17 & 4,13 & 1,61 & 2,00 \\
III & 3,00 & 3,19 & 2,21 & 4,54 & 1,61 & 2,00 \\
IV & 3,49 & 3,20 & 2,21 & 6,42 & 1,61 & 2,00 \\
V & 3,61 & 3,46 & 2,21 & 6,92 & 1,61 & 2,13 \\
VI & 3,85 & 3,47 & 2,46 & 6,92 & 1,65 & 2,33
\end{tabular}

Tabela 7.5 - Preços de aparelhos de rádio desde 1960.

\begin{tabular}{ccccccc}
\multicolumn{7}{c}{ Preços de rádios em quantidades de salários mínimos } \\
Ano & $\mathbf{1 9 6 0}$ & $\mathbf{1 9 7 0}$ & $\mathbf{1 9 8 0}$ & $\mathbf{1 9 9 0}$ & $\mathbf{2 0 0 0}$ & 2005* \\
preço & & & & & & \\
I & 0,33 & 0,18 & 0,36 & 0,63 & 0,08 & \\
II & 0,34 & 0,26 & 0,41 & 0,71 & 0,12 \\
III & 0,38 & 0,32 & 0,43 & 0,72 & 0,12 \\
IV & 0,38 & 0,37 & 0,55 & 0,81 & 0,12 \\
V & 0,42 & 0,42 & & 1,07 & 0,13 \\
VI & 0,42 & 0,48 & & 1,12 & 0,14 &
\end{tabular}

* em 2005 é difícil separar um rádio de outros itens do qual ele é parte. 
Tabela 7.6 - Preços de fogões a gás desde 1960.

\begin{tabular}{|c|c|c|c|c|c|c|}
\hline \multicolumn{7}{|c|}{ Preços de fogões em quantidades de salários mínimos } \\
\hline $\begin{array}{l}\text { Ano } \\
\text { preço }\end{array}$ & 1960 & 1970 & 1980 & 1990 & 2000 & 2005 \\
\hline I & 0,44 & 0,42 & 1,20 & 1,95 & 0,85 & 0,63 \\
\hline II & 0,99 & 0,48 & 1,30 & 1,98 & 0,99 & 1,06 \\
\hline III & 0,99 & 0,64 & 1,83 & 1,98 & 1,38 & 1,30 \\
\hline IV & 1,00 & 0,80 & 2,17 & 2,28 & 1,38 & 1,33 \\
\hline V & 1,04 & 1,07 & 2,41 & 2,28 & 1,44 & 1,99 \\
\hline VI & 1,13 & 1,22 & 2,41 & 2,30 & 1,49 & 2,00 \\
\hline
\end{tabular}

A constatação de que os preços, em quantidades de salários mínimos, mantêm valores relativamente próximos em períodos de 10 anos (exceção a 1990), não comprova a hipótese de que a redução de preços foi um fator de incentivo à difusão dessas inovações nos domicílios brasileiros. Para alguns dos produtos listados (exceção talvez à máquina de lavar roupa), os preços hoje praticados são até maiores que em 1960, quando não havia decorrido muito tempo do início do processo de difusão. Um secador de cabelo (apesar de ter sido identificado apenas um item em setembro de 1960) custava o equivalente a 0,33 salários mínimos, em 1980 entre 0,41 a 0,53 salários mínimos, sendo seu preço em 2005 entre 0,10 a 0,63 salários mínimos. Um liquidificador custava em 1960 o equivalente a 0,26 salários mínimos, em 1970 - 0,14 salários mínimos, em 1980 0,27 salários mínimos, em 1990 - 0,39 salários mínimos, em 2000 - 0,30 salários mínimos e em 2005 pode ser encontrado pelo equivalente a 0,13 salários mínimos.

Tabela 7.7 - Preços de máquinas de lavar roupa desde 1960.

\begin{tabular}{|c|c|c|c|c|c|c|}
\hline \multirow[b]{2}{*}{$\begin{array}{l}\text { Ano } \\
\text { preço }\end{array}$} & \multicolumn{6}{|c|}{ Preços de máq. lav. roupa - quantidades de salários mínimos } \\
\hline & 1960 & 1970 & 1980 & 1990 & 2000 & 2005 \\
\hline 1 & 5,56 & 4,01 & 3,01 & 7,41 & 1,71 & 2,66 \\
\hline II & 5,63 & 4,11 & 3,61 & 8,55 & 1,85 & 2,66 \\
\hline III & 6,23 & 4,54 & 5,85 & 8,55 & 1,85 & 3,63 \\
\hline IV & 6,47 & 4,80 & 5,90 & 8,55 & 2,90 & 3,73 \\
\hline $\mathrm{V}$ & & 5,07 & 10,12 & 9,06 & 3,57 & 4,00 \\
\hline $\mathrm{VI}$ & & 5,34 & & 9,56 & 3,57 & 4,33 \\
\hline
\end{tabular}

Estendendo a comparação para os demais preços listados no apêndice 2, vê-se que o fenômeno se repete para os demais bens duráveis de uso doméstico, e aqui 
poderia surgir uma dúvida sobre se o responsável pela diferença seriam os valores nominais do salário mínimo em relação a seu valor presente e, assim, foi elaborada a figura 7.21, que mostra a evolução do salário mínimo tendo como base sua atualização pelo IPC-SP FIPE e o INPC. O que se vê nesse período é que o salário mínimo sofreu intensas e repentinas oscilações, o que corrobora a tese de que o processo de difusão de uma inovação apresenta certo grau de descolamento da situação econômica vivida. Tomando-se como base o índice IPC-SP FIPE, percebe-se que o salário mínimo, depois de cair, vem mostrando uma ligeira evolução positiva ao longo dos últimos 30 anos, o que pode justificar, em parte, que o valor dos bens duráveis de uso domiciliar seja menor em salários mínimos, mas que não consegue justificar que atualmente a diferença seja tão significativa a ponto de incentivar a compra. Um ponto a ressaltar é que, apesar das diferenças apresentadas pelos dois índices, as tendências são comuns, o que reforça certa independência da difusão em relação ao potencial de compra. A variação do salário mínimo não apóia a variação registrada na difusão de algumas inovações no período 1995-96, o que suporta a leitura anteriormente feita, quando da discussão do problema.

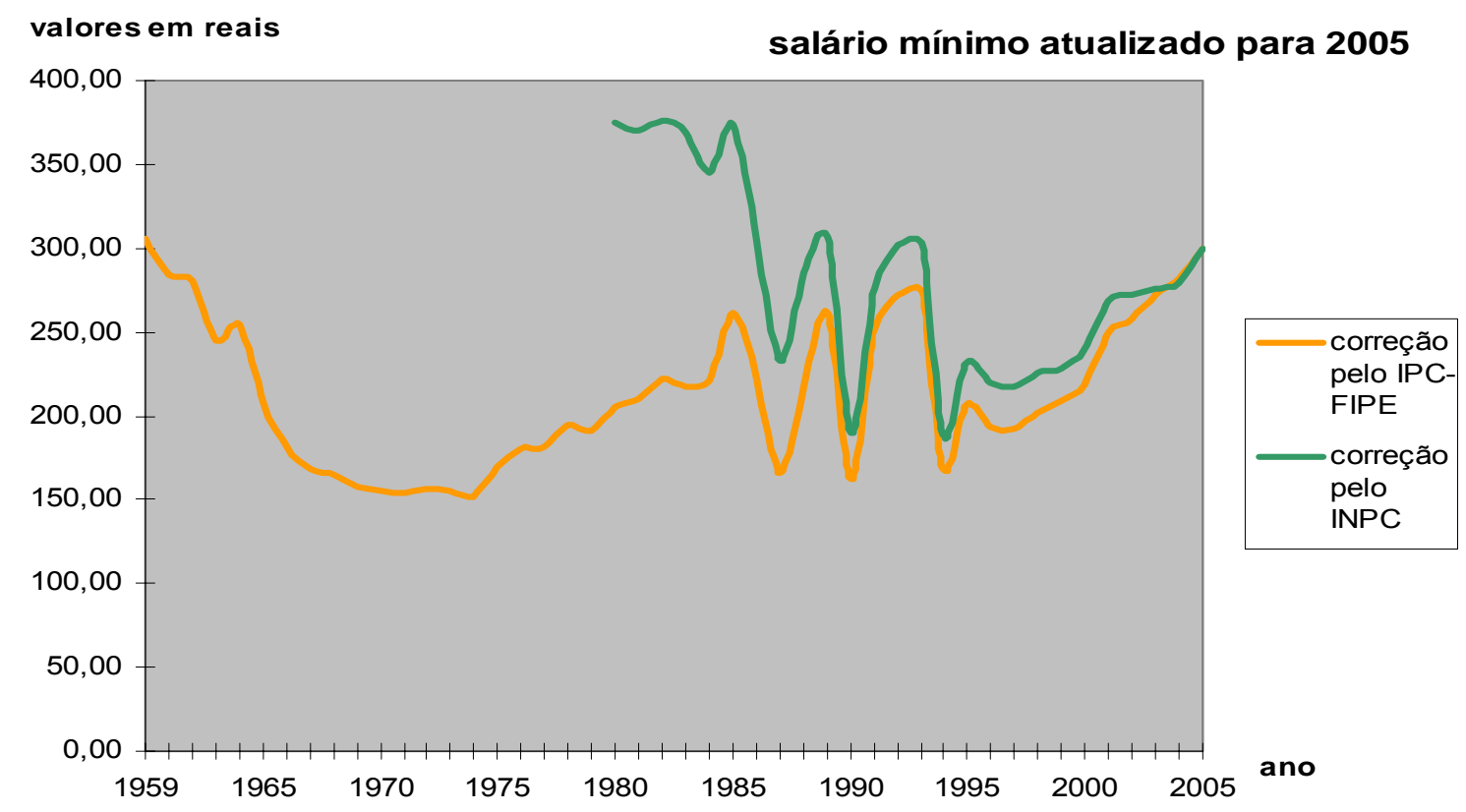

Figura 7.21 - Evolução do salário mínimo brasileiro desde 1959 corrigido pelo IPC-SP FIPE e INPC do IBGE (a partir de 1979). Fonte dos valores do salário mínimo - Ministério do Trabalho. 
Retomando as tabelas de preços, apesar de o valor do salário mínimo ter atingido um de seus menores patamares em torno de 1970, muitos bens também apresentam os patamares mais baixos de preços nesse período. Por outro lado, períodos de crise devem afetar a compra de produtos novos, e é reconhecido que o Brasil atravessou períodos de maior retração econômica nos períodos 19811983 e 1990-1992, que deveriam afetar a compra de produtos novos.

Assim, para melhor compreender o impacto do fenômeno, foi retomado o estudo do processo de difusão das geladeiras com um grau de detalhamento maior que o anteriormente apresentado, conforme pode ser visto na figura 7.22. ${ }^{7.10}$ Apesar de pequenas oscilações, conforme se percebe, o processo não sofre interrupções significativas em seu crescimento. ${ }^{7.11}$

DIFUSÃO DE GELADEIRAS NOS DOMICÍLIOS NO BRASIL

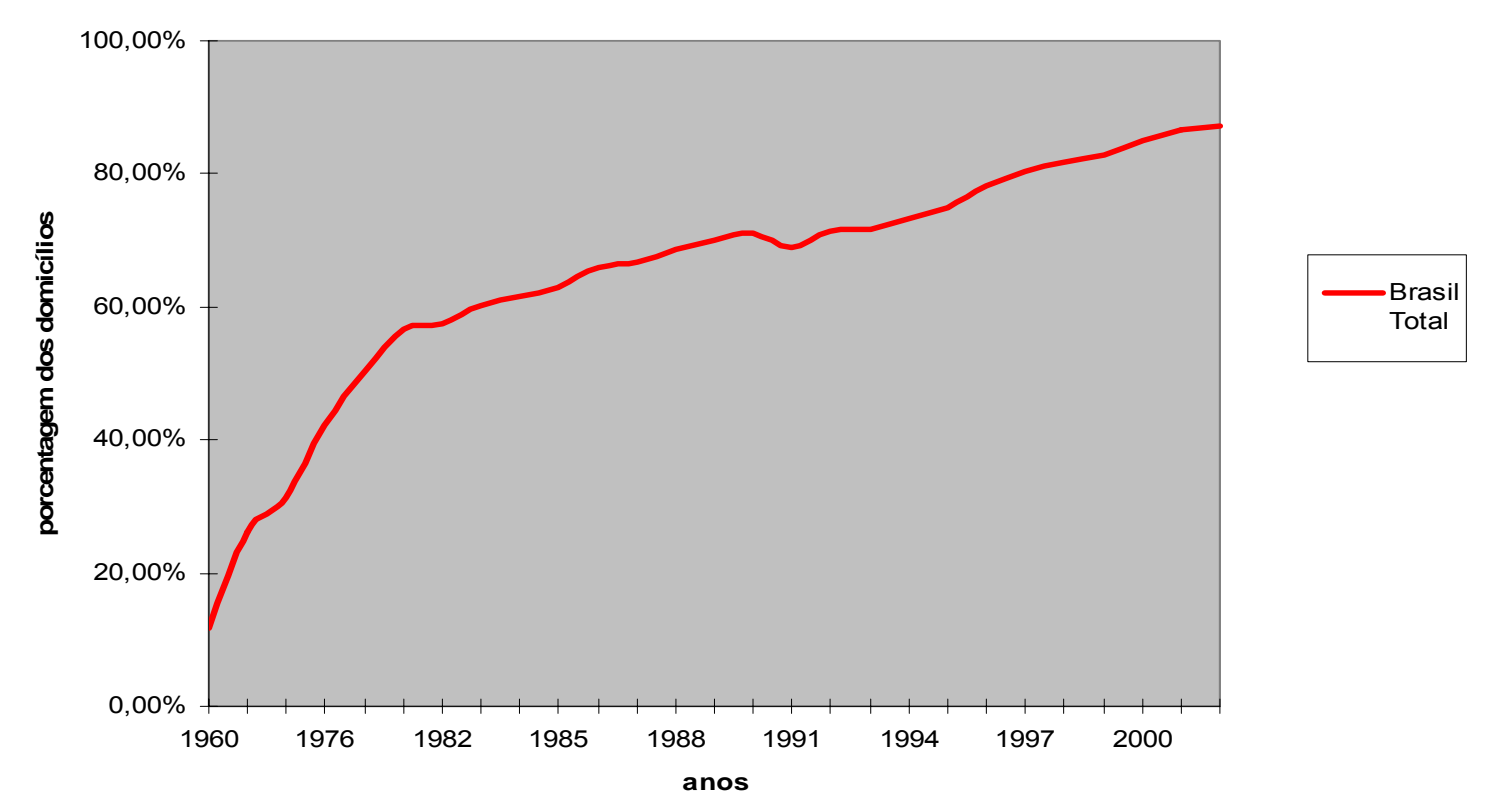

Figura 7.22 - Processo de difusão das geladeiras nos domicílios particulares permanentes brasileiros - detalhamento ano a ano. Fonte dos dados - IBGE.

\footnotetext{
${ }^{7.10}$ Como no ano de 1994, o IBGE não realizou nenhuma pesquisa de domicílios, o índice foi assumido por meio de interpolação simples, média aritmética do ano anterior e posterior.

${ }^{7.11}$ Aqui deve-se anotar que, no censo de 1991, houve a constatação de uma acentuada redução no crescimento populacional que vinha sendo projetado, portanto, implicando uma forte redução nos índices de correção de expectativas. Esta correção ficou em torno de $4 \%$ para menos, o que afetou a quantidade de domicílios e outros, contribuindo para a aparente redução na difusão. Fonte dos dados - IBGE. A pequena oscilação em 1995 já foi anteriormente analisada.
} 
Outro ponto a ser analisado é a correlação entre as difusões identificadas para as inovações analisadas. Essa comparação foi feita entre os diferentes produtos, e também entre classes de renda dentro do mesmo produto, e é objeto de discussão do próximo item.

\section{5 - Correlações do processo de difusão}

A pergunta se os processos de difusão das inovações nos domicílios brasileiros seguem tendências similares para classes de renda similares pode ser respondida, procedendo-se a uma análise estatística das possíveis correlações entre as diferentes distribuições encontradas. Esse estudo retomou a variação encontrada na quantidade porcentual de domicílios brasileiros, em termos da aceitação de determinadas inovações, conseguindo identificar, a partir dos dados disponíveis pelo IBGE, uma série composta por 19 períodos, que foram a base para os estudos de correlação realizados com o apoio do software SPSS 11.0, software estatístico de análise de dados. Além da verificação do índice $r$ de correlação de Pearson, e para evitar a possibilidade de um erro tipo I, as correlações encontradas foram submetidas ao método de Bonferroni (Kreyszig, 1970; Berenson e Levine, 1999; Pestana e Gageiro, 2000; Green e Salkind, 2003; Walld, 2003). A hipótese $\mathrm{H}_{0}$ afirma que não seriam encontradas correlações entre a difusão das diversas inovações e as classes de renda; como conseqüência, a hipótese $\mathrm{H}_{1}$, afirma que há correlação entre a difusão das diversas inovações e as difusões ocorridas nas diferentes classes de renda. O resultado completo das análises está disponível no apêndice 3 .

A primeira análise explorou as cinco inovações escolhidas na pesquisa e suas eventuais correlações, ficando comprovada forte correlação para todos os itens, com um grau médio de correlação na difusão entre geladeiras / filtros de água (correlação 0,664 para $p=0,01$ ) e televisores / filtros de água (correlação 0,690 para $p=0,01)$. Esse primeiro resultado reforça a hipótese inicial de que os processos de difusão ocorrem nos domicílios brasileiros, apresentando tendências 
comuns, portanto, devem ser considerados como um fator importante na estratégia de inovação de uma empresa.

A análise do processo de difusão prosseguiu para cada uma das inovações estudadas e os resultados encontrados encontram-se listados na tabela 7.8.

Tabela 7.8 - Análise do processo de difusão de diferentes inovações nos domicílios permanentes do Brasil em classes de renda distintas.

\begin{tabular}{|c|c|c|c|}
\hline Inovação & Análise & $\begin{array}{l}\text { Valores das } \\
\text { correlações mais } \\
\text { fracas e nível de } \\
\text { significância p }\end{array}$ & observações \\
\hline Geladeiras & 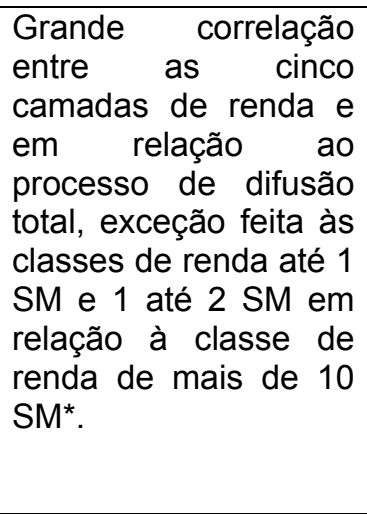 & $\begin{array}{l}\text { A correlação entre } \\
\text { classe de renda até } 1 \\
\text { SM e mais de } 10 \mathrm{SM} \text { é } \\
\text { igual a } 0,764 \text { ( } \mathrm{p}= \\
0,0001425) \text { e entre } \\
\text { classe de renda } 1 \text { até } \\
2 \mathrm{SM} \text { e mais de } 10 \mathrm{SM} \\
\text { é igual a } 0,768 \text { ( } \mathrm{p}= \\
0,0001234), \mathrm{o} \text { que } \\
\text { pode ser assumido } \\
\text { como uma correlação } \\
\text { de grau médio ou não } \\
\text { existente. }\end{array}$ & $\begin{array}{l}\text { Os resultados vêm reforçar que } \\
\text { o processo de difusão entre } \\
\text { diferentes camadas de renda } \\
\text { difere entre si, ao menos para } \\
\text { alguns produtos. Isto remete a } \\
\text { que deve ser necessário } \\
\text { analisar diferentes estratégias, } \\
\text { complementares ou não, para } \\
\text { uma inovação. }\end{array}$ \\
\hline $\begin{array}{ll}\text { Filtros } & \text { de } \\
\text { água } & \end{array}$ & $\begin{array}{l}\text { Encontra-se } \\
\text { correlação entre a } \\
\text { difusão nas camadas } \\
\text { acima de } 5 \text { SM, e } \\
\text { entre as classes } \\
\text { inferiores a } 5 \text { SM. }\end{array}$ & $\begin{array}{l}\text { Apesar da existência } \\
\text { de correlação na } \\
\text { difusão entre as três } \\
\text { classes inferiores de } \\
\text { renda, ela é mais } \\
\text { moderada entre as } \\
\text { classes } 2 \text { a } 5 \mathrm{SM} \text { e até } \\
1 \mathrm{SM}(p=0,0001380)\end{array}$ & $\begin{array}{l}\text { Os filtros de água mostram um } \\
\text { comportamento diferenciado no } \\
\text { tocante à difusão, percebendo- } \\
\text { se claramente uma } \\
\text { segmentação. Inovações deste } \\
\text { tipo requerem estratégias } \\
\text { diferenciadas. }\end{array}$ \\
\hline Rádios & \begin{tabular}{lr}
\multicolumn{2}{l}{ Todas as classes de } \\
renda mostram grande \\
correlação r nas \\
distribuições res de \\
difusão, somente \\
reduzindo um pouco à \\
medida quer se \\
distanciam \\
\multicolumn{2}{c}{ amadas de renda. } \\
\end{tabular} & $\begin{array}{l}\text { Não é identificada } \\
\text { correlação de grau } \\
\text { médio. }\end{array}$ & $\begin{array}{l}\text { Os rádios, uma das primeiras } \\
\text { inovações a entrar de forma } \\
\text { impactante nos domicílios } \\
\text { brasileiros, mudando a relação } \\
\text { do indivíduo com o mundo, } \\
\text { aponta para um processo de } \\
\text { difusão que ocorre de forma } \\
\text { similar há mais de } 70 \text { anos. }\end{array}$ \\
\hline Televisores & $\begin{array}{l}\text { Nota-se que a classe } \\
\text { de renda acima de } 10 \\
\text { SM apresenta um } \\
\text { comportamento } \\
\text { ligeiramente } \\
\text { diferenciado, mas } \\
\text { mantendo um forte } \\
\text { nivel de correlação } \\
\text { com as demais } \\
\text { classes de renda }\end{array}$ & Não encontrado. & $\begin{array}{l}\text { Na análise de televisores, nota- } \\
\text { se uma pequena indicação de } \\
\text { que os comportamentos de } \\
\text { difusão podem ser diferentes } \\
\text { entre as diferentes classes de } \\
\text { renda. }\end{array}$ \\
\hline
\end{tabular}




\begin{tabular}{|l|l|l|l|}
\hline $\begin{array}{l}\text { Canalização } \\
\text { interna de } \\
\text { água }\end{array}$ & $\begin{array}{l}\text { Todas as classes de } \\
\text { renda mostram uma } \\
\text { forte correlação. }\end{array}$ & Não encontrado. & $\begin{array}{l}\text { O processo parece indicar aqui } \\
\text { um processo de difusão de } \\
\text { influência mista. Todas as } \\
\text { classes de renda apresentam } \\
\text { comportamentos similares. }\end{array}$ \\
\hline Freezer & $\begin{array}{l}\text { Todas as classes de } \\
\text { renda mostram uma } \\
\text { forte correlação. }\end{array}$ & Não encontrado. & $\begin{array}{l}\text { O único ponto a ser ressaltado } \\
\text { é que uma análise mais } \\
\text { cuidadosa mostra uma } \\
\text { tendência de as curvas se } \\
\text { diferenciarem à medida que se } \\
\text { afastam as classes de renda. } \\
\text { Uma comparação da difusão de } \\
\text { geladeiras e de freezer mostrou } \\
\text { uma correlação forte, como } \\
\text { seria de se esperar. }\end{array}$ \\
\hline
\end{tabular}

*SM - salários mínimos vigentes.

Finalmente, foi verificada a correlação existente entre diferentes produtos na mesma classe de renda, e os resultados estão relatados na tabela 7.9.

Tabela 7.9 - Análise do processo de difusão das diferentes inovações nos domicílios permanentes do Brasil em uma mesma classe de renda.

\begin{tabular}{|c|c|c|c|}
\hline $\begin{array}{c}\text { Classes } \\
\text { de renda } \\
\text { em SM* }\end{array}$ & Análise & $\begin{array}{c}\text { Valores das } \\
\text { correlações mais } \\
\text { fracas e nível de } \\
\text { significância p }\end{array}$ & observações \\
\hline Até $1 \mathrm{SM}$ & $\begin{array}{l}\text { Nesta faixa de classe } \\
\text { de renda, as curvas de } \\
\text { difusão se mostram } \\
\text { bastante similares e as } \\
\text { correlações bastante } \\
\text { intensas. A pior } \\
\text { correlação encontrada } \\
\text { filtro de água l } \\
\text { geladeiras, r com } \\
\text { coeficiente } \\
\text { correlação r de } \\
\text { Pearson é de } 0,738 \text {, } \\
\text { com um nível de } \\
\text { significância p }= \\
0,0003110 .\end{array}$ & Não encontrado. & $\begin{array}{l}\text { Isso denota } \\
\text { comportamento mais padrão } \\
\text { nas respostas a inovações. } \\
\text { Esse comportamento indica } \\
\text { certo padrão na difusão da } \\
\text { inovação e deve auxiliar na } \\
\text { definição de estratégias para } \\
\text { aumentar o sucesso de uma } \\
\text { inovação }\end{array}$ \\
\hline 1 a 2 SM & $\begin{array}{l}\text { Não parece haver } \\
\text { correlação entre filtros } \\
\text { de água e os demais } \\
\text { itens. Isso já demonstra } \\
\text { uma tendência de que } \\
\text { a forma de resposta } \\
\text { dessa classe pode se } \\
\text { diferenciar dependendo } \\
\text { do item. Entretanto, a } \\
\text { correlação é forte entre } \\
\text { os demais itens, } \\
\text { reforçando um } \\
\text { determinado } \\
\text { comportamento padrão. }\end{array}$ & $\begin{array}{l}\text { A correlação tende a } \\
\text { ser mais moderada } \\
\text { entre canalização } \\
\text { interna de água e } \\
\text { filtros de água } \\
\text { (correlação } 0,721 \text { e p } \\
=0,0004962) \text {. }\end{array}$ & $\begin{array}{l}\text { Apesar de já apresentar certa } \\
\text { mudança em um determinado } \\
\text { item, nos demais a correlação } \\
\text { do processo de difusão é } \\
\text { intensa, podendo oferecer } \\
\text { oportunidades na definição da } \\
\text { estratégia da inovação. }\end{array}$ \\
\hline
\end{tabular}




\begin{tabular}{|c|c|c|c|}
\hline 2 a 5 SM & $\begin{array}{l}\text { Quase o mesmo } \\
\text { apontado para a classe } \\
\text { de renda anterior, } \\
\text { apenas mostrando que } \\
\text { em nenhum momento } \\
\text { há correlação no } \\
\text { processo de difusão } \\
\text { dos filtros de água e } \\
\text { dos demais itens. }\end{array}$ & Não encontrado. & $\begin{array}{l}\text { Mesmo do anterior, apenas } \\
\text { podendo-se acrescentar que } \\
\text { as diferenças nas respostas } \\
\text { das classes de renda existem } \\
\text { quanto à difusão de diferentes } \\
\text { inovações nos domicílios no } \\
\text { Brasil. }\end{array}$ \\
\hline 5 a $10 \mathrm{SM}$ & Idem anterior. & Não encontrado. & $\begin{array}{l}\text { Aqui pode se acrescentar } \\
\text { àquilo que foi colocado para a } \\
\text { classe de renda anterior é que } \\
\text { já se pode perceber um } \\
\text { processo de abandono dos } \\
\text { filtros de água por esta classe, } \\
\text { mostrando também que a } \\
\text { difusão do processo de } \\
\text { abandono se propaga entre } \\
\text { camadas diferentes de renda, } \\
\text { assim como no processo de } \\
\text { adoção. }\end{array}$ \\
\hline $\begin{array}{l}\text { Acima } \\
10 S M\end{array}$ & $\begin{array}{l}\text { Apesar de o processo } \\
\text { de abandono do uso de } \\
\text { filtros de água, nessa } \\
\text { classe de renda e na } \\
\text { anterior, terem iniciado } \\
\text { na mesma época, ele é } \\
\text { mais intenso aqui, } \\
\text { indicando sua posição } \\
\text { de referência para as } \\
\text { demais. }\end{array}$ & Não encontrado. & $\begin{array}{l}\text { Aqui pode ser identificado um } \\
\text { comportamento mais } \\
\text { autônomo desta classe de } \\
\text { renda, que parece ser mais } \\
\text { sensível a fatores externos } \\
\text { quando da difusão das } \\
\text { inovações. Em termos de } \\
\text { estratégia de inovação, esta } \\
\text { categoria mostra-se } \\
\text { importante, por orientar a } \\
\text { postura das demais, mas por } \\
\text { outro lado, parece fugir a } \\
\text { padrões de resposta comuns a } \\
\text { diferentes itens. Como } \\
\text { afirmado, aparenta ser mais } \\
\text { sensível aos processos de } \\
\text { difusão externos. }\end{array}$ \\
\hline
\end{tabular}

*SM - salários mínimos vigentes.

Conclui-se que há correlação nos diferentes processos de difusão de inovações nos domicílios particulares, entretanto, percebe-se que as velocidades e as formas das curvas de difusão mudam quando se estratificam em diferentes classes de renda, indicando que as faixas superiores de renda apresentam respostas diferenciadas para diferentes inovações e, nas classes de menor poder aquisitivo, um padrão mais constante. Em termos de importância na definição de uma estratégia de negócio de inovar para uma empresa, isso implica na necessidade da incorporação dessa variável no conjunto de itens a serem avaliados quando do estudo da viabilidade e sucesso de um novo produto. 
Tendo verificado que os processos de difusão apresentam grandes similaridades, portanto, podendo confirmar que há padrões identificáveis entre diferentes itens novos que adentram um domicílio, restou, ainda, confirmar se o processo de difusão verificado corresponde aos propostos pelos modelos teóricos. Este foi o objeto de estudo da última análise feita.

\section{6 - Analisando o conjunto de dados}

Como já inferido anteriormente as curvas encontradas a partir dos dados encontrados apresentam um aceitável grau de similaridade visual com aqueles propostos pelos modelos teóricos, principalmente em relação à classe de renda de maior poder aquisitivo (acima de $10 \mathrm{SM}$ ) e as curvas propostas no modelo de difusão externa (Costa Neto, 1977). Há de se considerar que os dados disponíveis representam uma tendência final de difusão, portanto, já se aproximando dos níveis de saturação.

Por não ser possível garantir que a exponencial seria a melhor distribuição a representar os dados encontrados, foi realizado o teste não paramétrico de aderência conhecido como teste K-S ou Kolmogorov-Smirnov, com a hipótese $\mathrm{H}_{0}$ em que é aceita a aderência à exponencial e $\mathrm{H}_{1}$ rejeitando a hipótese. $\mathrm{O}$ teste utilizou o SPSS, tomando como base o número de domicílios que ainda não haviam adquirido o bem (ou seja, equivalente a 1 - número de adotantes encontrados). (Kreyszig, 1970; Siegel, 1975; Costa Neto, 1977; Peters e Summers, 1978; Conover, 1980; Barr, 2001; Green e Salkind, 2003). Os resultados do teste são mostrados na tabela 7.10 . 
Tabela 7.10 - Teste K-S para geladeiras e televisores em relação à distribuição exponencial. Teste K-S para aqueles que não adquiriram o item no tempo $t$

One-Sample Kolmogorov-Smirnov Test

\begin{tabular}{|c|c|c|c|}
\hline & & $\begin{array}{c}\text { ainda nẫo } \\
\text { adquiriram } t v>10 \\
\mathrm{SM}\end{array}$ & $\begin{array}{c}\text { ainda não } \\
\text { adquiriram gelad > } \\
10 \mathrm{SM}\end{array}$ \\
\hline \multicolumn{2}{|l|}{$\mathrm{N}$} & 19 & 19 \\
\hline \multicolumn{2}{|c|}{ Exponential parameter ${ }^{\mathrm{a}, \mathrm{t}}$ Mean } & .02168677266359 & .01781113445759 \\
\hline \multirow{3}{*}{$\begin{array}{l}\text { Most Extreme } \\
\text { Differences }\end{array}$} & Absolute & .206 & .177 \\
\hline & Positive & .096 & .149 \\
\hline & Negative & -.206 & -.177 \\
\hline \multirow{2}{*}{\multicolumn{2}{|c|}{$\begin{array}{l}\text { Kolmogorov-Smirnov Z } \\
\text { Asymp. Sig. (2-tailed) }\end{array}$}} & .800 & .770 \\
\hline & & 393 & .594 \\
\hline
\end{tabular}

a. Test Distribution is Exponential.

b. Calculated from data.

Os resultados são mostrados na tabela 7.10 , com as seguintes condições: aceitar $H_{0}$ para um nível crítico $\alpha=0,05$ de significância, cujo valor crítico no teste K-S, para $\mathrm{N}=19$, corresponde a 0,301 (Kreyszig, 1970; Costa Neto, 1977) ou aceitar $\mathrm{H}_{1}$ (rejeitar a distribuição proposta) para valores maiores que o crítico. Nos dois casos se aceita $\mathrm{H}_{0}$, confirmando que a distribuições representam uma exponencial. Isso confirma que há uma preponderância entre os novos adquirentes de uma inovação nas classes de renda superior a $10 \mathrm{SM}$, em responderem de acordo com o modelo de influência externa.

A etapa seguinte foi verificar qual a curva que melhor estimaria as curvas representativas das amostras obtidas, sendo aplicado o método dos mínimos quadrados (Kreyszig, 1970; Costa Neto, 1977; Peter e Summers, 1978; Hair e outros, 1998; Berenson, Levine e Krehbiel, 2002; Green e Salkind, 2003). As análises foram realizadas no software SPSS e estão representadas nas figuras 7.23 a 7.27 para geladeiras e 7.28 a 7.32 para televisores. Como se vê a curva que melhor estima a resposta das classes de renda acima de $10 \mathrm{SM}$ é a exponencial e os valores de $R^{2}$ são respectivamente: 0,819 para geladeiras e 0,919 para televisores. (ver tabela 7.11 ). 


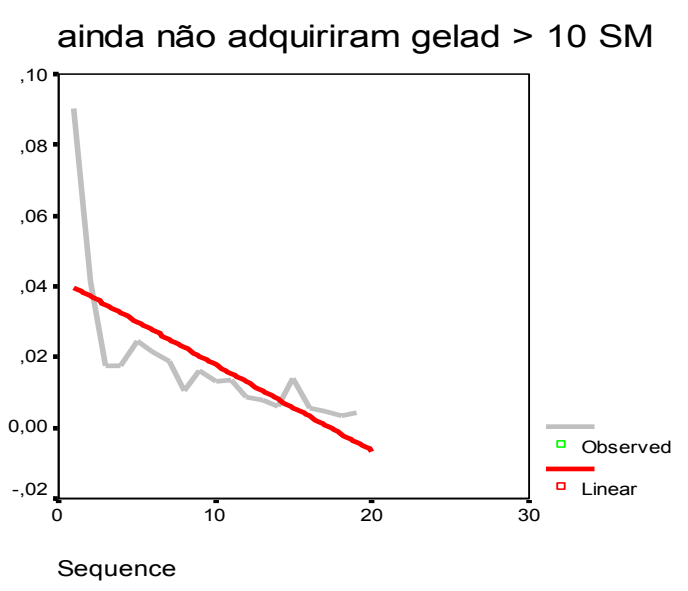

Figura 7.23 - Ajuste de curva por reta da função de difusão de geladeiras, renda acima de 10 SM.

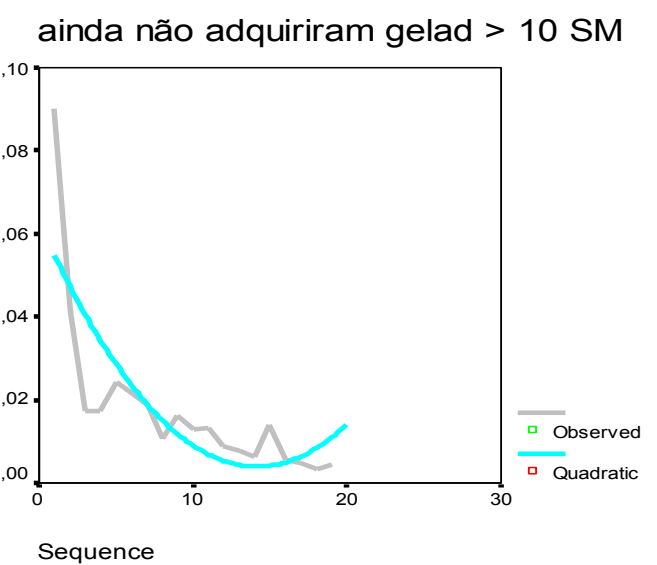

Figura 7.25 - Ajuste de curva por polinômio de segundo grau para função de difusão de geladeiras, renda acima de $10 \mathrm{SM}$.

ainda não adquiriram gelad $>10 \mathrm{SM}$

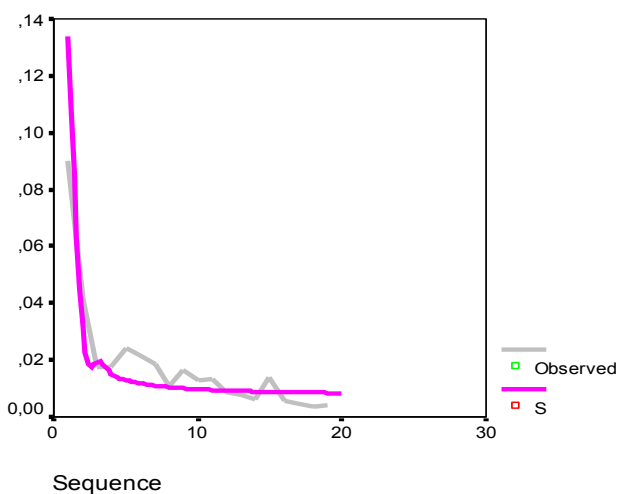

Figura 7.27 - Ajuste de curva pela curva S para função de difusão de geladeiras, renda acima de 10 SM. ainda não adquiriram gelad > 10 SM

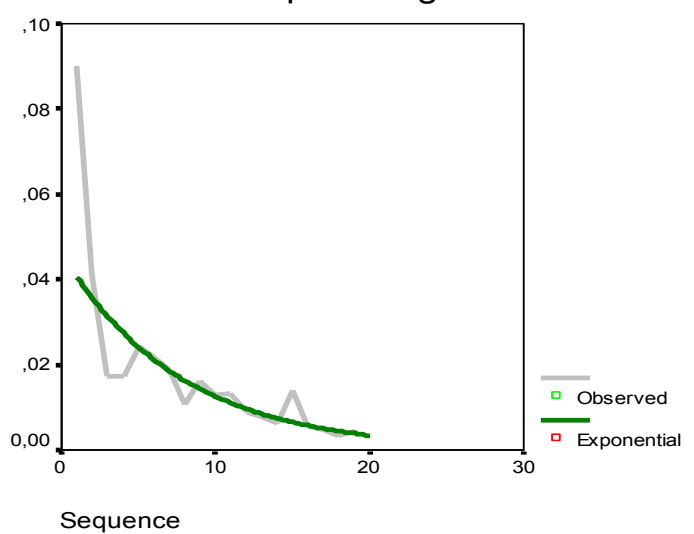

Figura 7.24 - Ajuste de curva pela exponencial para função de difusão de geladeiras, renda acima de $10 \mathrm{SM}$.

ainda não adquiriram gelad > 10 SM

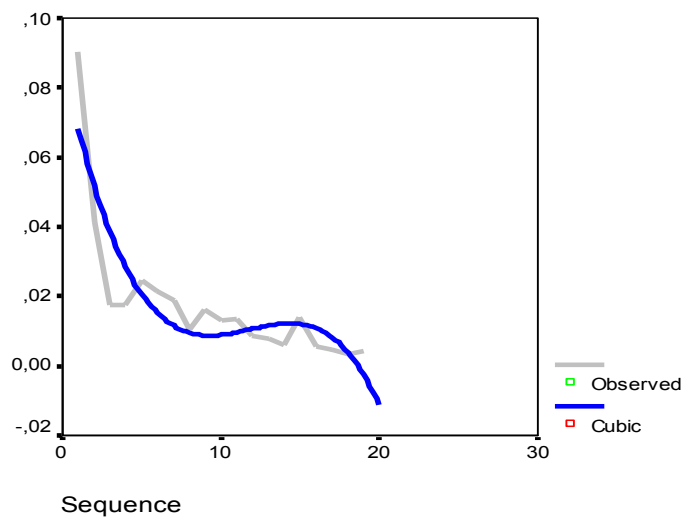

Figura 7.26 - Ajuste de curva por polinômio de terceiro grau para função de difusão de geladeiras, renda acima de 10 SM. 


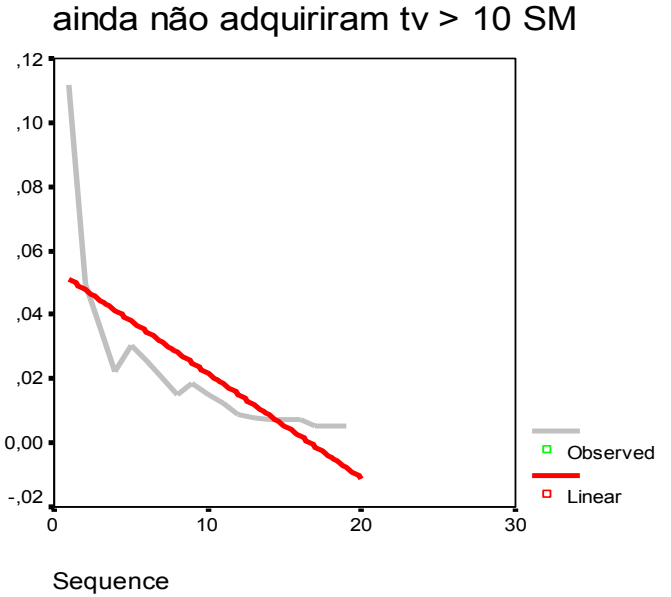

Figura 7.28 - Ajuste de curva por reta da função de difusão de televisores, renda acima de 10 SM.

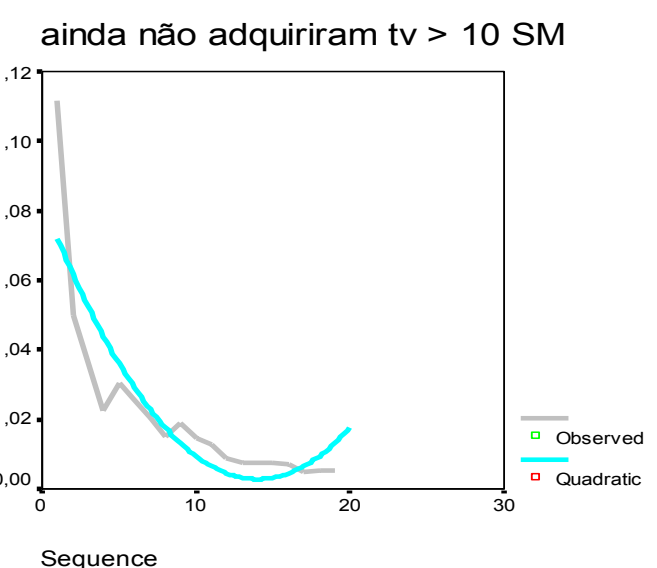

Figura 7.30 - Ajuste de curva por polinômio de segundo grau para função de difusão de televisores, renda acima de $10 \mathrm{SM}$.

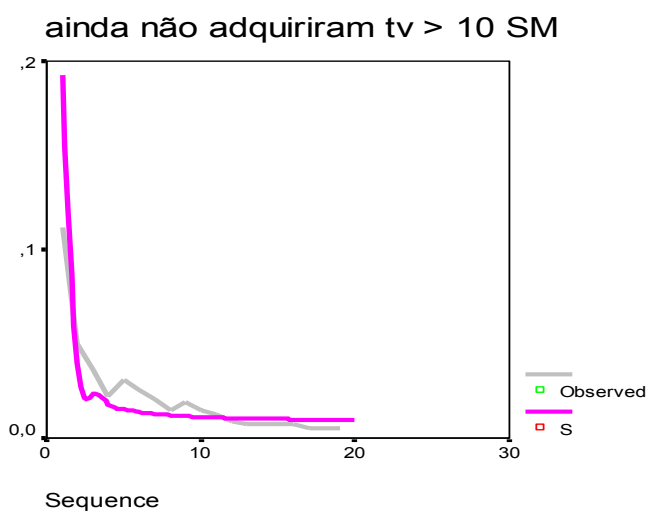

Figura 7.32 - Ajuste de curva pela curva S para função de difusão de televisores, renda acima de 10 SM.

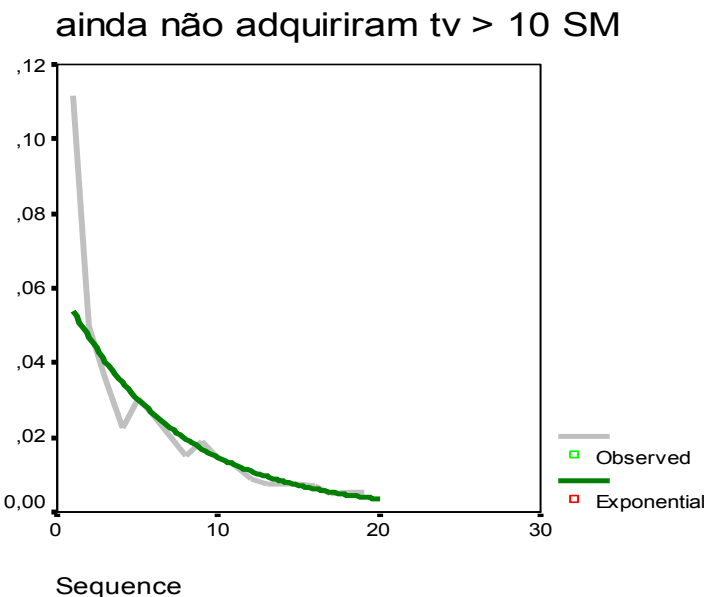

Figura 7.29 - Ajuste de curva pela exponencial para função de difusão de televisores, renda acima de 10 SM.

ainda não adquiriram tv > $10 \mathrm{SM}$

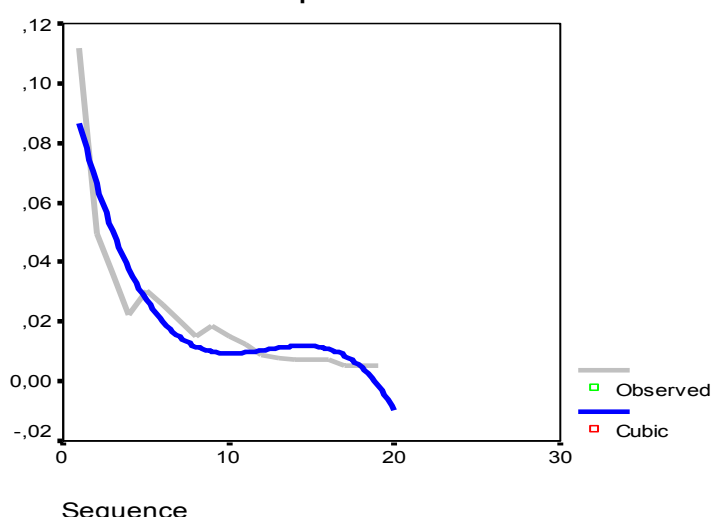

Figura 7.31 - Ajuste de curva por polinômio de terceiro grau para função de difusão de televisores, renda acima de 10 SM. 
Tabela 7.11 - $\mathrm{R}^{2}$ para ajuste de tendência de curvas pelo método dos mínimos quadrados para televisores e geladeiras.

\begin{tabular}{|c|c|c|c|c|c|c|c|c|c|}
\hline Dependente & Mth & $\mathrm{Rsq}$ & d.f. & $z$ & Sigf & bo & bl & b2 & b3 \\
\hline DIETV5 & LIN &, 548 & 17 & 20,60 &, 000 &, 0544 &,- 0033 & & \\
\hline DIETV5 & QUA & 753 & 16 & 24,36 & .000 & .0831 &,- 0115 &, 0004 & \\
\hline DIETVS & CUB & .850 & 15 & 28,44 &, 000 & .1107 &,- 0261 &, 0022 & $-6, \Xi-05$ \\
\hline DIETV5 & S & .719 & 17 & 43,44 &, 000 & $-4,8150$ & 3,1680 & & \\
\hline DIETV5 & EXP & .919 & 17 & 192,09 &, 000 & .0623 &,- 1448 & & \\
\hline DIEGELS & LIN &, 484 & 17 & 15,95 &, 001 &, 0422 &,- 0024 & & \\
\hline DIEGELS & QUA & .654 & 16 & 15,09 &, 000 & .0629 &,- 0084 &, 0003 & \\
\hline DIEGELS & CUB & .784 & 15 & 18,20 &, 000 &, 0881 &,- 0218 &, 0019 & $-5, \Xi-05$ \\
\hline DIEGELS & S & .665 & 17 & 33,79 &, 000 & $-4,9231$ & 2,9100 & & \\
\hline DIEGEL5 & EXP &, 819 & 17 & 76,93 & .000 &, 0462 &,- 1305 & & \\
\hline
\end{tabular}

Procedidas as análises de ajuste de tendência das curvas e das distribuições dos dados encontrados, pode-se afirmar que para classes de domicílios com renda superior a 10 salários mínimos, a forma preponderante de resposta dessa camada da população apresenta uma resposta que tende ao modelo de difusão externa, ou seja, para essa camada a influência da propaganda e de outros meios externos de comunicação (revista, jornais etc.) podem ser assumidos como preponderantes. Como a resposta a inovações de acordo com o modelo externo apresenta um crescimento mais rápido que os demais modelos (logístico ou difusão interna e misto), essa constatação pode ser utilizada como uma referência às tendências que serão seguidas pelas diversas camadas da população. Isso, de alguma forma, justifica o senso comum da influência dos formadores de opinião sobre o restante da população.

Analisados diversos aspectos do processo de difusão de inovações nos domicílios particulares permanentes no Brasil; não tendo sido encontrado nenhuma referência na literatura pesquisada quanto às diferenças nas curvas de difusão das diferentes classes de renda; ficando comprovado que os processos de difusão ocorrem mais rapidamente nas classes de renda de maior poder aquisitivo; que o processo de transmissão flui para as camadas de renda imediatamente inferior; que o processo de difusão nas camadas de renda inferior parece seguir uma curva de influência interna ou mista e que as camadas de renda mais alta seguem uma 
curva de influência externa, o próximo passo do trabalho é o de propor um modelo que possa representar o que ocorre auxiliando as empresas na evolução das compras de uma inovação destinada a domicílios no Brasil. Isso será discutido no próximo capítulo. 


\section{8- O modelo proposto}

A partir da pesquisa na literatura e, como resultado das conclusões obtidas na pesquisa de campo, bem como em metodologias e modelos mostrados anteriormente, neste capítulo será proposto um modelo que possa representar o fenômeno de difusão das inovações nos domicílios permanentes brasileiros. A literatura básica que orientou a proposta tem como referência Scheuing e Johnson, 1989; Fredericks e Salter (1998); Schiffman e Kanuk (2000); Rogers (2003). Mas, antes, será analisada a participação de diversos stakeholders no processo de inovar.

Moore (1991 e 1995) em Boyd e Mason (1999) afirma que é importante que as empresas compreendam a postura dos diversos tipos de consumidores em relação a uma determinada inovação e que se estruturem para tal, oferecendo o produto de acordo com o estágio em que ele se encontra no ciclo de vida. Isso reforça os cuidados em relação ao projeto da manufatura (particularmente na condição "production ramp-up", segundo Terwiesch e Bohn, 2001) e, também, como gerenciar o processo de difusão da inovação, de maneira a otimizar os recursos disponíveis na empresa ou a expansão do negócio. Problemas decorrentes de um lançamento em que haja uma procura maior que a capacidade instalada para resposta ao volume desejado podem ser tão problemáticos para uma empresa, quanto o caso de uma procura ser muito menor que o investimento feito onde o retorno financeiro pode ser frustrado.

Cooper, Edgett e Kleinschmidt (2004b) encontraram que a disponibilidade de recursos para as quatro principais áreas envolvidas no processo de desenvolvimento e sucesso de mercado de novos produtos - vendas, marketing, manufatura e operações e P\&D e engenharia - não é igual, sendo que a escassez de recursos está ligada às demais áreas que não a área de P\&D e Engenharia. Este pode ser um fator de limitação no correto dimensionamento das interfaces. Os autores afirmam que "os negócios devem olhar cuidadosamente para os recursos disponíveis a vendas e marketing 
voltados ao desenvolvimento de novos produtos. Sérias deficiências foram aqui detectadas, o que pode explicar fraquezas em várias das atividades de marketing / vendas, voz do consumidor e dados de mercado, bem como a qualidade das informações de mercado."

Com base na literatura, entende-se que as interfaces importantes para um correto desenvolvimento de um novo produto são: (Rosenau, Jr. e Moran, 1993; Dolan, 1993; Thomas, 1993; Shtub, Bard e Globerson, 1994; Bruce e Biemans, 1995; Wilson, Kennedy e Trammell, 1996; Utterback, 1996; Deschamps e Nayak, 1997; Nonaka e Takeuchi,1997; Shiba, Graham e Walden, 1997; Johne e Storey, 1998; Verizer Jr., 1998; Ozer, 1999; Debackere, 1999; Rimoli, 2001; Keeling, 2002; Juran, 2002; Palácios e González, 2002; Lee e O'Connor, 2003; Prasnikar e Skelj, 2005)

- Interface com função marketing - entrada das informações e necessidades do mercado, o tradutor da voz do consumidor, bem como a saída quando da disponibilização do produto para o mercado; portanto; é um elo vital para o correto desenvolvimento de um novo produto;

- Função P\&D - responsável pela criação de novos produtos / serviços ou pela modificação dos existentes, procurando antecipar-se às necessidades futuras do mercado e dos consumidores. Aqui cabe uma distinção em relação à atividade Pesquisa e a atividade Desenvolvimento, sendo que a primeira tem um trabalho interno, mais voltado a olhar o futuro, e a segunda tem como obrigação aplicar o que é proposto na primeira fase. A fase de desenvolvimento é a ponte entre a pesquisa e a engenharia. Por ser responsável, junto com a engenharia, pelas especificações e pela transformação da idéia em um produto ou serviço real, é fundamental para o sucesso de um novo produto;

- Interface com função produção - análise das conseqüências em relação aos equipamentos e pessoal que serão utilizados, aí incluídos lay-out e arranjo físico, são aqui consideradas; 
- Interface com função sistemas de informação - cada vez mais os sistemas de informação são fundamentais em qualquer operação como suporte e como facilitador e a análise de seu impacto nas operações deve ser considerada nas etapas iniciais;

- Interface com função contábil-financeira - o aspecto "custo" é um condicionante básico, imposto por vários dos stakeholders envolvidos (acionistas, mercado e fornecedores), principalmente devido aos ciclos de vida mais curtos dos produtos e a pressões por custos baixos, para permitir a competitividade (Terwiesch e Bohn, 2001);

- Interface com função legal e meio ambiente - responsável pelos aspectos legais e os impactos que o produto causará ao meio ambiente, estando ambos entrelaçados de certa forma e, portanto, considerados juntos;

- Interface com função logística - toda organização moderna opera em um sistema horizontal, ou seja, é parte de uma cadeia de suprimentos, e da qual é dependente, podendo interferir mais ou menos intensamente na consecução dos objetivos dessa cadeia. Essa função é muito importante para o sucesso de um novo produto, inclusive em relação ao processo de difusão da inovação, pela ação no coeficiente de influência externa.

Aqui se procura compreender como ocorre o processo interno em uma empresa para o desenvolvimento de um novo produto e seu lançamento, e isso está representado na figura 8.1. Esses aspectos influenciam a estratégia de uma empresa para inovar, pois, considerar apenas fatores externos pode implicar uma visão restrita das variáveis que atuam no processo decisório. 


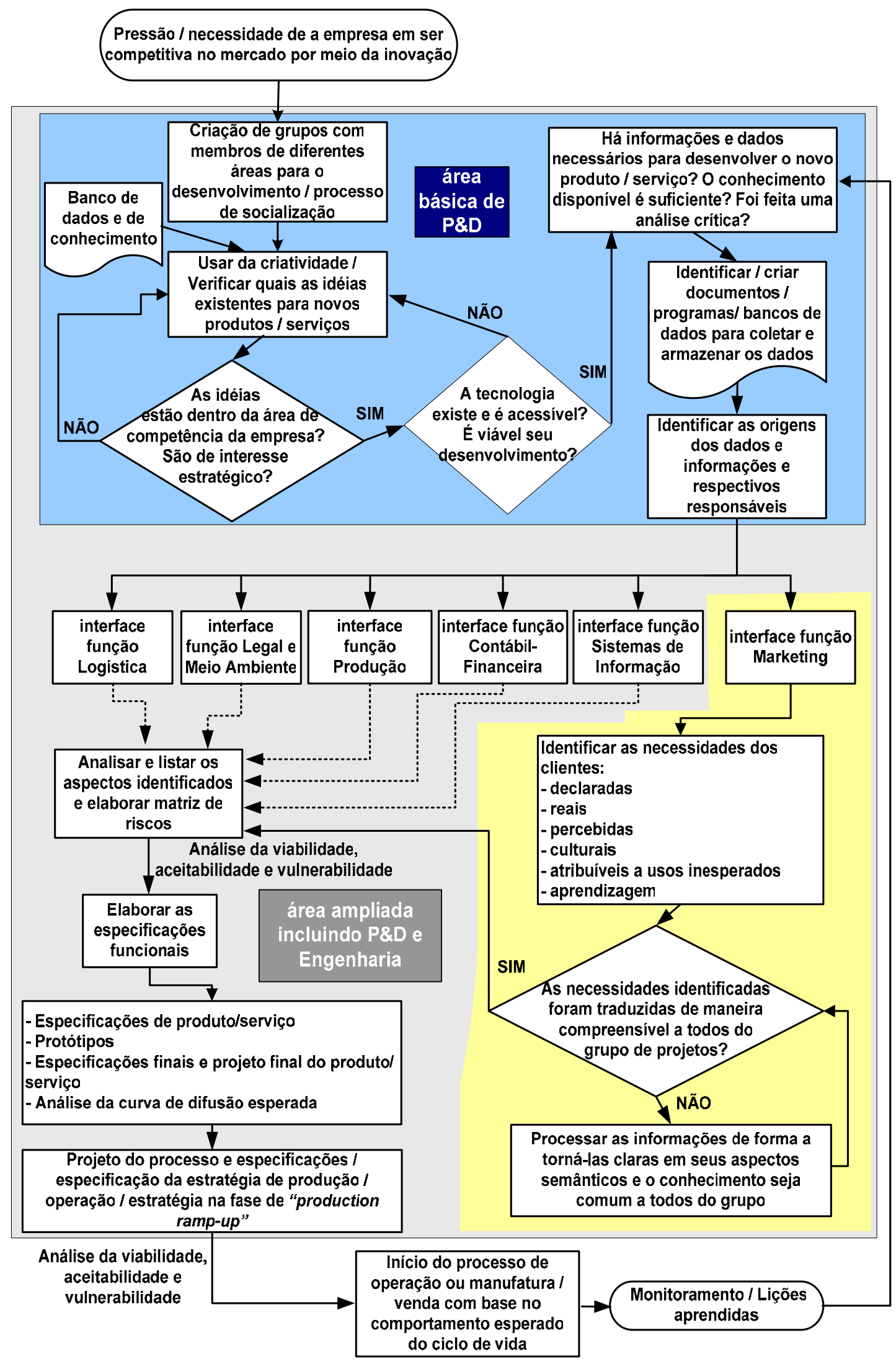

Figura 8.1 - Análise do processo de desenvolvimento de um novo produto / serviço 
A fig. 8.1 mostra que os fatores internos que infuenciam a estratégia e a operação de inovar são influenciados por diversos stakeholders. Começando pela área de P\&D, nota-se que várias condições auxiliam ou dificultam o processo de criação de um novo produto, como experiências anteriores, sucessos ou fracassos, valores culturais da empresa e subcultura específica da área de P\&D (Daft, 2002), além da capacidade da organização existente para processar a inovação, e esses são fatores que influenciam a estratégia de inovar (Browning, Deyst e Eppinger, 2002). Também influenciam o processo de inovar as diversas áreas colocadas como interfaces entre a área de P\&D e a manufatura, pois várias soluções podem ser incentivadas ou abortadas nesse momento, como se vê na posição de tais interfaces mostradas na figura 8.1. Superadas as necessidades e idiossincrasias das funções de interface mostradas, o processo entra em estágio mais operacional, onde são detalhadas as idéias e propostas e realizados testes de viabilidade (Cooper, Edgett e Kleinschmidt, 2002a; Cooper, Edgett e Kleinschmidt, 2002b). Em particular, a análise do processo interno mostrado explora, de forma um pouco mais detalhada, a interface marketing, pois a literatura citada, em geral, atribui a ela o canal de contato com o consumidor. Seu papel é compreender o mercado e transmitir às demais áreas o que foi encontrado. Este papel permite que o marketing tenha uma grande influência na estratégia de inovar da empresa (Antill, 1988; Anderson e Narus, 1998).

Na seqüência da análise daquilo que influencia a estratégia de inovar em uma empresa e, ainda, com base na literatura anteriormente citada, pode-se afirmar que um outro importante fator é a compreensão do processo decisório de um consumidor, em aceitá-la ou rejeitá-la, e que inclui diversos fatores listados a seguir.

- Necessidades declaradas - os clientes especificam o que o vêem, o que percebem, dentro de seu conhecimento do produto; as pesquisas, muitas vezes, limitam-se a solicitar a confirmação do que foi anteriormente estabelecido como importante ou significativo (Levitt, 1990), e isso conduz à necessidade de se compreender que a manifestação dos desejos do cliente, além da limitação natural de 
expressão dos termos técnicos e em linguagem técnica, adiciona-se o fato de que os clientes, em geral, revelam o que thes é concreto. Exemplo: os clientes solicitam um automóvel, uma TV, uma pintura de uma casa.

- Necessidades reais - o que é informado pelos clientes nem sempre é o que eles realmente precisam ou procuram e, portanto, há uma imperiosa necessidade de tradução de suas necessidades declaradas em reais, de maneira a traduzir aquilo que verdadeiramente foi afirmado e que se encontra por trás do que foi registrado. O diagrama de árvore, uma das novas ferramentas da qualidade, é de boa utilidade para tal processo. (Mizuno, 1988). Exemplo: os clientes desejam uma forma de transporte ou mostrar seu status no caso de um automóvel, o objetivo de uma TV é a possibilidade de entretenimento variado, uma pintura de uma casa é a aparência agradável, a beleza.

- Necessidades percebidas - os clientes desejam outros resultados além dos que são, em geral, percebidos pelas empresas, isto é, uma roupa não é comprada somente para a proteção do corpo, mas por uma série de outros fatores pessoais e psicológicos; um produto defeituoso pode não valer nada, entretanto, o mesmo produto, se percebido como raro, pode alcançar altos valores. Perceber características especiais e não necessariamente manifestadas por um cliente pode significar um produto com alto valor agregado aos olhos dos clientes. (Brown, 2001).

- Necessidades culturais - fatores culturais podem ser limitantes nas declarações dos desejos dos clientes, ou impedindo que eles percebam determinados aspectos ou então impedindo sua manifestação sobre o tema. (Rogers, 2003). Os fatores culturais também podem marcar a importância dos valores, de maneira diferente entre diferentes grupos. (Rapaille, 2001).

- Necessidades atribuídas a usos inesperados - envolvem aspectos de segurança, de clareza do real potencial do produto, o que muitas vezes 
não é percebido pelo cliente, ou pior, pode induzir o cliente a ações não projetadas. Exemplo seria o uso da chave de fenda para inúmeros outros usos que não o parafusar.

- Necessidade de aprendizagem - entre os diversos fatores apontados, o desconhecimento de um produto é um limite natural à sua compra. Essa necessidade implica esclarecer e reduzir o risco do novo para os clientes. Isto pode ser feito pela propaganda, mas não somente por ela, que pode ter efeitos contrários. Ocorre também pelo processo natural da divulgação, conhecida pelo processo de divulgação boca-a-boca, ou de simples imitação. Os estudos sobre a difusão da inovação discutem este aspecto, bem como seus modelos. (Gregan-Paxton e outros, 2002; Rogers, 2003; Tellis, Stremersch e Yin 2003).

Há diversas variáveis que precisam ser consideradas pelas empresas na decisão de inovar, mas uma delas é o processo de aprendizagem e de conhecimento que induz uma pessoa a experimentar um novo produto e, segundo a literatura sobre difusão da inovação, de repassar, de maneira consciente ou não, esta leitura aos demais integrantes da sociedade. Por outro lado, a literatura afirma que, de acordo com as categorias propostas por Rogers (2003), os adotantes iniciais têm obtido ganhos significativos (Benston e outros, 2003). Identificar rapidamente uma inovação é um fator de vantagem competitiva também para o cliente. Portanto, conhecer como o processo de difusão se dá e quais as categorias de pessoas que primeiro o percebem pode ser importante para uma empresa, ao fornecer condições de pesquisar esses clientes e deles obter informações para adequar melhor um produto. Como os clientes que primeiro percebem uma inovação, muitas vezes, são mais bemsucedidos, seu reforço em procurar e adotar novidades será maior (Ram e Jung, 1994). Há de se recordar que a reação não esperada dos consumidores é a responsável por muitos fracassos das empresas, ou mesmo de sucessos inesperados. (Drucker, 2000)

Assim, conhecer o potencial consumidor é fundamental para o sucesso de uma operação, e é importante aprofundar esse conhecimento, compreendendo 
como um determinado produto, após aceito pela sociedade, passa por um processo de difusão que possa ser conhecido ou ao menos antecipado em suas linhas gerais. O reconhecimento das formas de difusão, em suas diferentes categorias, seja pelo entendimento, mesmo empírico, de como ele ocorre, pode auxiliar a empresa em seu negócio. A literatura é afirmativa em suas conclusões de que o processo de difusão de uma inovação segue determinados padrões de resposta, e que um produto qualquer precisa de tempo para atingir os diversos potenciais compradores. Ignorar sua existência, quando da decisão de inovar, pode causar transtornos ou até fracassos às empresas.

Os estudos de campo realizados (apresentados no capítulo 7) mostraram que essa disposição existe no processo de difusão de inovações nos domicílios permanentes particulares do Brasil. Uma inovação irrompe, inicialmente, nas camadas de mais alta renda (que faz o papel dos inovadores proposto por Rogers, 2003) e se propaga para as demais, sendo que a descontinuidade ou substituição de uma inovação segue o mesmo caminho. É interessante notar que, da mesma maneira proposta por Rogers quanto às cinco categorias de adotantes de uma inovação (inovadores, adotantes iniciais, maioria inicial, maioria tardia e retardatários), que compõem a principal parcela de cada fase do ciclo de vida de um produto, a divisão em cinco classes de renda permitiu reproduzir um processo similar, em relação à quantidade de produtos comercializados pela primeira vez, onde a classe de mais alta renda participa mais intensamente na fase inicial, seguida pelas demais, e a classe de menor renda participa com mais intensidade nas fases mais tardias do ciclo correspondente. Essa leitura permite propor um modelo que represente a condição do processo de difusão por classes de renda, que é mostrado na figura 8.2, e será seguido por outro, que mostra o impacto na estratégia de uma empresa, pois a forma como é identificada a difusão nas diversas classes de renda deve auxiliar na revisão da estratégia do produto pela empresa. 


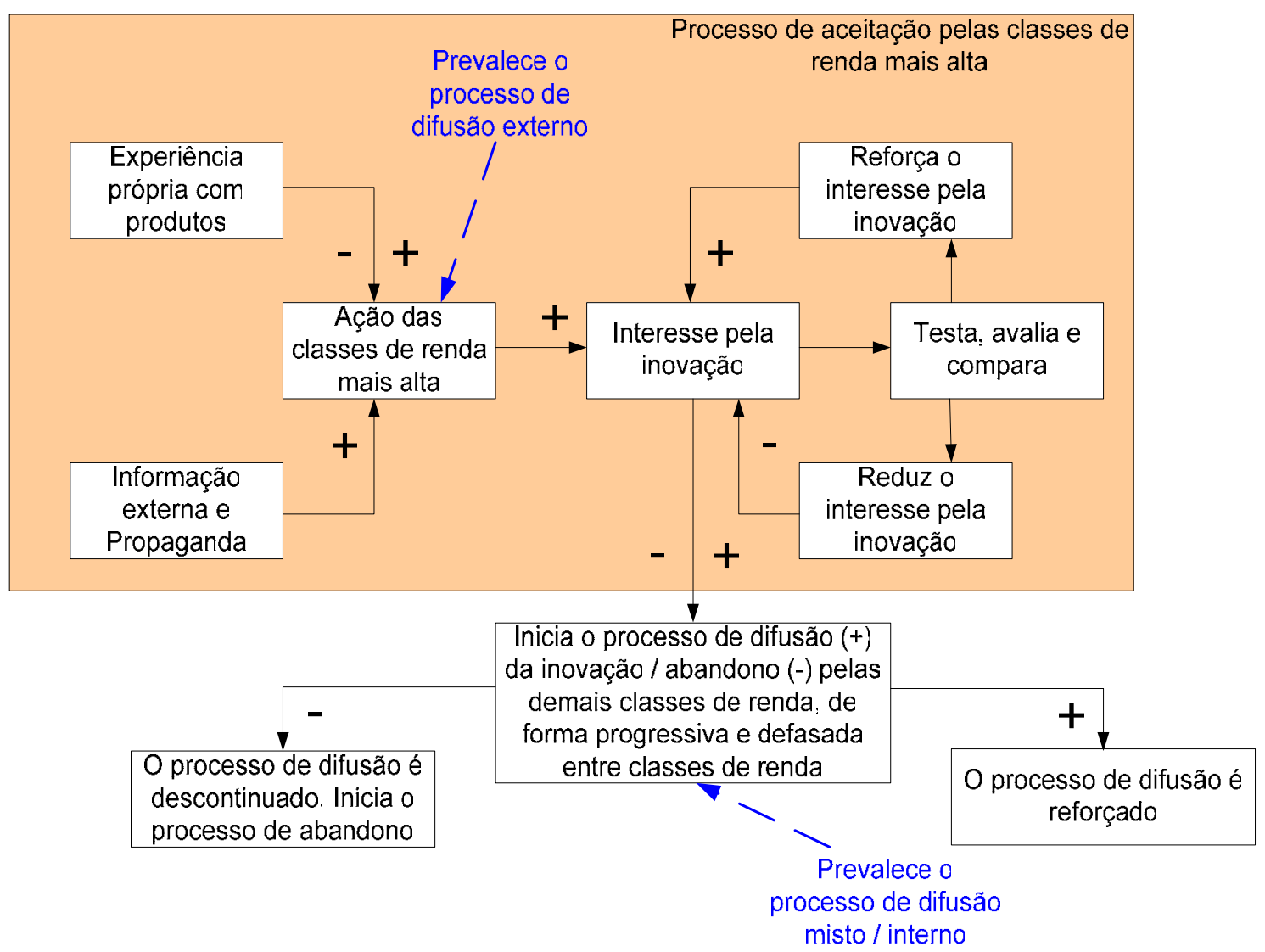

Figura 8.2 - Como ocorre o processo de difusão das inovações nas diferentes classes de renda, tendo a classe de renda mais alta como referência.

A classe de renda mais alta procura as informações que suportam sua decisão de inovar em sua experiência pessoal: com outros produtos similares (sob seu ponto de vista), em informações externas de cunho não-pessoal (revistas, Internet, etc.) e na propaganda. Um dos fatores a estimular tal ação é seu potencial financeiro que permite assumir riscos (assim como é apontado por Rogers para a categoria inovadores). Despertado o interesse pela inovação, inicia-se a fase de experimentação e avaliação do novo produto: para a condição de aceitação do novo produto, há um reforço positivo que auxilia na deflagração do processo de difusão; em caso contrário, a inovação é abandonada (conforme previsto por Rogers em seu modelo) e o processo de difusão é atenuado. O abandono pode se dar por várias razões, entre elas pelo surgimento de produtos substitutos. Isto pode ocorrer a qualquer momento (ver o processo de difusão dos filtros de água no Brasil, onde, mesmo com a presença em torno de $83 \%$ nos domicílios de classe de renda mais alta, assim que esta categoria iniciou o processo de abandono, foi seguida, de forma 
defasada no tempo, pelas demais, atingindo, assim, níveis menores de saturação (a classe de renda entre 5 a 10 salários mínimos somente atingiu um pico de $68 \%$ e a de renda entre 2 a 5 salários mínimos, um pico de posse deste bem durável de 57\%). É interessante notar que o rádio, apesar de também estar em um processo de abandono, atingiu valores de participação bem mais altos. Isso demonstra que não há um valor padrão de saturação e que ela depende de outras variáveis.

Quando o processo de difusão é disparado em um momento inicial pela classe de mais alta renda, ele se propaga às demais, nas seguintes condições: proximidade física da população (diferença na difusão das áreas urbanas e rurais) e acesso à informação e comparação (diferença na difusão entre classes de renda em estados mais distantes dos principais centros urbanos, portanto, menos atingidos pela propaganda e informação inicial, conforme verificação feita entre o processo de difusão em São Paulo, entre os maiores IDH - índice de desenvolvimento humano - do Brasil e Alagoas, entre os menores IDH. Ver apêndice 5).

Entender o processo de demanda de um novo produto em suas diversas fases do ciclo de vida pode ser vital para o sucesso de uma inovação, portanto, um conhecimento importante na definição e ajuste da estratégia da empresa; assim, foi proposto o modelo mostrado na figura 8.3. 


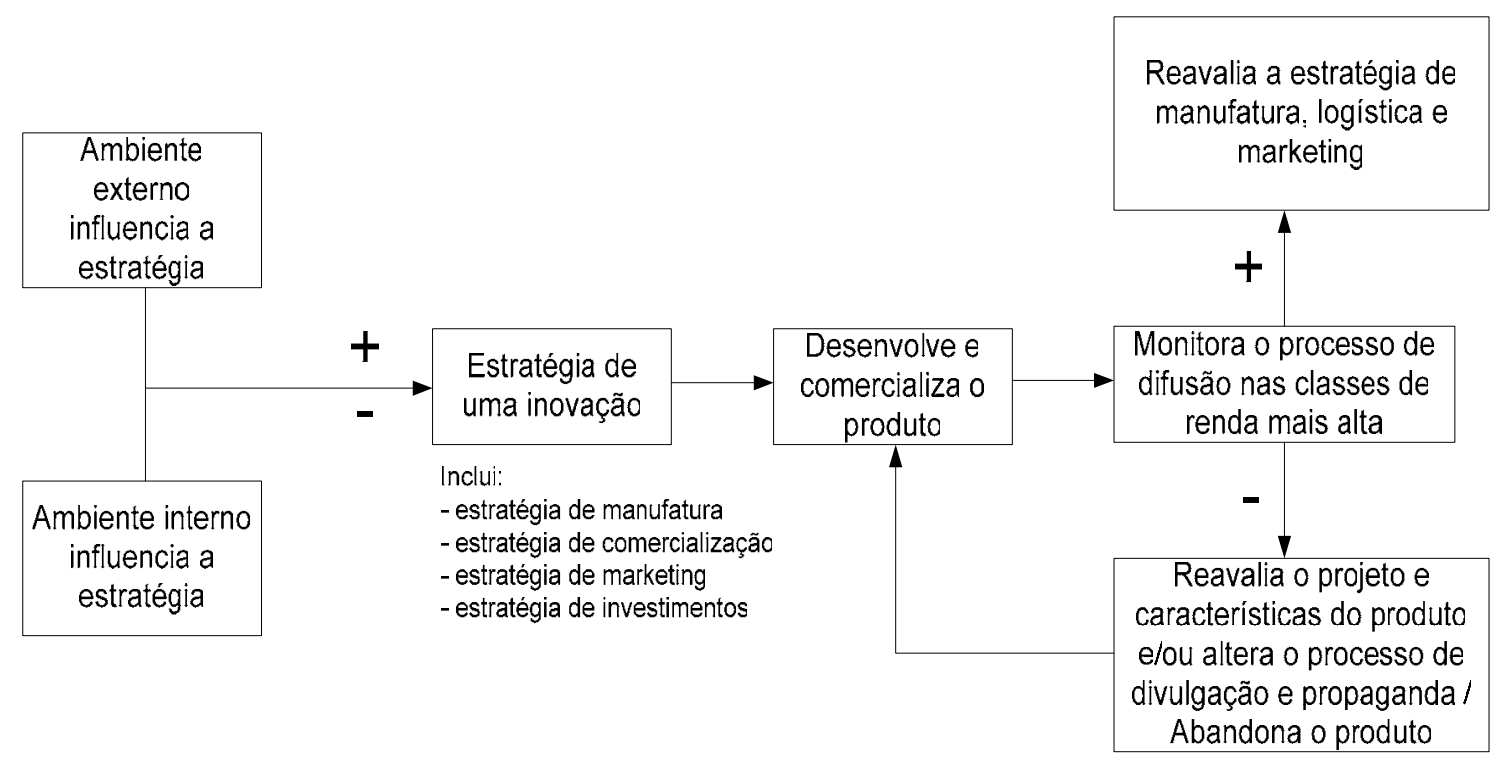

Figura 8.3 - Revisão da estratégia de inovação por uma empresa.

A partir do monitoramento do comportamento de aceitação da classe de mais alta renda, a empresa pode projetar sua estratégia futura estimando o parâmetro de difusão do produto, a partir do que ocorreu com um produto similar (ver processo de difusão de geladeiras e freezer estudado no capítulo 7). Isso permite que a empresa antecipe suas ações em dois casos: caso o processo apresente tendência positiva, reavaliar a estratégia de manufatura, logística e marketing, readequando-a, se necessário; caso o processo apresente tendência negativa, reavaliar o projeto, introduzindo alterações ou alterando a divulgação por meio de propaganda ou outros meios, ou ambos, ou abandonando o produto, ou forçando sua substituição.

O modelo proposto mostra que as empresas têm um indicador interessante para auxiliar suas decisões, isto é, ficou demonstrado que o comportamento das classes de renda mais alta mostra as tendências que serão seguidas pelas outras classes de renda, permitindo às empresas anteciparem suas estratégias de negócio. Esse indicador é de mais fácil obtenção que a tentativa de identificar os inovadores em uma população e monitorá-los, pois pessoas podem ter atitudes de inovadores para determinadas inovações e não para outras. Dividir em classes de renda para análise do comportamento do processo de difusão torna a ação mais fácil, pois esta condição é historicamente monitorada pelas pesquisas de marketing. Uma empresa, ao 
verificar a mudança de tendência na aquisição de uma inovação pelas classes de renda mais alta e sabendo que há defasagem para as demais classes, terá mais tempo para decidir suas ações. 


\section{9- Conclusões e recomendações}

O trabalho permitiu reforçar que os estudos sobre difusão das inovações podem auxiliar as empresas a obter mais um indicador para apoiá-las em suas decisões estratégicas. Atualmente os períodos entre o surgimento de uma inovação pura (novos produtos decorrentes de inovações que criam novas categorias de produtos) ou de inovações radicais (novos produtos decorrentes de inovações descontínuas ou de inovações multidisciplinares) sejam cada vez mais curtos, o tempo de substituição por novas gerações também está se reduzindo, o que impõe, às empresas, a necessidade de encontrar diferentes caminhos para o sucesso de suas decisões estratégicas em relação a essas inovações, incluindo como e quando substituí-las. Uma empresa pode preferir manter-se em um mercado, mesmo que um determinado grupo social comece a abandonar seu produto, mas isso implicará no reconhecimento de que sua estratégia deverá mudar, seja alterando canais de marketing, de comercialização, seja introduzindo alterações específicas e que atendam melhor aos grupos sociais que ainda demonstram interesse pelo produto. É mais fácil para uma empresa monitorar o comportamento de alguns grupos sociais do que acompanhar o de toda a sociedade, assim podendo decidir melhor sobre a extensão do investimento necessário no negócio e se este pode ou não ser vantajoso. Tais decisões são difíceis, e ter ferramentas que as auxiliem nesse processo decisório é de grande importância para seu sucesso. Portanto, conseguir projeções futuras tendo como base situações presentes, por meio do acompanhamento diferenciado de algumas das respostas de um determinado grupo social, pode ser uma ferramenta que facilita a decisão estratégica das empresas.

O trabalho mostrou que, ao menos para a difusão de bens duráveis e outras disposições que ocorrem em um domicílio particular permanente no Brasil, é possível identificar a existência de algum tipo de comportamento que se repete entre diferentes segmentos da sociedade. Identificar estes comportamentos pode auxiliar a empresa em suas decisões. 
Alguns critérios foram perseguidos: inicialmente foi utilizada como referência a principal obra no tema, Diffusion of Innovations de Everett Rogers e, a partir daí, foram localizadas outras publicações e artigos; em seguida, conforme se vê nas referências bibliográficas, diversas áreas do conhecimento foram exploradas, de maneira a reunir diversas visões existentes sobre o assunto. Desse ponto em diante, foi delineado o processo de pesquisa. Uma vez que o tempo é um dos fatores básicos a ser considerado na difusão das inovações, necessariamente seria preciso pesquisar as ocorrências, ao longo do tempo e na sociedade, pois a difusão de inovações somente faz sentido quando referida a reações de pessoas. A pesquisa deveria ser direcionada para bancos de dados confiáveis e que oferecessem confiabilidade em seus valores. Em uma primeira fase, foi possível perceber que, dentre as empresas contatadas, dados históricos da forma e com a confiabilidade necessária não estavam disponíveis. $\mathrm{Na}$ etapa seguinte, foi procurado o banco de dados resultante das diversas pesquisas realizadas pelo IBGE, que atenderam às expectativas em uma fase inicial. Entretanto, quando do aprofundamento das análises, as respostas não eram todas obtidas na documentação disponível e, assim, foi necessário pesquisar na base de dados "bruta" das pesquisas do IBGE, denominados micro dados. A análise foi realizada com o auxílio de um software específico de estatística denominado SPSS, e muitos dos valores mostrados nesse trabalho foram daí retirado, possibilitando a criação de uma série de dados que permitiram estudos confirmatórios das propostas iniciais, com base em análise estatística de correlações de Pearson. A utilização de outras ferramentas e técnicas estatísticas se fez necessária para comprovação de afirmações feitas, sendo utilizados o método de Kolmogorov-Smirnov e dos mínimos quadráticos.

Dessa forma foi possível a constatação de alguns pontos principais que se pretende possam auxiliar as empresas e futuras pesquisas::

- os itens estudados seguiram sempre um padrão de resposta que de alguma forma refletem as propostas das teorias sobre difusão das inovações, reforçando a importância que tais aspectos sejam efetivamente incorporados quando da análise de mercados, volume de vendas esperado ao longo do tempo e consequentemente da definição da estratégia de um negócio; 
- quando levantados os processos de difusão de algumas inovações no Brasil, ao longo das últimas décadas, a resposta esperada pela teoria se confirmou, conforme se pode ver nas curvas mostradas no capítulo 7 e tabelas mostradas no apêndice 1;

- as análises e estudos sobre difusão das inovações pouco exploram processos de segmentação da sociedade, dando indicações que o fenômeno de difusão ocorre de forma igual em toda ela, apenas dependendo de condições genéricas de homofilia e heterofilia, ligadas a alguns dos requisitos sociais relatados por Rogers, fatores estes difíceis de serem identificados. Isto não se mostrou verdadeiro quando do levantamento nos dados disponíveis analisados. Entendendo-se que um dos fatores que proporcionam a heterofilia está na diferença social, correlacionada fortemente à diferença de renda, constatou-se que grupos situados em diferentes classes de renda responderam de forma diferente aos estímulos de uma inovação, conforme constatado em 7.3. Isto permite uma análise diferenciada de como ocorre o processo;

- a segmentação da difusão na área urbana e rural, entre diferentes classes de renda (capítulo 7) e entre estados com diferentes IDHM (apêndice 5), permitiu identificar o retardo na adoção ou no abandono de uma determinada inovação, possibilitando assim indicar que a resposta a uma inovação: se propaga entre classes de renda, iniciando pela de mais alta renda; inicia e se propaga mais rapidamente na área urbana que na área rural; inicia e se propaga mais rapidamente em condições de IDHM mais alto;

- as análises e testes de aderência das curvas de distribuição encontradas apontam que as classes de renda mais alta apresentam respostas mais próximas de um processo de influência externa e que as de menor renda a processos de influência mista ou interna;

- dessa forma é possível verificar que há espaço para um modelo descritivo do processo o qual permitiria que o monitoramento das classes de renda mais alta fosse um indicador presente do futuro comportamento das demais classes de renda (ver capítulo 8), inclusive na intensidade da difusão (ver curvas de difusão apresentadas no capítulo 7);

- ao pesquisar a evolução dos preços dos itens pesquisados ao longo de 45 anos (ver item 7.4), identificou que os preços se mantiveram relativamente constantes ao longo do período, referenciados em quantidade de salários 
mínimos, e que o preço não foi uma variável de forte influência no processo de difusão;

- finalmente o trabalho apontou para possíveis padrões de comportamento da sociedade brasileira quando do surgimento de inovações, as quais devidamente exploradas permitiriam suportar melhor os processos estratégicos decisórios nas empresas.

Há de se ressaltar que o estudo não tratou do potencial de recompra ou substituição da mesma inovação durante seu ciclo de vida, mas sim da primeira entrada de uma inovação em um domicílio. Por outro lado, é possível assumir que o acompanhamento do processo de difusão aponta tendências comuns entre diferentes itens em um domicílio. O modelo proposto deve auxiliar as empresas na identificação dessas tendências, permitindo que elas se antecipem às mudanças futuras, pois as camadas de renda inferiores, em quantidade de pessoas e domicílios (até 2 SM representavam 32,1\% da população em 2004), são em número bem maior do que das classes mais altas (acima de 10 SM representavam 11,4\% do total em 2004).

Quanto às possíveis extensões decorrentes desse trabalho, vê-se a necessidade de um aprofundamento nos comportamentos dos domicílios em diferentes regiões do país, seja por meio da comparação da escolaridade com a difusão das inovações (IBGE, 2004a), seja pela localização geográfica ou outros fatores socioeconômicos, confirmando ou não os resultados aqui encontrados. Também pode ser interessante realizar estudos de aplicação de análises de regressão, de forma a procurar modelar, matematicamente, a resposta da sociedade na variável domicílios, além de confirmar ou não se os modelos aplicáveis correspondem àqueles hoje existentes. Uma linha de pesquisa interessante seria aprofundar estudos sobre a evolução dos preços ao longo do tempo, atualizados de maneira a correlacionar se as mudanças de preços são decorrentes de estratégias empresariais claras e definidas. Finalmente, estudos que mostrem se há prevalência de determinados tipos de inovações sobre outras, quanto ao nível de saturação na difusão, podem mostrar-se úteis para orientar as empresas em suas estratégias. 


\section{REFERÊNCIAS BIBLIOGRÁFICAS}

1 ADAMS, Richard J. Innovation types: configurations of attributes as a basis for innovation classification. In: $11^{\text {th }}$ International Product Development Management Conference, part 2, p. 1-19, June 20-22, 2004, Dublin, Ireland. Proceedings European Institute for Advanced Studies in Management - EIASM: The University of Dublin - Trinity College, 2004.

2 AKHAVEIN, Jalal; FRAME, W. Scott e WHITE, Lawrence J. The diffusion of financial innovations: an examination of the adoption of small business credit scoring by large banking organizations. Journal of Business, v. 78, $\mathrm{n}^{\circ} 2$, 2005.

3 ALBA, Joseph W. e HUTCHINSON, J. Wesley. Dimensions of Consumer Expertise. Journal of Consumer Research, v. 13, p. 411-54, March, 1987.

4 ALKEMADE, Floortje e CASTALDI, Carolina. Strategies for the diffusion of innovations on social networks. Computational Economics, v. 25, p. 3-23, 2005.

5 AMIDON, Debra M. The Innovation SuperHighway: Harnessing Intellectual Capital for Collaborative Advantage. Woburn: Elsevier, 2003.

6 AGGARWAL, Praveen; CHA, Taihoon e WILEMON, David. Barriers to the adoption of really-new products and the role of surrogate buyers. Journal of Consumer Marketing, v. 15, n 4, p. 358-71, 1998.

7 ANDERSON, James C. e NARUS, James A. Business marketing: understand what your customers value. Harvard Business Review, v. 76, n 6, November-December, 1998.

8 ANTIL, John $\mathrm{H}$. New product or service adoption: when does it happen? The Journal of Consumer Marketing, v. 5, $\mathrm{n}^{\circ} 2$, Spring, 1988.

9 BABBAR, Sunil; BEHARA, Ravi e WHITE, Edna. Mapping product usability. International Journal of Operations \& Production Management, v. 22, $\mathrm{n}^{\circ}$ 10, p. 1071-89, 2002.

10 BARR, Stewart. Quantitative data analysis for geographers using SPSS. 2001. Disponível em: http://www.projects.ex.ac.uk/ebrg/SPSS\%20Handbook\%202004.doc . Acessado em janeiro/2005. 
11 BEMOWSKI, Karen. Codes, cultural archetypes, and the collective cultural unconscious. Quality Progress, v. 28, n. ${ }^{0}$ 1, p. 33-6, Jan, 1995. (a)

12 .What makes americam teams tick? Quality Progress, v. 28, n. ${ }^{\circ}$ 1, p. 39-43, Jan, 1995. (b)

13 Americans' nostalgic affair with loyalty. Quality Progress, v. 29, n. ${ }^{\circ}$ 2. p. 33-6, Feb, 1996.

14 BENSTON, George e outros. Bank capital structure, regulatory capital, and securities innovations. Journal of Money, Credit, and Banking, v. 35, $n^{\circ} 3$, p. 301-22, June, 2003.

15 BERENSON, Mark L. e LEVINE, David M. Basic business statistics: concepts and applications. $7^{\text {th }}$ ed., Upper Saddle River: Prentice Hall, 1999.

16 e Krehbiel, Timothy C. Basic business statistics: concepts and applications. $8^{\text {th }}$ ed., Upper Saddle River: Prentice Hall, 2002.

17 BERTHON, Pierre; HULBERT, James Mac e PITT, Leyland. Innovation or customer orientation? An empirical investigation. European Journal of Marketing, v. 38, n 9/10, p. 1065-90, 2004.

18 BERTRAND, J. Will e FRANSOO, Jan C. Operations management research methodologies using quantitative modeling. International Journal of Operations \& Production Management, v. 22, n² 2, p. 241-264, 2002.

19 BLAU, Gary E. et all. Managing a portfolio of interdependent new product candidates in the pharmaceutical industry. The Journal of Product Innovation Management, v. 24, no 4, p. 227-45, 2004.

20 BLACKMORE, Susan. The power of memes. Scientific American, v. 283, no 4, p. 64-73, Oct, 2000.

21 BONOMA, Thomas $\mathrm{V}$. Case research in marketing: opportunities, problems, and a process. Journal of Marketing Research, v. 22, $\mathrm{n}^{\circ} 2$, p. 199-208, May, 1985.

22 BOULDING, WILLIAM e outros A dynamic process model of service quality: from expectations to behavioral intentions. Journal of Marketing Research, v. 30, p. 7-27, Feb, 1993.

23 BOYD, Thomas C. e MASON, Charlotte H. The link between attractiveness of "extrabrand" attributes and the adoption of innovations. Journal of the Academy of Marketing Science, v. 27, n 3, p. 306-19, Summer, 1999. 
24 BRAUN-LA TOUR, Kathryn A. e LA TOUR, Michael S. Transforming consumer experience. Journal of Advertising, v. 34, $n^{\circ} 3$, p. 19-30, Fall, 2005.

25 BROWN, Stephen. Torment your customers (they'll love it). Harvard Business Review, v. 79, no 9, p. 82-8, October, 2001.

26 BROWNING, Tyson R.; DEYST, John J. e EPPINGER, Steven D. Adding value in product development by creating information and reducing risk. IEEE Transactions on Engineering Management, v. 49, $n^{\circ} 4$, p. 443-58, November, 2002.

27 BRUCE, Margaret e BIEMANS, Win G. Product development: meeting the challenge of the design-marketing interface. Chichester: John Wiley \& Sons, 1995.

28 BUXEY, Geoff. Strategies in an era of global competition. International Journal of Operations \& Production Management, v. 20, n 9, p. 9971016, 2000.

29 CASTELLACI, Fulvio e outros. Advances and challenges in innovation studies. Journal of Economic Issues, v. 39, n 1, p. 91-121, March, 2005.

30 CASTRO, Ruy. Roquete Pinto: o homem multidão. Brasília: MEC, 2005.

Disponível em http://www.radiomec.com.br/roquettepinto/ohomemmultidao.asp\#inicio . Acessado em 15/11/2005. Formato HTML.

31 CATANIA, A. Charles. Aprendizagem: comportamento, linguagem e cognição. $4^{a}$ ed., Porto Alegre, Artes Médicas, 1999.

32 CAVUSGIL, S. Tamer; CALANTONE, Roger J. e ZHAO, Yushan. Tacit knowledge transfer and firm innovation capability. Journal of Business \& Industrial Marketing, Bradford, v. 18, $\mathrm{n}^{\circ}$ 1, p. 6-21, 2003.

33 CHAKRAVARTY, Sugato e DUBINSKY, Alan. Individual investors' reactions to decimalization: Innovation diffusion in financial markets. Journal of Economic Psychology, v. 26, no 1, p. 89-103, february, 2005. Elsevier.

34 CHAKRAVORTY, Bhascar. The new rules for bringing innovations to market. Boston: Harvard Business Review, v. 82, n 3, p. 58- , March, 2004.

35 CHANDON, Pierre, MORWITZ, Vicki G. e REINARTZ, Werner J. The shortand long-term effects of measuring intent to repurchase. Journal of Consumer Research, v. 31, n 3, p. 566-72, Dec, 2004. 
36 CHURCHILL Jr., Gilbert A. e PETER, J. Paul. Marketing: criando valor para o cliente. $2^{\mathrm{a}}$ ed., São Paulo: Saraiva, 2000.

37 CLARK, Kim B. e FUJIMOTO, Takahiro. Product development performance: strategy, organization and management in the world auto industry. Boston: Harvard Business School Press, 1991.

38 COLLARD, Mark; SHENNAN, Stephen, TEHRANI e Jamshid. Branching, blending, and the evolution of cultural similarities and differences among human populations. Evolution and Human Behavior, em publicação, 2005.

39 CONCHAR, Margy P. e outros. An integrated framework for the conceptualization of consumers' perceived-risk processing. Academy of Marketing Science Journal, v. 32, nº 4, p. 418-36, Fall, 2004.

40 CONDE, Enar R. e RUÍZ, Francisco José M. The distribution model in the diffusion of innovations: a comparison of different European countries. European Journal of Innovation Management, v. 4, nº 1, p. 6-19, 2001.

41 CONOVER, W. J. Practical nonparametric statistics. $2^{\text {nd }}$ ed., New York: John Wiley \& Sons, 1980.

42 COOPER, Robert G. Doing it right. Ivey Business Journal, v. 64, nº 6, p. 54-60, Jul/Aug, 2000.

43 COOPER, Robert G.; EDGETT, Scott J. e KLEINSCHMIDT, Elko J. Optimizing the stage-gate process: What best-practice companies do - I. Research Technology Management, v. 45, $n^{\circ}$ 5, p. 25-7, Sep/Oct, 2002 (a). . Optimizing the stage-gate process: What best-practice companies do - II. Research Technology Management, v. 45, nº 6, p. 43-9, Nov/Dec, 2002 (b).

best NPD practices - I. Research Technology Management, v. 47, $n^{\circ} 1, p$. 31-43, Jan/Feb, 2004 (a).

46 Benchmarking best NPD practices - II. Research Technology Management, v. 47, $\mathrm{n}^{0} 2$, p. 50-9, Mai/Jun, 2004 (b).

47

Benchmarking best NPD practices - III. Research Technology Management, v. 47, $\mathrm{n}^{\circ} 5$, p. 43-55, Nov/Dec, 2004 (c). 
48 CORRÊA, Henrique e CAON, Mauro. Gestão de serviços. São Paulo: Atlas, 2002.

49 COSTA, Sérgio E. G. Desenvolvimento de uma abordagem estratégica para a seleção de tecnologias avançadas de manufatura - AMT. 2003. 261 p. Tese (Doutorado em Engenharia) - Departamento de Engenharia de Produção, Escola Politécnica, Universidade de São Paulo, São Paulo.

50 COSTA NETO, Pedro Luiz de. Estatística. São Paulo: Edgard Blücher, 1977.

51 CRESWEL, John W. Research design: qualitative \& quantitative approaches. Thousand Oaks: Sage, 1994.

52 DAFT, Richard L. Organizações: Teoria e projeto. São Paulo: Thomson Pioneira, 2002.

53 DANAHER, Peter J.; HERDIE, Bruce G. e PUTSIS Jr., William P. Marketingmix variables and the diffusion of successive generations of a technological innovation. Journal of Marketing Research, v. 38, $n^{\circ} 4$, p. 501-14, November, 2001.

54 DATTA, Sumit e MUKHERJEE, S. J. Developing a risk management matrix for effective project planning - an empirical study. Project Management Journal - PMI, v. 32, n² 2, p. 45-57, 2001.

55 DAVIES-COOPER, Rachel e JONES, Tim. The interfaces between design and other key functions in product development. In: BRUCE, Margaret e BIEMANS, Wim G. Product development: meeting the challenge of the design-marketing interface. Chichester: John Wiley \& Sons, 1995.

56 DEBACKERE, Koenraad. Technologies to develop technology. Antwerpen: Maklu, 1999.

57 DEFFUANT, Guillaume; HUET, Sylvie e AMBLARD, Frédéric. An individualbased model of innovation diffusion mixing social value and individual benefit. The American Journal of Sociology, v. 110, n 4, p. 1041-69, Jan, 2005.

58 DE NEGRI, João Alberto; SALERNO, Mário S e CASTRO, Antonio B.. Inovações, padrões tecnológicos e desempenho das firmas industriais brasileiras. In.: DE NEGRI, João Alberto e SALERNO, Mário S. Inovações, padrões tecnológicos e desempenho das firmas industriais brasileiras. Brasília: IPEA. Org.: João Alberto de Negri e Mário Sérgio Salerno, 2005. 
59 DEROÏAN, Frédéric. Formation of social networks and diffusion of innovations. Research Policy, v. 31, p. 835-46, 2002.

60 DESCHAMPS, Jean-Philippe e NAYAK, P. Ranganath. Produtos irresistíveis: como operacionalizar um fluxo perfeito de produtos do produtor ao consumidor. São Paulo: Makron Books, 1997.

61 DOLAN, Robert J. Managing the new product development process: cases and notes. Reading: Addison-Wesley, 1993.

62 DRUCKER, Peter F. Inovação e espírito empreendedor entrepreneurship. $6^{a}$ ed., São Paulo: Pioneira, 2000.

63 DUBOIS, Bernard. Compreender o consumidor. Lisboa, Publicações Dom Quixote, 1993.

64 ENGEL, James F.; BLACKWELL, Roger D. e MINIARD, Paul W. Comportamento do consumidor. $8^{\mathrm{a}}$ ed., Rio de Janeiro: LTC, 2000.

65 EVANS, Joel R. e BERMAN, Barry. Marketing. 7ht ed., Upper Saddle River: Prentice Hall, 1997.

66 FAGERBERG, Jan. Schumpeter and the revival of evolutionary economics: an appraisal of the literature. Journal of Evolutionary Economics, v. 13, $n^{\circ} 2$, p. 125-59, April, 2003.

67 FOSTER, Joseph A; GOLDER, Peter N e TELLIS, Gerard J. Predicting Sales Takeoff for Whirlpool's New Personal Valet. Marketing Science, $v$. 23, n² 2, p. 182-5, Spring, 2004.

68 FREDERICKS, Joan O. e SALTER, James M. What does your customer really want? Quality Progress, v. 31, n 1, Jan, 1998.

69 FROEHLE, Craig M. e outros. Antecedents of new service development effectiveness: an exploratory examination of strategic operations choices. Journal of Service Research, v. 3, no 1, p. 3-17, Aug, 2000.

70 GAITHER, Norman e FRAZIER, Greg. Administração da produção e operações. $8^{\mathrm{a}}$ ed., São Paulo: Pioneira Thomson Learning, 2002.

71 GARDNER, Howard; KORNHABER, Mindy L. e WAKE, Warren K. Inteligência: múltiplas perspectivas. Porto Alegre: Artmed, 1998.

72 GEORGIOU, Stelios N. Synectics: A problem-solving tool for educational leaders. The International Journal of Educational Management, v. $8, n^{\circ}$ 2, p. 5-10, 1994. 
73 GOLDER, Peter N. e TELLIS, Gerard J. Will it ever fly? Modeling the takeoff of really new consumer durables. Marketing Science, v. 16, no 3, p. 256-70, Summer, 1997.

74 GOFFIN, Keith e NEW, Colin. Customer support and new product development: An exploratory study. International Journal of Operations \& Production Management, v. 21, no 3, p. 275-301, 2001.

75 GOPALAKRISHNAN, Shanti e DAMANPOUR, Fariborz. The impact of organizational context on innovation adoption in commercial banks. IEEE Transactions on Engineering Management, v. 47, $n^{0} 1$, p. 14-25, February, 2000.

76 GREEN, Samuel B. e SALKIND, Neil J. Using SPSS for Windows and Macintosh: analyzing and understanding data. ${ }^{\text {rd }}$. ed., Upper Saddle River: Prentice Hall, 2003.

77 GREGAN-PAXTON, Jennifer e outros. "So that's what that is": examining the impacto $f$ analogy on consumers' knowledge development for really new products. Psychology \& Marketing, v. 19, nº 6, p. 533-50, Jun, 2002.

78 GURLEY, Todd; LIN, Spencer e BALLOU, Steve. Consumer decision process modeling: how leaders can better understand buyers' choices. Strategy \& Leadership, v. 33, no 3, p. 30-40, 2005.

79 HAGEN, Abdalla F. e LODHA, Shiam S. How do CEOS perceive suggested new rules of global competitiveness in the twenty-first century? American Business Review, v. 22, no 1, p. 62-9, January, 2004.

80 HAIR, Joseph F. e outros. Multivariate data analysis. $5^{\text {th }}$ ed., Upper Saddle River: Prentice Hall, 1998.

81 HALL, Bronwyn H. Innovation and diffusion. Cambridge: NBER, working paper 10212, January, 2004. Disponível em http://www.nber.org/papers/w10212 . Formato Acrobat Adobe PDF.

82 HART, Susan. Where we've been and where we're going in new product development research. In: BRUCE, Margaret e BIEMANS, Wim G. Product development: meeting the challenge of the design-marketing interface. Chichester: John Wiley \& Sons, 1995.

83 HARTLEY, John R. Engenharia simultânea: um método para reduzir prazos, melhora a qualidade e reduzir custos. Porto Alegre: Bookman, 1998. 
84 HEGEDUS, Clovis E. A compreensão da percepção da qualidade pelo consumidor como base para a definição de estratégias pelas empresas e suas cadeias de fornecimento. 2000. 183 p. Dissertação (Mestrado em Engenharia) - Departamento de Engenharia de Produção, Escola Politécnica, Universidade de São Paulo, São Paulo.

85 HEIZER, Jay e RENDER, Barry. Principles of operations management. $4^{\mathrm{a}}$ ed., Upper Saddle River: Prentice Hall, 2001.

86 HOLAK, Susan L. e LEHMANN, Donald R. Purchase intentions and the dimension of innovation: an exploratory model. Journal of Product Innovation Management, v. 7, p. 59-73, 1990.

87 HOYER, Wayne D. e MACINNIS, Deborah J. Consumer behavior. Boston: Houghton Mifflin Company, 1997.

88 HUGHES, Kent $\mathrm{H}$. Facing the global competitiveness challenge. Issues in Science and Technology, v. 21, no 4, p. 72-8, Summer, 2005.

$89 \mathrm{HUI}$, Loi T. Business timeliness: the intersections of strategy and operations management. International Journal of Operations \& Production Management, v. 24, no 6, p. 605-24, 2004.

90 IBGE. Censo Demográfico de 1940. Rio de Janeiro: IBGE, 1943.

91 _. Censo Demográfico de 1950. Rio de Janeiro: IBGE, 1952.

92 _. Censo Demográfico de 1960. Rio de Janeiro: IBGE, 1961.

93 __ Censo Demográfico de 1970. Rio de Janeiro: IBGE, 1971.

94 _. Censo Demográfico de 1980. Rio de Janeiro: IBGE, 1982.

95 __. Censo Demográfico de 1991. Rio de Janeiro: IBGE, 1993.

96 __ Censo Demográfico de 2000. Rio de Janeiro: IBGE, 2002.

97 __ Censo Demográfico de 2000: questionário da amostra - microdados da amostra - regiões Norte, Nordeste, Sul, Sudeste e Centro-Oeste. Rio de Janeiro: IBGE, 2005a. 2 CD-ROM.

98 __ Estatísticas do século XX. Rio de Janeiro: IBGE, 2005b. Disponível em http://www.ibge.gov.br . Acessado em 03.nov.2005.

99 Pesquisa de orçamentos familiares 2003 - 2003: primeiros resultados - Brasil e Grandes Regiões. $2^{\mathrm{a}}$ ed., Rio de Janeiro, 2004a. 100 Pesquisa nacional por amostra de domicílios 1978 - PNAD.

Rio de Janeiro: IBGE, 2003a. 1 CD-ROM. 

Pesquisa nacional por amostra de domicílios 1983 - PNAD.

Rio de Janeiro: IBGE, 2003b. 2 CD-ROM.

102 Pesquisa nacional por amostra de domicílios 1988 - PNAD.

Rio de Janeiro: IBGE, 2005c. 1 CD-ROM. 103 Pesquisa nacional por amostra de domicílios 1990 - PNAD.

Rio de Janeiro: IBGE, 2003c. 1 CD-ROM. Pesquisa nacional por amostra de domicílios 1993 - PNAD.

Rio de Janeiro: IBGE, 1997a. 1 CD-ROM. 105 Pesquisa nacional por amostra de domicílios 1996 - PNAD. Rio de Janeiro: IBGE, 1997b. 1 CD-ROM. 106 Pesquisa nacional por amostra de domicílios 1997 - PNAD.

Rio de Janeiro: IBGE, 1998. 1 CD-ROM. 107 Pesquisa nacional por amostra de domicílios 1998 - PNAD.

Rio de Janeiro: IBGE, 2004b. 1 CD-ROM. 108 Pesquisa nacional por amostra de domicílios 1999 - PNAD.

Rio de Janeiro: IBGE, 2002. 1 CD-ROM. 109 Pesquisa nacional por amostra de domicílios 2001 - PNAD.

Rio de Janeiro: IBGE, 2004c. 1 CD-ROM. 110 Pesquisa nacional por amostra de domicílios 2002 - PNAD.

Rio de Janeiro: IBGE, 2004d. 1 CD-ROM. Pesquisa nacional por amostra de domicílios 2003 - PNAD. Rio de Janeiro: IBGE, 2005d. 1 CD-ROM. Pesquisa nacional por amostra de domicílios 2004 - PNAD. Rio de Janeiro: IBGE, 2005e. 1 CD-ROM.

113 IM, Subin; BAYUS, Barry L. e MASON, Charlotte H. An empirical study of innate consumer innovativeness, personal characteristics, and new-product adoption behavior. Journal of the Academy of Marketing Science, v. 31, $\mathrm{n}^{\circ} 1$, p. 61-73, Winter, 2003.

114 JAMAL, Ahmad e GOODE, Mark M. H. Consumers and brands: A study of the impact of self-image congruence on brand preference and satisfaction. Marketing Intelligence \& Planning, v. 19, $\mathrm{n}^{\circ} 7$, p. 482-92, 2001. 
115 JOHNE, Axel e STOREY, Chris. New service development: a review of the literature and annotated bibliography. European Journal of Marketing, v. 32, no 3/4, p. 184-251, 1998.

116 JONASH, Ronald S. e SOMMERLATTE, Tom. O valor da inovação: como as empresas mais avançadas atingem alto desempenho $\mathrm{e}$ lucratividade. Rio de Janeiro: Campus, 2001.

117 JURAN, J. M. A qualidade desde o projeto. São Paulo: Pioneira, 2002.

118 KEELING, Ralph. Gestão de projetos: uma abordagem global. São Paulo: Saraiva, 2002.

119 KODAMA, Fumio. Emerging patterns of innovation: sources of Japan's technological edge. Boston: Harvard Business School, 1995.

120 KOUDAL, Peter e COLEMAN, Gary C. Coordinating operations to enhance innovation in the global corporation. Strategy \& Leadership, v. 33, $n^{\circ} 4$, p. 20-32, 2005.

121 KREYSZIG, Erwin. Introductory mathematical statistics: principles and methods. New York: John Wiley \& Sons, 1970.

122 KRISHNAN, V. e ULRICH, Karl T. Product development decisions: a review of the literature. Management Science, v. 47, $n^{\circ} 1$, p. 1-21, Jan, 2001.

123 LANGLEY, David J.; PALS, Nico e ORTT, J. Roland. Adoption of behaviour: predicting success for major innovations. European Journal of Innovation Management, v. 8, $\mathrm{n}^{\circ}$ 1, p. 56-78, 2005.

124 LEE, Yikuan e O'CONNOR, Gina C. New product launch strategy for network effects products. Academy of Marketing Science Journal, v. 31, no 3, p. 241-55, Summer, 2003.

125 LENFLE, Sylvain. Innovations in services: the contributions of design theory. In: $11^{\text {th }}$ International Product Development Management Conference, part 2, p. 753-68, June 20-22, 2004, Dublin, Ireland. Proceedings European Institute for Advanced Studies in Management - EIASM: The University of Dublin - Trinity College, 2004.

126 LEONARD-BARTON, Dorothy. Wellsprings of knowledge: building and sustaining the sources of innovation. Boston: Harvard Business School, 1995. 
127 LEVITT, Theodore. A imaginação de marketing. $2^{\mathrm{a}}$ ed., São Paulo: Atlas, 1990.

128 LIEVENS, A. e MOENAERT, R. K. Communication flows during financial service innovation. The International Journal of Bank Marketing, v. 19, $n^{\circ}$ 2; p. 68-88, 2001.

129 LYNN, Michael e GELB, Betsy D. Identifying innovative national markets for technical consumer goods. International Marketing Review, v. $13, n^{\circ} 6$, p. 43-51, 1996.

130 MAHAJAN, Vijay e PETERSON, Robert A. Models for innovation diffusion. Newbury Park: California, 1985. ; MULLER, Eitan e SRIVASTAVA, Rajendra.

Determination of adopter categories by using innovation diffusion models. Journal of Marketing Research, vol. 27, ñ 1, p. 37-50, Feb, 1990.

132 MARSHALL, Catherine e ROSSMAN, Gretchen B. Designing qualitative research. $2^{\text {nd }}$ ed., Thousand Oaks: Sage, 1995.

133 McDANIEL, Carl e GATES, Roger. Pesquisa de marketing. São Paulo: Thomson Learning, 2003.

134 McDONALD, Heath; CORKINDALE, David e SHARP, Byron. Behavioral versus demographic predictors of early adoption: a critical analysis and comparative test. Journal of Marketing Theory and Practice, v. $11, n^{\circ} 3$, p. 84-95, Summer 2003.

135 MIZUNO, SHIGERU. Management for quality improvement - the 7 new QC tools. Cambridge: Productivity Press, 1988.

136 MONTAGUTI, Elisa; KUESTER, Sabine e ROBERTSON, Thomas S. Entry strategy for radical product innovations: a conceptual model and propositional inventory. International Journal of Research in Marketing, v. 19, p. 21-42, 2002.

137 MOREAU, C. Page; LEHMANN, Donald A. e MARKMAN, Arthur B. Entrenched knowledge structures and consumer response to new products. Journal of Marketing Research, v. 38, no 1, p. 14-29, Feb, 2001.

138 MOWEN, John C. e MINOR, Michael. Consumer behavior. $5^{\text {th }}$ ed., Upper Saddle River: Prentice-Hall, 1998. 
139 NIJSSEN, Edwin J. e FRAMBACH, Ruud T. Market research companies and new product development tools. Journal of Product \& Brand Management, v. 7, no 4, p. 305-18, 1998.

140 NOKE, Hannah e RADNOR, Zoe F. Navigating innovation: a diagnostic tool supporting the process. Journal of Manufacturing Technology Management, v. 15, $n^{\circ}$ 2, p. 172-83, 2004.

141 NONAKA, Ikujiro e TAKEUCHI, Hirotaka. Criação de conhecimento na empresa. $5^{a}$ ed., Rio de Janeiro: Campus, 1997.

142 OZER, Muammer. A survey of new product evaluation models. Journal of Product Innovation Management, v. 16, p. 77-94, 1999.

143 PALACIOS, Tomás M. B. e GONZÁLEZ, Francisco J. M. Assessing the validity of new product development techniques in Spanish firms. European Journal of Innovation Management, v. 5, no 2, p. 98-106, 2002.

144 PARASURAMAN, A. e COLBY, Charles L. Marketing para produtos inovadores - techno ready marketing. Porto Alegre: Bookman, 2002.

145 PARENTE, D. H.; PEGELS, C. Carl e SURESH, Nallan. An exploratory study of the sales-production relationship and customer satisfaction. International Journal of Operations \& Production Management, v. 22, $\mathrm{n}^{\circ}$ 9, p. 997-1013, 2002.

$146 \mathrm{PECH}$, Richard J. Memetics and innovation: profit through balanced meme management. European Journal of Innovation Management, v. 6 , no 2, p. 111-7, 2003.

147 PESTANA, Maria Helena e GAGEIRO, João N. Análise de dados para ciências sociais: a complementaridade do SPSS. $2^{\text {a }}$ ed., Lisboa: Silabo, 2000.

148 PERIN, Marcelo G.; SAMPAIO, Cláudio H. e FALEIRO, Sandro N. O impacto da orientação para o mercado e da orientação para aprendizagem sobre inovação de produto: uma comparação entre a indústria eletroeletrônica e o setor de ensino universitário de administração. RAC, v. 8, no 1, p. 79-103, jan / mar, 2004.

149 PETERS, William S. e SUMMERS, George W. Análise estatística e processo decisório. $2^{\mathrm{a}}$ ed., Rio de Janeiro: Fundação Getúlio Vargas, 1978. 
150 PLATTS, K. W. e GREGORY, M. J. Manufacturing audit in the process of strategy formulation. International Journal of Operations \& Production Management, v. 10, nº 9, p. 5-26, 1990.

151 PLSEK, Paul E. Creativity, innovation and quality. Milwaukee: ASQC, 1997.

152 PORTER, Michael E. A vantagem competitiva das nações. Rio de Janeiro: Campus, 1993.

153 Competição - on competition: estratégias competitivas essenciais. 6ª ed., Rio de Janeiro: Campus, 1999.

154 PRASNIKAR, Janez e SKERLJ, Tina. New product development process and time-to-market in the generic pharmaceutical industry. Industrial Marketing Management, 2005 (em publicação)

155 RAM, S. e JUNG, Hyung-Shik. Innovativeness in product usage: a comparison of early adopters and early majority. Psychology \& Marketing, v. 11, no 1, p. 57-67, Jan-Feb, 1994.

156 RAPAILLE, G. Clotaire. 7 secrets of marketing in a multi-cultural world. Provo: Executive Excellence Publishing, 2001.

157 RIMOLI, Celso A. O processo de desenvolvimento e administração de produtos: um estudo de casos múltiplos em empresas brasileiras de ortopedia. 2001. 242 p. Tese. (Doutorado em Administração de Empresas) - Departamento de Administração, Faculdade de Economia, Administração e Contabilidade, Universidade de São Paulo, São Paulo.

158 RINGLAND, Gill. Scenario planning: persuading operating managers to take ownership. Strategy \& Leadership, v. 31, nº 6, p. 22-8, 2003.

159 ROGERS, Everett M. Diffusion of innovations. $5^{\mathrm{a}}$ ed., New York: Free Press, 2003. Disponível em formato Adobe Acrobat eBook.

160 ROSEN, Deborah E.; SCHROEDER, Jonathan E. e PURINTON, Elizabeth F. Marketing high tech products: lessons in customer focus from the marketplace. Academy of Marketing Science Review; v. 1998; nº 6, p. 1-17, 1998.

161 ROSEN, Emmanuel. The anatomy of buzz: how to create word-ofmouth marketing. New York: Doubleday, 2000. Acessado no formato de livro eletrônico. Disponível em formato PDF. 
162 ROSENAU Jr., Milton D. e MORAN, John J. Managing the development of new products. New York: Van Nostrand Reinhold, 1993.

163 ROUSSEL, Philip A. ; SAAD, Kamal N. e BOHLIN, Nils. Pesquisa e desenvolvimento : como integrar P\&D ao plano estratégico e operacional das empresas como fator de produtividade e competitividade. São Paulo: Makron Books, 1992.

164 SAAKSJARVI, Maria. Consumer adoption of technological innovations.

European Journal of Innovation Management, v. 6, nº 2, p. 90-100, 2003. 165 SABOIA, João L. M. As causas da difusão da posse dos bens de consumo duráveis no Brasil. Rio de Janeiro: ANPEC, 1983. Apoio do PNPE - Programa Nacional de Pesquisa Econômica.

166 SCHEUING, Eberhard E. e JOHNSON, Eugene M. A proposed model for new service development. The Journal of Services Marketing, v. 3, $n^{\circ} 2$, p. 25-34, Spring, 1989.

167 SCHIFFMAN, Leon G. E KANUK, Leslie L. Comportamento do consumidor. 6a ed., Rio de Janeiro: LTC, 2000.

168 SCHOORMANS, Jan P. L. e outros Enhancing concept test validity by using expert consumers. Journal of Product Innovation Management, n. ${ }^{\circ}$ 12, p. 153-162, 1995.

169 SCHUMPETER, Joseph A. Teoria do desenvolvimento econômico: uma investigação sobre lucros, capital, crédito, juro e o ciclo econômico. São Paulo: Nova Cultural, 1988.

170 SHIBA, Shoji; GRAHAM, Alan e WALDEN, David. TQM quatro revoluções na gestão da qualidade. Porto Alegre: Bookman, 1997.

171 SHIMP, Terence A. Propaganda e promoção: aspectos complementares da comunicação integrada de marketing. $5^{\mathrm{a}}$ ed., Porto Alegre: Bookman, 2002.

172 SHTUB, Avraham, BARD, Jonathan F. e GLOBERSON, Shlomo. Project management: engineering, technology and implementation. Upper Saddle River: Prentice-Hall, 1994.

173 SIEGEL, Sidney. Estatística não-paramétrica. São Paulo: McGraw-Hill, 1975.

174 SIMONIS, Jan B. D. Institutions and the imperfect market. International Journal of Social Economics, v. 28, nº 3, p. 295-307, 2001. 
175 SLACK, Nigel: CHAMBERS, Stuart e JOHNSTON, Robert. Administração da produção, $2^{\mathrm{a}}$ ed., São Paulo: Atlas, 2002.

176 SOUTAR, Geoffrey N. e SWEENEY, Jilian C. Are there cognitive dissonance segments? Australian Journal of Management, v. 28, $n^{\circ} 3, p$. 227-49, December, 2003.

177 SPOLAORE, Enrico e WACZIARG, Romain. The diffusion of development. Stanford Graduate School of Business, Research Paper Series $n^{0}$ 1898, June, 2005.

178 STERMAN, John D. Business dynamics: systems thinking and modeling for a complex world. Boston: Irwin McGraw Hill, 2000.

179 STRANG, David e SOULE, Sarah A. Diffusion in organizations and social movements: From hybrid corn to poison pills. Annual Review of Sociology, v. 24, p. 265-90, 1998.

180 SUA, Chao-Ton; CHENB, Yung-Hsin e SHAB, D. Y. Linking innovative product development with customer knowledge: a data-mining approach. Technovation, v. xx, p. 1-12, 2005. (em publicação)

181 SVIZZERO, Serge e TISDELL, Clem. Income inequality between skilled individuals. International Journal of Social Economics, v. 30, $\mathrm{n}^{0} 11, \mathrm{p}$. 1118-30, 2003.

182 TELLIS, Gerard J.; STREMERSCH, Stefan e YIN, Eden. The international takeoff of new products: the role of economics, culture, and country innovativeness. Marketing Science, v. 22, nº 2, p. 188-208, Spring, 2003.

183 TENG, James T. C.; GROVER, Varun e GÜTTLER, Wolfgang. Information technology innovations: general diffusion patterns and its relationships to innovation characteristics. IEEE Transactions on Engineering Management, v. 49, no 1, p. 13-27, February, 2002.

184 TERWIESCH, Christian e BOHN, Roger E. Learning and process improvement during production ramp-up. International Journal of Production Economics, v. 70, p. 1-19, 2001.

185 THOMAS, Robert J. New product development: managing and forecasting for strategic success. New York: John Wiley \& Sons, 1993.

186 THOMKE, Stefan. P\&D chega aos serviços: experimentos revolucionários do Bank of América. Harvard Business Review (port): Impact Media, v. 83, nº 4, p. 55-63, abril, 2003. 
187 TIDD, Joe; BESSANT, John e PAVITT, Keith. Managing innovation: integrating technological, market and organizational change. Chichester: John Wiley \&Sons, 1997.

188 TRACEY, Michael. A holistic approach to new product development: new insights. Journal of Supply Chain Management, v. 40, no 4, p. 37-55, Fall, 2004.

189 URBAN, Glen e HAUSER, John. Designing and marketing of new products. $2^{\text {nd }}$ ed., Upper Saddle River: Prentice Hall, 1993.

190 UTTERBACK, James M. Mastering the dynamics of innovation. Boston: Harvard Business School, 1996.

191 VAN DEN BULTE, Cristophe e MOENAERT, Rudy K. The effects of R\&D team co-location on communication patterns among R\&D, marketing, and manufacturing..Management Science, v. 44, nº 11, p. S1-S18, Nov, 1998.

192 VALENTE, Thomas W. Diffusion of innovations and policy decisionmaking. Journal of Communication, v. 43, n 1, p. 30-45, 1993.

193 VEREECKE, Ann e DIERDONCK, Roland Van. The strategic role of the plant: testing Ferdows's model. International Journal of Operations \& Production Management, v. 22, nº 5, p. 492-514, 2002.

194 VERHEES, Frank J. H. M. e MEULENBERG, Matthew T. G. Market orientation, innovativeness, product innovation, and performance in small firms. Journal of Small Business Marketing, v. 42, $n^{0} 2$, p. 134-54, April, 2004.

195 VERYZER Jr., Robert W. Discontinuous innovation and the new product development process. Journal of Product Innovation Management, v. 15, p. 304-21, 1998.

196 VILLAS-BOAS, J. Miguel. Consumer learning, brand loyalty, and competition. Marketing Science, v. 23, nº 1, p. 134-45, Winter, 2004.

197 VOSS, Chris; TSIKRIKTSIS, Nikos e FROHLICH, Mark. Case research in operations management. International Journal of Operations \& Production Management, v. 22, n² 2, p. 195-219, 2002.

198 WALLD, Randy. Bonferroni correction. Winnipeg: University of Manitoba, Canada, 2003. Disponível em http://www.umanitoba.ca/centres/mchp/concept/dict/Statistics/bonferroni.htm I. Acessado em 02/11/2005. 
199 WEJNERT, Barbara. Integrating models of diffusion of innovations: A conceptual framework. Annual Review of Sociology, v. 28, p. 297-326, 2002.

200 WHEELWRIGHT, Steven C. e CLARK, Kim B. Revolutionizing product development. New York: The Free Press, 1992.

201 WILSON, Clement C., KENNEDY, Michael E. e TRAMMELL, Carmen J. Superior product development: managing the process for innovative products. Cambridge: Blackwell, 1996.

202 WOODSIDE, Arch G. e WILSON, Elizabeth J. Case study research methods for theory building. Journal of Business \& Industrial Marketing, v. 18, no 6/7, p. 493-508, 2003.

$203 \mathrm{XU}$, Jing e outros. Ethnic identity, socialization factors, and culture consumption behavior. Psychology \& Marketing, v. 21, no 2, p. 93-112, 2004.

204 YIN, Robert K. Estudos de caso: planejamento e métodos.2a ed., Porto Alegre: Bookman, 2001.

205 ZAJAC, E. J.; GOLDEN, B. R. e SHORTELL, S. M. New organizational forms for enhancing innovation: the case of internal corporate joint ventures. Management Science, v. 37, nº 2, p. 170-84, Feb, 1991. 


\section{APÊNDICE 1 - Tabulação dos dados da pesquisa}

Neste anexo estão as tabulações das pesquisas que se encontram representadas no capítulo Pesquisas de Campo.

Tabela A1.1 - Domicílios particulares permanentes com geladeira. Fonte dos dados IBGE.

\begin{tabular}{|c|c|c|c|}
\hline & $\begin{array}{l}\text { domicílios } \\
\text { com } \\
\text { geladeira no } \\
\text { Brasil }\end{array}$ & $\begin{array}{c}\text { total de } \\
\text { domicilios } \\
\text { no Brasil }\end{array}$ & $\begin{array}{l}\text { Porcentual } \\
\text { dos domicílios }\end{array}$ \\
\hline 1960 & 1.570 .924 & 13.497 .823 & $11,64 \%$ \\
\hline 1970 & 4.594 .920 & 17.628 .699 & $26,06 \%$ \\
\hline 1980 & 12.697 .296 & 25.210 .639 & $50,36 \%$ \\
\hline 1990 & 25.296.597 & 35.578 .857 & $71,10 \%$ \\
\hline 2000 & 37.361 .071 & 44.721 .434 & $83,54 \%$ \\
\hline
\end{tabular}

Tabela A1.2 - Domicílios particulares permanentes com aparelhos de rádio. Fonte dos dados - IBGE.

\begin{tabular}{|rrrr|}
\hline & $\begin{array}{c}\text { domicílios cl } \\
\text { aparelhos } \\
\text { de rádio no } \\
\text { Brasil }\end{array}$ & $\begin{array}{c}\text { total de } \\
\text { domicílios } \\
\text { no Brasil }\end{array}$ & $\begin{array}{c}\text { porcentual } \\
\text { dos domicílios }\end{array}$ \\
1960 & 4.776 .300 & 13.497 .823 & $35,39 \%$ \\
1970 & 10.386 .763 & 17.628 .699 & $58,92 \%$ \\
1980 & 19.203 .907 & 25.210 .639 & $76,17 \%$ \\
1990 & 29.993 .272 & 35.578 .857 & $84,30 \%$ \\
\hline 2000 & 39.351 .595 & 44.721 .434 & $87,99 \%$ \\
\hline
\end{tabular}

Tabela A1.3 - Domicílios particulares permanentes com aparelhos de TV. Fonte dos dados - IBGE.

\begin{tabular}{|rrrr|}
\hline & $\begin{array}{c}\text { domicilios of } \\
\text { aparelhos de } \\
\text { TV no Brasil }\end{array}$ & $\begin{array}{c}\text { total de } \\
\text { domicilios } \\
\text { no Brasil }\end{array}$ & $\begin{array}{c}\text { porcentual dos } \\
\text { domicílios }\end{array}$ \\
1960 & 621.919 & 13.497 .823 & $4,61 \%$ \\
1970 & 4.250 .404 & 17.628 .699 & $24,11 \%$ \\
1980 & 14.142 .924 & 25.210 .639 & $56,10 \%$ \\
1990 & 26.226 .212 & 35.578 .857 & $73,71 \%$ \\
2000 & 38.906 .707 & 44.721 .434 & $87,00 \%$ \\
\hline
\end{tabular}


Tabela A1.4 - Correlação de Pearson da difusão de TVs, geladeiras, rádios, canalização interna de água e filtros de água. (análise feita com o software SPSS).

\begin{tabular}{|c|c|c|c|c|c|c|}
\hline & & geladeiras & $\begin{array}{l}\text { rede interna } \\
\text { de água }\end{array}$ & TVs & radio & $\begin{array}{c}\text { filltros de } \\
\text { água }\end{array}$ \\
\hline \multirow[t]{3}{*}{ geladeiras } & $\begin{array}{r}\text { Pearson } \\
\text { Correlation }\end{array}$ & 1 &, $996^{\star *}$ &, $995^{\star \star}$ &, $957^{\star}$ &, $928^{\star}$ \\
\hline & Sig. (2-tailed) & &, 000 &, 000 & 010 & ,023 \\
\hline & $\mathbf{N}$ & 5 & 5 & 5 & 5 & 5 \\
\hline \multirow[t]{3}{*}{$\begin{array}{r}\text { rede interna } \\
\text { de água }\end{array}$} & $\begin{array}{l}\text { Pearson } \\
\text { Correlation }\end{array}$ &, $996 * *$ & 1 & $993 * *$ &, $957^{\star}$ & $943^{*}$ \\
\hline & Sig. (2-tailed) & ,000 & , & ,001 & ,011 & ,016 \\
\hline & $\mathrm{N}$ & 5 & 5 & 5 & 5 & 5 \\
\hline \multirow[t]{3}{*}{ TVs } & $\begin{array}{r}\text { Pearson } \\
\text { Correlation }\end{array}$ &, $995^{\star *}$ &, $993^{\star *}$ & 1 &, $974^{\star \star}$ & ,956* \\
\hline & Sig. (2-tailed) &, 000 & ,001 & &, 005 & ,011 \\
\hline & $\mathbf{N}$ & 5 & 5 & 5 & 5 & 5 \\
\hline \multirow[t]{3}{*}{ radio } & $\begin{array}{l}\text { Pearson } \\
\text { Correlation }\end{array}$ &, $957^{*}$ &, $957^{*}$ & $974^{* \star}$ & 1 & $969 * *$ \\
\hline & Sig. (2-tailed) & ,010 & ,011 & ,005 & & ,007 \\
\hline & $\mathrm{N}$ & 5 & 5 & 5 & 5 & 5 \\
\hline \multirow[t]{3}{*}{$\begin{array}{r}\text { filtros de } \\
\text { água }\end{array}$} & $\begin{array}{r}\text { Pearson } \\
\text { Correlation }\end{array}$ & ,928* & ,943* & ,956* &, $969 * \star$ & 1 \\
\hline & Sig. (2-tailed) & 023 & 016 & 011 & 007 & \\
\hline & N & 5 & 5 & 5 & 5 & 5 \\
\hline
\end{tabular}

** Correlation is significant at the 0.01 level (2-tailed). * Correlation is significant at the 0.05 level (2-tailed).

Tabela A1.5 - Domicílios particulares permanentes com canalização interna de água. Fonte dos dados - IBGE.

\begin{tabular}{|r|r|}
\hline & $\begin{array}{l}\text { Brasil cl } \\
\text { canalização } \\
\text { interna de } \\
\text { água* }\end{array}$ \\
\hline 1940 & $13,00 \%$ \\
1950 & $15,60 \%$ \\
1960 & $24,30 \%$ \\
1970 & $33,20 \%$ \\
1980 & $56,00 \%$ \\
1990 & $66,44 \%$ \\
2000 & $77,95 \%$ \\
\hline
\end{tabular}

*Somente foi possível obter dados porcentuais do IBGE para os censos de 1940 e 1950.

Tabela A1.6 - Domicílios particulares permanentes com filtro de água. Fonte dos dados IBGE.

\begin{tabular}{|cccc|}
\hline & $\begin{array}{c}\text { domicílios } \\
\text { c/ filtros de } \\
\text { água no } \\
\text { Brasil** }\end{array}$ & $\begin{array}{c}\text { total de } \\
\text { domicílios } \\
\text { no Brasil }\end{array}$ & $\begin{array}{c}\text { porcentual } \\
\text { dos } \\
\text { domicílios }\end{array}$ \\
\hline 1960 & 1.414 .996 & 13.497 .823 & $10,48 \% *$ \\
\hline 1970 & 4.137 .179 & 17.628 .699 & $23,47 \%$ \\
\hline 1981 & 13.466 .628 & 25.210 .639 & $53,42 \%$ \\
\hline 1991 & 19.946 .012 & 35.578 .857 & $56,06 \%$ \\
\hline 2001 & 24.495 .094 & 44.721 .434 & $54,77 \%$ \\
\hline
\end{tabular}

* dados de 1960 foram estimados. ** nos anos de 1980 e 2000 não foram pesquisados. 
Tabela A1.7 - Difusão de aparelhos celulares móveis no Brasil desde seu início. Fonte dos dados - Anatel.

\begin{tabular}{|c|c|c|c|c|c|c|c|c|c|}
\hline $\begin{array}{c}\text { Cresc. } \\
(\%)\end{array}$ & Banda B & $\begin{array}{c}\text { Cresc. } \\
(\%)\end{array}$ & Banda D & $\begin{array}{c}\text { Cresc. } \\
(\%)\end{array}$ & $\begin{array}{c}\text { Banda } \\
\text { E }\end{array}$ & $\begin{array}{c}\text { Cresc. } \\
(\%)\end{array}$ & $\begin{array}{c}\text { Banda A } \\
+B+D \\
+E\end{array}$ & $\begin{array}{c}\text { Cresc. } \\
\text { Total } \\
(\%)\end{array}$ & \\
\hline 0 & 0 & 0 & 0 & 0 & 0 & 0 & 667 & 0 & 1990 \\
\hline 904,5 & 0 & 0 & 0 & 0 & 0 & 0 & 6.700 & 904,5 & 1991 \\
\hline 373,5 & 0 & 0 & 0 & 0 & 0 & 0 & 31.726 & 373,5 & 1992 \\
\hline 503,3 & 0 & 0 & 0 & 0 & 0 & 0 & 191.402 & 503,3 & 1993 \\
\hline 294,6 & 0 & 0 & 0 & 0 & 0 & 0 & 755.224 & 294,6 & 1994 \\
\hline 87,6 & 0 & 0 & 0 & 0 & 0 & 0 & 1.416 .500 & 87,6 & 1995 \\
\hline 93,8 & 0 & 0 & 0 & 0 & 0 & 0 & 2.744 .549 & 93,8 & 1996 \\
\hline 65,2 & 15.684 & 0 & 0 & 0 & 0 & 0 & 4.550 .175 & 65,8 & 1997 \\
\hline 34,5 & 1.268 .665 & $7.988,90$ & 0 & 0 & 0 & 0 & 7.368.218 & 61,9 & 1998 \\
\hline 76,4 & 4.275 .927 & 237 & 0 & 0 & 0 & 0 & 15.032 .698 & 104 & 1999 \\
\hline 45,5 & 7.535 .291 & 76,2 & 0 & 0 & 0 & 0 & 23.188 .171 & 54,3 & 2000 \\
\hline 23,2 & 9.467 .908 & 25,6 & 0 & 0 & 0 & 0 & 28.745 .769 & 24 & 2001 \\
\hline 15,1 & 11.006 .739 & 16,3 & 1.609 .102 & 0 & 83.653 & 0 & 34.880 .967 & 21,3 & 2002 \\
\hline 19,2 & 13.501 .057 & 22,6 & 5.673 .703 & 252,6 & 749.741 & 796,2 & 46.373 .266 & 32,9 & 2003 \\
\hline 23,79 & 19.145 .011 & 41,8 & 11.304 .627 & 99,25 & 2.413 .947 & 321,97 & 65.605 .577 & 141,47 & 2004 \\
\hline 7,52 & 22.188 .934 & 15,9 & 14.097 .877 & 24,71 & 4.028 .002 & 66,86 & 75.517 .674 & 15,11 & 2005 \\
\hline
\end{tabular}

Fonte Anatel em dezembro de 2005.

Tabela A1.8 - Processo de difusão e abandono de televisores preto e branco nos domicílios permanentes no Brasil. Fonte dos dados - IBGE.

\begin{tabular}{|rrrr|}
\hline & $\begin{array}{c}\text { domicilios } \\
\text { cl TVs } \\
\text { P\&B no } \\
\text { Brasil }\end{array}$ & $\begin{array}{c}\text { total de } \\
\text { domicílios } \\
\text { no Brasil }\end{array}$ & $\begin{array}{c}\text { porcentual } \\
\text { domicilios } \\
\text { domilo }\end{array}$ \\
\hline 1960 & 621.919 & 13.497 .823 & $4,61 \%$ \\
\hline 1970 & 4.250 .404 & 17.628 .699 & $24,11 \%$ \\
\hline 1972 & 5.863 .444 & 18.048 .039 & $32,49 \%$ \\
\hline 1976 & 9.356 .382 & 21.789 .855 & $42,94 \%$ \\
\hline 1980 & 11.197 .039 & 25.210 .639 & $44,41 \%$ \\
\hline 1991 & 12.560 .042 & 34.743 .433 & $36,15 \%$ \\
\hline 1992 & 9.808 .436 & 36.035 .265 & $27,22 \%$ \\
\hline 1993 & 9.462 .668 & 36.957 .963 & $25,60 \%$ \\
\hline 1995 & 7.855 .639 & 38.969 .714 & $20,16 \%$ \\
\hline 1996 & 5.997 .482 & 39.745 .768 & $15,09 \%$ \\
\hline 1997 & 4.917 .167 & 40.644 .623 & $12,10 \%$ \\
\hline 1998 & 3.921 .088 & 41.839 .703 & $9,37 \%$ \\
\hline 1999 & 3.449 .700 & 42.851 .326 & $8,05 \%$ \\
\hline 2001 & 2.818 .625 & 46.507 .196 & $6,06 \%$ \\
\hline 2003 & 2.036 .218 & 49.142 .171 & $4,14 \%$ \\
\hline 2004 & 1.753 .221 & 51.752 .528 & $3,39 \%$ \\
\hline
\end{tabular}


Tabela A1.9 - Difusão dos aparelhos de rádio nos domicílios permanentes no Brasil. Fonte dos dados - IBGE.

\begin{tabular}{|c|c|c|c|}
\hline & $\begin{array}{l}\text { Brasil total } \\
\text { rádios }\end{array}$ & $\begin{array}{l}\text { Urbana cl } \\
\text { rádios } \\
\text { Brasil }\end{array}$ & $\begin{array}{l}\text { Rural cl } \\
\text { rádios } \\
\text { Brasil }\end{array}$ \\
\hline 1960 & $35,40 \%$ & $61,10 \%$ & $12,10 \%$ \\
\hline 1970 & $58,90 \%$ & $72,40 \%$ & $40,10 \%$ \\
\hline 1980 & $76,17 \%$ & $79,08 \%$ & $69,22 \%$ \\
\hline 1991 & $82,69 \%$ & $86,08 \%$ & $70,53 \%$ \\
\hline 2001 & $88,05 \%$ & $89,03 \%$ & $82,40 \%$ \\
\hline 2004 & $87,78 \%$ & $88,99 \%$ & $81,15 \%$ \\
\hline
\end{tabular}

Tabela A1.10 - Difusão de televisores nos domicílios permanentes no Brasil. Fonte dos dados - IBGE.

\begin{tabular}{|c|c|c|c|}
\hline & $\begin{array}{l}\text { Brasil total } \\
\text { televisores }\end{array}$ & $\begin{array}{l}\text { Urbana cl } \\
\text { televisores } \\
\text { Brasil }\end{array}$ & $\begin{array}{l}\text { Rural cl } \\
\text { televisores } \\
\text { Brasil }\end{array}$ \\
\hline 1960 & $4,60 \%$ & $9,50 \%$ & $0,30 \%$ \\
\hline 1970 & $36,55 \%$ & $40,23 \%$ & $1,58 \%$ \\
\hline 1980 & $54,92 \%$ & $73,09 \%$ & $14,68 \%$ \\
\hline 1991 & $79,58 \%$ & $92,39 \%$ & $33,66 \%$ \\
\hline 2001 & $89,05 \%$ & $93,27 \%$ & $64,77 \%$ \\
\hline 2004 & $90,30 \%$ & $95,03 \%$ & $69,15 \%$ \\
\hline
\end{tabular}

Tabela A1.11 - Difusão de geladeiras nos domicílios permanentes no Brasil. Fonte dos dados - IBGE.

\begin{tabular}{|c|c|c|c|}
\hline & $\begin{array}{l}\text { Brasil total } \\
\text { geladeiras }\end{array}$ & $\begin{array}{l}\text { Urbana cl } \\
\text { geladeiras } \\
\text { Brasil }\end{array}$ & $\begin{array}{l}\text { Rural cl } \\
\text { geladeiras } \\
\text { Brasil }\end{array}$ \\
\hline 1960 & $11,60 \%$ & $23,30 \%$ & $1,30 \%$ \\
\hline 1970 & $26,10 \%$ & $42,50 \%$ & $3,20 \%$ \\
\hline 1980 & $49,51 \%$ & $66,19 \%$ & $12,58 \%$ \\
\hline 1991 & $68,82 \%$ & $79,68 \%$ & $29,86 \%$ \\
\hline 2001 & $85,13 \%$ & $90,34 \%$ & $55,19 \%$ \\
\hline 2004 & $87,40 \%$ & $92,10 \%$ & $61,52 \%$ \\
\hline
\end{tabular}

Tabela A1.12 - Difusão da energia elétrica da rede geral de energia para os domicílios permanentes no Brasil. Fonte dos dados - IBGE.

\begin{tabular}{|c|c|c|c|}
\hline & $\begin{array}{l}\text { Brasil cl } \\
\text { instalação } \\
\text { elétrica }\end{array}$ & $\begin{array}{l}\text { Urbana cl } \\
\text { instalação } \\
\text { elétrica } \\
\text { Brasil }\end{array}$ & $\begin{array}{l}\text { Rural cl } \\
\text { instalação } \\
\text { elétrica } \\
\text { Brasil }\end{array}$ \\
\hline 1940 & $16,70 \%$ & $39,80 \%$ & $3,10 \%$ \\
\hline 1950 & $24,60 \%$ & $60,00 \%$ & $3,60 \%$ \\
\hline 1960 & $38,50 \%$ & $72,40 \%$ & $8,40 \%$ \\
\hline 1970 & $47,50 \%$ & $75,50 \%$ & $8,40 \%$ \\
\hline 1980 & $68,50 \%$ & $88,20 \%$ & $21,44 \%$ \\
\hline 1991 & $86,87 \%$ & $97,31 \%$ & $49,42 \%$ \\
\hline 2001 & $96,01 \%$ & $99,21 \%$ & $77,65 \%$ \\
\hline 2004 & $96,84 \%$ & $99,58 \%$ & $81,77 \%$ \\
\hline
\end{tabular}


Tabela A1.13 - Difusão da canalização interna de água nos domicílios permanentes no Brasil. Fonte dos dados - IBGE.

\begin{tabular}{|c|c|c|c|}
\hline & $\begin{array}{l}\text { Brasil cl } \\
\text { canalização } \\
\text { interna }\end{array}$ & $\begin{array}{l}\text { Urbana cl } \\
\text { canalização } \\
\text { interna } \\
\text { Brasil }\end{array}$ & $\begin{array}{l}\text { Rural cl } \\
\text { canalização } \\
\text { interna } \\
\text { Brasil }\end{array}$ \\
\hline 1940 & $13,00 \%$ & $38,20 \%$ & $1,20 \%$ \\
\hline 1950 & $15,60 \%$ & $39,50 \%$ & $1,40 \%$ \\
\hline 1960 & $24,30 \%$ & $47,80 \%$ & $3,40 \%$ \\
\hline 1970 & $33,20 \%$ & $52,60 \%$ & $6,20 \%$ \\
\hline 1980 & $56,00 \%$ & $71,89 \%$ & $18,07 \%$ \\
\hline 1990 & $66,44 \%$ & $82,72 \%$ & $12,94 \%$ \\
\hline 2000 & $77,95 \%$ & $89,76 \%$ & $18,06 \%$ \\
\hline
\end{tabular}

Tabela A1.14 - Difusão de filtros de água nos domicílios permanentes no Brasil. Fonte dos dados - IBGE.

\begin{tabular}{|rrrr|}
\hline & $\begin{array}{c}\text { Filtros de } \\
\text { água no } \\
\text { Brasil }\end{array}$ & $\begin{array}{c}\text { Filtros de } \\
\text { água na } \\
\text { área } \\
\text { urbana }\end{array}$ & $\begin{array}{c}\text { Filtros de } \\
\text { água na } \\
\text { área rural }\end{array}$ \\
\hline 1981 & $51,74 \%$ & $58,65 \%$ & $32,32 \%$ \\
\hline 1985 & $54,54 \%$ & $60,44 \%$ & $36,27 \%$ \\
\hline 1990 & $57,18 \%$ & $62,38 \%$ & $40,11 \%$ \\
\hline 1995 & $57,82 \%$ & $61,22 \%$ & $41,36 \%$ \\
\hline 1999 & $55,63 \%$ & $58,54 \%$ & $42,88 \%$ \\
\hline 2004 & $51,35 \%$ & $53,19 \%$ & $41,21 \%$ \\
\hline
\end{tabular}

Tabela A1.15 - Difusão de televisores por classe de renda nos domicílios no Brasil. Fonte dos dados - IBGE.

\begin{tabular}{|c|c|c|c|c|c|}
\hline & \multicolumn{5}{|c|}{ Classes de renda em salários mínimos } \\
\hline & Até 1sm & $1-2 \mathrm{sm}$ & $2-5 s m$ & $5-10 \mathrm{sm}$ & mais $10 \mathrm{sm}$ \\
\hline 1972 & $4,08 \%$ & $21,45 \%$ & $53,55 \%$ & $79,58 \%$ & $88,84 \%$ \\
\hline 1980 & $13,17 \%$ & $36,41 \%$ & $67,70 \%$ & $88,79 \%$ & $95,03 \%$ \\
\hline 1988 & $27,27 \%$ & $49,97 \%$ & $77,07 \%$ & $91,77 \%$ & $97,76 \%$ \\
\hline 1993 & $38,08 \%$ & $60,14 \%$ & $82,01 \%$ & $94,29 \%$ & $98,14 \%$ \\
\hline 1995 & $45,18 \%$ & $60,78 \%$ & $81,83 \%$ & $94,76 \%$ & $98,52 \%$ \\
\hline 1998 & $58,94 \%$ & $75,25 \%$ & $90,05 \%$ & $97,27 \%$ & $99,23 \%$ \\
\hline 2001 & $66,58 \%$ & $81,35 \%$ & $92,62 \%$ & $97,79 \%$ & $99,28 \%$ \\
\hline 2004 & $70,28 \%$ & $84,42 \%$ & $93,71 \%$ & $98,22 \%$ & $99,47 \%$ \\
\hline
\end{tabular}

Tabela A1.16 - Abandono de TVs P\&B por classe de renda nos domicílios no Brasil. Fonte dos dados - IBGE.

\begin{tabular}{|rrrrrr}
\hline Ano & Até 1 SM & \multicolumn{5}{c|}{ 1-2 SM } & $\mathbf{2 - 5}$ SM & $\mathbf{5 - 1 0 ~ S M ~}$ & mais 10 SM \\
\hline $\mathbf{1 9 8 0}$ & $12,69 \%$ & $34,59 \%$ & $59,96 \%$ & $63,79 \%$ & $51,54 \%$ \\
\hline $\mathbf{1 9 8 8}$ & $21,40 \%$ & $38,67 \%$ & $50,21 \%$ & $42,02 \%$ & $33,00 \%$ \\
\hline $\mathbf{1 9 9 1}$ & $26,87 \%$ & $41,22 \%$ & $43,99 \%$ & $34,37 \%$ & $27,60 \%$ \\
\hline $\mathbf{1 9 9 3}$ & $26,37 \%$ & $37,43 \%$ & $33,10 \%$ & $15,71 \%$ & $3,93 \%$ \\
\hline $\mathbf{1 9 9 5}$ & $27,21 \%$ & $33,41 \%$ & $28,17 \%$ & $12,41 \%$ & $2,70 \%$ \\
\hline $\mathbf{1 9 9 8}$ & $22,35 \%$ & $22,59 \%$ & $17,71 \%$ & $9,64 \%$ & $2,74 \%$ \\
\hline $\mathbf{2 0 0 1}$ & $16,44 \%$ & $11,24 \%$ & $4,59 \%$ & $1,18 \%$ & $0,26 \%$ \\
\hline $\mathbf{2 0 0 3}$ & $11,79 \%$ & $7,31 \%$ & $2,66 \%$ & $0,53 \%$ & $0,00 \%$ \\
\hline
\end{tabular}


Tabela A1.17 - Difusão de geladeiras por classe de renda nos domicílios no Brasil. Fonte dos dados - IBGE.

\begin{tabular}{lrrrrrrrrr|}
$\begin{array}{l}\text { Classes } \\
\text { de renda } \\
\text { em SM }\end{array}$ & $\mathbf{1 9 7 2}$ & $\mathbf{1 9 8 0}$ & $\mathbf{1 9 8 3}$ & $\mathbf{1 9 8 8}$ & $\mathbf{1 9 9 1}$ & $\mathbf{1 9 9 5}$ & $\mathbf{1 9 9 8}$ & $\mathbf{2 0 0 1}$ & $\mathbf{2 0 0 4}$ \\
até 1SM & $4,42 \%$ & $9,51 \%$ & $16,26 \%$ & $23,27 \%$ & $30,07 \%$ & $33,65 \%$ & $43,89 \%$ & $52,42 \%$ & $59,45 \%$ \\
\hline $\mathbf{1 < S M < 2}$ & $20,21 \%$ & $26,09 \%$ & $34,16 \%$ & $43,25 \%$ & $53,64 \%$ & $46,63 \%$ & $61,27 \%$ & $73,13 \%$ & $78,72 \%$ \\
\hline $\mathbf{2}<\mathbf{S M}<5$ & $51,93 \%$ & $59,23 \%$ & $69,09 \%$ & $73,25 \%$ & $79,59 \%$ & $73,92 \%$ & $84,97 \%$ & $90,69 \%$ & $92,52 \%$ \\
\hline $\mathbf{5}<$ SM $<10$ & $83,17 \%$ & $85,96 \%$ & $91,44 \%$ & $91,85 \%$ & $93,79 \%$ & $92,90 \%$ & $97,07 \%$ & $97,98 \%$ & $98,35 \%$ \\
\hline $\mathbf{1 0 S M}$ & $95,07 \%$ & $95,87 \%$ & $98,26 \%$ & $98,27 \%$ & $98,12 \%$ & $98,71 \%$ & $99,22 \%$ & $99,44 \%$ & $99,57 \%$ \\
\hline
\end{tabular}

Tabela A1.18 - Difusão de aparelhos de rádio por classe de renda nos domicílios no Brasil. Fonte IBGE.

\begin{tabular}{|c|c|c|c|c|c|}
\hline \multirow[b]{2}{*}{ Ano } & \multicolumn{5}{|c|}{ Classes de renda em salários mínimos** } \\
\hline & Até 1 SM & 1-2 SM & 2-5 SM & 5-10 SM & mais $10 \mathrm{SM}$ \\
\hline 1972* & $53,21 \%$ & $67,63 \%$ & $78,24 \%$ & $88,23 \%$ & $93,68 \%$ \\
\hline 1980 & $57,31 \%$ & $69,39 \%$ & $80,37 \%$ & $88,96 \%$ & $94,31 \%$ \\
\hline 1988 & $60,18 \%$ & $71,78 \%$ & $83,27 \%$ & $92,46 \%$ & $97,22 \%$ \\
\hline 1991 & $63,97 \%$ & $76,58 \%$ & $87,52 \%$ & $94,15 \%$ & $97,19 \%$ \\
\hline 1995 & $70,35 \%$ & $79,11 \%$ & $89,27 \%$ & $95,13 \%$ & $98,03 \%$ \\
\hline 1998 & $74,61 \%$ & $83,98 \%$ & $90,92 \%$ & $95,95 \%$ & $98,10 \%$ \\
\hline 2001 & $73,16 \%$ & $82,01 \%$ & $89,58 \%$ & $94,65 \%$ & $97,07 \%$ \\
\hline 2004 & $72,62 \%$ & $81,96 \%$ & $89,87 \%$ & $95,00 \%$ & $97,17 \%$ \\
\hline \multicolumn{6}{|c|}{ * Os dados foram obtidos pelo cruzamento de dados de diversas tabelas. } \\
\hline \multicolumn{6}{|c|}{ **Rádios não foram pesquisados no período 1980 até 1988.} \\
\hline \multicolumn{6}{|c|}{$\begin{array}{l}\text { Tabela A1.19 - Difusão de sistemas internos de canalização de água por classe de re } \\
\text { nos domicílios no Brasil. Fonte IBGE. }\end{array}$} \\
\hline & \multicolumn{5}{|c|}{ Classes de renda em salários mínimos } \\
\hline Ano & Até 1 SM & 1-2 SM & 2-5 SM & 5-10 SM & mais $10 \mathrm{SM}$ \\
\hline 1970 & $7,25 \%$ & $26,61 \%$ & $53,32 \%$ & $71,11 \%$ & $89,28 \%$ \\
\hline 1978 & $13,62 \%$ & $28,74 \%$ & $57,56 \%$ & $84,32 \%$ & $95,67 \%$ \\
\hline 1980 & $18,88 \%$ & $35,82 \%$ & $63,72 \%$ & $87,14 \%$ & $96,15 \%$ \\
\hline 1983 & $24,59 \%$ & $41,78 \%$ & $71,42 \%$ & $91,06 \%$ & $97,83 \%$ \\
\hline 1988 & $32,44 \%$ & $50,14 \%$ & $76,08 \%$ & $91,99 \%$ & $98,09 \%$ \\
\hline 1991 & $41,31 \%$ & $62,43 \%$ & $83,57 \%$ & $95,02 \%$ & $98,62 \%$ \\
\hline 1995 & $46,51 \%$ & $59,49 \%$ & $79,76 \%$ & $94,66 \%$ & $98,93 \%$ \\
\hline 1998 & $54,87 \%$ & $67,35 \%$ & $86,86 \%$ & $97,12 \%$ & $99,31 \%$ \\
\hline 2001 & $61,41 \%$ & $77,53 \%$ & $91,14 \%$ & $98,05 \%$ & $99,49 \%$ \\
\hline 2004 & $68,63 \%$ & $81,88 \%$ & $92,91 \%$ & $98,57 \%$ & $99,61 \%$ \\
\hline
\end{tabular}

Tabela A1.20 - Difusão dos filtros de água nos domicílios permanentes no Brasil. Fonte IBGE.

\begin{tabular}{|rrrrrr}
\hline \multicolumn{7}{|c|}{ Ano } & Até 1 SM & 1-2 SM & 2-5 SM & $\mathbf{5 - 1 0 ~ S M ~}$ & mais 10 SM \\
11972 & $9,77 \%$ & $25,92 \%$ & $41,57 \%$ & $58,91 \%$ & $70,75 \%$ \\
\hline 1983 & $30,61 \%$ & $41,32 \%$ & $53,75 \%$ & $67,82 \%$ & $82,67 \%$ \\
\hline 1988 & $36,05 \%$ & $44,55 \%$ & $54,76 \%$ & $66,33 \%$ & $81,55 \%$ \\
\hline 1991 & $39,99 \%$ & $48,44 \%$ & $56,58 \%$ & $67,18 \%$ & $79,26 \%$ \\
\hline 1993 & $41,06 \%$ & $49,02 \%$ & $57,22 \%$ & $66,47 \%$ & $78,28 \%$ \\
\hline 1995 & $41,09 \%$ & $46,01 \%$ & $53,35 \%$ & $63,03 \%$ & $76,04 \%$ \\
\hline 1998 & $41,06 \%$ & $45,75 \%$ & $53,02 \%$ & $62,22 \%$ & $72,91 \%$ \\
\hline 2001 & $42,64 \%$ & $45,23 \%$ & $51,62 \%$ & $58,27 \%$ & $66,01 \%$ \\
\hline 2004 & $39,78 \%$ & $45,41 \%$ & $51,25 \%$ & $57,30 \%$ & $63,76 \%$ \\
\hline & & & & & \\
\hline
\end{tabular}


Tabela A1.21 - Atualização do salário mínimo desde 1980 pelo IPC-SP FIPE e INPC do IBGE. Fonte Ministério do Trabalho - Brasil.*

\begin{tabular}{|c|c|c|c|c|c|}
\hline Ano & $\begin{array}{l}\text { Correção } \\
\text { IPC-SP FIPE }\end{array}$ & $\begin{array}{l}\text { Correção } \\
\text { INPC }\end{array}$ & $\begin{array}{c}\text { Valor } \\
\text { histórico }\end{array}$ & $\begin{array}{l}\text { Mês do } \\
\text { reajuste }\end{array}$ & Moeda \\
\hline 1959 & 305,53 & & $6.000,00$ & jan/59 & Cruzeiros \\
\hline 1960 & 283,83 & & $9.600,00$ & out $/ 60$ & Cruzeiros \\
\hline 1961 & 280,83 & & $13.440,00$ & out/61 & Cruzeiros \\
\hline 1963 & 244,23 & & $21.000,00$ & jan/63 & Cruzeiros \\
\hline 1964 & 254,01 & & $42.000,00$ & fev/64 & Cruzeiros \\
\hline 1965 & 207,96 & & $66.000,00$ & mar/65 & Cruzeiros \\
\hline 1966 & 181,75 & & $84.000,00$ & mar/66 & Cruzeiros \\
\hline 1967 & 168,77 & & 105,00 & mar/67 & Cruzeiros novos \\
\hline 1968 & 164,82 & & 129,60 & mar/68 & Cruzeiros novos \\
\hline 1969 & 157,06 & & 156,00 & mai/69 & Cruzeiros novos \\
\hline 1970 & 155,01 & & 187,20 & $\mathrm{mai} / 70$ & Cruzeiros novos \\
\hline 1971 & 154,49 & & 225,60 & mai/71 & Cruzeiros \\
\hline 1972 & 156,25 & & 268,80 & mai/72 & Cruzeiros \\
\hline 1973 & 154,81 & & 312,00 & $\mathrm{mai} / 73$ & Cruzeiros \\
\hline 1974 & 151,53 & & 376,80 & mai/74 & Cruzeiros \\
\hline 1974 & 147,05 & & 415,20 & dez/74 & Cruzeiros \\
\hline 1975 & 169,14 & & 532,80 & mai/75 & Cruzeiros \\
\hline 1976 & 179,86 & & 768,00 & $\mathrm{mai} / 76$ & Cruzeiros \\
\hline 1977 & 181,89 & & $1.106,40$ & mai/77 & Cruzeiros \\
\hline 1978 & 194,20 & & $1.560,00$ & mai/78 & Cruzeiros \\
\hline 1979 & 191,36 & 363,62 & $2.268,00$ & mai/79 & Cruzeiros \\
\hline 1979 & 193,17 & 367,94 & $2.932,80$ & nov/79 & Cruzeiros \\
\hline 1980 & 205,60 & 374,83 & $4.149,60$ & $\mathrm{mai} / 80$ & Cruzeiros \\
\hline 1981 & 210,58 & 370,49 & $8.484,80$ & $\mathrm{mai} / 81$ & Cruzeiros \\
\hline 1982 & 222,68 & 375,60 & $16.608,00$ & $\mathrm{mai} / 82$ & Cruzeiros \\
\hline 1983 & 216,99 & 368,48 & $34.776,00$ & $\mathrm{mai} / 83$ & Cruzeiros \\
\hline 1984 & 220,39 & 345,65 & $97.176,00$ & $\mathrm{mai} / 84$ & Cruzeiros \\
\hline 1985 & 261,47 & 373,66 & $333.120,00$ & $\mathrm{mai} / 85$ & Cruzeiros \\
\hline 1986 & 222,59 & 304,64 & 804,00 & $\mathrm{mar} / 86$ & Cruzados \\
\hline 1987 & 165,38 & 232,45 & $2.400,00$ & set/87 & Cruzados \\
\hline 1988 & 217,72 & 285,66 & $18.960,00$ & set/88 & Cruzados \\
\hline 1989 & 261,51 & 307,36 & 249,48 & set/89 & Novos cruzados \\
\hline 1990 & 162,58 & 189,76 & $6.056,31$ & set/90 & Cruzeiros \\
\hline 1991 & 251,71 & 276,18 & $42.000,00$ & set/91 & Cruzeiros \\
\hline 1992 & 272,01 & 301,62 & $522.186,94$ & set/92 & Cruzeiros \\
\hline 1993 & 274,36 & 302,76 & $9.606,00$ & set/93 & Cruzeiros \\
\hline 1994 & 167,87 & 188,85 & 70,00 & set/94 & Cruzeiros \\
\hline 1995 & 206,88 & 231,57 & 100,00 & mai/95 & Reais \\
\hline 1996 & 193,04 & 219,38 & 112,00 & mai/96 & Reais \\
\hline 1997 & 191,67 & 217,23 & 120,00 & mai/97 & Reais \\
\hline 1998 & 201,30 & 226,02 & 130,00 & mai/98 & Reais \\
\hline 1999 & 209,22 & 227,62 & 136,00 & mai/99 & Reais \\
\hline 2000 & 218,93 & 239,89 & 151,00 & $\mathrm{abr} / 00$ & Reais \\
\hline 2001 & 248,96 & 269,09 & 180,00 & $\mathrm{abr} / 01$ & Reais \\
\hline 2002 & 258,48 & 272,49 & 200,00 & $\mathrm{abr} / 02$ & Reais \\
\hline 2003 & 272,39 & 275,84 & 240,00 & $\mathrm{abr} / 03$ & Reais \\
\hline 2004 & 281,63 & 279,12 & 260,00 & mai/04 & Reais \\
\hline 2005 & 300,00 & 300,00 & 300,00 & mai/05 & Reais \\
\hline
\end{tabular}

* a correção foi feita utilizando-se a calculadora do cidadão na página eletrônica do BACEN Brasil. 


\section{APÊNDICE 2 - Preços de diferentes produtos ao longo do tempo}

Neste anexo estão as tabulações das pesquisas que se encontram representadas no capítulo Pesquisas de Campo no tocante a preços.

Os preços estão colocados em valores históricos, em quantidades de salários mínimos, em valores de novembro de 2005 corrigidos pelo salário mínimo vigente em 2005 e corrigidos pelo índice IPC-SP da FIPE. Nas tabelas encontram-se também citadas as fontes e localização, a loja que anunciou o produto e quando possível, a descrição do produto e fabricante. As tabelas estão classificadas pelo código do produto e produto, conforme codificação mostrada na tabela Anexo 2.1.

Tabela A2.1 - Códigos de produtos para fins de classificação usados na pesquisa.

\begin{tabular}{|c|l|c|l|}
\hline Código & \multicolumn{1}{|c|}{ produto } & código & \multicolumn{1}{c|}{ produto } \\
\hline 1 & Maq lavar roupa & 18 & chuveiro \\
\hline 2 & TV P\&B & 19 & freezer \\
\hline 2,1 & TV a cores & 20 & Forno microondas \\
\hline 2,2 & TV plasma & 22 & Camera filmadora \\
\hline 2,3 & TV LCD & 22,1 & camera film digital \\
\hline 3 & geladeira & 23 & Vídeo cassete \\
\hline 4 & Fogão a gás & 24 & conjunto de som \\
\hline 5 & Rádio & 25 & lavadora tanquinho \\
\hline 6 & Maq costura & 26 & cafeteira elétrica \\
\hline 7 & Ferro eletrico & 27 & torradeira de pão \\
\hline 8 & secador de cabelo & 28 & secadora roupas \\
\hline 9 & enceradeira & 29 & aquecedor elétrico \\
\hline 10 & aspirador de pó & 30 & espremedor elétrico \\
\hline 11 & liquidificador & 31 & geladeira 2 portas \\
\hline 12 & Maq fotográfica & 32 & lava louça maq \\
\hline 12,1 & Maq fotog digital & 33 & Forno elétrico \\
\hline 13 & barbeador & 34 & ar condicionado \\
\hline 14 & Toca discos & 35 & toca disco laser \\
\hline 15 & ventilador & 36 & DVD \\
\hline 16 & batedeira bolo & gravador DVD \\
\hline 17 & panela de pressão & \\
\hline
\end{tabular}

Obs.: Alguns produtos somente foram lançados nos últimos anos. 
Tabela A2.2 - Preços de produtos de 1960 até 2005: em valores históricos, em valores atualizados e em quantidades de salários mínimos.

\begin{tabular}{|c|c|c|c|c|c|c|c|c|c|c|c|c|c|}
\hline mês / ano -s & seter & ibro de 1960 & Ealári & io minimo em 01.0 & $1.1959-\operatorname{CrS} 6.000,00$ & & & & & pesq. em: Bblioteca Municipal Mário de & rquivo d & be Estado d & le Sấo Pa \\
\hline produto - div & versos & & salári & io mínimo em 18.1 & $.1960-\operatorname{CrS} 9.600,00$ & & & & & data: $18 / 12 / 2005-18 / 12 / 2005$ & & & \\
\hline data & pág. & jornal consultado & $\begin{array}{l}\text { cod } \\
\text { prod. }\end{array}$ & produto & loja & $\begin{array}{c}\text { prest. à } \\
\text { prazo }\end{array}$ & preço à vist= & $\begin{array}{c}\mathrm{n}^{\circ} \\
\text { parc. }\end{array}$ & $\begin{array}{c}\text { qtd de } \\
\text { SM }\end{array}$ & descriçâo do produto & $\begin{array}{c}\text { qtd de } \\
\text { SMM }\end{array}$ & $\begin{array}{l}\text { atualiz. p } \\
\text { IPC-SP } \\
\text { FIPE }\end{array}$ & $\begin{array}{l}\text { atual z. p } \\
\text { SM de } \\
2005\end{array}$ \\
\hline $11 / 9 / 1960$ & 83 & Estado de Săo Paulo & & Imaq lavar roupa & A Sensação & $2.390,00$ & & 26 & 7,97 & marca Bendix & 7,97 & 1881,28 & 1941,88 \\
\hline $2 / 9 / 1960$ & 5 & Folha de São Paulo & & 1 maq lavar roupa & Cássio Muniz & $1.130,00$ & & $?$ & $\mathrm{mx}$ & & $\mathrm{mx}$ & $?$ & $?$ \\
\hline $25 / 9 / 1960$ & 108 & Estado de Săo Paulo & & maq lavar roupa & EletroRadiobraz & $1.780,00$ & & 30 & 6,85 & Brastemp & 6,85 & 1616,68 & 1668,75 \\
\hline $25 / 9 / 1960$ & 108 & Estado de Săo Paulo & & Imaq lavar roupa & EletroRadiobraz & $1.800,00$ & & 30 & 6,82 & Westinghouse & 6,92 & 1634,84 & 1687,50 \\
\hline $11 / 9 / 1960$ & & Estado de Säo Paulo & & maq lavar roupa & Isnard & $1.560,00$ & & $?$ & $\mathrm{xx}$ & Bendix & $\mathrm{mx}$ & $?$ & $?$ \\
\hline $5 / 9 / 1960$ & 2 & Folha de São Paulo & 1 & maq lavar roupa & Rádio Simis & & $59.800,00$ & & 7,67 & & 7,67 & 1810,44 & 1868,75 \\
\hline $5 / 9 / 1960$ & & Folha de São Paulo & 2 & TV P\&B & $?$ & & $20.000,00$ & & 2,56 & marca BellSouth - TV $21^{\circ}$ & 2,56 & 605,50 & 625,00 \\
\hline $11 / 9 / 1960$ & 83 & Estado de Săo Paulo & 2 & TV P\&B & A Sensação & $3.290,00$ & & 26 & 10,97 & & 10,97 & 2589,71 & 2673,13 \\
\hline 6/8/1960 & & Folha de São Paulo & 2 & TVP\&B & Bidu & $1.495,00$ & & 25 & 4,79 & TV $21^{\prime \prime}$ & 4,79 & 1131,52 & 1167,97 \\
\hline $5 / 9 / 1960$ & 5 & Folha de São Paulo & 2 & TVPSB & Cibramar & $1.960,00$ & & $?$ & $\mathrm{xx}$ & TV $21^{\prime \prime}$ & \begin{tabular}{l|l}
$m+x$ \\
\end{tabular} & \begin{tabular}{l|}
$?$ \\
\end{tabular} & $?$ \\
\hline $11 / 9 / 1960$ & & Estado de Săo Paulo & 2 & TVP\&B & Columbia & & $49.700,00$ & & 6,37 & TV Colúmbia $21^{\prime \prime}$ & 6,37 & 1504,66 & 1553,13 \\
\hline $25 / 9 / 1960$ & 1 & Estado de Săo Paulo & 2 & TVPSB & Columbia & & $49.700,00$ & & 6,37 & TV $21^{\prime \prime}$ & 6,37 & 1504,66 & 1553,13 \\
\hline $1 / 9 / 1960$ & 1 & Estado de Săo Paulo & 2 & TV P\&B & Fábrica & & $49.700,00$ & & 6,37 & Colúmbia - TV 21" & 6,37 & 1504,66 & 1553,13 \\
\hline $2 / 9 / 1960$ & 15 & Folha de São Paulo & 2 & TVP\&B & Loja Empório & & $37.000,00$ & & 4,74 & TV $21^{\prime \prime}$ & 4,74 & 1120,17 & 1156,25 \\
\hline $5 / 9 / 1960$ & & Folha de São Paulo & 2 & TVPSB & Lojas Pirani & $2.060,00$ & & 12 & 3,17 & marca Semp - TV $21^{\circ}$ & 3,17 & 748,40 & 772,50 \\
\hline 5/9/1960 & & Folha de São Paulo & 2 & TVPSB & Lojas Pirani & $2.400,00$ & & 12 & 3,69 & marca Standard Electric - TV 21" & 3,60 & 871,92 & 900,00 \\
\hline 5/9/1960 & & Folha de São Paulo & 2 & TVPSB & Lojas Pirani & $2.790,00$ & & 12 & 4,29 & marca Philips - TV $21^{\circ}$ & 4,29 & 1013,60 & 1046,25 \\
\hline $5 / 9 / 1960$ & & Folha de São Paulo & 2 & TVPSB & Lojas Pirani & $2.890,00$ & & 12 & 4,45 & marca Decorama GE - TV 21' & 4,45 & 1049,83 & 1083,75 \\
\hline $6 / 9 / 1960$ & & Folha de São Paulo & 2 & TVPSB & Marabá & & $61.500,00$ & & 7,88 & TV $21^{\prime \prime}$ & 7,88 & 1861,91 & 1921,88 \\
\hline 4/9/1960 & 85 & Estado de Säo Paulo & 2 & TVPSB & propaganda $o /$ end & & $37.000,00$ & & 4,74 & TV $21^{\prime \prime}$ & 4,74 & 1120,17 & 1156,25 \\
\hline $13 / 9 / 1960$ & 40 & Estado de Săo Paulo & 2 & TVPSB & propaganda of end & & $37.000,00$ & & 4,74 & TV $21^{\prime \prime}$ & 4,74 & 1120,17 & 1156,25 \\
\hline $5 / 9 / 1960$ & 2 & Folha de São Paulo & 2 & TVP\&B & Rádio Simis & & $75.000,00$ & & 9,62 & TV $21^{\prime \prime}$ & 9,62 & 2270,62 & 2343,75 \\
\hline 6/9/1960 & & Folha de São Paulo & 2 & TVPSB & Strauss & & $39.000,00$ & & 5,00 & marca Strauss TV 21" & 5,00 & 1180,72 & 1218,75 \\
\hline $18 / 9 / 1960$ & 85 & Estado de Săo Paulo & 2 & TVPSB & Supercap & & $84.000,00$ & & 10,77 & Empire TV 21" & 10,77 & 2543,09 & 2625,00 \\
\hline $18 / 9 / 1960$ & 85 & Estado de Săo Paulo & 2 & \begin{tabular}{|l|l|} 
TV PSB \\
\end{tabular} & TV Greif & $2.940,00$ & & 25 & 9,42 & Philoo TV 21" & 9,42 & 2225,21 & 2296,88 \\
\hline 7/9/1960 & & Estado de Săo Paulo & & geladeira & A Exposiçăo & & $39.500,00$ & & 5,06 & geladeira Climax & 5,06 & 1195,86 & 1234,38 \\
\hline $11 / 8 / 1960$ & 83 & Estado de Săo Paulo & & geladeira & A Sensação & 995,00 & & 26. & 3,32 & geladeira Climax & 3,32 & 783,21 & 808,44 \\
\hline $7 / 9 / 1960$ & & Estado de Săo Paulo & 3 & geladeira & Cibramar & & $39.500,00$ & & 5,06 & geladeira Climax & 5,06 & 1195,86 & 1234,38 \\
\hline 8/9/1960 & & Folha de São Paulo & 3 & geladeira & Climax & & $39.450,00$ & & 5,06 & venda de fábrica & 5,06 & 1194,34 & 1232,81 \\
\hline $7 / 9 / 1960$ & & Estado de Săo Paulo & 3 & geladeira & Eletroradiobraz & & $39.500,00$ & & 5,06 & geladeira Climax & 5,06 & 1195,86 & 1234,38 \\
\hline $14 / 9 / 1960$ & 15 & Estado de Săo Paulo & 3 & 3 geladeira & EletroRadiobraz & & $39.450,00$ & & 5,06 & Climax & 5,06 & 1194,34 & 1232,81 \\
\hline $25 / 9 / 1960$ & 108 & Estado de Săo Paulo & 3 & geladeira & EletroRadiobraz & 795,00 & & 30 & 3,06 & Climax & 3,06 & 722,06 & 745,31 \\
\hline $25 / 9 / 1960$ & 108 & Estado de Săo Paulo & 3 & 3 geladeira & EletroRadiobraz & 985,00 & & 30 & 3,83 & Gelomatic 8 pés & 3,83 & 903,71 & 832,81 \\
\hline $25 / 9 / 1960$ & 108 & Estado de Săo Paulo & 3 & 3 geladeira & EletroRadiobraz & $1.595,00$ & & 30 & 6,13 & GE Econolar 8.5 pés & 6,13 & 1448,65 & 1495,31 \\
\hline $25 / 9 / 1960$ & 108 & Estado de Săo Paulo & 3 & 3 geladeira & EletroRadiobraz & $1.960,00$ & & 30 & 7,54 & Brastemp Imperador & 7,54 & 1780,16 & 1837,50 \\
\hline $25 / 9 / 1960$ & 108 & Estado de Săo Paulo & & geladeira & EletroRadiobraz & $2.350,00$ & & 30 & 9,04 & GE Retilinea 11,3 pés & 9,04 & 2134,38 & 2203,13 \\
\hline 8/8/1960 & & Folha de São Paulo & & geladeira & Marabá & & $29.900,00$ & & 3,83 & & 3,83 & 905.22 & 934,38 \\
\hline
\end{tabular}




\begin{tabular}{|c|c|c|c|c|c|c|c|c|c|c|c|c|c|}
\hline \multicolumn{3}{|c|}{ mês / ano - setembro de 1960} & \multicolumn{7}{|c|}{ salário mínimo em 01.01.1959 - CrS 6.000.00 } & \multicolumn{4}{|c|}{ pesq. em: Brblioteca Municipal Mário de Andrade/SP/ Arquivo de Estado de Săo Pa } \\
\hline \multicolumn{3}{|c|}{ produto - diversos } & \multicolumn{7}{|c|}{ salário mínimo em 18.10.1960 - Cr\$ 9.600,00 } & \\
\hline data & pág. & jornal consultado & $\begin{array}{l}\text { cod } \\
\text { prod. }\end{array}$ & produto & Ioja & $\begin{array}{c}\text { prest. à } \\
\text { prazo }\end{array}$ & preço à vist: & $\begin{array}{c}n^{\circ} \\
\text { parcc. }\end{array}$ & $\begin{array}{l}\text { qtd de } \\
\text { SM }\end{array}$ & descriçâo do produto & $\begin{array}{l}\text { qtod des } \\
\text { SMM }\end{array}$ & \begin{tabular}{|c|} 
atualiz. p. \\
IPC-SP \\
FIPE
\end{tabular} & $\begin{array}{l}\text { atual'z. p' } \\
\text { SM de } \\
2005\end{array}$ \\
\hline $7 / 9 / 1960$ & & Estado de Săo Paulo & 3 & geladeira & Norogas & & $39.500,00$ & & 5,06 & geladeira Climax & 5,06 & 1195,86 & 1234,38 \\
\hline 5/9/1960 & 2 & Folha de São Paulo & 3 & geladeira & Rádio Simis & & $46.500,00$ & & 5,86 & & 5,96 & 1407,78 & 1453,13 \\
\hline $18 / 9 / 1960$ & 144 & Estado de Săo Paulo & 3 & geladeira & Reino da Geladeira & & $17.500,00$ & & 2,24 & Climax 7.5 pés & 2,24 & 529,81 & 546,88 \\
\hline $18 / 9 / 1960$ & 144 & Estado de Săo Paulo & 3 & geladeira & Reino da Geladeira & & $27.900,00$ & & 3,58 & Gelomatic 4 pés para apto & 3,58 & 844,67 & 871,88 \\
\hline $18 / 9 / 1960$ & 144 & Estado de Săo Paulo & 3 & geladeira & Reino da Geladeira & & $41.000,00$ & & 5,26 & Philoo Super Luxo 8 pés & 5,26 & 1241,27 & 1281,25 \\
\hline $18 / 9 / 1960$ & 144 & Estado de Săo Paulo & 3 & \begin{tabular}{|l|} 
geladeira \\
\end{tabular} & Reino da Geladeira & & $52.900,00$ & & 6,78 & Admiral 11 pés & 6,78 & 1801,54 & 1653,13 \\
\hline $18 / 9 / 1960$ & 144 & Estado de Săo Paulo & 3 & geladeira & Reino da Geladeira & & $57.500,00$ & & 7,37 & Hotpoint Luxo 10,5 pés & 7,37 & 1740,81 & 1796,88 \\
\hline $11 / 8 / 1960$ & 83 & Estado de Săo Paulo & 4 & fogẫo & A Sensação & 570,00 & & 26 & 1,80 & & 1,80 & 448,67 & 463,13 \\
\hline $5 / 8 / 1960$ & & Folha de São Paulo & 4 & fogấ & Casas Scarpini & & $9.980,00$ & & 1,28 & & 1,28 & 302,14 & 311,88 \\
\hline $22 / 9 / 1960$ & & Folha de São Paulo & 4 & fogâo & Lojas Pirani & 350,00 & & 12 & 0,54 & marca Semer & 0,54 & 127.15 & 131,25 \\
\hline $22 / 8 / 1960$ & & Folha de São Paulo & 4 & fogâo & Lojas Pirani & 900,00 & & 12 & 1,38 & marca Walig & 1,38 & 326,97 & 337,50 \\
\hline $22 / 9 / 1960$ & & Folha de São Paulo & 4 & fogâo & Lojas Pirani & $1.080,00$ & & 12 & 1,68 & marca Bras & 1,66 & 392,36 & 405,00 \\
\hline $8 / 8 / 1960$ & & Folha de São Paulo & 4 & fogâo & Marabá & & $14.500,00$ & & 1,86 & & 1,86 & 438,99 & 453,13 \\
\hline 5/8/1960 & 5 & Folha de São Paulo & 4 & fogâo & Móveis Teperman & & $9.600,00$ & & 1,23 & & 1,23 & 290,64 & 300,00 \\
\hline $8 / 8 / 1960$ & & Folha de São Paulo & 4 & fogâo & Móveis Teperman & & $9.500,00$ & & 1,22 & marca Dako & 1,22 & 287,61 & 296,88 \\
\hline $22 / 8 / 1960$ & & Folha de São Paulo & 4 & fogâo & Móveis Teperman & & 9.500 .00 & & 1,22 & & 1,22 & 287,61 & 296,88 \\
\hline $5 / 8 / 1960$ & 2 & Folha de São Paulo & 4 & fogâo & Rádio Simis & & $43.500,00$ & & 5,58 & & 5,58 & 1316,96 & 1359,38 \\
\hline $18 / 9 / 1960$ & & Estado de Săo Paulo & 4 & fogấ & Sears & & $39.995,00$ & & 5,13 & Kenmore 6 bocas & 5,13 & 1210,84 & 1249,84 \\
\hline $21 / 9 / 1960$ & & Folha de São Paulo & 5 & rádio & $?$ & & $3.200,00$ & & 0,41 & & 0,41 & 96,88 & 100,00 \\
\hline $4 / 8 / 1960$ & 85 & Estado de Săo Paulo & 5 & rádio & Casa Itália & & 3.600 .00 & & 0,46 & radio pilha Spica & 0,46 & 108,99 & 112,50 \\
\hline 8/9/1960 & & Folha de São Paulo & 5 & rádio & Import. Nova York & & $3.600,00$ & & 0,46 & marca Standard & 0,46 & 108,99 & 112,50 \\
\hline 4/9/1960 & 85 & Estado de Săo Paulo & 5 & rádio & Loja Anita & & $3.300,00$ & & 0,42 & radio pilha Spica & 0,42 & 99,81 & 103,13 \\
\hline $25 / 9 / 1960$ & 144 & Estado de Săo Paulo & 5 & rádio & Mundex & & $5.100,00$ & & 0,65 & Sharp & 0,85 & 154,40 & 159,38 \\
\hline $1 / 9 / 1960$ & 53 & Estado de Săo Paulo & 5 & rádio & propaganda c/ end & & $4.000,00$ & & 0,51 & rádio transistor 1 faixa & 0,51 & 121,10 & 125,00 \\
\hline $1 / 9 / 1960$ & 53 & Estado de Săo Paulo & 5 & rádio & propaganda of end & & $5.800,00$ & & 0,74 & rádio transistor 2 faixas & 0,74 & 175,59 & 181,25 \\
\hline 1/9/1960 & 53 & Estado de Săo Paulo & 5 & rádio & propaganda $\mathrm{c} /$ end & & 7.500 .00 & & 0,96 & rádio transistor 3 faixas & 0,86 & 227,06 & 234,38 \\
\hline $25 / 8 / 1960$ & 127 & Estado de Săo Paulo & 5 & rádio & Sensaçă̄o & & $3.890,00$ & & 0,51 & & 0,51 & 120,80 & 124,68 \\
\hline $4 / 9 / 1960$ & 85 & Estado de Săo Paulo & 5 & rádio & Supercap & & 6.500 .00 & & 0,83 & rádio GE ondas médias & 0,83 & 196,79 & 203,13 \\
\hline $5 / 9 / 1960$ & & Folha de São Paulo & 5 & rádio & Supercap & & $6.500,00$ & & 0,83 & & 0,83 & 196,79 & 203,13 \\
\hline $21 / 9 / 1960$ & & Folha de São Paulo & 6 & maq costura & A Sensação & & $18.800,00$ & & 2,41 & & 2,41 & 569,17 & 587,50 \\
\hline $21 / 9 / 1960$ & & Folha de São Paulo & 8 & maq costura & A Sensação & & $19.400,00$ & & 2,49 & & 2,48 & 587,33 & 606,25 \\
\hline $21 / 9 / 1960$ & & Folha de São Paulo & 6 & maq costura & A Sensação & & $20.600,00$ & & 2,64 & & 2,64 & 623,66 & 643,75 \\
\hline $22 / 9 / 1960$ & & Folha de São Paulo & 6 & maq costura & Móveis Teperman & & $13.240,00$ & & 1,70 & & 1,70 & 400,84 & 413,75 \\
\hline $21 / 9 / 1960$ & & Folha de São Paulo & 7 & ferro elétrico & A Sensação & & 295,00 & & 0,04 & & 0,04 & 8,93 & 9.22 \\
\hline $18 / 9 / 1960$ & 124 & Estado de Săo Paulo & 7 & ferro elétrico & Sensaçăa & & 295,00 & & 0,04 & Ferro elétrico & 0,04 & 8,83 & 9.22 \\
\hline $8 / 9 / 1960$ & & Folha de São Paulo & 8 & secador cabelo & Isnard & & $2.580,00$ & & 0,33 & & 0,33 & 78,11 & 80,63 \\
\hline $11 / 9 / 1960$ & 121 & Estado de Săo Paulo & 9 & enceradeira & A Sensação & & 6.750 .00 & & 0,87 & & 0,87 & 204,36 & 210,84 \\
\hline
\end{tabular}




\begin{tabular}{|c|c|c|c|c|c|c|c|c|c|c|c|c|c|}
\hline \multicolumn{3}{|c|}{ mês / ano - setembro de 1960} & \multicolumn{7}{|c|}{ salário mínimo em 01.01.1959 - Cr\$ 6.000.00 } & \multirow{2}{*}{\multicolumn{4}{|c|}{ pesq. em: Bblioteca Municipal Mário de Andrade/SP/ Arquivo de Estado de Sấo Pa }} \\
\hline produto - div & ersos & & saláric & o mínimo em 18.1 & $0.1960-\operatorname{Cr} \$ 8$ & & & & & & & & \\
\hline data & pág. & jornal consultado & $\begin{array}{l}\text { cod } \\
\text { prod. }\end{array}$ & produto & loja & $\begin{array}{c}\text { prest. à } \\
\text { prazo }\end{array}$ & preço à vist= & parce & $\begin{array}{l}\text { qtd de } \\
\text { SM }\end{array}$ & descriçâo do produto & qtod de & $\begin{array}{l}\text { atualiz. P } \\
\text { IPC-SP } \\
\text { FIPE }\end{array}$ & $\begin{array}{l}\text { atualiz. p } \\
\text { SM de } \\
2005\end{array}$ \\
\hline $11 / 9 / 1960$ & 83 & Estado de Săo Paulo & 9 & enceradeira & A Sensação & 310,00 & & 26 & 1,03 & & 1,03 & 244,02 & 251,88 \\
\hline $8 / 8 / 1960$ & & Folha de São Paulo & 9 & enceradeira & Isnard & & $5.880,00$ & & 0,75 & & 0,75 & 178,02 & 183,75 \\
\hline $18 / 9 / 1960$ & 85 & Estado de Săo Paulo & 9 & enceradeira & Supercap & & $10.880,00$ & & 1,40 & Bandeirante & 1,40 & 329,69 & 340,31 \\
\hline $8 / 9 / 1960$ & & Folha de São Paulo & 10 & aspirador de pó & Isnard & 740,00 & & ? & $\mathrm{xx}$ & & $\mathrm{nx}$ & $?$ & $?$ \\
\hline $8 / 9 / 1960$ & & Folha de São Paulo & 11 & liquidificador & Isnard & & $1.990,00$ & & 0,26 & & 0,26 & 60,25 & 62,18 \\
\hline $18 / 9 / 1960$ & 12 & Estado de Săo Paulo & 12 & maq fotografica & Cinótica & & $18.500,00$ & & 2,37 & & 2,37 & 560,09 & 578,13 \\
\hline $4 / 9 / 1860$ & 22 & Estado de Săo Paulo & 12 & maq fotografica & Fotoptica & & $9.645,00$ & & 1,24 & camera fotografica Yashica A 3,5 & 1,24 & 292,00 & 301,41 \\
\hline $4 / 8 / 1960$ & 22 & Estado de Săo Paulo & 12 & maq fotografica & Fotoptica & & $10.370,00$ & & 1,33 & camera fotografica Yashica $44-3,5$ & 1,33 & 313,95 & 324,08 \\
\hline $4 / 9 / 1960$ & 22 & Estado de Säo Paulo & 12 & maq fotografica & Fotoptica & & $15.550,00$ & & 1,88 & camera fotografica Yashica 3,5 & 1,89 & 470,77 & 485,84 \\
\hline $4 / 9 / 1960$ & 22 & Estado de Săo Paulo & 12 & maq fotografica & Fotoptica & & $18.145,00$ & & 2,33 & camera fotografica Yashica 635 & 2,33 & 549,34 & 567,03 \\
\hline $4 / 9 / 1960$ & 22 & Estado de Săo Paulo & 12 & maq fotografica & Fotoptica & & $18.150,00$ & & 2,33 & camera fotografica Yashica LM & 2,33 & 549,49 & 567,18 \\
\hline $4 / 9 / 1960$ & 22 & Estado de Säo Paulo & 12 & maq fotografica & Fotoptica & & $22.770,00$ & & 2,82 & camera fotografica Yashica 3,5 & 2,82 & 689,36 & 711,56 \\
\hline $5 / 8 / 1960$ & 2 & Folha de São Paulo & 12 & maq fotografica & Mappin & & $7.795,00$ & & 1,00 & marca - Zeiis Veitter & 1,00 & 235,99 & 243,59 \\
\hline 4/8/1960 & 85 & Estado de Săo Paulo & 13 & barbeador & Supercap & & $2.880,00$ & & 0,38 & barbeador & 0,38 & 20.22 & 93,13 \\
\hline 4/9/1960 & 85 & Estado de Säo Paulo & 14 & toca discos & Player & & $3.200,00$ & & 0,41 & vendida pelo fabricante & 0,41 & 96,88 & 100,00 \\
\hline
\end{tabular}




\begin{tabular}{|c|c|c|c|c|c|c|c|c|c|c|c|c|c|}
\hline \multicolumn{3}{|c|}{$\begin{array}{l}\text { mês / ano - setembro de } 1970 \\
\text { produto - diversos }\end{array}$} & \multicolumn{8}{|c|}{ Salário mínimo em 01.05.1970 - NCr\$ 187,20} & \multicolumn{3}{|c|}{$\begin{array}{l}\text { pesq. em: Arquivo de Estado de São Paulo } \\
\text { data: 18/12/2005 }\end{array}$} \\
\hline data & pág. & jornal consultado & $\begin{array}{l}\text { cod } \\
\text { prod }\end{array}$ & produto & Ioja & $\begin{array}{c}\text { prest. à } \\
\text { prazo }\end{array}$ & entrada & $\begin{array}{c}\text { preço à } \\
\text { vista }\end{array}$ & $\begin{array}{c}\mathrm{n}^{\circ} \\
\text { parc. }\end{array}$ & $\begin{array}{l}\text { atd de } \\
\text { SM }\end{array}$ & descrição do produto & $\begin{array}{l}\text { atualiz. pV } \\
\text { IPC-SP } \\
\text { FIPE }\end{array}$ & $\begin{array}{l}\text { atualiz. p } \\
\text { SM de } \\
2005\end{array}$ \\
\hline $13 / 9 / 1970$ & 10 & Estado de Săo Paulo & & 1 maq lavar roupa & EletroRadiobraz & & & 999,00 & & 5,34 & GE & 788,23 & 1600,96 \\
\hline 13/9/1970 & 85 & Estado de Săo Paulo & & 1 maq lavar roupa & EletroRadiobraz & & & 999,00 & & 5,34 & $\mathrm{GE}$ & 788,23 & 1600,96 \\
\hline $20 / 9 / 1970$ & 132 & Estado de Săo Paulo & & 1 maq lavar roupa & Exposição & 65,70 & & & 24 & $\mathrm{mx}$ & Brastemp Plenomática & $?$ & $?$ \\
\hline $4 / 9 / 1970$ & 2 & Estado de Săo Paulo & & 1 maq lavar roupa & G.Aronson & & & 750,00 & & 4,01 & Bendix Economatic & 591,77 & 1201,92 \\
\hline $4 / 9 / 1970$ & 2 & Estado de Săo Paulo & & 1 maq lavar roupa & G.Aronson & & & 850,00 & & 4,54 & Bendix Luxo & 670,67 & 1362,18 \\
\hline 13/9/1970 & 21 & Estado de Săo Paulo & & 1 maq lavar roupa & Mappin & & & 769,00 & & 4,11 & Torga & 606,76 & 1232,37 \\
\hline $6 / 9 / 1970$ & 125 & Estado de Săo Paulo & & 1 maq lavar roupa & Uiltralar & 69,90 & & & 24 & $\mathrm{xm}$ & Brastemp & $?$ & $?$ \\
\hline $13 / 9 / 1970$ & 132 & Estado de Săo Paulo & & 1 maq lavar roupa & Uiltralar & 69,90 & & & 24 & $x \times$ & Brastemp Plenomática & $?$ & $?$ \\
\hline $20 / 8 / 1970$ & 84 & Estado de Săo Paulo & & 1 maq lavar roupa & Ultralar & & & 899,00 & & 4,80 & GE & 709,33 & 1440,71 \\
\hline $27 / 9 / 1970$ & 38 & Estado de Săo Paulo & & 1 maq lavar roupa & Ultralar & & & 949,00 & & 5,07 & GE & 748,78 & 1520,83 \\
\hline $20 / 9 / 1970$ & 109 & Estado de Săo Paulo & & 1 maq lavar roupa & Utibras & & & 999,00 & & 5,34 & Brastemp & 788,23 & 1600,96 \\
\hline $13 / 9 / 1970$ & 10 & Estado de Săo Paulo & & \begin{tabular}{|l|l|}
2 & TV P\&B \\
\end{tabular} & EletroRadiobraz & & & 699,00 & & 3,73 & Millen $23^{\prime \prime}$ - modelo mesa & 551,53 & 1120,18 \\
\hline $13 / 9 / 1970$ & 10 & Estado de Săo Paulo & 2 & 2 TV PSB & EletroRadiobraz & & & 895,00 & & 4,78 & Philips $19^{\prime \prime}$ - Stab Imatic & 706,18 & 1434.28 \\
\hline $13 / 9 / 1970$ & 10 & Estado de Săo Paulo & & \begin{tabular}{|l|l|} 
TV PSB \\
\end{tabular} & EletroRadiobraz & & & 999,50 & & 5,34 & Philoo B127 - $23^{\circ}$ & 788,63 & 1601,76 \\
\hline $13 / 9 / 1970$ & 85 & Estado de Săo Paulo & 2 & 2 TV P\&B & EletroRadiobraz & & & 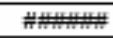 & & 5,56 & Apollo $23^{\circ}$ & 820,58 & 1666,67 \\
\hline $13 / 9 / 1970$ & 85 & Estado de Săo Paulo & 2 & \begin{tabular}{|l|l|} 
TV P\&B \\
\end{tabular} & EletroRadiobraz & & & H\#\#\# & & 5,74 & Decorama 23" & 848,20 & 1722,76 \\
\hline $20 / 9 / 1970$ & 85 & Estado de Săo Paulo & & \begin{tabular}{|l|l|} 
& TV PSB \\
\end{tabular} & EletroRadiobraz & & & 820,00 & & 4,38 & Philoo 8253 & 647,00 & 1314,10 \\
\hline $20 / 9 / 1970$ & 85 & Estado de Săo Paulo & & 2 TV PSB & EletroRadiobraz & & & 890,00 & & 4,75 & Philoo B254 portátil & 702,23 & 1426.28 \\
\hline $20 / 9 / 1970$ & 85 & Estado de Săo Paulo & 2 & 2 TV P\&B & EletroRadiobraz & & & \#\#\#\# & & 6,62 & Philco B125 23" & 978,39 & 1987,18 \\
\hline $20 / 9 / 1970$ & 85 & Estado de Săo Paulo & 2 & 2 TV PSB & EletroRadiobraz & & & \#\#\#\# & & 8,33 & Philco B197 23" & 1230,88 & 2500,00 \\
\hline $20 / 9 / 1970$ & 132 & Estado de Săo Paulo & 2 & 2 TV PSB & Exposição & 47,40 & & & 24 & $\mathrm{mx}$ & Philoo B254 41cm & $?$ & $?$ \\
\hline $4 / 9 / 1970$ & 21 & Estado de Săo Paulo & & 2 TV P\&B & Mappin & 25,20 & & 398,00 & 24 & 2,13 & Millen 11 " portát & 314,03 & 637.82 \\
\hline 4/9/1970 & 21 & Estado de Săo Paulo & 2 & 2 TV P\&B & Mappin & 42,20 & & 668,00 & 24 & 3,57 & Semp $16^{\prime \prime}$ & 527,07 & 1070,51 \\
\hline $4 / 9 / 1970$ & 21 & Estado de Săo Paulo & 2 & 2 TV PSB & Mappin & 47,90 & & 758,00 & 24 & 4,05 & Semp 23" & 598,08 & 1214.74 \\
\hline $13 / 8 / 1970$ & 21 & Estado de Săo Paulo & 2 & 2 TV P\&B & Mappin & & & 598,00 & & 3,18 & Polivideo $23^{\prime \prime}$ & 471,84 & 958,33 \\
\hline $20 / 9 / 1970$ & 17 & Estado de Săo Paulo & & \begin{tabular}{|l|l|} 
TV PSB \\
\end{tabular} & Mappin & & & 648,00 & & 3,46 & Semp $16^{\prime \prime}$ & 511,29 & 1038,46 \\
\hline $20 / 8 / 1970$ & 17 & Estado de Săo Paulo & 2 & $2 \mid T V P S B$ & Mappin & & & 748,00 & & 4,00 & Invictus Falcon $23^{\prime \prime}$ & 590,19 & 1198,72 \\
\hline $20 / 8 / 1970$ & 17 & Estado de Săo Paulo & 2 & 2 TV PSB & Mappin & & & 998,00 & & 5,33 & Philoo Solid State $23^{\circ}$ & 787,44 & $1599,3 \mathrm{e}$ \\
\hline $6 / 9 / 1970$ & 125 & Estado de Săo Paulo & 2 & \begin{tabular}{|l|l|} 
TV P\&B \\
\end{tabular} & Uiltralar & 55,90 & & & 24 & $\mathrm{mx}$ & Millen $59 \mathrm{~cm} 23^{\prime}$ & $?$ & $?$ \\
\hline $6 / 9 / 1970$ & 125 & Estado de Săo Paulo & 2 & \begin{tabular}{|l|l|}
2 TV PSB \\
\end{tabular} & Uiltralar & 69,90 & & & 24 & $\mathrm{xm}$ & Telefunken $59{\mathrm{~cm} 23^{\circ}}^{\circ}$ & $?$ & $?$ \\
\hline $13 / 9 / 1970$ & 132 & Estado de Săo Paulo & 2 & 2 TV P\&B & Uiltralar & 55,90 & & & 24 & $\mathrm{mx}$ & Millen $23^{\prime \prime}$ & $?$ & $?$ \\
\hline $13 / 9 / 1970$ & 132 & Estado de Săo Paulo & 2 & \begin{tabular}{|l|l|}
2 & TV P\&B \\
\end{tabular} & Ultralar & 49,90 & & & 24 & $\mathrm{mx}$ & Semp Pimentinha & $?$ & $?$ \\
\hline $13 / 9 / 1970$ & 132 & Estado de Săo Paulo & 2 & 2 TV PSB & Uiltralar & 79,90 & & & 24 & $\mathrm{mx}$ & Philco & $?$ & $?$ \\
\hline $20 / 9 / 1970$ & 84 & Estado de Săo Paulo & 2 & 2 TV P\&B & Uiltralar & & & 599,00 & & 3,20 & Picolo 70 & 472,62 & 959,94 \\
\hline $27 / 9 / 1970$ & 38 & Estado de Săo Paulo & & 2 TV P\&B & Uiltralar & & & 499,00 & & 2,67 & Invictus Faloon $23^{\prime \prime}$ & 393,72 & 799.68 \\
\hline
\end{tabular}




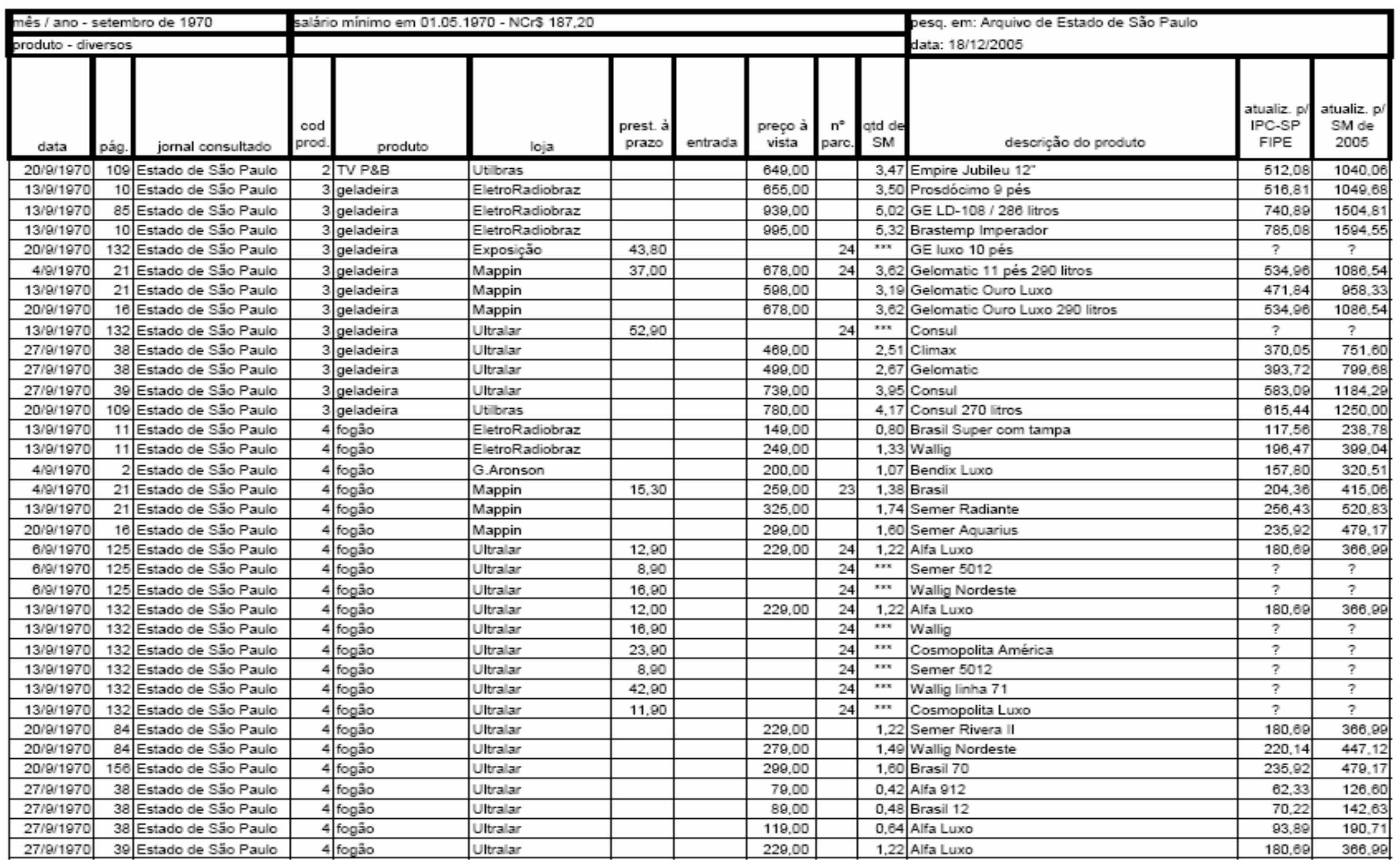




\begin{tabular}{|c|c|c|c|c|c|c|c|c|c|c|c|c|c|}
\hline \multicolumn{3}{|c|}{$\begin{array}{l}\text { mês / ano - setembro de } 1970 \\
\text { produto - diversos }\end{array}$} & \multicolumn{8}{|c|}{ Salário mínimo em 01.05 .1970 - NCrs 187,20} & \multicolumn{3}{|c|}{$\begin{array}{l}\text { pesq. em: Arquivo de Estado de São Paulo } \\
\text { data: } 18 / 12 / 2005\end{array}$} \\
\hline data & pág. & jornal consultado & $\begin{array}{l}\text { cod } \\
\text { prod. }\end{array}$ & produto & loja & $\begin{array}{c}\text { prest. à } \\
\text { prazo }\end{array}$ & entrada & $\begin{array}{c}\text { preço à } \\
\text { vista }\end{array}$ & $\begin{array}{l}\mathrm{n}^{\circ} \\
\text { parc. }\end{array}$ & $\begin{array}{l}\text { qtd de } \\
\text { SM }\end{array}$ & descrição do produto & $\begin{array}{l}\text { atualiz. pv } \\
\text { IPC-SP } \\
\text { FIPE }\end{array}$ & $\begin{array}{c}\text { atualiz. p/ } \\
\text { SM de } \\
2005\end{array}$ \\
\hline $20 / 8 / 1970$ & 109 & Estado de Săo Paulo & 4 & fogão & Utibras & & & 255,00 & & 1,36 & Brasil & 201,20 & 408,65 \\
\hline $13 / 9 / 1970$ & 132 & Estado de Săo Paulo & 5 & \begin{tabular}{|l|l|} 
rádio \\
\end{tabular} & Baú da Felicidade & 11,00 & & 33,00 & 3 & 0,18 & Sonia II & 26,04 & 52,88 \\
\hline $13 / 8 / 1970$ & 10 & Estado de Săo Paulo & & \begin{tabular}{|l|l|} 
rádio \\
\end{tabular} & EletroRadiobraz & & & 59,00 & & 0,32 & Bolso & 46,55 & 94,55 \\
\hline $13 / 9 / 1970$ & 10 & Estado de Săo Paulo & & rádio & EletroRadiobraz & & & 89,00 & & 0,48 & Spica & 70,22 & 142,63 \\
\hline $20 / 8 / 1970$ & 85 & Estado de Săo Paulo & & |rádio & EletroRadiobraz & & & 150,00 & & 0,80 & Philco portát| & 118,35 & 240,38 \\
\hline $20 / 8 / 1970$ & 85 & Estado de Săo Paulo & & \begin{tabular}{|l|l|} 
rádio \\
\end{tabular} & EletroRadiobraz & & & 420,00 & & 2,24 & Transglober Philco & 331,39 & 673,08 \\
\hline $8 / 9 / 1970$ & 11 & Estado de Săo Paulo & & Fádio & Mappin & & & 48,00 & & 0,26 & Osaka 70 portátil & 37,87 & 76,82 \\
\hline $27 / 9 / 1970$ & 38 & Estado de Săo Paulo & & Fádio & Ultralar & & & 69,00 & & 0,37 & bolso & 54,44 & 110,58 \\
\hline $27 / 9 / 1970$ & 38 & Estado de Săo Paulo & & |rádio & Ultralar & & & 79,00 & & 0,42 & Philco portátil & 62,33 & 126,60 \\
\hline $13 / 9 / 1970$ & 11 & Estado de Säo Paulo & & maq costura & EletroRadiobraz & & & 340,00 & & 1,82 & Vigorelli $43 / 73$ & 268,27 & 544,87 \\
\hline $13 / 9 / 1970$ & 11 & Estado de Săo Paulo & e & maq costura & EletroRadiobraz & & & 375,00 & & 2,00 & Singer $660 / 491$ & 295,88 & 600,96 \\
\hline $20 / 8 / 1970$ & 16 & Estado de Săo Paulo & e & maq costura & Mappin & & & 269,00 & & 1,44 & Singer Ponto de Ouro & 212,35 & 431,09 \\
\hline $27 / 9 / 1970$ & 39 & Estado de Săo Paulo & 6 & maq costura & Ultralar & & & 299,00 & & 1,60 & Elgin portátil & 235,92 & 479,17 \\
\hline $13 / 9 / 1970$ & & Estado de Săo Paulo & & ferro elétrico & Casa Centro & & & 8,80 & & 0,05 & \begin{tabular}{|l|} 
Tupi \\
\end{tabular} & 7,02 & 14,26 \\
\hline $13 / 9 / 1970$ & 11 & Estado de Săo Paulo & & ferro elétrico & EletroRadiobraz & & & 7,90 & & 0,04 & Eletrónica & 6,23 & 12,66 \\
\hline $13 / 9 / 1970$ & 85 & Estado de Săo Paulo & & 7ferro elétrico & EletroRadiobraz & & & 59,00 & & 0,32 & GE automático & 46,55 & 94,55 \\
\hline $8 / 9 / 1970$ & 11 & Estado de Săo Paulo & 7 & ferro elétrico & Mappin & & & 7,80 & & 0,04 & Mundial automático & 6,23 & 12,66 \\
\hline $13 / 9 / 1970$ & 109 & Estado de Săo Paulo & 7 & ferro elétrico & Sears & & & 18,00 & & 0,10 & Sears & 14,20 & 28,85 \\
\hline $20 / 8 / 1970$ & 100 & Estado de Săo Paulo & 7 & ferro elétrico & Utibras & & & 59,00 & & 0,32 & automático & 46,55 & 94,55 \\
\hline $13 / 9 / 1970$ & 11 & Estado de Săo Paulo & 8 & enceradeira & EletroRadiobraz & & & 189,00 & & 1,01 & & 149,13 & 302,88 \\
\hline $13 / 9 / 1970$ & 85 & Estado de Säo Paulo & 8 & enceradeira & EletroRadiobraz & & & 189,00 & & 1,01 & cromada & 149,13 & 302,88 \\
\hline $13 / 8 / 1970$ & 132 & Estado de Săo Paulo & 8 & enceradeira & Ultralar & & & 138,00 & & 0,74 & EletroBras & 108,89 & 221,15 \\
\hline $13 / 9 / 1970$ & 85 & Estado de Săo Paulo & 10 & aspirador de pó & EletroRadiobraz & & & 300,00 & & 1,60 & GE grande & 236,71 & 480,77 \\
\hline $27 / 9 / 1970$ & 140 & Estado de Săo Paulo & 11 & liquidificador & Baú da Felicidade & 9,00 & & 27,00 & 3 & 0,14 & Amo & 21,30 & 43,27 \\
\hline 6/8/1970 & 142 & Estado de Săo Paulo & 12 & maq fotografica & Gabriel Gonçalves & & & 655,00 & & 3,50 & Minolta Himatic 75 & 516,81 & 1049,68 \\
\hline $6 / 8 / 1970$ & & Estado de Săo Paulo & 15 & 5 ventilador & Exposição & & & 98,00 & & 0,52 & Británia 3 velocidades & 77,32 & 157,05 \\
\hline 13/9/1970 & 11 & Estado de Săo Paulo & 16 & batedeira bolo & EletroRadiobraz & & & 169,00 & & 0,80 & GE & 133,34 & 270,83 \\
\hline $13 / 9 / 1970$ & 85 & Estado de Săo Paulo & 16 & batedeira bolo & EletroRadiobraz & & & 169,00 & & 0,80 & & 133,34 & 270,83 \\
\hline $13 / 9 / 1970$ & 132 & Estado de Säo Paulo & 16 & batedeira bolo & Ultralar & & & 54,00 & & 0,29 & Mix & 42,61 & 86,54 \\
\hline $20 / 9 / 1970$ & 109 & Estado de Săo Paulo & 16 & batedeira bolo & Utibras & & & 143,00 & & 0,76 & Nova Arno & 112,83 & 229,17 \\
\hline $20 / 9 / 1970$ & 100 & Estado de Săo Paulo & 16 & batedeira bolo & Utibras & & & 185,00 & & 0,90 & Walita Jubileu & 145,97 & 296,47 \\
\hline $13 / 9 / 1970$ & 11 & Estado de Săo Paulo & 17 & panela de pressâo & EletroRadiobraz & & & 22,50 & & 0,12 & Clock & 17,75 & 36,06 \\
\hline $13 / 9 / 1970$ & 132 & Estado de Săo Paulo & 18 & chuveiro & Ultralar & & & 39,80 & & 0,21 & Lorenzetti & 31,48 & 63,84 \\
\hline $27 / 9 / 1970$ & 39 & Estado de Săo Paulo & 18 & freezer & Ultralar & & & 769,00 & & 4,11 & Westinghouse & 606,76 & 1232,37 \\
\hline
\end{tabular}




\begin{tabular}{|c|c|c|c|c|c|c|c|c|c|c|c|c|c|}
\hline \multicolumn{3}{|c|}{ mês / ano - setembro de 1980} & \multicolumn{7}{|c|}{ Salário mínimo em 01.05.1980 - Cr\$ 4.149,60 } & \multicolumn{4}{|c|}{ pesq. em: Arquivo de Estado de Săo Paulo } \\
\hline \multicolumn{3}{|c|}{ produto - diversos } & \multicolumn{7}{|c|}{ Salário mínimo em 01.11.1980 - Cr\$ 5.788,80 } & \multicolumn{4}{|c|}{ data: $18 / 12 / 2005$} \\
\hline data & pág_. & jornal consultado & $\begin{array}{l}\text { cod } \\
\text { prod. }\end{array}$ & produto & loja & $\begin{array}{c}\text { prest. à } \\
\text { prazo }\end{array}$ & entrada & preço à vista & $\begin{array}{c}n^{\circ} \\
\text { parc. }\end{array}$ & $\begin{array}{c}\text { atd de } \\
\text { SM }\end{array}$ & descriçăo do produto & $\begin{array}{c}\text { atualiz. p/ } \\
\text { IPC-SP } \\
\text { FIPE }\end{array}$ & $\begin{array}{l}\text { atualz. p/ } \\
\text { SM de } \\
2005\end{array}$ \\
\hline $7 / 9 / 1980$ & 10 & O Estado de Sắo Paulo & & Imaq lavar roupa & Arapuă & 2.499 .00 & $2.290,00$ & $24.290,00$ & 15 & 5,85 & Lavinia $6 \mathrm{~kg}$ & 981,58 & $1.756,07$ \\
\hline 14/9/1980 & 13 & O Estado de Săo Paulo & 1 & maq lavar roupa & Arapuă & & & $24,490,00$ & & 5,80 & Lavinia $6 \mathrm{~kg}$ & 989,66 & $1.770,53$ \\
\hline $7 / 8 / 1980$ & 37 & O Estado de Sắo Paulo & & maq lavar roupa & Jumbo Eletro & & & $12.490,00$ & & 3,01 & Brastemp Minimática & 504,73 & 902,98 \\
\hline $7 / 9 / 1980$ & 33 & O Estado de Sắo Paulo & & maq lavar roupa & 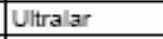 & & & $14.990,00$ & & 3,61 & Brastemp 521 & 605,76 & $1.083,72$ \\
\hline $7 / 9 / 1980$ & 33 & O Estado de Sắo Paulo & 1 & maq lavar roupa & Ultralar & & & $41.990,00$ & & 10,12 & Brastemp & $1.696,85$ & $3.035,71$ \\
\hline $7 / 9 / 1980$ & 11 & O Estado de Săo Paulo & 2 & TV PSB & Arapuä & 995,00 & & $8.690,00$ & 15 & 2,00 & Colorado Itaipu 14" & 351,17 & 628,25 \\
\hline $7 / 9 / 1980$ & 11 & O Estado de Săo Paulo & 2 & TVPSB & Arapuă & 1.145 .00 & 890,00 & $10.890,00$ & 15 & 2,62 & Colorado Araguaia $17^{\prime \prime}$ & 440,07 & 787,30 \\
\hline $7 / 9 / 1980$ & 11 & O Estado de Sắo Paulo & 2 & TVPSB & Arapuă & 1.477 .00 & $1.490,00$ & $14.490,00$ & 15 & 3,49 & Philco 8-143 - 24 & 585,55 & $1.047,57$ \\
\hline $14 / 9 / 1980$ & 17 & O Estado de Săo Paulo & 2 & TV PSB & Arapuă & & & $9.190,00$ & & 2,21 & Philco B-265 2M - 12' & 371,37 & 684,40 \\
\hline $14 / 9 / 1980$ & 13 & O Estado de Săo Paulo & 2 & TVPSB & Arapuă & & & $10.990,00$ & & 2,05 & \begin{tabular}{|l|} 
Colorado Araguaia $17^{\prime \prime}$ \\
\end{tabular} & 444,11 & 794,53 \\
\hline 14/9/1980 & 17 & O Estado de Săo Paulo & 2 & TVPSB & Arapuă & & & $14,490,00$ & & 3,48 & Philco B-143-24 & 585,55 & $1.047,57$ \\
\hline $21 / 9 / 1980$ & 13 & O Estado de Sắo Paulo & 2 & TVP\&B & Arapuă & & & $10.890,00$ & & 2,62 & Colorado Araguaia 17" & 440,07 & 787,30 \\
\hline $21 / 9 / 1980$ & 11 & O Estado de Săo Paulo & 2 & TVPSB & Arapuă & & & $14,490,00$ & & 3,49 & Philco B-143-24 & 585,55 & $1.047,57$ \\
\hline $28 / 9 / 1980$ & 11 & O Estado de Săo Paulo & 2 & TVP\&B & Arapuă & & & $10.890,00$ & & 2,62 & \begin{tabular}{|l} 
Colorado Araguaia $17^{\prime \prime}$ \\
\end{tabular} & 440,07 & 787,30 \\
\hline $7 / 9 / 1980$ & 37 & O Estado de Sä́o Paulo & 2 & TV PSB & Jumbo Eletro & & & $9.190,00$ & & 2,21 & Philco Safari $12^{\star}$ & 371,37 & 684,40 \\
\hline $21 / 9 / 1980$ & 31 & O Estado de Săo Paulo & 2 & TVPSB & Jumbo Eletro & & & $10.980,00$ & & 2,65 & Philips 662 - $24^{\prime \prime}$ & 443,71 & 793,81 \\
\hline $28 / 9 / 1980$ & 34 & O Estado de Săo Paulo & 2 & TVPSB & Jumbo Eletro & & & $9.190,00$ & & 2,21 & Philco Safari $12^{\prime}$ & 371,37 & 664,40 \\
\hline $28 / 9 / 1980$ & 34 & O Estado de Sắo Paulo & 2 & TVPSB & Jumbo Eletro & & & $12.290,00$ & & 2,86 & Philco 20" & 496,65 & 888,52 \\
\hline $7 / 9 / 1980$ & 21 & O Estado de Sắo Paulo & 2 & TV P\&B & Mappin & & & $10.190,00$ & & 2,46 & Philips T672 - 24" & 411,79 & 736,70 \\
\hline $7 / 9 / 1980$ & 33 & O Estado de Săo Paulo & 2 & TVPSB & \begin{tabular}{|l|l|l} 
Ultralar \\
\end{tabular} & & & $10.290,00$ & & 2,48 & Philips T643 - 20" & 415,83 & 743,93 \\
\hline $7 / 9 / 1980$ & 33 & O Estado de Sắo Paulo & 2 & TVPSB & Ultralar & & & $12.290,00$ & & 2,80 & Philoo $151-20^{\prime \prime}$ & 496,65 & 888,52 \\
\hline $7 / 9 / 1980$ & 33 & O Estado de Săo Paulo & 2 & TV P\&B & Ultralar & & & $13.590,00$ & & 3,28 & Telefunken $500 \mathrm{~T}-20^{\circ}$ & 549,18 & 882,50 \\
\hline $21 / 9 / 1980$ & 29 & O Estado de Săo Paulo & 2 & TVP\&B & \begin{tabular}{|l|l|} 
Ultralar \\
\end{tabular} & & & $8.990,00$ & & 2,17 & Philips B-710 & 363,29 & 849,94 \\
\hline 7/8/1980 & 11 & O Estado de Sä́o Paulo & 2,1 & TV a cores & Arapuă & 3.899 .00 & $3.150,00$ & $38.150,00$ & 15 & 9,19 & Sharp $14^{\circ}$ & $1.541,67$ & $2.758,10$ \\
\hline $7 / 9 / 1980$ & 13 & O Estado de Sắo Paulo & 2,1 & TV a cores & Arapuă & $4.799,00$ & $2.000,00$ & $44.990,00$ & 15 & 10,84 & Philips 20" & $1.818,08$ & $3.252,60$ \\
\hline $14 / 9 / 1980$ & 17 & O Estado de Săo Paulo & 2,1 & TV a cores & Arapuă & & & $34.790,00$ & & 8,38 & Philco 8-819M - $17^{\prime \prime}$ & $1.405,89$ & $2.515,18$ \\
\hline $14 / 9 / 1980$ & 17 & O Estado de Săo Paulo & 2,1 & TV a cores & Arapuă & & & $35.490,00$ & & 8,55 & Philoo 8-814 - $14^{-}$ & $1.434,18$ & $2.585,79$ \\
\hline 14/9/1980 & 13 & O Estado de Săo Paulo & 2,1 & TV a cores & Arapuă & & & $51.990,00$ & & 12,53 & Philips 320 & $2.100,85$ & $3.758,68$ \\
\hline $21 / 9 / 1980$ & 11 & O Estado de Săo Paulo & 2,1 & TV a cores & Arapuă & & & $34.790,00$ & & 8,38 & Philoo 8-819M - 17" & $1.405,89$ & $2.515,18$ \\
\hline $21 / 9 / 1980$ & 11 & O Estado de Săo Paulo & 2,1 & TV a cores & Arapuă & & & $35.490,00$ & & 8,55 & Philco 8-814M - 14" & $1.434,18$ & $2.585,79$ \\
\hline 21/9/1980 & 12 & O Estado de Săo Paulo & 2,1 & TV a cores & Arapuă & & & $38.150,00$ & & 9,19 & Sharp $1401-14^{\prime \prime}$ & $1.541,67$ & $2.758,10$ \\
\hline $21 / 9 / 1980$ & 13 & O Estado de Săo Paulo & 2,1 & TV a cores & Arapuă & & & $44.990,00$ & & 10,84 & Philips 310 & $1.818,08$ & $3.252,60$ \\
\hline $21 / 9 / 1980$ & 12 & O Estado de Săo Paulo & 2,1 & TV a cores & Arapuă & & & $46.630,00$ & & 11,24 & Sharp 2006A - $20^{\prime \prime}$ & $1.884,35$ & $3.371,17$ \\
\hline $28 / 9 / 1980$ & 11 & O Estado de Săo Paulo & 2,1 & TV a cores & Arapuä & & & $51.990,00$ & & 12,53 & Philips $320-20^{\prime \prime}$ & $2.100,85$ & $3.758,68$ \\
\hline $28 / 9 / 1980$ & 11 & O Estado de Săo Paulo & 2,1 & TV a cores & Arapuă & & & $52.490,00$ & & 12,65 & Mitsubishi TC $2020-20^{\circ}$ & $2.121,16$ & $3.794,82$ \\
\hline $7 / 8 / 1980$ & 37 & O Estado de Săo Paulo & 2,1 & TV a cores & Jumbo Eletro & & & $32.490,00$ & & 7,83 & Sanyo $14^{\prime \prime}$ & $1.312,84$ & $2.348,90$ \\
\hline $7 / 9 / 1980$ & 37 & O Estado de Săo Paulo & 2,1 & TV a cores & Jumbo Eletro & & & $40.460,00$ & & 8,75 & Sharp Color Linytron $16^{\circ}$ & $1.635,02$ & $2.825,10$ \\
\hline
\end{tabular}




\begin{tabular}{|c|c|c|c|c|c|c|c|c|c|c|c|c|c|}
\hline \multicolumn{3}{|c|}{ mês / ano - setembro de 1980} & \multicolumn{7}{|c|}{ Esalário mínimo em 01.05.1980 - Cr5 4.149,60 } & \multicolumn{4}{|c|}{ pesq. em: Arquivo de Estado de Săo Paulo } \\
\hline \multicolumn{3}{|c|}{ produto - diversos } & \multicolumn{7}{|c|}{ Salário mínimo em 01.11.1980 - Cr5 5.788,80 } & \\
\hline data & pág. & jornal consultado & $\begin{array}{l}\text { cod } \\
\text { prod. }\end{array}$ & produto & loja & $\begin{array}{c}\text { prest. à } \\
\text { prazo }\end{array}$ & entrada & preço à vista & $\begin{array}{c}\mathrm{n}^{\circ} \\
\text { parc. }\end{array}$ & $\begin{array}{c}\text { qtd de } \\
\text { SM }\end{array}$ & descrição do produto & $\begin{array}{l}\text { atualiz. p/ } \\
\text { IPC-SP } \\
\text { FIPE }\end{array}$ & $\begin{array}{l}\text { atual } z \text { p } \\
\text { SM de } \\
2005\end{array}$ \\
\hline $14 / 2 / 1980$ & 30 & O Estado de Săo Paulo & 2,1 & TV a cores & Jumbo Eletro & & & $38.150,00$ & & 9,19 & Sharp color Linytron $14^{*}$ & $1.541,67$ & $2.758,10$ \\
\hline $14 / 9 / 1980$ & 30 & O Estado de Săo Paulo & 2,1 & TV a cores & Jumbo Eletro & & & $40.460,00$ & & 9,75 & Sharp color Linytron $16^{\circ}$ & $1.635,02$ & $2.825,10$ \\
\hline $14 / 9 / 1980$ & 32 & O Estado de Săo Paulo & 2,1 & TV a cores & Jumbo Eletro & & & $45.890,00$ & & 11,06 & Philips color tecla verde $20^{\circ}$ & $1.854,45$ & $3.317,67$ \\
\hline $14 / 9 / 1980$ & 30 & O Estado de Săo Paulo & 2,1 & TV a cores & Jumbo Eletro & & & $46.630,00$ & & 11,24 & Sharp color Linytron $20^{\circ}$ & $1.884,35$ & $3.371,17$ \\
\hline $21 / 2 / 1980$ & 31 & O Estado de Săo Paulo & 2,1 & TV a cores & Jumbo Eletro & & & $32.490,00$ & & 7,83 & Sanyo color de luxe $14^{\prime \prime}$ & $1.312,94$ & $2.348,90$ \\
\hline $21 / 9 / 1980$ & 31 & O Estado de Săo Paulo & 2,1 & TV a cores & Jumbo Eletro & & & $41.790,00$ & & 10,07 & National Panacolor 18" & $1.688,76$ & $3.021,26$ \\
\hline $21 / 9 / 1980$ & 31 & O Estado de Săo Paulo & 2,1 & TV a cores & Jumbo Eletro & & & $48.390,00$ & & 11,68 & National Panacolor 20" & $1.955,47$ & $3.488,41$ \\
\hline $28 / 9 / 1980$ & 34 & O Estado de Săo Paulo & 2,1 & TV a cores & Jumbo Eletro & & & $49.490,00$ & & 11,83 & Sanyo color $20^{\prime \prime}$ & $1.999,83$ & $3.577,94$ \\
\hline $14 / 2 / 1980$ & 21 & O Estado de Săo Paulo & 2,1 & TV a cores & Mappin & & & $39.990,00$ & & 9,84 & Philips C309 - 20" & $1.616,02$ & $2.891,12$ \\
\hline $7 / 9 / 1980$ & 33 & O Estado de Săo Paulo & 2,1 & TV a cores & Ultralar & & & $33.990,00$ & & 8,18 & Telefunken Palcolor $336-14^{\prime \prime}$ & $1.373,56$ & $2.457,35$ \\
\hline $7 / 9 / 1980$ & 33 & O Estado de Săo Paulo & 2,1 & TV a cores & Ultralar & & & $40.890,00$ & & 9,85 & Philips colorscope B828 - $20^{\circ}$ & $1.652,39$ & $2.856,19$ \\
\hline $7 / 9 / 1980$ & 33 & O Estado de Săo Paulo & 2,1 & TV a cores & Ultralar & & & $46.630,00$ & & 11,24 & Sharp color C-2006 - 20 & $1.884,35$ & $3.371,17$ \\
\hline $7 / 9 / 1980$ & 10 & O Estado de Săo Paulo & 3 & geladeira & Arapuă & $1.195,00$ & & $10.650,00$ & 15 & 2,57 & Climax Primavera Luxo & 430,37 & 769,95 \\
\hline $28 / 9 / 1980$ & 8 & O Estado de Săo Paulo & 3 & geladeira & Arapuă & & & $17.490,00$ & & 4,21 & Frigidaire $32 \mathrm{~L}-320$ litros & 706,78 & $1.264,46$ \\
\hline $7 / 8 / 1980$ & 37 & O Estado de Săo Paulo & 3 & geladeira & Jumbo Eletro & & & $12.840,00$ & & 3,09 & GE Luxo 330 itros & 518,87 & 928,28 \\
\hline $7 / 8 / 1980$ & 37 & O Estado de Săo Paulo & 3 & geladeira & Jumbo Eletro & & & $14.590,00$ & & 3,52 & Prosdócimo Super Luxo & 589,59 & $1.054,80$ \\
\hline $21 / 9 / 1980$ & 33 & O Estado de Săo Paulo & 3 & geladeira & Jumbo Eletro & & & $11.980,00$ & & 2,89 & Consul Super Luxo & 484,12 & 866,11 \\
\hline $21 / 9 / 1980$ & 33 & O Estado de Săo Paulo & 3 & geladeira & Jumbo Eletro & & & $13.980,00$ & & 3,37 & GE Lua de Mel Luxo & 584,94 & $1.010,70$ \\
\hline $7 / 9 / 1980$ & 20 & O Estado de Săo Paulo & 3 & geladeira & Mappin & & & $13.690,00$ & & 3,30 & GE Luxo 330 Itros & 553,22 & 989,73 \\
\hline $14 / 9 / 1980$ & 21 & O Estado de Săo Paulo & 3 & geladeira & Mappin & & & $9.790,00$ & & 2,36 & Climax Luxo & 395,62 & 707.78 \\
\hline $7 / 8 / 1980$ & 33 & O Estado de Săo Paulo & 3 & geladeira & Ultralar & & & $10.690,00$ & & 2,58 & Climax Primavera Luxo & 431,99 & 772,85 \\
\hline $7 / 9 / 1980$ & 33 & O Estado de Săo Paulo & 3 & geladeira & Ultralar & & & $10.990,00$ & & 2,05 & Consul Luxo 285 litros & 444,11 & 794,53 \\
\hline $7 / 8 / 1980$ & 33 & O Estado de Săo Paulo & 3 & geladeira & Ultralar & & & $13.990,00$ & & 3,37 & Gelomatic 330 litros & 565,35 & $1.011,42$ \\
\hline $21 / 9 / 1980$ & 16 & O Estado de Săo Paulo & 3,1 & geladeira & Mappin & & & $21.490,00$ & & 5,18 & Frigidaire 340 litros & 868,43 & $1.553,64$ \\
\hline $7 / 9 / 1980$ & 10 & O Estado de Săo Paulo & 4 & fogäo & Arapuä & 598,00 & 400,00 & $4.990,00$ & 12 & 1,20 & Alvorada Ouro & 201,65 & 360,76 \\
\hline 7/9/1980 & 10 & O Estado de Săo Paulo & 4 & fogăo & Arapuă & 989,00 & $1.290,00$ & $9.990,00$ & 15 & 2,41 & Continental 2001 Arabesque 4 bocas & 403,70 & 722,24 \\
\hline $7 / 9 / 1980$ & 10 & O Estado de Săo Paulo & 4 & fogäo & Arapuă & $1.695,00$ & $1.890,00$ & $14.890,00$ & 12 & 3,59 & Continental 2001 Arabesque II - 6 bocas & 601,72 & $1.076,48$ \\
\hline 14/9/1980 & 13 & O Estado de Săo Paulo & 4 & fogäo & Arapuä & & & $9.990,00$ & & 2,41 & Continental 2001 Arabesque 15 & 403,70 & 722,24 \\
\hline $28 / 9 / 1980$ & 10 & O Estado de Săo Paulo & 4 & fogăo & Arapuă & & & $4.990,00$ & & 1,20 & Esmaltec Alvorada Ouro & 201,65 & 360,76 \\
\hline $28 / 9 / 1980$ & 10 & O Estado de Săo Paulo & 4 & fogăo & Arapuă & & & $9.990,00$ & & 2,41 & Continental 2001 & 403,70 & 722,24 \\
\hline $7 / 9 / 1980$ & 37 & O Estado de Săo Paulo & 4 & fogăo & Jumbo Eletro & & & $5.380,00$ & & 1,30 & Dako Super Palace & 217,41 & 388,25 \\
\hline $21 / 9 / 1980$ & 33 & O Estado de Săo Paulo & 4 & fogăo & Jumbo Eletro & & & $12.590,00$ & & 3,03 & Continental 2001 Lumiere & 508,77 & 910.21 \\
\hline $28 / 9 / 1980$ & 21 & O Estado de Săo Paulo & 4 & fogăo & Mappin & & & $12.990,00$ & & 3,13 & Continental 2001 Mirage & 524,93 & 939,13 \\
\hline $14 / 9 / 1980$ & 6 & O Estado de Săo Paulo & 4 & fogăo & Mesbla & & & $8.990,00$ & & 2,17 & Continental Caprice & 363,29 & 648,94 \\
\hline $14 / 9 / 1980$ & 6 & O Estado de Săo Paulo & 4 & fogäo & Mesbla & & & $15.090,00$ & & 3,64 & Continental Caprice 15 & 609,80 & $1.080,95$ \\
\hline $21 / 9 / 1980$ & 20 & O Estado de Săo Paulo & & fogäo & Ultralar & & & $7.590,00$ & & 1,83 & Continental Meridien 4 bocas & 306,72 & 548,73 \\
\hline $7 / 8 / 1980$ & 37 & O Estado de Săo Paulo & & rádio & Jumbo Eletro & & & $1.490,00$ & & 0,38 & Philips Beira Rio portát| & 60,21 & 107,72 \\
\hline
\end{tabular}




\begin{tabular}{|c|c|c|c|c|c|c|c|c|c|c|c|c|c|}
\hline \multirow{2}{*}{\multicolumn{3}{|c|}{$\begin{array}{l}\text { mès / ano - setembro de } 1980 \\
\text { produto - diversos }\end{array}$}} & \multirow{2}{*}{\multicolumn{7}{|c|}{ Salário mínimo em 01.05.1980 - Cr5 4.149.60 }} & \multirow{2}{*}{\multicolumn{4}{|c|}{$\begin{array}{l}\text { pesq. em: Arquivo de Estado de Săo Paulo } \\
\text { data: } 18 / 12 / 2005\end{array}$}} \\
\hline & & & salário i & & & & & & & & & & \\
\hline data & pág. & jornal consultado & $\begin{array}{l}\text { cod } \\
\text { prod. }\end{array}$ & produto & loja & $\begin{array}{l}\text { prest. à } \\
\text { prazo }\end{array}$ & entrada & preço à vista & $\begin{array}{c}\mathrm{n}^{\circ} \\
\text { parc. }\end{array}$ & $\begin{array}{c}\text { qtd de } \\
\text { SM }\end{array}$ & descriçăo do produto & $\begin{array}{c}\text { atualiz. p' } \\
\text { IPC-SP } \\
\text { FIPE }\end{array}$ & $\begin{array}{l}\text { atualiz. p/ } \\
\text { SM de } \\
2005\end{array}$ \\
\hline $7 / 9 / 1980$ & 33 & O Estado de Săo Paulo & & rádio & Ultralar & & & $1.690,00$ & & 0,41 & Philips RL197 portátil & 68,29 & 122,18 \\
\hline $7 / 9 / 1980$ & 33 & O Estado de Säo Paulo & 5 & rádio & Ultralar & & & $1.790,00$ & & 0,43 & Philips RL150 portátil & 72,34 & 129,41 \\
\hline 7/9/1980 & 35 & O Estado de Sắo Paulo & 5 & rádio & Ultralar & & & 2290,00 & & 0,55 & Nissei RP36 & 92,54 & 165,56 \\
\hline 7/9/1980 & 12 & O Estado de Sắo Paulo & $8 \mid 1$ & maq costura & Arapuă & 1.125 .00 & & $9.990,00$ & 15 & 2,41 & Singer Standard & 403,70 & 722,24 \\
\hline $7 / 9 / 1980$ & 12 & O Estado de Săo Paulo & 6 & maq costura & Arapuä & $1.799,00$ & & $15.940,00$ & 15 & 3,84 & Singer Zig-zag & 644,15 & $1.152,40$ \\
\hline 21/8/1980 & 13 & O Estado de Sä́o Paulo & 81 & maq costura & Arapuă & & & $8.890,00$ & & 2,14 & Elgin Standard & 359,25 & 642,71 \\
\hline 28/9/1980 & 10 & O Estado de Sắ Paulo & 6 & maq costura & Arapuă & & & $14.990,00$ & & 3,61 & Elgin Zig-zag & 605,78 & $1.083,72$ \\
\hline $7 / 7 / 1980$ & 20 & O Estado de Săo Paulo & 6 , & maq costura & Mappin & & & $9.850,00$ & & 2,40 & Elgin Bracolivive 2000 & 402,00 & 719,35 \\
\hline 7/9/1980 & 20 & O Estado de Sắo Paulo & $8 \mid$ & maq costura & Mappin & & & $12.890,00$ & & 3,11 & Singer Zig-zag & 520,89 & 931,90 \\
\hline 7/9/1980 & 33 & O Estado de Săo Paulo & 81 & maq costura & Ultralar & & & $8.590,00$ & & 2,07 & Singer Standard & 347,13 & 621,02 \\
\hline $7 / 9 / 1980$ & 33 & O Estado de Sắo Paulo & 6 & maq costura & Ultralar & & & $16.499,00$ & & 3,88 & Singer Zig-zag & 666,74 & $1.182,81$ \\
\hline $7 / 9 / 1980$ & 33 & O Estado de Săo Paulo & 8 & maq costura & Ultralar & & & $19.399,00$ & & 4,67 & Singer Facilita & 783,83 & $1.402,47$ \\
\hline $21 / 9 / 1980$ & 29 & O Estado de Săo Paulo & $6 \mid$ & maq costura & Ultralar & & & $14.790,00$ & & 3,56 & Singer Zig-zag & 597,67 & $1.069,26$ \\
\hline $7 / 7 / 1980$ & 10 & O Estado de Sắo Paulo & $7 f_{f}$ & ferro elétrico & Arapuă & & & 330,00 & & 0,08 & Tupi elétrico & 13,34 & 23,86 \\
\hline $21 / 8 / 1980$ & 33 & O Estado de Sắo Paulo & $7 \mathrm{f}$ & ferro elétrico & Jumbo Eletro & & & 320,00 & & 0,08 & Cobra & 12,83 & 23,13 \\
\hline $7 / 7 / 1980$ & 20 & O Estado de Săo Paulo & 7 f $\mathrm{f}$ & ferro elétrico & Mappin & & & 795,00 & & 0,10 & GE automático & 32,13 & 57,48 \\
\hline 7/9/1980 & 33 & O Estado de Săo Paulo & 8 & secador de cabelo & Ultralar & & & $1.690,00$ & & 0,41 & Braun & 68,29 & 122,18 \\
\hline 7/9/1980 & 33 & O Estado de Sắo Paulo & 8 & secador de cabelo & Ultralar & & & $1.790,00$ & & 0,43 & Braun & 72,34 & 128,41 \\
\hline $7 / 9 / 1980$ & 33 & O Estado de Sắo Paulo & 8 & secador de cabelo & Ultralar & & & $2.190,00$ & & 0,53 & Arno & 88,50 & 158,33 \\
\hline 28/9/1980 & 10 & O Estado de Săo Paulo & of & enceradeira & Arapuă & & & $3.390,00$ & & 0,82 & Walita WI & 136,99 & 245,08 \\
\hline $7 / 9 / 1980$ & 37 & O Estado de Săo Paulo & 10 & aspirador de pó & Jumbo Eletro & & & $5.950,00$ & & 1,43 & GE Luxo & 240,44 & 430,16 \\
\hline $21 / 9 / 1980$ & 33 & O Estado de Săo Paulo & 10 & aspirador de pó & Jumbo Eletro & & & $4.750,00$ & & 1,14 & Arno & 181,95 & 343,41 \\
\hline 28/9/1980 & 10 & O Estado de Săo Paulo & 111 & liquidificador & Arapuă & & & $1.699,00$ & & 0,41 & Walita Polivalente LS & 68,66 & 122,83 \\
\hline $7 / 9 / 1980$ & 37 & O Estado de Sắo Paulo & 11 & liquidificador & Jumbo Eletro & & & $1.480,00$ & & 0,36 & Walita Polivalente & 59,81 & 107,00 \\
\hline $21 / 8 / 1980$ & 33 & O Estado de Săo Paulo & 111 & liquidificador & Jumbo Eletro & & & $1.140,00$ & & 0,27 & Arno & 46,07 & 82,42 \\
\hline 21/8/1980 & 15 & O Estado de Săo Paulo - & 111 & liquidificador & reportagem & & & $1.950,00$ & & 0,47 & Arno LR & 78,80 & 140,98 \\
\hline $21 / 8 / 1980$ & 15 & O Estado de Săo Paulo - & $11 \mid$ & liquidificador & reportagem & & & $2.900,00$ & & 0,70 & Walita Polivalente & 117,19 & 209,66 \\
\hline $21 / 2 / 1980$ & 15 & O Estado de Săo Paulo - & 111 & liquidificador & reportagem & & & $3.200,00$ & & 0,77 & Arno Eletrônico & 129,31 & 231,35 \\
\hline $7 / 9 / 1980$ & 37 & O Estado de Săo Paulo & $18 \mid$ & batedeira bolo & Jumbo Eletro & & & $3.740,00$ & & 0,80 & Arno 5 velocidades & 151,14 & 270,39 \\
\hline $21 / 9 / 1980$ & 33 & O Estado de Săo Paulo & 16 & batedeira bolo & Jumbo Eletro & & & $1.980,00$ & & 0,48 & Arno Super & 80,01 & 143,15 \\
\hline $7 / 9 / 1980$ & 10 & O Estado de Săo Paulo & $\left.17\right|_{1}$ & panela pressão & Arapuă & & & 530,00 & & 0,13 & Rochedo 4,5 litros & 21,42 & 38,32 \\
\hline $28 / 9 / 1980$ & 21 & O Estado de Săo Paulo & 28 & secadora roupas & Mappin & & & $24.480,00$ & & 5,80 & Consul & 889,25 & $1.709,81$ \\
\hline 28/9/1980 & 25 & O Estado de Săo Paulo & 28 & secadora roupas & Mesbla & & & $24.500,00$ & & 5,80 & Consul & 900,06 & $1.771,26$ \\
\hline $7 / 9 / 1980$ & 21 & O Estado de Sä́o Paulo & $32 \mid$ & lava louça maq & Mappin & & & $36.990,00$ & & 8,81 & Brastemp Luxo automática & $1.494,79$ & $2.674,23$ \\
\hline 7/9/1980 & 33 & O Estado de Sắo Paulo & $32 \mid$ & Iava louça maq & Ultralar & & & $56.800,00$ & & 13,60 & Continental 2001 & $2.295,33$ & $4.106,42$ \\
\hline
\end{tabular}




\begin{tabular}{|c|c|c|c|c|c|c|c|c|c|c|c|c|c|}
\hline \multicolumn{3}{|c|}{$\begin{array}{l}\text { més / ano - setembro de } 1990 \\
\text { oroduto - diversos }\end{array}$} & \multicolumn{7}{|c|}{ Salário mínimo em 01.09.1990 - Cr\$ 6.056,31 } & \multicolumn{4}{|c|}{$\begin{array}{l}\text { pesq. em: Arquivo de Estado de Săo Paulo } \\
\text { data: } 18 / 12 / 2005-22 / 12 / 2005\end{array}$} \\
\hline data & pág. & jornal consultado & $\begin{array}{l}\text { cod } \\
\text { prod. }\end{array}$ & produto & loja & $\begin{array}{l}\text { prest. à } \\
\text { prazo }\end{array}$ & entrada & preço à vista & $\begin{array}{c}n^{\circ} \\
\text { parc. }\end{array}$ & $\begin{array}{l}\text { qtd de } \\
\text { SM }\end{array}$ & descrição do produto & $\begin{array}{l}\text { atualiz.p p/ } \\
\text { IPC-SP } \\
\text { FIPE }\end{array}$ & $\begin{array}{l}\text { atualiz. p/ } \\
\text { SM de } \\
2005\end{array}$ \\
\hline $2 / 9 / 1990$ & 24 & O Estado de São Paulo & & maq lavar roupa & Arapuã & $15.900,00$ & & $58.900,00$ & $\bar{\theta}$ & 9,73 & Frigidaine & $1.601,16$ & $2.817,62$ \\
\hline 9/9/1990 & 30 & O Estado de São Paulo & & maq lavar roupa & Arapuã & $13.800,00$ & $13.800,00$ & $62.900,00$ & 8 & 10,39 & Brastemp Mondial 56M GA & $1.709,80$ & $3.115,76$ \\
\hline 2/8/1990 & 15 & O Estado de São Paulo & & maq lavar roupa & Casas Bahia & $20.380,00$ & & $63.900,00$ & 4 & 10,55 & Brastemp Mondial 56M GA & $1.737,08$ & 3.165 .29 \\
\hline $9 / 9 / 1900$ & 10 & O Estado de São Paulo & & maq lavar roupa & Casas Bahia & $19.600,00$ & $19.600,00$ & $50.900,00$ & 3 & 9,89 & White Westinghouse eletrônica até $6 \mathrm{Kg}$ & $1.628,35$ & $2.867,15$ \\
\hline 13/9/1900 & 10 & O Estado de São Paulo & & maq lavar roupa & Casas Bahia & $19.600,00$ & $19.600,00$ & $59.900,00$ & 3 & 9,89 & White Westinghouse Eletrơnica até $6 \mathrm{~kg}$ & $1.628,35$ & $2.867,15$ \\
\hline $16 / 9 / 1990$ & 11 & O Estado de São Paulo & & maq lavar roupa & Casas Bahia & $19.600,00$ & $19.600,00$ & $59.900,00$ & 3 & 8,89 & White Westinghouse Eletrónica até $6 \mathrm{~kg}$ & $1.628,35$ & $2.867,15$ \\
\hline 16/8/1990 & 9 & O Estado de São Paulo & & maq lavar roupa & Jumbo Eletro & & & $62.500,00$ & & 10,32 & Brastemp Mondial $6 \mathrm{~kg}$ & $1.699,03$ & $3.085,94$ \\
\hline $9 / 9 / 1900$ & 27 & O Estado de São Paulo & & maq lavar roupa & Jumbo Extra & & & $44.900,00$ & & 7.41 & Brastemp BL 1000 & $1.220,58$ & $2.224,13$ \\
\hline 9/8/1980 & 8 & O Estado de São Paulo & & maq lavar roupa & Mahfuz & $21.900,00$ & & $54.890,00$ & 3 & 9,06 & Brastemp Luxo Plus $6 \mathrm{~kg}$ & $1.492,15$ & $2.718,98$ \\
\hline 16/9/1980 & 25 & O Estado de São Paulo & & maq lavar roupa & Mappin & & & $57.900,00$ & & 9.56 & Brastemp Mondial & $1.573,88$ & $2.868,08$ \\
\hline 6/9/1980 & 13 & O Estado de São Paulo & & maq lavar roupa & Ponto Frio & & & $51.800,00$ & & 8.55 & Brastemp BLK 24 MSA Luxo Plus c/ Magic Mix & $1.408,15$ & $2.565,92$ \\
\hline 9/9/1980 & 4 & O Estado de Sâo Paulo & & maq lavar roupa & Ponto Frio & $13.570,00$ & & $51.800,00$ & 6 & 8,55 & Brastemp BLK 24 MSA Luxo Plus c/ Magic Mix & $1.408,15$ & $2.585,92$ \\
\hline 9/9/1990 & 4 & O Estado de São Paulo & & maq lavar roupa & Ponto Frio & $13.570,00$ & & $51.800,00$ & 8 & 8,55 & Brastemp BLK 24 MSA Luxo Plus c/ Magic Mix & $1.408,15$ & $2.586,92$ \\
\hline 9/8/1980 & 31 & O Estado de São Paulo & & TV P\&B & Arapuã & $5.480,00$ & $5.480,00$ & $20.900,00$ & 5 & 3,45 & Philips $12^{\circ}$ & 568,15 & 1.035 .28 \\
\hline 9/8/1980 & 27 & O Estado de São Paulo & & TV P\&B & Jumbo Extra & & & $25.000,00$ & & 4.13 & Philips TL6138 17* & 879,61 & $1.238,38$ \\
\hline 9/8/1980 & 27 & O Estado de São Paulo & & TVPBB & Paes Mendonça & & & $27.485,00$ & & 4,54 & Philips TL.6138 $17^{*}$ & 747,16 & 1.361 .47 \\
\hline 9/8/1980 & 31 & O Estado de São Paulo & 2,1 & TV a cores & Arapuã & & & $41.900,00$ & & 6,92 & Philips $14^{\circ}$ UHF e VHF & $1.139,03$ & $2.075,52$ \\
\hline $9 / 9 / 1980$ & 31 & O Estado de Sâo Paulo & 2,1 & TV a cores & Arapuã & $15.800,00$ & $15.800,00$ & $64.900,00$ & 6 & 10,72 & Toshiba - $16^{\prime \prime}-31$ funcões & $1.784,27$ & $3.214,83$ \\
\hline 16/9/1900 & 17 & O Estado de São Paulo & 2,1 & TV a oores & Audio & & & $59.980,00$ & & 9,81 & Mitsubishi TC 1441 - $14^{\prime \prime}$ ol controle remoto & $1.630,79$ & 2.971 .61 \\
\hline 16/9/1980 & 17 & O Estado de São Paulo & 2,1 & TV a cores & Audio & & & $63.980,00$ & & 10,57 & Philips GL $1310-14^{\prime \prime}$ ol controle remoto & $1.739,53$ & $3.169,75$ \\
\hline $16 / 9 / 1990$ & 17 & O Estado de São Paulo & 2,1 & TV a cores & Audio & & & $73.980,00$ & & 12,22 & Panasonic $20 \mathrm{C} 2-20^{\circ} \mathrm{c} /$ controle remoto & $2.011,37$ & $3.685,10$ \\
\hline 16/8/1990 & 17 & O Estado de Sâo Paulo & 2,1 & TV a cores & Audio & & & $78.980,00$ & & 13,04 & Philips GL $1340-20^{\prime \prime}$ d controle remoto & $2.147,30$ & $3.912,78$ \\
\hline 16/9/1900 & 17 & O Estado de São Paulo & 2,1 & TV a cores & Audio & & & $78.980,00$ & & 13,04 & Mitsubishi TC 2091 - 20" ol controle remoto & $2.147,30$ & $3.912,78$ \\
\hline $16 / 9 / 1980$ & 17 & O Estado de Sâo Paulo & 2,1 & TV a cores & Audio & & & $89.980,00$ & & 16,51 & Mitsubishi TC 2094 - 20" of controle remoto & $2.718,17$ & $4.853,02$ \\
\hline $2 / 9 / 1980$ & 10 & O Estado de São Paulo & 2,1 & TV a cores & Buri & $25.600,00$ & $25.680,00$ & $76.900,00$ & 3 & 12,70 & Panasonic $20^{\circ} \mathrm{cl}$ controle remoto 25 funcōes/timer TVC $20 \mathrm{C2}$ & $2.090,48$ & 3.800 .25 \\
\hline 2/8/1990 & 10 & O Estado de São Paulo & 2,1 & TV a cores & Buri & & & $89.500,00$ & & 14,78 & Toshiba TS-218 - $21^{\prime}$ & $2.433,00$ & $4,433,39$ \\
\hline $8 / 8 / 1980$ & 19 & O Estado de São Paulo & 2,1 & TV a cores & Buri & & & $60.000,00$ & & 8,21 & Toshiba $20^{\circ}$ TS $205-\mathrm{VHF} / \mathrm{UHF}$ & $1.631,06$ & $2.972,11$ \\
\hline 9/9/1990 & 27 & O Estado de São Paulo & 2,1 & TV a cores & Carrefour & & & $54.900,00$ & & 9,06 & Philips GL $1030-16^{\prime \prime}$ & $1.492,42$ & 2.719 .48 \\
\hline 9/9/1990 & 27 & O Estado de São Paulo & 2,1 & TV a cores & Carrefour & & & $68.900,00$ & & 11,38 & Philips GL $1340-20^{\prime \prime}$ ol controle remoto & $1.873,01$ & $3.412,97$ \\
\hline $2 / 9 / 1900$ & 6 & O Estado de São Paulo & 2,1 & TV a cores & Casa Centro & & & $41.900,00$ & & 6,92 & Semp Toshiba $143-14^{*}$ UHF-VHF & $1.139,03$ & $2.075,52$ \\
\hline 16/9/1980 & 6 & O Estado de São Paulo & 2,1 & TV a cores & Casa Centro & & & $48.900,00$ & & 8,07 & Semp Toshiba $147-14^{\circ} \mathrm{c} /$ controle remoto & $1.329,32$ & 2.422 .27 \\
\hline $2 / 9 / 1990$ & 38 & O Estado de São Paulo & 2,1 & TV a cores & Casas Bahia & $14.000,00$ & $14.000,00$ & $43.900,00$ & 3 & 7,25 & Mitsubishi TC-1427 - $14^{*}$ VHF e UHF & $1.193,40$ & $2.174,50$ \\
\hline $2 / 9 / 1980$ & 38 & O Estado de São Paulo & 2,1 & TV a cores & Casas Bahia & $15.920,00$ & $15.820,00$ & $49.900,00$ & 3 & 8.24 & Philoo Hitachi PC-2027 UHF/VHF & $1.356,50$ & $2.471,80$ \\
\hline $2 / 8 / 1990$ & 38 & O Estado de São Paulo & 2,1 & TV a cores & Casas Bahia & $19.100,00$ & $19.100,00$ & $59.900,00$ & 3 & 9,89 & Philoo Hitachi PC-2028 c/ controle remoto UHF/VHF - 20" & $1.828,35$ & $2.867,15$ \\
\hline $2 / 8 / 1980$ & 14 & O Estado de São Paulo & 2,1 & TV a cores & Casas Bahia & $21.850,00$ & & $69.900,00$ & 4 & 11,54 & Mitsubishi TC-2091 ol controle remoto / VHF e UHF & $1.800,19$ & $3.462,50$ \\
\hline $8 / 8 / 1980$ & 10 & O Estado de São Paulo & 2,1 & TV a cores & Casas Bahia & $18.780,00$ & $18.790,00$ & $58.900,00$ & 3 & 9,73 & Mitsubishi TC2090 - $20^{\circ}-$ VHF e UHF & $1.601,18$ & $2.917,62$ \\
\hline $6 / 8 / 1980$ & 10 & O Estado de Sâo Paulo & 2,1 & TV a cores & Casas Bahia & $18.100,00$ & $19.100,00$ & $59.900,00$ & 3 & 8,89 & Sanyo CTP 6756 - 20" ol controle remoto VHF e UHF & $1.628,35$ & $2.867,15$ \\
\hline 6/8/1990 & 10 & O Estado de São Paulo & 2,1 & TV a cores & Casas Bahia & $21.950,00$ & $21.850,00$ & $69.900,00$ & 3 & 11,54 & Mitsubishi TC2091 - 20 c/ controle remoto & $1.800,19$ & $3.462,50$ \\
\hline 9/8/1980 & 10 & O Estado de Sâo Paulo & 2,1 & TV a cores & Casas Bahia & $13.700,00$ & $13.700,00$ & $41.900,00$ & 3 & 6,92 & Telefunken C-2200 $16^{\circ}$ seletor rotativo & $1.139,03$ & $2.075,52$ \\
\hline
\end{tabular}




\begin{tabular}{|c|c|c|c|c|c|c|c|c|c|c|c|c|c|}
\hline \multicolumn{3}{|c|}{$\begin{array}{l}\text { més / ano - setembro de } 1990 \\
\text { groduto - diverso5 }\end{array}$} & \multicolumn{7}{|c|}{ Salário mínimo em 01.09.1990 - Cr\$ 6.056,31 } & \multicolumn{4}{|c|}{$\begin{array}{l}\text { pesq. em: Arquivo de Estado de Săo Paulo } \\
\text { data: } 18 / 12 / 2005-22 / 12 / 2005\end{array}$} \\
\hline data & pág. & jornal consultado & $\begin{array}{c}\text { cod } \\
\text { prod. }\end{array}$ & produto & loja & $\begin{array}{l}\text { prest. à } \\
\text { prazo }\end{array}$ & entrada & preço à vista & $\begin{array}{c}\mathrm{n}^{\circ} \\
\text { parc. }\end{array}$ & $\begin{array}{l}\text { qtd de } \\
\text { SM }\end{array}$ & descrição do produto & $\begin{array}{c}\text { atualiz. pl } \\
\text { IPC-SP } \\
\text { FIPE }\end{array}$ & $\begin{array}{l}\text { atualiz. p' } \\
\text { SM de } \\
2005\end{array}$ \\
\hline 9/9/1980 & 10 & O Estado de São Paulo & 2,1 & TV a cores & Casas Bahia & $15.700,00$ & $15.700,00$ & $47.900,00$ & 3 & 7,21 & Telefunken C-2250 20' - VHF e UHF & $1.302,13$ & 2.372 .73 \\
\hline 919/19e0 & 13 & O Estado de Sâo Paulo & 2,1 & TV a cores & Casas Bahia & $12.300,00$ & $12.300,00$ & $47.900,00$ & 5 & 7,21 & CCE HPS $2010-20^{\prime \prime}$ UHF e VHF & $1.302,13$ & $2.372,73$ \\
\hline 9/9/1990 & 13 & Estado de São Paulo & 2,1 & TV a cores & Casas Bahia & 14.880 .00 & $14.880,00$ & $57.900,00$ & 5 & 9,56 & CCE HPS $2050-20^{\prime \prime}$ UHF $\in$ VHF ol controle remoto & $1.573,98$ & $2.888,08$ \\
\hline 9/9/1980 & 13 & O Estado de São Paulo & 2,1 & TV a cores & Casas Bahia & 15.140 .00 & $15.140,00$ & $58.900,00$ & 5 & 9,73 & Mitsubishi TC-2080 20" UHF/NHF seletor soft touch & $1.601,18$ & $2.917,62$ \\
\hline 13/8/1980 & 11 & O Estado de São Paulo & 2,1 & TV a cores & Casas Bahia & $16.320,00$ & $16.320,00$ & $49.900,00$ & 3 & 8.24 & Semp Toshiba TVC-185 - $16^{\prime \prime}$ & $1.356,50$ & $2.471,80$ \\
\hline $13 / 8 / 1990$ & 11 & O Estado de Sâo Paulo & 2,1 & TV a cores & Casas Bahia & $16.320,00$ & $16.320,00$ & $49,900,00$ & 3 & 8,24 & Telefunken C-3250- $20^{*}$ & $1.356,50$ & $2.471,80$ \\
\hline 13/9/1990 & 11 & O Estado de São Paulo & 2,1 & TV a cores & Casas Bahia & $16.320,00$ & $16.320,00$ & $49.900,00$ & 3 & 8,24 & Telefunken C-2250 $20^{\circ}-\mathrm{VHF}$ e UHF & $1.356,50$ & $2.471,80$ \\
\hline $13 / 8 / 1980$ & 12 & O Estado de Sâo Paulo & 2,1 & TV a cores & Casas Bahia & 19.580 .00 & $19.590,00$ & $59.900,00$ & 3 & 9.89 & Mitsubishi TC-1441 - $14^{*}$ clcontrole remoto & $1.628,35$ & $2.867,15$ \\
\hline $13 / 8 / 1980$ & 12 & Estado de São Paulo & 2,1 & TV a cores & Casas Bahia & $15.380,00$ & $15.390,00$ & $59.900,00$ & 5 & 9,89 & Mitsubishi TC-2080 - $20^{\circ}$ & $1.628,35$ & $2.867,15$ \\
\hline 13/8/1980 & 11 & O Estado de São Paulo & 2,1 & TV a cores & Casas Bahia & $20.570,00$ & $20.570,00$ & $62.900,00$ & 3 & 10,38 & Sanyo CTP $6756-20^{\prime \prime}$ ol controle remoto VHF e UHF & $1.709,80$ & $3.115,76$ \\
\hline $13 / 8 / 1980$ & 12 & O Estado de São Paulo & 2,1 & TV a cores & Casas Bahia & $20.570,00$ & $20.570,00$ & $62.900,00$ & 3 & 10,39 & Mitsubishi TC-1631 - $16^{\circ} \mathrm{c} /$ controle remoto & $1.709,20$ & $3.115,76$ \\
\hline $16 / 9 / 1990$ & 15 & O Estado de São Paulo & 2,1 & TV a cores & Casas Bahia & $14.360,00$ & $14.360,00$ & $43.900,00$ & 3 & 7,25 & CCE $1415-14^{\prime} \mathrm{VHF}$ e UHF & $1.193,40$ & $2.174,59$ \\
\hline $16 / 8 / 1980$ & 10 & O Estado de São Paulo & 2,1 & TV a cores & Casas Bahia & 18.320 .00 & $16.320,00$ & $49.900,00$ & 3 & 8,24 & Telefunken $\mathrm{C}-3250-20^{\circ}$ & $1.356,50$ & $2.471,80$ \\
\hline 16/8/1980 & 15 & O Estado de Sấ Paulo & 2,1 & TV a cores & Casas Bahia & $12.800,00$ & $12.800,00$ & $49.900,00$ & 5 & 8,24 & CCE HPS $2010-20^{\prime \prime}$ UHF e VHF & $1.356,50$ & $2.471,80$ \\
\hline $16 / 8 / 1980$ & 10 & O Estado de Sâo Paulo & 2,1 & TV a cores & Casas Bahia & $15.380,00$ & $15.390,00$ & $58.900,00$ & 5 & 9,89 & Mitsubishi TC-2080 - $20^{*}$ cl controle remoto & $1.628,35$ & $2.867,15$ \\
\hline 16/8/1980 & 15 & O Estado de São Paulo & 2,1 & TV a cores & Casas Bahia & $15.400,00$ & $15.400,00$ & $58.900,00$ & 5 & 9,89 & CCE HPS $2050-20^{\prime \prime}$ UHF e VHF cl controle remoto & $1.628,35$ & $2.867,15$ \\
\hline $9 / 9 / 1990$ & 27 & O Estado de São Paulo & 2,1 & TV a cores & Eldorado & & & $68.024,00$ & & 11,23 & Philips GL $1340-20^{\prime \prime}$ ol controle remoto & $1.849,19$ & 3.360 .58 \\
\hline 9/9/1980 & 27 & O Estado de São Paulo & 2,1 & TV a cores & Eldorado & & & $74.000,00$ & & 12,22 & Philips GL $1310-14^{\prime \prime}$ d controle remoto & $2.011,65$ & $3.685,60$ \\
\hline 8/9/1900 & 7 & Estado de São Paulo & 2,1 & TV a cores & Jumbo Eletro & & & $58.000,00$ & & 9,58 & Philips color 20 - $1040-20^{\prime \prime}$ & $1.576,70$ & $2.873,04$ \\
\hline 8/9/1900 & 27 & O Estado de São Paulo & 2,1 & TV a cores & Jumbo Extra & & & $49.800,00$ & & 8,22 & Philips GL 1030 - 16" & $1.353,78$ & $2.468,85$ \\
\hline 919/1980 & 27 & O Estado de Sâo Paulo & 2,1 & TV a cores & Jumbo Extra & & & $54,000,00$ & & 8,92 & Philips GL 1310 - $14^{\prime \prime}$ d controle remoto & $1.467,86$ & $2.674,80$ \\
\hline 9/9/1990 & 27 & Estado de São Paulo & 2,1 & TV a cores & Jumbo Extra & & & $62.800,00$ & & 10,37 & Philips GL $1340-20^{\prime \prime}$ d controle remoto & $1.707,18$ & $3.110,81$ \\
\hline $16 / 8 / 1980$ & 20 & O Estado de São Paulo & 2,1 & TV a cores & Mappin & & & $49.800,00$ & & 8,22 & Philips GL 1040 - 20" & $1.353,78$ & $2.468,85$ \\
\hline 9/9/1980 & 27 & O Estado de Sâo Paulo & 2,1 & TV a cores & Paes Mendonça & & & $54.880,00$ & & 9,06 & Philips GL $1030-16^{\prime \prime}$ & $1.491,34$ & $2.717,50$ \\
\hline 919/1900 & 27 & O Estado de São Paulo. & 2,1 & TV a cores & Paes Mendonça & & & $63.615,00$ & & 10,50 & Philips GL $1310-14^{\prime \prime}$ d controle remoto & $1.729,34$ & $3.151,18$ \\
\hline $2 / 9 / 1900$ & 25 & O Estado de São Paulo & 2,1 & TV a cores & Ponto Frio & $15.145,00$ & & $57.800,00$ & 6 & 9.54 & Mitsubishi TC-2080 20' UHF/NHF seletor soft touch & $1.571,26$ & $2.863,13$ \\
\hline $8 / 9 / 1980$ & 13 & O Estado de Sâo Paulo & 2,1 & TV a cores & Ponto Frio & & & $43.900,00$ & & 7.25 & Sharp TVC Wild C-1410 14" & $1.193,40$ & $2.174,59$ \\
\hline 6/9/1980 & 13 & O Estado de São Paulo & 2,1 & TV a cores & Ponto Frio & & & $49,900,00$ & & 8,24 & Sharp TV-2035 B TV Winner 20' 111 canais & $1.356,50$ & $2.471,80$ \\
\hline 9/9/1980 & 4 & O Estado de São Paulo & 2,1 & TV a cores & Ponto Frio & $11.160,00$ & & $42,600,00$ & 6 & 7,03 & Semp Toshiba TVC $143-14^{\circ}$ tecla TV-VTR & $1.158,06$ & 2.110 .20 \\
\hline 9/9/1980 & 4 & O Estado de São Paulo & 2,1 & TV a cores & Ponto Frio & 12.260 .00 & & $46.800,00$ & 6 & 7,73 & Semp Toshba TVC $165-16^{*}$ tecla TV-VTR & $1.272,23$ & 2.318 .24 \\
\hline 9/9/1990 & 4 & O Estado de São Paulo & 2,1 & TV a cores & Ponto Frio & $13.600,00$ & & $51.900,00$ & 6 & 8,57 & Semp Toshiba TVC $205-20^{\circ}$ tecla TV-VTR & $1.410,87$ & $2.570,87$ \\
\hline 13/9/1990 & 9 & O Estado de São Paulo & 2,1 & TV a cores & Ponto Frio & & & $47,200,00$ & & 7,79 & Philips 1030 - $18^{\prime \prime}$ & $1.283,10$ & $2.338,06$ \\
\hline $13 / 8 / 1980$ & 9 & O Estado de Sâo Paulo & 2,1 & TV a cores & Ponto Frio & & & $59.900,00$ & & 9.89 & Sharp Wild C-2050 20" d/ controle remoto & $1.628,35$ & $2.867,15$ \\
\hline 2/9/1990 & 41 & O Estado de São Paulo & 2,1 & TV a cores & Veneza Som & $13.254,00$ & $13.254,00$ & $38.890,00$ & 3 & 6,42 & Telefunken $14 \mathrm{C} 3250-14^{\prime \prime}$ & $1.057,20$ & $1.928,42$ \\
\hline $2 / 8 / 1980$ & 41 & O Estado de São Paulo & 2,1 & TV a cores & Veneza Som & $14.278,00$ & $14.276,00$ & $41.890,00$ & 3 & 6,22 & Telefunken $16 \mathrm{C} 3250-16^{\prime \prime}$ & $1.138,75$ & $2.075,03$ \\
\hline 2/9/1990 & 24 & O Estado de São Paulo & 3 & \begin{tabular}{|l|} 
geladeira \\
\end{tabular} & Arapuã & $9.900,00$ & & $38.900,00$ & 6 & 6.42 & Brastemp Quality 360 litros & $1.057,47$ & $1.926,92$ \\
\hline $2 / 9 / 1900$ & 24 & O Estado de São Paulo & 3. & geladeira & Arapuã & $11.800,00$ & & $49.990,00$ & 8 & 8.25 & Frigidaire 270 litros eletrónico & $1.358,25$ & 2.476 .26 \\
\hline 9/9/1990 & 30 & O Estado de São Paulo & & geladeira & Arapuã & $9.480,00$ & $9.490,00$ & $38.900,00$ & 6 & 6,42 & Brastemp Quality 380litros & $1.057,47$ & $1.928,92$ \\
\hline $2 / 9 / 1990$ & 10 & O Estado de São Paulo & & geladeira & Buri & & & $04.000,00$ & & 10,57 & Consul Biplex 430 litros & $1.739,80$ & 3.170 .25 \\
\hline
\end{tabular}




\begin{tabular}{|c|c|c|c|c|c|c|c|c|c|c|c|c|c|}
\hline \multicolumn{3}{|c|}{$\begin{array}{l}\text { més / ano - setembro de } 1990 \\
\text { groduto - diversos }\end{array}$} & \multicolumn{7}{|c|}{ Salário mínimo em 01.09.1990 - Cr\$ 6.056,31 } & \multicolumn{4}{|c|}{$\begin{array}{l}\text { pesq. em: Arquivo de Estado de Săo Paulo } \\
\text { data: 18/12/2005-22/12/2005 }\end{array}$} \\
\hline data & pág. & jornal consultado & \begin{tabular}{|l} 
cod \\
prod.
\end{tabular} & produto & loja & $\begin{array}{l}\text { prest. à } \\
\text { prazo }\end{array}$ & entrada & preço à vista & $\begin{array}{c}n^{\circ} \\
\text { parc. }\end{array}$ & $\begin{array}{l}\text { qtd de } \\
\text { SM }\end{array}$ & descrição do produto & $\begin{array}{l}\text { atualiz. p/ } \\
\text { IPC-SP } \\
\text { FIPE }\end{array}$ & $\begin{array}{l}\text { atualiz. p) } \\
\text { SM de } \\
2005\end{array}$ \\
\hline 6/9/1990 & 19 & O Estado de São Paulo & & 3. geladeira & Buri & $8.320,00$ & $8.320,00$ & $24.900,00$ & 3 & 4,11 & Climax 240 litros Super Luxo & 676,89 & $1.233,42$ \\
\hline $2 / 9 / 1990$ & 15 & O Estado de São Paulo & & | geladeira & Casas Bahia & $8.800,00$ & & $29.700,00$ & 3 & 4,90 & Brastemp 28X & 807,38 & $1.471,18$ \\
\hline 6/9/1900 & 15 & O Estado de São Paulo & & geladeira & Casas Bahia & $7.840,00$ & $7.840,00$ & $24.900,00$ & 3 & 4,11 & Climax 240 litros Super Luxo & 676,89 & $1.233,42$ \\
\hline 6/9/1980 & 15 & O Estado de São Paulo & & geladeira & Casas Bahia & $8.580,00$ & $8.580,00$ & $26.900,00$ & 3 & 4,44 & Climax 300 litros Luxo & 731,26 & 1.332 .48 \\
\hline 6/9/1980 & 10 & O Estado de São Paulo & & 3 geladera & Casas Bahia & $9.380,00$ & $9.380,00$ & $29.900,00$ & 3 & 4,94 & Consul 280 Itros & 812,81 & $1.481,10$ \\
\hline 9/9/19e0 & 10 & O Estado de São Paulo & & geladera & Casas Bahia & $8.800,00$ & $8.800,00$ & $26.900,00$ & 3 & 4,44 & Climax Super Luxo 300 Fitros & 731,28 & 1.332 .49 \\
\hline 9/8/1980 & 13 & O Estado de São Paulo & & geladera & Casas Bahia & $7.600,00$ & $7.600,00$ & $29.700,00$ & 5 & 4,90 & Brastemp 28X & 807,38 & $1.471,19$ \\
\hline 13/9/1980 & 10 & O Estado de São Paulo & & geladeira & Casas Bahia & $8.800,00$ & $8.800,00$ & $26.900,00$ & 3 & 4,44 & Climax Super Luxo 300 itros & 731,28 & 1.332 .49 \\
\hline 16/8/1990 & 11 & O Estado de Sâo Paulo & & geladeira & Casas Bahia & $8.800,00$ & $8.800,00$ & $26.900,00$ & 3 & 4,44 & Climax 300 litros Luxo & 731,28 & 1.332 .49 \\
\hline 9/9/1980 & 8 & O Estado de São Paulo & & geladera & Jumbo Eletro & & & $38.800,00$ & & 6,41 & Brastemp Quality || - 360 litros & $1.054,75$ & 1.921 .98 \\
\hline 16/8/1980 & 8 & O Estado de São Paulo & & geladera & Jumbo Eletro & & & $34.800,00$ & & 5.75 & Brastemp Quality 284 Itros & 946,02 & 1.723 .82 \\
\hline 9/8/1990 & 9 & O Estado de São Paulo & & | geladeira & Mahfuz & $9.380,00$ & & $23.500,00$ & 3 & 3,88 & Climax 240 litros Super Luxo & 638,83 & $1.104,08$ \\
\hline 9/9/1980 & 8 & O Estado de São Paulo & & geladeira & Mahfuz & $15.520,00$ & & $38.880,00$ & 3 & 6.42 & Brastemp 380 litros & $1.057,20$ & 1.826 .42 \\
\hline 9/9/1990 & 20 & O Estado de São Paulo & & geladeira & Mappin & & & $49.900,00$ & & 8,24 & Brastemp Duplex 340 Itros & $1.356,50$ & $2.471,80$ \\
\hline 16/8/1980 & 20 & O Estado de São Paulo & & geladeira & Mappin & & & $25.900,00$ & & 4.28 & Prosdócimo Spazio 310 litros & 704,08 & 1.282 .96 \\
\hline $2 / 8 / 1990$ & 25 & O Estado de São Paulo & & geladera & Ponto Frio & $6.850,00$ & & $26.520,00$ & 8 & 4,38 & Consul BU 28L - 253 litros & 720,83 & $1.313,67$ \\
\hline 9/9/1980 & 4 & O Estado de São Paulo & & geladeira & Ponto Frio & $9.930,00$ & & $37.900,00$ & 8 & 6.26 & Brastemp BR $36 \mathrm{ABC}-324$ litros & $1.030,29$ & $1.877,38$ \\
\hline 13/2/1990 & 9 & O Estado de São Paulo & & geladeira & Ponto Frio & & & $24.600,00$ & & 4,06 & Prosdócimo Flat escritório 150 litros & 668,74 & $1.218,56$ \\
\hline $16 / 9 / 1990$ & 40 & O Estado de São Paulo & & |geladeira & Ponto Frio & $9.230,00$ & & $33.800,00$ & 8 & 5,58 & Brastemp BRV 38 X - BRA 32 ABC - 294 litros & 218,83 & 1.674 .29 \\
\hline 2/9/1990 & 24 & O Estado de São Paulo & 3,1 & geladeira & Arapuã & $12.900,00$ & & $59.500,00$ & 8 & 9,82 & White-Westinghouse Super Freezer 450 litros & $1.817,47$ & $2.947,34$ \\
\hline 6/9/1980 & 15 & O Estado de São Paulo & 3,1 & geladeira & Casas Bahia & 19.110 .00 & $19.110,00$ & $59.900,00$ & 3 & 9,89 & White Westinghouse Duplex Luxo 450 litros Super Freezer & $1.628,35$ & $2.867,15$ \\
\hline 9/8/1980 & 10 & O Estado de São Paulo & 3,1 & geladeira & Casas Bahia & $19.590,00$ & $19.590,00$ & $59.900,00$ & 3 & 9,89 & White Westinghouse Duplex Luxo 450 litros Super Freezer & $1.828,35$ & $2.867,15$ \\
\hline 13/8/1990 & 10 & O Estado de São Paulo & 3,1 & geladeira & Casas Bahia & $18.590,00$ & $19.590,00$ & $59.900,00$ & 3 & 9,89 & White Westinghouse Duplex Luxo 450 litros Super Freezer & $1.628,35$ & $2.867,15$ \\
\hline 16/2/1990 & 11 & O Estado de São Paulo & 3,1 & geladera & Casas Bahia & $18.300,00$ & $18.300,00$ & $55.900,00$ & 3 & 9,23 & White Westinghouse Duplex Luxo 430 litros & $1.519,81$ & 2.769 .01 \\
\hline $2 / 9 / 1980$ & 35 & O Estado de São Paulo & 3,1 & geladeira & Eldorado Plaza & & & $65.900,00$ & & 10,88 & Prosolócimo geladeira e freezer duplo & $1.791,45$ & $3.264,36$ \\
\hline 9/9/1990 & 8 & O Estado de Sâo Paulo & 3,1 & geladeira & Jumbo Eletro & & & $89.000,00$ & & 14,70 & Brastemp Quality III Frost Free Duplex 420 litros & $2.419,41$ & $4,408,63$ \\
\hline $8 / 9 / 1980$ & 13 & O Estado de Sâo Paulo & 3,1 & geladera & Ponto Frio & & & $59.800,00$ & & 9.87 & Consul Biplex RD 43G 430 litros & $1.625,83$ & 2.862 .20 \\
\hline 9/8/1980 & 4 & O Estado de São Paulo & 3,1 & geladeira & Ponto Frio & $18.840,00$ & & $71.900,00$ & 8 & 11,87 & Brastemp Duplex BRF 44ABCSkyline - 440 litros & $1.954,56$ & $3.561,57$ \\
\hline 13/9/1980 & 8 & O Estado de Sâo Paulo & 3,1 & geladeira & Ponto Frio & & & $59.800,00$ & & 9.87 & Consul Biplex RD 43 G - 430 itros & $1.825,83$ & 2.802 .20 \\
\hline 16/8/1980 & 40 & O Estado de Sâo Paulo & 3,1 & geladera & Ponto Frio & $19.575,00$ & & $71.700,00$ & 6 & 11,84 & Brastemp Duplex BRF 44ABC Skyline - 440 lifros & $1.849,12$ & $3.551,67$ \\
\hline $2 / 8 / 1980$ & 24 & O Estado de São Paulo & & f fogão & Arapuã & 3.080 .00 & & $17.280,00$ & 10 & 2,85 & Continental Reno & 470,02 & 856.46 \\
\hline 9/9/1990 & 30 & O Estado de São Paulo & & 4 fogăo & Arapuã & $8.800,00$ & $8.800,00$ & $38.900,00$ & 3 & 6,42 & Brastemp Quality II - 4 bocas & $1.057,47$ & $1.826,82$ \\
\hline 9/9/1980 & 27 & O Estado de São Paulo & & 4 fogão & Carrefour & & & $24.390,00$ & & 4,03 & Continental 2001 Caprice 4 bocas & 663,03 & $1.208,16$ \\
\hline 9/8/1980 & 27 & O Estado de São Paulo & & 4 fogăo & Carrefour & & & $34.900,00$ & & 5,76 & Brastemp 51 NPB AL -4 bocas & 848,74 & $1.728,78$ \\
\hline 13/2/1980 & 6 & O Estado de São Paulo & & ffogão & Casa Centro & & & $23.900,00$ & & 3,25 & Continental 2001 Caprice 4 bocas & 849,71 & $1.183,89$ \\
\hline $2 / 8 / 1980$ & 14 & O Estado de São Paulo & & 4 fogão & Casas Bahia & $4.430,00$ & & $13.900,00$ & 4 & 2,30 & Semer Milano 4 bocas com tampa de vidro & 377,86 & 688,54 \\
\hline 2/8/1980 & 15 & O Estado de São Paulo & & 4 fogăo & Casas Bahia & $7.620,00$ & & $23.900,00$ & 4 & 3,25 & Brastemp 56P 4 bocas & 849,71 & $1.183,89$ \\
\hline 2/8/1980 & 14 & O Estado de São Paulo & & 4 fogão & Casas Bahia & $7.940,00$ & & $24.900,00$ & 4 & 4,11 & Semer Century 6 bocas $d$ tampa de vidro & 676,89 & $1.233,42$ \\
\hline 6/9/19e0 & 11 & O Estado de São Paulo & & 4 fogão & Casas Bahia & $4.430,00$ & 4.430 .00 & $13.900,00$ & 3 & 2,30 & Semer Milano 4 bocas com tampa de vidro & 377,86 & 688,54 \\
\hline
\end{tabular}




\begin{tabular}{|c|c|c|c|c|c|c|c|c|c|c|c|c|c|}
\hline \multicolumn{3}{|c|}{$\begin{array}{l}\text { més / ano - setembro de } 1990 \\
\text { produto - diversos }\end{array}$} & \multicolumn{7}{|c|}{ ário mínimo em } & \multicolumn{4}{|c|}{$\begin{array}{l}\text { pesq. em: Arquivo de Estado de São Paulo } \\
\text { data: } 18 / 12 / 2005-22 / 12 / 2005\end{array}$} \\
\hline data & pág. & jornal consultado & \begin{tabular}{|l} 
cod \\
prod.
\end{tabular} & produto & loja & $\begin{array}{l}\text { prest. à } \\
\text { prazo }\end{array}$ & entrada & preço à vista & $\begin{array}{c}n^{\circ} \\
\text { parc. }\end{array}$ & $\begin{array}{c}\text { qtd de } \\
\text { SM }\end{array}$ & descrição do produto & \begin{tabular}{|c|} 
atualiz. pl \\
IPC-sP \\
FIPE
\end{tabular} & $\begin{array}{c}\text { atualiz. p } \\
\text { SM de } \\
2005\end{array}$ \\
\hline 9/9/1990 & 11 & O Estado de São Paulo & & fogăo & Casas Bahia & $4.550,00$ & $4.550,00$ & $13.900,00$ & 3 & 2,30 & Semer Milano 4 bocas com tampa de vidro & 377,86 & 688,54 \\
\hline 9/8/1980 & 13 & O Estado de Sâo Paulo & & fogão & Casas Bahia & $8.400,00$ & $8.400,00$ & $24,900,00$ & 5 & 4,11 & Semer Century 8 bocas of tampa de vidro & 876,89 & $1.233,42$ \\
\hline 13/8/1980 & 11 & O Estado de Sâo Paulo & & fogão & Casas Bahia & $4.550,00$ & $4.550,00$ & $13.900,00$ & 3 & 2,30 & Semer Milano 4 bocas com tampa de vidro & 377,86 & 688,54 \\
\hline 13/8/1980 & 12 & O Estado de Sâo Paulo & & fogão & Casas Bahia & $8.110,00$ & $8.110,00$ & $24,800,00$ & 3 & 4.09 & Continental 2001 Caprice 4 bocas & 874,17 & 1.228 .47 \\
\hline 13/8/1980 & 11 & O Estado de Sâo Paulo & & fogão & Casas Bahia & 6.400 .00 & $6.400,00$ & $24,900,00$ & 5 & 4,11 & Semer Century 6 bocas $d$ tampa de vidro & 876,89 & $1.233,42$ \\
\hline $13 / 9 / 1980$ & 10 & O Estado de Sâo Paulo & & fogão & Casas Bahia & $11.080,00$ & $11.090,00$ & $33.900,00$ & 3. & 5,60 & White Westinghouse 6 bocas autolimpante acendimento autor & 921,55 & 1.679 .24 \\
\hline $16 / 9 / 1980$ & 10 & O Estado de Sấo Paulo & & fogăo & Casas Bahia & $6.600,00$ & 6.600 .00 & $25.900,00$ & 5 & 4.28 & Semer Century 6 bocas of tampa de vidro & 704,08 & $1.282,98$ \\
\hline $16 / 8 / 1990$ & 11 & O Estado de Sâo Paulo & & fogăo & Casas Bahia & $11.400,00$ & $11.400,00$ & $34.900,00$ & 3 & 5,76 & White Westinghouse 6 bocas autolimpante acendimento autor & 848,74 & $1.728,78$ \\
\hline 9/8/1980 & 27 & O Estado de Sâo Paulo & & fogão & Eldorado & & & $26.048,00$ & & 4,30 & Continental 2001 Caprice 4 bocas & 708,10 & 1.280 .28 \\
\hline 9/9/1990 & 27 & O Estado de Sâo Paulo & & fogão & Eldorado & & & $31.856,00$ & & 5,26 & Brastemp 51NPB AL - 4 bocas & 865,89 & 1.577 .98 \\
\hline 2/9/1990 & 40 & O Estado de Sâo Paulo & & fogão & Jumbo Eletro & & & $13.800,00$ & & 2,28 & Continental Fenix 4 bocas & 375,14 & 683,58 \\
\hline $2 / 8 / 1990$ & 40 & O Estado de Sâo Paulo & & fogão & Jumbo Eletro & & & $23.800,00$ & & 3,93 & Continental 2001 Caprice 4 bocas & 646,89 & $1.178,94$ \\
\hline $16 / 2 / 1980$ & 9 & O Estado de Sâo Paulo & & fogăo & Jumbo Eletro & & & $13.800,00$ & & 2,28 & Continental 2001 Fenix 4 bocas & 375,14 & 683,58 \\
\hline 9/8/1980 & 27 & O Estado de Sâo Paulo & & fogão & Jumbo Extra & & & $23.500,00$ & & 3,88 & Continental 2001 Caprice 4 bocas & 638,83 & $1.104,08$ \\
\hline 9/8/1980 & 27 & O Estado de São Paulo & & fogăo & Jumbo Extra & & & $30.300,00$ & & 5,00 & Brastemp 51NPB AL - 4 bocas & 823,69 & $1.500,81$ \\
\hline 9/8/1980 & 8 & O Estado de São Paulo & & fogão & \begin{tabular}{|l|} 
Mahfuz \\
\end{tabular} & $6.145,00$ & & $15.400,00$ & 3 & 2,54 & Continental Plaza 20014 bocas & 418,24 & 762,84 \\
\hline $16 / 9 / 1990$ & 20 & O Estado de Sâo Paulo & & fogão & Mappin & & & $22.900,00$ & & 3,78 & Continental Caprice 4 bocas acendimento automátioo & 622,52 & $1.134,35$ \\
\hline 9/9/1990 & 27 & O Estado de Sâo Paulo & & fogăo & Paes Mendonça & & & $37.510,00$ & & 6,19 & Brastemp 51NPB AL - 4 bocas & $1.019,69$ & $1.858,08$ \\
\hline $2 / 9 / 1980$ & 25 & O Estado de Sâo Paulo & & fogăo & Ponto Frio & $3.080,00$ & & $11.790,00$ & 8 & 1,25 & Dako Palace Plus 4 bocas & 320,50 & 584.02 \\
\hline $16 / 9 / 1980$ & 40 & O Estado de Sâo Paulo & & fogăo & Ponto Frio & $9.900,00$ & & $36.260,00$ & 6 & 5,99 & Brastemp Quality II autolimpante NPB 51 & 985,71 & $1.796,14$ \\
\hline $2 / 8 / 1990$ & 37 & O Estado de Sâo Paulo & & fogão & Singer & & & $11.980,00$ & & 1,98 & Singer & 325,84 & 583,93 \\
\hline $2 / 8 / 1980$ & 37 & O Estado de Sấ Paulo & & fogăo & Singer & & & $13.890,00$ & & 2,31 & Singer Plus & 380,31 & 693,00 \\
\hline 16/8/1980 & 30 & O Estado de Sâo Paulo & & fogão & Singer & & & $11.890,00$ & & 1,98 & Singer 4 bocas & 325,84 & 503,83 \\
\hline 16/9/1980 & 30 & O Estado de Sâo Paulo & & fogăo & Singer & & & $13.990,00$ & & 2,31 & Singer Plus & 380,31 & 693,00 \\
\hline $9 / 9 / 1990$ & 31 & O Estado de São Paulo & & Frádio & Arapuã & $2.480,00$ & $2.480,00$ & $7.890,00$ & 3 & 1,30 & Sanyo rádio relógio AM/FM & 214,48 & 390,83 \\
\hline 16/9/1980 & 17 & O Estado de Sâo Paulo & & rádio & Audio & & & $3.790,00$ & & 0,63 & Sanyo RP-5040 portátil & 103,03 & 187,74 \\
\hline $16 / 8 / 1980$ & 17 & O Estado de Sấo Paulo & & rádio & Audio & & & $4.290,00$ & & 0,71 & CCE DLE 370 AMFM - rádio relógio & 116,62 & 212.51 \\
\hline 16/8/1980 & 17 & O Estado de Sấo Paulo & & Frádio & Audio & & & $7.290,00$ & & 1,20 & Sanyo RM 6100 AM/FM - rádio relógio & 198,17 & 381,11 \\
\hline $16 / 9 / 1980$ & 17 & O Estado de Sâo Paulo & & rádio & Audio & & & $7.290,00$ & & 1,20 & Sanyo RP-7160 portátil & 198,17 & 361,11 \\
\hline 16/8/1980 & 17 & O Estado de Sâo Paulo & & rádio & Audio & & & $8.590,00$ & & 1,42 & Sanyo RM 6700 AMIFM - rádio relógio & 233,51 & 425,51 \\
\hline $2 / 8 / 1990$ & 2 & O Estado de Sâo Paulo & & Prádio & \begin{tabular}{|l|l|} 
Casa Centro \\
\end{tabular} & & & $4.390,00$ & & 0,72 & Rádio relógio CCE DLE370 & 119,34 & 217,46 \\
\hline 13/8/1980 & 11 & O Estado de Sâo Paulo & & rádio & Casas Bahia & $2.130,00$ & $2.130,00$ & $6.500,00$ & 3 & 1,07 & Motorádio $65 \mathrm{AC} 6$ faixas & 176,70 & 321,98 \\
\hline 13/9/1990 & 11 & O Estado de Sấo Paulo & & rádio & Casas Bahia & $2.260,00$ & $2.260,00$ & $6.900,00$ & 3 & 1,14 & Philips DS-183 AM/FM - rádio relógio & 187,57 & 341,78 \\
\hline $2 / 8 / 1990$ & 22 & O Estado de Sấo Paulo & & rádio & Jumbo Eletro & & & $7.800,00$ & & 1,29 & Philips AL 331 AMFMOC & 212,04 & 396,37 \\
\hline 9/8/1990 & 7 & O Estado de São Paulo & & rádio & Jumbo Eletro & & & $6.800,00$ & & 1,12 & Philips rádio relógio AM/FM & 184,85 & 336,84 \\
\hline 9/9/1990 & & O Estado de Sâo Paulo & & rádio & Jumbo Eletro & & & $7.500,00$ & & 1,24 & Toshiba TR 556 - portátli AM/FM & 203,88 & 371,51 \\
\hline $16 / 8 / 1980$ & 29 & O Estado de Sấo Paulo & & Frádio & Lojas Glória & & & $4.900,00$ & & 0,81 & Philips DS 183/184 - rádio relógio & 133,20 & 242,72 \\
\hline $16 / 8 / 1990$ & 29 & O Estado de Sấo Paulo & & rádio & Lojas Glória & & & $7.700,00$ & & 1,27 & Philips AR 150 rádio gravador & 209,32 & 381,42 \\
\hline $16 / 2 / 1980$ & 29 & O Estado de São Paulo & & rádio & Lojas Glória & & & $8.900,00$ & & 1,63 & Philips AR 250 rádio gravador & 269,13 & 490,40 \\
\hline
\end{tabular}




\begin{tabular}{|c|c|c|c|c|c|c|c|c|c|c|c|c|c|}
\hline \multicolumn{3}{|c|}{$\begin{array}{l}\text { més / ano - setembro de } 1990 \\
\text { groduto - diversos }\end{array}$} & \multicolumn{7}{|c|}{ Salário mínimo em 01.09.1990 - Cr\$ 6.056,31 } & \multicolumn{4}{|c|}{$\begin{array}{l}\text { pesq. em: Arquivo de Estado de Săo Paulo } \\
\text { data: } 18 / 12 / 2005-22 / 12 / 2005\end{array}$} \\
\hline data & pág. & jornal consultado & $\begin{array}{l}\text { cod } \\
\text { prod. }\end{array}$ & produto & loja & $\begin{array}{l}\text { prest. à } \\
\text { prazo }\end{array}$ & entrada & preço à vista & $\begin{array}{c}n^{\circ} \\
\text { parc. }\end{array}$ & $\begin{array}{l}\text { qtd de } \\
\text { SM }\end{array}$ & descrição do produto & $\begin{array}{l}\text { atualiz. pl } \\
\text { IPC-SP } \\
\text { FIPE }\end{array}$ & $\begin{array}{c}\text { atualiz. p' } \\
\text { SM de } \\
2005\end{array}$ \\
\hline 9/9/1990 & 20 & O Estado de São Paulo & & Frádio & Mappin & & & $6.990,00$ & & 1,15 & Philips DS-184 AMFM & 190,02 & 346,25 \\
\hline $16 / 8 / 1980$ & 20 & O Estado de Sâo Paulo & & rádio & Mappin & & & $7.380,00$ & & 1,22 & Semp Toshiba RR 7100 AMMFM - rádio relógio & 200,89 & 386,06 \\
\hline 2/8/1980 & 14 & O Estado de São Paulo & & maq costura & Casas Bahia & $8.260,00$ & & $25.900,00$ & 4. & 4,28 & Singer Zig-Zag com móvel 1996 & 704,08 & $1.282,96$ \\
\hline 8/9/1980 & 10 & O Estado de São Paulo & & maq costura & Casas Bahia & $8.260,00$ & $8.260,00$ & $25.900,00$ & 3 & 4.28 & Singer Zig-Zag com móvel 1996 & 704,08 & 1.282 .96 \\
\hline 9/9/1980 & 10 & O Estado de São Paulo & & maq costura & Casas Bahia & $8.800,00$ & $8.800,00$ & $26.900,00$ & 3 & 4,44 & Singer Zig-Zag com móvel 1996 & 731,28 & 1.332 .49 \\
\hline $16 / 9 / 1990$ & 10 & O Estado de São Paulo & & maq costura & Casas Bahia & $9.120,00$ & $8.120,00$ & $27.900,00$ & 3 & 4.61 & Singer Zig-Zag com móvel 1996 & 758,44 & 1.382 .03 \\
\hline 9/9/1980 & 20 & O Estado de São Paulo & & maq costura & Mappin & & & $17.900,00$ & & 2,96 & Elgin Zig-zag G 31/19 & 486,60 & 886,68 \\
\hline $16 / 8 / 1980$ & 20 & O Estado de Sâo Paulo & & maq costura & Mappin & & & $22.900,00$ & & 3,78 & Singer Facilita prática portátil & 822,52 & $1.134,35$ \\
\hline 9/8/1980 & 27 & O Estado de São Paulo & & ferro elétrico & Carrefour & & & $3.570,00$ & & 0,59 & Walita FE 23 a vapor & 97,05 & 176,84 \\
\hline $13 / 9 / 1980$ & 6 & O Estado de São Paulo & & ferro elétrico & Casa Centro & & & $3.900,00$ & & 0,64 & Black \& Decker a vapor 1411 & 106,02 & 183,19 \\
\hline 2/8/1980 & 14 & O Estado de Sâo Paulo & & ferro elétrico & Casas Bahia & & & $2,090,00$ & & 0,35 & Walita & 56,82 & 103,53 \\
\hline 6/9/19e0 & 11 & O Estado de Sâo Paulo & & ferro elétrico & Casas Bahia & & & $2.090,00$ & & 0,35 & Walita automático & 56,82 & 103,53 \\
\hline 9/9/1900 & 27 & O Estado de São Paulo & & ferro elétrico & Eldorado & & & $5.083,00$ & & 0,84 & Walita FE 23 a vapor & 138,18 & 251,79 \\
\hline 2/9/1980 & 22 & O Estado de São Paulo & & ferro elétrico & Jumbo Eletro & & & $4.290,00$ & & 0,71 & Black \& Decker a vapor & 116,62 & 212,51 \\
\hline 16/8/1980 & 9 & O Estado de São Paulo & & ferro elétrico & Jumbo Eletro & & & 2250,00 & & 0,37 & Black \& Decker automático & 61,16 & 111,45 \\
\hline 16/9/1980 & 9 & O Estado de São Paulo & & ferro elétrico & Jumbo Eletro & & & $4.380,00$ & & 0,72 & Black \& Decker à vapor & 119,07 & 216,96 \\
\hline 9/9/1980 & 27 & O Estado de São Paulo & & ferro elétrico & Jumbo Extra & & & 3200,00 & & 0,53 & Walita FE 23 a vapor & 86,89 & 158,51 \\
\hline 9/9/1980 & 8 & O Estado de São Paulo & & ferro elétrico & Mahfuz & 870,00 & & $2.180,00$ & 3 & 0,36 & Black \& Decker automático 1110 & 58,26 & 107,99 \\
\hline 2/9/1990 & 25 & O Estado de São Paulo & & ferro elétrico & Ponto Frio & $1.185,00$ & & $4.560,00$ & 6 & 0,75 & Black \& Decker a vapor Spray PFE-411 & 123,86 & 225,88 \\
\hline 16/9/1980 & 30 & O Estado de São Paulo & & ferro elétrico & Singer & & & 2290,00 & & 0,38 & Walita nowo cabo aberto & 62,25 & 113,44 \\
\hline 9/9/1980 & 27 & O Estado de Sâo Paulo & & secador de cabelo & Carrefour & & & $4.280,00$ & & 0,71 & Tayfff profissional & 116,35 & 212,01 \\
\hline 13/8/1990 & 12 & O Estado de São Paulo & & secador de cabelo & Casas Bahia & $1.140,00$ & $1.140,00$ & $3.490,00$ & 3 & 0,58 & Tany Yuss 1800 & 84,87 & 172,88 \\
\hline $16 / 8 / 1980$ & 10 & O Estado de São Paulo & & secador de cabelo & Casas Bahia & $1.080,00$ & $1.080,00$ & $3.290,00$ & 3 & 0,54 & Faet Styler Set HLD-6 bivolt & 89,44 & 162,97 \\
\hline $8 / 9 / 1990$ & & O Estado de São Paulo & & secador de cabelo & Comercial Eduard & & & $1.700,00$ & & 0.28 & Arno Elelela portátil & 46,21 & 84.21 \\
\hline 919/1900 & 27 & O Estado de São Paulo & & secador de cabelo & Jumbo Extra & & & $3.200,00$ & & 0,53 & Tayff profissional & 86,89 & 158,51 \\
\hline 9/9/1900 & 8 & O Estado de São Paulo & & secador de cabelo & Mahfuz & 710,00 & & $1.780,00$ & 3 & 0.29 & Arno Eliela portátil & 48,39 & 88,17 \\
\hline 919/1990 & 27 & O Estado de São Paulo & & enceradeira & Carrefour & & & $8.480,00$ & & 1,40 & Arno EA1 & 230,52 & 420,06 \\
\hline $2 / 9 / 1900$ & 14 & O Estado de São Paulo & & enceradeira & Casas Bahia & $2.840,00$ & & $8.900,00$ & 4 & 1,47 & Black \& Decker Standard & 241,24 & 440,86 \\
\hline 8/9/1980 & 11 & O Estado de São Paulo & & enceradeira & Casas Bahia & $2.840,00$ & $2.840,00$ & $8.900,00$ & 3 & 1,47 & Black \& Decker Standard & 241,84 & 440,86 \\
\hline $2 / 9 / 1980$ & 23 & O Estado de São Paulo & & enceradeira & Jumbo Eletro & & & $8.700,00$ & & 1,44 & Arno $\mathrm{d} /$ cinta protetora PVC & 236,50 & 430,96 \\
\hline 8/9/1900 & 27 & O Estado de São Paulo & & enceradeira & Jumbo Extra & & & $8.200,00$ & & 1,35 & Arno EA1 & 222,81 & 406,19 \\
\hline 9/9/1900 & 8 & O Estado de São Paulo & & enceradeira & Mahfuz & $3.870,00$ & & $9.700,00$ & 3 & 1,60 & Electrolux & 263,60 & 480,49 \\
\hline 919/1980 & 20 & O Estado de Sâo Paulo & & enceradeira & Mappin & & & $7.990,00$ & & 1,32 & Arno haste dupla 250 watts & 217,20 & 395,79 \\
\hline 9/9/1900 & 27 & O Estado de São Paulo & & enceradeira & Paes Mendonça & & & $8.780,00$ & & 1,45 & Arno EA1 & 238,68 & 434,92 \\
\hline $2 / 8 / 1980$ & 14 & O Estado de São Paulo & 10 & aspirador de pó & Casas Bahia & $4.430,00$ & & $13.900,00$ & 4 & 2,30 & Black \& Decker 7 acessónios & 377,86 & 688,54 \\
\hline $13 / 9 / 1980$ & 12 & O Estado de São Paulo & 10 & aspirador de pó & Casas Bahia & $2.810,00$ & $2.810,00$ & $8.900,00$ & 3 & 1,47 & Amo portátil & 241,84 & 440,86 \\
\hline 13/9/1990 & 12 & O Estado de São Paulo & 10 & aspirador de pó & Casas Bahia & $4.510,00$ & $4.510,00$ & $13,800,00$ & 3. & 2,28 & Black \& Decker 7 acessónios & 375,14 & 683,58 \\
\hline $16 / 8 / 1980$ & 10 & O Estado de São Paulo & 10 & aspirador de pó & Casas Bahia & $4.510,00$ & $4.510,00$ & $13.800,00$ & 3 & 2,28 & Black \& Decker & 375,14 & 683,58 \\
\hline 2/8/1980 & 22 & O Estado de São Paulo & & aspirador de pó & Jumbo Eletro & & & $13.800,00$ & & 2,28 & Black \& Decker & 375,14 & 683,58 \\
\hline
\end{tabular}




\begin{tabular}{|c|c|c|c|c|c|c|c|c|c|c|c|c|c|}
\hline \multicolumn{3}{|c|}{$\begin{array}{l}\text { més / ano - setembro de } 1990 \\
\text { groduto - diversos }\end{array}$} & \multicolumn{7}{|c|}{ Salário mínimo em 01.09.1990 - Cr5 6.056,31 } & \multicolumn{4}{|c|}{$\begin{array}{l}\text { pesq. em: Arquivo de Estado de Săo Paulo } \\
\text { data: } 18 / 12 / 2005-22 / 12 / 2005\end{array}$} \\
\hline data & pág. & jornal consultado & \begin{tabular}{|l} 
cod \\
prod.
\end{tabular} & produto & loja & $\begin{array}{l}\text { prest. à } \\
\text { prazo }\end{array}$ & entrada & preço à vista & $\begin{array}{c}\mathrm{n}^{\circ} \\
\text { parc. }\end{array}$ & $\begin{array}{c}\text { qtd de } \\
\text { SM }\end{array}$ & descrição do produto & $\begin{array}{l}\text { atualiz. p/ } \\
\text { IPC-SP } \\
\text { FIPE }\end{array}$ & $\begin{array}{l}\text { atualiz. p' } \\
\text { SM de } \\
2005\end{array}$ \\
\hline 16/9/1990 & 8 & O Estado de Sâo Paulo & 10 & aspirador de pó & Jumbo Eletro & & & $8.800,00$ & & 1,45 & Arno portátil 8 peças & 239,22 & 435,81 \\
\hline 16/8/1980 & & O Estado de Sâo Paulo & 10 & aspirador de pó & Jumbo Eletro & & & $13.800,00$ & & 2,28 & Black \& Decker & 375,14 & 683,58 \\
\hline 9/9/1990 & 8 & O Estado de Sâo Paulo & 10 & aspirador de pó & Mahfuz & $3.550,00$ & & $8.900,00$ & 3 & 1,47 & Arno APA & 241,24 & 440,86 \\
\hline 8/9/1980 & 12 & O Estado de Sâo Paulo & 11 & liquidficador & Casa Centro & & & 2380,00 & & 0,39 & Arno LS 3 velocidades & 64,70 & 117,89 \\
\hline 6/8/1990 & 11 & O Estado de Sâo Paulo & 11 & liquidficador & Casas Bahia & $1.180,00$ & $1.180,00$ & $3.590,00$ & 3 & 0,59 & Walita Beta & 97,59 & 177,83 \\
\hline $2 / 8 / 1980$ & 23 & O Estado de São Paulo & 11 & liquid ficador & Jumbo Eletro & & & 2850,00 & & 0,47 & Arno 3 velocidades $\alpha$ pulsar copo transparente e 2 itros capa & 77,48 & 141,18 \\
\hline 16/8/1990 & 8 & O Estado de Sâo Paulo & 11 & liquidficador & Jumbo Eletro & & & $2.850,00$ & & 0,47 & Arno 3 velocidades ol pulsar copo transparente e 2 Itros capa & 77,48 & 141,18 \\
\hline $16 / 2 / 1990$ & 8 & O Estado de São Paulo & 11 & liquidficador & Jumbo Eletro & & & $3.480,00$ & & 0,57 & Arno 3 velocidades ol botăo deslizante & 84,60 & 172,38 \\
\hline 16/2/1980 & 29 & O Estado de Sâo Paulo & 11 & liquidificador & Lojas Glória & & & $3.900,00$ & & 0,64 & Walita Beta & 106,02 & 183,18 \\
\hline $16 / 8 / 1980$ & 28 & O Estado de Sâo Paulo & 11 & liquidficador & Lojas Glónia & & & $4.700,00$ & & 0.78 & Walita Gama & 127,77 & 232,82 \\
\hline 9/8/1980 & 8 & O Estado de São Paulo & 11 & liquidficador & Mahfuz & $1.340,00$ & & $3.350,00$ & 3 & 0,55 & Walita Beta & 91,07 & 105,94 \\
\hline 9/8/1980 & 8 & O Estado de Sâo Paulo & 11 & liquidficador & Mahfuz & $3.180,00$ & & $7.990,00$ & 3 & 1,32 & Arno multiprocessador & 217,20 & 385,79 \\
\hline 16/8/1980 & 20 & O Estado de Sâo Paulo & 11 & liquidficador & Mappin & & & $3.590,00$ & & 0,59 & Walita Beta 3 & 97,59 & 177,83 \\
\hline 16/8/1980 & 30 & O Estado de Sâo Paulo & 11 & liquidificador & Singer & & & $3.490,00$ & & 0,58 & Amo & 84,87 & 172,88 \\
\hline $16 / 2 / 1990$ & 17 & O Estado de Sấo Paulo & 12 & maq fotográfica & Audio & & & $4.390,00$ & & 0,72 & Kodak S-100 EF & 119,34 & 217,46 \\
\hline 16/8/1990 & 17 & O Estado de São Paulo & 12 & maq fotográfica & Audio & & & $4.590,00$ & & 0,76 & \begin{tabular}{|l|} 
Frata T-20 \\
\end{tabular} & 124,78 & 227,37 \\
\hline 16/8/1980 & 17 & O Estado de São Paulo & 12 & maq fotográfica & Audio & & & $5.390,00$ & & 0,89 & Kodak S-10 & 146,52 & 266.98 \\
\hline 16/9/1980 & 17 & O Estado de Sâo Paulo & 12 & maq fotográfica & Audio & & & $5.580,00$ & & 0,92 & Frata T 40 & 151,86 & 276,90 \\
\hline 16/9/1980 & 17 & O Estado de São Paulo & 12 & maq fotográfica & Audio & & & $13.890,00$ & & 2,31 & Kodak S-400SL & 380,31 & 693,00 \\
\hline 16/8/1990 & 17 & O Estado de Sâo Paulo & 12 & maq fotográfica & Audio & & & $21.980,00$ & & 3,63 & Kodak S-500 AF & 597,78 & 1.089 .28 \\
\hline 9/8/1980 & 11 & O Estado de Sâo Paulo & 12 & maq fotográfica & Casas Bahia & $1.730,00$ & $1.730,00$ & $5.290,00$ & 3 & 0,87 & Kodak S-10 & 143,81 & 262,04 \\
\hline 9/9/1980 & 8 & O Estado de Sâo Paulo & 15 & ventilador & Mahfuz & $1.735,00$ & & $4.350,00$ & 3 & 0,72 & Faet $1047-3$ velocidades & 118,25 & 215,48 \\
\hline $8 / 8 / 1990$ & 12 & O Estado de Sâo Paulo & 16 & batedeira bolo & Casa Centro & & & $4.590,00$ & & 0,76 & Arno Ciranda Super & 124,78 & 227,37 \\
\hline 13/2/1980 & 12 & O Estado de Sâo Paulo & 16 & batedeira bolo & Casas Bahia & $1.830,00$ & $1.930,00$ & $5.900,00$ & 3 & 0,97 & Arno Ciranda Super & 160,39 & 292.26 \\
\hline $2 / 8 / 1990$ & 23 & O Estado de São Paulo & 16 & batedeira bolo & Jumbo Eletro & & & $5.500,00$ & & 0,91 & Arno Ciranda Super & 148,51 & 272,44 \\
\hline 16/8/1980 & & O Estado de Sâo Paulo & 16 & batedeira bolo & Jumbo Eletro & & & $5.500,00$ & & 0,91 & Arno Ciranda Super & 149,51 & 272,44 \\
\hline 9/8/1990 & 8 & O Estado de Sâo Paulo & 16 & batedeira bolo & Mahfuz & $2.810,00$ & & $7.300,00$ & 3 & 1,21 & Walita DBT 400 & 198,45 & 381,61 \\
\hline 16/2/1990 & 20 & O Estado de Sâo Paulo & 16 & batedeira bolo & Mappin & & & $3.890,00$ & & 0,64 & Walita mix & 105,75 & 182,68 \\
\hline 2/8/1980 & 37 & O Estado de Sâo Paulo & 16 & batedeira bolo & Singer & & & $5.980,00$ & & 0,99 & Arno Ciranda Super & 162,83 & 296,72 \\
\hline 2/8/1980 & 24 & O Estado de Sâo Paulo & 18 & freezer & Arapuã & & & $27.900,00$ & & 4,61 & Consul 80 Itros & 758,44 & $1.382,03$ \\
\hline 9/8/1980 & 31 & O Estado de Sâo Paulo & 18 & freezer & Arapuã & $8.480,00$ & $8.490,00$ & $34.900,00$ & 6 & 5,76 & Consul 180 Itros vertical fast freezing & 948,74 & 1.728 .78 \\
\hline 13/8/1980 & 6 & O Estado de São Paulo & 18 & freezer & Casa Centro & & & $35.900,00$ & & 5,93 & Consul 230 itros vertical & 975,82 & $1.778,31$ \\
\hline 6/8/1990 & 10 & O Estado de Sâo Paulo & 18 & freezer & Casas Bahia & 11.770 .00 & $11.770,00$ & $36.900,00$ & 3 & 6,09 & Consul 230 itros vertical & $1.003,10$ & $1.827,85$ \\
\hline 9/9/1990 & 8 & O Estado de Sâo Paulo & 18 & freezer & Jumbo Eletro & & & $45.800,00$ & & 7,56 & Brastemp Quality III - 270 litros & $1.245,05$ & $2.268,71$ \\
\hline 9/8/1990 & 8 & O Estado de Sâo Paulo & 18 & freezer & Mahfuz & $19.110,00$ & & $47.900,00$ & 3 & 7,21 & Brastemp 27A - 270 litros & $1.302,13$ & $2.372,73$ \\
\hline 2/9/1990 & 25 & O Estado de Sâo Paulo & 18 & freezer & Ponto Frio & $8.330,00$ & & $31.800,00$ & 6 & 5,25 & Prosdócimo Classic Luxo 418 - 180 itros & 864,46 & $1.575,22$ \\
\hline 9/8/1980 & 4 & O Estado de São Paulo & 18 & freezer & Ponto Frio & $20.050,00$ & & $78.800,00$ & 8 & 13.01 & Brastemp Frost Free 31ABC - 310 itros & $2.142,13$ & $3.903,37$ \\
\hline $16 / 9 / 1980$ & 40 & O Estado de Sâo Paulo & 18 & freezer & Ponto Frio & $14.960,00$ & & $54.800,00$ & 6 & 9,05 & Brastemp BCA 27 AC - 270 itros & $1.489,71$ & $2.714,52$ \\
\hline $16 / 9 / 1980$ & 17 & O Estado de Sâo Paulo & 20 & formo microondas & Audio & & & $37.900,00$ & & 6.26 & Prosdócimo seletor & $1.030,29$ & $1.877,38$ \\
\hline
\end{tabular}




\begin{tabular}{|c|c|c|c|c|c|c|c|c|c|c|c|c|c|}
\hline \multirow{2}{*}{\multicolumn{3}{|c|}{$\begin{array}{l}\text { més / ano - setembro de } 1990 \\
\text { groduto - diverso5 }\end{array}$}} & \multirow{2}{*}{\multicolumn{7}{|c|}{ Salário mínimo em 01.09.1990 - Cr\$ 6.056,31 }} & \multirow{2}{*}{\multicolumn{4}{|c|}{$\begin{array}{l}\text { pesq. em: Arquivo de Estado de Săo Paulo } \\
\text { data: 18/12/2005-22/12/2005 }\end{array}$}} \\
\hline & & & & & & & & & & & & & \\
\hline data & pág. & jornal consultado & $\begin{array}{l}\text { cod } \\
\text { prod. }\end{array}$ & produto & loja & $\begin{array}{l}\text { prest. à } \\
\text { prazo }\end{array}$ & entrada & preço à vista & $\begin{array}{c}\mathrm{n}^{\circ} \\
\text { parc. }\end{array}$ & $\begin{array}{c}\text { qtd de } \\
\text { SM }\end{array}$ & descrição do produto & $\begin{array}{l}\text { atuaiz. p/ } \\
\text { IPC-SP } \\
\text { FIPE }\end{array}$ & \begin{tabular}{|c|} 
atualiz pl \\
SM de \\
2005 \\
\end{tabular} \\
\hline 16/8/19e0 & 17 & O Estado de São Paulo & 20 & forno microondas & Audio & & & $46.900,00$ & & 7,74 & Prosdócimo digital & $1.274,95$ & $2.323,20$ \\
\hline 16/8/1980 & 17 & O Estado de São Paulo & 20 & formo microondas & Audio & & & $49.900,00$ & & 8,24 & White Westinghouse FW 3700 & $1.356,50$ & $2.471,80$ \\
\hline 16/8/1980 & 17 & O Estado de São Paulo & 20 & formo microondas & Audio & & & $54,900,00$ & & 9,06 & Panasonic NE 7689 & $1.492,42$ & 2.719 .48 \\
\hline 16/8/1980 & & O Estado de Sâo Paulo & 20 & formo microondas & Audio & & & $62.900,00$ & & 10,30 & Sharp 615 A digital & $1.709,80$ & $3.115,76$ \\
\hline 16/8/19e0 & 17 & O Estado de Sâo Paulo & 20 & forno microondas & Audio & & & $68.900,00$ & & 11,05 & Panasonic NE 7777 & $1.818,34$ & $3.313,80$ \\
\hline $2 / 9 / 1990$ & 10 & O Estado de São Paulo & 20 & formo microondas & Buri & & & $45.300,00$ & & 7,48 & Panasonic NE 7608 & $1.231,45$ & $2.243,94$ \\
\hline 9/9/19e0 & 27 & O Estado de Sâo Paulo & 20 & formo microondas & Carrefour & & & $48.900,00$ & & 8,07 & Brastemp seletor & $1.329,32$ & 2.422 .27 \\
\hline $2 / 8 / 1980$ & 6 & O Estado de São Paulo & 20 & formo microondas & Casa Centro & & & $37.900,00$ & & 6,26 & Continental 200 Junior & $1.030,28$ & $1.877,38$ \\
\hline 16/8/1980 & 6 & O Estado de São Paulo & 20 & forno microondas & Casa Centro & & & $33.900,00$ & & 5,60 & CCE microoooking 19 litros & 921,55 & 1.679 .24 \\
\hline $2 / 9 / 1990$ & 14 & O Estado de São Paulo & 20 & formo microondas & Casas Bahia & $19.000,00$ & & $57.000,00$ & 3 & 8,41 & Sharp $515 \mathrm{~A} \mathrm{c} /$ seletor $110 \mathrm{~V}$ & $1.549,51$ & $2.823,50$ \\
\hline 6/9/1980 & 10 & O Estado de Sâo Paulo & 20 & formo microondas & Casas Bahia & $18.000,00$ & $19.000,00$ & $57.000,00$ & 2 & 8.41 & Sharp $515 \mathrm{~A}$ cl seletor $110 \mathrm{~V}$ & $1.549,51$ & $2.823,50$ \\
\hline 13/8/1980 & 12 & O Estado de Sâo Paulo & 20 & forno microondas & Casas Bahia & $19.000,00$ & $19.000,00$ & $57.000,00$ & 2 & 9.41 & Sharp $515 \mathrm{~A} \mathrm{c} /$ seletor $110 \mathrm{~V}$ & $1.549,51$ & 2.823 .50 \\
\hline 9/9/1980 & 27 & O Estado de Sâo Paulo & 20 & forno microondas & Jumbo Extra & & & $45.300,00$ & & 7,48 & Brastemp seletor & $1.231,45$ & $2.243,94$ \\
\hline 9/9/1990 & 27 & O Estado de Sâo Paulo & 20 & forno microondas & Jumbo Extra & & & $49.500,00$ & & 8,17 & Brastemp digital & $1.345,63$ & $2.451,99$ \\
\hline 9/9/1980 & 20 & O Estado de Sâo Paulo & 20 & formo microondas & Mappin & & & $59.900,00$ & & 9.89 & Sharp MW-615 A auto touch com prato giratónio & $1.628,35$ & $2.867,15$ \\
\hline 919/1980 & 27 & O Estado de Sâo Paulo & 20 & forno microondas & Paes Mendonça & & & $51.285,00$ & & 8.47 & Brastemp seletor & $1.394,42$ & $2.540,80$ \\
\hline 919/1980 & 27 & O Estado de Sâo Paulo & 20 & formo microondas & Paes Mendonça & & & $61.500,00$ & & 10,15 & Brastemp digital & $1.671,84$ & 3.046 .41 \\
\hline 16/8/19e0 & 17 & O Estado de São Paulo & 22 & Camera filmadora & Audio & & & $220.000,00$ & & 36,33 & Sony Handicam & $5.980,57$ & 10.897 .72 \\
\hline 2/8/1980 & 6 & O Estado de Sâo Paulo & 22 & Camera filmadora & Casa Centro & & & $139.000,00$ & & 22,95 & JVC GR AV-1 & $3.778,63$ & $6.885,38$ \\
\hline 6/9/1980 & 13 & O Estado de Sâo Paulo & 22 & Camera filmadora & Color Som & & & $223.600,00$ & & 36,92 & Pro Line VHS Camcorder & $6.078,43$ & $11.076,05$ \\
\hline $16 / 9 / 1900$ & 17 & O Estado de São Paulo & 23 & video cassete & Audio & & & $72.900,00$ & & 12,04 & Philips VR-6558 - 4 cabecas & $1.881,74$ & $3.611,11$ \\
\hline 16/8/19e0 & 17 & O Estado de Sâo Paulo & 23 & video cassete & Audio & & & $83.900,00$ & & 13,85 & Gradiente SV 21 Stereo & $2.280,77$ & $4.156,00$ \\
\hline 2/8/1980 & 10 & O Estado de Sâo Paulo & 23 & video cassete & Buri & $27.680,00$ & $27.690,00$ & $82.900,00$ & 3 & 13,60 & Sharp VC-7948 -4 cabecas & $2.253,59$ & 4.108 .48 \\
\hline 8/9/1980 & 19 & O Estado de São Paulo & 23 & video cassete & Buri & & & $84.000,00$ & & 13,87 & Philips VR- 6558 - 4 cabecas & $2.283,49$ & $4.160,85$ \\
\hline 16/8/1980 & & O Estado de Sâo Paulo & 23 & video cassete & Casa Centro & & & $58.900,00$ & & 8,73 & Philoo Hitachi PVC-5000 com controle remoto & 1.601 .16 & $2.817,62$ \\
\hline $2 / 8 / 1990$ & 38 & O Estado de Sâo Paulo & 23 & video cassete & Casas Bahia & $19.100,00$ & $19.100,00$ & $59.900,00$ & 3 & 9,89 & Philoo Hitachi PVC-5000 com controle remoto & $1.628,35$ & $2.967,15$ \\
\hline $2 / 9 / 1900$ & 14 & O Estado de Sâo Paulo & 23 & video cassete & Casas Bahia & 25.080 .00 & & $79.900,00$ & 4 & 13,18 & Toshiba M 5330B ol controle remoto & $2.172,03$ & $3.857,88$ \\
\hline 6/9/1990 & 10 & O Estado de Sâo Paulo & 23 & video cassete & Casas Bahia & $25.000,00$ & $25.090,00$ & $79.900,00$ & 3 & 13,18 & Toshiba V- $5330 \mathrm{~B}$ of controle remoto & $2.172,03$ & $3.857,88$ \\
\hline 919/1980 & 10 & O Estado de Sâo Paulo & 23 & video cassete & Casas Bahia & $18.000,00$ & $18.000,00$ & $54.900,00$ & 3 & 9,06 & CCE VCR $12 x$ com controle remoto & $1.492,42$ & 2.719 .48 \\
\hline 919/1980 & 13 & O Estado de Sâo Paulo & 23 & video cassete & Casas Bahia & $15.380,00$ & $15.390,00$ & $58.900,00$ & 5 & 9,89 & Sanyo VHR $5200 \mathrm{~d} /$ controle remoto & $1.828,35$ & $2.867,15$ \\
\hline 9/9/1980 & 10 & O Estado de São Paulo & 23 & video cassete & Casas Bahia & $27.110,00$ & $27.110,00$ & $82.900,00$ & 3 & 13,68 & Toshiba M $5330 \mathrm{~B}$ of controle remoto & $2.253,59$ & $4.106,46$ \\
\hline 13/8/1990 & 11 & O Estado de Sâo Paulo & 23 & video cassete & Casas Bahia & $15.380,00$ & $15.390,00$ & $59.900,00$ & 3 & 9,88 & Sanyo VHR $5200 \mathrm{o} /$ controle remoto & $1.828,35$ & $2.867,15$ \\
\hline 13/8/1980 & 11 & O Estado de Sâo Paulo & 23 & video cassete & Casas Bahia & $27.110,00$ & $27.110,00$ & $82.900,00$ & 3 & 13,60 & Toshiba M5330B c/ controle remoto 4 cabecas & $2.253,59$ & 4.108 .48 \\
\hline 16/8/1980 & 10 & O Estado de Sâo Paulo & 23 & video cassete & Casas Bahia & $15.400,00$ & $15.400,00$ & $59.900,00$ & 5 & 9,89 & Sanyo VHR 5200 ol controle remoto & $1.628,35$ & $2.867,15$ \\
\hline 16/8/1900 & 10 & O Estado de São Paulo & 23 & video cassete & Casas Bahia & $27.440,00$ & $27.440,00$ & $83.900,00$ & 3 & 13,85 & Toshiba M- $5330 \mathrm{~B}$ c/ controle remoto & $2.280,77$ & $4.156,00$ \\
\hline 9/8/1980 & 7 & O Estado de São Paulo & 23 & video cassete & Jumbo Eletro & & & $69.800,00$ & & 11,53 & Panasonic 611 - 3 cabeças & 1.897 .47 & $3.457,55$ \\
\hline $16 / 8 / 1900$ & 20 & O Estado de Sâo Paulo & 23 & video cassete & Mappin & & & $69.800,00$ & & 11,53 & Philips VR-31 - 3 cabecas $c /$ controle remoto & $1.897,47$ & 3.457 .55 \\
\hline 9/9/1900 & 4 & O Estado de Sâo Paulo & 23 & video cassete & Ponto Frio & $16.180,00$ & & $61.800,00$ & 8 & 10,20 & Toshiba M 5130B 2 cabeças & $1.880,00$ & $3.081,27$ \\
\hline $2 / 9 / 1980$ & & O Estado de São Paulo & 24 & conjunto de som & Buri & $8.320,00$ & 8.320 .00 & $24.900,00$ & 3 & 4.11 & Toshiba SM-150/3 em 1 & 676,89 & $1.233,42$ \\
\hline
\end{tabular}




\begin{tabular}{|c|c|c|c|c|c|c|c|c|c|c|c|c|c|}
\hline \multicolumn{3}{|c|}{$\begin{array}{l}\text { més / ano - setembro de } 1990 \\
\text { oroduto - diversos }\end{array}$} & \multicolumn{7}{|c|}{ Salário mínimo em 01.09.1990 - Cr\$ 6.056,31 } & \multicolumn{4}{|c|}{$\begin{array}{l}\text { pesq. em: Arquivo de Estado de Săo Paulo } \\
\text { data: } 18 / 12 / 2005-22 / 12 / 2005\end{array}$} \\
\hline data & pág. & jornal consultado & $\begin{array}{l}\text { cod } \\
\text { prod. }\end{array}$ & produto & loja & $\begin{array}{l}\text { prest. à } \\
\text { prazo }\end{array}$ & entrada & preço à vista & $\begin{array}{c}n^{\circ} \\
\text { parc }\end{array}$ & $\begin{array}{l}\text { qtd de } \\
\text { SM }\end{array}$ & descrição do produto & $\begin{array}{l}\text { atualiz. p/ } \\
\text { IPC-SP } \\
\text { FIPE }\end{array}$ & $\begin{array}{l}\text { atualiz. p' } \\
\text { SM de } \\
2005\end{array}$ \\
\hline 2/9/1980 & 10 & O Estado de São Paulo & 24 & oonjunto de som & Buri & $12.330,00$ & & $36.900,00$ & 4 & 6,09 & Sony AD-1500 & $1.003,10$ & $1.827,85$ \\
\hline $2 / 9 / 1980$ & 14 & O Estado de São Paulo & 25 & Iavadora tanquinho & Casas Bahia & 4.630 .00 & & $14.500,00$ & 4 & 2,39 & Color Maq & 394,17 & 718.26 \\
\hline 8/9/1990 & 11 & O Estado de São Paulo & 25 & $\begin{array}{l}\text { Iavadora tanquinho } \\
\end{array}$ & Casas Bahia & $4.630,00$ & $4.630,00$ & $14,500,00$ & 3 & 2,39 & Color Maq & 394,17 & 718.26 \\
\hline 9/9/1990 & 11 & O Estado de São Paulo & 25 & Iavadora tanquinho & Casas Bahia & $4.870,00$ & $4.870,00$ & $14.900,00$ & 3 & 2,46 & Color Maq & 405,05 & 738.07 \\
\hline 13/9/1980 & 12 & O Estado de São Paulo & 25 & Iavadora tanquinho & Casas Bahia & $4.870,00$ & $4.870,00$ & $14.900,00$ & 3 & 2,46 & Color Maq & 405,05 & 738.07 \\
\hline 16/8/1900 & 10 & O Estado de São Paulo & 25 & Iavadora tanquinho & Casas Bahia & $4.870,00$ & $4.870,00$ & $14.900,00$ & 3 & 2,46 & Color Maq & 405,05 & 738.07 \\
\hline 8/9/1980 & 8 & O Estado de Sâo Paulo & 25 & Iavadora tanquinho & Mahfuz & $5.865,00$ & & $14.700,00$ & 3 & 2,43 & Mueller Pop Tank & 399,61 & 728,17 \\
\hline 9/9/1990 & 27 & O Estado de São Paulo & 28 & cafeteira elétrica & Carrefour & & & $5.190,00$ & & 0,86 & Amo 24 xicaras & 141,09 & 257,09 \\
\hline $2 / 9 / 1990$ & 14 & O Estado de São Paulo & 28 & cafeteira elétrica & Casas Bahia & $1.340,00$ & & $4.190,00$ & 4 & 0,69 & Arno 16 xícaras de café & 113,80 & 207,55 \\
\hline $8 / 8 / 1990$ & 11 & O Estado de Sâo Paulo & 28 & cafeteira elétrica & Casas Bahia & $1.340,00$ & $1.340,00$ & $4.180,00$ & 3 & 0,69 & Arno 16 xicaras de café & 113,20 & 207,55 \\
\hline $6 / 8 / 1980$ & 11 & O Estado de São Paulo & 28 & fogăo & Casas Bahia & $7.840,00$ & $7.940,00$ & $24.900,00$ & 3 & 4,11 & Semer Century 8 bocas $o f$ tampa de vidro & 876,89 & $1.233,42$ \\
\hline 13/9/1980 & 12 & O Estado de Sâo Paulo & 26 & cafeteira elétrica & Casas Bahia & $1.440,00$ & $1.440,00$ & $4.380,00$ & 3 & 0,72 & Amo 16 xicaras de café & 118,34 & 217,46 \\
\hline 8/9/1900 & 27 & O Estado de São Paulo & 26 & cafeteira elétrica & Jumbo Extra & & & $4.700,00$ & & 0,78 & Arno 24 xicaras & 127,77 & 232.82 \\
\hline $16 / 9 / 1900$ & 20 & O Estado de São Paulo & 28 & cafeteira elétrica & Mappin & & & $3.790,00$ & & 0,63 & Walita 10 xicaras & 103,03 & 187,74 \\
\hline 9/9/1990 & 27 & O Estado de Sâo Paulo & 28 & cafeteira elétrica & Paes Mendonça & & & $5.340,00$ & & 0,88 & Arno 24 xicaras & 145,16 & 264.52 \\
\hline 2/8/1990 & 37 & O Estado de Sâo Paulo & 28 & cafeteira elétrica & Singer & & & $4.990,00$ & & 0,82 & Arno 16 xicaras de café & 135,05 & 247,18 \\
\hline $2 / 9 / 1990$ & 14 & O Estado de Sâo Paulo & 27 & torradeira de păo & Casas Bahia & $1.500,00$ & & $4.690,00$ & 4 & 0,77 & Arno Multitost & 127,49 & 232.32 \\
\hline 6/9/1990 & 11 & O Estado de São Paulo & 27 & torradeira de pão & Casas Bahia & $1.500,00$ & $1.500,00$ & $4,690,00$ & 3 & 0,77 & Arno Multitost & 127,49 & 232.32 \\
\hline 13/8/1980 & 12 & O Estado de São Paulo & 27 & torradeira de pão & Casas Bahia & $1.630,00$ & $1.630,00$ & $4.990,00$ & 3 & 0,82 & Amo Multitost & 135,05 & 247,18 \\
\hline 9/8/1980 & 20 & O Estado de São Paulo & 27 & torradeira de pão & Mappin & & & $4.490,00$ & & 0,74 & Arno Multitost & 122,06 & 222.41 \\
\hline 9/9/1990 & 20 & O Estado de São Paulo & 27 & torradeira de pão & Mappin & & & $8.890,00$ & & 1,47 & Amo Superchef & 241,67 & 440,37 \\
\hline 2/9/1980 & 24 & O Estado de São Paulo & 28 & secadora roupas & Arapuã & $8.800,00$ & & $41.900,00$ & 12 & 6,92 & Frigidaire compacta & $1.139,03$ & $2.075,52$ \\
\hline $9 / 9 / 1980$ & 27 & O Estado de Sâo Paulo & 28 & secadora roupas & Carrefour & & & $12.900,00$ & & 2,13 & Suggar com timer & 350,68 & 639,00 \\
\hline 9/9/1980 & 27 & O Estado de São Paulo & 28 & secadora roupas & Carrefour & & & $45.900,00$ & & 7,58 & Brastemp 61ELB & $1.247,78$ & $2.273,68$ \\
\hline $8 / 8 / 1980$ & 15 & O Estado de São Paulo & 28 & secadora roupas & Casas Bahia & $13.300,00$ & $13.300,00$ & $39.900,00$ & 2 & 6,59 & White Westinghouse Super Luxo até $4 \mathrm{~kg}$ & $1.084,66$ & $1.978,45$ \\
\hline 9/8/1980 & 10 & O Estado de São Paulo & 28 & secadora roupas & Casas Bahia & $13.300,00$ & $13.300,00$ & $39.900,00$ & 2 & 6,59 & White Westinghouse Super Luxo até $4 \mathrm{~kg}$ & $1.084,66$ & $1.976,45$ \\
\hline 9/9/1900 & 13 & O Estado de São Paulo & 28 & secadora roupas & Casas Bahia & $10.770,00$ & $10.770,00$ & $41.900,00$ & 5 & 6,92 & Brastemp $61 \mathrm{E}$ & $1.139,03$ & $2.075,52$ \\
\hline 13/8/1900 & 10 & O Estado de Sâo Paulo & 28 & secadora roupas & Casas Bahia & $13.300,00$ & $13.300,00$ & $39.900,00$ & 2 & 6,59 & White Westinghouse Super Luxo ate $4 \mathrm{~kg}$ & $1.084,66$ & $1.976,45$ \\
\hline 16/9/1980 & 11 & O Estado de Sâo Paulo & 28 & secadora roupas & Casas Bahia & 13.300 .00 & $13.300,00$ & $39.900,00$ & 2 & 6,59 & White Westinghouse Super Luxo atê $4 \mathrm{~kg}$ & $1.084,86$ & 1.978 .45 \\
\hline 9/9/1980 & 27 & O Estado de São Paulo & 28 & secadora roupas & Jumbo Extra & & & $41.900,00$ & & 6,92 & Brastemp 61ELB & $1.139,03$ & $2.075,52$ \\
\hline $2 / 8 / 1990$ & 22 & O Estado de São Paulo & 29 & aquecedor elétrioo & Jumbo Eletro & & & $2.900,00$ & & 0,48 & Punktal quartzo $1200 \mathrm{~W}$ & 78,83 & 143,65 \\
\hline 2/9/1980 & 23 & O Estado de Sâo Paulo & 30 & espremedor frutas & Jumbo Eletro & & & $2.580,00$ & & 0,43 & Arno espremedor fruta elétrico & 70,14 & 127,80 \\
\hline $16 / 9 / 1990$ & 8 & O Estado de Sâo Paulo & 30 & espremedor frutas & Jumbo Eletro & & & $2.350,00$ & & 0,39 & Arno & 63,88 & 116.41 \\
\hline $16 / 9 / 1980$ & 29 & O Estado de Sâo Paulo & 30 & espremedor frutas & Lojas Glória & & & $2.900,00$ & & 0,48 & Walita ES 49 & 78,83 & 143,65 \\
\hline $9 / 9 / 1980$ & 8 & O Estado de Sâo Paulo & 30 & espremedor frutas & Mahfuz & $1.185,00$ & & $2.890,00$ & 3 & 0,49 & Arno EFA capacidade 1 litro & 81,28 & 148,11 \\
\hline 2/9/1990 & 25 & O Estado de São Paulo & 30 & espremedor firutas & Ponto Frio & & & $1.980,00$ & & 0,33 & Británia SL automático & 54,10 & 98,57 \\
\hline 9/9/1980 & 31 & O Estado de Sâo Paulo & 32 & lava louça maq & Arapuã & $6.890,00$ & $8.890,00$ & $30.900,00$ & 8 & 5,10 & Enxula automática 047 & 840,00 & $1.530,63$ \\
\hline 9/9/1990 & 27 & O Estado de Sâo Paulo & 32 & lava louça maq & Carrefour & & & $27.900,00$ & & 4,61 & Enxuta automática 047 & 758,44 & $1.382,03$ \\
\hline 9/8/1980 & 27 & O Estado de São Paulo & 32 & Iava louca maq & Carrefour & & & $30.290,00$ & & 5,00 & Enxuta eletrônica 077 & 823,42 & $1.500,42$ \\
\hline
\end{tabular}




\begin{tabular}{|c|c|c|c|c|c|c|c|c|c|c|c|c|c|}
\hline més / ano & - seten & mbro de 1990 & salário & o mínimo em 01.0 & $1990-\operatorname{Cr} 56.056,3$ & & & & & pesq er er & m: Arquivo de Estado de Săo Paulo & & \\
\hline produto $-\mathrm{d}$ & liverso & & & & & & & & & |data: 18 & $8 / 12 / 2005-22 / 12 / 2005$ & & \\
\hline data & pág. & jornal consultado & \begin{tabular}{|c|} 
cod \\
prod.
\end{tabular} & produto & loja & $\begin{array}{c}\text { prest. à } \\
\text { prazo }\end{array}$ & entrada & preço à vista & $\begin{array}{c}n^{\circ} \\
\text { parc. }\end{array}$ & $\begin{array}{l}\text { qtd de } \\
\text { SM }\end{array}$ & descrição do produto & $\begin{array}{l}\text { atualiz. p| } \\
\text { IPC-SP } \\
\text { FIPE }\end{array}$ & $\begin{array}{l}\text { atualiz. p } \\
\text { SM de } \\
2005\end{array}$ \\
\hline $16 / 9 / 1980$ & 6 & O Estado de São Paulo & 32 & lava louça maq & Casa Centro & & & $28.900,00$ & & 4,77 & Semer automática até 6 pessoas & 785,63 & $1.431,56$ \\
\hline 9/8/1980 & 27 & O Estado de São Paulo & 32 & lava louça maq & Eldorado & & & $40.216,00$ & & 6,64 & Enxuta eletrônica 077 & $1.093,25$ & $1.892,10$ \\
\hline 9/8/1980 & 8 & O Estado de São Paulo & 32 & lava louça maq & Jumbo Eletro & & & $39.800,00$ & & 6,57 & Brastemp Compacta para 6 pessoas & $1.081,84$ & $1.971,50$ \\
\hline 9/8/1980 & 27 & O Estado de Sâo Paulo & 32 & lava louça maq & Jumbo Extra & & & $25.900,00$ & & 4,28 & Enxuta automática 047 & 704,08 & $1.282,96$ \\
\hline 9/8/1980 & 27 & O Estado de Sâo Paulo & 32 & lava louça maq & Jumbo Extra & & & $28.900,00$ & & 4,77 & Enxuta eletrônica 077 & 785,63 & $1.431,56$ \\
\hline 9/8/1980 & 27 & O Estado de Sâo Paulo & 32 & lava louça maq & Paes Mendonça & & & $26.900,00$ & & 4,44 & Enxuta automática 047 & 731,28 & $1.332,48$ \\
\hline 2/8/1980 & 25 & O Estado de Sâo Paulo & 32 & lava louça maq & Ponto Frio & $15.590,00$ & & $59.500,00$ & 6 & 9,82 & Continental Luxo 279 & $1.617,47$ & $2.847,34$ \\
\hline $918 / 1990$ & 4 & O Estado de São Paulo & 32 & lava louça maq & Ponto Frio & $18.740,00$ & & $71.500,00$ & 6 & 11,81 & Brastemp Quality 62 Y BVS 62 DKB & $1.843,68$ & $3.541,76$ \\
\hline 16/8/1980 & 40 & O Estado de São Paulo & 32 & lava louca maq & Ponto Frio & $10.810,00$ & & $39.600,00$ & 6 & 6,54 & Brastemp compacta BVM 48SB & $1.076,50$ & $1.861,58$ \\
\hline 6/8/1980 & 12 & O Estado de Sâo Paulo & 33 & formo elétrico & Casa Centro & & & $8.900,00$ & & 1,47 & Arno Superchef & 241,84 & 440,86 \\
\hline 9/8/1980 & 27 & O Estado de Sâo Paulo & 33 & fomo elétrico & Eldorado & & & $20.685,00$ & & 3,41 & Fisher & 561,77 & $1.023,64$ \\
\hline 9/8/1980 & 27 & O Estado de Sâo Paulo & 33 & formo elétrico & Jumbo Extra & & & $15.800,00$ & & 2,81 & Fisher & 428,51 & 782,65 \\
\hline 9/8/1980 & 8 & O Estado de Sâo Paulo & 33 & formo elétrico & Mahfuz & $8.740,00$ & & $21.900,00$ & 3 & 3,62 & Fisher & 595,34 & $1.084,82$ \\
\hline 9/8/1980 & 30 & O Estado de Sâo Paulo & 34 & ar condicionado & Arapuã & $13.900,00$ & $13.800,00$ & $59.900,00$ & 7 & 9,89 & Consul Air Master 10000 BTUs quente e frio & $1.828,35$ & $2.867,15$ \\
\hline 9/8/1990 & 2 & O Estado de São Paulo & 34 & ar condicionado & Casa Centro & & & $42.900,00$ & & 7,08 & Springer 7000 BTU/h & $1.166,21$ & $2.125,08$ \\
\hline 9/8/1980 & 8 & O Estado de Sâo Paulo & 34 & ar condicionado & Mahfuz & $15.320,00$ & & $38.400,00$ & 3 & 6,34 & Consul 7000 BTUs & $1.043,88$ & $1.802,15$ \\
\hline 9/8/1980 & 8 & O Estado de Sâo Paulo & 34 & ar condicionado & Mahfuz & $21.745,00$ & & $54.500,00$ & 3 & 8,00 & Consul 10000 BTUs & $1.481,55$ & $2.609,68$ \\
\hline 9/8/1980 & 31 & O Estado de Sâo Paulo & 35 & toca disco laser & Arapuã & & & $46.900,00$ & & 7,74 & Philips G10 & $1.274,85$ & $2.323,20$ \\
\hline 9/8/1980 & 27 & O Estado de São Paulo & 35 & toca disco laser & Jumbo Extra & & & $28.980,00$ & & 4,79 & Semp Toshiba XRV 15 & 787,80 & $1.435,53$ \\
\hline 16/8/1980 & 20 & O Estado de Sâo Paulo & 35 & toca disco laser & Mappin & & & $32.900,00$ & & 5.43 & Philco PDA 6000 & 884,37 & $1.629,71$ \\
\hline
\end{tabular}




\begin{tabular}{|c|c|c|c|c|c|c|c|c|c|c|c|c|c|}
\hline \multicolumn{3}{|c|}{$\begin{array}{l}\text { mês / ano - setembro de } 2000 \\
\text { produto - diversos }\end{array}$} & \multicolumn{7}{|c|}{ Salário mínimo em 01.04 .2000 - RS 151.00} & \multicolumn{4}{|c|}{$\begin{array}{l}\text { pesq. em: Arquivo de Estado de Săo Paulo } \\
\text { data: } 18 / 12 / 2005-22 / 12 / 2005\end{array}$} \\
\hline data & pág. & jomal consultado & $\begin{array}{l}\text { cod } \\
\text { prod. }\end{array}$ & produto & loja & $\begin{array}{l}\text { prest. à } \\
\text { prazo }\end{array}$ & entrada & $\begin{array}{l}\text { preco à } \\
\text { vista }\end{array}$ & $\begin{array}{c}\mathrm{n}^{\circ} \\
\text { parc. }\end{array}$ & qtd de & descriçăo do produto & $\begin{array}{c}\text { atualiz. p/ } \\
\text { IPC-SP } \\
\text { FIPE }\end{array}$ & $\begin{array}{r}\text { atualiz. } p / \\
\text { SM de } 2008\end{array}$ \\
\hline $21 / 9 / 2000$ & $\mathrm{CB}$ & Follha de Săo Paulo & & maq lavar roupa & Arapuã & 28,90 & & 258,00 & 12 & 1,71 & Plenna Capri Latina semi-automática & 366,77 & 512,58 \\
\hline $21 / 9 / 2000$ & $\mathrm{CB}$ & Folha de Săo Paulo & & maq lavar roupa & Arapuâ & 49,80 & & 438,00 & 12 & & Continental Evolution 13 programas & 622.65 & 870,20 \\
\hline $5 / 8 / 2000$ & C1 & Follha de Săo Paulo & & maq lavar roupa & BestMix & & & 789,00 & & & Brastemp BWF22 - Simples Toque & $1.121,62$ & $1.567,55$ \\
\hline $5 / 9 / 2000$ & $\mathrm{C} 1$ & Folha de Săo Paulo & 1 & maq lavar roupa & BestMix & & & 869,00 & & & Brastemp BWC24 & $1.235,34$ & $1.726,49$ \\
\hline 14/9/2000 & encarte & O Estado de São Paulo & 1 & maq lavar roupa & Best:Mix & 188,81 & 188,81 & 879,00 & 4 & & Brastemp BWQ-24A - $7 \mathrm{~kg}$ & $1.249,56$ & $1.746,36$ \\
\hline $3 / 9 / 2000$ & encarte & O Estado de São Paulo & & maq lavar roupa & Casas Bahia & 127,00 & & 899,00 & 8 & & Brastemp BWQ-24A - $7 \mathrm{~kg}$ & $1.277,89$ & $1.786,00$ \\
\hline $7 / 9 / 2000$ & $\mathrm{C} 3$ & Folha de Săo Paulo - cal & 1 & maq lavar roupa & Casas Bahia & 77.96 & & 549,00 & 8 & & Enxuta $5 \mathrm{~kg} 11$ programas & 780,44 & $1.090,73$ \\
\hline $7 / 9 / 2000$ & $\mathrm{C3}$ & Follha de Săo Paulo - cal & 1 & maq lavar roupa & Casas Bahia & 92,16 & & 249,00 & 8 & & Enxuta Super $6 \mathrm{~kg} 17$ programas & 922,60 & $1.289,40$ \\
\hline $7 / 9 / 2000$ & $\mathrm{C} 3$ & Follha de Săo Paulo - cas & & maq lavar roupa & Casas Bahia & 83,00 & & 744,00 & 8 & & Continental Evolution $10 \mathrm{~kg}$ & $1.057,05$ & $1.478,15$ \\
\hline $7 / 9 / 2000$ & $\mathrm{C} 3$ & Folha de Săo Paulo - ca & 1 & maq lavar roupa & Casas Bahia & 113.46 & & 799,00 & 8 & & Brastemp BWF22A & $1.135,83$ & $1.587,42$ \\
\hline $7 / 9 / 2000$ & $\mathrm{C} 3$ & Folha de Săo Paulo & & maq lavar roupa & Casas Bahia & 117,58 & & 828,00 & 8 & & Electrolux LE 08 - $8 \mathrm{~kg}$ - 9 programas & $1.177,08$ & $1.845,03$ \\
\hline $7 / 9 / 2000$ & $\mathrm{C} 3$ & Follha de Săo Paulo - cas & 1 & maq lavar roupa & Casas Bahia & 126,06 & & 892,00 & 8 & & Electrolux LE 08/A - $8 \mathrm{~kg}-13$ programas & $1.268,04$ & $1.772,18$ \\
\hline $7 / 9 / 2000$ & $\mathrm{C} 3$ & Folha de Săo Paulo - cal & 1 & maq lavar roupa & Casas Bahia & 127,00 & & 899,00 & 8 & & Brastemp BWQ-24A - $7 \mathrm{~kg}$ & $1.277,89$ & $1.786,00$ \\
\hline 17/9/2000 & encarte & O Estado de São Paulo & 1 & maq lavar roupa & Casas Bahia & 127,00 & & 899,00 & 8 & & Brastemp Eletrönica $7 \mathrm{~kg}$ & $1.277,89$ & $1.786,00$ \\
\hline $21 / 9 / 2000$ & B3 & O Estado de Săo Paulo & & maq lavar roupa & Casas Bahia & 77.96 & & 549,00 & 8 & & Enxuta Superluxo $5 \mathrm{~kg} 11$ programas & 780,44 & $1.090,73$ \\
\hline $21 / 9 / 2000$ & B3 & O Estado de São Paulo & & maq lavar roupa & Casas Bahia & 92,16 & & 249,00 & 8 & & Enxuta Super $6 \mathrm{~kg} 17$ programas & 922,60 & $1.289,40$ \\
\hline $21 / 9 / 2000$ & B3 & O Estado de São Paulo & & maq lavar roupa & Casas Bahia & 93,00 & & 744,00 & 8 & & Continental Evolution $10 \mathrm{~kg}$ & $1.057,65$ & $1.478,15$ \\
\hline $21 / 9 / 2000$ & B3 & O Estado de São Paulo & 1 & maq lavar roupa & Casas Bahia & 117,58 & & 828,00 & 8 & & Electrolux $8 \mathrm{~kg} 11$ programas & $1.177,08$ & $1.845,03$ \\
\hline $21 / 9 / 2000$ & $\mathrm{~B} 3$ & O Estado de São Paulo & & maq lavar roupa & Casas Bahia & 126,66 & & 892,00 & 8 & & Electrolux $8 \mathrm{~kg} 13$ programas & $1.288,04$ & $1.772,19$ \\
\hline $21 / 9 / 2000$ & $\mathrm{~B} 3$ & O Estado de São Paulo & 1 & maq lavar roupa & Casas Bahia & 127,00 & & 899,00 & 8 & & Brastemp Eletrônica $7 \mathrm{~kg}$ & $1.277,89$ & $1.786,00$ \\
\hline $3 / 9 / 2000$ & A10 & Folha de Săo Paulo & 1 & maq lavar roupa & Eletro & 81,59 & & 598,00 & 8 & & Electrolux LE 750 - $5 \mathrm{~kg}$ - 15 programas - dispenser múltiplo & 850,10 & $1.188,08$ \\
\hline $7 / 9 / 2000$ & 06 & Folha de Săo Paulo & & maq lavar roupa & Extra & 60,80 & & 249,00 & 12 & & Enxuta 6.0 & 922,60 & $1.289,40$ \\
\hline 15/9/2000 & encarte & Folha de Săo Paulo & 1 & maq lavar roupa & Extra & 67,31 & & 748,00 & 15 & & Electrolux LE 08 & $1.084,76$ & $1.488,08$ \\
\hline $17 / 9 / 2000$ & $\mathrm{C} 1$ & Follha de Săo Paulo & & maq lavar roupa & Fast Shop & 106,50 & & 639,00 & 8 & & Continental Evolution $215-5 \mathrm{~kg}$ & 908,38 & $1.269,54$ \\
\hline $3 / 9 / 2000$ & encarte & O Estado de Săo Paulo & 1 & maq lavar roupa & Ponto Frio & 38.22 & & 279,00 & 8 & & Suggar Superluxo $4,5 \mathrm{~kg}$ & 396.62 & 554,30 \\
\hline $3 / 9 / 2000$ & encarte & O Estado de São Paulo & & maq lavar roupa & Ponto Frio & 59.29 & & 539,00 & 13 & & Enxuta $5 \mathrm{~kg} 11$ programas & 768.23 & $1.070,86$ \\
\hline $3 / 9 / 2000$ & encarte & O Estado de Săo Paulo & 1 & maq lavar roupa & Ponto Frio & 72.49 & & 659,00 & 13 & & Consul automática CWC22 - $5 \mathrm{~kg}$ & 836.81 & $1.309,27$ \\
\hline 10/9/2000 & encarte & O Estado de Săo Paulo & 1 & maq lavar roupa & Ponto Frio & 38.22 & & 279,00 & 8 & & Suggar Superluxo $4.5 \mathrm{~kg}$ & 396.62 & 564,30 \\
\hline 10/9/2000 & encarte & O Estado de São Paulo & 1 & maq lavar roupa & Ponto Frio & 59.29 & & 539,00 & 13 & & Enxuta Superluxo $5 \mathrm{~kg} 11$ programas & 786.23 & $1.070,88$ \\
\hline 13/9/2000 & A11 & Follha de Săo Paulo & 2,1 & TV a cores & Arapuâ & 101,55 & & 479,00 & 5 & & Semp Toshiba 2083 FAV - $20^{\prime \prime}$ & 680,83 & 851,08 \\
\hline 13/9/2000 & A11 & Folha de Săo Paulo & 2,1 & TV a cores & Arapuâ & 189,10 & & 939,00 & 5 & & Semp Toshiba 2988 ASU - $29^{\circ}$ & $1.334,85$ & $1.865,58$ \\
\hline 13/9/2000 & A.11 & Follha de Săo Paulo & 2,1 & TV a cores & Arapuã & 443,25 & & $2.090,00$ & 5 & & Gradiente Impact M-341 - 34" & $2.971,08$ & $4.152,32$ \\
\hline 14/9/2000 & encarte & O Estado de São Paulo & 2,1 & TV a cores & BestMix & 208,14 & 208,14 & 969,00 & 4 & & Sony Wega $21^{\prime \prime}$ - KV21FV120 & $1.377,50$ & $1.925,17$ \\
\hline $14 / 9 / 2000$ & encarte & O Estado de São Paulo & 2,1 & TV a cores & BestMix & 375,68 & 375,68 & $1.749,00$ & 4 & & Sony Wega $29^{\prime \prime}$ - KV29F512B & $2.486,33$ & $3.474,83$ \\
\hline 14/9/2000 & encarte & O Estado de Săo Paulo & 2,1 & TV a cores & BestMix & 556,33 & 556,33 & $2.590,00$ & 4 & & Phico 32- T32W10 & $3.681,87$ & $5.145,70$ \\
\hline $14 / 9 / 2000$ & encarte & O Estado de Săo Paulo & 2,1 & TV a cores & BestMix & $1.108,37$ & $1.108,37$ & $5.160,00$ & 4 & & Sony Wega 38" d PIP - KV38FV158 & $7.335,30$ & $10.251,68$ \\
\hline $14 / 9 / 2000$ & encarte & O Estado de Săo Paulo & 2,1 & TV a cores & Best:Mix & $1.415,53$ & $1.415,53$ & $6.590,00$ & 4 & & $P h i c 0$ 50' - T250V61 & $9.368,15$ & $13.092,72$ \\
\hline $3 / 9 / 2000$ & encarte & O Estado de São Paulo & 2,1 & TV a cores & Casas Bahia & 49,00 & & 349,00 & 8 & & Philoo $14^{*}$ & 496,13 & 693,38 \\
\hline $3 / 9 / 2000$ & encarte & O Estado de Săo Paulo & 2,1 & TV a cores & Casas Bahia & 62,00 & & 439,00 & 8 & & Mitsubishi TC-1409-14" & 624,07 & 872,18 \\
\hline
\end{tabular}




\begin{tabular}{|c|c|c|c|c|c|c|c|c|c|c|c|c|c|}
\hline \multicolumn{3}{|c|}{$\begin{array}{l}\text { mês / ano - setembro de } 2000 \\
\text { produto - diversos }\end{array}$} & \multicolumn{7}{|c|}{ salário minimo em 01.04 .2000 - RS 151,00} & \multicolumn{4}{|c|}{$\begin{array}{l}\text { pesq. em: Arquivo de Estado de Săo Paulo } \\
\text { data: 18/12/2005-22/12/2005 }\end{array}$} \\
\hline data & pág. & jomal consultado & \begin{tabular}{|l} 
cod \\
prod.
\end{tabular} & produto & Ioja & $\begin{array}{c}\text { prest. à } \\
\text { prazo }\end{array}$ & entrada & $\begin{array}{l}\text { prepo à } \\
\text { vista }\end{array}$ & $\begin{array}{c}n^{\circ} \\
\text { parc. }\end{array}$ & atd de & descriçăo do produto & $\begin{array}{l}\text { atualiz. } p / \\
\text { IPC-SP } \\
\text { FIPE }\end{array}$ & $\begin{array}{r}\text { atualiz. } p^{\prime} \\
\text { SM de } 200\end{array}$ \\
\hline $3 / 9 / 2000$ & encarte & O Estado de São Paulo & 2,1 & TV a cores & Casas Bahia & 63,00 & & 449,00 & 8 & & Philoo $20^{*}$ - PalM-NTSC & 638,29 & 892,05 \\
\hline 3/9/2000 & encarte & O Estado de Săo Paulo & 2,1 & TV a cores & Casas Bahia & 77,00 & & 549,00 & 8 & & Mitsubishi TC-2009-20 & 780.44 & $1.090,73$ \\
\hline 3/9/2000 & encarte & O Estado de São Paulo & 2,1 & TV a cores & Casas Bahia & 80,80 & & 569,00 & 8 & & Gradiente $20^{\circ}$ & 808,87 & $1.130,46$ \\
\hline $3 / 9 / 2000$ & encarte & O Estado de São Paulo & 2,1 & TV a cores & Casas Bahia & 134,76 & & 848,00 & 8 & & $\mathrm{Ph}$ ico $29^{\circ}$ - PalM-NTSC & $1.349,07$ & $1.885,43$ \\
\hline 14/9/2000 & $\mathrm{C5}$ & Folha de Săo Paulo - ca & 2,1 & TV a cores & Casas Bahia & 62,00 & & 439,00 & 8 & & Mitsubishi TC $1409-14$ & 624,07 & 872,18 \\
\hline $14 / 9 / 2000$ & $c 5$ & Folha de Săo Paulo - ca & 2,1 & TV a cores & Casas Bahia & 77,00 & & 548,00 & 8 & & Mitsubishi TC $2009-20^{\circ}$ & 780,44 & $1.090,73$ \\
\hline $17 / 9 / 2000$ & encarte & O Estado de São Paulo & 2,1 & TV a cores & Casas Bahia & 49,00 & & 349,00 & 8 & & Philoo 14* & 486,13 & 693,38 \\
\hline $17 / 9 / 2000$ & encarte & O Estado de Săo Paulo & 2,1 & TV a cores & Casas Bahia & 62,00 & & 439,00 & 8 & & Mitsubishi TC $1409-14^{\prime \prime}$ & 624,07 & 872,19 \\
\hline $17 / 9 / 2000$ & encarte & O Estado de São Paulo & 2,1 & TV a cores & Casas Bahia & 63,00 & & 449,00 & 8 & & Phico 20 - PalM-NTSC & 638.28 & 892,05 \\
\hline $17 / 9 / 2000$ & encarte & O Estado de São Paulo & 2,1 & TV a cores & Casas Bahia & 77,00 & & 549,00 & 8 & & Mitsubishi TC $2009-20^{\circ}$ & 780,44 & $1.090,73$ \\
\hline $17 / 9 / 2000$ & encarte & OEstado de São Paulo & 2,1 & TV a cores & Casas Bahia & 88,80 & & 569,00 & 8 & & Aiwa AR205 - $20^{\circ}$ & 808,87 & $1.130,46$ \\
\hline $3 / 9 / 2000$ & A11 & Follha de Săo Paulo & 2,1 & TV a cores & Eletro & 111,75 & & 819,00 & 8 & & Philoo Platinum PCS2956 & $1.184,27$ & $1.627,15$ \\
\hline $3 / 9 / 2000$ & AQ & Folha de Săo Paulo & 2,1 & TV a cores & Extra & 178,85 & & $1.990,00$ & 15 & & Mitsubishi $33^{\circ} \mathrm{TC} 3309 \mathrm{com}$ PIP & $2.828,82$ & $3.853,24$ \\
\hline $14 / 9 / 2000$ & $C 6$ & Follha de Săo Paulo & 2,1 & TV a cores & Extra & 31,78 & & 339,00 & 12 & & LG CP 14B85 - 14" & 481,81 & 673,51 \\
\hline $14 / 9 / 2000$ & encarte & Follha de Săo Paulo & 2,1 & TV a cores & Extra & 46.25 & & 339,00 & 8 & & Semp Toshiba 1483AAV - $14^{-}$ & 481,81 & 673,51 \\
\hline 14/9/2000 & encarte & Follha de Săo Paulo & 2,1 & TV a cores & Extra & 46.25 & & 339,00 & 8 & & Panasonic 14A10 - 14" & 481,91 & 673,51 \\
\hline 14/9/2000 & encarte & Follha de Săo Paulo & 2,1 & TV a cores & Extra & 58,53 & & 428,00 & 8 & & Philco Platinum TP-2052N - 20" & 609.85 & 852,32 \\
\hline $14 / 9 / 2000$ & encarte & Follha de Săo Paulo & 2,1 & TV a cores & Extra & 49,09 & & 489,00 & 12 & & Aiwa AR 205ST - 20" & 685,15 & 971,52 \\
\hline $14 / 9 / 2000$ & encarte & Follha de Săo Paulo & 2,1 & TV a cores & Extra & 73.49 & & 732,00 & 12 & & Philco Dueto PTV 1418 - $14^{-}$ & $1.040,59$ & $1.454,30$ \\
\hline $14 / 9 / 2000$ & $C 6$ & Folha de Săo Paulo & 2,1 & TV a cores & Extra & 74,76 & & 798,00 & 12 & & Aiwa AR2 $295-29^{\circ}$ & $1.134,41$ & $1.585,43$ \\
\hline 14/9/2000 & $C 6$ & Follha de Săo Paulo & 2,1 & TV a cores & Extra & 76,73 & & 819,00 & 12 & & Phico Platinum PCS2956 & $1.184,27$ & $1.627,15$ \\
\hline 14/9/2000 & encarte & Follha de Săo Paulo & 2,1 & TV a cores & Extra & 82.22 & & 819,00 & 12 & & Philco Platinum PCS2956 - $29^{\circ}$ & $1.184,27$ & $1.627,15$ \\
\hline $14 / 9 / 2000$ & $\mathrm{C} 7$ & Follha de Săo Paulo & 2,1 & TV a cores & Extra & 83,59 & & 899,00 & 12 & & Toshiba Channel guide 2808P PIP - $28^{\circ}$ & $1.420,15$ & $1.984,77$ \\
\hline 14/9/2000 & $C 6$ & Follha de Săo Paulo & 2,1 & TV a cores & Extra & 159,17 & & $1.699,00$ & 12 & & Toshiba 3488 of PIP - $34^{\prime \prime}$ & $2.415,25$ & $3.375,50$ \\
\hline $14 / 9 / 2000$ & $\mathrm{C} 7$ & Follha de Săo Paulo & 2,1 & TV a cores & Extra & 177.07 & & $1.890,00$ & 12 & & Mitsubishi TC 3309 PIP - 33" & $2.686,77$ & $3.754,97$ \\
\hline $14 / 9 / 2000$ & encarte & Folha de Săo Paulo & 2,1 & TV a cores & Extra & 189,75 & & $1.890,00$ & 12 & & LG CP29Q12P Flatron - $29^{\circ}$ & $2.686,77$ & $3.754,97$ \\
\hline $14 / 9 / 2000$ & $\mathrm{C} 7$ & Follha de Săo Paulo & 2,1 & TV a cores & Extra & 439,40 & & $4.690,00$ & 12 & & Toshiba TZ 43V81 - 43' & $6.667,16$ & $9.317,88$ \\
\hline $15 / 9 / 2000$ & encarte & Follha de Săo Paulo & 2,1 & TV a cores & Extra & 71,72 & & 798,00 & 15 & & Aiwa AR 295 ST - $29^{\circ}$ & $1.134,41$ & $1.585,43$ \\
\hline $15 / 9 / 2000$ & encarte & Follha de Săo Paulo & 2,1 & TV a cores & Extra & 73.61 & & 818,00 & 15 & & Philoo $2956-29^{\prime \prime}$ & $1.164,27$ & $1.627,15$ \\
\hline $15 / 9 / 2000$ & encarte & Follha de Săo Paulo & 2,1 & TV a cores & Extra & 97,87 & & $1.089,00$ & 15 & & Gradiente M291 - $2 g^{\prime \prime}$ & $1.548,00$ & $2.163,58$ \\
\hline $3 / 9 / 2000$ & A17 & O Estado de São Paulo & 2,1 & TV a cores & Fast Shop & 228.00 & & $1.599,00$ & 8 & & LG Flatron CP 25Q20 - 20" & $2.273,09$ & $3.176,82$ \\
\hline $3 / 9 / 2000$ & A.17 & O Estado de São Paulo & 2,1 & TV a cores & Fast Shop & 292,00 & & $2.049,00$ & 8 & & LG Flatron CP 29Q12P - $29^{\prime \prime}$ & $2.812,80$ & $4.070,86$ \\
\hline 10/9/2000 & $\mathrm{A} 15$ & Follha de Săo Paulo & 2,1 & TV a cores & Fast Shop & 228,00 & & $1.599,00$ & 8 & & LG Flatron CP $25020-20^{\circ}$ & $2.273,08$ & $3.176,82$ \\
\hline $10 / 9 / 2000$ & A.15 & Follha de Săo Paulo & 2,1 & TV a cores & Fast Shop & 292,00 & & $2.049,00$ & 8 & & LG Flatron CP 29Q12P - $29^{\prime \prime}$ & $2.812,80$ & $4.070,88$ \\
\hline $14 / 9 / 2000$ & $\mathrm{C} 12$ & Follha de Săo Paulo & 2,1 & TV a cores & Panashop & 218,00 & 218,00 & $1.060,00$ & 4 & & Panasonic PVIM2079 - 20" & $1.506,86$ & $2.105,86$ \\
\hline 10/9/2000 & encarte & O Estado de São Paulo & 2,1 & TV a cores & Pernambucanas & 56,10 & 56,10 & 439,00 & 8 & & LG CP-2085S - $20^{\circ}$ & 624,07 & 872,19 \\
\hline $3 / 9 / 2000$ & encarte & O Estado de São Paulo & 2,1 & TV a cores & Ponto Frio & 37,29 & & 339,00 & 13 & & CCE HPS $1403-14^{\prime \prime}$ & 481.91 & 673,51 \\
\hline $3 / 9 / 2000$ & encarte & O Estado de São Paulo & 2,1 & TV a cores & Ponto Frio & 40,48 & & 368,00 & 13 & & Semp Toshiba BAV - $14^{*}$ & 523,14 & 731,13 \\
\hline $3 / 9 / 2000$ & encarte & O Estado de São Paulo & 2,1 & TV a cores & Ponto Frio & 40,50 & & 369,00 & 13 & & Phips PT 314/316 - 14" & 524,56 & 733,11 \\
\hline
\end{tabular}




\begin{tabular}{|c|c|c|c|c|c|c|c|c|c|c|c|c|c|}
\hline \multicolumn{3}{|c|}{$\begin{array}{l}\text { mês / ano - setembro de } 2000 \\
\text { produto - diversos }\end{array}$} & \multicolumn{7}{|c|}{ salário mínimo em 01.04 .2000 - RS 151.00} & \multicolumn{4}{|c|}{$\begin{array}{l}\text { pesq. em: Arquivo de Estado de Săo Paulo } \\
\text { data: } 18 / 12 / 2005-22 / 12 / 2005\end{array}$} \\
\hline data & pág. & jomal consultado & $\begin{array}{c}\text { cod } \\
\text { prod. }\end{array}$ & produto & loja & $\begin{array}{c}\text { prest. à } \\
\text { prazo }\end{array}$ & entrada & $\begin{array}{l}\text { preco à } \\
\text { vista }\end{array}$ & $\begin{array}{c}n^{\circ} \\
\text { parc. }\end{array}$ & $\begin{array}{c}\text { qtal de } \\
\text { SM }\end{array}$ & descriçăo do produto & $\begin{array}{l}\text { atualiz. p/ } \\
\text { IPC-SP } \\
\text { FIPE }\end{array}$ & $\begin{array}{r}\text { atualiz. } p^{\prime} \\
\text { SM de } 2005\end{array}$ \\
\hline $3 / 9 / 2000$ & encarte & O Estado de São Paulo & 2,1 & TV a cores & Ponto Frio & 42,79 & & 389,00 & 13 & & Aiwa AR145 - 14" & 552,89 & 772,85 \\
\hline $3 / 9 / 2000$ & encarte & O Estado de Săo Paulo & 2,1 & TV a cores & Ponto Frio & 43,89 & & 399,00 & 13 & & CCE HPS 2002 - 20" - Pal N-Pal M-NTSC & 567.21 & 792,72 \\
\hline $3 / 9 / 2000$ & encarte & O Estado de Săo Paulo & 2,1 & TV a cores & Ponto Frio & 47,08 & & 428,00 & 13 & & LG CP-20K40 - $20^{\circ}$ & 608,43 & 850,33 \\
\hline $3 / 9 / 2000$ & encarte & O Estado de Săo Paulo & 2,1 & TV a cores & Ponto Frio & 51,59 & & 469,00 & 13 & & Philips PT 324/326 - 20" & 686,72 & 831,79 \\
\hline $3 / 9 / 2000$ & encarte & O Estado de Săo Paulo & 2,1 & TV a cores & Ponto Frio & 51,59 & & 469,00 & 13 & & Semp Toshiba $2083-20^{\circ}$ & 666,72 & 831,79 \\
\hline $3 / 8 / 2000$ & \begin{tabular}{|l} 
encarte \\
\end{tabular} & O Estado de Săo Paulo & 2,1 & TV a cores & Ponto Frio & 53,79 & & 489,00 & 13 & & Aiwa Stereo $20^{\prime \prime}$ & 685,15 & 971,52 \\
\hline $3 / 8 / 2000$ & encarte & O Estado de São Paulo & 2,1 & TV a cores & Ponto Frio & 53,79 & & 489,00 & 13 & & Phinico Platinum 20' & 685,15 & 971,52 \\
\hline $3 / 8 / 2000$ & encarte & O Estado de São Paulo & 2,1 & TV a cores & Ponto Frio & 54,89 & & 499,00 & 13 & & Gradiente $20^{\circ}$ & 700,36 & 891,39 \\
\hline $3 / 9 / 2000$ & encarte & O Estado de Săo Paulo & 2,1 & TV a cores & Ponto Frio & 87,89 & & 799,00 & 13 & & LG CP21Q22 - Flatron $21^{\circ}$ & $1.135,83$ & $1.587,42$ \\
\hline $3 / 8 / 2000$ & encarte & O Estado de Săo Paulo & 2,1 & TV a cores & Ponto Frio & 104,39 & & 849,00 & 13 & & Phips PT $554-29^{\circ}$ & $1.349,07$ & $1.885,43$ \\
\hline $3 / 8 / 2000$ & encarte & O Estado de São Paulo & 2,1 & TV a cores & Ponto Frio & 105.48 & & 859,00 & 13 & & Semp Toshiba 2988 ASU - $29^{\prime}$ & $1.363,28$ & $1.805,30$ \\
\hline $3 / 8 / 2000$ & \begin{tabular}{|l} 
encarte \\
\end{tabular} & O Estado de Săo Paulo & 2,1 & TV a cores & Ponto Frio & 123,09 & & $1.119,00$ & 13 & & Sony KV-29175 - $29^{\circ}$ & $1.590,74$ & $2.223,18$ \\
\hline $3 / 8 / 2000$ & \begin{tabular}{|l} 
encarte \\
\end{tabular} & O Estado de Săo Paulo & 2,1 & TV a cores & Ponto Frio & 186,89 & & $1.699,00$ & 13 & & Phips PT $654-29^{\circ}$ tela plana & $2.415,25$ & $3.375,50$ \\
\hline $3 / 9 / 2000$ & encarte & O Estado de Săo Paulo & 2,1 & TV a cores & Ponto Frio & 230,89 & & $2.099,00$ & 13 & & Sony Wega 29FV158 - $29^{\circ}$ & $2.883,88$ & $4.170,20$ \\
\hline $10 / 9 / 2000$ & encarte & O Estado de Săo Paulo & 2,1 & TV a cores & Ponto Frio & 36,19 & & 329,00 & 13 & & CCE HPS-1402-14* & 467,70 & 653,64 \\
\hline 10/9/2000 & encarte & O Estado de São Paulo & 2,1 & TV a cores & Ponto Frio & 40,59 & & 369,00 & 13 & & Ph'ips PT 314/316 - 14" & 524,56 & 733,11 \\
\hline 10/9/2000 & encarte & O Estado de São Paulo & 2,1 & TV a cores & Ponto Frio & 51,59 & & 469,00 & 13 & & Semp Toshiba $2083-20^{\circ}$ & 686,72 & 831,79 \\
\hline 10/9/2000 & encarte & O Estado de São Paulo & 2,1 & TV a cores & Ponto Frio & 53,79 & & 489,00 & 13 & & Aiwa A.J203 - 20' stereo & 685,15 & 971,52 \\
\hline 10/9/2000 & \begin{tabular}{|l} 
encarte \\
\end{tabular} & O Estado de Săo Paulo & 2,1 & TV a cores & Ponto Frio & 104,39 & & 848,00 & 13 & & Phips PT $554-29^{\circ}$ & $1.349,07$ & $1.885,43$ \\
\hline 10/9/2000 & encarte & O Estado de Săo Paulo & 2,1 & TV a cores & Ponto Frio & 106,59 & & 869,00 & 13 & & Sony Wega $21 F V 128-21^{*}$ & $1.377,50$ & $1.925,17$ \\
\hline $10 / 9 / 2000$ & encarte & O Estado de Săo Paulo & 2,1 & TV a cores & Ponto Frio & 192,39 & & $1.749,00$ & 13 & & Sony Wega $28 F 512 \mathrm{~B}-2 \mathrm{~g}^{\circ}$ & $2.486,33$ & $3.474,83$ \\
\hline 17/9/2000 & A13 & O Estado de Săo Paulo & 2,1 & TV a cores & Ponto Frio & 110,08 & & 949,00 & 12 & & Phīips PT-554 - 29" & $1.349,07$ & $1.885,43$ \\
\hline $3 / 9 / 2000$ & A7 & O Estado de Săo Paulo & 2,1 & TV a cores & Wal Mart & 58,33 & & 349,88 & 6 & & Matsui 20' M T20 - PALM-PALN-NTSC - entrada audio video $c$ & 497,52 & 695,32 \\
\hline $3 / 9 / 2000$ & C11 & Folha de Săo Paulo & 2,1 & TV a cores & Wal Mart & 58,33 & & 349,88 & 6 & & Matsui 20' M T20 - PALM-PALN-NTSC - entrada audio video $C$ & 497,52 & 605,32 \\
\hline $10 / 9 / 2000$ & $\mathrm{C} 3$ & O Estado de Săo Paulo & 2,1 & TV a cores & Wal Mart & 69.83 & & 419,00 & 6 & & Semp Toshiba $2083-20^{\circ}$ & 585,64 & 832,45 \\
\hline 12/9/2000 & $\mathrm{C} 7$ & Folha de Săo Paulo & 3 & geladeira & Arapuã & 89,90 & & 249,00 & 8 & & Bosch RD 31 BA & 922,60 & $1.289,40$ \\
\hline $21 / 9 / 2000$ & $\mathrm{CB}$ & Follha de Săo Paulo & 3 & geladeira & Arapuâ & 49,80 & & 419,00 & 12 & & Electrolux Compactro R130 & 585,04 & 832,45 \\
\hline $21 / 9 / 2000$ & $\mathrm{CB}$ & Folha de Săo Paulo & 3 & geladeira & Arapuã & 59,80 & & 498,00 & 12 & & Electrolux RC-28 & 707,84 & 889,40 \\
\hline $3 / 9 / 2000$ & encarte & O Estado de Săo Paulo & 3 & geladeira & Casas Bahia & 70,86 & & 499,00 & 8 & & Consul 213 Ftros & 700,36 & 891,39 \\
\hline $3 / 9 / 2000$ & \begin{tabular}{|l} 
encarte \\
\end{tabular} & O Estado de Săo Paulo & 3 & geladeira & Casas Bahia & 85,00 & & 680,00 & 8 & & Electrolux 284 litros & 966,67 & $1.350,89$ \\
\hline 17/8/2000 & \begin{tabular}{|l} 
encarte \\
\end{tabular} & O Estado de Săo Paulo & 3 & geladeira & Casas Bahia & 73,00 & & 584,00 & 8 & & Electrolux 260 lifros - R 280 & 830.20 & $1.160,26$ \\
\hline 17/8/2000 & encarte & O Estado de Săo Paulo & 3 & geladeira & Casas Bahia & 81,00 & & 248,00 & 8 & & CCE Super Luxo 298 litros & 921,18 & $1.287,42$ \\
\hline $3 / 9 / 2000$ & A11 & Folha de Săo Paulo & 3 & geladeira & Eletro & 81,73 & & 599,00 & 8 & & Brastemp BRA31 & 851,52 & $1.190,07$ \\
\hline $3 / 9 / 2000$ & encarte & O Estado de Săo Paulo & 3 & geladeira & Ponto Frio & 60,39 & & 549,00 & 13 & & Electrolux R-280 - 281 Itros & 780,44 & $1.090,73$ \\
\hline $3 / 8 / 2000$ & \begin{tabular}{|l} 
encarte \\
\end{tabular} & O Estado de Săo Paulo & 3 & geladeira & Ponto Frio & 60,39 & & 549,00 & 13 & & Electrolux R-280 - 281 litros & 780,44 & $1.090,73$ \\
\hline $3 / 9 / 2000$ & \begin{tabular}{|l} 
encarte \\
\end{tabular} & O Estado de Săo Paulo & 3 & geladeira & Ponto Frio & 70,29 & & 639,00 & 13 & & Consul CRA 30/31 - 303 Fitros & 908,38 & $1.269,54$ \\
\hline $3 / 9 / 2000$ & encarte & O Estado de Săo Paulo & 3 & geladeira & Ponto Frio & 76,89 & & 699,00 & 13 & & Consul CRA 30/31 - 346 Fitros & 883,68 & $1.388,74$ \\
\hline 10/9/2000 & \begin{tabular}{|l} 
encarte \\
\end{tabular} & O Estado de Săo Paulo & & geladeira & Ponto Frio & 69,19 & & 629,00 & 13 & & Electrolux R-310 - 284 Itros & 894,17 & $1.249,67$ \\
\hline 10/9/2000 & $\mathrm{C} 3$ & O Estado de São Paulo & & Bgeladeira & Wal Mart & 24,99 & & 389,87 & 6 & & Consul CRC-23 - 230 litros - CRC23CB 1NA & 564,37 & 774,77 \\
\hline
\end{tabular}




\begin{tabular}{|c|c|c|c|c|c|c|c|c|c|c|c|c|c|}
\hline \multicolumn{3}{|c|}{ mês / ano - setembro de 2000} & \multicolumn{7}{|c|}{ salário mínimo em 01.04 .2000 - RS 151,00} & \multirow{2}{*}{\multicolumn{4}{|c|}{$\begin{array}{l}\text { pesq. em: Arquivo de Estado de Săo Paulo } \\
\text { data: } 18 / 12 / 2005-22 / 12 / 2005\end{array}$}} \\
\hline produtio - div & ersos & & & & & & & & & & & & \\
\hline data & pág. & jomal consultado & $\begin{array}{l}\text { cod } \\
\text { prod. }\end{array}$ & produto & loja & $\begin{array}{l}\text { prest. à } \\
\text { prazo }\end{array}$ & entrada & $\begin{array}{l}\text { prepo à } \\
\text { vista }\end{array}$ & $\begin{array}{c}n^{\circ} \\
\text { parc. }\end{array}$ & atd de & descriçăo do produto & $\begin{array}{l}\text { IPC-SP } \\
\text { FIPE }\end{array}$ & $\begin{array}{r}\text { atualiz. } p^{\prime} \\
\text { SM de } 2005\end{array}$ \\
\hline $12 / 9 / 2000$ & $\mathrm{C} 7$ & Follha de Săo Paulo & 3,1 & geladeira & Arapuã & 129,90 & & 853,00 & 8 & & Continental RC 34 & $1.212,60$ & $1.694,70$ \\
\hline $12 / 9 / 2000$ & $\mathrm{C7}$ & Follha de Săo Paulo & 3,1 & geladeira & Arapuâ & 159.80 & & $1.050,00$ & 8 & & Bosch RD $31 \mathrm{~A}$ & $1.492,05$ & $2.086,09$ \\
\hline $12 / 9 / 2000$ & $\mathrm{C7}$ & Folha de Săo Paulo & 3,1 & geladeira & Arapuâ & 184,80 & & $1.090,00$ & 8 & & Electrolux DC 440 & $1.549,51$ & $2.185,56$ \\
\hline $12 / 9 / 2000$ & $\mathrm{C7}$ & Follha de Săo Paulo & 3,1 & geladeira & Arapuâ & 218,80 & & $1.379,00$ & 8 & & Brastemp BRM 37 & $1.860,35$ & $2.739,74$ \\
\hline 14/9/2000 & encarte & O Estado de São Paulo & 3,1 & geladeira & BestMix & 187,33 & 167,33 & 779,00 & 4 & & Brastemp BRB35 - 329 itros & 1.107 .40 & $1.547,68$ \\
\hline $14 / 9 / 2000$ & encarte & O Estado de São Paulo & 3,1 & geladeira & BestMix & 337,02 & 337,02 & $1.569,00$ & 4 & & Brastemp BRM-43 BR & $2.230,44$ & $3.117,22$ \\
\hline $14 / 9 / 2000$ & encarte & O Estado de São Paulo & 3,1 & geladeira & BestMix & 427.45 & 427,45 & $1.990,00$ & 4 & & Brastemp Inox BRB35 & $2.828,82$ & $3.953,64$ \\
\hline $3 / 9 / 2000$ & encarte & O Estado de São Paulo & 3,1 & geladeira & Casas Bahia & 118.00 & & 928,00 & 8 & & CCE Super Luxo 337 litros & $1.319,22$ & $1.843,71$ \\
\hline $3 / 8 / 2000$ & encarte & O Estado de Săo Paulo & 3,1 & geladeira & Casas Bahia & 142.00 & & $1.136,00$ & 8 & & Electrolux 427 litros & $1.614,80$ & $2.256,85$ \\
\hline 17/9/2000 & encarte & O Estado de São Paulo & 3,1 & geladeira & Casas Bahia & 142,00 & & $1.136,00$ & 8 & & Electrolux 427 litros - DC440 & $1.614,80$ & $2.256,85$ \\
\hline $3 / 9 / 2000$ & $\mathrm{~A} 10$ & Folha de Săo Paulo & 3,1 & geladeira & Eletro & 143,13 & & $1.049,00$ & 8 & & Brastemp BRM 33 Frost Free & $1.491,23$ & $2.084,11$ \\
\hline $7 / 9 / 2000$ & $\mathrm{Cb}$ & Follha de Săo Paulo & 3,1 & geladeira & Extra & 74,85 & & 799,00 & 12 & & CCE C35 & $1.135,83$ & $1.587,42$ \\
\hline $15 / 9 / 2000$ & encarte & Follha de Săo Paulo & 3,1 & geladeira & Extra & 69,11 & & 769,00 & 15 & & CCE C35 duplex & $1.093,19$ & $1.527,81$ \\
\hline $3 / 9 / 2000$ & encarte & O Estado de São Paulo & 3,1 & geladeira & Ponto Frio & 130,79 & & $1.189,00$ & 13 & & Brastemp BRD 46 A - 480 litros & $1.090,25$ & $2.362,25$ \\
\hline $3 / 9 / 2000$ & encarte & O Estado de São Paulo & 3,1 & geladeira & Ponto Frio & 172,50 & & $1.569,00$ & 13 & & Brastemp BRIM43 - 428 litros & $2.230,44$ & $3.117,22$ \\
\hline 10/9/2000 & encarte & O Estado de São Paulo & 3,1 & geladeira & Ponto Frio & 130,79 & & $1.189,00$ & 13 & & Brastemp BRD 45 A - 432 litros & $1.690,25$ & $2.362,25$ \\
\hline 10/9/2000 & encarte & O Estado de São Paulo & 3,1 & geladeira & Ponto Frio & 172,59 & & $1.569,00$ & 13 & & Brastemp BRIM43 - 417 litros & $2.230,44$ & $3.117,22$ \\
\hline 17/9/2000 & $\mathrm{A} 13$ & O Estado de São Paulo & 3,1 & geladeira & Ponto Frio & 133.28 & & $1.149,00$ & 12 & & Bosch RB-43 - 446 itros & $1.633,38$ & $2.282,78$ \\
\hline $21 / 9 / 2000$ & $\mathrm{CB}$ & Follha de Săo Paulo & 4 & fogấo & Arapuâ & 17.80 & & 149,00 & 12 & & Esmaltec Verona 4 bocas & 211.81 & 296,03 \\
\hline $21 / 9 / 2000$ & $\mathrm{CB}$ & Follha de Săo Paulo & 4 & fogẫo & Arapuã & 32.80 & & 289,00 & 12 & & Continental Prince 4 bocas & 410,83 & 574,17 \\
\hline $14 / 9 / 2000$ & encarte & O Estado de São Paulo & 4 & fogấo & BestMix & 221,03 & 221,03 & $1.029,00$ & 4 & & Brastemp Quality Grill Prata - BFH-76P & $1.462,80$ & $2.044,37$ \\
\hline $3 / 9 / 2000$ & encarte & O Estado de São Paulo & 4 & fogấ & Casas Bahia & 33.94 & & 239,00 & 8 & & Consul 4 bocas & 339,76 & 474,83 \\
\hline $3 / 9 / 2000$ & encarte & O Estado de Săo Paulo & 4 & fogấ & Casas Bahia & 56,68 & & 399,00 & 8 & & Consul 6 bocas - $C A A 76 C$ & 567.21 & 792,72 \\
\hline $3 / 9 / 2000$ & encarte & O Estado de São Paulo & 4 & fogẫo & Casas Bahia & 70,86 & & 499,00 & 8 & & Brastemp De Ville - 4 bocas & 700,36 & 891,39 \\
\hline $3 / 9 / 2000$ & encarte & O Estado de Săo Paulo & 4 & fogấo & Casas Bahia & 79,00 & & 559,00 & 8 & & Continental Stratus Grill 4 bocas & 794.66 & $1.110,60$ \\
\hline $3 / 9 / 2000$ & encarte & O Estado de São Paulo & 4 & fogấ & Casas Bahia & 92,16 & & 249,00 & 8 & & Brastemp De Ville - 6 bocas & 922,60 & $1.289,40$ \\
\hline $3 / 9 / 2000$ & encarte & O Estado de São Paulo & 4 & fogấo & \begin{tabular}{|l|} 
Casas Bahia \\
\end{tabular} & 110,00 & & 779,00 & 8 & & Continental Stratus Grill 6 bocas & $1.107,40$ & $1.547,68$ \\
\hline 17/9/2000 & encarte & O Estado de São Paulo & 4 & fogẫo & Casas Bahia & 33.94 & & 239,00 & 8 & & Consul 4 bocas & 339,76 & 474,83 \\
\hline 17/9/2000 & encarte & O Estado de Săo Paulo & 4 & fogấ & Casas Bahia & 45,30 & & 319,00 & 8 & & Dako Civic 4 bocas - 6684 & 453.48 & 633,77 \\
\hline $17 / 9 / 2000$ & encarte & O Estado de Săo Paulo & 4 & fogẫo & Casas Bahia & 58,66 & & 399,00 & 8 & & Consul 6 bocas - CA $76 C$ & 567.21 & 792,72 \\
\hline 17/8/2000 & encarte & O Estado de São Paulo & 4 & fogấo & \begin{tabular}{|l|} 
Casas Bahia \\
\end{tabular} & 68,60 & & 469,00 & 8 & & Dako Civic 8 bocas- 6685 & 686,72 & 831,79 \\
\hline 17/9/2000 & encarte & O Estado de São Paulo & 4 & fogấ & Casas Bahia & 79,00 & & 569,00 & 8 & & Continental Stratus Grill 4 bocas & 794,66 & $1.110,60$ \\
\hline 17/8/2000 & encarte & O Estado de Săo Paulo & 4 & fogẫo & Casas Bahia & 110,00 & & 779,00 & 8 & & Continental Stratus Grill 6 bocas & $1.107,40$ & $1.547,68$ \\
\hline $3 / 9 / 2000$ & $\mathrm{~A} 10$ & Follha de Săo Paulo & 4 & fogấo & Eletro & 40,79 & & 299,00 & 8 & & Consul CFJ50A - automático - 4 bocas & 425,05 & 504,04 \\
\hline $15 / 9 / 2000$ & encarte & Follha de Săo Paulo & 4 & fogấo & Extra & 11,59 & & 129,00 & 15 & & Esmaltec Verona 4 bocas & 183,38 & 256,29 \\
\hline $3 / 9 / 2000$ & encarte & O Estado de São Paulo & 4 & fogấo & Ponto Frio & 28,63 & & 200,00 & 8 & & Atlas Tropical Luxo 4 bocas & 297.11 & 415,23 \\
\hline 3/9/2000 & encarte & O Estado de São Paulo & 4 & fogấo & Ponto Frio & 24,75 & & 225,00 & 13 & & Continental Astra autolimpante 4 bocas & 312,85 & 447,02 \\
\hline 3/9/2000 & encarte & O Estado de São Paulo & 4 & fogẫo & Ponto Frio & 45,90 & & 335,00 & 2 & & Atlas Tropical Luxo 6 bocas & 476,23 & 685,56 \\
\hline $3 / 9 / 2000$ & encarte & O Estado de Săo Paulo & 4 & fogấ & Ponto Frio & 40,82 & & 372,00 & 13 & & Continental Astra autolimpante 6 bocas & 528,82 & 739,07 \\
\hline
\end{tabular}




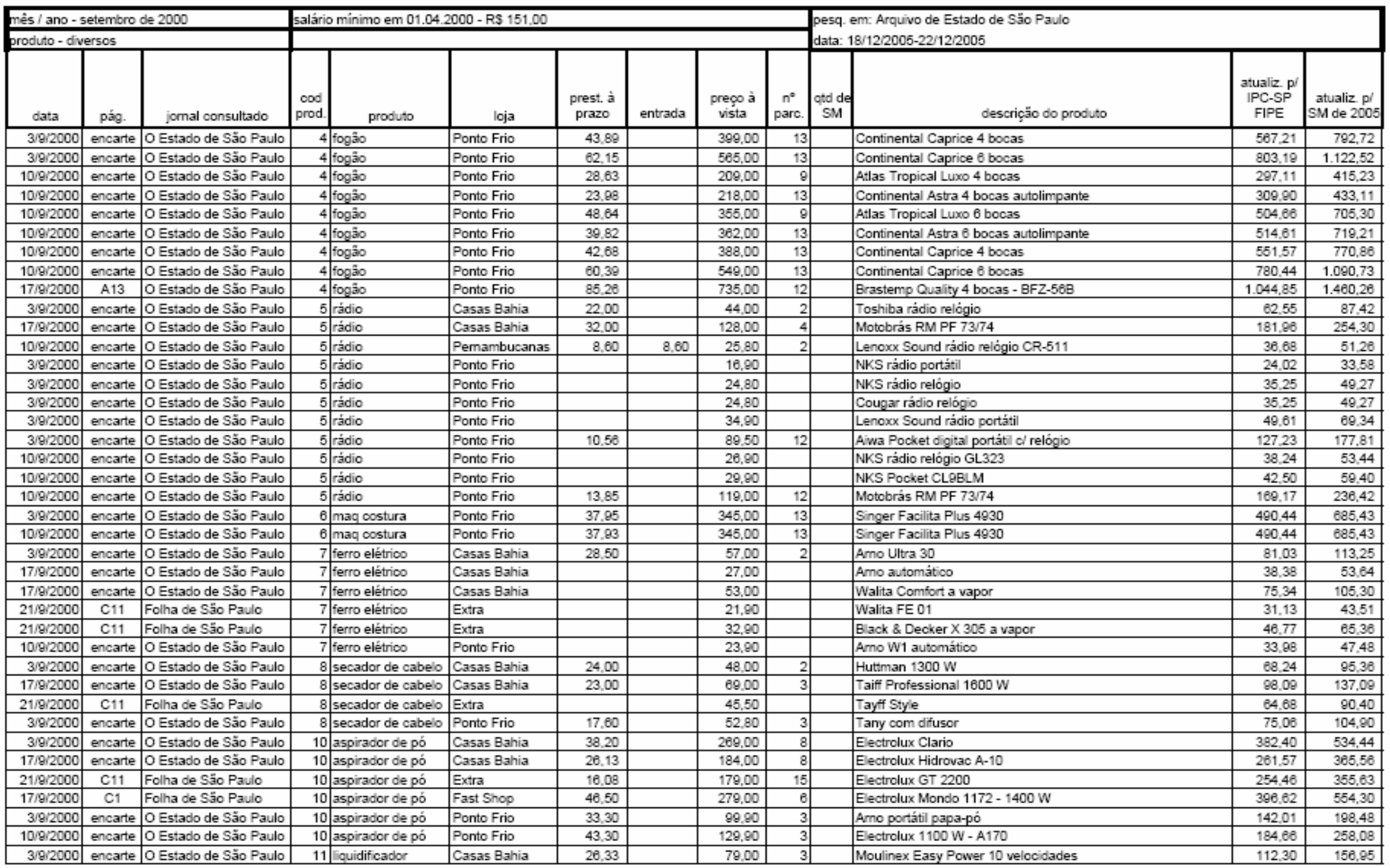




\begin{tabular}{|c|c|c|c|c|c|c|c|c|c|c|c|c|c|}
\hline \multicolumn{3}{|c|}{$\begin{array}{l}\text { mès / ano - setembro de } 2000 \\
\text { produtio - civersos }\end{array}$} & \multicolumn{7}{|c|}{ salário mínimo em 01.04 .2000 - RS 151,00} & \multicolumn{4}{|c|}{$\begin{array}{l}\text { pesq. em: Arquivo de Estado de Săo Paulo } \\
\text { data: } 18 / 12 / 2005-22 / 12 / 2005\end{array}$} \\
\hline data & pág. & jomal consultado & $\begin{array}{c}\text { cod } \\
\text { prod. }\end{array}$ & produto & Ioja & $\begin{array}{l}\text { prest. à } \\
\text { prazo }\end{array}$ & entrada & $\begin{array}{l}\text { prepo à } \\
\text { vista }\end{array}$ & $\begin{array}{c}n^{\circ} \\
\text { parc. }\end{array}$ & atd de & descriçăo do produto & $\begin{array}{l}\text { atualiz. p/ } \\
\text { IPC-SP } \\
\text { FIPE }\end{array}$ & $\begin{array}{l}\text { atualiz. } p \text { ' } \\
\text { SM de } 2005\end{array}$ \\
\hline $17 / 9 / 2000$ & encarte & O Estado de Săo Paulo & 11 & 1 Iquidificador & Casas Bahia & 26,00 & & 78,00 & 3 & & Walita Paris 3 velocidades & 110,88 & 154,97 \\
\hline $21 / 9 / 2000$ & C11 & Follha de Săo Paulo & 11 & iquidificador & Extra & & & 45,80 & & & Walita Paris 3 velocidades & 65.25 & 91,19 \\
\hline 10/9/2000 & \begin{tabular}{|l} 
encarte \\
\end{tabular} & O Estado de São Paulo & 11 & Iquidificador & Ponto Frio & 13,30 & & 39,80 & 3 & & Mondial 400 W 3 velocidades com pulsar & 56,72 & 79.27 \\
\hline $21 / 9 / 2000$ & $\begin{array}{ll}\mathrm{C} 7 \\
\end{array}$ & Follha de Săo Paulo & 12 & maq fotográíica & Extra & & & 21,80 & & & Magna TR 20 & 31,13 & 43,51 \\
\hline $21 / 9 / 2000$ & $\mathrm{C} 7$ & Folha de Săo Paulo & 12 & maq fotográíica & Extra & & & 33,80 & & & Kodak KB 10 & 48,19 & 67,35 \\
\hline $21 / 9 / 2000$ & $\mathrm{C7}$ & Follha de Săo Paulo & 12 & maq fotográíca & Extra & & & 74,80 & & & Kodak KB 20 & 108,48 & 148,81 \\
\hline $21 / 9 / 2000$ & $\mathrm{C7}$ & Folha de Săo Paulo & 12 & maq fotográfica & Extra & & & 84,80 & & & Olympus Trip 300 & 120,68 & 168,68 \\
\hline $21 / 9 / 2000$ & $\mathrm{C7}$ & Follha de Săo Paulo & 12 & maq fotográíica & Extra & 20,22 & & 225,00 & 15 & & Kodak KD 60 & 319,85 & 447,02 \\
\hline $3 / 9 / 2000$ & \begin{tabular}{|l} 
encarte \\
\end{tabular} & O Estado de Săo Paulo & 12 & maq fotográíica & Ponto Frio & 24,98 & & 99,80 & 4 & & Canon zoom 38-60 - DX - disparador automátioo & 142.01 & 188,48 \\
\hline 10/9/2000 & \begin{tabular}{|l} 
encarte \\
\end{tabular} & O Estado de São Paulo & 12 & maq fotográfica & Ponto Frio & 28,30 & & 78,80 & 3 & & Yashica LZ Mate & 112,16 & 156,75 \\
\hline 10/9/2000 & \begin{tabular}{|l} 
encarte \\
\end{tabular} & O Estado de São Paulo & 12 & maq fotográfica & Ponto Frio & 32.80 & & 98,70 & 3 & & Tron BV Metal & 140,31 & 196,09 \\
\hline 10/9/2000 & \begin{tabular}{|l} 
encarte \\
\end{tabular} & O Estado de São Paulo & 12 & maq fotográrica & Ponto Frio & 43,30 & & 129,80 & 3 & & Canon Prima Quick Super & 184,06 & 258,08 \\
\hline $17 / 9 / 2000$ & \begin{tabular}{|l} 
encarte \\
\end{tabular} & O Estado de Săo Paulo & 16 & batedera bolo & Casas Bahia & 21,33 & & 84,00 & 3 & & Britânia Pérola & 90,88 & 127,15 \\
\hline $17 / 9 / 2000$ & C1 & Follha de Săo Paulo & 16 & batedeira bolo & Fast Shop & 39,50 & & 237,00 & 8 & & Arno Planetária BPA & 336.81 & 470,86 \\
\hline $3 / 9 / 2000$ & encarte & O Estado de Săo Paulo & 16 & batedera bolo & Ponto Frio & 22,30 & & 66,80 & 3 & & Arno 3 velocidades e pulsar & 85,10 & 132,91 \\
\hline 10/9/2000 & \begin{tabular}{|l} 
encarte \\
\end{tabular} & O Estado de Săo Paulo & 16 & batedeira bolo & Ponto Frio & 21,90 & & 65,70 & 3 & & Walita Topa Tudo Standard & 93,40 & 130,53 \\
\hline $12 / 9 / 2000$ & $\begin{array}{ll}\mathrm{C} 7 \\
\end{array}$ & Folha de Săo Paulo & 19 & freezer & Arapuâ & 117,80 & & 739,00 & 8 & & Bosch FB 23 & $1.050,54$ & $1.468,21$ \\
\hline $12 / 9 / 2000$ & $\mathrm{C7}$ & Follha de Säo Paulo & 18 & freezer & Arapuâ & 117,80 & & 774,00 & 8 & & Bosch FR 23 & $1.100,30$ & $1.537,75$ \\
\hline 14/9/2000 & \begin{tabular}{|l} 
encarte \\
\end{tabular} & O Estado de São Paulo & 18 & freezer & BestMix & 218,88 & 218.88 & $1.019,00$ & 4 & & Brastemp BVQ27 - 264 litros & $1.448,58$ & $2.024,50$ \\
\hline $3 / 9 / 2000$ & \begin{tabular}{|l} 
encarte \\
\end{tabular} & O Estado de Săo Paulo & 18 & freezer & Casas Bahia & 84,00 & & 672,00 & 8 & & CCE Super Luxo 209 litros & 955,30 & $1.335,10$ \\
\hline $3 / 9 / 2000$ & \begin{tabular}{|l} 
encarte \\
\end{tabular} & O Estado de Săo Paulo & 18 & freezer & Casas Bahia & 124,00 & & 892,00 & 8 & & Electrolux horizontal 399 itros & $1.410,20$ & $1.970,88$ \\
\hline $17 / 9 / 2000$ & encarte & O Estado de Săo Paulo & 18 & freezer & Casas Bahia & 84,00 & & 672,00 & 8 & & CCE Super Luxo 209 litros & 855,30 & $1.335,10$ \\
\hline $3 / 9 / 2000$ & \begin{tabular}{|l} 
encarte \\
\end{tabular} & O Estado de Săo Paulo & 18 & freezer & Ponto Frio & 76,89 & & 699,00 & 13 & & Consul CHA 228 - horizontal - 223 litros & 993,68 & $1.388,74$ \\
\hline $3 / 9 / 2000$ & \begin{tabular}{|l} 
encarte \\
\end{tabular} & O Estado de Săo Paulo & 18 & freezer & Ponto Frio & 81,29 & & 739,00 & 13 & & Electrolux F210 - 210 litros & $1.050,54$ & $1.468,21$ \\
\hline $3 / 8 / 2000$ & \begin{tabular}{|l} 
encarte \\
\end{tabular} & O Estado de São Paulo & 18 & freezer & Ponto Frio & 85,68 & & 779,00 & 13 & & Electrolux F248 - 248 litros & $1.107,40$ & $1.547,68$ \\
\hline $3 / 9 / 2000$ & encarte & O Estado de São Paulo & 18 & freezer & Ponto Frio & 101,09 & & 818,00 & 13 & & Metalfrio HC4288 - 419 litros & $1.306,42$ & $1.825,83$ \\
\hline $3 / 9 / 2000$ & \begin{tabular}{|l|} 
encarte \\
\end{tabular} & O Estado de São Paulo & 18 & freezer & Ponto Frio & 114,28 & & $1.039,00$ & 13 & & Brastemp SVG27A - 264 litros & $1.477,01$ & $2.084,24$ \\
\hline 10/9/2000 & \begin{tabular}{|l} 
encarte \\
\end{tabular} & O Estado de Săo Paulo & 18 & freezer & Ponto Frio & 74,68 & & 679,00 & 13 & & Consul CVU20A - 148 Iitros & 905,25 & $1.349,01$ \\
\hline 10/9/2000 & \begin{tabular}{|l} 
encarte \\
\end{tabular} & O Estado de São Paulo & 18 & freezer & Ponto Frio & 101,08 & & 819,00 & 13 & & Metalffio HC4288 - 419 litros & $1.306,42$ & $1.825,83$ \\
\hline $3 / 9 / 2000$ & \begin{tabular}{|l} 
encarte \\
\end{tabular} & O Estado de São Paulo & 20 & forno microondas & Casas Bahia & 52,40 & & 369,00 & 8 & & Continental 27 litros & 524,56 & 733,11 \\
\hline 14/9/2000 & $\mathrm{C} 3$ & Follha de Săo Paulo - ca & 20 & forno microondas & Casas Bahia & 52,40 & & 369,00 & 8 & & Continental P-158-27 litros & 524,56 & 733,11 \\
\hline 14/9/2000 & $\mathrm{C} 3$ & Follha de Săo Paulo - ca & 20 & forno microondas & Casas Bahia & 52,40 & & 369,00 & 8 & & Panasonic 28 itros - $900 \mathrm{~W}$ & 524,56 & 733,11 \\
\hline 14/9/2000 & $\mathrm{C} 3$ & Follha de Săo Paulo - ca & 20 & forno microondas & Casas Bahia & 62,34 & & 439,00 & 8 & & Brastemp BMU 27 litros & 624,07 & 872,19 \\
\hline $14 / 9 / 2000$ & $\mathrm{C} 3$ & Folha de Săo Paulo - ca & 20 & forno microondas & Casas Bahia & 66,60 & & 469,00 & 8 & & Continental P-160 Dourador - 27 litros & 686,72 & 831,79 \\
\hline 14/9/2000 & $\mathrm{C} 3$ & Follha de Săo Paulo - ca & 20 & forno microondas & Casas Bahia & 77,96 & & 549,00 & 8 & & Brastemp BMB Dourador 27 Itros & 780,44 & $1.090,73$ \\
\hline 14/9/2000 & $\mathrm{C} 3$ & Folha de Säo Paulo - ca & 20 & forno microondas & Casas Bahia & 85,08 & & 509,00 & 8 & & Brastemp BMC Crisp e Dourador 27 itros & 851,52 & $1.190,07$ \\
\hline 14/9/2000 & \begin{tabular}{|c|}
$\mathrm{C} 3$ \\
\end{tabular} & Follha de Săo Paulo - ca & 20 & forno microondas & Casas Bahia & 102,10 & & 719,00 & 8 & & Brastemp BMC Crisp e Dourador 38 Itros & $1.022,11$ & $1.428,48$ \\
\hline $15 / 9 / 2000$ & \begin{tabular}{|l} 
encarte \\
\end{tabular} & Folha de Săo Paulo & 20 & fiorno microondas & Extra & 22,37 & & 249,00 & 15 & & CCE M30130 litros & 353,97 & 494,70 \\
\hline $17 / 9 / 2000$ & C1 & Follha de Săo Paulo & 20 & forno microondas & Fast Shop & 49,50 & & 297,00 & 8 & & LG MS $118 \mathrm{ML}-30$ litros & 422.21 & 580,07 \\
\hline
\end{tabular}




\begin{tabular}{|c|c|c|c|c|c|c|c|c|c|c|c|c|c|}
\hline \multicolumn{3}{|c|}{ mês / ano - setembro de 2000} & \multicolumn{7}{|c|}{ Salário mínimo em 01.04 .2000 - RS 151,00} & \multicolumn{4}{|c|}{$\begin{array}{l}\text { pesq. em: Arquivo de Estado de Săo Paulo } \\
\text { data: } 18 / 12 / 2005-22 / 12 / 2005\end{array}$} \\
\hline data & pág. & jomal consultado & $\begin{array}{c}\text { cod } \\
\text { prod. }\end{array}$ & produto & Ioja & $\begin{array}{l}\text { prest. à } \\
\text { prazo }\end{array}$ & entrada & $\begin{array}{l}\text { preco à } \\
\text { vista }\end{array}$ & $\begin{array}{c}\mathrm{n}^{\circ} \\
\text { parc. }\end{array}$ & qtal de & descriçăo do produto & $\begin{array}{l}\text { atualiz. p/ } \\
\text { IPC-SP } \\
\text { FIPE }\end{array}$ & $\begin{array}{l}\text { atualiz. } p^{\prime} \\
\text { SM de } 2005\end{array}$ \\
\hline $3 / 9 / 2000$ & encarte & O Estado de Săo Paulo & 20 & forno microondas & Ponto Frio & 28,29 & & 239,00 & 13 & & LG 19 litros $-750 \mathrm{~W}$ & 339,76 & 474,83 \\
\hline $3 / 9 / 2000$ & \begin{tabular}{|l} 
encarte \\
\end{tabular} & O Estado de Săo Paulo & 20 & forno microondas & Ponto Frio & 32,79 & & 298,00 & 13 & & Panasonic 28 itros - $900 \mathrm{~W}$ & 423,63 & 592,05 \\
\hline $3 / 8 / 2000$ & \begin{tabular}{|l} 
encarte \\
\end{tabular} & O Estado de Săo Paulo & 20 & forno microondas & Ponto Frio & 42,79 & & 389,00 & 13 & & LG 30 litros - $850 \mathrm{~W}$ & 552,89 & 772,85 \\
\hline $3 / 9 / 2000$ & encarte & O Estado de São Paulo & 20 & forno microondas & Ponto Frio & 58,19 & & 529,00 & 13 & & Brastemp Sensor Crisp - $850 \mathrm{~W}$ & 752.01 & $1.050,89$ \\
\hline $10 / 9 / 2000$ & encarte & O Estado de São Paulo & 20 & forno microondas & Ponto Frio & 26,29 & & 239,00 & 13 & & LG MS-74 $700 \mathrm{~W}-19$ litros & 339,76 & 474,83 \\
\hline 10/9/2000 & \begin{tabular}{|l} 
encarte \\
\end{tabular} & O Estado de São Paulo & 20 & forno microondas & Ponto Frio & 32,78 & & 298,00 & 13 & & Panasonic NH-550B $900 \mathrm{~W}$ - 28 litros & 423,63 & 592,05 \\
\hline $7 / 9 / 2000$ & $\mathrm{C6}$ & Follha de Săo Paulo & 22 & camera filmadora & Extra & 84,22 & & 899,00 & 12 & & JVC GRAX787 & $1.277,98$ & $1.786,00$ \\
\hline $3 / 8 / 2000$ & \begin{tabular}{|l} 
encarte \\
\end{tabular} & O Estado de São Paulo & 22 & camera filmadora & Ponto Frio & 126,39 & & $1.149,00$ & 13 & & Panasonic zoom 150x - PV-D300 & $1.633,38$ & $2.282,78$ \\
\hline $3 / 9 / 2000$ & \begin{tabular}{|l} 
encarte \\
\end{tabular} & O Estado de São Paulo & 22 & camera filmadora & Ponto Frio & 153,89 & & $1.399,00$ & 13 & & JVC GR5X-9877 & $1.888,78$ & $2.779,47$ \\
\hline 13/9/2000 & A11 & Follha de Săo Paulo & 23 & video cassete & Arapuâ & 80,35 & & 379,00 & 5 & & Semp Toshiba VCR X $685-5$ cabecas & 538,78 & 752,88 \\
\hline 13/9/2000 & A11 & Follha de Săo Paulo & 23 & video cassete & Arapuâ & 85.20 & & 449,00 & 5 & & Gradiente VCR V7 - 7 cabeças & 638.28 & 892,05 \\
\hline $3 / 9 / 2000$ & encarte & O Estado de Săo Paulo & 23 & video cassete & Casas Bahia & 52.40 & & 369,00 & 8 & & Panasonic & 524,56 & 733,11 \\
\hline $14 / 9 / 2000$ & \begin{tabular}{|l} 
encarte \\
\end{tabular} & Follha de Săo Paulo & 23 & video cassete & Extra & 43,52 & & 319,00 & 8 & & Semp Toshiba VCX 685 & 453.48 & 633,77 \\
\hline $14 / 9 / 2000$ & encarte & Follha de Săo Paulo & 23 & video cassete & Extra & 53,07 & & 389,00 & 8 & & Semp Toshiba $686 \mathrm{HI}-\mathrm{Fl}$ - 7 cabeças & 552.89 & 772,85 \\
\hline $14 / 9 / 2000$ & encarte & Follha de Săo Paulo & 23 & video cassete & Extra & 53,07 & & 389,00 & 8 & & Phips $799 \mathrm{HI}-\mathrm{Fl}-6$ cabeças & 552,89 & 772,85 \\
\hline 10/9/2000 & \begin{tabular}{|l} 
encarte \\
\end{tabular} & O Estado de São Paulo & 23 & video cassete & Pemambucanas & 42,60 & 42,60 & 339,00 & 8 & & Panasonic NV-SJ405 & 481,81 & 673,51 \\
\hline $3 / 9 / 2000$ & \begin{tabular}{|l} 
encarte \\
\end{tabular} & O Estado de Săo Paulo & 23 & video cassete & Ponto Frio & 35,09 & & 319,00 & 13 & & LG BC 490 - 5 cabeças & 453.48 & 633,77 \\
\hline $3 / 8 / 2000$ & \begin{tabular}{|l} 
encarte \\
\end{tabular} & O Estado de Săo Paulo & 23 & video cassete & Ponto Frio & 37,29 & & 339,00 & 13 & & Panasonic NV-SJ4058R 5 cabeças & 481,81 & 673,51 \\
\hline $3 / 8 / 2000$ & \begin{tabular}{|l} 
encarte \\
\end{tabular} & O Estado de São Paulo & 23 & video cassete & Ponto Frio & 38,39 & & 349,00 & 13 & & Sony BC $981 \mathrm{~B} / 980$ - 5 cabeças & 486,13 & 693,38 \\
\hline $3 / 8 / 2000$ & encarte & O Estado de São Paulo & 23 & video cassete & Ponto Frio & 43,89 & & 399,00 & 13 & & Panasonic NV-SJ6058R 5 cabeças & 567,21 & 792,72 \\
\hline $10 / 8 / 2000$ & \begin{tabular}{|l} 
encarte \\
\end{tabular} & O Estado de Săo Paulo & 23 & video cassete & Ponto Frio & 35,09 & & 319,00 & 13 & & LG 5 cabeças PT $4900 / 450$ & 453,48 & 633,77 \\
\hline 10/9/2000 & encarte & O Estado de Săo Paulo & 23 & video cassete & Ponto Frio & 43,89 & & 399,00 & 13 & & Panasonic 7 cabeças NV-FJ605BR & 567.21 & 792,72 \\
\hline $3 / 9 / 2000$ & encarte & O Estado de São Paulo & 25 & Iavadora tanquinho & Casas Bahia & 19,17 & & 135,00 & 8 & & Crayon Lavy & 191,81 & 288,21 \\
\hline $3 / 9 / 2000$ & encarte & O Estado de São Paulo & 25 & Iavadora tanquinho & Ponto Frio & 21,10 & & 154,00 & 9 & & Colormaq $4 \mathrm{~kg}$ & 218,92 & 305,96 \\
\hline $3 / 9 / 2000$ & \begin{tabular}{|l} 
encarte \\
\end{tabular} & O Estado de São Paulo & 25 & Iavadora tanquinho & Ponto Frio & 27,26 & & 199,00 & 9 & & Arno Pratic & 282,89 & 395,36 \\
\hline $10 / 9 / 2000$ & \begin{tabular}{|l} 
encarte \\
\end{tabular} & O Estado de Săo Paulo & 25 & Iavadora tanquinho & Ponto Frio & 21,10 & & 154,00 & 8 & & Colormaq $4 \mathrm{~kg}$ & 218,92 & 305,96 \\
\hline $3 / 9 / 2000$ & \begin{tabular}{|l} 
encarte \\
\end{tabular} & O Estado de São Paulo & 26 & cafeteira elétrica & Casas Bahia & 26,33 & & 79.00 & 3 & & Walita 10 xicaras & 112,30 & 156,85 \\
\hline $17 / 9 / 2000$ & \begin{tabular}{|l} 
encarte \\
\end{tabular} & O Estado de Săo Paulo & 26 & cafeteira elétrica & Casas Bahia & 22,68 & & 68,00 & 3 & & Mallory New Nice 24 xicaras & 96,67 & 135,10 \\
\hline $3 / 9 / 2000$ & \begin{tabular}{|l} 
encarte \\
\end{tabular} & O Estado de Săo Paulo & 26 & cafeteira elétrica & Ponto Frio & 19,80 & & 50,70 & 3 & & Entânia 36 xicaras & 84,87 & 118,61 \\
\hline $10 / 9 / 2000$ & encarte & O Estado de Săo Paulo & 26 & cafeteira elétrica & Ponto Frio & 24,80 & & 74,70 & 3 & & Arno Periorma & 108,19 & 148,41 \\
\hline $10 / 9 / 2000$ & encarte & O Estado de São Paulo & 27 & torradeira de pâo & Ponto Frio & 13,30 & & 39,80 & 3 & & Black \& Decker T-200 & 56,72 & 79.27 \\
\hline $5 / 9 / 2000$ & $\mathrm{C} 1$ & Folha de Săo Paulo & 28 & secadora roupas & BestMix & & & 909,00 & & & Brastemp BSR20 - $10 \mathrm{~kg} 6$ programas & $1.420,15$ & $1.984,77$ \\
\hline $3 / 9 / 2000$ & \begin{tabular}{|l} 
encarte \\
\end{tabular} & O Estado de São Paulo & 28 & secadora roupas & Casas Bahia & 16,76 & & 118,00 & 8 & & Enxuta & 167.75 & 234,44 \\
\hline $3 / 9 / 2000$ & encarte & O Estado de São Paulo & 28 & secadora roupas & Ponto Frio & 16,17 & & 118,00 & 9 & & Enxuta automática & 167,75 & 234,44 \\
\hline $3 / 9 / 2000$ & \begin{tabular}{|l} 
encarte \\
\end{tabular} & O Estado de São Paulo & 28 & secadora roupas & Ponto Frio & 105,05 & & 855,00 & 13 & & Continental Evolution $10 \mathrm{~kg}$ & $1.357,60$ & $1.897,35$ \\
\hline $10 / 9 / 2000$ & encarte & O Estado de São Paulo & 28 & secadora roupas & Ponto Frio & 16,17 & & 118,00 & 9 & & Enxuta automática & 167,75 & 234,44 \\
\hline 17/9/2000 & \begin{tabular}{|l} 
encarte \\
\end{tabular} & O Estado de Săo Paulo & 30 & espremedor frutas & Casas Bahia & & & 38,00 & & & Eritânia Nectar & 54,02 & 75,50 \\
\hline $3 / 9 / 2000$ & \begin{tabular}{|l} 
encarte \\
\end{tabular} & O Estado de São Paulo & 30 & espremedor frutas & Ponto Frio & & & 28,80 & & & Mallory Extra Juicer II & 42,50 & 59,40 \\
\hline $5 / 9 / 2000$ & $\mathrm{C} 1$ & Follha de Săo Paulo & 32 & Iava louça maq & BestMix & & & $1.850,00$ & & & Brastemp BLF24D - eletrónica 5 programas lavagem & $2.345,59$ & $3.278,15$ \\
\hline
\end{tabular}




\begin{tabular}{|c|c|c|c|c|c|c|c|c|c|c|c|c|c|}
\hline \multicolumn{3}{|c|}{$\begin{array}{l}\text { mês / ano - setembro de } 2000 \\
\text { produto - diversos }\end{array}$} & \multicolumn{7}{|c|}{ salário mínimo em 01.04.2000 - R\$ 151,00 } & \multicolumn{4}{|c|}{$\begin{array}{l}\text { pesq. em: Arquivo de Estado de Săo Paulo } \\
\text { data: } 18 / 12 / 2005-22 / 12 / 2005\end{array}$} \\
\hline data & pág. & jornal consultado & $\begin{array}{l}\text { cod } \\
\text { prod. }\end{array}$ & produto & loja & $\begin{array}{l}\text { prest. à } \\
\text { prazo }\end{array}$ & entrada & $\begin{array}{l}\text { prepo à } \\
\text { vista }\end{array}$ & $\begin{array}{c}n^{\circ} \\
\text { parc. }\end{array}$ & $\begin{array}{c}\text { qtd de } \\
\text { SM }\end{array}$ & descriçăo do produto & $\begin{array}{l}\text { atualiz. p/ } \\
\text { IPC-SP } \\
\text { FIPE }\end{array}$ & $\begin{array}{l}\text { atualiz. } p^{\prime} \\
\text { SM de } 2005\end{array}$ \\
\hline $5 / 8 / 2000$ & C1 & Folha de Săo Paulo & 32 & Iava louça maq & Best:Mix & & & $2.550,00$ & & & Brastemp BLF24D Inox - eletrónica 5 programas lavagem & $3.625,00$ & $5.066,23$ \\
\hline $14 / 9 / 2000$ & encarte & O Estado de Săo Paulo & 32 & Iava louça maq & Best:Mix & 120,08 & 120,06 & 569,00 & 4 & & Brastemp compacta BLC 18FT & 794,68 & $1.110,60$ \\
\hline $3 / 8 / 2000$ & encarte & O Estado de Săo Paulo & 32 & Iava louça maq & Ponto Frio & 40,58 & & 368,00 & 13 & & Enxuta Futura 6 pessoas & 524,56 & 733,11 \\
\hline $3 / 9 / 2000$ & encarte & O Estado de Săo Paulo & 32 & Iava louça maq & Ponto Frio & 197,78 & & $1.798,00$ & 13 & & Brastemp BLF24D - eletrónica 5 programas lavagem & $2.565,88$ & $3.572,19$ \\
\hline 10/9/2000 & encarte & O Estado de Săo Paulo & 32 & Iava louça maq & Ponto Frio & 40,58 & & 369,00 & 13 & & Enxuta Futura 6 pessoas & 524,56 & 733,11 \\
\hline $3 / 9 / 2000$ & encarte & O Estado de Săo Paulo & 33 & forno elétrico & Casas Bahia & 32,38 & & 228,00 & 8 & & Gran Luxo Eco 44 litros & 324,12 & 452,88 \\
\hline 10/8/2000 & encarte & O Estado de Săo Paulo & 33 & forno elétrico & Ponto Frio & 59,70 & & 179,10 & 3 & & Fischer 44 litros & 254,60 & 355,83 \\
\hline 3/9/2000 & A11 & Folha de Săo Paulo & 36 & DVD & Eletro & 85,37 & & 699,00 & 8 & & Toshiba SD 2109 & 983,68 & $1.388,74$ \\
\hline $14 / 9 / 2000$ & encarte & Follha de Săo Paulo & 36 & DVD & Extra & 70,17 & & 699,00 & 12. & & Toshiba SD 2100 & 883,68 & $1.388,74$ \\
\hline $15 / 8 / 2000$ & encarte & Follha de Săo Paulo & 36 & DVD & Extra & 62,82 & & 699,00 & 15 & & LG DVD 2240N & 983,68 & $1.388,74$ \\
\hline $15 / 8 / 2000$ & encarte & Folha de Săo Paulo & 36 & DVD & Extra & 62,82 & & 699,00 & 15 & & Toshiba SD 2109 & 983,68 & $1.388,74$ \\
\hline 14/9/2000 & $\mathrm{C} 12$ & Folha de Săo Paulo & 36 & DVD & Panashop & 159,80 & 159,80 & 783,00 & 4 & & Panasonic DVD RV30 & $1.113,09$ & $1.555,03$ \\
\hline $3 / 8 / 2000$ & encarte & O Estado de Săo Paulo & 36 & DVD & Ponto Frio & 76,89 & & 609,00 & 13 & & LG 2240N - zoom 4x e 16x & 903,68 & $1.388,74$ \\
\hline $3 / 9 / 2000$ & encarte & O Estado de Săo Paulo & 36 & DVD & Ponto Frio & 76,89 & & 609,00 & 13 & & Gradiente $6500 \mathrm{HT}$ & 883,68 & $1.388,74$ \\
\hline $10 / 9 / 2000$ & encarte & O Estado de São Paulo & 36 & DVD & Ponto Frio & 83,39 & & 848,00 & 13 & & Sony DVP 5360-D & $1.206,81$ & $1.686,75$ \\
\hline $17 / 8 / 2000$ & A13 & O Estado de Săo Paulo & 36 & DVD & Ponto Frio & 81,08 & & 609,00 & 12 & & Gradiente $6500 \mathrm{HT}$ & 983,68 & $1.388,74$ \\
\hline $3 / 9 / 2000$ & A7 & O Estado de Săo Paulo & 36 & DVD & Wal Mart & 98,00 & & 584,00 & 6 & & Toshiba 2109 padrão cor NTSC of controle remoto & 844,41 & $1.180,13$ \\
\hline $3 / 8 / 2000$ & C11 & Folha de Săo Paulo & 36 & DVD & Wal Mart & 89,00 & & 584,00 & 6 & & Toshiba 2109 padrão cor NTSC o/ controle remoto & 844,41 & $1.180,13$ \\
\hline $3 / 9 / 2000$ & encarte & OEstado de Săo Paulo & 37 & multiprocessador & Camefour & 18,08 & 18,08 & 179,00 & 12 & & Moulinex Ovatio3 Duo & 254,46 & 355,63 \\
\hline $3 / 9 / 2000$ & encarte & OEstado de Săo Paulo & 37 & multiprocessador & Casas Bahia & 48,00 & & 338,00 & 8 & & Walita Mega Master Pro & 480,48 & 671,52 \\
\hline $3 / 8 / 2000$ & encarte & O Estado de Săo Paulo & 37 & multiprocessador & Ponto Frio & 48,80 & & 148,70 & 3 & & Walita Mega Master Pro & 212,81 & 297,42 \\
\hline
\end{tabular}




\begin{tabular}{|c|c|c|c|c|c|c|c|c|c|c|c|c|c|}
\hline \multicolumn{3}{|c|}{$\begin{array}{l}\text { mês / ano - novembroldezembro de } 2005 \\
\text { produto - diversos }\end{array}$} & \multicolumn{7}{|c|}{ Salário mínimo en 01.05 .2005 - R\$ 300.00 } & \multicolumn{4}{|c|}{$\begin{array}{l}\text { pesq. em: Jornais / intemet / encartes distribuidos em lojas e domicílios } \\
\text { data: durante dezembro de } 2005\end{array}$} \\
\hline data & pág. & jomal / mídia consultado & $\begin{array}{l}\infty \\
\text { prod. } \\
\text { prod. }\end{array}$ & produto & loja & $\begin{array}{c}\text { prest. à } \\
\text { prazo }\end{array}$ & entrada & preço à vista & $\begin{array}{c}\mathrm{n}^{\circ} \\
\text { parc. }\end{array}$ & qtd de & descriçấo do produto & $\begin{array}{l}\text { atual z. } \\
\text { pl IPC } \\
\text { SP } \\
\text { FIPE }\end{array}$ & $\begin{array}{l}\text { atualiz. } \mathrm{p} / \\
\text { SM de } 2008\end{array}$ \\
\hline $16 / 12 / 2005$ & 7 & Folheto $18 / 12-24 / 12 / 05$ & & 1 maq lavar roupa & Pernambucanas & 79,80 & 79,90 & 1.299 .00 & 20 & 4,33 & Brastemp BWL07 - $7 \mathrm{~kg}$ & - & $1.299,00$ \\
\hline $16 / 12 / 2005$ & 8 & Folheto $16 / 12-24 / 12 / 05$ & & 1 maq lavar roupa & Pernambucanas & 64,50 & 64,50 & 799,00 & 20 & 2,66 & Consul CWID5A Super Jato $5 \mathrm{~kg}$ & - & 789,00 \\
\hline $16 / 12 / 2005$ & 8 & Folheto $16 / 12-24 / 12 / 05$ & & 1 | maq lavar roupa & Pernambucanas & 96,75 & 96,75 & $1.199,00$ & 20 & 4,00 & Consul CWL_ 8 SP Cargo 8 kg & - & $1.199,00$ \\
\hline $16 / 12 / 2005$ & 8 & Folheto $18 / 12-24 / 12 / 05$ & & 1 maq lavar roupa & Pernambucanas & 112,20 & 112,90 & $1.399,00$ & 20 & 4,86 & GE BC Super $11 \mathrm{~kg}$ ( 5 anos garantia) & - & $1.399,00$ \\
\hline $16 / 12 / 2005$ & encarte & Folha de Săo Paulo & & 1 maq lavar roupa & Casas Bahia & 300,79 & & $4.999,00$ & 24 & 16,66 & LG WD-14311D $10 \mathrm{~kg}$ lavadora e secadora & - & $4.899,00$ \\
\hline $26 / 12 / 2005$ & 4 & Folheto 26/12 - 31/12/05 & & 1 maq lavar roupa & Extra & 71,20 & & 799,00 & 12 & 2,66 & Electrolux & - & 789,00 \\
\hline $18 / 12 / 2005$ & A29 & O Estado de São Paulo & & 1 maq lavar roupa & Casas Bahia & 99,90 & & $1.299,00$ & 24 & 4,33 & Electrolux LF-90 - $9 \mathrm{~kg}$ & - & $1.299,00$ \\
\hline $20 / 12 / 2005$ & AQ & O Estado de São Paulo & & 1 maq lavar roupa & Casas Bahia & 99,80 & & $1.299,00$ & 24 & 4,33 & Electrolux LF- $90-9 \mathrm{~kg}$ & - & $1.299,00$ \\
\hline $23 / 12 / 2005$ & A10 & O Estado de São Paulo & & 1 maq lavar roupa & Casas Bahia & 99,80 & & $1.299,00$ & 24 & 4,33 & Electrolux LF-90 - $9 \mathrm{~kg}$ & - & $1.299,00$ \\
\hline $18 / 12 / 2005$ & A20 & Folha de São Paulo & & 1 maq lavar roupa & Shoptime.com & 93,25 & & $1.119,00$ & 12 & 3,73 & Electrolux LF75 - 7,5 kg & - & $1.119,00$ \\
\hline $23 / 12 / 2005$ & 88 & Folha de Săo Paulo & & 1 maq lavar roupa & Casas Bahia & 79,80 & & $1.090,00$ & 24 & 3,63 & Electrolux LF-75-7.5 kg & - & $1.090,00$ \\
\hline $16 / 12 / 2005$ & 1 & Follheto $18 / 12-24 / 12 / 05$ & 2,1 & \begin{tabular}{l|l|l|} 
TV a cores \\
\end{tabular} & Pernambucanas & 64,25 & 64,25 & 998,00 & 20 & 3,33 & LG 29CC25/26/90 - 29: & - & 800,00 \\
\hline $16 / 12 / 2005$ & 1 & Follheto $18 / 12-24 / 12 / 05$ & 2,1 & 1 TV a cores & Pernambucanas & 48,35 & 48,35 & 599,00 & 20 & 2,00 & LG RP-20CB $2 / 67-20^{\circ}$ & - & 509,00 \\
\hline $16 / 12 / 2005$ & 2 & Follheto $16 / 12-24 / 12 / 05$ & 2,1 & $\begin{array}{l}1 \text { TV a cores } \\
\end{array}$ & Pernambucanas & 44,80 & 44,90 & 698,00 & 20 & 2,33 & Samsung CL-21M6 - $21^{\prime \prime}$ & - & 609.00 \\
\hline $16 / 12 / 2005$ & 2 & Folheto $18 / 12-24 / 12 / 05$ & 2,1 & \begin{tabular}{l|l}
1 & TV a cores \\
\end{tabular} & Pernambucanas & 72,60 & 72,60 & 889,00 & 20 & 3,00 & Ph-ips 25PT5541-25" Real Flat & - & 899,00 \\
\hline $16 / 12 / 2005$ & 2 & Folheto $16 / 12-24 / 12 / 05$ & 2,1 & 1 TV a cores & Pernambucanas & 80,60 & 80,60 & 998,00 & 20 & 3,33 & Toshiba 2009 MS - $29^{\prime \prime}$ & - & 800,00 \\
\hline $16 / 12 / 2005$ & 2 & Folheto $18 / 12-24 / 12 / 05$ & 2,1 & 1 TV a cores & Pernambucanas & 145,20 & 145.20 & $1.789,00$ & 20 & 5,96 & Toshiba 3489 MS - $33^{m}$ & - & $1.789,00$ \\
\hline $16 / 12 / 2005$ & 2 & Folheto $18 / 12-24 / 12 / 05$ & 2,1 & \begin{tabular}{l|l}
1 & TV a cores \\
\end{tabular} & Pernambucanas & 112,80 & 112,90 & $1.399,00$ & 20 & 4,66 & LG RP-29FA30/35A Flatron - $29^{\prime \prime}$ & - & $1.399,00$ \\
\hline $16 / 12 / 2005$ & 2 & Folheto $18 / 12-24 / 12 / 05$ & 2,1 & 1 TV a cores & Pernambucanas & 274,30 & 274.30 & $3.389,00$ & 20 & 11,33 & LG RP32FZ40P Lafinion - 32" & - & $3.399,00$ \\
\hline $16 / 12 / 2005$ & 2 & Folheto $18 / 12-24 / 12 / 05$ & 2,1 & 1 TV a cores & Pernambucanas & 290,50 & 290,50 & $3.599,00$ & 20 & 12,00 & Sony KV-34FS110 - 34" & - & $3.599,00$ \\
\hline $18 / 12 / 2005$ & 1 & Follheto $18 / 12-24 / 12 / 05$ & 2,1 & $\begin{array}{l}1 \text { TV a cores } \\
\end{array}$ & Ponto Frio & 89,80 & 89,90 & 889,00 & 12 & 3,00 & Graciente $2822-29^{\circ}$ & - & 889,00 \\
\hline $18 / 12 / 2005$ & 2 & Follheto $18 / 12-24 / 12 / 05$ & 2,1 & $\begin{array}{l}1 \text { TV a cores } \\
\end{array}$ & Panto Frio & 69,50 & 69,50 & 728,00 & 14 & 2,43 & Panasonic TC21FJ32L plana - $21^{*}$ & - & 728,00 \\
\hline $18 / 12 / 2005$ & 3 & Folheto $18 / 12-24 / 12 / 05$ & 2,1 & 1 TV a cores & Ponto Frio & 66,70 & 66,70 & 698,00 & 14 & 2,33 & LG RP 21F010/F015 - 21" & - & 688,00 \\
\hline $18 / 12 / 2005$ & 4 & Follheto $18 / 12-24 / 12 / 05$ & 2,1 & $\begin{array}{l}1 \text { TV a cores } \\
\end{array}$ & Ponto Frio & 69,90 & 69,90 & 698,00 & 14 & 2,33 & Phips PT 5433/5435 & - & 698,00 \\
\hline $18 / 12 / 2005$ & 7 & Follheto $18 / 12-24 / 12 / 05$ & 2,1 & 1 TV a cores & Ponto Frio & 71,50 & 71,50 & 748,00 & 14 & 2,48 & Sony Wega $21 \mathrm{KV} 21 \mathrm{FV} 210$ - 21 & - & 748,00 \\
\hline $18 / 12 / 2005$ & 7 & Folheto $18 / 12-24 / 12 / 05$ & 2,1 & 1 TV a cores & Ponto Frio & 149,70 & 149,70 & $1.569,00$ & 14 & 5,23 & Sony Wega $29 K V$ FS $110-29$ & - & $1.569,00$ \\
\hline $18 / 12 / 2005$ & 7 & Folheto $18 / 12-24 / 12 / 05$ & 2,1 & 1 TV a cores & Ponto Frio & 359,24 & & $3.598,00$ & 12 & 11,88 & Sony Wega KV34FS1 10 - 34 & - & $3.598,00$ \\
\hline $18 / 12 / 2005$ & 7 & Folheto $18 / 12-24 / 12 / 05$ & 2,1 & 1 TV a cores & Ponto Frio & 549,20 & & $5.498,00$ & 12 & 18,33 & Sony Wega KV38FV 310 - $38^{\circ}$ & - & $5.499,00$ \\
\hline $18 / 12 / 2005$ & 8 & Follheto $18 / 12-24 / 12 / 05$ & 2,1 & \begin{tabular}{l|l} 
& TV a cores \\
\end{tabular} & Ponto Frio & 79,20 & 79,90 & 799,00 & 12 & 2,86 & CCE HPS-2971 - $29^{\circ}$ & - & 789,00 \\
\hline $18 / 12 / 2005$ & 8 & Folheto $18 / 12-24 / 12 / 05$ & 2,1 & 1 TV a cores & Panto Frio & 59,80 & 58,90 & 509,00 & 12 & 2,00 & CCE HPS-2171FS - $21^{\prime \prime}$ & - & 589,00 \\
\hline $26 / 12 / 2005$ & 4 & Follheto $26 / 12$ - 31/12/05 & 2,1 & \begin{tabular}{l|l}
1 & TV a cores \\
\end{tabular} & Extra & 57,50 & & 589,00 & 12 & 2,00 & Samsung CL-21M6 - 21" & - & 589,00 \\
\hline $26 / 12 / 2005$ & 4 & Follheto $28 / 12$ - 31/12/05 & 2,1 & 1. TV a cores & Extra & 93,50 & & 979,00 & 12 & 3,26 & Semp Toshiba 2999MS - $29^{\prime}$ & - & 979,00 \\
\hline $26 / 12 / 2005$ & 4 & Follheto $28 / 12-31 / 12 / 05$ & 2,1 & \begin{tabular}{l|l}
1 & TV a cores \\
\end{tabular} & Extra & 17,50 & & 179,00 & 12 & 0,80 & Cougar & - & 179,00 \\
\hline $23 / 12 / 2005$ & 14 & Follheto $23 / 12-28 / 12 / 05$ & 2,1 & 1.TV a cores & Carrefour & 119,20 & & $1.199,00$ & 10 & 4,00 & Philoo TPF29S4F - 29" & - & $1.199,00$ \\
\hline $23 / 12 / 2005$ & 14 & Folheto 23/12 - 28/12/05 & 2,1 & 1 TV a cores & Camefour & 533,00 & 533.00 & $1.599,00$ & 2 & 5,33 & Sony $29 \mathrm{FS} 110-29^{\circ}$ & - & $1.599,00$ \\
\hline $17 / 12 / 2005$ & 1 & Folheto $17 / 12-24 / 12 / 05$ & 2,1 & 1 TV a cores & FNAC & 99,00 & & $1.188,00$ & 12 & 3,96 & Toshiba Tela Plana $29^{\circ}$ & - & $1.188,00$ \\
\hline \begin{tabular}{|l|}
$10 / 12 / 2005$ \\
\end{tabular} & 3 & Folheto $10 / 12-25 / 12 / 05$ & 2,1 & $\begin{array}{l}1 \text { TV a cores } \\
\end{array}$ & BestMix & 189,20 & & $1.889,00$ & 10 & 6,33 & Ph & - & $1.899,00$ \\
\hline $10 / 12 / 2005$ & 1 & Folheto $10 / 12-25 / 12 / 05$ & 2,1 & 1 TV a cores & BestMix & 254,68 & & $1.528,00$ & 6 & 5,08 & Sony KV-29F 110 tela plana - $29^{\circ}$ & - & $1.528,00$ \\
\hline $23 / 12 / 2005$ & A11 & O Estado de São Paulo & 2,1 & 1 TV a cores & Casas Bahia & 52,80 & & 698,00 & 24 & 2,33 & $\mathrm{Ph}^{-1}$ ps PT 5433 FLAT - $21^{\circ}$ & - & 600,00 \\
\hline
\end{tabular}




\begin{tabular}{|c|c|c|c|c|c|c|c|c|c|c|c|c|c|}
\hline \multicolumn{3}{|c|}{ mês / ano - novembro/dezembro de 2005} & \multicolumn{7}{|c|}{ salário mínimo em 01.05 .2005 - R\$ 300.00} & \multicolumn{4}{|c|}{$\begin{array}{l}\text { pesq. em: Jornais / intemet / encartes distribuídos em lojas e domicilios } \\
\text { data: durante dezembro de } 2005\end{array}$} \\
\hline data & pág. & jomal / midia consultado & $\begin{array}{c}\text { ood } \\
\text { prod. }\end{array}$ & produto & loja & $\begin{array}{c}\text { prest. à } \\
\text { prazo }\end{array}$ & entrada & preço à vista & $\begin{array}{c}\mathrm{n}^{\circ} \\
\text { parc. }\end{array}$ & qtd de & descriçấo do produto & \begin{tabular}{|l} 
atual'z. \\
pl/PC- \\
SP \\
FIPE
\end{tabular} & $\begin{array}{l}\text { atualiz, pl } \\
\text { SM de } 2005\end{array}$ \\
\hline $18 / 12 / 2005$ & A22 & Folha de Săo Paulo & 2,1 & TV a cores & Shoptime com & 191,59 & & $2.299,00$ & 12 & 7,66 & Philoo TPF 32 S55 - $32^{\prime \prime}$ tela plana & - & $2.299,00$ \\
\hline $18 / 12 / 2005$ & A22 & Folha de Săo Paulo & 2,1 & TV a cores & Shoptime com & 141,59 & & $1.699,00$ & 12 & 5,66 & Ph'ps HDTV 28 PT $^{-1} 422-2 \theta^{\circ}$ & - & $1.609,00$ \\
\hline $23 / 12 / 2005$ & B14 & Folha de Săo Paulo & 2,1 & TV a cores & Americanas.com & 53,24 & & 639,00 & 12 & 2,13 & Philoo TPF-2121C - $21^{\prime \prime}$ tela plana & - & 639,00 \\
\hline $23 / 12 / 2005$ & B14 & Folha de Săo Paulo & 2,1 & TV a cores & Americanas.com & 133,25 & & $1.599,00$ & 12 & 5,33 & Ph'ips PW6542/78 - $28^{\prime}$ tela plana & - & $1.599,00$ \\
\hline $23 / 12 / 2005$ & $\mathrm{B9}$ & Folha de Săo Paulo & 2,1 & TV a cores & Casas Bahia & 42,90 & & 568,00 & 24 & 1,20 & $\mathrm{Ph}^{-1} \mathrm{ps}$ PT $-4331-20^{\prime \prime}$ & - & 500,00 \\
\hline $22 / 12 / 2005$ & C11 & Folha de Săo Paulo & 2,1 & TV a cores & Eletro Outlet Direto & & & $1.099,00$ & & 3,66 & Gradiente $2950-29^{\circ}$ com DVD & - & $1.099,00$ \\
\hline $22 / 12 / 2005$ & C11 & Folha de Săo Paulo & 2,1 & TV a cores & Eletro Outlet Direto & & & 699,00 & & 2,33 & Semp Toshiba $2157-21^{\prime \prime}$ - tela plana & - & 609,00 \\
\hline $22 / 12 / 2005$ & C11 & Folha de Săo Paulo & 2,1 & TV a cores & Eletro Outlet Direto & & & $1.998,00$ & & 6,66 & Sony $28 F A 310-28^{\circ}$ - tela plana & - & $1.899,00$ \\
\hline $22 / 12 / 2005$ & C11 & Folha de Săo Paulo & 2,1 & TV a cores & Eletro Outlet Direto & & & $1.339,00$ & & 4,40 & $\mathrm{Ph}^{-1}$ ps 29PT564S - 29" - tela plana & - & $1.339,00$ \\
\hline $16 / 12 / 2005$ & 3 & Folheto $16 / 12-24 / 12 / 05$ & 2,2 & TV plasma & Pernambucanas & 833,25 & & $9.999,00$ & 12 & 33,33 & Ph'ps 42PF7320 - 42' & - & $9.899,00$ \\
\hline $16 / 12 / 2005$ & encarte & Folha de São Paulo & 2,2 & TV plasma & Casas Bahia & 631,50 & & $10.499,00$ & 24 & 35,00 & Samsung 42SSSX-XAZ - 42' & - & $10.489,00$ \\
\hline $18 / 12 / 2005$ & 3 & Folheto $18 / 12-24 / 12 / 05$ & 2,2 & TV plasma & Ponto Frio & 833.25 & & $8.998,00$ & 12 & 33,33 & LG 42PX4RV MC - $42^{\prime \prime}$ & - & $9.899,00$ \\
\hline $18 / 12 / 2005$ & 5 & Folheto $18 / 12-24 / 12 / 05$ & 2,2 & TV plasma & Ponto Frio & 999,00 & & $9.999,00$ & 10 & 33,33 & Gradiente PL $4230-42^{\prime \prime}$ & - & $9.899,00$ \\
\hline $17 / 12 / 2005$ & 2 & Folheto $17 / 12-24 / 12 / 05$ & 2,2 & TV plasma & FNAC & 833.25 & & $9.998,00$ & 12 & 33,33 & LG 42 PX 4 RV MC $-42^{\circ}$ & - & $9.899,00$ \\
\hline $17 / 12 / 2005$ & 2 & Follheto $17 / 12-24 / 12 / 05$ & 2,2 & TV plasma & FNAC & 874,81 & & $10.490,00$ & 12 & 35,00 & Samsung PL $42 \mathrm{~S} 5 \mathrm{~S}-42^{*}$ & - & $10.489,00$ \\
\hline $10 / 12 / 2005$ & 2 & Follheto $10 / 12-25 / 12 / 05$ & 2,2 & TV plasma & BestMix & 999,90 & & $9.998,00$ & 10 & 33,33 & LG 42PX4D - 42" & - & $9.899,00$ \\
\hline $10 / 12 / 2005$ & 3 & Follheto $10 / 12-25 / 12 / 05$ & 2,2 & TV plasma & BestMix & 799,80 & & $7.999,00$ & 10 & 26,66 & Ph'ps 32PF5320/28-32' & - & $7.899,00$ \\
\hline $18 / 12 / 2005$ & $A B$ & O Estado de São Paulo & 2,2 & TV plasma & Casas Bahia & 629,00 & & $10.499,00$ & 24 & 35,00 & Samsung 42SSSX-XAZ - 42" & - & $10.499,00$ \\
\hline $20 / 12 / 2005$ & $A B$ & O Estado de São Paulo & 2,2 & TV plasma & Casas Bahia & 750,00 & & $9.989,00$ & 24 & 33,33 & LG 42PX4RV MC - $42^{\prime \prime}$ & 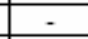 & $9.899,00$ \\
\hline $24 / 12 / 2005$ & A10 & O Estado de São Paulo & 2,2 & TV plasma & Casas Bahia & 750,00 & & $9.999,00$ & 24 & 33,33 & LG 42PX4RV MC - 42" & - & $9.899,00$ \\
\hline $22 / 12 / 2005$ & A17 & Folha de São Paulo & 2,2 & TV plasma & Extra & $1.916,58$ & & $22.980,00$ & 12 & 76,66 & LG 50PX5R-MC - $50^{\circ}$ & - & $22.999,00$ \\
\hline $22 / 12 / 2005$ & A17 & Folha de São Paulo & 2,2 & TV plasma & Extra & 833,25 & & $9.999,00$ & 12 & 33,33 & LG 42PX4RV MC - $42^{\prime \prime}$ & - & $9.899,00$ \\
\hline $17 / 12 / 2005$ & 2 & Folheto $17 / 12-24 / 12 / 05$ & 2,3 & TVLCD & FNAC & 866,58 & & $7.999,00$ & 12 & 26,66 & Phips 32PF5320/28 - 32' & - & $7.899,00$ \\
\hline $17 / 12 / 2005$ & 2 & Folheto $17 / 12-24 / 12 / 05$ & 2,3 & TV LCD & FNAC & 249,21 & & $2.999,00$ & 12 & 10,00 & Phips 20 PF $8946 / 78-20^{\prime \prime}$ & - & $2.899,00$ \\
\hline $22 / 12 / 2005$ & D4 & Folha de Săo Paulo & 2,3 & TV LCD & Panashop & 799,80 & & $7.999,00$ & 10 & 26,66 & $\mathrm{Ph}-195$ 32PF5320/28 - 32 & - & $7.899,00$ \\
\hline $16 / 12 / 2005$ & 1 & Folheto $18 / 12-24 / 12 / 05$ & 3 & geladeira & Pernambucanas & 72,55 & 72,55 & 899,00 & 20 & 3,00 & Electrolux RDE 30 & - & 890,00 \\
\hline $16 / 12 / 2005$ & 6 & Follheto $18 / 12-24 / 12 / 05$ & & geladeira & \begin{tabular}{|l|} 
Pernambucanas \\
\end{tabular} & 88,70 & 88,70 & $1.099,00$ & 20 & 3,66 & Consul CRA 34D - 303 litros & - & $1.099,00$ \\
\hline $16 / 12 / 2005$ & & internet & & geladeira & Americanas.com.br & & & 769,00 & & 2,56 & Consul 213 litros - CRC24 & - & 700,00 \\
\hline $16 / 12 / 2005$ & & intemet & & geladeira & Americanas.com.br & & & 838,00 & & 2,80 & Continental - 252 litros - RC27 & - & 839.00 \\
\hline $16 / 12 / 2005$ & & intemet & 3 & geladeira & Americanas.com.br & & & 839,00 & & 2,80 & Electrolux - 253 litros - RE26 & - & 839.00 \\
\hline $16 / 12 / 2005$ & & intemet & 3 & geladeira & Americanas.com.br & & & 859,00 & & 2,86 & Dako - 254 litros - DR280 & - & 859.00 \\
\hline $16 / 12 / 2005$ & & intemet & & geladeira & Americanas.com.br & & & 999,00 & & 3,33 & Consul - 300 litros - CRA 320 & - & 900,00 \\
\hline $16 / 12 / 2005$ & & intemet & & geladeira & Americanas.com.br & & & $1.129,00$ & & 3,78 & Consul - 303 litros - CRA34D & - & $1.128,00$ \\
\hline $16 / 12 / 2005$ & & intemet & 3 & geladeira & Americanas.com.br & & & $1.219,00$ & & 4,06 & Esmaltec - 257 litros - RUP280 & - & $1.219,00$ \\
\hline $16 / 12 / 2005$ & & intemet & 3 & geladeira & Americanas.com.br & & & $1.249,00$ & & 4,16 & Consul - 303 litros com dispenser água - CRP34A & - & $1.249,00$ \\
\hline $16 / 12 / 2005$ & & intemet & 3 & geladeira & Americanas.com.br & & & $1.390,00$ & & 4,66 & Brastemp - BRC12 Inox & - & $1.399,00$ \\
\hline $16 / 12 / 2005$ & & intemet & & geladeira & Americanas.com.br & & & $1.949,00$ & & 6,50 & Brastemp - 330 litros - BRF 36 & - & $1.849,00$ \\
\hline $16 / 12 / 2005$ & & intemet & & geladeira & Americanas.com.br & & & $1.998,00$ & & 6,66 & Bosch - 371 litros - KSR39 & - & $1.809,00$ \\
\hline $16 / 12 / 2005$ & & intemet & & geladeira & Americanas.com.br & & & $2.899,00$ & & 9,66 & Brastemp - 330 litros - XRF36D & - & $2.899,00$ \\
\hline
\end{tabular}




\begin{tabular}{|c|c|c|c|c|c|c|c|c|c|c|c|c|c|}
\hline \multicolumn{3}{|c|}{ mês / ano - novembroldezembro de 2005} & \multicolumn{6}{|c|}{ Salário mínimo em 01.05.2005 - R3 300,00 } & & \multicolumn{4}{|c|}{$\begin{array}{l}\text { pesq. em: Jornais / intemet / encartes distribuidos em lojas e domicílios } \\
\text { data: durante dezembro de } 2005\end{array}$} \\
\hline data & pág. & jomal / midia consultado & $\begin{array}{c}\text { ood } \\
\text { prod. }\end{array}$ & produto & boja & $\begin{array}{l}\text { prest. à } \\
\text { prazo }\end{array}$ & entrada & preço à vist: & $\begin{array}{c}n^{\circ} \\
\text { parc. }\end{array}$ & $\begin{array}{l}\text { qtd de } \\
\text { SM }\end{array}$ & descriçấo do produto & \begin{tabular}{|l|} 
atual $z$. \\
pl IPC- \\
SP \\
FIPE
\end{tabular} & $\begin{array}{l}\text { atualiz. pl } \\
\text { SM de } 200\end{array}$ \\
\hline $16 / 12 / 2005$ & & internet & & geladeira & Pontofrio combr & & & $2.079,00$ & & 6,83 & Brastemp - 330 litro5 - BRF $36 \mathrm{D}$ & - & $2.079,00$ \\
\hline $16 / 12 / 2005$ & & internet & 3 & geladeira & Pontofrio.combr br & & & $1.699,00$ & & 5,66 & Bosch - 371 litros - KSR39 & - & $1.699,00$ \\
\hline $16 / 12 / 2005$ & & intemet & 3 & geladeira & Pontofrio combr br & & & $1.290,00$ & & 4,33 & Consul - 303 litros - CRP34 & - & $1.299,00$ \\
\hline $16 / 12 / 2005$ & & internet & & geladeira & Pontofrio.com.br & & & $1.289,00$ & & 4,30 & Brastemp - 303 litros - BRA34D & - & $1.289,00$ \\
\hline $16 / 12 / 2005$ & & internet & 3 & gelsdeira & Pontofrio com br & & & $1.249,00$ & & 4,16 & Electrolux - 317 litros - RDE34 & - & $1.249,00$ \\
\hline $23 / 12 / 2005$ & B8 & Folha de Săo Paulo & & geladeira & Casas Bahia & 79,80 & & 998,00 & 22 & 3,33 & Electrolux RDE $30-275$ Itros & - & 800,00 \\
\hline $16 / 12 / 2005$ & 6 & Folheto $18 / 12-24 / 12 / 05$ & 3,1 & geladeira & Pernambucanas & 99,20 & 99,20 & $1.229,00$ & 20 & 4,10 & Electrolux DC 34 - 320 lifros & - & $1.229,00$ \\
\hline $16 / 12 / 2005$ & 6 & Folheto $18 / 12-24 / 12 / 05$ & 3,1 & geladeira & Pernambucanas & 104,85 & 104,85 & $1.299,00$ & 20 & 4,33 & Bosch KSV 36 - 342 Itros & - & $1.299,00$ \\
\hline $16 / 12 / 2005$ & 6 & Folheto $18 / 12-24 / 12 / 05$ & 3,1 & geladeira & Pernambucanas & 112,90 & 112,90 & $1.399,00$ & 20 & 4,86 & Electrolux DC 38 - 380 litros & - & $1.399,00$ \\
\hline $16 / 12 / 2005$ & 6 & Follheto $18 / 12-24 / 12 / 05$ & 3,1 & geladeira & Pernambucanas & 129,00 & 129,00 & $1.598,00$ & 20 & 5,33 & Electrolux DC $45-430$ litros & - & $1.599,00$ \\
\hline $16 / 12 / 2005$ & 6 & Follheto $18 / 12-24 / 12 / 05$ & 3,1 & geladeira & Pernambucanas & 145,20 & 145,20 & $1.799,00$ & 20 & 6,00 & Bosch KSV 47 - 457 itros & - & $1.799,00$ \\
\hline $16 / 12 / 2005$ & 6 & Folheto $18 / 12-24 / 12 / 05$ & 3,1 & geladeira & Pernambucanas & 153,25 & 153.25 & $1.899,00$ & 20 & 6,33 & Consul CRD 48D - 460 litros & - & $1.899,00$ \\
\hline $16 / 12 / 2005$ & 6 & Folheto $18 / 12-24 / 12 / 05$ & 3,1 & geladeira & Pernambucanas & 193,60 & 183,60 & $2.399,00$ & 20 & 8,00 & Electrolux DF 45 - 413 litros & - & $2.399,00$ \\
\hline \begin{tabular}{|l|}
$16 / 12 / 2005$ \\
\end{tabular} & 6 & Folheto $18 / 12-24 / 12 / 05$ & 3,1 & gelsdeira & Pernambucanas & 583,25 & & $6.999,00$ & 12 & 23,33 & Electrolux Side by Side SS74 - 700 litros & - & $6.899,00$ \\
\hline $16 / 12 / 2005$ & 6 & Folheto $18 / 12-24 / 12 / 05$ & 3,1 & gelsdeira & Pernambucanas & 88,00 & 88,00 & $1.090,00$ & 20 & 3,63 & Dako DU 320 & - & $1.000,00$ \\
\hline $16 / 12 / 2005$ & 7 & Folheto $18 / 12-24 / 12 / 05$ & 3,1 & gelsdeira & Pernambucanas & 173,45 & 173,45 & $2.149,00$ & 20 & 7,16 & Brastemp XRX 48D - 439 itros & - & $2.149,00$ \\
\hline $16 / 12 / 2005$ & 7 & Follheto $18 / 12-24 / 12 / 05$ & 3,1 & geladeira & Pernambucanas & 374,20 & 374,90 & $4.499,00$ & 12 & 15,00 & Brastemp BRD $48 D$ - 460 litros água na porta & - & $4.489,00$ \\
\hline $16 / 12 / 2005$ & encarte & Folha de Săo Paulo & 3,1 & geladeira & Casas Bahia & 360,96 & & $5.998,00$ & 24 & 20,00 & Samsung Side by Side 532 litros & - & $5.89 \theta, 00$ \\
\hline $23 / 12 / 2005$ & 16 & Folheto $23 / 12-28 / 12 / 05$ & 3,1 & geladeira & Camefour & 124,80 & & $1.498,80$ & 12 & 5,00 & Electrolux DC45 & - & $1.498,80$ \\
\hline $10 / 12 / 2005$ & 4 & Follheto $10 / 12-25 / 12 / 05$ & 3,1 & geladeira & BestMix & 899,75 & & $3.999,00$ & 4 & 13,33 & Brastemp BRX 48 Frost Free sexto sentido & - & $3.899,00$ \\
\hline $10 / 12 / 2005$ & 4 & Follheto $10 / 12-25 / 12 / 05$ & 3,1 & geladeira & BestMix & 999,75 & & $3.998,00$ & 4 & 13,33 & Brastemp BRE48 Inverse Frost Free & - & $3.890,00$ \\
\hline $18 / 12 / 2005$ & A27 & O Estado de São Paulo & 3,1 & geladeira & Casas Bahia & 149,00 & & $1.999,00$ & 24 & 6,66 & Brastemp BRM-36E - 321 litros & - & $1.899,00$ \\
\hline $18 / 12 / 2005$ & A27 & O Estado de São Paulo & 3,1 & geladeira & Casas Bahia & 89,80 & & $1.199,00$ & 24 & 4,00 & Electrolux DC-360 - 351 litros & - & $1.199,00$ \\
\hline $20 / 12 / 2005$ & A9 & O Estado de São Paulo & 3,1 & geladeira & Casas Bahia & 149,00 & & $1.999,00$ & 24 & 6,66 & Brastemp RM-36E - 321 litros & - & $1.89 \theta, 00$ \\
\hline $23 / 12 / 2005$ & A10 & O Estado de São Paulo & 3,1 & geladeira & Casas Bahia & 149,00 & & $1.999,00$ & 24 & 6,66 & Brastemp BRM-36E - 321 litros & - & $1.899,00$ \\
\hline $25 / 12 / 2005$ & A11 & O Estado de São Paulo & 3,1 & gelsdeira & Casas Bahia & 279,00 & & $3.199,00$ & 18 & 10,66 & Brastemp BRM-48 Frost Free & - & $3.199,00$ \\
\hline $25 / 12 / 2005$ & A11 & O Estado de São Paulo & 3,1 & geladeira & Casas Bahia & 99,80 & & $1.198,00$ & 21 & 4,00 & sem marca especificada 2 portas & - & $1.199,00$ \\
\hline $22 / 12 / 2005$ & C11 & Folha de São Paulo & 3,1 & geladeira & Eletro Outlet Direto & & & $1.449,00$ & & 4,83 & Continental RSV 47 - 446 litros & - & $1.449,00$ \\
\hline $16 / 12 / 2005$ & 7 & Follheto $18 / 12-24 / 12 / 05$ & 4 & fogão & Pernambucanas & 84,70 & 84,70 & $1.049,00$ & 20 & 3,50 & Brastemp BFW $76 \mathrm{G}$ De Vle 6 bocas & - & $1.049,00$ \\
\hline $16 / 12 / 2005$ & 7 & Folheto $18 / 12-24 / 12 / 05$ & 4 & fogão & Pernambucanas & 56,40 & 56,40 & 699,00 & 20 & 2,33 & Brastemp BFW $76 \mathrm{G}$ De Vile 4 bocas & - & 600,00 \\
\hline $16 / 12 / 2005$ & 7 & Follheto $18 / 12-24 / 12 / 05$ & 4 & fogão & Pernambucanas & 80,60 & 80,60 & 999,00 & 20 & 3,33 & Brastemp BF $160 \mathrm{~A}$ Unique 4 bocas & - & 900,00 \\
\hline $16 / 12 / 2005$ & 8 & Folheto $18 / 12-24 / 12 / 05$ & 4 & fogão & Pernambucanas & 25,70 & 25,70 & 319,00 & 20 & 1,06 & Clarice Delicato Plus 4 bocas & - & 319,00 \\
\hline $16 / 12 / 2005$ & 8 & Folheto $18 / 12-24 / 12 / 05$ & & fogão & Pernambucanas & 31,50 & 31,50 & 390,00 & 20 & 1,30 & Dako Palace Plus 4 bocas & - & 380,00 \\
\hline $16 / 12 / 2005$ & 8 & Folheto $18 / 12-24 / 12 / 05$ & & fogão & Pernambucanas & 68,50 & 68,50 & 849,00 & 20 & 2,83 & Continental Quantum 6 bocas & - & 849,00 \\
\hline $16 / 12 / 2005$ & 8 & Follheto $16 / 12-24 / 12 / 05$ & 4 & fogão & Pernambucanas & 48,20 & 48,20 & 598,00 & 20 & 1,99 & Continental Quantum 4 bocas & - & 588,00 \\
\hline $16 / 12 / 2005$ & encarte & Folha de Săo Paulo & 4 & fogão & Casas Bahia & 84,18 & & $1.399,00$ & 24 & 4,86 & Fogão Deluxxe 5 bocas acendimento automático & - & $1.399,00$ \\
\hline $16 / 12 / 2005$ & encarte & Folha de Săo Paulo & 4 & fogão & Casas Bahia & 78,16 & & $1.299,00$ & 24 & 4,33 & Brastemp Maison 5 bocas acendimento automático & - & $1.289,00$ \\
\hline $26 / 12 / 2005$ & 4 & Follheto $28 / 12$ - 31/12/05 & 4 & fogão & Extra & 18,50 & & 189,00 & 12 & 0,83 & Cassino NL Piso 4 bocas & - & 189,00 \\
\hline $18 / 12 / 2005$ & A28 & O Estado de São Paulo & 4 & fogão & Casas Bahia & 59,20 & & 739,00 & 20 & 2,46 & Dako Diplomata 4 bocas & - & 739.00 \\
\hline
\end{tabular}




\begin{tabular}{|c|c|c|c|c|c|c|c|c|c|c|c|c|c|}
\hline \multicolumn{3}{|c|}{ mês / ano - novembro/dezembro de 2005} & \multicolumn{7}{|c|}{ salário mínimo em 01.05 .2005 - R\$ 300,00 } & \multicolumn{4}{|c|}{$\begin{array}{l}\text { pesq. em: Jornais / intemet / encartes distribuidos em lojas e domicílios } \\
\text { data: durante dezembro de } 2005\end{array}$} \\
\hline data & pág. & jomal / midia consultado & $\begin{array}{l}\text { ood } \\
\text { prod. }\end{array}$ & produto & loja & $\begin{array}{c}\text { prest. à } \\
\text { prazo }\end{array}$ & entrada & preço à vista & $\begin{array}{c}\mathrm{n}^{\circ} \\
\text { parc. }\end{array}$ & $\begin{array}{c}\text { qtd de } \\
\text { SM }\end{array}$ & descriçấo do produto & \begin{tabular}{|l|} 
atua \\
$P^{\prime} / P C$ \\
$S P$ \\
SP \\
FIPE
\end{tabular} & $\begin{array}{l}\text { atualiz. pl } \\
\text { SM de } 200\end{array}$ \\
\hline $20 / 12 / 2005$ & $A 9$ & O Estado de São Paulo & & fogão & Casas Bahia & 59,80 & & 699,00 & 18 & 2,33 & Continental Caprice I 4 bocas & - & 600,00 \\
\hline $23 / 12 / 2005$ & A11 & O Estado de São Paulo & & fogão & Casas Bahia & 89,20 & & 989,00 & 18 & 3,33 & Brastemp BF-160A 4 bocas & - & 800,00 \\
\hline $24 / 12 / 2005$ & A11 & O Estado de São Paulo & & fogão & Casas Bahia & 59,20 & & 739,00 & 20 & 2,46 & Dako Diplomata Grill 4 bocas & - & 739,00 \\
\hline $25 / 12 / 2005$ & A13 & O Estado de São Paulo & & fogão & Casas Bahia & 59,20 & & 699,00 & 18 & 2,33 & Continental Caprice 14 bocas & - & 600,00 \\
\hline $23 / 12 / 2005$ & $\mathrm{BQ}$ & Folha de São Paulo & & fogão & Casas Bahia & 35,20 & & 399,00 & 18 & 1,33 & Consul Essencial Plus CFA-50D - 4 bocas & - & 389,00 \\
\hline $22 / 12 / 2005$ & C11 & Folha de Săo Paulo & & fogão & Eletro Outlet Direto & & & 598,00 & & 2,00 & Brastemp BFA 50C -4 bocas & - & 500,00 \\
\hline $22 / 12 / 2005$ & C11 & Folha de São Paulo & & fogão & Eletro Outlet Direto & & & 699,00 & & 2,33 & Bosch HSC44K - 4 bocas & - & 609,00 \\
\hline $16 / 12 / 2005$ & 10 & Follheto $16 / 12-24 / 12 / 05$ & & ferro elétrico & Pernambucanas & 11,10 & 11,10 & 42,80 & 3 & 0,14 & Black \& Decker VFA110 & - & 42,90 \\
\hline $16 / 12 / 2005$ & 10 & Follheto $16 / 12-24 / 12 / 05$ & & ferro elétrico & Pernambucanas & 12,80 & 12,90 & 49,80 & 3 & 0,17 & Británia FB 165 a vapor & - & 49,90 \\
\hline $16 / 12 / 2005$ & 11 & Folheto $16 / 12$ - 24/12/05 & & ferro elétrico & Pernambucanas & 10,30 & 10,30 & 39,80 & 3 & 0,13 & Britânia FB 160 a vapor & - & 39,90 \\
\hline $16 / 12 / 2005$ & 11 & Folheto $18 / 12$ - 24/12/05 & & ferro elétrico & Pernambucanas & 20,40 & 20,40 & 79,00 & 3 & 0,28 & Black \& Decker X560 a vapor & - & 79,00 \\
\hline $16 / 12 / 2005$ & 11 & Follheto $16 / 12-24 / 12 / 05$ & & ferro elétrico & Pernambucanas & 15,20 & 15,20 & 59,00 & 3 & 0,20 & Black \& Decker X527 a vapor & - & 50,00 \\
\hline $21 / 12 / 2005$ & $B 8$ & Folha de São Paulo & & ferro elétrico & Fast Shop & 26,33 & & 79,00 & 3 & 0,26 & Black \& Decker Spray Tefion X580 & - & 79,00 \\
\hline $21 / 12 / 2005$ & $\mathrm{~B} 8$ & Folha de São Paulo & & ferro elétrico & Fast Shop & 15,80 & & 79,00 & 5 & 0,28 & Black \& Decker T1747B - viagem & - & 79,00 \\
\hline $16 / 12 / 2005$ & 11 & Folheto $16 / 12-24 / 12 / 05$ & & secador de cabelo & Pernambucanas & & & 29,00 & & 0,10 & Vec SC 601 portátil & - & 29,00 \\
\hline $16 / 12 / 2005$ & 11 & Follheto $16 / 12$ - 24/12/05 & & secador de cabelo & Pernambucanas & 25,55 & 25,55 & 99,00 & 3 & 0,33 & Taiff Turbo $6000-1700 \mathrm{~W}$ & - & 89,00 \\
\hline $16 / 12 / 2005$ & 11 & Follheto $16 / 12-24 / 12 / 05$ & & secador de cabelo & Pernambucanas & 24,70 & 24,70 & 189,00 & 9 & 0,83 & Amo Lissima 2 velocidades & - & 189,00 \\
\hline $22 / 12 / 2005$ & A18 & Folha de São Paulo & & secador de cabelo & Extra & 23,50 & & 94,00 & 4 & 0,31 & Taiff Turbo $6000-1700 \mathrm{~W}$ & - & 94,00 \\
\hline $16 / 12 / 2005$ & 10 & Folheto $18 / 12-24 / 12 / 05$ & 10 & aspirador de pó & Pernambucanas & 27,20 & 27,20 & 219,00 & 9 & 0,73 & Electrolux Maxtrio & - & 219,00 \\
\hline $26 / 12 / 2005$ & 4 & Folheto $26 / 12$ - 31/12/05 & 10 & aspirador de pó & Extra & 63,00 & & 189,00 & 3 & 0,83 & Electrolux A10 Smart & - & 189,00 \\
\hline $21 / 12 / 2005$ & $B 8$ & Folha de Săo Paulo & 10 & aspirador de pó & Fast Shop & 166,33 & & 498,00 & 3 & 1,66 & Electrolux Easy Box - $1600 \mathrm{~W}$ & - & 489,00 \\
\hline $21 / 12 / 2005$ & $B 8$ & Folha de São Paulo & 10 & aspirador de pó & Fast Shop & 29,80 & & 298,00 & 10 & 1,00 & Electrolux Max Trio 1600 - 5 niveis de filtragem & - & 289,00 \\
\hline $16 / 12 / 2005$ & 10 & Follheto $16 / 12-24 / 12 / 05$ & 11 & liquidificador & Pernambucanas & 18,00 & 18,00 & 69,90 & 3 & 0,23 & Británia Bellagio V5 - 5 velocidades & - & 69,90 \\
\hline $16 / 12 / 2005$ & 10 & Follheto $16 / 12-24 / 12 / 05$ & 11 & liquidificador & Pernambucanas & 33,27 & 33,27 & 129,00 & 3 & 0,43 & Walita Art com filtro 5 velocidades e pulsar & - & 128,00 \\
\hline $16 / 12 / 2005$ & 11 & Folheto $16 / 12-24 / 12 / 05$ & 11 & liquidificador & Pernambucanas & 10,30 & 10,30 & 39,90 & 3 & 0,13 & Faet Shake 222 copo inquebrável & - & 39,80 \\
\hline $16 / 12 / 2005$ & 11 & Folheto $16 / 12-24 / 12 / 05$ & 11 & liquidificador & Pernambucanas & 27,20 & 27,90 & 108,00 & 3 & 0,36 & Amo Periorma & - & 108,00 \\
\hline $21 / 12 / 2005$ & $\mathrm{BB}$ & Folha de São Paulo & 11 & liquidificador & Fast Shop & 59,98 & & 298,90 & 5 & 1,00 & Westinghouse intelliblend $-425 \mathrm{~W}-5$ velocidades + pulsar & - & 280.90 \\
\hline $16 / 12 / 2005$ & 8 & Follheto $18 / 12-24 / 12 / 05$ & 12 & maq fotográfica & Pernambucanas & 24,20 & 24,20 & 299,00 & 20 & 1,00 & Olympus Infinity 76 automática & - & 289,00 \\
\hline $26 / 12 / 2005$ & 16 & Folhet 26/12/05-04/01/06 & 12 & maq fotográfica & Wal Mart & 6,05 & & 79,87 & 12 & 0,27 & Fuji Crystal 20 & - & 79,87 \\
\hline $26 / 12 / 2005$ & 16 & Folhet $26 / 12 / 05-04 / 01 / 00$ & 12 & maq fotográfica & Wal Mart & 13,25 & & 158,00 & 12 & 0,53 & Olympus Trip 505 & - & 159,00 \\
\hline $16 / 12 / 2005$ & 8 & Folheto $18 / 12-24 / 12 / 05$ & 12,1 & maq fotog digital & Pernambucanas & 56,50 & 56,50 & 698,00 & 20 & 2,33 & Vivitar Vivicam 5,0 megapixel 5105 zoom digital 4x memór & - & 000.00 \\
\hline $16 / 12 / 2005$ & 8 & Follheto $16 / 12-24 / 12 / 05$ & 12,1 & maq fotog digital & Pernambucanas & 40,30 & 40,30 & 498,00 & 20 & 1,66 & Mirage Steel 3.0 megapixels zoom digital $4 x$ memória inter & - & 489,00 \\
\hline $16 / 12 / 2005$ & 9 & Folheto $18 / 12-24 / 12 / 05$ & 12,1 & maq fotog digital & Pernambucanas & 68,60 & 68,60 & 849,00 & 20 & 2,83 & Yashica Classy 5.0 megapixels zoom digital $8 x$ memónia in & - & 849,00 \\
\hline $18 / 12 / 2005$ & 10 & Follheto $18 / 12-24 / 12 / 05$ & 12,1 & maq fotog digital & Ponto Frio & 69,80 & 69,90 & 699,00 & 12 & 2,33 & Kodak C310-4,0 megapixels-zoom digital 5x-memónia $16 \mathrm{NA}$ & - & 609,00 \\
\hline $18 / 12 / 2005$ & 10 & Folheto $18 / 12-24 / 12 / 05$ & 12,1 & maq fotog digital & Ponto Frio & 99,80 & 99,90 & 999,00 & 12 & 3,33 & Pentax OPTIO 50 - 5,0 megapixels-zoom ótico 3x-macro 6 & - & 800,00 \\
\hline $18 / 12 / 2005$ & 10 & Folheto $18 / 12-24 / 12 / 05$ & 12,1 & maq fotog digital & Ponto Frio & 79,80 & 79,90 & 998,00 & 17 & 3,33 & Sony 4,1 megapixels - zoom ótico $3 \mathrm{x}$ memória interna $32 \mathrm{M}$ & - & 980,00 \\
\hline $18 / 12 / 2005$ & 10 & Follheto $18 / 12-24 / 12 / 05$ & 12,1 & maq fotog digital & Ponto Frio & 169,80 & 169,90 & $1.699,00$ & 12 & 5,66 & Sony 5,1 megapixels - soom ótico $3 \mathrm{x}$ memória interna $32 \mathrm{M}$ & - & $1.699,00$ \\
\hline $26 / 12 / 2005$ & 4 & Folheto $28 / 12-31 / 12 / 05$ & 12,1 & maq fotog digital & Extra & 43,20 & & 459,00 & 12 & 1,53 & Mirage Fox $-3,3$ megapixel - zoom ótico $2 x$ & - & 450,00 \\
\hline $26 / 12 / 2005$ & 16 & Folhet 26/12/05-04/01/06 & 12,1 & maq fotog digital & Wal Mart & 566,33 & & $1.699,00$ & & 5,66 & Sony DSCW5 zoom ótico 3x- memória $32 \mathrm{Mb}$ & - & $1.699,00$ \\
\hline
\end{tabular}




\begin{tabular}{|c|c|c|c|c|c|c|c|c|c|c|c|c|c|}
\hline \multicolumn{3}{|c|}{ mês / ano - novembro/dezembro de 2005} & \multicolumn{7}{|c|}{ Salário mínimo em 01.05.2005 - R\$ 300.00} & \multicolumn{4}{|c|}{$\begin{array}{l}\text { pesq. em: Jornais / intemet / encartes distribuidos em lojas e domicilios } \\
\text { data: durante dezembro de } 2005\end{array}$} \\
\hline data & pág. & jomal / mídia consultado & $\begin{array}{c}\text { ood } \\
\text { prod. }\end{array}$ & produto & loja & $\begin{array}{c}\text { prest. à } \\
\text { prazo }\end{array}$ & entrada & preço à vista & $\begin{array}{c}\mathrm{n}^{\circ} \\
\text { parc. }\end{array}$ & $\begin{array}{c}\text { qtd de } \\
\text { SM }\end{array}$ & descriçấo do produto & \begin{tabular}{|l|} 
atual $z$. \\
p/ IPC \\
SP \\
FIPE
\end{tabular} & $\begin{array}{l}\text { atualiz. pl } \\
\text { SM de } 2005\end{array}$ \\
\hline $26 / 12 / 2005$ & 16 & Folhet 26/12/05-04/01/00 & 12,1 & maq fotog digital & Wal Mart & 333,00 & & 999,00 & 3 & 3,33 & Sony DSCS 40 - 4,1 megapixels zoomótioo $3 \mathrm{x}$ - mem inten & - & 809,00 \\
\hline $21 / 12 / 2005$ & $B 6$ & Folha de São Paulo & 12,1 & maq fotog digital & Fast Shop & 833,00 & & $1.899,00$ & 3 & 6,33 & Sony DSC-P200 - 7,2 megapixels - zoom ótico 3x & - & $1.899,00$ \\
\hline $21 / 12 / 2005$ & 86 & Folha de Săo Paulo & 12,1 & maq fotog digital & Fast Shop & 333,00 & & 999,00 & 3 & 3,33 & Sony DSC-S40 - 4,1 megapixels - zoom ótico $3 x$ & - & 909,00 \\
\hline $21 / 12 / 2005$ & $B 6$ & Folha de Săo Paulo & 12,1 & maq fotog digital & Fast Shop & 399,80 & & $1.999,00$ & 5 & 6,66 & Panasonic DMC-FX8PL-S - 5,0 megapixels & - & $1.899,00$ \\
\hline $23 / 12 / 2005$ & B14 & Folha de Săo Paulo & 12,1 & maq fotog digital & Americanas.com & 332,99 & & 999,90 & 3 & 3,33 & Sony DSC-S40 - 4,1 megapixels - zoom ótico $3 x$ & - & 909,80 \\
\hline $16 / 12 / 2005$ & 11 & Follheto $16 / 12-24 / 12 / 05$ & 15 & ventilador & Pernambucanas & 12,80 & 12,90 & 48,90 & 3 & 0,17 & Faet $104830 \mathrm{~cm}$ & - & 49,80 \\
\hline $16 / 12 / 2005$ & 11 & Follheto $16 / 12-24 / 12 / 05$ & 15 & ventilador & Pernambucanas & 16,80 & 16,80 & 64,90 & 3 & 0,22 & Británia Protect $30 \mathrm{~cm}$ & - & 24,90 \\
\hline $23 / 12 / 2005$ & 14 & Follheto $23 / 12$ - 28/12/05 & 15 & ventilador & Camefour & 56,00 & 56,00 & 168,00 & 2 & 0,56 & Amo RF10 hélice repelente $40 \mathrm{~cm}$ & - & 168,00 \\
\hline $16 / 12 / 2005$ & 10 & Follheto $10 / 12-24 / 12 / 05$ & 16 & aatedeira bolo & Pernambucanas & 20,60 & 20,60 & 79,80 & 3 & 0,27 & Británia Bellagio & - & 79,90 \\
\hline $22 / 12 / 2005$ & A18 & Folha de Săo Paulo & 16 & batedeira bolo & Extra & 32,80 & & 328,00 & 10 & 1,10 & Amo Planetária & - & 329,00 \\
\hline $18 / 12 / 2005$ & 1 & Folheto 18/12 - 24/12/105 & 20 & forno microondas & Panto Frio & 48,90 & 48,90 & 488,00 & 11 & 1,63 & Brastemp BMS 27 - 27 litros - $850 \mathrm{~W}$ & - & 489.00 \\
\hline $18 / 12 / 2005$ & 9 & Follheto $18 / 12-24 / 12 / 05$ & 20 & forno microondas & Ponto Frio & 37,80 & 37,90 & 379,00 & 11 & 1,26 & Panasonic NN 545 - $800 \mathrm{~W}$ - 22 Ftros & - & 379,00 \\
\hline $18 / 12 / 2005$ & 8 & Follheto $18 / 12-24 / 12 / 05$ & 20 & forno microondas & Ponto Frio & 52,80 & 52,90 & 529,00 & 11 & 1,76 & Panasonic NN-G55B - $900 \mathrm{~W}-27$ litros & - & 529,00 \\
\hline $18 / 12 / 2005$ & 9 & Follheto $18 / 12-24 / 12 / 05$ & 20 & forno microondas & Ponto Frio & 65,90 & 65,90 & 659,00 & 11 & 2,20 & Brastemp BMG 27 GRILL - $950 \mathrm{~W}$ - 27 litros & - & 659,00 \\
\hline $18 / 12 / 2005$ & 8 & Follheto $18 / 12-24 / 12 / 05$ & 20 & forno microondas & Ponto Frio & 53,80 & 53,90 & 539,00 & 11 & 1,80 & Panasonic NN-S85B - $1000 \mathrm{~W}$ - 35 litros & - & 539,00 \\
\hline $23 / 12 / 2005$ & 14 & Folheto 23/12 - 28/12/05 & 20 & forno microondas & \begin{tabular}{|l|l|} 
Carrefour \\
\end{tabular} & 58,17 & & 349,00 & 6 & 1,16 & Electrolux ME 21S - 21 litros & - & 349,00 \\
\hline $23 / 12 / 2005$ & B14 & \begin{tabular}{|l|l|} 
Folha de Sằo Paulo \\
\end{tabular} & 20 & forno microondas & Americanas.com & 29,08 & & 349,00 & 12 & 1,16 & Panasonic NN-S45B 22 litros & - & 349,00 \\
\hline $22 / 12 / 2005$ & A18 & Folha de Săo Paulo & 20 & forno microondas & Extra & 29,90 & & 299,00 & 10 & 1,00 & sem marca especificada & - & 289,00 \\
\hline $22 / 12 / 2005$ & C11 & Folha de Săo Paulo & 20 & forno microondas & Eletro Outlet Direto & & & 449,00 & & 1,50 & Electrolux ME28 & - & 449,00 \\
\hline $16 / 12 / 2005$ & 9 & Follheto $16 / 12-24 / 12 / 05$ & 22 & camera filmadora & \begin{tabular}{|l|} 
Pernambucanas \\
\end{tabular} & 121,00 & 121,00 & $1.499,00$ & 20 & 5,00 & JVC GR-SXM289UB zoom 25x ótico e 1200x dig tal & - & $1.499,00$ \\
\hline $23 / 12 / 2005$ & 1 & Follheto 23/12 - 28/12/05 & 22 & camera filmadora & Camrefour & 566,33 & 566,33 & $1.699,00$ & 2 & 5,66 & Sony TRV138 Night Shot Plus & - & $1.699,00$ \\
\hline $18 / 12 / 2005$ & 7 & Folheto $18 / 12-24 / 12 / 05$ & 22,1 & camera film digital & Ponto Frio & 270,00 & & 899,00 & 12 & 9,00 & Sony DCR-DVD 92 digital zoom ótioo 20x / digital $800 \mathrm{x}$ nig & - & $2.609,00$ \\
\hline $26 / 12 / 2005$ & 16 & Folhet 26/12/05-04/01/06 & 22,1 & camera film digital & Wal Mart & 599,83 & & $3.599,00$ & 6 & 12,00 & Sony DCR-DVD 203 digital zoom ótioo $12 \mathrm{x} /$ digital $480 \mathrm{x}$ ni & - & $3.599,00$ \\
\hline $21 / 12 / 2005$ & $B 6$ & \begin{tabular}{|l|l} 
Folha de Săo Paulo \\
\end{tabular} & 22,1 & camera film digital & Fast Shop & 449,83 & & $2.699,00$ & 6 & 9,00 & Sony DCR -HC43 zoom ótico $12 \mathrm{x}$ & - & $2.699,00$ \\
\hline $21 / 12 / 2005$ & $B 6$ & Folha de Săo Paulo & 22,1 & camera film digital & Fast Shop & 599,83 & & $3.599,00$ & 6 & 12,00 & Sony DSC-DVD203 - grava em DVD & - & $3.599,00$ \\
\hline $21 / 12 / 2005$ & $B 6$ & Folha de Săo Paulo & 22,1 & camera film digital & Fast Shop & 799,80 & & $3.999,00$ & 5 & 13,33 & JVC GZ-MG2O - HD 20Gb & - & $3.899,00$ \\
\hline $16 / 12 / 2005$ & 8 & Follheto $10 / 12-24 / 12 / 05$ & 23 & forno microondas & Pernambucanas & 33,20 & 33,90 & 419,00 & 20 & 1,40 & Panasonic NN-S 55B - 28 litros & - & 418,00 \\
\hline $16 / 12 / 2005$ & 8 & Folheto $16 / 12-24 / 12 / 05$ & 23 & forno microondas & Pernambucanas & 35,20 & 35,90 & 445.00 & 20 & 1,48 & Electrolux ME $28 \mathrm{~S}-28$ litros & - & 445,00 \\
\hline $16 / 12 / 2005$ & 8 & Folheto $16 / 12-24 / 12 / 05$ & 25 & lavadora tanquinho & Pernambucanas & 40 & 15,40 & 190,00 & 20 & 0,83 & Iracema Top Cleaness & - & 180,00 \\
\hline $16 / 12 / 2005$ & 8 & Folheto $16 / 12-24 / 12 / 05$ & 25 & lavadora tanquinho & Pernambucanas & 22,50 & 22,50 & 279,00 & 20 & 0,93 & Colormaq Style & - & 279,00 \\
\hline $26 / 12 / 2005$ & 4 & Folheto $28 / 12-31 / 12 / 05$ & 25 & lavadora tanquinho & Extra & 17,50 & & 179.00 & 12 & 0,60 & Lav Star & - & 179,00 \\
\hline $16 / 12 / 2005$ & 10 & Folheto $18 / 12-24 / 12 / 05$ & 26 & cafeteira elétrica & Pernambucanas & 12,88 & 12,88 & 49,80 & 3 & 0,17 & NKS TSK200 12 xicaras & - & 49,90 \\
\hline $16 / 12 / 2005$ & 10 & Follheto $16 / 12-24 / 12 / 05$ & 27 & torradeira de pão & Pernambucanas & 10,30 & 10,30 & 39,80 & 3 & 0,13 & NKS TOR927 & - & 39,90 \\
\hline $22 / 12 / 2005$ & A18 & \begin{tabular}{|l|} 
Folha de Sắo Paulo \\
\end{tabular} & 27 & torradeira de pão & Extra & 9,80 & & 29,70 & 3 & 0,10 & Home Leader & - & 29,70 \\
\hline $21 / 12 / 2005$ & $\mathrm{BB}$ & Folha de Săo Paulo & 30 & espremedor frutas & Fast Shop & 21,80 & & 109,00 & 5 & 0,36 & Electrolux Chef Jiuce $500 \mathrm{ml}$ suoolmin - $200 \mathrm{~W}$ & - & 100,00 \\
\hline $16 / 12 / 2005$ & encarte & Folha de Săo Paulo & 32 & lava louça maq & Casas Bahia & 221,37 & & 3.679 .00 & 24 & 12,26 & Electrolux ESX61 - 5 programas 12 serviços & - & $3.679,00$ \\
\hline $18 / 12 / 2005$ & 8 & Follheto 18/12 - 24/12/05 & 32 & lava louça maq & Ponto Frio & 149,80 & 149,90 & $1.499,00$ & 11 & 5,00 & Brastemp BLE 20B 6 programas & - & $1.498,00$ \\
\hline $23 / 12 / 2005$ & 14 & Folheto $23 / 12-28 / 12 / 05$ & 32 & lava louça maq & Carrefour & 134,20 & & $1.349,00$ & 12 & 4,50 & Brastemp BLE 20B 6 programas & - & $1.349,00$ \\
\hline $16 / 12 / 2005$ & 8 & Folheto $18 / 12-24 / 12 / 05$ & 33 & forno elétrico & Pernambucanas & 27,40 & 27,40 & 339,00 & 20 & 1,13 & Fischer Gril Star - 44 Itros & - & 339,00 \\
\hline
\end{tabular}




\begin{tabular}{|c|c|c|c|c|c|c|c|c|c|c|c|c|c|}
\hline mês / ano-r & novembr & aldezembro de 2005 & salánio & mínimo em 01.05 & $005-R \$ 300,00$ & & & & & pesq. e & m: Jornais / intemet / encartes distribuídos em lojas & & \\
\hline produto - div & ersos & & & & & & & & & data: d. & urante dezembro de 2005 & & \\
\hline data & pág. & jomal / mícia consultado & \begin{tabular}{|c|} 
\\
pod \\
prod.
\end{tabular} & produto & boja & $\begin{array}{c}\text { prest. à } \\
\text { prazo }\end{array}$ & entrada & preço à vista & $\begin{array}{c}\mathrm{n}^{\circ} \\
\text { parc. }\end{array}$ & $\begin{array}{l}\text { qtd de } \\
\text { SM }\end{array}$ & descriçấo do produto & $\begin{array}{c}\text { atualz. } \\
\text { p/ IPC- } \\
\text { SP } \\
\text { FIPE }\end{array}$ & $\begin{array}{c}\text { atualiz. pl } \\
\text { SM de } 2006\end{array}$ \\
\hline $16 / 12 / 2005$ & 8 & Follheto $18 / 12-24 / 12 / 05$ & 34 & ar condicionado & Pernambucanas & 64,50 & 64,50 & 799,00 & 20 & 2,66 & LG 7500 BTU/h frio & - & 789,00 \\
\hline $16 / 12 / 2005$ & 8 & Folheto $18 / 12-24 / 12 / 05$ & 34 & ar condicionado & Pernambucanas & 69,30 & 69,30 & 859,00 & 20 & 2,86 & LG 7500 BTU/h quente e frio & - & 859,00 \\
\hline $16 / 12 / 2005$ & 3 & Folheto $18 / 12-24 / 12 / 05$ & 36 & DVD & Pernambucanas & 28,80 & 28,90 & 358,00 & 20 & 1,19 & Phips DVP 3005 & - & 358,00 \\
\hline $16 / 12 / 2005$ & 3 & Folheto $18 / 12-24 / 12 / 05$ & 36 & DVD & Pernambucanas & 17,70 & 17,70 & 219,00 & 20 & 0,73 & Lenoxx DV-401 & - & 219,00 \\
\hline $16 / 12 / 2005$ & 3 & Follheto 16/12 - 24/12/05 & 36 & DVD & Pernambucanas & 26,50 & 26,50 & 328,00 & 20 & 1,10 & Panasonic S29LB-S & - & 329,00 \\
\hline $16 / 12 / 2005$ & 3 & Folheto $10 / 12$ - 24/12/05 & 36 & DVD & Pernambucanas & 28,80 & 28,90 & 358,00 & 20 & 1,19 & LG DZ 9311N & - & 358,00 \\
\hline $16 / 12 / 2005$ & 3 & Follheto $16 / 12-24 / 12 / 05$ & 36 & DVD & Pernambucanas & 28,80 & 28,80 & 358,00 & 20 & 1,19 & Sony DVP-NS50P & - & 358,00 \\
\hline $16 / 12 / 2005$ & 3 & Follheto $18 / 12-24 / 12 / 05$ & 36 & DVD & Pernambucanas & 32,20 & 32,20 & 398,00 & 20 & 1,33 & $\mathrm{Ph}^{-1}$ ps DVP $3005 \mathrm{~K}$ & - & 389,00 \\
\hline $16 / 12 / 2005$ & 3 & Follheto $10 / 12$ - 24/12/05 & 36 & DVD & Pernambucanas & 32,20 & 32,20 & 399,00 & 20 & 1,33 & Tec Toy Karaokê DVT-F500 & - & 389,00 \\
\hline $16 / 12 / 2005$ & 3 & Folheto $16 / 12-24 / 12 / 05$ & 36 & DVD & Pernambucanas & 48,35 & 48,35 & 599,00 & 20 & 2,00 & Samsung V5500 inclui video cassete of 4 cabeças & - & 580,00 \\
\hline $16 / 12 / 2005$ & encarte & Follha de Săo Paulo & 36 & DVD & Casas Bahia & 19,50 & & 329,00 & 24 & 1,10 & Panasonic S29LB-S & - & 329,00 \\
\hline $18 / 12 / 2005$ & 3 & Follheto $18 / 12-24 / 12 / 05$ & 36 & DVD & Ponto Frio & 35,80 & 35,90 & 358,00 & 14 & 1,19 & LG DZ 9311 & - & 358,00 \\
\hline $18 / 12 / 2005$ & 7 & Folheto $18 / 12-24 / 12 / 05$ & 36 & DVD & Ponto Frio & 35,21 & 35,81 & 359,00 & 14 & 1,20 & Sony NS20-P & - & 359,00 \\
\hline $18 / 12 / 2005$ & 8 & Follheto 18/12 - 24/12/05 & 36 & DVD & Ponto Frio & 30,80 & 30,80 & 309,00 & 12 & 1,03 & CCE 4500X & - & 300,00 \\
\hline $10 / 12 / 2005$ & 2 & Folheto 10/12 - 25/12/05 & 36 & DVD & BestMix & 35,80 & & 359,00 & 10 & 1,20 & LG DVD 9311 & - & 350,00 \\
\hline $20 / 12 / 2005$ & $A 8$ & O Estado de São Paulo & 36 & DVD & Casas Bahia & 27,80 & & 359,00 & 24 & 1,20 & Sony DVP-NS31P & - & 359,00 \\
\hline $23 / 12 / 2005$ & A10 & O Estado de São Paulo & 36 & DVD & Casas Bahia & 28,80 & & 329,00 & 18 & 1,10 & Panasonic 528BL-S & - & 329,00 \\
\hline 23/12/2005 & B14 & Folha de Săo Paulo & 36 & DVD & Americanas.com & 21,58 & & 259,00 & 12 & 0,86 & Phīps DVP4000BK portátil & - & 250,00 \\
\hline $23 / 12 / 2005$ & $B 8$ & Folha de Săo Paulo & 36 & DVD & Casas Bahia & 19,80 & & 229,00 & 18 & 0,76 & Britânia Slim & - & 228,00 \\
\hline $22 / 12 / 2005$ & D4 & Folha de São Paulo & 36 & DVD & Panashop & 27,90 & & 279,00 & 10 & 0,83 & Phīps DVP4000BK portátil & - & 279,00 \\
\hline $22 / 12 / 2005$ & C11 & Folha de Săo Paulo & 36 & DVD & Eletro Outlet Direto & & & 359,00 & & 1,20 & Sony DVD NS50P & - & 350,00 \\
\hline $22 / 12 / 2005$ & C11 & Folha de Săo Paulo & 36 & DVD & Eletro Outlet Direto & & & 339,00 & & 1,13 & Panasonic S 29 & - & 339,00 \\
\hline $16 / 12 / 2005$ & 3 & Follheto $18 / 12-24 / 12 / 05$ & 36,1 & gravador DVD & Pernambucanas & 80,60 & 80,60 & 999,00 & 20 & 3,33 & LG DR7621B & - & 980,00 \\
\hline $18 / 12 / 2005$ & 3 & Folheto $18 / 12-24 / 12 / 05$ & 36,1 & gravador DVD & Ponto Frio & 99,80 & & 998,00 & 12 & 3,33 & LG DR7621B & - & 988,00 \\
\hline $18 / 12 / 2005$ & 4 & Folheto $18 / 12-24 / 12 / 05$ & 36,1 & gravador DVD & Ponto Frio & 34,20 & 34,20 & 358,00 & 14 & 1,18 & Phips 3005 & - & 358,00 \\
\hline $17 / 12 / 2005$ & 1 & Folheto $17 / 12-24 / 12 / 05$ & 36,1 & gravador DVD & FNAC & 83,00 & & 996,00 & 12 & 3,32 & Panasonic DMR ES 10 PLS & - & 886,00 \\
\hline $24 / 12 / 2005$ & A11 & O Estado de São Paulo & 36,1 & gravador DVD & Casas Bahia & 75,00 & & 999,00 & 24 & 3,33 & DVD-R121/XA2 & - & 809,00 \\
\hline
\end{tabular}




\section{APÊNDICE 3 - Resultados das análises de correlação da difusão}

Neste anexo estão os resultados dos estudos de correlação entre diferentes produtos e também entre classes de renda de domicílios no Brasil. A análise utilizou o software SPSS versão 11.0. Os dados foram reunidos em 19 períodos para os seguintes itens: geladeira, aparelhos de rádio, televisores, filtros de água e canalização interna de água, e apresentam 15 graus de liberdade. Quanto ao freezer o estudo analisou 15 períodos e apresentam 13 graus de liberdade. Foi analisada a correlação de Pearson para duas regiões de rejeição (2 tailed test) e os resultados foram verificados em relação a significância da correlação pela aplicação do Método de Bonferroni, evitando assim a introdução de erros tipo I nas conclusões. (Kreiszig, 1970; Berenson e Levine, 1999; Green e Salkind, 2003; Walld, 2003) ${ }^{1}$. Deve-se notar que na área de ciências sociais níveis de correlação 0,10; 0,30 e 0,50 (independente do sinal) são convencionados como pequena, média e grande correlação. (Green e Salkind, 2003).

${ }^{1}$ O método de Bonferroni é bastante simples, mas é criticado por alguns como muito conservador podendo levar a erros do tipo II. (Walld, 2003) 
Tabela A3.1 - Correlações no processo de difusão de diferentes inovações nos domicílios particulares permanentes no Brasil. Correlação entre diferentes produtos e sua difusão no Brasil

Correlations

\begin{tabular}{|c|c|c|c|c|c|c|}
\hline & & geladeira total & $\begin{array}{l}\text { filtro agua } \\
\text { total }\end{array}$ & radio total & TV total & $\begin{array}{c}\text { canal } \\
\text { agua total }\end{array}$ \\
\hline \multirow[t]{3}{*}{ geladeira total } & Pearson Correlation & 1 &, $664^{\text {*x }}$ &, $943^{\text {*x }}$ &, $995^{\star \star}$ &, $985^{*}$ \\
\hline & Sig. (2-tailed) & &, 002 &, 000 &, 000 &, 000 \\
\hline & $\mathrm{N}$ & 19 & 19 & 19 & 19 & 19 \\
\hline \multirow[t]{3}{*}{ filtro agua total } & Pearson Correlation & $664^{\star 1}$ & 1 & $707^{\text {*x/ }}$ & $690^{\star \star *}$ & $723^{\star}$ \\
\hline & Sig. (2-tailed) & ,002 & &, 001 &, 001 &, 000 \\
\hline & $\mathrm{N}$ & 19 & 19 & 19 & 19 & 19 \\
\hline \multirow[t]{3}{*}{ radio total } & Pearson Correlation &, $943^{\star 1}$ & $707^{* \times}$ & 1 & $961^{\text {k* }}$ & $943^{\star \prime}$ \\
\hline & Sig. (2-tailed) &, 000 &, 001 & , &, 000 &, 000 \\
\hline & $\mathrm{N}$ & 19 & 19 & 19 & 19 & 19 \\
\hline \multirow[t]{3}{*}{ TV total } & Pearson Correlation & ,995** & $690 * x$ & $961^{* *}$ & 1 & $985^{\star}$ \\
\hline & Sig. (2-tailed) & 000 & ,001 & 000 & , &, 000 \\
\hline & $\mathrm{N}$ & 19 & 19 & 19 & 19 & 19 \\
\hline \multirow[t]{3}{*}{ canal agua total } & Pearson Correlation &, $985^{\star *}$ & $723^{* \times x}$ & $943^{\star * x}$ & $985^{\star \star}$ & 1 \\
\hline & Sig. (2-tailed) & 000 & 000 & 000 & 000 & \\
\hline & $\mathrm{N}$ & 19 & 19 & 19 & 19 & 19 \\
\hline
\end{tabular}

${ }^{* \star}$. Correlation is significant at the 0.01 level (2-tailed).

Há correlação no processo de difusão no Brasil dos diversos itens pesquisados, mostrando-se menor entre filtros de água e os demais itens e bastante intensa entre os outros quatro. A aplicação do método de Bonferroni, entretanto mostra que para a correlação da difusão de filtros de água e geladeiras, assim como televisores e filtros de água é menor e pode não existir, pois os níveis de significância p observados são respectivamente: 0,0019521 e 0,0010675. 
Tabela A3.2 - Correlações no processo de difusão de geladeiras nos domicílios particulares permanentes no Brasil pelas diferentes classes de renda.

\section{Correlações entre total de geladeiras no Brasil e nas diferentes classes de renda}

\section{Correlations}

\begin{tabular}{|c|c|c|c|c|c|c|c|}
\hline & & $\begin{array}{l}\text { geladeira } \\
\text { até } 1 \mathrm{SM}\end{array}$ & $\begin{array}{c}\text { geladeira } \\
1<\mathrm{SM}<2\end{array}$ & $\begin{array}{l}\text { geladeira } \\
2<S M<5\end{array}$ & $\begin{array}{l}\text { geladeira } \\
5<S M<10\end{array}$ & $\begin{array}{c}\text { geladeira } \\
>10 S M\end{array}$ & geladeira total \\
\hline \multirow[t]{3}{*}{ geladeira ate $15 \mathrm{M}$} & Pearson Correlation & 1 &, $990^{* 2}$ &, $952^{\mathrm{m}}$ &, $905^{*-1}$ &, $764^{\star x}$ &, $926^{*}$ \\
\hline & Sig. (2-tailed) & &, 000 &, 000 &, 000 &, 000 &, 000 \\
\hline & $\mathrm{N}$ & 19 & 19 & 19 & 19 & 19 & 19 \\
\hline \multirow[t]{3}{*}{ geladeira $1<\mathrm{SM}<2$} & Pearson Correlation & $990^{* *}$ & 1 & ,968*0. & $914^{* 2}$ & $768^{*}$ & $915^{*}$ \\
\hline & Sig. (2-tailed) &, 000 & , &, 000 &, 000 &, 000 & 000 \\
\hline & $\mathrm{N}$ & 19 & 19 & 19 & 19 & 19 & 19 \\
\hline \multirow[t]{3}{*}{ geladeira $2<5 M<5$} & Pearson Correlation & $952^{* *}$ & $968^{* 2}$ & 1 & $977^{* 2}$ & $863^{\star * 3}$ & $936^{*}$ \\
\hline & Sig. (2-tailed) &, 000 &, 000 & , &, 000 &, 000 &, 000 \\
\hline & $\mathrm{N}$ & 19 & 19 & 19 & 19 & 19 & 19 \\
\hline \multirow[t]{3}{*}{ geladeira $5<\mathrm{SM}<10$} & Pearson Correlation &, $905^{* *}$ & $914^{* 2}$ &, $977^{* 2}$ & 1 &, $939^{* *}$ & $957^{*}$ \\
\hline & Sig. (2-tailed) &, 000 &, 000 &, 000 & , &, 000 &, 000 \\
\hline & $\mathrm{N}$ & 19 & 19 & 19 & 19 & 19 & 19 \\
\hline \multirow[t]{3}{*}{ geladeira $>10 S M$} & Pearson Correlation & $764^{* *}$ & $768^{* 2}$ & $863^{*=}$ & $939 *-1$ & 1 &, $925^{\star}$ \\
\hline & Sig. (2-tailed) &, 000 &, 000 &, 000 &, 000 & , &, 000 \\
\hline & $\mathrm{N}$ & 19 & 19 & 19 & 19 & 19 & 19 \\
\hline \multirow[t]{3}{*}{ geladeira total } & Pearson Correlation & $926^{* *}$ & $915^{* * 1}$ & $936^{*-1}$ & $957^{*-1}$ & $925 *$ & 1 \\
\hline & Sig. (2-tailed) &, 000 &, 000 &, 000 &, 000 &, 000 & , \\
\hline & $\mathrm{N}$ & 19 & 19 & 19 & 19 & 19 & 19 \\
\hline
\end{tabular}

$* *$. Correlation is significant at the 0.01 level (2-tailed)

É forte a correlação ocorrida no processo de difusão de geladeiras entre as diversas classes de renda nos domicílios brasileiros, exceção feita a relação entre classes de renda até 1 SM (salários mínimos vigentes) e de 1 até 2 SM em relação à classe de mais de 10 SM. 
Tabela A3.3 - Correlações no processo de difusão de filtros de água nos domicílios particulares permanentes no Brasil pelas diferentes classes de renda.

\section{Correlações entre filtro de água total no Brasil e nas diferentes classes de renda}

Correlations

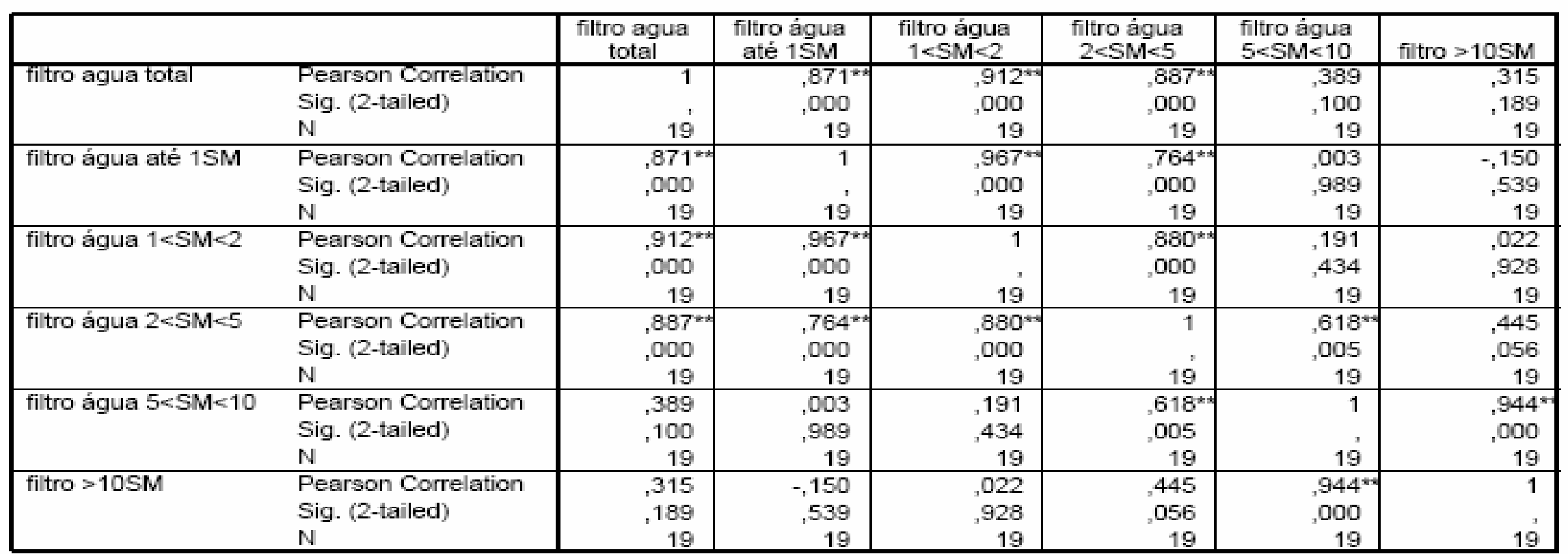

$* *$. Correlation is significant at the 0.01 level (2-tailed).

No caso de filtros de água o processo de difusão apresenta certa diferença em relação aos padrões esperados, pois as diferentes classes de renda diferem entre si de forma significativa, sendo possível dividi-las em dois grandes grupos: até 5 SM e acima de 5 SM. A faixa de renda acima de 10 SM somente mostra correlação para a faixa imediatamente inferior (5 a 10 SM) e esta também somente mostra correlação com a classe imediatamente inferior (2 a $5 \mathrm{SM}$ ). As três classes inferiores de renda mantém correlação entre si, apesar de um grau de correlação mais moderado entre a faixa (2 a 5 SM) e até 1 SM (correlação 0,764 e p = 0,0001380). 
Tabela A3.4 - Correlações no processo de difusão de aparelhos de rádio nos domicílios particulares permanentes no Brasil pelas diferentes classes de renda.

\section{Correlação entre aparelhos de rádio no Brasil e nas diferentes classes de renda}

\section{Correlations}

\begin{tabular}{|c|c|c|c|c|c|c|c|}
\hline & & radio total & rádio até $1 S M$ & rádio $1<S M<2$ & rádio $2<\mathrm{SM}<5$ & $\begin{array}{c}\text { rádio } \\
5<S M<10\end{array}$ & rádio $>10 S M$ \\
\hline \multirow[t]{3}{*}{ radio total } & Pearson Correlation & 1 &, $929^{* x}$ &, $908^{x-2}$ &, $934^{* 2}$ &, $933^{\star x}$ &, $917^{\star}$ \\
\hline & Sig. (2-tailed) & &, 000 &, 000 &, 000 &, 000 &, 000 \\
\hline & $N$ & 19 & 19 & 19 & 19 & 19 & 19 \\
\hline \multirow[t]{3}{*}{ rádio até $1 S M$} & Pearson Correlation &, $929 \times$ & 1 & $981^{* 2 \times 3}$ & $945^{* 2}$ & $887^{\star *}$ &, $743^{*}$ \\
\hline & Sig. (2-tailed) &, 000 & , &, 000 &, 000 &, 000 &, 000 \\
\hline & $\mathrm{N}$ & 19 & 19 & 19 & 19 & 19 & 19 \\
\hline \multirow[t]{3}{*}{ rádio $1<\mathrm{SM}<2$} & Pearson Correlation &, $908^{*-1}$ & $981^{* *}$ & 1 & $973^{* 2}$ & $927^{\star *}$ & $749^{*}$ \\
\hline & Sig. (2-tailed) &, 000 &, 000 & , &, 000 &, 000 &, 000 \\
\hline & $\mathrm{N}$ & 19 & 19 & 19 & 19 & 19 & 19 \\
\hline \multirow[t]{3}{*}{ rádio $2<\mathrm{SM}<5$} & Pearson Correlation &, $934^{*-4}$ & $945^{* *}$ & $973^{* * 2}$ & 1 & $977^{\star *}$ & $837^{*}$ \\
\hline & Sig. (2-tailed) &, 000 &, 000 &, 000 & ， &, 000 &, 000 \\
\hline & $\mathrm{N}$ & 19 & 19 & 19 & 19 & 19 & 19 \\
\hline \multirow[t]{3}{*}{ rádio $5<S M<10$} & Pearson Correlation &, $933^{*-4}$ & $887^{* * 2}$ & $927^{* * 2}$ & $977^{* * 2}$ & 1 &, $913^{*}$ \\
\hline & Sig. (2-tailed) &, 000 &, 000 &, 000 &, 000 & , &, 000 \\
\hline & $\mathrm{N}$ & 19 & 19 & 19 & 19 & 19 & 19 \\
\hline \multirow[t]{3}{*}{ rádio $>10 \mathrm{SM}$} & Pearson Correlation & $917^{*-1}$ &, $743^{* *}$ & $749^{*=1}$ & $837^{* * 2}$ &, $913^{\star x}$ & 1 \\
\hline & Sig. (2-tailed) &, 000 &, 000 &, 000 &, 000 &, 000 & , \\
\hline & $\mathrm{N}$ & 19 & 19 & 19 & 19 & 19 & 19 \\
\hline
\end{tabular}

**. Correlation is significant at the 0.01 level (2-tailed).

Neste caso há forte correlação no processo de difusão nas diferentes classes de renda, apesar da diminuição a medida que se distanciam as classes de renda (classe de renda 10 SM para até 1 SM - correlação 0,743 e p = 0,0002680 e 10 SM para classe de renda entre 2 a 5 SM - correlação 0, 749 e p = 0,0002239 para um valor de 0,000833 de acordo com o método de Bonferroni). Isso reforça a proposta de diferentes comportamentos de difusão entre diferentes classes de renda. 
Tabela A3.5 - Correlações no processo de difusão de televisores nos domicílios particulares permanentes no Brasil pelas diferentes classes de renda.

Correlações entre total de televisores no Brasil e nas diferentes classes de renda

\section{Correlations}

\begin{tabular}{|c|c|c|c|c|c|c|c|}
\hline & & TV total & TV até 1SM & $\mathrm{TV} 1<\mathrm{SM}<2$ & TV $2<\mathrm{SM}<5$ & TV $5<S M<10$ & TV $>10 S M$ \\
\hline \multirow[t]{3}{*}{ TV total } & Pearson Correlation & 1 &, $927^{\star \star x}$ &, $946^{* m}$ &, $970^{* x}$ &, $982^{* \pi}$ &, $962^{\star}$ \\
\hline & Sig. (2-tailed) & &, 000 &, 000 &, 000 &, 000 &, 000 \\
\hline & $\mathrm{N}$ & 19 & 19 & 19 & 19 & 19 & 19 \\
\hline \multirow[t]{3}{*}{ TV até $1 S M$} & Pearson Correlation & $927^{*}$ & 1 & $993^{* 4}$ & $964 * *$ & $927^{\star *}$ & $810^{\star}$ \\
\hline & Sig. (2-tailed) & 000 & & 000 & 000 & 000 & 000 \\
\hline & $\mathrm{N}$ & 19 & 19 & 19 & 19 & 19 & 19 \\
\hline \multirow[t]{3}{*}{$\mathrm{TV} 1<\mathrm{SM}<2$} & Pearson Correlation & $946^{*}$ & $993^{* x}$ & 1 & $986^{* *}$ & $956^{\star *}$ & $853^{\star}$ \\
\hline & Sig. (2-tailed) &, 000 &, 000 & &, 000 &, 000 &, 000 \\
\hline & $\mathrm{N}$ & 19 & 19 & 19 & 19 & 19 & 19 \\
\hline \multirow[t]{3}{*}{$\mathrm{TV} 2<\mathrm{SM}<5$} & Pearson Correlation & $970 *$ & $964 * 2$ & $986^{*}$ & 1 & $986^{\star}$ & $916^{\star}$ \\
\hline & Sig. (2-tailed) & 000 & 000 & 000 & & 000 & 000 \\
\hline & $\mathrm{N}$ & 19 & 19 & 19 & 19 & 19 & 19 \\
\hline \multirow[t]{3}{*}{ TV $5<S M<10$} & Pearson Correlation & $982^{* 1}$ & $927^{* *}$ & $956^{*}$ & $986^{* *}$ & 1 & $961^{\star}$ \\
\hline & Sig. (2-tailed) &, 000 &, 000 &, 000 &, 000 & &, 000 \\
\hline & $\mathrm{N}$ & 19 & 19 & 19 & 19 & 19 & 19 \\
\hline \multirow[t]{3}{*}{ TV $>10 S M$} & Pearson Correlation & $962^{*}$ & $810^{* 2}$ & $853^{* 4}$ & $916^{* *}$ & $961^{\star \star}$ & 1 \\
\hline & Sig. (2-tailed) &, 000 &, 000 &, 000 &, 000 &, 000 & \\
\hline & $\mathrm{N}$ & 19 & 19 & 19 & 19 & 19 & 19 \\
\hline
\end{tabular}

**. Correlation is significant at the 0.01 level (2-tailed).

Nota-se que a classe de renda acima de 10 SM apresenta um comportamento diferenciado, pois apresenta correlação mais forte com a classe de renda imediatamente inferior; reduzindo pouco em relação às demais classes de renda. Entretanto todas estão fortemente correlacionadas. 
Tabela A3.6 - Correlações no processo de difusão de canalização interna de água nos domicílios particulares permanentes no Brasil pelas diferentes classes de renda.

\section{Correlação entre canalização interna de água no Brasil e nas diferentes classes de renda}

\section{Correlations}

\begin{tabular}{|c|c|c|c|c|c|c|c|}
\hline & & $\begin{array}{c}\text { canal } \\
\text { agua total }\end{array}$ & $\begin{array}{c}\text { canal água } \\
\text { até } 1 \mathrm{SM}\end{array}$ & $\begin{array}{c}\text { canal águaa } \\
1<\mathrm{SM}<2 \\
\end{array}$ & $\begin{array}{c}\text { canal água } \\
2<\mathrm{SM}<5 \\
\end{array}$ & $\begin{array}{c}\text { canal água } \\
5<\mathrm{SM}<10\end{array}$ & $\begin{array}{l}\text { canal água } \\
>10 \mathrm{SM}\end{array}$ \\
\hline \multirow[t]{3}{*}{ canal agua total } & Pearson Correlation & 1 &, $934^{\text {* }}$ &, $919^{\text {*2x }}$ &, $949^{* 12}$ &, $973^{\text {축 }}$ &, $958^{\circ}$ \\
\hline & Sig. (2-tailed) & &, 000 &, 000 &, 000 &, 000 &, 000 \\
\hline & $\mathrm{N}$ & 19 & 19 & 19 & 19 & 19 & 19 \\
\hline \multirow[t]{3}{*}{ canal água até $1 S M$} & Pearson Correlation &, $934 *=$ & 1 &, $989 * 2$ & $971^{* * 1}$ &, $894^{* 2}$ & $831^{*}$ \\
\hline & Sig. (2-tailed) &, 000 & &, 000 &, 000 &, 000 & 000 \\
\hline & $\mathrm{N}$ & 19 & 19 & 19 & 19 & 19 & 19 \\
\hline \multirow[t]{3}{*}{ canal água $1<\mathrm{SM}<2$} & Pearson Correlation &, $919^{*-1}$ &, $989 *$ & 1 & $985^{* * 2}$ & $899^{* * 2}$ & $828^{*}$ \\
\hline & Sig. (2-tailed) &, 000 &, 000 & 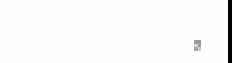 &, 000 &, 000 &, 000 \\
\hline & $\mathrm{N}$ & 19 & 19 & 19 & 19 & 19 & 19 \\
\hline \multirow[t]{3}{*}{ canal água $2<\mathrm{SM}<5$} & Pearson Correlation &, $949 *$ & $971^{*=1}$ & $985^{\star *}$ & 1 & $950 *$ & ,894* \\
\hline & Sig. (2-tailed) &, 000 &, 000 &, 000 & , &, 000 &, 000 \\
\hline & $\mathrm{N}$ & 19 & 19 & 19 & 19 & 19 & 19 \\
\hline \multirow[t]{3}{*}{ canal água $5<\mathrm{SM}<10$} & Pearson Correlation & $973^{* 4}$ &, $894^{*-1}$ & $899^{\star *}$ &, $950 * 1$ & 1 & $987^{*}$ \\
\hline & Sig. (2-tailed) &, 000 &, 000 & 000 &, 000 & , & 000 \\
\hline & $\mathrm{N}$ & 19 & 19 & 19 & 19 & 19 & 19 \\
\hline \multirow[t]{3}{*}{ canal água >10SM } & Pearson Correlation &, $958^{*-1}$ &, $831^{*-1}$ & $828^{\star 2}$ & $894^{* 2}$ & $987^{* * 2}$ & 1 \\
\hline & Sig. (2-tailed) & , 000 &, 000 &, 000 &, 000 &, 000 & , \\
\hline & $\mathrm{N}$ & 19 & 19 & 19 & 19 & 19 & 19 \\
\hline
\end{tabular}

**. Correlation is significant at the 0.01 level (2-tailed).

Neste caso todas as camadas apresentam forte correlação entre si, mostrando um processo que parece ser de difusão misto. 
Tabela A3.7 - Correlações no processo de difusão de freezer nos domicílios particulares permanentes no Brasil pelas diferentes classes de renda. Correlaçäo do freezer no Brasil e nas diferentes classes de renda

\section{Correlations}

\begin{tabular}{|c|c|c|c|c|c|c|c|}
\hline & & fineezer total & $\begin{array}{l}\text { freezer } \\
\text { até } 1 \mathrm{SM}\end{array}$ & $\begin{array}{l}\text { freezer } \\
1<5 M<2\end{array}$ & $\begin{array}{c}\text { freezer } \\
2<5 M<5\end{array}$ & $\begin{array}{c}\text { freezer } \\
5<5 \mathrm{~S}<10\end{array}$ & fineezer $>105 \mathrm{M}$ \\
\hline \multirow[t]{3}{*}{ freezer total } & Pearson Conrelation & 1 & $872^{\pi}$ & $825^{*}$ & $833^{\mathrm{m}}$ & a00 & $865^{\pi}$ \\
\hline & Sig. (2-tailed) & . & 000 & 000 & 000 & .000 & 000 \\
\hline & $\mathrm{N}$ & 15 & 15 & 15 & 15 & 15 & 15 \\
\hline \multirow[t]{3}{*}{ freezer até $1 \mathrm{SM}$} & Pearson Comrelation & $872^{-3}$ & 1 & $87 a^{3=}$ & $866^{m}$ & $924=$ & $837^{3}$ \\
\hline & Sig. (2-tailed) & 000 & . & 000 & 000 & .000 & 000 \\
\hline & $\mathrm{N}$ & 15 & 15 & 15 & 15 & 15 & 15 \\
\hline \multirow[t]{3}{*}{ freezer $1<S M<2$} & Pearson Comrelation & $825^{*}$ & $978^{\text {Na }}$ & 1 & $984^{x}$ & $949=$ & $825^{x}$ \\
\hline & Sig. (2-tailed) & 000 & 000 & 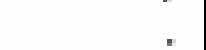 & 000 & 000 & 000 \\
\hline & $\mathrm{N}$ & 15 & 15 & 15 & 15 & 15 & 15 \\
\hline \multirow[t]{3}{*}{ freezer $2<S M<5$} & Pearson Comelation & $833^{*}$ & $966^{-10}$ & $884^{*}$ & 1 & 982 & $873^{3}$ \\
\hline & Sig. (2-tailed) & 000 & 000 & 000 & & .000 & 000 \\
\hline & $\mathrm{N}$ & 15 & 15 & 15 & 15 & 15 & 15 \\
\hline \multirow[t]{3}{*}{ freezer $5<5 M<10$} & Pearson Conrelation & $808^{2}$ & $924^{\text {*n }}$ & $849^{-2}$ & $082^{20}$ & 1 & $025^{m}$ \\
\hline & Sig. (2-tailed) & 000 & 000 & 000 & 000 & 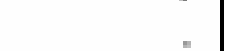 & 000 \\
\hline & $\mathrm{N}$ & 15 & 15 & 15 & 15 & 15 & 15 \\
\hline \multirow[t]{2}{*}{ freezer >10SM } & Pearson Comelation & 855 & $837^{* 1}$ & $825^{\circ}$ & $873^{-1}$ & 925 & 1 \\
\hline & Sig. (2-tailed) & 000 & 000 & 000 & 000 & 000 & , \\
\hline
\end{tabular}

". Correlation is significant at the 0.01 level (2-tailed)

Como anteriormente apontado uma análise extra de um outro produto foi realizada, o freezer mostrou correlação no processo de difusão das diferentes classes de renda e novamente apresentando uma ligeira tendência a se distanciarem as formas de resposta entre as classes de renda colocadas nos extremos (até 1 SM e mais que $10 \mathrm{SM}$ ). Quanto mais próximas as classes de renda mais intenso o grau de correlação apresentado. 
Tabela A3.8 - Correlações no processo de difusão na classe de renda de até 1 SM.

\section{Correlação entre diferentes produtos na classe de renda de até $1 \mathrm{SM}$}

\section{Correlations}

\begin{tabular}{|c|c|c|c|c|c|c|}
\hline & & $\begin{array}{l}\text { geladeira } \\
\text { até } 1 S M\end{array}$ & $\begin{array}{l}\text { filtro água } \\
\text { até } 1 S M\end{array}$ & rádio até $1 \mathrm{SM}$ & TV até $1 \mathrm{SM}$ & $\begin{array}{l}\text { canal água } \\
\text { até } 1 \mathrm{SM}\end{array}$ \\
\hline \multirow[t]{3}{*}{ geladeira ate $1 S M$} & Pearson Correlation & 1 &, $738^{x / 2}$ &, $894^{\star \star}$ &, $984^{*-7}$ &, $975^{\circ}$ \\
\hline & Sig. (2-tailed) & &, 000 &, 000 &, 000 &, 000 \\
\hline & $\mathrm{N}$ & 19 & 19 & 19 & 19 & 19 \\
\hline \multirow[t]{3}{*}{ filtro água até $1 \mathrm{SM}$} & Pearson Correlation &, $738^{* 2}$ & 1 &, $750^{* x}$ & $747^{*-1}$ & $808^{*}$ \\
\hline & Sig. (2-tailed) &, 000 & &, 000 &, 000 &, 000 \\
\hline & $\mathrm{N}$ & 19 & 19 & 19 & 19 & 19 \\
\hline \multirow[t]{3}{*}{ rádio até $1 S M$} & Pearson Correlation & $894^{k=1}$ &, $750^{* x}$ & 1 & $951^{*-4}$ & $899^{*}$ \\
\hline & Sig. (2-tailed) &, 000 &, 000 & , &, 000 &, 000 \\
\hline & $\mathrm{N}$ & 19 & 19 & 19 & 19 & 19 \\
\hline \multirow[t]{3}{*}{ TV até 1SM } & Pearson Correlation &, $984^{* *}$ &, $747^{* x}$ &, $951^{\star x}$ & 1 &, $965^{*}$ \\
\hline & Sig. (2-tailed) &, 000 &, 000 &, 000 & , &, 000 \\
\hline & $\mathrm{N}$ & 19 & 19 & 19 & 19 & 19 \\
\hline \multirow[t]{3}{*}{ canal água até $1 \mathrm{SM}$} & Pearson Correlation & $975^{* m}$ & $808^{* x}$ & $899^{* x}$ &, $965^{*-1}$ & 1 \\
\hline & Sig. (2-tailed) &, 000 &, 000 &, 000 &, 000 & , \\
\hline & $\mathrm{N}$ & 19 & 19 & 19 & 19 & 19 \\
\hline
\end{tabular}

${ }^{* *}$. Correlation is significant at the 0.01 level (2-tailed).

Nesta faixa de classe de renda as curvas de difusão se mostram bastante similares e as correlações bastante intensas, a pior correlação encontrada filtro de água / geladeiras, com coeficiente de correlação do momento r de Pearson é de 0,738, com um nível de significância $p=0,0003110$. Isso denota um comportamento mais padrão nas respostas a inovações. 
Tabela A3.9 - Correlações no processo de difusão na classe de renda de 1 SM até 2 SM.

Correlação entre diferentes produtos na classe de renda de 1 até $2 \mathrm{SM}$

Correlations

\begin{tabular}{|c|c|c|c|c|c|c|}
\hline & & $\begin{array}{l}\text { geladeira } \\
1<\mathrm{SM}<2\end{array}$ & $\begin{array}{c}\text { filtro água } \\
1<\mathrm{SM}<2\end{array}$ & rádio $1<\mathrm{SM}<2$ & TV $1<\mathrm{SM}<2$ & $\begin{array}{c}\text { canal água } \\
1<\mathrm{SM}<2\end{array}$ \\
\hline \multirow[t]{2}{*}{ geladeira $1<$ SIM $<2$} & $\begin{array}{l}\text { Pearson Correlation } \\
\text { Sig. (2-tailed) }\end{array}$ & 1 & $\begin{array}{l}, 649^{* x} \\
, 003\end{array}$ & $\begin{array}{l}, 892^{\star *} \\
, 000\end{array}$ & $\begin{array}{l}, 973^{m} \\
, 000\end{array}$ & $\begin{array}{l}, 973^{\star} \\
, 000\end{array}$ \\
\hline & $\mathrm{N}$ & 19 & 19 & 19 & 19 & 19 \\
\hline \multirow[t]{3}{*}{ filtro água $1<\mathrm{SM}<2$} & Pearson Correlation &, $649^{*-1}$ & 1 & $629 *$ & $674^{2 *}$ & ,721* \\
\hline & Sig. (2-tailed) &, 003 & &, 004 &, 002 &, 000 \\
\hline & $\mathrm{N}$ & 19 & 19 & 19 & 19 & 19 \\
\hline \multirow[t]{3}{*}{ rádio $1<\mathrm{SM}<2$} & Pearson Correlation & $892^{*-1}$ & $629 * x$ & 1 &, $950^{* m}$ &, $900^{\star}$ \\
\hline & Sig. (2-tailed) &, 000 &, 004 & , &, 000 &, 000 \\
\hline & $\mathrm{N}$ & 19 & 19 & 19 & 19 & 19 \\
\hline \multirow[t]{3}{*}{ TV $1<\mathrm{SM}<2$} & Pearson Correlation &, $973^{* 4}$ & ,674**3 &, $950^{* 2}$ & 1 & $958^{\star}$ \\
\hline & Sig. (2-tailed) &, 000 &, 002 &, 000 & , &, 000 \\
\hline & $\mathrm{N}$ & 19 & 19 & 19 & 19 & 19 \\
\hline \multirow[t]{3}{*}{ canal água $1<\mathrm{SM}<2$} & Pearson Correlation & $973^{*-1}$ & $721 * *$ &, $900^{* *}$ & $958^{* m}$ & 1 \\
\hline & Sig. (2-tailed) &, 000 &, 000 &, 000 &, 000 & \\
\hline & $\mathrm{N}$ & 19 & 19 & 19 & 19 & 19 \\
\hline
\end{tabular}

**. Correlation is significant at the 0.01 level (2-tailed).

Não há correlação provável entre filtros de água e os demais itens, somente surgindo de maneira mais moderada entre canalização interna de água e filtros de água (correlação 0,721 e p =0,0004962). Isso demonstra uma tendência de que a resposta dessa classe pode se diferenciar dependendo do item. Entretanto, a correlação é forte entre os demais itens, reforçando um determinado comportamento padrão. 
Tabela A3.10 - Correlações no processo de difusão na classe de renda de 2 SM até 5 SM.

Correlação entre diferentes produtos na classe de renda de 2 até 5 SM

\section{Correlations}

\begin{tabular}{|c|c|c|c|c|c|c|}
\hline & & $\begin{array}{l}\text { geladeira } \\
2<\mathrm{SM}<5\end{array}$ & $\begin{array}{l}\text { filtro água } \\
2<\mathrm{SM}<5\end{array}$ & rádio $2<\mathrm{SM}<5$ & TV $2<\mathrm{SM}<5$ & $\begin{array}{l}\text { canal água } \\
2<\mathrm{SM}<5\end{array}$ \\
\hline \multirow[t]{3}{*}{ geladeira $2<$ SIM $<5$} & Pearson Correlation & 1 & 436 & $876^{\star 2}$ &, $969^{* m}$ & $991^{\star}$ \\
\hline & Sig. (2-tailed) & & 062 & 000 & 000 &, 000 \\
\hline & $\mathrm{N}$ & 19 & 19 & 19 & 19 & 19 \\
\hline \multirow[t]{3}{*}{ filtro água $2<\mathrm{SM}<5$} & Pearson Correlation & 436 & 1 & 455 & $462^{*}$ &, $500^{\star}$ \\
\hline & Sig. (2-tailed) & 062 & , & 050 & 047 & 029 \\
\hline & $\mathrm{N}$ & 19 & 19 & 19 & 19 & 19 \\
\hline \multirow[t]{3}{*}{ rádio $2<\mathrm{SM}<5$} & Pearson Correlation & $876^{* n}$ & 455 & 1 &, $931^{* m}$ &, $913^{\star}$ \\
\hline & Sig. (2-tailed) &, 000 & 050 & , &, 000 &, 000 \\
\hline & $\mathrm{N}$ & 19 & 19 & 19 & 19 & 19 \\
\hline \multirow[t]{3}{*}{ TV $2<\mathrm{SM}<5$} & Pearson Correlation &, $969^{* n}$ & $462^{\star}$ & ,931*3 & 1 &, $971^{\star}$ \\
\hline & Sig. (2-tailed) & 000 & 047 & 000 & 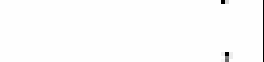 & 000 \\
\hline & $\mathrm{N}$ & 19 & 19 & 19 & 19 & 19 \\
\hline \multirow[t]{3}{*}{ canal água $2<\mathrm{SM}<5$} & Pearson Correlation &, $991^{* *}$ &, $500^{\star}$ & $913^{\star * 3}$ & $971^{\text {kn }}$ & 1 \\
\hline & Sig. (2-tailed) & 000 & 029 & 000 & 000 & , \\
\hline & $\mathrm{N}$ & 19 & 19 & 19 & 19 & 19 \\
\hline
\end{tabular}

**. Correlation is significant at the 0.01 level (2-tailed).

*. Correlation is significant at the 0.05 level (2-tailed).

Aqui ocorre o mesmo fenômeno apresentado na classe de renda inferior (2 a 5 SM), somente com a ressalva que o processo de difusão dos filtros de água mostra total diferença em relação aos demais itens. Quanto as demais correlações elas existem e são fortes. 
Tabela A3.11 - Correlações no processo de difusão na classe de renda de 5 SM até 10 SM.

\section{Correlação entre diferentes produtos na classe de renda de 5 até $10 \mathrm{SM}$}

\section{Correlations}

\begin{tabular}{|c|c|c|c|c|c|c|}
\hline & & $\begin{array}{l}\text { geladeira } \\
5<S M<10\end{array}$ & $\begin{array}{l}\text { filtro água } \\
5<S M<10\end{array}$ & $\begin{array}{c}\text { rádio } \\
5<S M<10\end{array}$ & TV $5<S M<10$ & $\begin{array}{c}\text { canal água } \\
5<\mathrm{SM}<10\end{array}$ \\
\hline geladeira $5<$ SIM $<10$ & $\begin{array}{l}\text { Pearson Correlation } \\
\text { Sig. (2-tailed) }\end{array}$ & 1 & $\begin{array}{r}-, 240 \\
, 322 \\
10\end{array}$ & $\begin{array}{l}, 896^{* x} \\
, 000 \\
19\end{array}$ & $\begin{array}{l}, 972^{\star} \\
, 000\end{array}$ & $\begin{array}{r}, 978^{\star} \\
, 000\end{array}$ \\
\hline filtro água $5<S M<10$ & $\begin{array}{l}\text { Pearson Correlation } \\
\text { Sig. (2-tailed) } \\
\text { N }\end{array}$ & $\begin{array}{r}-, 240 \\
, 322 \\
19\end{array}$ & 19 & $\begin{array}{r}-, 183 \\
, 454 \\
19\end{array}$ & $\begin{array}{r}-, 240 \\
, 322 \\
19\end{array}$ & $\begin{array}{r}-, 101 \\
, 680 \\
19\end{array}$ \\
\hline rádio $5<\mathrm{SM}<10$ & $\begin{array}{l}\text { Pearson Correlation } \\
\text { Sig. (2-tailed) } \\
\mathrm{N}\end{array}$ & $\begin{array}{r}, 896^{\star x} \\
, 000 \\
19\end{array}$ & $\begin{array}{r}-, 183 \\
, 454 \\
19\end{array}$ & $\begin{array}{r}1 \\
19\end{array}$ & $\begin{array}{c}903^{\star} \\
000 \\
19\end{array}$ & $\begin{array}{r}, 882^{*} \\
, 000 \\
19\end{array}$ \\
\hline TV $5<\mathrm{SM}<10$ & $\begin{array}{l}\text { Pearson Correlation } \\
\text { Sig. (2-tailed) } \\
\text { N }\end{array}$ & $\begin{array}{c}972^{\star x} \\
, 000 \\
19\end{array}$ & $\begin{array}{r}-, 240 \\
, 322 \\
19\end{array}$ & $\begin{array}{c}, 903^{* *} \\
, 000 \\
19\end{array}$ & $\begin{array}{r}1 \\
19\end{array}$ & $\begin{array}{r}972^{*} \\
1900 \\
19\end{array}$ \\
\hline canal água $5<\mathrm{SM}<10$ & $\begin{array}{l}\text { Pearson Correlation } \\
\text { Sig. (2-tailed) } \\
\mathrm{N}\end{array}$ & $\begin{array}{r}978^{\star x} \\
000 \\
19 \\
\end{array}$ & $\begin{array}{r}-, 101 \\
, 680 \\
19 \\
\end{array}$ & $\begin{array}{r}882^{* *} \\
000 \\
19 \\
\end{array}$ & $\begin{array}{r}972^{\star x} \\
000 \\
19 \\
\end{array}$ & $19 \dot{2}$ \\
\hline
\end{tabular}

**. Correlation is significant at the 0.01 level (2-tailed).

É interessante notar que para esta classe de renda, além de não ser identificada correlação entre filtros de água e os demais itens, já está ocorrendo um processo de abandono deste. As correlações encontradas para os demais itens são grandes. 
Tabela A3.12 - Correlações no processo de difusão na classe de renda acima de 10 SM.

Correlação entre diferentes produtos na classe de renda acima de $10 \mathrm{SM}$

Correlations

\begin{tabular}{|c|c|c|c|c|c|c|}
\hline & & $\begin{array}{l}\text { geladeira } \\
>10 \mathrm{SM}\end{array}$ & filtro $>10 S M$ & rádio >10SM & $T V>10 S M$ & $\begin{array}{c}\text { canal água } \\
>10 \mathrm{SM}\end{array}$ \\
\hline geladeira >10sm & $\begin{array}{l}\text { Pearson Correlation } \\
\text { Sig. (2-tailed) } \\
\text { N }\end{array}$ & $\begin{array}{r}1 \\
19\end{array}$ & $\begin{array}{r}-, 174 \\
, 477 \\
19\end{array}$ & $\begin{array}{c}, 839^{\star 2} \\
, 000 \\
19\end{array}$ & $\begin{array}{r}, 984^{\star 2} \\
, 000 \\
19\end{array}$ & $\begin{array}{r}, 995^{*} \\
, 000 \\
19\end{array}$ \\
\hline filtro $>10 S M$ & $\begin{array}{l}\text { Pearson Correlation } \\
\text { Sig. (2-tailed) } \\
\mathrm{N}\end{array}$ & $\begin{array}{r}-, 174 \\
, 477 \\
19 \\
\end{array}$ & $\begin{array}{r}1 \\
19\end{array}$ & $\begin{array}{r}-, 129 \\
, 599 \\
19\end{array}$ & $\begin{array}{r}-, 210 \\
, 389 \\
19\end{array}$ & $\begin{array}{r}-, 185 \\
, 449 \\
19\end{array}$ \\
\hline rádio >10SM & $\begin{array}{l}\text { Pearson Correlation } \\
\text { Sig. (2-tailed) } \\
\text { N }\end{array}$ & $\begin{array}{c}, 839^{* *} \\
000 \\
19\end{array}$ & $\begin{array}{r}-, 129 \\
, 599 \\
19\end{array}$ & $\begin{array}{r}1 \\
19\end{array}$ & $\begin{array}{c}, 877^{\star * 2} \\
, 000 \\
19\end{array}$ & $\begin{array}{c}844^{*} \\
1000 \\
19\end{array}$ \\
\hline TV $>10 S M$ & $\begin{array}{l}\text { Pearson Correlation } \\
\text { Sig. (2-tailed) } \\
\text { N }\end{array}$ & $\begin{array}{c}, 984^{*} \times \\
, 000 \\
19 \\
\end{array}$ & $\begin{array}{r}-, 210 \\
, 389 \\
19 \\
\end{array}$ & $\begin{array}{c}, 877^{\star *} \\
000 \\
19\end{array}$ & $\begin{array}{r}1 \\
19 \\
\end{array}$ & $\begin{array}{r}.991^{*} \\
, 000 \\
19\end{array}$ \\
\hline canal água >10SM & $\begin{array}{l}\text { Pearson Correlation } \\
\text { Sig. (2-tailed) } \\
\text { N }\end{array}$ & $\begin{array}{c}995^{* *} \\
000 \\
19\end{array}$ & $\begin{array}{r}-, 185 \\
, 449 \\
19\end{array}$ & $\begin{array}{c}844^{\star *} \\
000 \\
19\end{array}$ & $\begin{array}{c}, 991^{* *} \\
000 \\
19\end{array}$ & $\begin{array}{r}1 \\
19 \\
\end{array}$ \\
\hline
\end{tabular}

**. Correlation is significant at the 0.01 level (2-tailed).

É nessa classe de renda que os processos de difusão mais se diferenciam, pois além dos filtros de água não apresentarem nenhuma correlação no processo de difusão com os demais itens, também se percebe uma ligeira redução na força de correlação dos diversos itens. Nada significativo. 


\section{APÊNDICE 4 - Resultados da análise de aderência e ajuste de tendência das curvas}

Neste anexo estão os resultados dos estudos estatísticos de suporte às afirmações feitas no texto, item 7.6. A análise utilizou o software SPSS versão 11.0. Os dados foram reunidos em diferentes períodos para os seguintes itens: geladeira, aparelhos de rádio, televisores, filtros de água e canalização interna de água. Foram realizados testes não paramétricos de Kolmogorov- Smirnov para aderência de distribuição de curvas (2 tailed test) e os resultados foram verificados em relação a significância $\alpha=0,05$. (Kreiszig, 1970; Costa Neto, 1977; Peters e Summers, 1978; Conover, 1980; Barr, 2001; Green e Salkind, 2003). Em seguida estão alguns dos resultados das análises dos ajustes de tendência das curvas. 
Tabela A4.1 - Quantidade porcentual de domicílios possuidores de televisores e geladeiras.

\begin{tabular}{|c|r|r|r|r|}
\hline ANO & $\begin{array}{c}\text { Possuem } \\
\text { televisores }\end{array}$ & $\begin{array}{c}\text { Não } \\
\text { possuem } \\
\text { televisores }\end{array}$ & $\begin{array}{r}\text { Possuem } \\
\text { geladeira }\end{array}$ & $\begin{array}{c}\text { Não } \\
\text { possuem } \\
\text { geladeiras }\end{array}$ \\
\hline \hline 1972 & $88,84 \%$ & $11,16 \%$ & $90,98 \%$ & $9,02 \%$ \\
1980 & $95,03 \%$ & $4,97 \%$ & $95,87 \%$ & $4,13 \%$ \\
1983 & $96,40 \%$ & $3,60 \%$ & $98,26 \%$ & $1,74 \%$ \\
1988 & $97,76 \%$ & $2,24 \%$ & $98,27 \%$ & $1,73 \%$ \\
1989 & $96,94 \%$ & $3,06 \%$ & $97,56 \%$ & $2,44 \%$ \\
1990 & $97,44 \%$ & $2,56 \%$ & $97,85 \%$ & $2,15 \%$ \\
1991 & $97,97 \%$ & $2,03 \%$ & $98,12 \%$ & $1,88 \%$ \\
1992 & $98,51 \%$ & $1,49 \%$ & $98,94 \%$ & $1,06 \%$ \\
1993 & $98,12 \%$ & $1,88 \%$ & $98,37 \%$ & $1,63 \%$ \\
1995 & $98,52 \%$ & $1,48 \%$ & $98,71 \%$ & $1,29 \%$ \\
1996 & $98,74 \%$ & $1,26 \%$ & $98,67 \%$ & $1,33 \%$ \\
1997 & $99,10 \%$ & $0,90 \%$ & $99,13 \%$ & $0,87 \%$ \\
1998 & $99,23 \%$ & $0,77 \%$ & $99,22 \%$ & $0,78 \%$ \\
\hline 1999 & $99,25 \%$ & $0,75 \%$ & $99,38 \%$ & $0,62 \%$ \\
\hline 2000 & $99,26 \%$ & $0,74 \%$ & $98,62 \%$ & $1,38 \%$ \\
\hline 2001 & $99,28 \%$ & $0,72 \%$ & $99,44 \%$ & $0,56 \%$ \\
\hline 2002 & $99,50 \%$ & $0,50 \%$ & $99,54 \%$ & $0,46 \%$ \\
2003 & $99,48 \%$ & $0,52 \%$ & $99,65 \%$ & $0,35 \%$ \\
2004 & $99,47 \%$ & $0,53 \%$ & $99,57 \%$ & $0,43 \%$ \\
\hline
\end{tabular}




\section{ainda não adquiriram gelad $>10 \mathrm{SM}$}

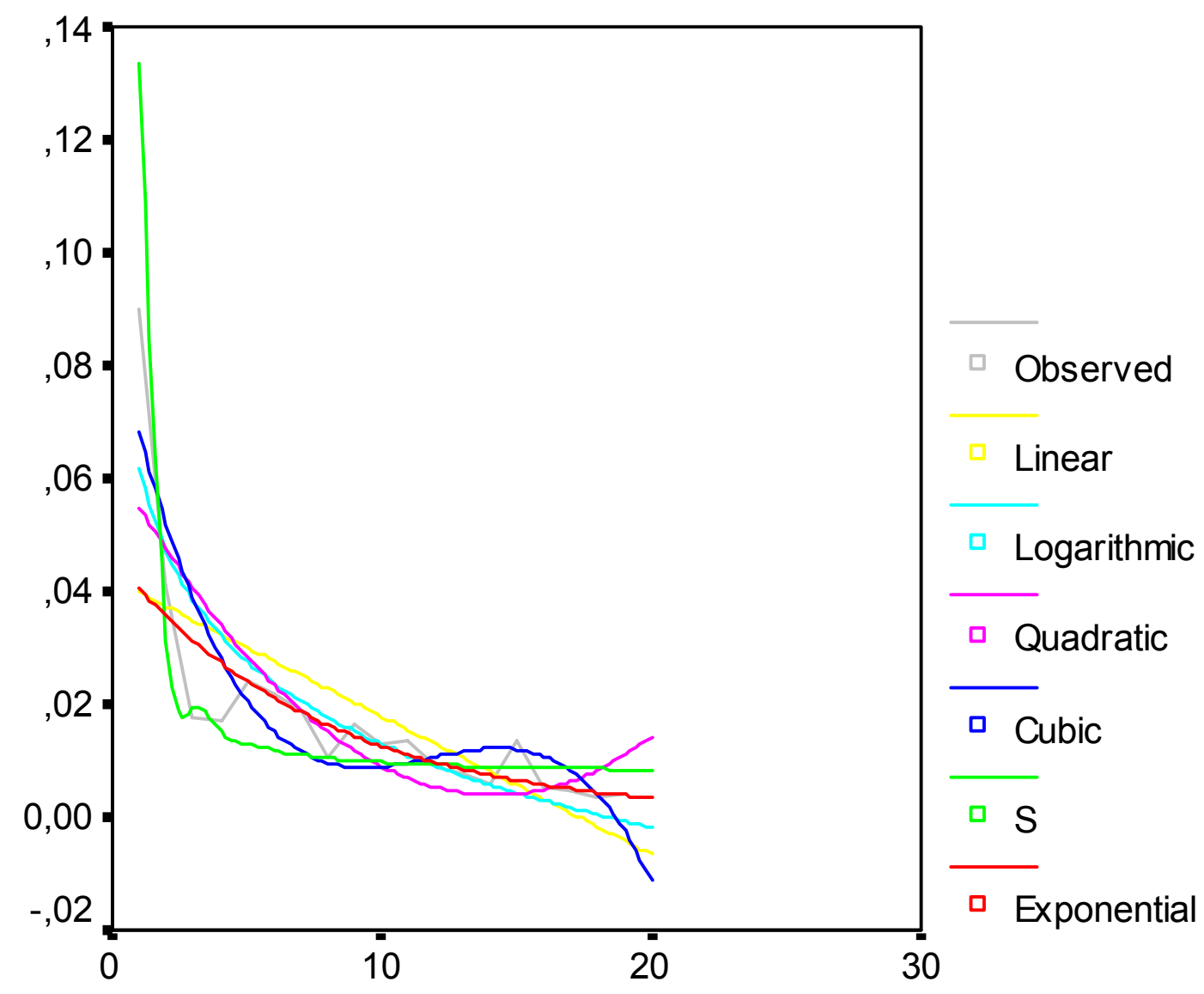

\section{Sequence}

Figura A4.1 - Análise da curva estimada para difusão de geladeiras em classes de renda acima de 10 SM em domicílios brasileiros.

Tabela A4.2 - Ajuste de curva de tendência para geladeiras

Independente: Tempo

$\begin{array}{lccccccccc}\text { Dependente } & \text { Mth } & \text { Rsq } & \text { d.f. } & \text { F } & \text { Sigf } & \text { b0 } & \text { b1 } & \text { b2 } & \text { b3 } \\ \text { DIFGEL5 } & \text { LIN } & , 484 & 17 & 15,95 & , 001 & , 0422 & -, 0024 & & \\ \text { DIFGEL5 } & \text { LOG } & , 753 & 17 & 51,76 & , 000 & , 0617 & -, 0212 & & \\ \text { DIFGEL5 } & \text { QUA } & , 654 & 16 & 15,09 & , 000 & , 0629 & -, 0084 & , 0003 & \\ \text { DIFGEL5 } & \text { CUB } & , 784 & 15 & 18,20 & , 000 & , 0881 & -, 0218 & , 0019 & -5, \text { E- } 05 \\ \text { DIFGEL5 } & \text { S } & , 665 & 17 & 33,79 & , 000 & -4,9231 & 2,9100 & & \\ \text { DIFGEL5 } & \text { EXP } & , 819 & 17 & 76,93 & , 000 & , 0462 & -, 1305 & & \end{array}$




\section{Não possuem can. agua > 10 SM}

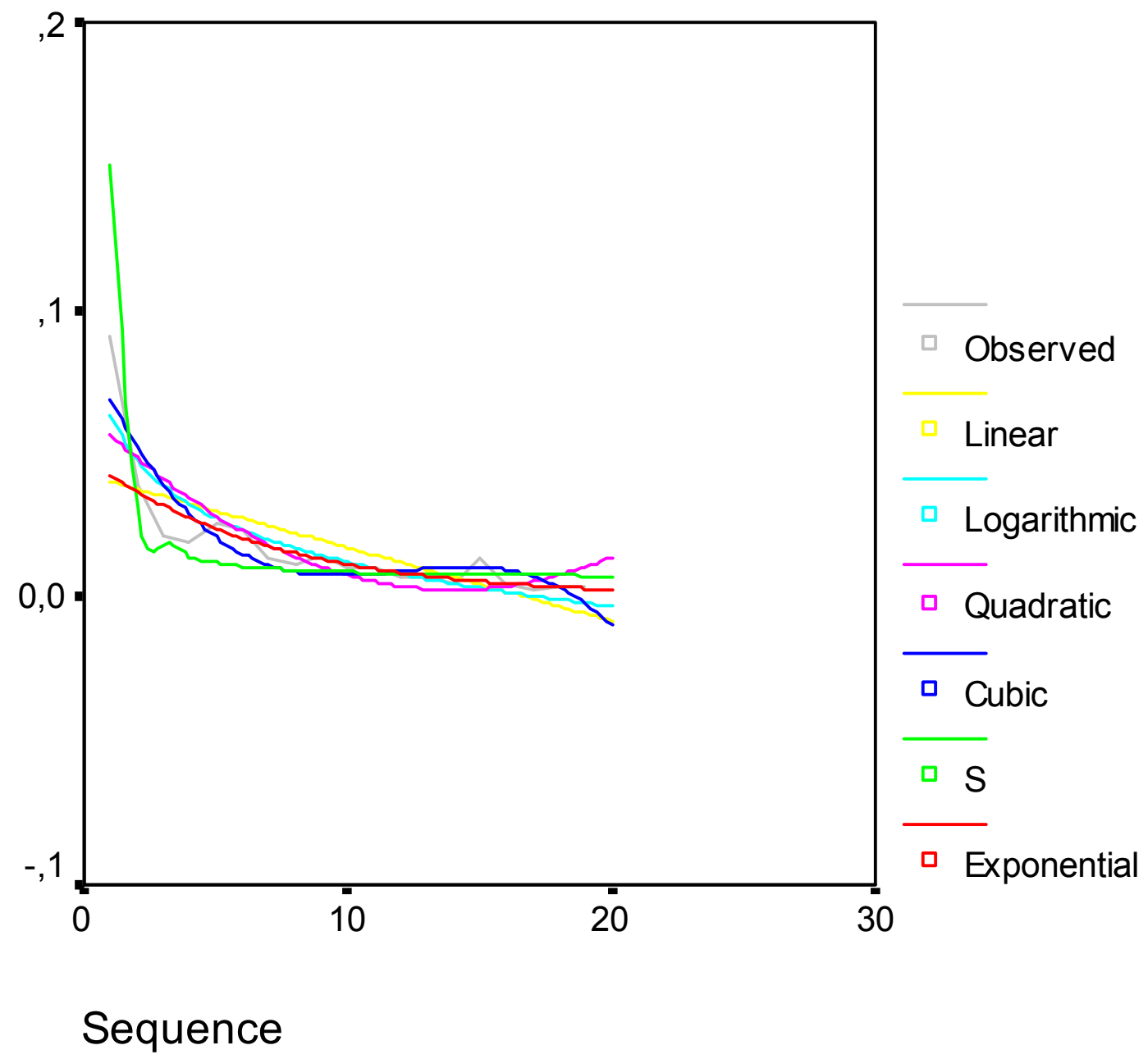

Figura A4.2 - Análise da curva estimada para difusão de canalização interna de água em classes de renda acima de 10 SM em domicílios brasileiros.

Tabela A4.3 - Ajuste de curva de tendência para canalização interna de água

Independente: Tempo

$\begin{array}{llcccccccc}\text { Dependente } & \text { Mth } & \text { Rsq } & \text { d.f. } & \text { F } & \text { Sigf } & \text { b0 } & \text { b1 } & \text { b2 } & \text { b3 } \\ \text { DIFAGUA5 } & \text { LIN } & , 507 & 17 & 17,51 & , 001 & , 0428 & -, 0025 & & \\ \text { DIFAGUA5 } & \text { LOG } & , 782 & 17 & 60,82 & , 000 & , 0629 & -, 0220 & & \\ \text { DIFAGUA5 } & \text { QUA } & , 696 & 16 & 18,28 & , 000 & , 0650 & -, 0089 & , 0003 & \\ \text { DIFAGUA5 } & \text { CUB } & , 810 & 15 & 21,32 & , 000 & , 0891 & -, 0218 & , 0019 & -5, \text { E- } 05 \\ \text { DIFAGUA5 } & \text { S } & , 656 & 17 & 32,41 & , 000 & -5,0567 & 3,1628 & & \\ \text { DIFAGUA5 } & \text { EXP } & , 852 & 17 & 97,78 & , 000 & , 0493 & -, 1457 & & \end{array}$




\section{ainda não adquiriram tv > $10 \mathrm{SM}$}

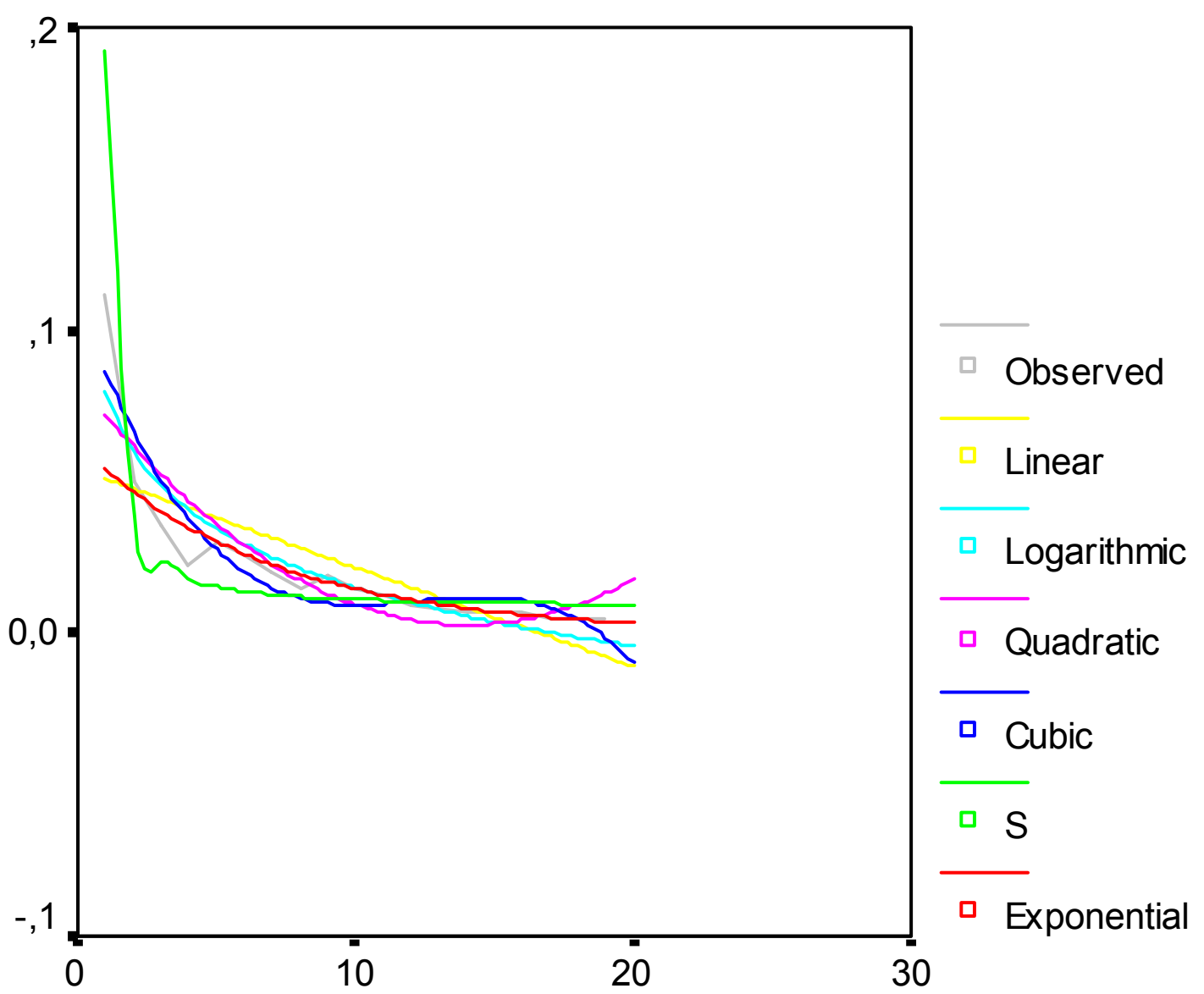

Sequence

Figura A4.3 - Análise da curva estimada para difusão de televisores em classes de renda acima de 10 SM em domicílios brasileiros.

Tabela A4.4 - Ajuste de curva de tendência para televisores

Independente: Tempo

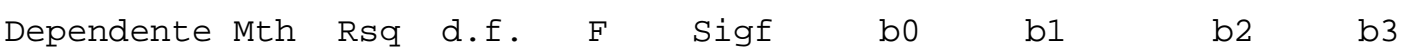

$\begin{array}{llllrlrlll}\text { DIFTV5 } & \text { LIN } & , 548 & 17 & 20,60 & , 000 & , 0544 & -, 0033 & & \\ \text { DIFTV5 } & \text { LOG } & , 829 & 17 & 82,41 & , 000 & , 0798 & -, 0281 & & \\ \text { DIFTV5 } & \text { QUA } & , 753 & 16 & 24,36 & , 000 & , 0831 & -, 0115 & , 0004 & \\ \text { DIFTV5 } & \text { CUB } & , 850 & 15 & 28,44 & , 000 & , 1107 & -, 0261 & , 0022 & -6, \mathrm{E}-05 \\ \text { DIFTV5 } & \text { S } & , 719 & 17 & 43,44 & , 000 & -4,8150 & 3,1680 & & \\ \text { DIFTV5 } & \text { EXP } & , 919 & 17 & 192,09 & , 000 & , 0623 & -, 1448 & & \end{array}$




\section{APÊNDICE 5 - Comparação entre o processo de difusão de inovações em São Paulo e em Alagoas}

Neste anexo ${ }^{A 1.1}$ são apresentados os resultados dos estudos feitos com algumas inovações e como e quando elas adentraram os domicílios brasileiros em diferentes estados. Foram escolhidos dois estados: São Paulo, com IDHM - Índice de Desenvolvimento Humano Municipal - de 0,778 em 1991 e 0,82 em 2000 ( $2^{\circ}$ maior do Brasil) e Alagoas com IDHM de 0,548 em 1991 e 0,649 em 2000 (penúltimo no Brasil), sendo que o IDHM do Brasil em 1991 era igual a 0,696 e em 2000 igual a 0,766. A escolha das duas unidades da federação teve como objetivo analisar os dois extremos e se ocorreriam diferenças nos respectivos processos de difusão de inovações em seus domicílios.

Os resultados mostram que realmente há defasagem na difusão dentro da mesma camada de renda, e entre camadas de renda, conforme tabelas adiante, aparentemente apontando para uma prevalência das camadas mais altas de renda das áreas mais desenvolvidas sobre as demais áreas. Um processo comum na difusão de inovações, segundo Rogers (2003), e possivelmente, ligado à percepção da utilidade da inovação.

Tabela A5.1 - Comparação dos processos de difusão de geladeiras em Alagoas e São Paulo, para diferentes classes de renda.

\begin{tabular}{|c|c|c|c|c|c|c|c|c|}
\hline \multirow[t]{2}{*}{ ano } & \multicolumn{2}{|c|}{$\begin{array}{l}>10 \mathrm{SM} \\
\text { geladeira }\end{array}$} & \multirow[t]{2}{*}{ ano } & \multicolumn{2}{|c|}{$\begin{array}{l}5 \text { a } 10 \text { SM } \\
\text { geladeira }\end{array}$} & \multirow[t]{2}{*}{ ano } & \multicolumn{2}{|c|}{$\begin{array}{l}2 \text { a } 5 \text { SM } \\
\text { geladeira }\end{array}$} \\
\hline & $A L$ & $\mathrm{SP}$ & & $\mathrm{AL}$ & $\mathrm{SP}$ & & $A L$ & $\mathrm{SP}$ \\
\hline 1983 & $96,19 \%$ & $99,37 \%$ & 1983 & $77,42 \%$ & $94,71 \%$ & 1983 & $43,45 \%$ & $80,00 \%$ \\
\hline 1988 & $94,12 \%$ & $99,23 \%$ & 1988 & $83,15 \%$ & $94,25 \%$ & 1988 & $55,25 \%$ & $83,85 \%$ \\
\hline 1997 & $100,00 \%$ & $99,29 \%$ & 1997 & $94,74 \%$ & $98,41 \%$ & 1997 & $67,04 \%$ & $94,53 \%$ \\
\hline 2004 & $100,00 \%$ & $99,95 \%$ & 2004 & $96,08 \%$ & $99,71 \%$ & 2004 & $87,86 \%$ & $97,98 \%$ \\
\hline
\end{tabular}

\footnotetext{
A1.1 Os dados foram retirados do Atlas de Desenvolvimento do PNUD - Programa das Nações Unidas para o Desenvolvimento, órgão da ONU. Disponível em http://www.pnud.org.br/atlas/tabelas/index.php . Acessado em 15/12/2005.
} 
Tabela A5.2 - Comparação dos processos de difusão de canalização interna de água em Alagoas e São Paulo, para diferentes classes de renda.

\begin{tabular}{|c|c|c|c|c|c|c|c|c|}
\hline \multirow[t]{2}{*}{ ano } & \multicolumn{2}{|c|}{$\begin{array}{c}>10 \mathrm{SM} \\
\text { Canal. Int. Água }\end{array}$} & \multicolumn{4}{|c|}{5 a 10 SM } & \multicolumn{2}{|c|}{$\begin{array}{c}2 \text { a } 5 \text { SM } \\
\text { Canal. Int. Água }\end{array}$} \\
\hline & $\mathrm{AL}$ & SP & & $\mathrm{AL}$ & SP & & $\mathrm{AL}$ & SP \\
\hline 1983 & $96,17 \%$ & $99,61 \%$ & 1983 & $69,42 \%$ & $97,23 \%$ & 1983 & $43,71 \%$ & $88,91 \%$ \\
\hline 1988 & $88,23 \%$ & $99,79 \%$ & 1988 & $76,84 \%$ & $97,42 \%$ & 1988 & $48,07 \%$ & $92,41 \%$ \\
\hline 1997 & $100,00 \%$ & $99,87 \%$ & 1997 & $94,74 \%$ & $99,28 \%$ & 1997 & $71,06 \%$ & $97,70 \%$ \\
\hline 2004 & $93,75 \%$ & $99,91 \%$ & 2004 & $98,04 \%$ & $99,90 \%$ & 2004 & $82,34 \%$ & $99,50 \%$ \\
\hline
\end{tabular}

Tabela A5.3 - Comparação dos processos de difusão de televisores em Alagoas e São Paulo, para diferentes classes de renda.

\begin{tabular}{|c|c|c|c|c|c|c|c|c|}
\hline \multirow[t]{2}{*}{ ano } & \multicolumn{2}{|c|}{$\begin{array}{c}>10 \mathrm{SM} \\
\text { Televisores }\end{array}$} & \multirow[t]{2}{*}{ ano } & \multicolumn{2}{|c|}{5 a 10 SM } & \multirow[t]{2}{*}{ ano } & \multicolumn{2}{|c|}{$\begin{array}{c}2 \text { a } 5 \text { SM } \\
\text { Televisores }\end{array}$} \\
\hline & $\mathrm{AL}$ & $\mathrm{SP}$ & & $\mathrm{AL}$ & $\mathrm{SP}$ & & $\mathrm{AL}$ & $\mathrm{SP}$ \\
\hline 1988 & $95,59 \%$ & $98,72 \%$ & 1988 & $77,89 \%$ & $94,44 \%$ & 1988 & $60,22 \%$ & $87,25 \%$ \\
\hline 1997 & $99,16 \%$ & $99,19 \%$ & 1997 & $96,24 \%$ & $97,65 \%$ & 1997 & $85,67 \%$ & $93,58 \%$ \\
\hline 2004 & $100,00 \%$ & $99,68 \%$ & 2004 & $96,08 \%$ & $98,76 \%$ & 2004 & $92,05 \%$ & $97,17 \%$ \\
\hline
\end{tabular}

Tabela A5.4 - Comparação dos processos de difusão de microcomputadores em Alagoas e São Paulo, para diferentes classes de renda.

\begin{tabular}{|c|c|c|c|c|c|c|c|c|}
\hline \multirow[t]{2}{*}{ ano } & \multicolumn{2}{|c|}{$\begin{array}{l}>10 \mathrm{SM} \\
\text { microcomputador }\end{array}$} & \multicolumn{4}{|c|}{5 a 10 SM } & \multicolumn{2}{|c|}{$\begin{array}{l}2 \text { a } 5 \text { SM } \\
\text { microcomputador }\end{array}$} \\
\hline & $\mathrm{AL}$ & $\mathrm{SP}$ & & $\mathrm{AL}$ & $\mathrm{SP}$ & & $\mathrm{AL}$ & $\mathrm{SP}$ \\
\hline 2001 & $55,26 \%$ & $57,90 \%$ & 2001 & $19,62 \%$ & $20,19 \%$ & 2001 & $2,27 \%$ & $5,32 \%$ \\
\hline 2004 & $64,07 \%$ & $72,37 \%$ & 2004 & $24,51 \%$ & $31,76 \%$ & 2004 & $3,31 \%$ & $10,70 \%$ \\
\hline
\end{tabular}

